\title{
Fabrication and Scale-up of Polybenzimidazole (PBI) Membrane Based System for Precombustion- Based Capture of Carbon Dioxide
}

\section{Final Technical Report}

Reporting Period: April 1, 2007 through March 30, 2012

SRI Project P17789

Cooperative Agreement No.: DE-FC26-07NT43090

Prepared by:

Gopala N. Krishnan, Indira Jayaweera, and Angel Sanjrujo

SRI International

333 Ravenswood Avenue

Menlo Park, CA 94025

Contibutors:

Kevin O'Brien, energy Commercialization, Inc.

Richard Callahan, Enrefex, Inc

Kathryn Berchtold, Los Almaos National Laboratory,

Daryl-Lynn Roberts, and Will Johnson, Visage Energy

Project Partners:

SRI International, Los Alamos National Laboratory, Whitefox Technologies, Visage Energy, Enerfex Inc, BP Alternative Energy, Southern Co.

Project Manager:

Mr. Robie Lewis

Prepared for:

U.S. Department of Energy

National Energy Technology Laboratory

3600 Collins Ferry Road

Morgantown, WV 26505 


\section{DISCLAIMER}

This report was prepared as an account of work sponsored by an agency of the United States Government. Neither the United States Government nor any agency thereof, nor any of their employees, makes any warranty, express or implied, or assumes any legal liability or responsibility for the accuracy, completeness, or usefulness of any information, apparatus, product, or process disclosed, or represents that its use would not infringe privately owned rights. Reference herein to any specific commercial product, process, or service by trade name, trademark, manufacturer, or otherwise does not necessarily constitute or imply endorsement, recommendation, or favoring by the United States Government or any agency thereof. The views and opinions of authors expressed herein do not necessarily state or reflect those of the United States Government or any agency thereof. 


\section{CONTENTS}

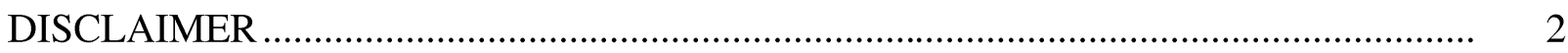

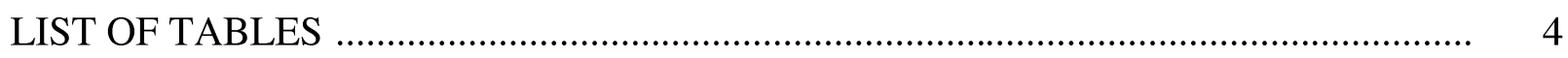

LIST OF FIGURES ........................................................................................... 6

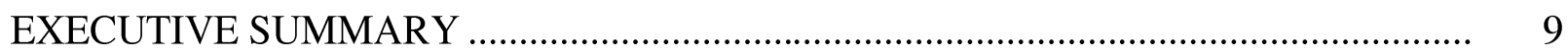

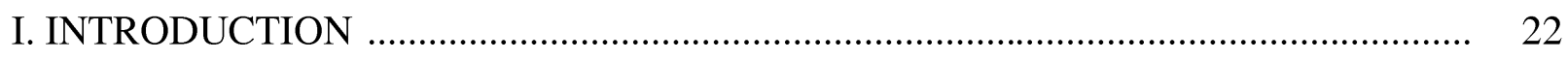

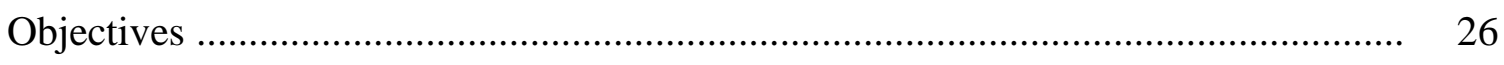

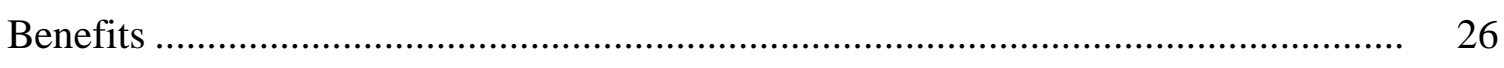

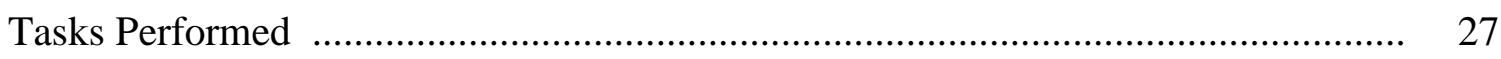

II. DEVELOPMENT OF PBI-BASED HOLLOW FIBER MEMBRANE AND

MODULE....................................................................................... 29

Initial Work with Whitefox Technology Membranes ............................................... 29

PBI Hollow-Fiber Fabrication at SRI ................................................................. 41

Membrane Module (50 Kwth) Fabrication and Testing ............................................ 58

III. MEMBRANE PERFORMANCE SIMULATION AND ECONONOMIC

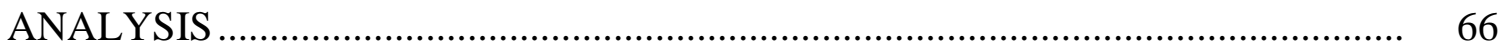

Comparison of Porous PBI Substrate vs Metal Substrate .......................................... 66

Simulation of Hollow Fiber Membrane Systems ...................................................... 67

Process Modeling and Cost of $\mathrm{CO}_{2}$ Capture .......................................................... 70

IV. STRATEGIC PLAN DEVELOPMENT ……….............................................. 108

Future of Coal Gasification Technology ……........................................................... 109

Financial, Insurance, Regulatory, and Legal Issues ................................................. 111

Pre-commercialization Pathway Schedule ………………..................................... 114

V. CONCLUSIONS AND RECOMMENDATIONS ............................................. 121

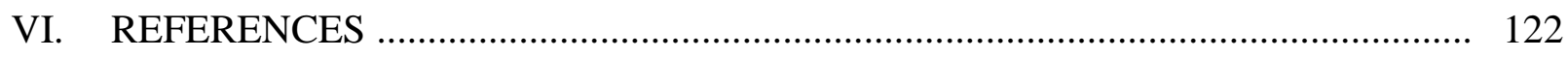

APPENDIX A: INITIAL HOLLOW FIBER DEVELOPMENT ……………………....... A-1

APPENDIX B: POTTING MATERIAL DEVELOPMENT ............................................... B-1

APPENDIX C: STRATEGIC DEVELOPMENT PLAN …………………………......... C-1

APPENDIX D: MEMBRANE SIMULATION CALCULATIONS …………………......... D-1 


\section{LIST OF TABLES}

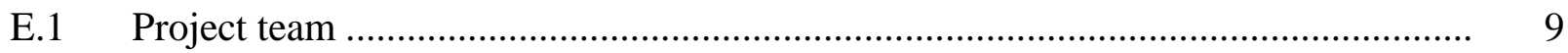

E.2 Summary of economic estimates by scenario ………………………………........ 19

E.3 Summary of economic estimates with process improvements ................................. 20

E.4 Risks to the Implementation of the Commercialization Pathway and Actions to Mitigate Risks ........................................................................................... 21

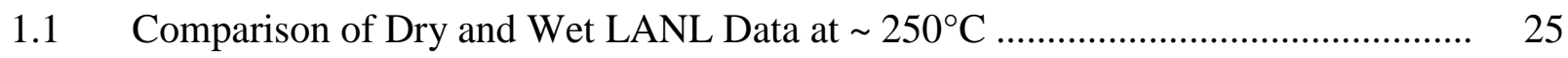

II- $1 \quad \mathrm{H}_{2}$ permeability and $\mathrm{H}_{2} / \mathrm{CO}_{2}$ selectivity of the WF-MB-102208 PBI fibers ............ 34

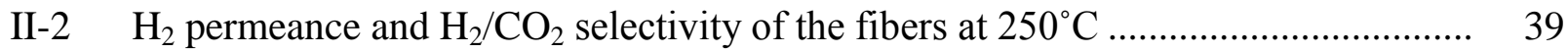

II-3 Hollow fiber spinning parameters..................................................................... 44

II-4 Relationship between process parameters and fiber properties ................................ 45

II-5 Parameters affecting macro-voids and their associated levels to be tested ............... 47

II-6 Module specification for $0.6 \mathrm{~mm}$ O.D. fiber with a $0.45 \mu \mathrm{m}$ thick dense layer........ 59

II-7 The simulation of a membrane module with for a $50 \mathrm{kWth}$ system......................... 59

II-8 Gas flow rates in feed, retentate and permeate streams for a 50 KWth System........ 60

III-1 PBI hollow fiber vs PBI coated on a metal substrate................................................ 67

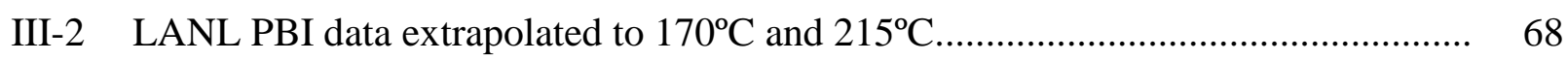

III-3 Hollow fiber membrane performance at $98 \% \mathrm{H}_{2}$ recovery at different temperatures and permeate pressures ................................................................................ 68

III-4 LANL permeation data for gas mixtures ................................................................. 69

III-5 Extrapolated LANL Data for a separation layer of $0.5 \mu \mathrm{m} \ldots \ldots \ldots \ldots \ldots \ldots \ldots \ldots \ldots \ldots \ldots \ldots \ldots \ldots . . . \quad 70$

III-6 Simulation projection of a membrane with $0.5 \mu \mathrm{m}$ separation layer.......................... 70

III-7 Effect of $\mathrm{N}_{2}$ permeate sweep gas .................................................................

III-8 Effect of $\mathrm{H}_{2} \mathrm{O}$ on percent $\mathrm{N}_{2}$ permeate sweep gas ............................................... 72

III-9 Energy balance based on "Plot To Enerfex From LANL" data................................. 72

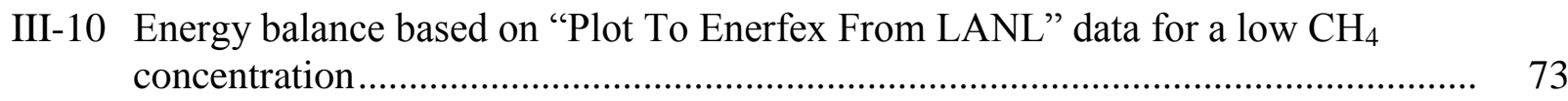

III-11 Membrane performance at $750 \mathrm{psia}$ and $1,015 \mathrm{psia}$ feed pressure ……................... 73 
III-12 LANL empirical data ........................................................................... 73

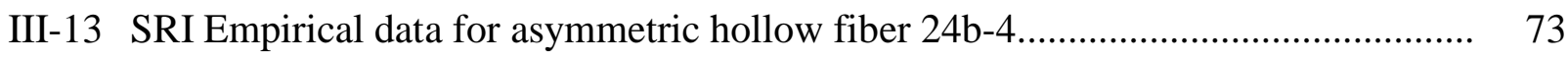

III-14 Characteristics of temperatures, pressures, and gas flows for Scenario 1 .............. 77

III-15 Characteristics of temperatures, pressures, and gas flows for Scenario 2 .............. 82

III-16 Characteristics of temperatures, pressures, and gas flows for Scenario 3 .............. 87

III-17 Characteristics of temperatures, pressures, and gas flows for Scenario 4 ............. 91

III-18 Characteristics of temperatures, pressures, and gas flows for Scenario 5 .............. 96

III-19 Summary of plant performance for various scenarios .................................... 100

III-20 Comparison of No-CO $\mathrm{CO}_{2}$ capture IGCC plants ........................................... 101

III-21 Comparison of Selexol $\mathrm{CO}_{2}$ capture IGCC plants ......................................... 102

III-22 Comparison of Scenario 2 (NETL Selexol) with NETL and SRI Selexol $\mathrm{CO}_{2}$ capture IGCC plants.............................................................................. 103

III-23 Summary of preliminary economic estimates for various scenarios .................... 105

III-24 Sensitivity analysis of the $\mathrm{CO}_{2}$ capture ..................................................... 106

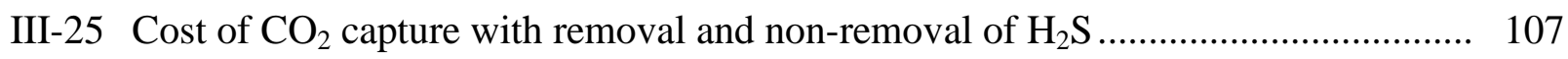

IV-1 PBI team stakeholder classification ........................................................ 108

IV-2 Typical stages of maturation for energy technologies .................................... 115

IV-3 Potential commercialization pathway schedule ............................................. 117

IV-4 Risks to the implementation of the commercialization pathway and actions to

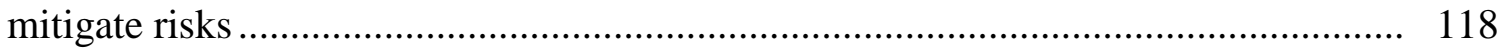




\section{LIST OF FIGURES}

E-1 The measured permeance of $\mathrm{H}_{2}$ in GPU and $\mathrm{H}_{2} / \mathrm{CO}_{2}$ selectivity of selected WFXPBI hollow fiber at $250^{\circ} \mathrm{C}$.

E-2 Image of a bundle of PBI-based, asymmetric hollow fibers made at SRI................ 12

E-3 High magnification photographs of cross-sections near shell and lumen sides of SRI Series A fiber

E-4 Relationship between selectivity for $\mathrm{H}_{2} / \mathrm{CO}_{2}$ and $\mathrm{H}_{2}$ permeance at $250^{\circ} \mathrm{C}$ for SRIfabricated fibers

E-5 Comparison of $\mathrm{H}_{2} / \mathrm{CO}_{2}$ selectivity and $\mathrm{H}_{2}$ permeability in polymers...................... 14

E-6 Measured selectivity for $\mathrm{H}_{2} / \mathrm{CO}_{2}$ and $\mathrm{H}_{2}$ permeance at $225^{\circ} \mathrm{C}$ measured over $1000 \mathrm{~h} 14$

E-7 A photograph of 3-in diameter $\mathrm{x} 1$ - $\mathrm{ft}$ long HF element for insertion in the pressure

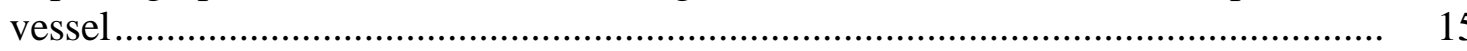

I-1 Chemical structure of polybenzimidazole ............................................................ 23

I-2 Tradeoff plot between $\mathrm{H}_{2}$ permeability and $\mathrm{H}_{2} / \mathrm{CO}_{2}$ selectivity in polymers ........... 24

I-3 Permeance of PBI on metallic substrate as a function of time at $250^{\circ} \mathrm{C} \ldots \ldots \ldots \ldots \ldots \ldots . . . . . .25$

I-3 SEMs of PBI-based multi-bore hollow fibers with varied outer diameters and bore diameters

II-1 Porous structure leading to a non-optimized "dense" layer at the inner (lumen) surface of the multi-bore fiber

II-3 The cross section of PBI fiber WF-MB-102208 ................................................... 31

II-4 The cross section of the PBI fiber illustrating the porous walls .............................. 32

II-5 High magnification image of the interior walls of the membrane ............................. 32

II-6 The surface of a membrane at a magnification of 100,000X .................................... 33

II-7 Cross section of the WFX-07a membrane with a $0.60 \mathrm{~mm}$-substrate + lumen-side selective layer (Set 1)

II-8 The measured permeance for $\mathrm{H}_{2}, \mathrm{~N}_{2}$ and $\mathrm{CO}_{2}$ as a function of pressure difference at $250^{\circ} \mathrm{C}$ of WFX-07 membrane

II-9 The measured permeance of $\mathrm{H}_{2}$ in GPU and $\mathrm{H}_{2} / \mathrm{CO}_{2}$ selectivity of selected WFXPBI hollow fiber set 2 at $250^{\circ} \mathrm{C}$

II-10 SEM images of the lumen surfaces of the previous (WFX-3b) and new (WFX-00) porous substrate fiber 
II-11 SEM image of the cross section of the porous substrate fiber at low and high magnifications

II-12 The measured permeance of $\mathrm{H}_{2}$ in GPU and $\mathrm{H}_{2} / \mathrm{CO}_{2}$ selectivity of selected WFXPBI hollow fiber at $250^{\circ} \mathrm{C}$

II-13 The measured permeance of $\mathrm{H}_{2}$ in GPU and $\mathrm{H}_{2} / \mathrm{CO}_{2}$ selectivity of selected WFXPBI hollow fiber at $250^{\circ} \mathrm{C}$.

II-14 Schematic of the SRI bench Scale spinning line

II-15 SRI bench Scale spinning line

II-16 A photograph of PBI hollow fiber bundles fabricated at SRI.

II-17 Processing steps in fabricating hollow fiber modules.

II-18 Fiber spinning process factors and responses flow chart.

II-19 A photograph of a cross section of an asymmetric PBI hollow fiber membrane ......

II-19a Photographs of the cross section of bulk porous sections of PBI fibers drawn from four different coagulation solvent combinations

II-20 Photographs of a fiber without macro-defects and the cross section illustrating the porous substrate

II-21 A cross section of the PBI asymmetric hollow fiber made at SRI with no finger voids

II-22 Image of a bundle of PBI-based, asymmetric hollow fibers made at SRI................

II-23 Photograph of coils of $0.6 \mathrm{~mm}$ diameter PBI hollow fibers fabricated at SRI

II-24 High magnification photographs of cross-sections near shell and lumen sides of SRI Series A fiber

II-25 Fiber bundle potted with PBI sealant.

II-26 Potted hollow fiber membrane elements, 1-in x 14-in size

II-27 Potted Fiber bundles assembled with varying packing densities to assess the potting performance

II-28 Measured permeance values for $\mathrm{H}_{2}$ and $\mathrm{CO}_{2}$ at $150^{\circ}$ to $225^{\circ} \mathrm{C}$ as a function of applied pressure difference across the hollow fiber membrane

II-29 Measured selectivity for $\mathrm{H}_{2} / \mathrm{CO}_{2}$ as a function of $\mathrm{H}_{2}$ permeance in GPU units at temperatures from $150^{\circ}$ to $250^{\circ} \mathrm{C}$

II-30 Measured selectivity for $\mathrm{H}_{2} / \mathrm{CO}_{2}$ and $\mathrm{H}_{2}$ permeance at $225^{\circ} \mathrm{C}$ measured over $1000 \mathrm{~h} 55$ 
II-31 Relationship between selectivity for $\mathrm{H}_{2} / \mathrm{CO}_{2}$ and $\mathrm{H}_{2}$ permeance at $250^{\circ} \mathrm{C}$ as a function of the dense layer thickness.....

II-32 Comparison of $\mathrm{H}_{2} / \mathrm{CO}_{2}$ selectivity and $\mathrm{H}_{2}$ permeability in polymers.................... 56

II-32a A photograph of assembled sub-scale 1-in module with SRI PBI hollow fiber membrane

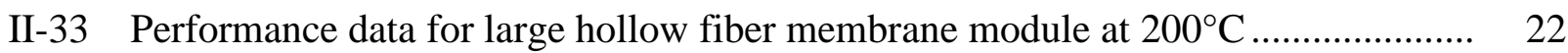

II-34 A block diagram showing mass balances for the test skid with a feed gas processing capacity of $50 \mathrm{~kW}_{\text {th }}$

II-35 Schematic diagram of the nominal 4 inch shell side feed test module .................... 61

II-36 The skid containing two pressure vessels in as-fabricated stage .......................... 62

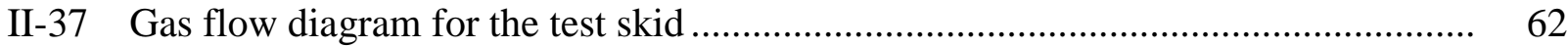

II-38 A photograph of 3-in dia. x1-ft long HF element in a pressure vessel ................... 63

II-39 A photograph showing the installed skid with instrumentation............................. 64

II-40 The selectivity of $\mathrm{H}_{2} / \mathrm{CO}_{2}$ and $\mathrm{H}_{2}$ permeance of fibers at $225^{\circ} \mathrm{C}$ measured for $120 \mathrm{~h} \quad 65$

III-1 Plot of LANL PBI $\mathrm{H}_{2} / \mathrm{CO}_{2}$ selectivity vs. $\mathrm{H}_{2}$ permeability at two temperatures...... 67

III-2 Block flow diagram for Scenario 1 .........................................................

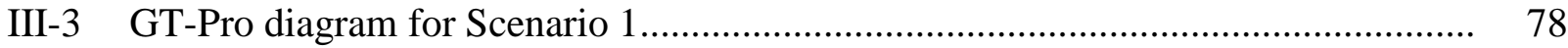

III-4 Block flow diagram for Scenario 2 ..................................................... 81

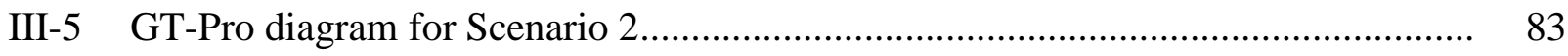

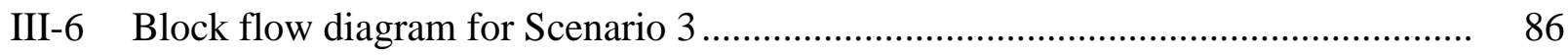

III-7 GT-Pro diagram for Scenario 3 ............................................................... 88

III-8 Block flow diagram for Scenario 4 ......................................................... 90

III-9 GT-Pro diagram for Scenario 4 ............................................................. 92

III-10 Block flow diagram for Scenario 5 ......................................................... 95

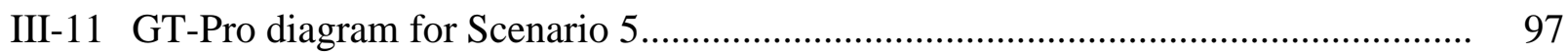

IV-1 Past capacity announcements vs. actual.................................................... 110

IV-2 Global IGCC project pipeline ........................................................... 112 


\section{EXECUTIVE SUMMARY}

The management of greenhouse gas emissions, in particular $\mathrm{CO}_{2}$, produced during energy generation from coal is a critical factor to ensure that sufficient clean energy is available for economic growth in the U.S. New investments are needed in capital equipment, research, development, and demonstration of new technologies to manage $\mathrm{CO}_{2}$ emissions using carbon capture and storage (CCS) technologies. Successful deployment of CCS technologies hinges not only on the economics of the process but also on the ability to create a regulatory environment that encourages investment in technologies and rewards early adopters of the technologies.

The primary objectives of this project are to (1) demonstrate the performance and fabrication of a technically and economically viable pre-combustion-based $\mathrm{CO}_{2}$ capture system based on the high temperature stability and permeance of PBI membranes, (2) optimize a plan for integration of PBI capture system into an IGCC plant and (3) develop a commercialization plan that addresses technical issues and business issues to outline a clear path for technology transfer of the PBI membrane technology. This report describes research conducted from April 1, 2007 to March 30, 2012 and focused on achieving the above objectives.

The project team consisted of several companies as shown in Table E-1 each contributing different expertise to the success of the project.

Table E-1. Project Team

\begin{tabular}{|l|l|}
\hline \multicolumn{1}{|c|}{ PBI Project Team Member } & \multicolumn{1}{c|}{ Role } \\
\hline SRI International & $\begin{array}{l}\text { Prime contractor and Technology } \\
\text { Developer }\end{array}$ \\
\hline Los Alamos National Laboratory & Technology Developer \\
\hline Whitefox Technologies & OEM \& Suppliers \\
\hline Enerfex, Inc. & OEM \& Suppliers \\
\hline BP Alternative Energy & Utilities \\
\hline Southern Company & Utilities \\
\hline Visage Energy & Business/Financial \\
\hline $\begin{array}{l}\text { US DOE National Energy Technology } \\
\text { Laboratory }\end{array}$ & Government \\
\hline
\end{tabular}




\section{Development of PBI-Based Hollow Fiber Membrane and Module}

The PBI membrane used for this application consists of a porous support/substrate and a dense selective layer. Previous work at LANL used a PBI-based selective layer in concert with rigid and relatively thick metallic or metallic/ceramic porous substrates. In this project, we developed a flexible and thin PBI porous substrate with a PBI selective layer (hollow fiber). This improvement enables the fabrication of compact membrane modules needed to reduce the capital cost for gas separation in the high-pressure and hightemperature environment of the IGCC gas stream.

WhiteFox Technologies Limited (WFX), a company specializing in the commercial use of polymer membranes for ethanol dehydration, became involved in the fabrication of PBI hollow fiber membranes for this project. Initially WFX fabricated multi-bore/multi-lumen hollow fibers. Multi-bore tubular membranes can retain the surface area to volume ratio of small OD membranes while the external area where they are sealed to a tube sheet is minimized.

The seven-bore hollow fiber PBI membranes fabricated by WFX were evaluated at SRI and LANL. Appendix A is a detailed report of the activities performed at WFX, LANL, and SRI. The permeability for $\mathrm{H}_{2}$ and $\mathrm{H}_{2} / \mathrm{CO}_{2}$ selectivity of the multi-bore membranes were lower than expected. In addition, the multi-bore membranes could not sustain a large pressure differential between the outer and inner surfaces, necessary to obtain the necessary $\mathrm{H}_{2}$ flux. Further, WFX decided to discontinue the fabrication of the multi-bore PBI membranes because of environmentally unacceptable processing methods. Instead they focused on coating a dense PBI layer on the surfaces of porous PBI hollow fiber tubing.

WFX fabricated four sets of single bore PBI hollow fiber membranes. In Set 1, they used an asymmetric fiber substrate and deposited the $\mathrm{H}_{2}$ selective dense layer on the inner surface of porous fiber. Gas permeation tests showed that both the $\mathrm{H}_{2} / \mathrm{CO}_{2}$ selectivity of 15 and $\mathrm{H}_{2}$ permeance of $45 \mathrm{GPU}$ are low for the current $\mathrm{CO}_{2}$ capture application. In Set 2, to improve the selectivity and permeability value, WFX deposited selective layers of about 1 to $2 \mu \mathrm{m}$ in thickness with different polymer densities on the surface of the asymmetric fiber ( $1 \mathrm{~mm} \mathrm{OD}$ ). The $\mathrm{H}_{2}$ permeance values were in the range 5 to $125 \mathrm{GPU}$ and the corresponding $\mathrm{H}_{2} / \mathrm{CO}_{2}$ selectivities were in the range 6 to 40 . The high value of permeance was associated with a low value of selectivity and vice versa. The relatively high surface roughness of the substrate fiber prevented deposition of a thin and defect-free dense layer that is necessary to obtain both high selectivity and permeance. In Set 3, a new substrate fiber $(0.6 \mathrm{~mm})$ with a reduced surface roughness was used to deposit an ultra-thin and 
defect-free dense coating. The performance evaluation at SRI had indicated $\mathrm{H}_{2} / \mathrm{CO}_{2}$ selectivities in the range 15 to 40 with $\mathrm{H}_{2}$ permeance of 150 to $200 \mathrm{GPU}$ at $250^{\circ}$ (Figure E1). However, a significant variation in the fiber performances was observed for multiple fibers that were coated using the same procedure. These variations are due to an inherent difficulty controlling the quality while applying the dense layer on the porous substrate fiber. In Set 4, the substrate fiber was heat treated before applying the coating and in some cases, the fiber was also heat treated after coating. $\mathrm{H}_{2} / \mathrm{CO}_{2}$ selectivity (9 to 38) and $\mathrm{H}_{2}$ permeation (150 to $350 \mathrm{GPU}$ ) values varied significantly between fibers.

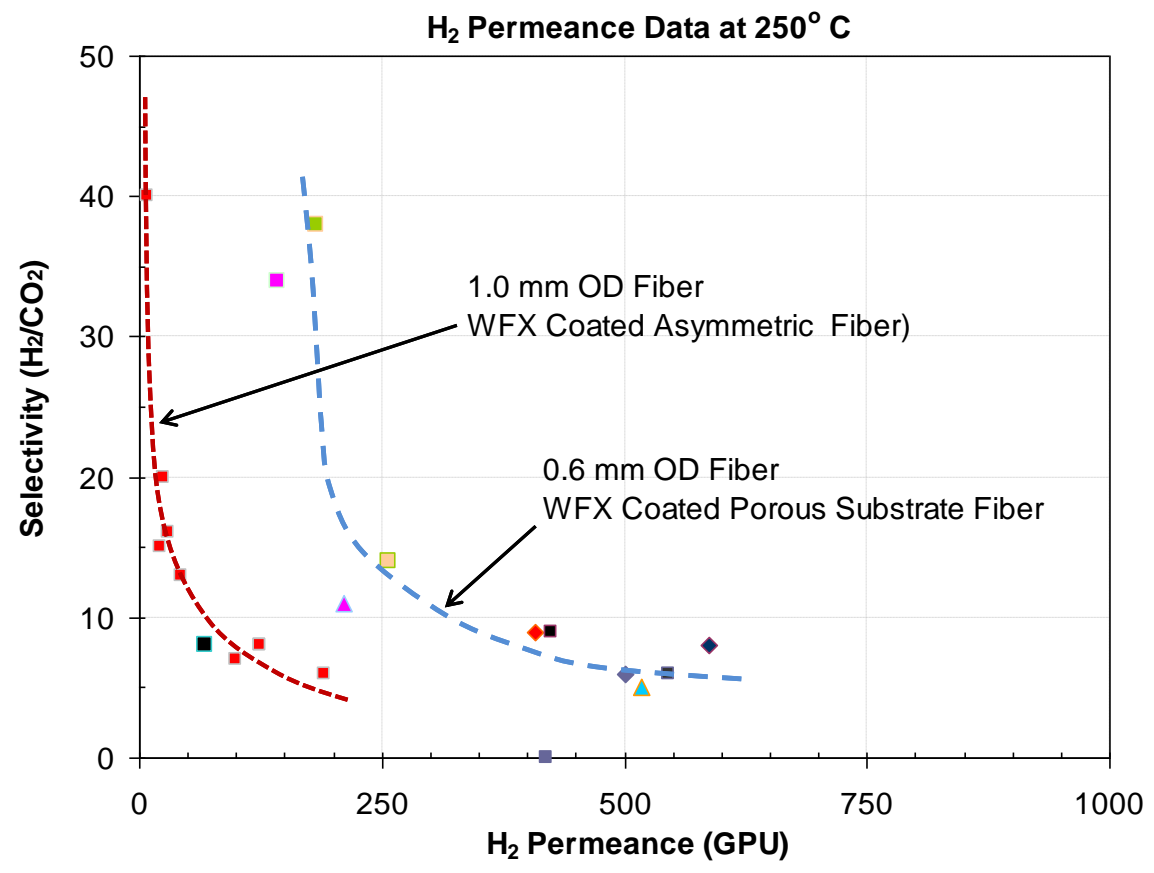

Figure E-1. The measured permeance of $\mathrm{H}_{2}$ in GPU and $\mathrm{H}_{2} / \mathrm{CO}_{2}$ selectivity of selected WFX-PBI hollow fiber at $250^{\circ} \mathrm{C}$.

The coating procedure used at WFX resulted in relatively short length fibers $(\sim 1$ meter $)$ with variable quality. The unavailability of the required fiber lengths $(\sim 5 \mathrm{~km})$ and poor quality control became the barriers in progressing to module fabrication. SRI under-took a program in which a porous substrate and dense layer were fabricated in a single step spinning an asymmetric membrane from a PBI polymer solution (PBI dope). This approach expedited the process to fabricate fibers in large quantities with minimal defects.

To identify the critical process parameters in the fiber spinning, we used a generic design of experiment (DOE) approach with two level-factorial design to quickly identify the controllable input factors that can be modified to optimize the quality of the hollow fiber. Based on that work, we selected two possible dope formulations that will produce 
asymmetric hollow fiber membranes $(0.6 \mathrm{~mm}$ and $0.3 \mathrm{~mm}$ OD) with $<0.5 \mu \mathrm{m}$ selective dense layer membrane. Figure E-2 shows examples of the PBI hollow fiber membranes produced and Figure E-3 shows a high magnification of the cross section of the fibers. The cross section images show a dense and ultrathin exterior layer and a porous interior. The $\mathrm{H}_{2} / \mathrm{CO}_{2}$ selectivity and $\mathrm{H}_{2}$ permeation characteristics of SRI-fabricated membranes are shown in Figure E-4.

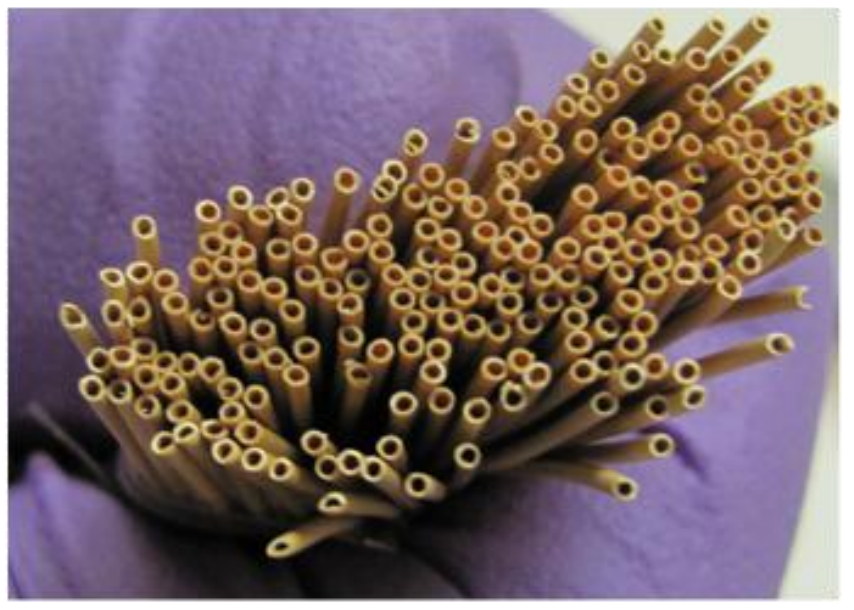

Figure E-2. Image of a bundle of PBI-based, asymmetric hollow fibers made at SRI.

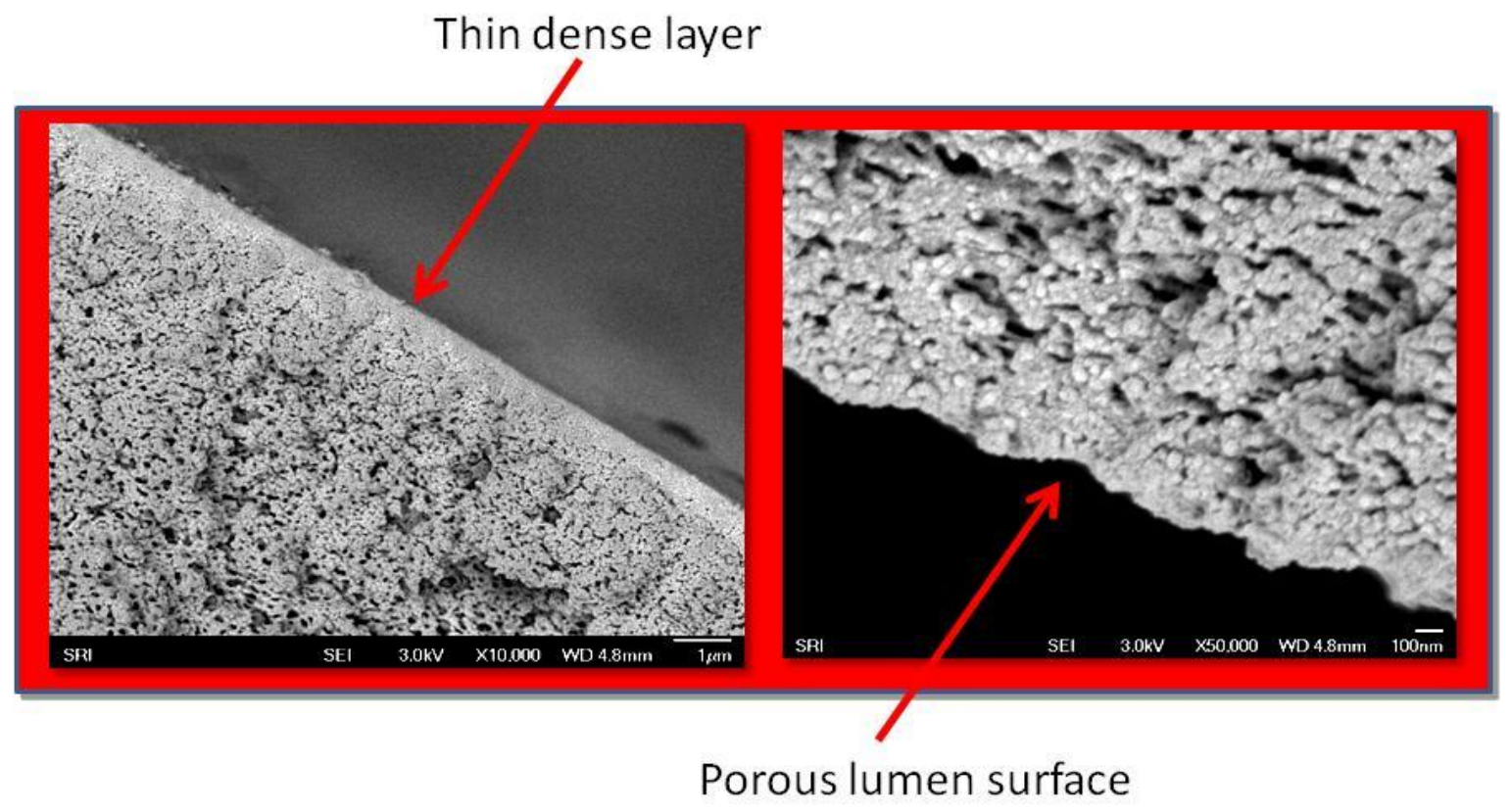

Figure E-3. High magnification photographs of cross-sections near shell and lumen sides of SRI Series A fiber. 


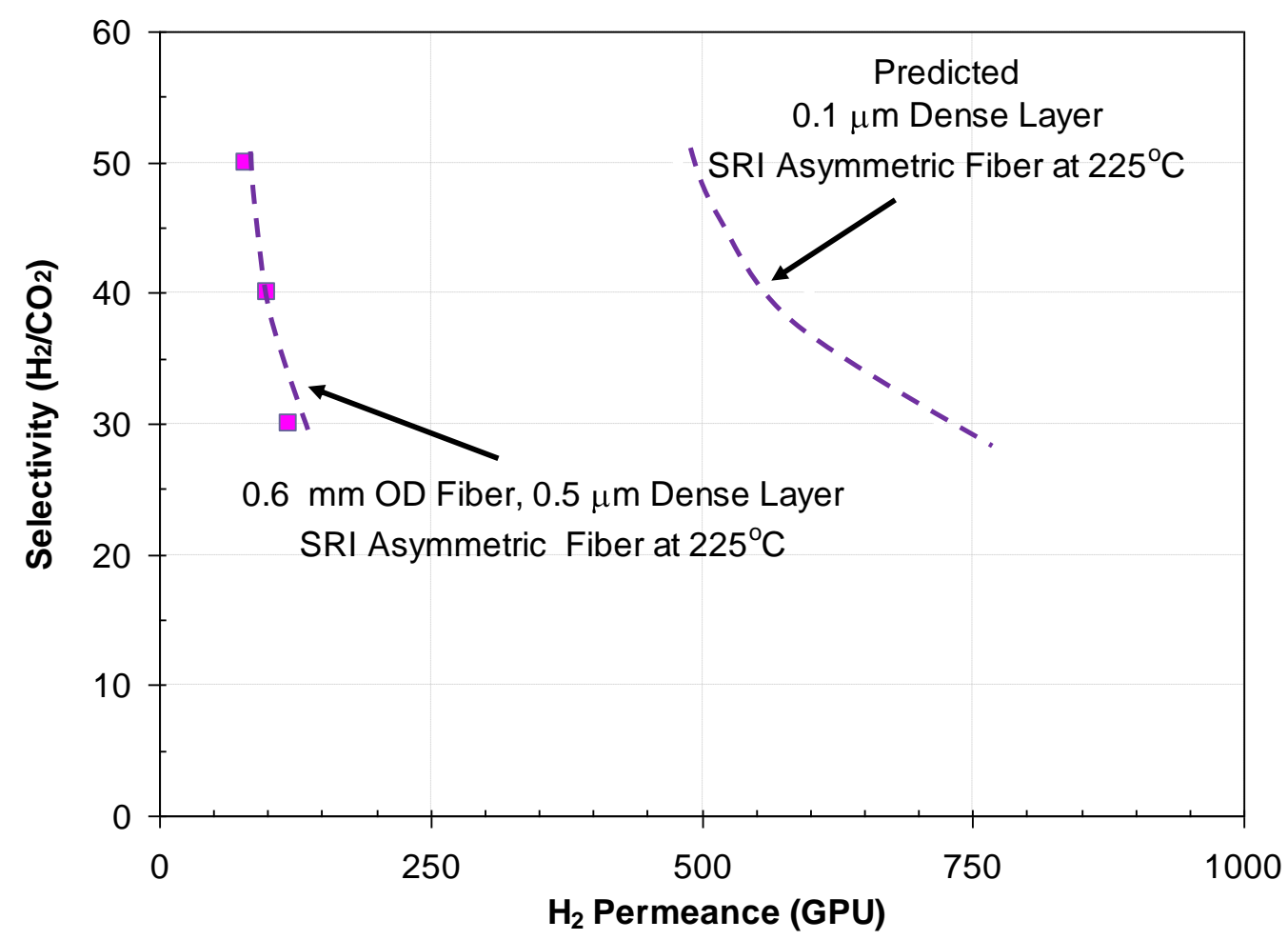

Figure E-4. Relationship between selectivity for $\mathrm{H}_{2} / \mathrm{CO}_{2}$ and $\mathrm{H}_{2}$ permeance at $250^{\circ} \mathrm{C}$ for SRI fabricated fibers.

Figure E-5 compares the $\mathrm{H}_{2} / \mathrm{CO}_{2}$ with $\mathrm{H}_{2}$ permeability using the well-known Robeson plot. It shows clearly, the hollow fibers produced at SRI have higher selectivities and/or permeance than other polymers and approach the values observed at Los Alamos National Laboratory with PBI dense layer deposited on a porous stainless steel substrate. The PBI hollow fiber geometry provides an order-of-magnitude decrease in the module size over the stainless steel substrate.

The performance of SRI fiber series A was evaluated over 50 days, representing the performance over 1000 hours. The selectivity for $\mathrm{H}_{2} / \mathrm{CO}_{2}$ improved with time increasing from 35 to 50, exceeding the design target of 40. Long term performance evaluation data are shown in Figure E-6. The $\mathrm{H}_{2}$ permeance value at $225^{\circ} \mathrm{C}$ remained at about $80 \mathrm{GPU}$ throughout the test period and this value is also above the target value. At the end of the 1000 -h test period, the $\mathrm{H}_{2}$ permeance was measured to be $130 \mathrm{GPU}$ at $250^{\circ} \mathrm{C}$. 


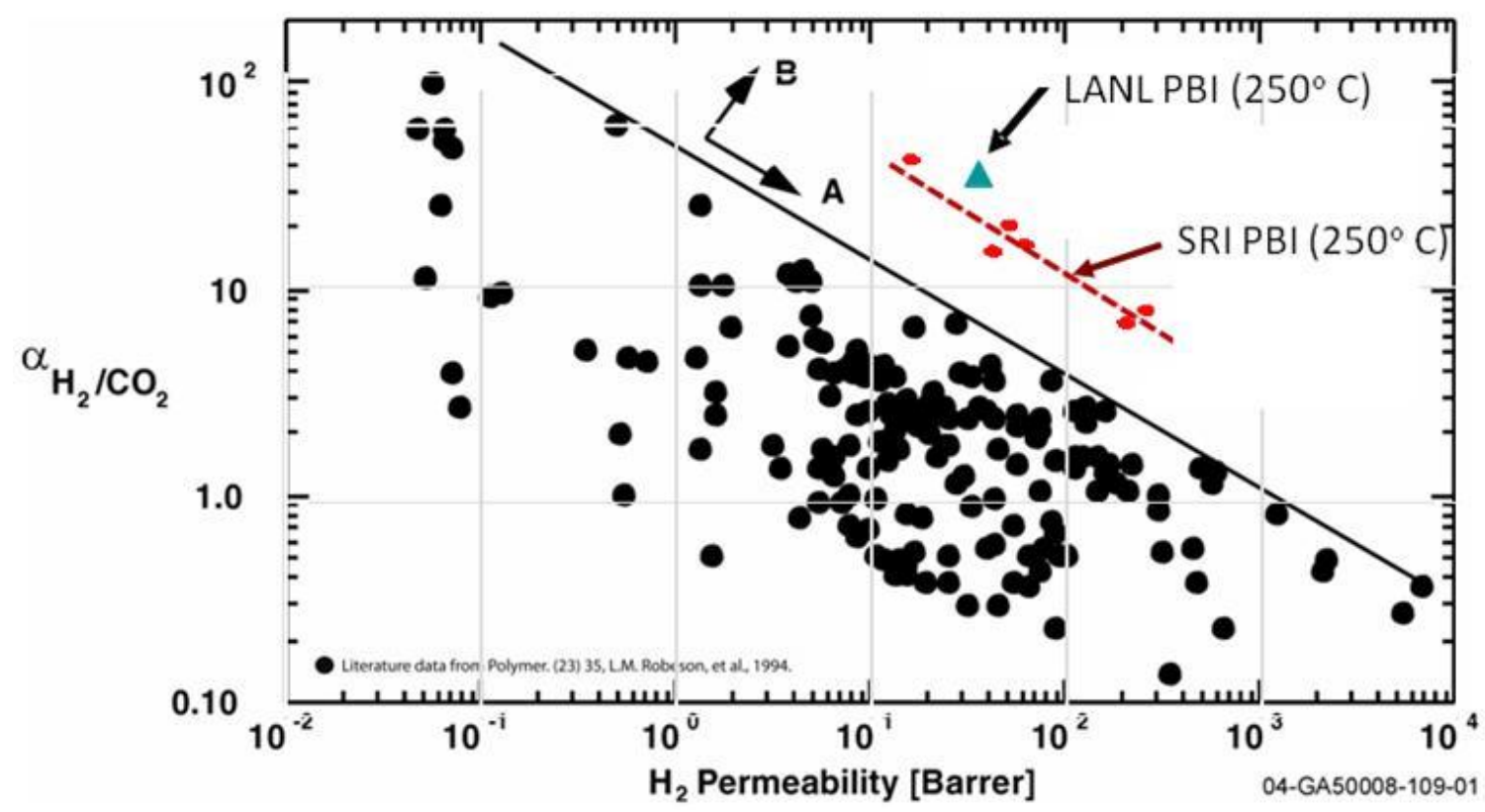

Figure E-5. Comparison of $\mathrm{H}_{2} / \mathrm{CO}_{2}$ selectivity and $\mathrm{H}_{2}$ permeability in polymers.

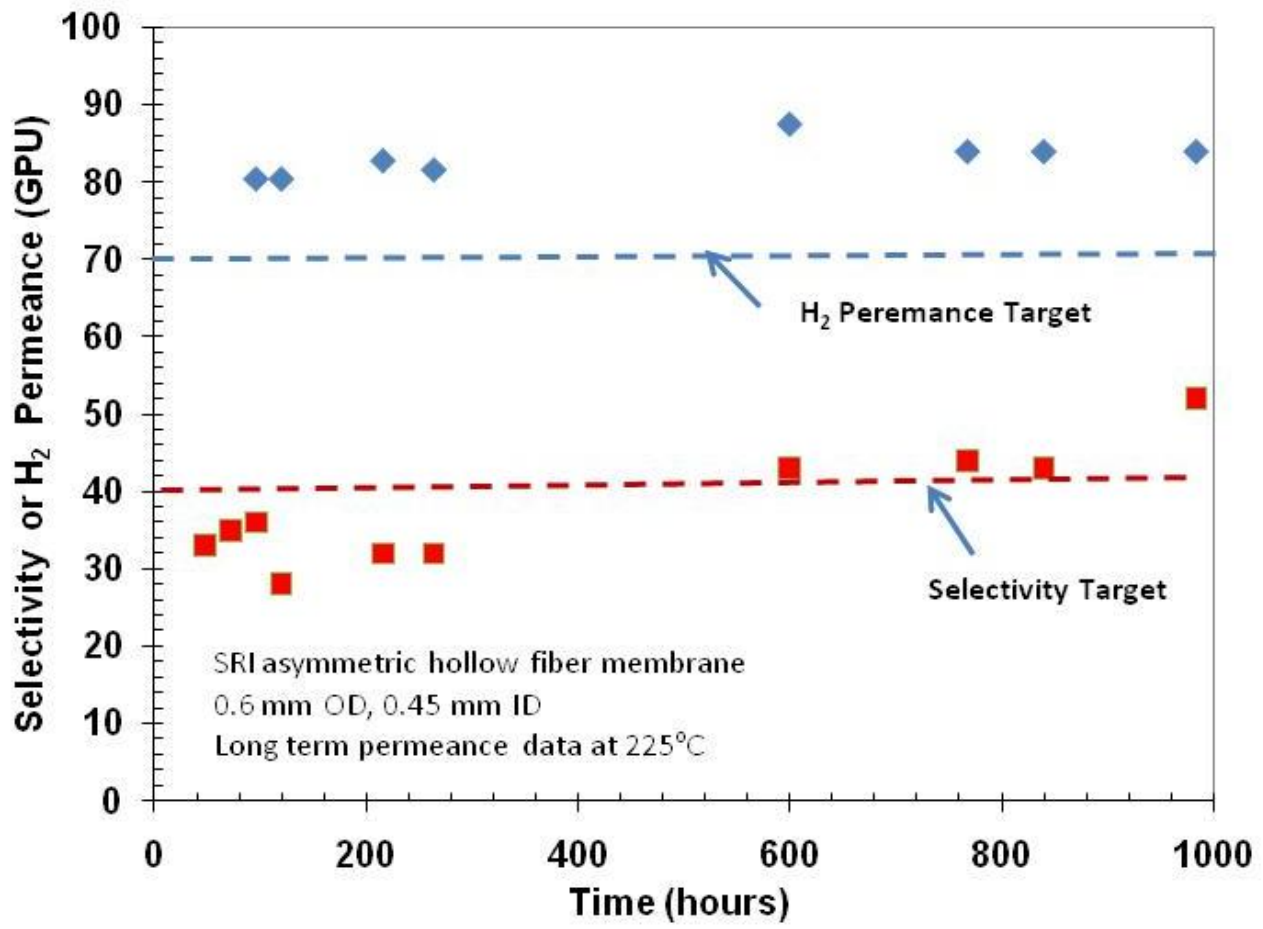

Figure E-6. Measured selectivity for $\mathrm{H}_{2} / \mathrm{CO}_{2}$ and $\mathrm{H}_{2}$ permeance at $225^{\circ} \mathrm{C}$ measured over $1000 \mathrm{~h}$. 
We constructed a $50 \mathrm{~kW}_{\text {th }}$ test skid which consisted of two membrane modules. We selected 4-in ID pressure vessels for installation of the hollow fiber (HF) elements and capable of operation at $600 \mathrm{psi}$ and $250^{\circ} \mathrm{C}$. SRI fabricated about $10 \mathrm{~km}$ of asymmetric hollow fiber membranes made of PBI polymer. The test skid consisted of two 4" x 1' pressure vessels for housing the hollow fiber. The skid system used commercial off the shelf (COTS) control systems and connectors.

A $120 \mathrm{~h}$ test of the hollow fiber element showed the $\mathrm{H}_{2} / \mathrm{CO}_{2}$ selectivity and $\mathrm{H}_{2}$ permeance are similar to those observed earlier. The selectivity for $\mathrm{H}_{2} / \mathrm{CO}_{2}$ remained constant with time at about 30 and the $\mathrm{H}_{2}$ permeance value remained at about 85 to $96 \mathrm{GPU}$ throughout the test period and these values are well above the target value of 75 . At the end of the 120-h test period, the $\mathrm{H}_{2}$ permeance was measured to be 92 GPU at a temperature of $225^{\circ} \mathrm{C}$.

In summary, the project has produced successfully, for the first time, a high temperature, PBI-based hollow fiber module for the separation of $\mathrm{CO}_{2}$ from $\mathrm{H}_{2}$. We demonstrated long term stability of these fibers with a relatively high $\mathrm{H}_{2} / \mathrm{CO}_{2}$ selectivity and $\mathrm{H}_{2}$ permeance in the target range. The experience gained in this project will be transferred to the industry to demonstrate the separation process at pilot- and commercialscale levels.

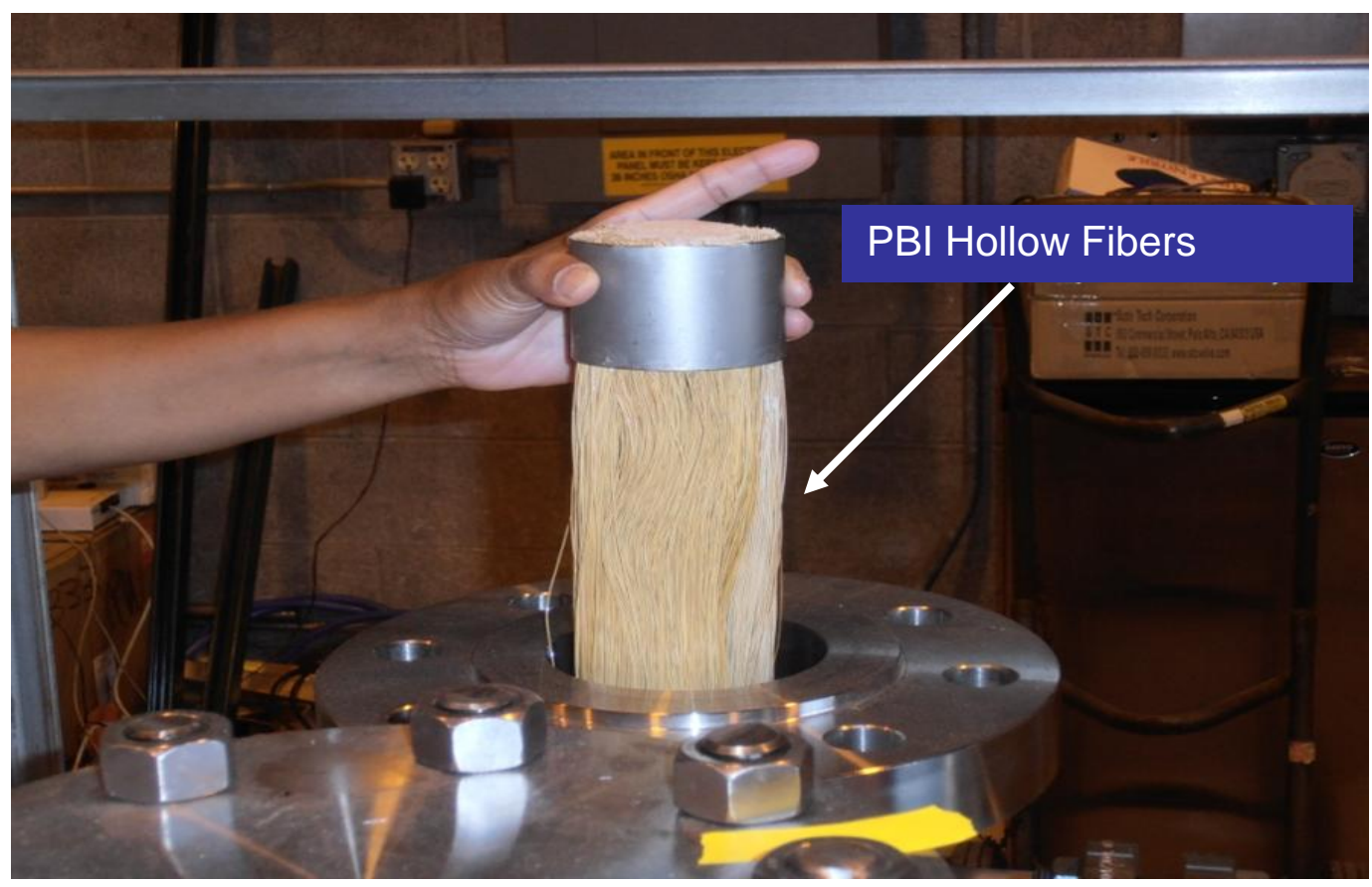

Figure E-7. A photograph of 3-in diameter x1-ft long HF element for insertion in the pressure vessel. 


\section{Membrane Performance Simulation and Economic Analysis}

Aspen modeling was used at SRI to evaluate the location and performance effects that the PBI membrane system will have on the overall power plant performance. The performance of the membrane system was simulated using a proprietary model of Enerfex, Inc. To optimize the overall plant and take advantage of the beneficial characteristics of the membrane system, we considered six scenarios:

- Scenario 1: Base case IGCC plant with no $\mathrm{CO}_{2}$ capture: In this base case scenario, the gas stream from the gasifier is cooled, and $\mathrm{NH}_{3}$ and $\mathrm{Hg}$ vapor are removed before $\mathrm{H}_{2} \mathrm{~S}$ is removed using Selexol solvent. The clean fuel gas stream is sent to the gas turbine.

The following scenarios are IGCC plants equipped with $\mathrm{CO}_{2}$ capture. In these scenarios, WGSRs are used to convert $\mathrm{CO}$ in the fuel gas to $\mathrm{CO}_{2}$ (sour gas shift). The major components of the gas leaving the shift reactors are $\mathrm{H}_{2}, \mathrm{CO}_{2}$, and steam with minor levels of $\mathrm{H}_{2} \mathrm{~S}$ and $\mathrm{NH}_{3}$.

- Scenario 2: Selexol units are used to separate $\mathrm{CO}_{2}$ and $\mathrm{H}_{2} \mathrm{~S}$ from $\mathrm{H}_{2}$. Most of the steam is condensed out during the cool-down of the gas to the operating temperature of the Selexol unit.

- Scenario 3: The PBI membrane is used to separate the $\mathrm{H}_{2}$ and steam from the $\mathrm{CO}_{2}$. The $\mathrm{H}_{2} \mathrm{~S}$ is in the retentate stream, separated from the $\mathrm{CO}_{2}$ using Selexol and sent to a Claus unit for $\mathrm{S}$ recovery.

- Scenario 4: The PBI membrane is used to separate the $\mathrm{H}_{2}$ and steam from the $\mathrm{CO}_{2}$. The $\mathrm{H}_{2} \mathrm{~S}$ in the retentate stream and is not separated from the $\mathrm{CO}_{2}$

- Scenario 5: The PBI membrane is used to separate the $\mathrm{H}_{2}$ and steam from the $\mathrm{CO}_{2}$. The $\mathrm{H}_{2} \mathrm{~S}$ permeates with the $\mathrm{H}_{2}$ and is separated with Selexol and sent to a Claus unit.

In our simulation, the process conditions were made as consistent as possible with the NETL results presented in 2007.

An Aspen/GT-Pro model was used to simulate the various IGCC scenarios. In all scenarios, the IGCC plant uses a GEE (Texaco) radiant only gasifier and two GE F-class gas turbines, each of which produces $232 \mathrm{MW}$. The two gas turbines dictate the sizing of the entire IGCC plant because, depending on the fuel's composition, they can require a specific amount of fuel. For this reason, both the total power output and the coal feed rate vary on the basis of the parameters of each scenario. The syngas fuel composition found in Aspen was entered into the GT-Pro model. Both GT-Pro and Aspen calculated a required syngas fuel flow rate to the gas turbines. Once both programs were in agreement, heat integration was performed with the heating and cooling streams required in the Aspen 
model accounted for in the GT-Pro model. Given these heating and cooling inputs along with the syngas composition, GT-Pro calculated the steam turbine power output. Finally, the NETL spread-sheet was used to estimate the cost of $\mathrm{CO}_{2}$ capture for the different scenarios.

The economic summaries by scenario are shown in Table E-2. The two NETL cases are included to provide a basis for comparison. Because the NETL cost estimates were used as guidelines to generate the costs for the official scenarios, although the models may differ, the costs should be equivalent for equivalent plants. The data show that Scenario 1 and NETL Case 1 have only a $0.2 \%$ deviation in the total COE. On the other hand, Scenario 2 and NETL Case 2 have a deviation of $5.2 \%$ for the reasons cited above. The PBI scenarios shown in Table E-2 are based on conservative estimates concerning both the PBI membrane ( $0.5 \mu \mathrm{m}$ thick separation layer) and the operation parameters (fuel gas inlet pressure: 450 psia) of the gas turbine.

Table E-3 contains PBI scenarios that rely on achievable characteristics of the PBI membrane and the operation of the gas turbine. Specifically, the separation layer of the membrane has been decreased from 0.5 to $0.1 \mu \mathrm{m}$. In addition, the fuel pressure for the gas turbine is assumed to be 290 psia instead of 450 psia. We also assumed that the $\mathrm{H}_{2} \mathrm{~S}$ present in the $\mathrm{CO}_{2}$ retentate stream will not be converted to elemental sulfur using Selexol solvent and Claus process. Separation of $\mathrm{H}_{2} \mathrm{~S}$ and $\mathrm{CO}_{2}$ can be achieved by an alternative process that is currently being tested by SRI in the National Carbon Capture Center. The Bechtel High Pressure Swing Claus Process (BHTS) converts $\mathrm{H}_{2} \mathrm{~S}$ under elevated pressure without the need to separate $\mathrm{H}_{2} \mathrm{~S}$ from $\mathrm{CO}_{2}$. The resulting decrease in cost is dramatic. In the case of Scenario 4, the $\mathrm{COE}$ increase required for the capture and compression of $\mathrm{CO}_{2}$ is under $10 \%$. However, when the cost of transporting, storing, and monitoring the $\mathrm{CO}_{2}$ is accounted for, the increase in the COE is $14.4 \%$, approaching the DoE goal.

\section{Strategic Plan Development}

To support this overall program goal, the project team has used a commercialization approach to infuse the business perspective and acumen into the technology development process to ensure that the needs and requirements of stakeholders with a vested interest in the success of the technology are taken into account during the research and development phase. Visage Energy in cooperation with SRI, Energy Commercialization and other team members prepared a topical report on the strategic development plan. The report is attached as Appendix C. 
The results of this work showed that accelerated deployment of CCS technologies hinges not only on the economics of the process, but also on the ability to create a regulatory environment that encourages investment in these technologies and rewards early technology adopters. The CCS technology learning curve could be decreased by the timely and coordinated deployment of utility-scale state-of-the-art technologies enabling the sharing of best practices concerning the permitting process, design, construction, startup, and operation of power generation facilities with CCS within each of the different technology pathways.

A commercialization pathway schedule was developed based on the on the technical progress and expected time line for availability of modules for pilot testing. Several factors were considered when establishing this schedule:

- Upstream factors such as gasifier type and characteristics of fuel source may cause variation in the performance of capture systems.

- Non-technical factors such as regulatory changes and public opinion could impact timelines for pilot, demonstration, and deployment of new capture systems.

- Commercialization of PBI capture systems will impact supply chains such as the global supply of PBI hollow fibers and PBI polymer.

- Mitigating these risks was important in order to rapidly transition PBI capture systems from pilot to demonstration to deployment.

Several technical and business risks could impact the commercialization pathway. The risks and actions that need to be taken to mitigate these risks are summarized in Table E-4.

The global nature of carbon capture coupled with the international relationships developed by the Department of Energy and NETL have created an environment that facilitates international cooperation. This enables pilot and demonstration projects to be performed in parallel. Pre-planning on a global scale between research institutes coupled with experimental design and data sharing should accelerate the commercialization process. This approach mitigates the risks listed below and enables an efficient and effective method to enable PBI capture systems to be transitioned into full deployment. 
Table E-2. Summary of Economic Estimates by Scenario

Project Cases (Conservative Estimates)

\begin{tabular}{|c|c|c|c|c|c|c|c|c|}
\hline & Units & $\begin{array}{l}\text { No Capture } \\
\text { NETL Case } 1\end{array}$ & $\begin{array}{c}\text { Selexol Capture } \\
\text { NETL Case } 2\end{array}$ & $\begin{array}{l}\text { No Capture } \\
\text { Scenario } 1\end{array}$ & $\begin{array}{c}\text { Selexol } \\
\text { Capture } \\
\text { Scenario } 2\end{array}$ & $\begin{array}{c}\mathrm{PBI} \text { Capture, } \\
\mathrm{H}_{2} \mathrm{~S} \text { removal } \\
\text { from } \mathrm{CO}_{2} \\
\text { Scenario } 3\end{array}$ & $\begin{array}{l}\mathrm{PBI} \text { Capture, } \\
\mathrm{No} \mathrm{H}_{2} \mathrm{~S} \\
\text { removal from } \\
\mathrm{CO}_{2} \\
\text { Scenario } 4\end{array}$ & $\begin{array}{l}\mathrm{PBI} \text { Capture, } \\
\mathrm{H}_{2} \mathrm{~S} \text { removal } \\
\text { from } \mathrm{H}_{2} \\
\text { Scenario } 5\end{array}$ \\
\hline Power Production @ 100\% Capacity & GWh/yr & 5609 & 4868 & 5,455 & 4,460 & 4,566 & 4,755 & 4,519 \\
\hline Power Plant Capital & $\mathrm{c} / \mathrm{kWh}$ & 4.53 & 5.97 & 4.50 & 6.19 & 6.24 & 5.43 & 6.35 \\
\hline Power Plant Fuel & $\mathrm{c} / \mathrm{kWh}$ & 1.94 & 2.28 & 1.90 & 2.47 & 2.68 & 2.54 & 2.73 \\
\hline Variable Plant O\&M & $\mathrm{c} / \mathrm{kWh}$ & 0.75 & 0.94 & 0.78 & 1.00 & 0.98 & 0.95 & 0.99 \\
\hline Fixed Plant O\&M & $\mathrm{c} / \mathbf{k W h}$ & 0.58 & 0.72 & 0.60 & 0.79 & 0.77 & 0.74 & 0.78 \\
\hline Cost of Electricity (COE)* & c/kWh & 7.80 & 9.91 & 7.78 & 10.44 & 10.67 & 9.66 & 10.85 \\
\hline Cost of Electricity (COE) & $\mathrm{c} / \mathrm{kWh}$ & 7.80 & 10.33 & 7.78 & 10.86 & 11.09 & 10.06 & 11.27 \\
\hline Increase in $\mathrm{COE}^{\star}$ & $\%$ & $\mathrm{n} / \mathrm{a}$ & $27.3 \%$ & $\mathrm{n} / \mathrm{a}$ & $34.2 \%$ & $37.1 \%$ & $24.1 \%$ & $39.3 \%$ \\
\hline Increase in COE & $\%$ & $\mathrm{n} / \mathrm{a}$ & $32.7 \%$ & $\mathrm{n} / \mathrm{a}$ & $39.5 \%$ & $42.5 \%$ & $29.2 \%$ & $44.8 \%$ \\
\hline
\end{tabular}


Table E-3. Summary of economic estimates with process improvements

\begin{tabular}{|c|c|c|c|c|}
\hline & & $\begin{array}{l}\mathrm{PBI} \text { Capture, } \\
\mathrm{H}_{2} \mathrm{~S} \text { removal } \\
\text { from } \mathrm{CO}_{2}\end{array}$ & $\begin{array}{c}\mathrm{PBI} \text { Capture, } \\
\mathrm{No}_{2} \mathrm{~S} \\
\text { removal from } \\
\mathrm{CO}_{2}\end{array}$ & $\begin{array}{c}\text { PBI Capture, } \\
\mathrm{H}_{2} \mathrm{~S} \text { removal } \\
\text { from } \mathrm{H}_{2}\end{array}$ \\
\hline & Units & Scenario 3 & Scenario 4 & Scenario 5 \\
\hline Power Production @ 100\% Capacity & $\mathrm{GWh} / \mathrm{yr}$ & 4,980 & 5,152 & 4,944 \\
\hline Power Plant Capital & $\mathbf{c} / \mathbf{k W h}$ & 5.39 & 4.75 & 5.45 \\
\hline Power Plant Fuel & $\mathrm{c} / \mathrm{kWh}$ & 2.30 & 2.22 & 2.31 \\
\hline Variable Plant O\&M & c/kWh & 0.91 & 0.89 & 0.92 \\
\hline Fixed Plant O\&M & $\mathrm{c} / \mathrm{kWh}$ & 0.71 & 0.68 & 0.71 \\
\hline Cost of Electricity (COE) ${ }^{\star}$ & $\mathrm{c} / \mathrm{kWh}$ & 9.30 & 8.54 & 9.39 \\
\hline Cost of Electricity (COE) & $\mathrm{c} / \mathrm{kWh}$ & 9.68 & 8.90 & 9.77 \\
\hline Increase in $\mathrm{COE}^{\star}$ & $\%$ & $19.5 \%$ & $9.7 \%$ & $20.6 \%$ \\
\hline Increase in COE & $\%$ & $24.4 \%$ & $14.4 \%$ & $25.5 \%$ \\
\hline
\end{tabular}


Table E-4. Risks to the Implementation of the Commercialization Pathway and Actions to Mitigate Risks

\begin{tabular}{|c|c|}
\hline Risk & Mitigation \\
\hline $\begin{array}{l}\text { Limited worldwide PBI production } \\
\text { capacity requires new PBI production } \\
\text { plants }\end{array}$ & $\begin{array}{l}\text { PBI supplier becomes member of } \\
\text { development team and provides input on } \\
\text { commercialization pathway. PBI supplier } \\
\text { provides plan to support pathway. }\end{array}$ \\
\hline $\begin{array}{l}\text { PBI hollow fiber production capacity } \\
\text { requires significant increase in capacity }\end{array}$ & $\begin{array}{l}\text { PBI hollow fiber supplier is currently team } \\
\text { member. Supplier provides feedback on } \\
\text { pathway and plan for capacity increase to } \\
\text { support pathway. }\end{array}$ \\
\hline $\begin{array}{l}\text { Geographic variations in fuel supply result } \\
\text { in large variations in system performance. }\end{array}$ & $\begin{array}{l}\text { Parallel pilot testing and a Design of } \\
\text { Experiment Approach provide a means to } \\
\text { quickly identify sources of variation and } \\
\text { potential solutions. International } \\
\text { cooperation provides the intellectual capital } \\
\text { to solve issues. }\end{array}$ \\
\hline $\begin{array}{l}\text { Regulatory requirements and/or public } \\
\text { opinion extend approval times and hence } \\
\text { project time lines }\end{array}$ & $\begin{array}{l}\text { Parallel testing in a variety of international } \\
\text { markets with a range of regulatory and } \\
\text { public opinion processes increases } \\
\text { probability that projects move forward in at } \\
\text { least one region. }\end{array}$ \\
\hline $\begin{array}{l}\text { Variation in gasifier types creates variation } \\
\text { in system performance }\end{array}$ & $\begin{array}{l}\text { Design of Experiment Approach and } \\
\text { parallel evaluations provide a means to } \\
\text { identify and resolve issues. }\end{array}$ \\
\hline $\begin{array}{l}\text { Increase in worldwide demand for ancillary } \\
\text { membrane equipment drives up capital } \\
\text { costs }\end{array}$ & $\begin{array}{l}\text { Increase in production capacity of PBI } \\
\text { polymer and hollow fiber should help } \\
\text { reduce cost of fiber and provide some } \\
\text { offset to other potential cost increases. } \\
\text { Competition from other technologies will } \\
\text { also limit increases in costs to the end-user. }\end{array}$ \\
\hline
\end{tabular}

\section{Conclusions and Recommendations}

Based on the experimental and analytical results obtained in this project, we reach the following conclusions:

- PBI-based hollow fibers have been fabricated at kilometer lengths and bundled as modules at a bench-scale level for the separation of $\mathrm{CO}_{2}$ from $\mathrm{H}_{2}$ at high temperatures and pressures. 
- Long term stability of these fibers has been demonstrated with a relatively high $\mathrm{H}_{2} / \mathrm{CO}_{2}$ selectivity ( 35 to 50 ) and $\mathrm{H}_{2}$ permeance ( $80 \mathrm{GPU}$ ) at temperatures exceeding $225^{\circ} \mathrm{C}$.

- The experience gained in this project is ready for transfer to the industry to demonstrate the separation process at pilot- and commercial-scale levels.

- Membrane performance simulations and systems analysis of an IGCC system incorporating a PBI hollow fiber membrane modules have demonstrated that the cost of electricity for $\mathrm{CO}_{2}$ capture $(<10 \%)$ using such a high temperature separator. When the cost of transporting, storing, and monitoring the $\mathrm{CO}_{2}$ is accounted for, the increase in the COE is only $14.4 \%$, approaching the DoE goal.

- A commercialization pathway schedule was developed based on the on the technical progress and expected time line for availability of modules for pilot testing.

The following recommendations are made:

- The development of the PBI hollow fiber fabrication should be continued at a pilotscale level using commercially appropriate equipment.

- The PBI hollow fibers shall be assembled into modules and made into a system that is capable of handling gas streams equivalent of a 0.25 MWe IGCC system.

- The system should be tested using the gas stream from an operating gasifier for extended period of time to validate the long-term stability of PBI membranes.

- System level studies should be continued to update the cost of $\mathrm{CO}_{2}$ capture using the PBI membrane systems. 


\section{INTRODUCTION}

Capturing carbon dioxide from mixed-gas streams is a first and critical step in carbon sequestration. To be technically and economically viable, a successful separation method must be applicable to industrially relevant gas streams at realistic temperatures, and be compatible with large gas volumes. While the separation of $\mathrm{CO}_{2}$ from process streams is readily accomplished via standard separation techniques such as amine scrubbing and pressure-swing adsorption, the effectiveness of these current technologies for separating $\mathrm{CO}_{2}$ is limited. These techniques require low temperatures and produce a low-pressure $\mathrm{CO}_{2}$ stream, resulting in a significant energy penalty for separating $\mathrm{CO}_{2}$. In contrast, polymer-based membrane separations are less energy intensive, requiring no phase change in the process, and typically provide lowmaintenance operations. Polymers exhibit a high selectivity due to the combination of size-based and solubility-based molecular separation, a dual-mode mechanism not shared by size-driven, inorganic membrane separations. Polymer membranes have been used successfully in a number of industrial applications, including the production of high-purity nitrogen, gas dehydration, removal of acid gases, and recovery of hydrogen from process streams for recycle [Koros and Fleming, 1993; Hagg, 1998; Koros and Mahajan, 2000]. However, successful use of a polymer membrane in a synthesis gas separation requires a membrane that is thermally, chemically, and mechanically stable at high temperature and high pressure in the presence of the chemically challenging syngas components. Unfortunately, the commercially available polymeric materials currently used in separation applications are not stable in these demanding environments to the degree required. Current membrane materials are often subject to chemical degradation by minor components in the process stream, a problem that is exacerbated by elevated temperature. Additionally, as the glass transition temperature of the polymer is approached, membrane selectivity is significantly reduced, and the gas flux declines due to increase in membrane compaction (creep). Consequently, there is a compelling need for membrane materials and subsequently capture systems based on those materials that can operate under more extreme environmental conditions for extended periods of time while providing a level of performance that is economically sustainable by the end user.

Alternatives to polymer membranes are the inorganic membranes, which include zeolites [Tuan et al., 2000], carbon molecular sieves, and selective surface-flow (SSF) membranes [Anand et al, 1997; Rao and Sircar, 1993-a, Rao and Sircar, 1993-b, Vu and Koros, 2002; Armonr, 1998; Larbot et al., 1988; Lee, 2002; Lin, 2001; Prabhu and Oyama, 2000].These membranes currently suffer from lack of reproducibility, densification due to humidity and elevated temperatures, and high-cost fabrication. Given these limitations, mixed matrix membranes and cross-linked membranes have been suggested as viable development pathways 
of the future [Koros and Mahajan, 2000]. Mixed matrix membranes are composed of carbon molecular sieves or zeolites embedded in a polymer matrix [Mahajan and Koros, 2002].Although permeabilities and selectivities have been increased above the traditional upper bound for polymers, application temperatures are still limited by the polymer matrix.Alternatively, crosslinked membranes can reduce the plasticization effects at elevated pressures [Staudt and Bickel, 1999] as well as increase membrane selectivity [Kita et al., 1994; Liu et al., 1999]; however, permeability is adversely affected. Hence, the development of high-performance polymer membranes remains a very attractive and viable engineering approach to filling the critical need for high-temperature membrane separations.

Use of a high-temperature stable polymer such as poly-benzo-imidazole-(PBI) as a membrane material will address the above-mentioned limitations of the current state of the art and the corresponding separations needs of the utility sector. Prior to this project, a team at the Los Alamos National Laboratory (LANL) indicated that the composite membranes made with a dense PBI layer on a porous metal substrate function at significantly higher temperatures than current commercially available polymeric membranes $\left(<150^{\circ} \mathrm{C}\right)$.In addition, the composite membranes provide improved performance while exhibiting long-term temperature stability, sulfur tolerance, and overall durability.

PBI, the membrane selective layer, (structure shown in Figure 2), is a commercially available (Celanese Corp.) high-temperature polymer that is stable to temperatures approaching $500^{\circ} \mathrm{C}$. PBI possesses excellent chemical resistance, a very high glass transition temperature ( 460$500^{\circ} \mathrm{C}$ ), good mechanical properties, and an appropriate level of processability [Berchtoldet. Al., 2006].

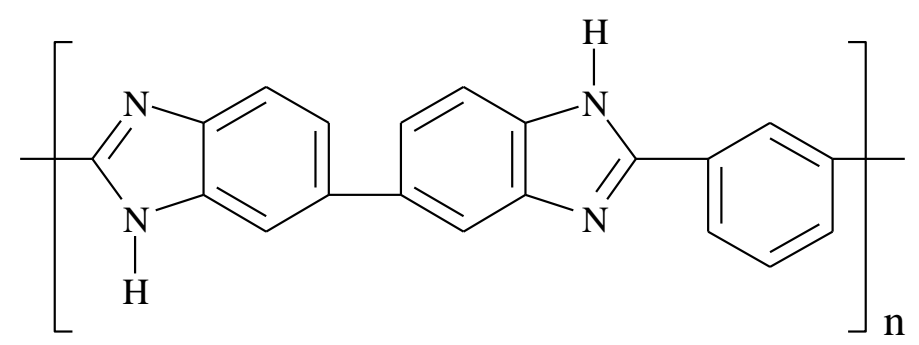

Figure I-1. Chemical structure of polybenzimidazole.

The approach used at LANL was to deposit a thin dense layer of PBI on a porous metal substrate that provided mechanical support. This approach is similar to fabricating polyimide selective layers on ceramic supports that have previously been developed [Rezak and Koros, 1992]. Composite membranes have been formed at LANL by coating a dense, thin (1 to $15+\mu \mathrm{m})$ selective layer of PBI onto a commercially available metallic substrate. 
The PBI selective layer is used for separating $\mathrm{H}_{2}$, the primary fuel gas in the coal-derived syngas stream, from $\mathrm{CO}_{2}$ and the other gases in the feed stream. In a mixed gas feed stream that primarily contains $\mathrm{H}_{2}$ and $\mathrm{CO}_{2}$, the $\mathrm{CO}_{2}$ remains as the raffinate (rejected by the membrane), while the $\mathrm{H}_{2}$ is the permeate (goes through the membrane). It is this ability to retain $\mathrm{CO}_{2}$ in the raffinate, and thus, at the high feed pressure,reduces the compression energy needed to transport $\mathrm{CO}_{2}$ through pipelines. The results obtained at LANL showed that the $\mathrm{H}_{2} / \mathrm{CO}_{2}$ selectivity of the PBI-

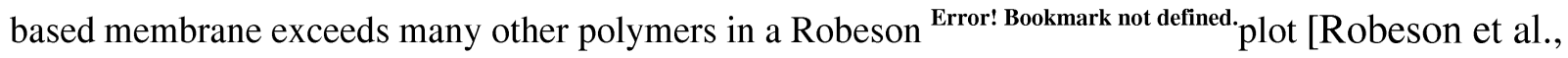
1994], as shown in Figure 5.

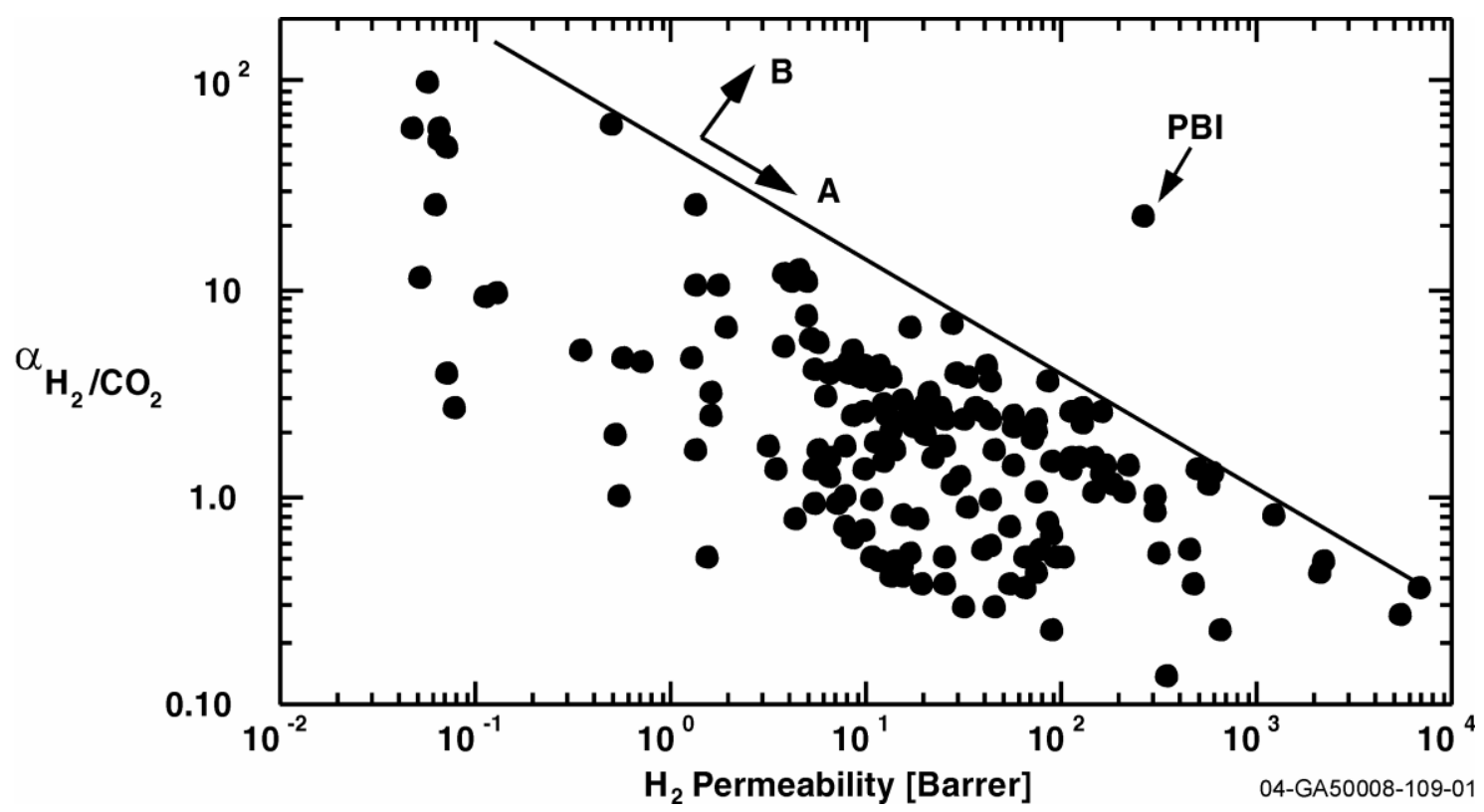

Figure I-2. Tradeoff plot between $\mathrm{H}_{2}$ permeability and $\mathrm{H}_{2} / \mathrm{CO}_{2}$ selectivity in polymers.

The research at LANL provided important information about the long-duration temperature stability, sulfur tolerance, productivity, and overall durability of the composite membrane. Long-term temperature stability at $250^{\circ} \mathrm{C}$ is evidenced by operation at that temperature for $>330$ days while maintaining commercially attractive separation characteristics (Figure 8). 


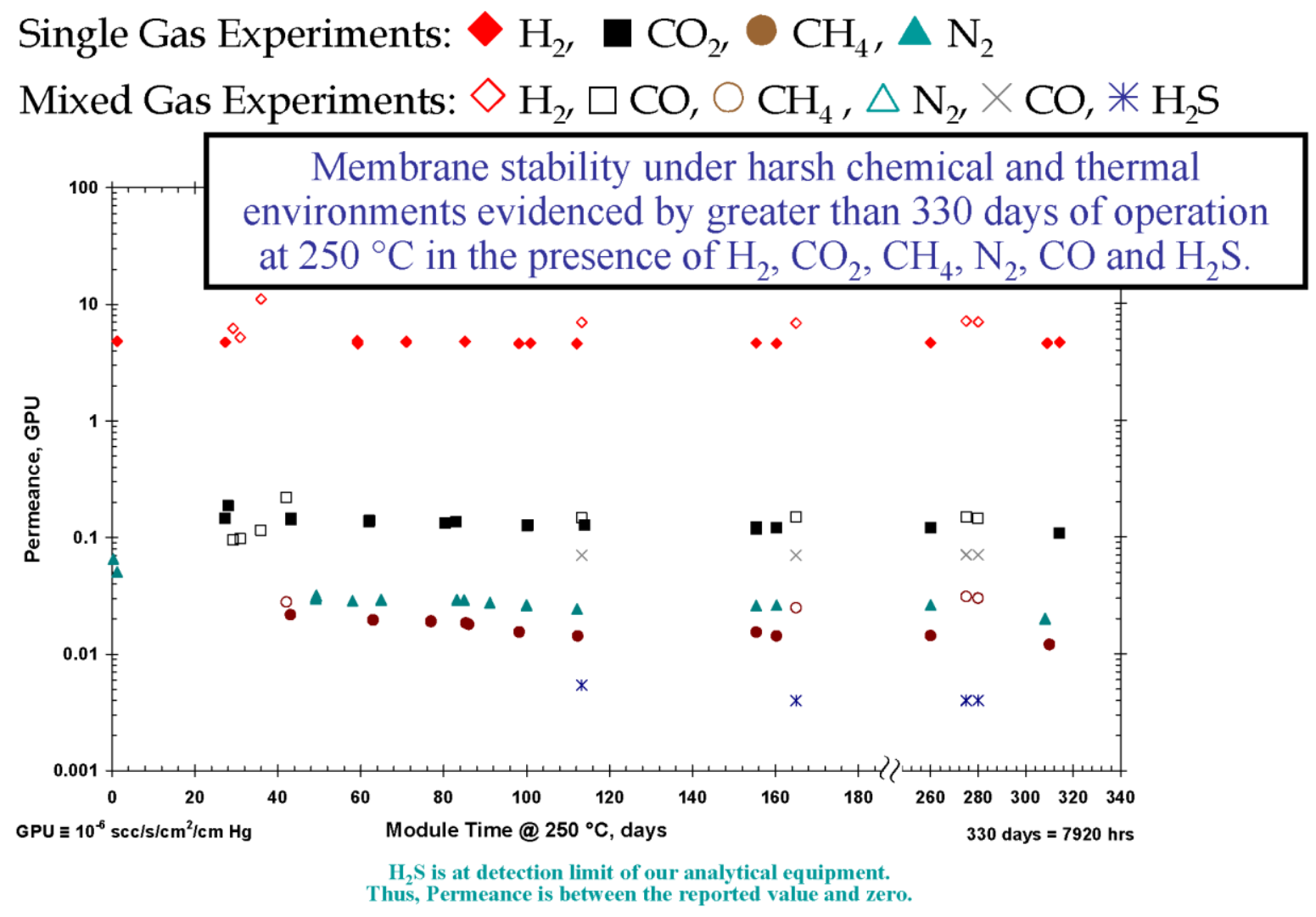

Figure I-3.Permeance of PBI on metallic substrate as a function of time at $250^{\circ} \mathrm{C}$.

Tests were also conducted by LANL using a water-gas shifted syngas stream (obtained by steam reforming of methane) at the laboratories of Gas Technology Institute (GTI). These results showed that the $\mathrm{H}_{2} / \mathrm{CO}_{2}$ selectivity are similar both in dry and steam containing syngas streams.

Table I-1: Comparison of Dry and Wet LANL Data at $\sim 250^{\circ} \mathrm{C}$.

\begin{tabular}{|c|c|c|c|}
\hline & Temperature, ${ }^{\circ} \mathbf{C}$ & $\begin{array}{c}\text { Trans-Membrane } \\
\text { Pressure, } \mathbf{p s i}\end{array}$ & $\mathbf{H}_{\mathbf{2}} / \mathbf{C O}_{\mathbf{2}}$ Selectivity \\
\hline LANL - Dry & 235 & 35.5 & 43.0 \\
\hline GTI - Dry & 255 & 37.9 & 40.3 \\
\hline GTI - Wet & 258 & 35.6 & 41.4 \\
\hline
\end{tabular}


These results showed that the PBI membranes function at significantly higher temperatures than current commercially available polymeric membranes $\left(<150^{\circ} \mathrm{C}\right)$.In addition, the composite membranes provide improved performance while exhibiting long-term temperature stability, sulfur tolerance, and overall durability over a broad range of industrially relevant operating conditions.

\section{OBJECTIVES}

The overall goal of this project is to develop a PBI-based capture system that is capable of operation under a broad range of conditions relevant to the power industry while meeting the Carbon Sequestration Program goals of $90 \% \mathrm{CO}_{2}$ capture at less than a $10 \%$ increase in the cost of energy services.

The primary goals of this project are to demonstrate the performance and fabrication of a technically and economically viable pre-combustion-based $\mathrm{CO}_{2}$ capture system based on PBI polymer. In addition, the optimization of that PBI-based capture system for integration into an IGCC plant was addressed. To that end, larger scale/larger throughput membrane-based separation modules were designed, fabricated, and evaluated during the project. We developed a commercialization plan that addresses technical issues (e.g., a roadmap for the scale-up of production of PBI membrane modules) and business issues (e.g., insurance considerations and potential joint venture opportunities) to outline a clear path for technology transfer of the PBI membrane technology.

\section{BENEFITS}

A Department of Energy research goal in the area of $\mathrm{CO}_{2}$ capture is the production of a $\mathrm{CO}_{2}$ rich stream at elevated pressuresby capturing $90 \% \mathrm{CO}_{2}$ at less than a $10 \%$ increase in the cost of energy services. The results of this project team is aligned directly with these capture goals and uses a pre-combustion capture approach focused on the integration of high-temperature polymerbased membranes into an advanced IGCC process. The membranes that have been developed and will continue to be optimized in the future outperform other polymer-based membrane reported in the literature for separations involving $\mathrm{H}_{2}$.

This achievement is validated via membrane productivity (separation factor and flux) comparisons. The improved performance of this technology in an application such as IGCCintegrated capture is further substantiated by the accessible operating temperature range (up to $250^{\circ} \mathrm{C}$ ), long-term hydrothermal stability, sulfur tolerance, and overall durability of the composite membrane materials in these challenging pre-combustion environments. Additionally, 
the modular, low-maintenance, and flexible design of our membrane technology, combined with the technology achievements anticipated over the course of the project, make it an exceptional candidate for use for pre-combustion capture of $\mathrm{CO}_{2}$. The improvement in the combined economics and performance represent a new separations tool that meets and exceeds, in stepchange fashion, DOE's goals for carbon capture.

\section{TASKS PERFORMED}

The project was divided into several tasks as described below:

Task 1:Establish Specifications and Testing Protocol.

Task 2: Supply Hollow Fiber Module

Task 3: Compare Performance of Hollow Fiber Substrate vs. Metallic Substrate

Task 4: Design Review on Substrates and Selection

Task 5:SubcomponentDesign and Evaluation

Task 6: Integrate Membrane Module and Connectors into a skid

Task 7: Summary Report of Technical Achievements of Project

Task 8: Membrane Mounted on Skid with Connectors

Task 9: Compilation of Commercialization Issues and Requirements

Task 10: Analysis of Commercialization Issues and Requirements

Task 11: Commercialization Plan Recommendation

Task 12: Management \& Reporting.

This report describes the technical results of the project as follows:

- Development of PBI-based hollow fiber membrane and module: Successful development of the membrane module is critical to achieve the objectives of the program. We devoted a major portion of the program to fabricate hollow fiber membranes with desired $\mathrm{H}_{2} / \mathrm{CO}_{2}$ selectivity and $\mathrm{H}_{2}$ permeance at elevated temperatures and pressures and assemble them into a module. This section contains results from Tasks 2 through 8 .

- Development of economic analysis for $\mathrm{CO}_{2}$ capture: In this section, we describe (1) the establishment of specifications of a PBI-based membranes for $\mathrm{CO}_{2}$ capture 
from IGCC systems, (2) the performance of membrane modules based on expected or measured $\mathrm{H}_{2} / \mathrm{CO}_{2}$ selectivity and $\mathrm{H}_{2}$ permeance, (3) the development of a process model that describes the heat and mass balances of various streams in an IGCC train, (4) calculation of the cost of $\mathrm{CO}_{2}$ capture using DOE guidelines. This section contains results from Task 1 .

- Commercialization plan issues, requirements, and recommendations. This section contains results from Tasks 9 through 11. 


\section{DEVELOPMENT OF PBI-BASED HOLLOW FIBER MEMBRANE AND MODULE}

The results from an earlier work at LANL with $\mathrm{PBI} /$ metal composite membranes had a relatively thick dense PBI separation layer $(12 \mu \mathrm{m})$ coated on a porous metal substrate which was available from Pall Corporation as a sintered stainless steel 0.25 in. diameter tube. Normalized permeability values in Barrer units were calculated from the LANL data and then used to simulate projected performance of an asymmetric hollow fiber PBI membrane having a $0.5 \mu \mathrm{m}$ thick dense PBI separation layer. The results were compared with the performance of an asymmetric PBI hollow fiber was made totally from PBI polymer and comprised a microporous supporting hollow fiber with a thin dense separating layer formed in situ on either the inside bore or the outside shell of the porous hollow fiber wall. Our calculations (described in detail in Section III) showed that the asymmetric hollow fiber configuration (dense PBI layer on porous PBI substrate) can provide a higher membrane area for a given reactor volume by a factor of 350 than a configuration based on dense PBI on a porous metal tube. A major reason is the large OD and wall thickness of the substrate. Typical hollow fiber membrane has an OD of 200 to 500 $\mu \mathrm{m}$, a dense separating layer thickness of 0.1 to $0.5 \mu \mathrm{m}$ and a supporting microporous substrate wall thickness of about $100 \mu \mathrm{m}$. In contrast, stainless steel porous metal tubes are available readily in large diameters ( $1.3 \mathrm{~cm}$ OD) which limit the surface to volume ratio. Based on this analysis, we focused our efforts on developing asymmetric membrane based on PBI polymer alone.

\section{INITIAL WORK WITH WHITEFOX TECHNOLOGY MEMBRANES}

WhiteFox Technologies Ltd. (WFX), located in Oregon, Canada, and the United Kingdom, has expertise in the fabrication of hollow fiber based PBI membranes. The company is experienced in the fabrication of PBI based hollow fiber membranes for liquid separations. The technology was originally developed by Bend Research and WFX was scaling-up the technology for the production of PBI-based hollow fibers. WFX was exploring the use of PBI membranes for the high temperature purification and dehydration of ethanol. The results related to the fabrication of WFX membranes and their evaluation at SRI and LANL are summarized here and are described in detail in Appendix A.

\section{Multi-bore Hollow Fiber Fabrication at WFX}

Initially WFX fabricated multi-bore/multi-lumen hollow fibers. Hollow fiber membranes afford a high area density membrane platform, which is needed to reduce the size of the hightemperature-tolerant membrane module housing. Multi-bore tubular membranes can retain the surface area to volume ratio of small OD membranes while the external area where they are 
sealed to a tube sheet is minimized. As an approximation, for an equivalent fiber outer diameter and length, a multi-bore ( 7 bore)-configuration will double the selective area over the single bore configuration. The multi-bore configuration also provides a platform that may have enhanced mechanical stability and durability. WFX fabricated two types of multi-bore PBI fibers (Figure II-1). The cross section of the one of the bore shows that the interior is porous whereas the lumen surface is relatively dense (Figure II-2).

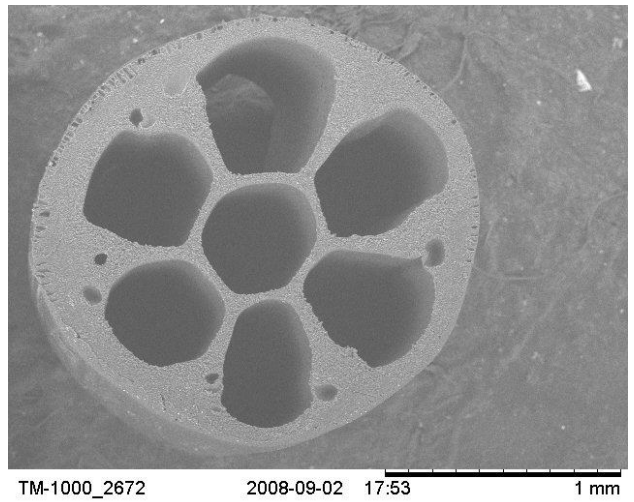

(a)

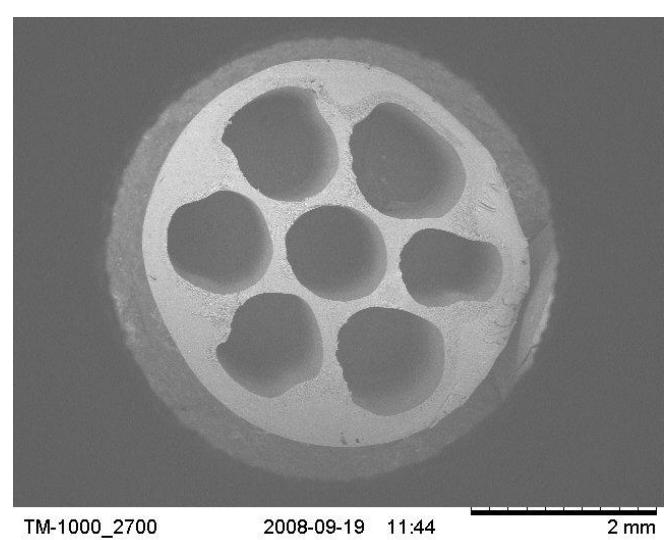

(b)

Figure II-1. SEMs of PBI-based multi-bore hollow fibers with varied outer diameters and bore diameters: (a) 7-bore, O.D. $2 \mathrm{~mm}$ (b) 7-bore, O.D. $4.2 \mathrm{~mm}$.

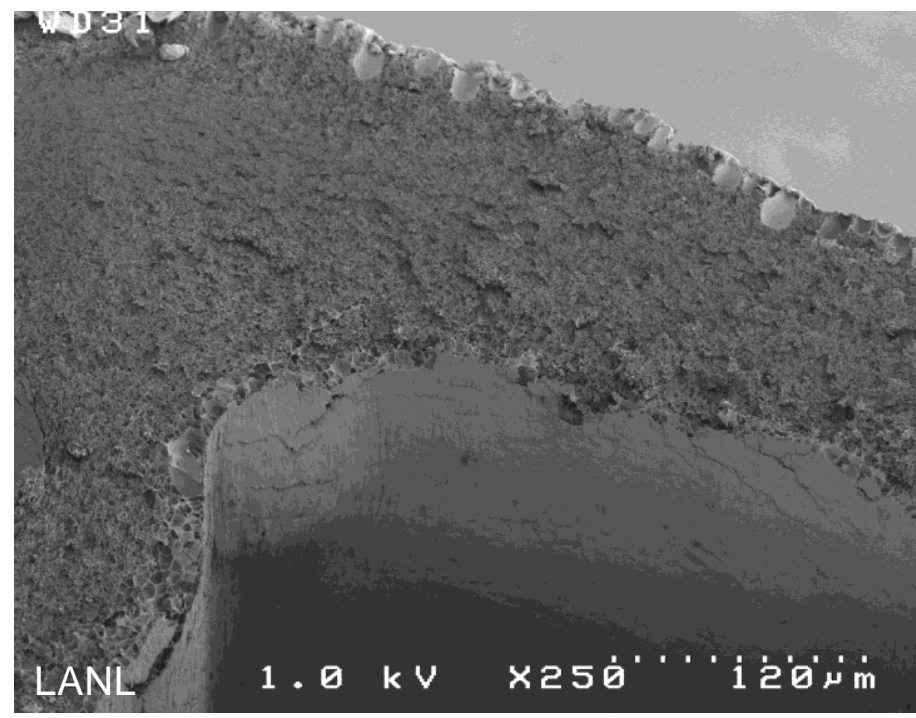

Figure II-2. Porous structure leading to a nonoptimized "dense" layer at the inner (lumen) surface of the multibore fiber. 
Evaluation of the Multi-bore Hollow Fibers. SRI and LANL evaluated a set of multi-bore hollow fibers that was received from WFX. Since these fibers are from the initial attempts at fabricating a multi-bore geometry and many process parameters were not yet optimized. The separation layer area was not well defined, and the gas may have to diffuse through a number of dense walls. The fibers were tested to be water-tight at the factory. The fibers had a nominal outside diameter of $1.5 \mathrm{~mm}$ and had 7 internal bores, 6 on the periphery and 1 in the center (Figure II-3). The internal bores were generally circular, although the shape was distorted in some cases. The internal bore diameters were in the range 0.2 to $0.3 \mathrm{~mm}$. The wall thickness between the bore also varied from about 0.1 to $0.2 \mathrm{~mm}$. The average length of each fiber, asreceived, was $25 \mathrm{~cm}$.

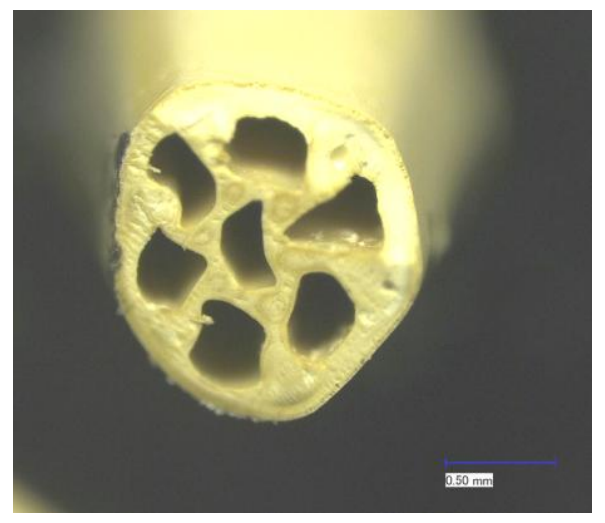

Figure II-3.The cross section of PBI fiber WF-MB-102208.

The physical morphology of both the surface and cross section of the fibers were examined using SEM. A magnified image of the cross section showed that the walls were porous with an apparently dense skin at the outer and inner surfaces (Figure II-4). High magnification examination showed that the pores were generally 1 to $5 \mu \mathrm{m}$ in size (Figure II-5). In the areas that we examined, it appeared that the pores may not have been interconnected. However, it is possible that the nanometer-size necks may connect the micron-size pores, thereby providing a path for gas flow. The external skin of the membrane at a very high magnification $(100,000 \mathrm{X})$, had a mud-crack appearance (II-6), and the cracks may allow the gas to penetrate the skin layer. The width of the crack appeared to be about 10 to $20 \mathrm{~nm}$. 


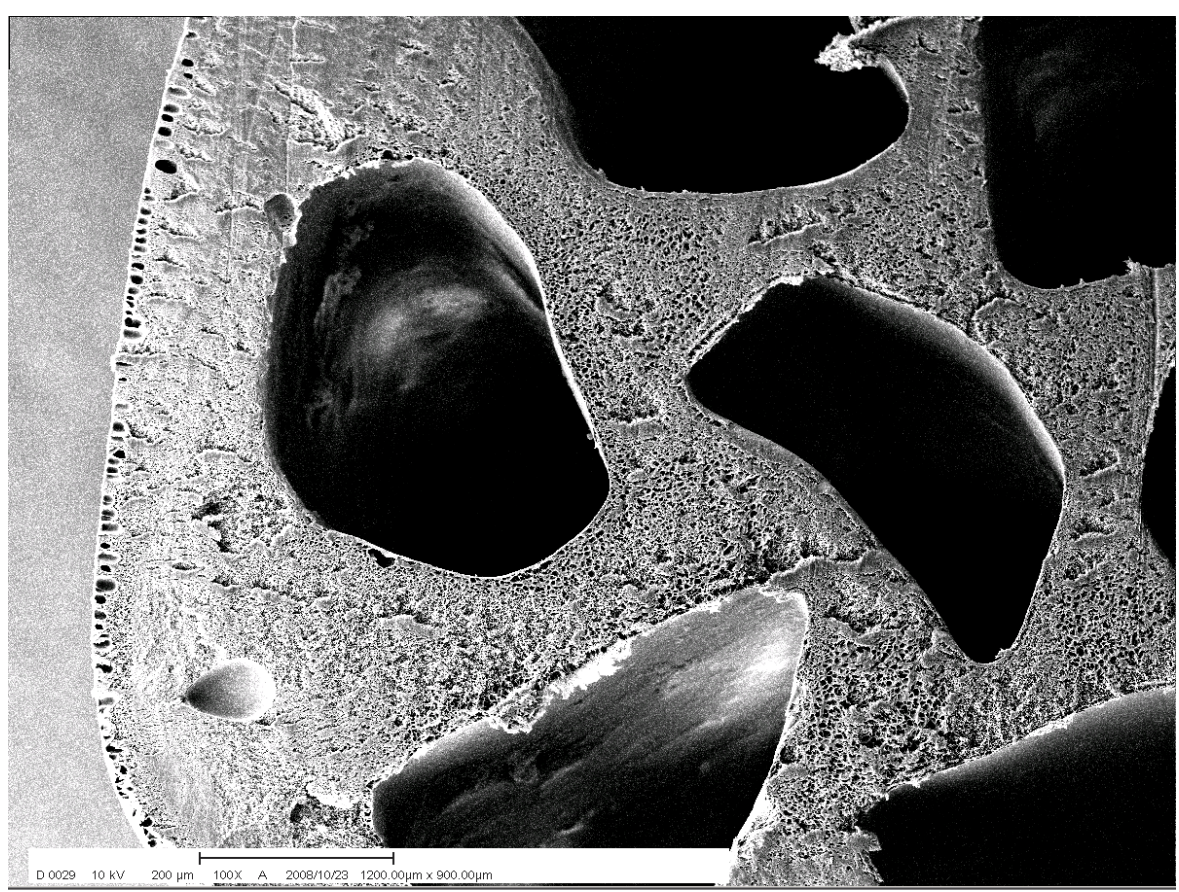

Figure II-4. The cross section of the PBI fiber illustrating the porous walls.

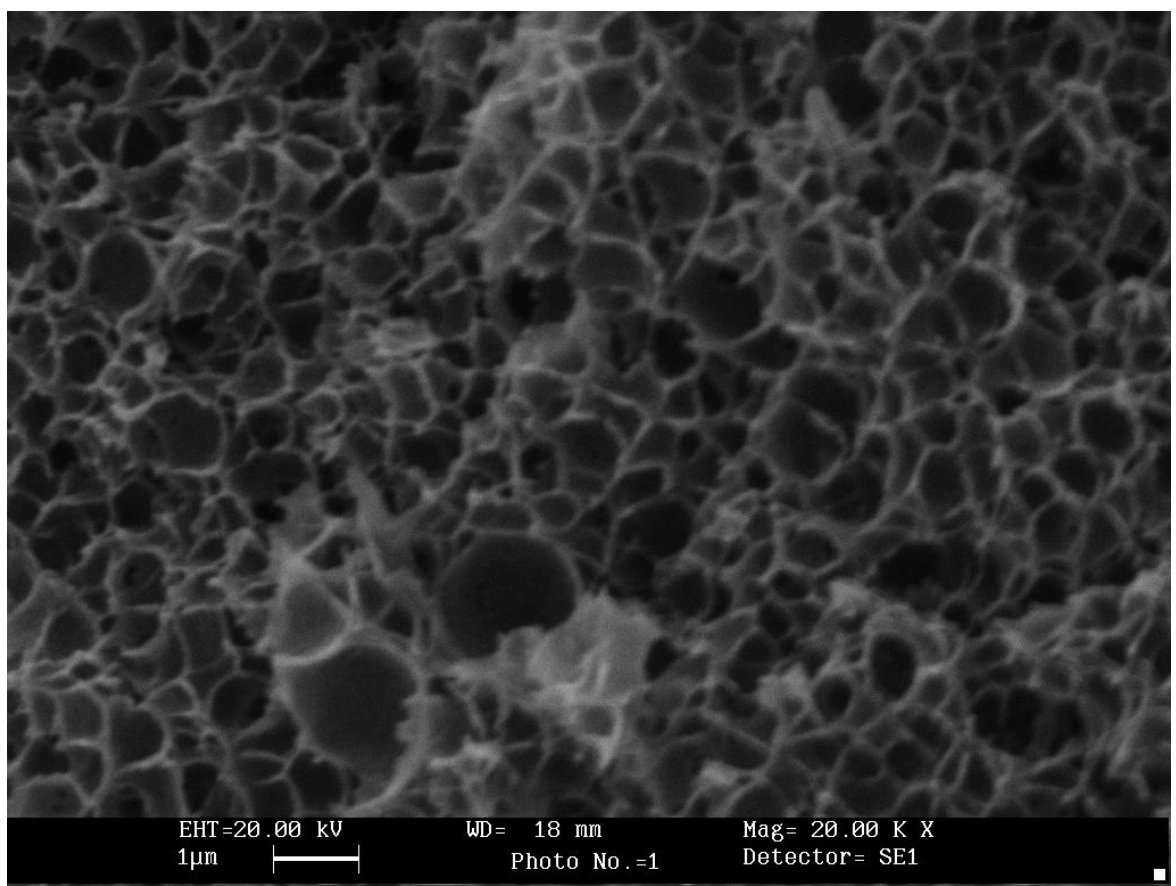

Figure II-5. High magnification image of the interior walls of the membrane. 


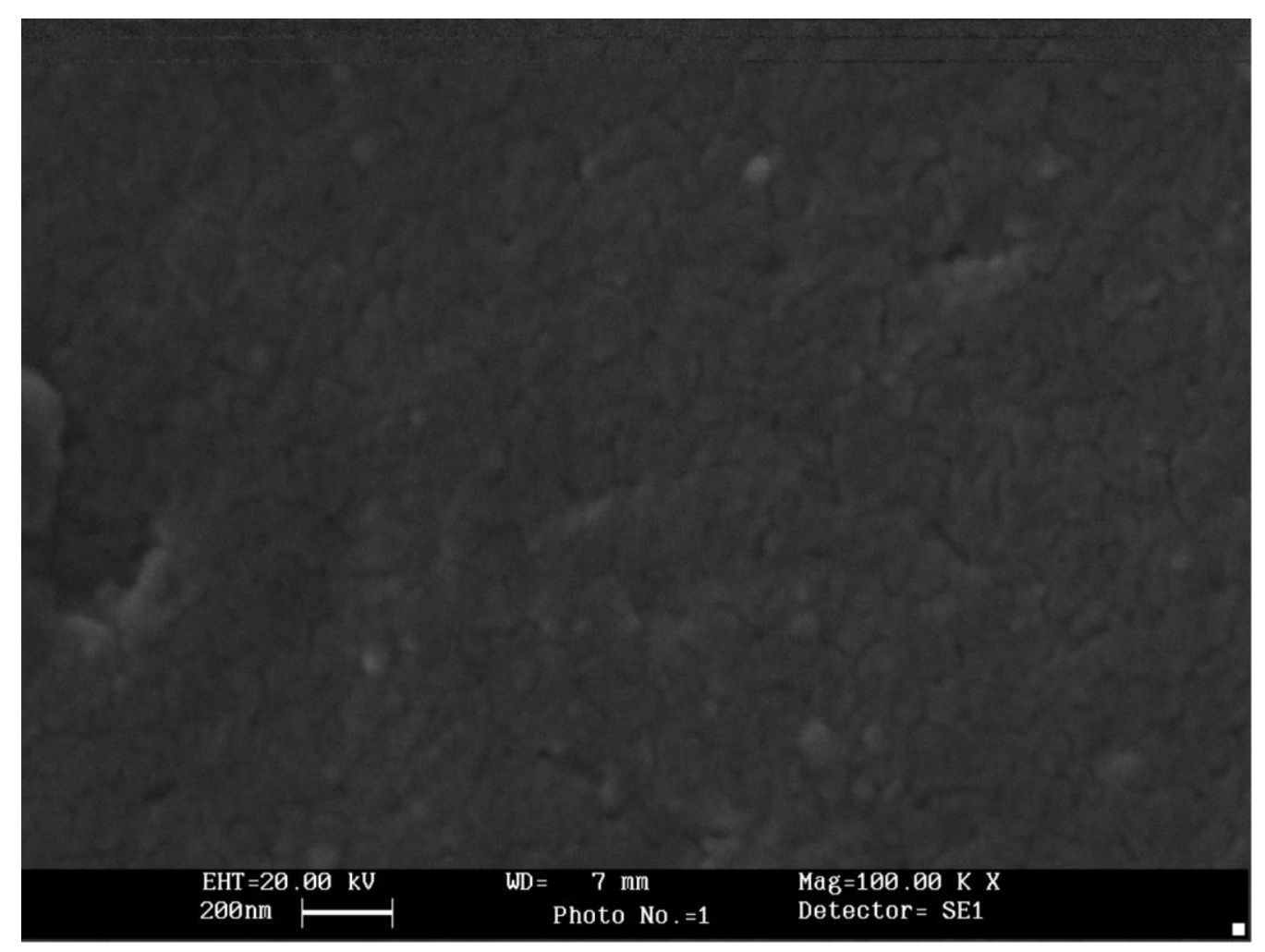

Figure II-6. The surface of a membrane at a magnification of 100,000X.

Gas Flow Measurements: We found that the gas permeance and selectivity varied among different fibers. Such variation was not unexpected because the fiber spinning process has not been optimized for the multi-bore geometry. We tested 3 fibers from the same batch to ascertain the variability in the fiber characteristics and the results from these tests are described below.

The dense PBI membrane is relatively impermeable to $\mathrm{H}_{2}$ or $\mathrm{CO}_{2}$ at $25^{\circ} \mathrm{C}$, and the gas transport at this temperature observed was through the cracks or pores in the walls. As the temperature increased, additional $\mathrm{H}_{2}$ diffused through the dense walls, increasing the total permeance for $\mathrm{H}_{2}$. Table 22 summarizes the observed $\mathrm{H}_{2}$ permeance and the $\mathrm{H}_{2} / \mathrm{CO}_{2}$ selectivity as a function of temperature for the three fibers tested. Fibers 1 and 3 had similar characteristics, whereas fiber 2 had increased $\mathrm{H}_{2} / \mathrm{CO}_{2}$ selectivity but with a reduced permeance at $250^{\circ} \mathrm{C}$. These data were collected at a pressure differential of 65 to 75 psi. 
Table II-1. $\mathrm{H}_{2}$ Permeability and $\mathrm{H}_{2} / \mathrm{CO}_{2}$ Selectivity of the WF-MB-102208 PBI Fibers

\begin{tabular}{|c|c|c|c|c|c|c|}
\hline $\begin{array}{c}\text { Temperature } \\
\left({ }^{\circ} \mathbf{C}\right)\end{array}$ & \multicolumn{2}{|c|}{ Fiber 1 } & \multicolumn{2}{|c|}{ Fiber 2 } & \multicolumn{2}{c|}{ Fiber 3 } \\
\hline & $\begin{array}{c}\mathbf{H}_{2} \\
\mathbf{G P U}\end{array}$ & $\begin{array}{c}\mathbf{H}_{2} / \mathbf{C O}_{2} \\
\text { Selectivity }\end{array}$ & $\begin{array}{c}\mathbf{H}_{2} \\
\mathbf{G P U}\end{array}$ & $\begin{array}{c}\mathbf{H}_{2} / \mathbf{C O}_{2} \\
\text { Selectivity }\end{array}$ & $\mathbf{H}_{2} \mathbf{G P U}$ & $\begin{array}{c}\mathbf{H}_{2} / \mathbf{C O}_{2} \\
\text { Selectivity }\end{array}$ \\
\hline 25 & 9.0 & 2.5 & - & - & - & - \\
\hline 150 & 13.2 & 5.0 & 6.0 & - & 14.3 & 7.7 \\
\hline 200 & 17.8 & 6.9 & - & - & - & - \\
\hline 250 & 21.0 & 8.2 & 12.0 & 13.8 & 18.8 & 7.2 \\
\hline 300 & & & 16.0 & 16.0 & - & - \\
\hline
\end{tabular}

In summary, the multi-bore, hollow fiber PBI membrane WF-MB-102208 constituted a good start for making high-temperature polymer fibers for gas separation leading to the fabrication of compact modules. The permeability for $\mathrm{H}_{2}$ and $\mathrm{H}_{2} / \mathrm{CO}_{2}$ selectivity were lower than expected. In addition, the multi-bore membranes could not sustain a large pressure differential between the outer and inner surfaces, necessary to obtain the desired $\mathrm{H}_{2}$ flux. In addition, WFX decided to discontinue the fabrication of the multi-bore PBI membranes for environmentally unacceptable processing methods. Instead they focused on fabricating single bore PBI hollow fibers using both asymmetric fibers and porous fiber hollow fiber tubing substrates. Such fibers require a coating a dense PBI layer coating on the surfaces of porous PBI fiber.

\section{Single-bore Hollow Fiber Fabrication at WFX}

Set 1: WFX fabricated four sets of single bore PBI hollow fiber membranes. In the Set 1, they used an asymmetric fiber ( $1 \mathrm{~mm} \mathrm{OD}$ ) substrate and deposited the $\mathrm{H}_{2}$ selective dense layer on the inner surface of porous fiber (Figure II-7). Gas permeation tests showed that both the $\mathrm{H}_{2} / \mathrm{CO}_{2}$ selectivity (13) and $\mathrm{H}_{2}$ permeance (45 GPU) are low. 


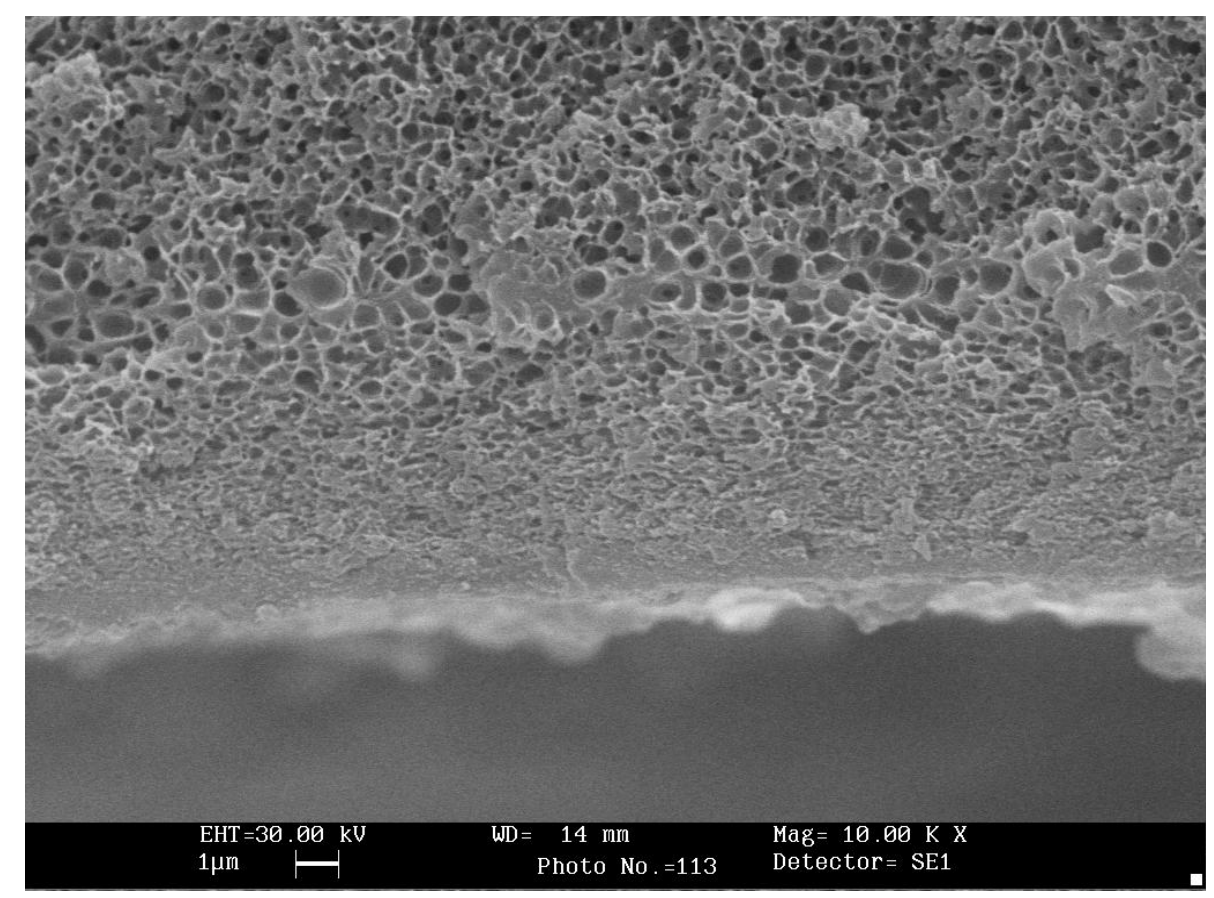

Figure II-7. Cross section of the WFX-07a membrane with a $0.60 \mathrm{~mm}$-substrate + lumen-side selective layer (set 1).

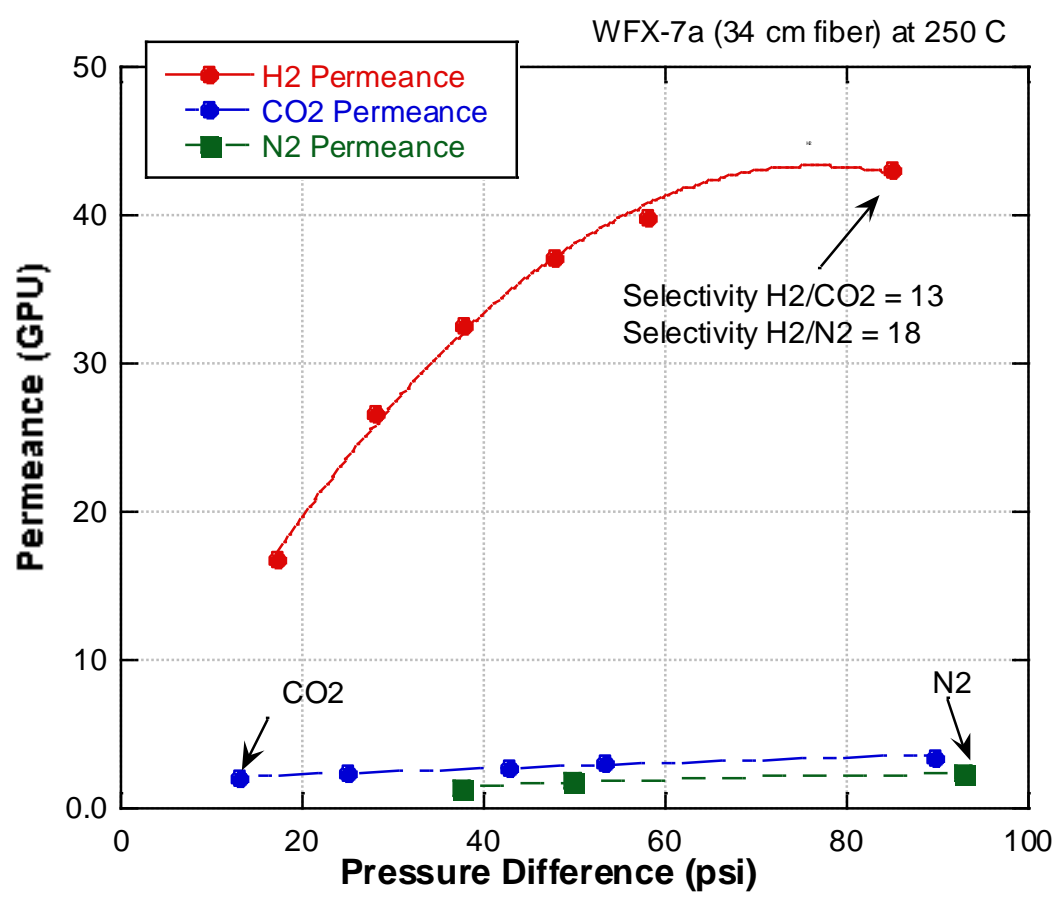

Figure II-8. The measured permeance for $\mathrm{H}_{2}, \mathrm{~N}_{2}$ and $\mathrm{CO}_{2}$ as a function of pressure difference at $250^{\circ} \mathrm{C}$ of WFX-07 membrane.

Set 2: In fabricating the hollow fiber membrane Set 2, modified procedures were implemented at WFX to deposit selective layers of about 1 to $2 \mu \mathrm{m}$ in thickness with different 
polymer densities on the surface of the asymmetric fiber $(1 \mathrm{~mm})$. The following fibers WFX-8b, WFX-9, WFX-10, WFX-16, WFX-23, WFX-27 and WFX-29 were tested at SRI. Among these fibers, WFX-9 had the highest polymer density at the lumen surface while WFX-28 had the least polymer density. All these fibers had apparent selective layer thickness about $2 \mu \mathrm{m}$. The measured permeation data for fibers WFX-16b, WFX-8b, WFX-9b, WFX-10b, WFX-23, WFX27, and WFX-28 are depicted in Figure II-9. The $\mathrm{H}_{2}$ permeance values were in the range 5 to $125 \mathrm{GPU}$ and the corresponding $\mathrm{H}_{2} / \mathrm{CO}_{2}$ selectivities were in the range 6 to 40 . The moderate selectivity in WFX-28, WFX-23 and WFX-16 is due to the fact that the dense selective layer is not as dense as it needs to be while it had the desired $\mathrm{H}_{2}$ permeance. The moderate permeance in WFX-8, WFX-9, WFX-10, and WFX-27 is due to very high density of the dense layer than it needs to be.

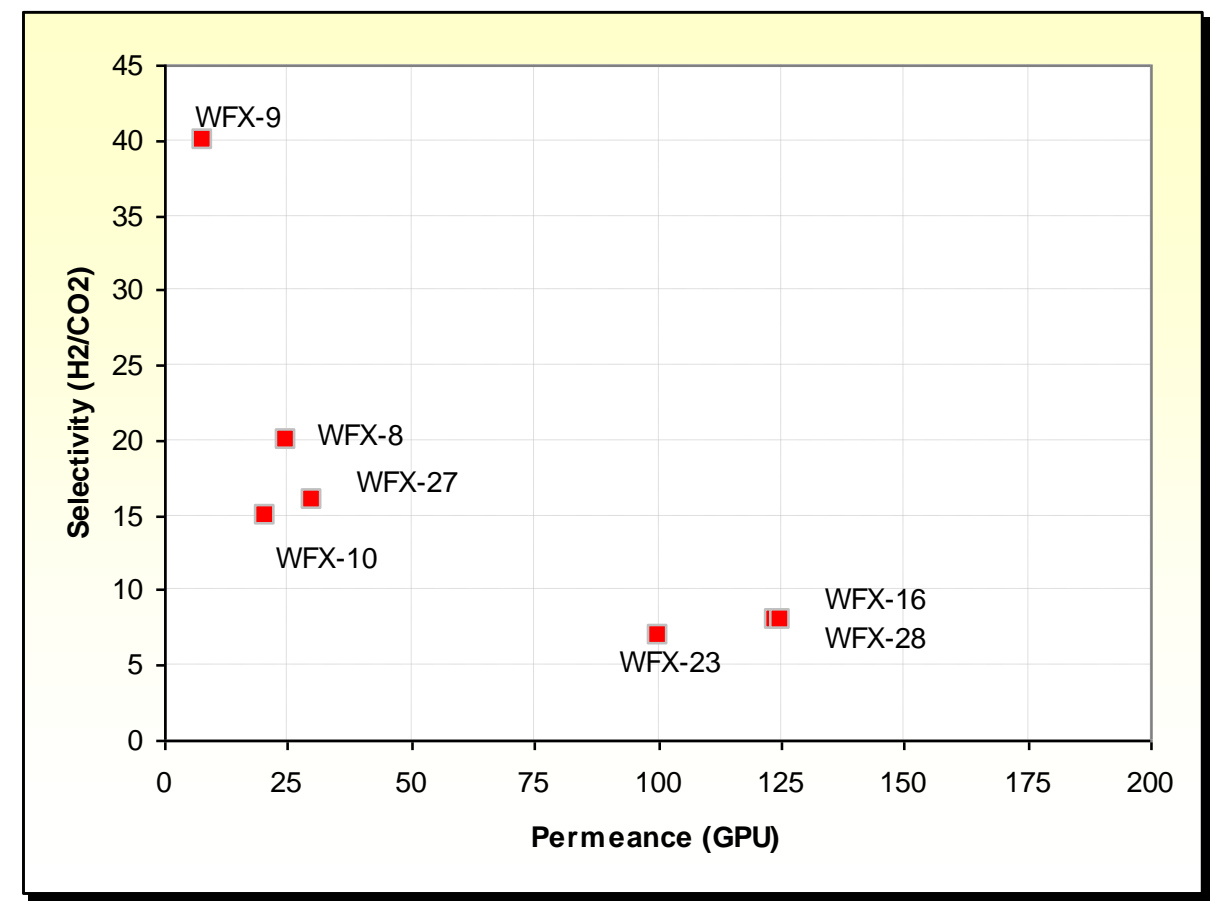

Figure II-9. The measured permeance of $\mathrm{H}_{2}$ in GPU and $\mathrm{H}_{2} / \mathrm{CO}_{2}$ selectivity of selected WFXPBI hollow fiber set 2 at $250^{\circ} \mathrm{C}$. 
Although the $\mathrm{H}_{2} / \mathrm{CO}_{2}$ selectivity of set 2 fibers was relatively high, the $\mathrm{H}_{2}$ permeance was not at the required level. The relatively high surface roughness of the substrate fiber prevented deposition of a thin and defect-free dense layer that is necessary to obtain both high selectivity and permeance. Hence, WFX used a new substrate fiber with a $0.6 \mathrm{~mm}$ OD and $0.4 \mathrm{~mm}$ ID that had a much reduced surface roughness compared to the earlier tested WFX-3b based fibers. Figure II-10 compares the lumen surface roughness of the old (WFX-3b) and the new fibers series (WFX-00). Since the new fiber has a reduced surface roughness, it was assumed to be suitable substrate for depositing an ultra-thin and defect-free dense coating.
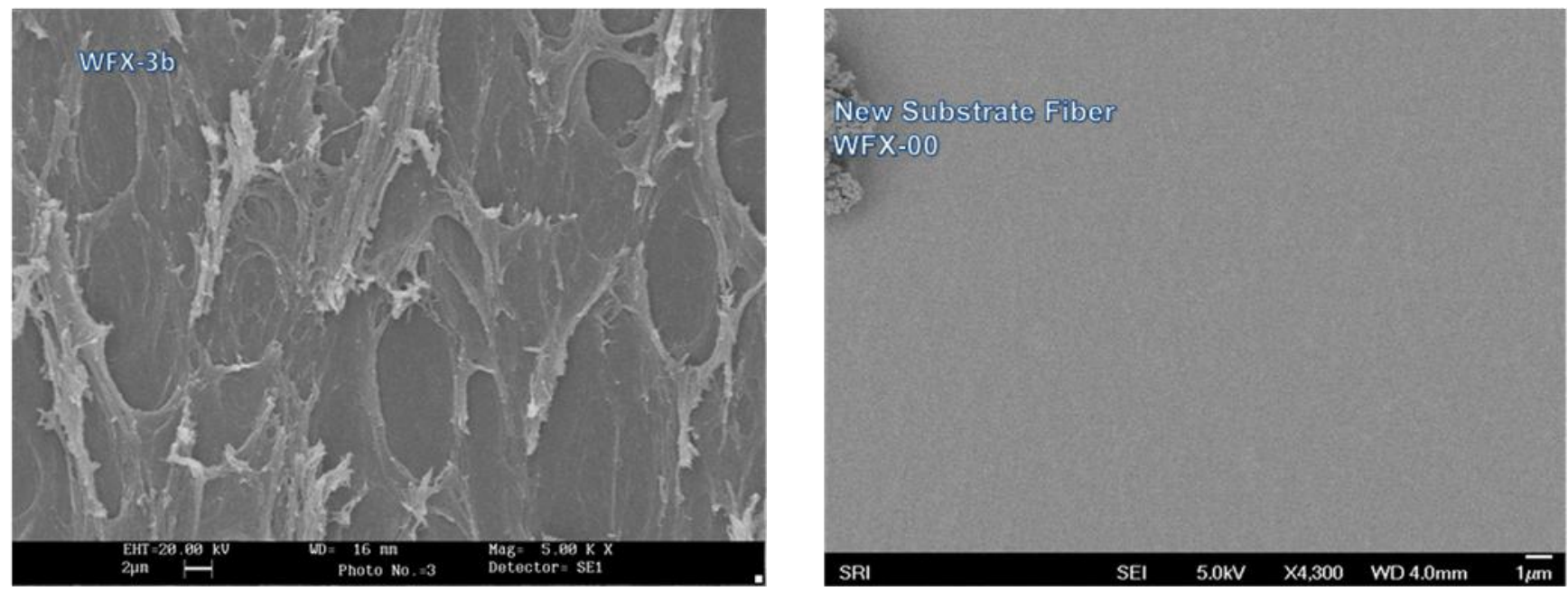

Figure II-10. SEM images of the lumen surfaces of the previous (WFX-3b) and new (WFX-00) porous substrate fiber.

Set 3: The new substrate fiber (WFX-00) also had an open pore structure necessary to function as a substrate for Set 3. Figure II-11 shows the images of the cross section of the new substrate fiber at low and high magnifications. The images show that the interior of the fiber is highly porous and has many inter-connected pores. The dense layer coating procedure was modified to accommodate the reduced diameter ( $0.6 \mathrm{~mm}$ OD) and the wall thickness of the new fiber in comparison to earlier substrate fibers ( $1 \mathrm{~mm} \mathrm{OD})$. The modifications involved identification of the optimum PBI concentration in the coating solution and the pressure at which the solution was injected inside the fiber. A series of coated fibers based on this substrate fiber were prepared by Whitefox and tested at SRI. These fibers are identified as WFX-34 through WFX-38.

Figure II-12 compares the permeation data of the coated fibers based on WFX-00 substrates with those that were tested in Set 1. The new set of fibers (Set 2) exhibited a higher $\mathrm{H}_{2}$ permeance and increased selectivity than the old set of fibers. The trend shown in Figure II-12 is 
a clear indication that the desired selectivity and permeance is achievable with the WFX-00 series fibers.
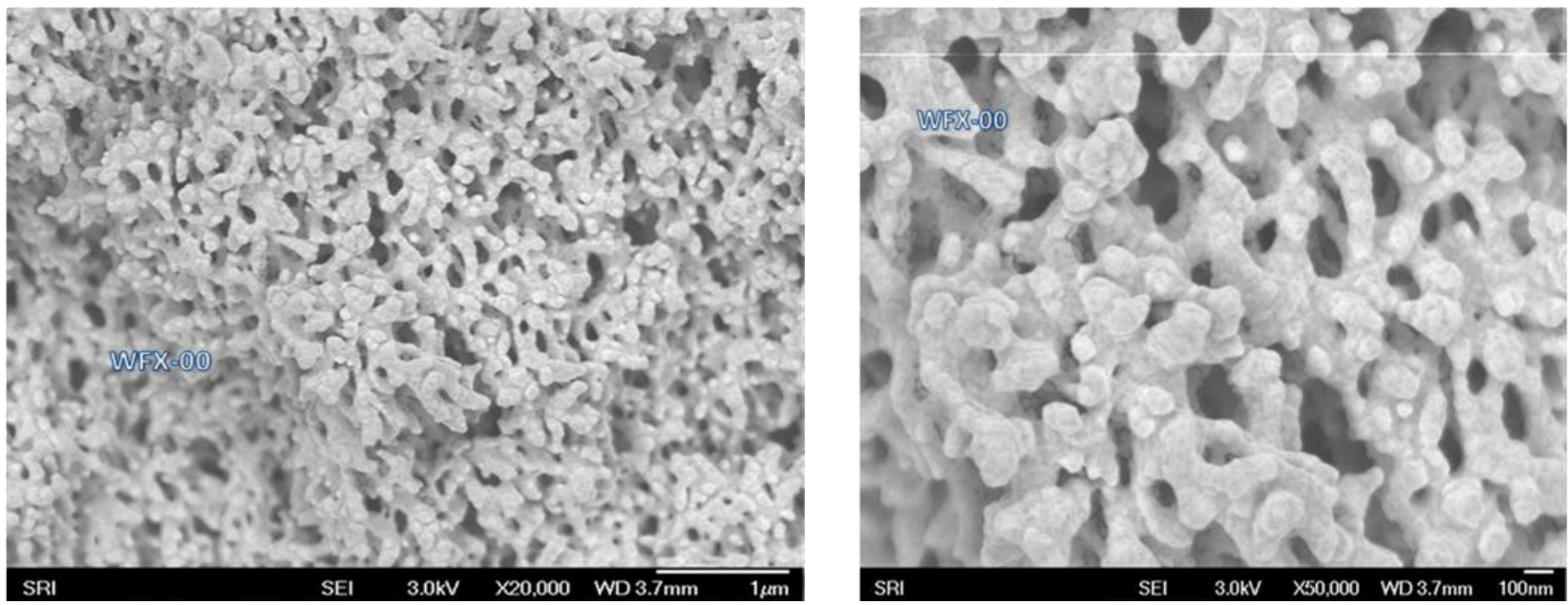

Figure II-11. SEM image of the cross section of the porous substrate fiber at low and high magnifications.

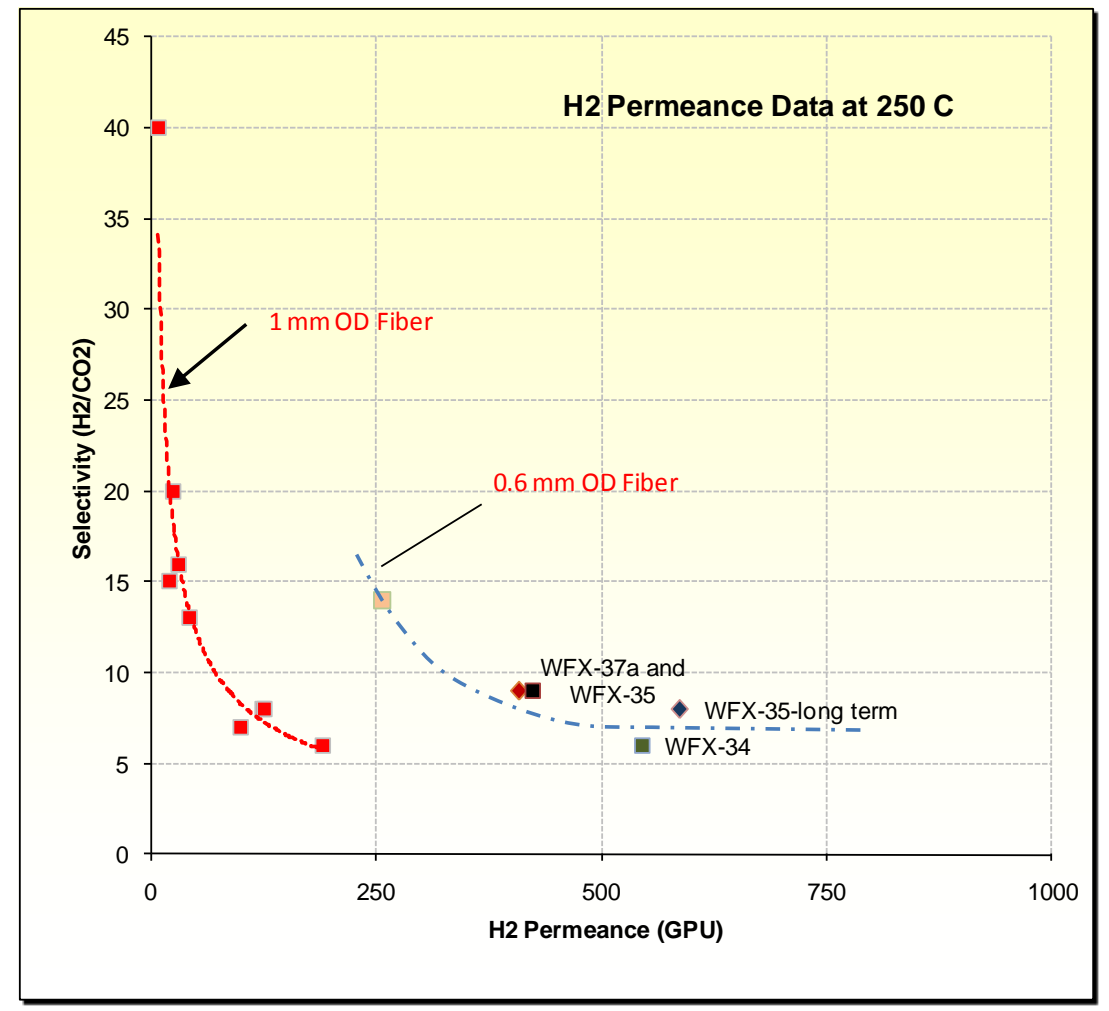

Figure II-12. The measured permeance of $\mathrm{H}_{2}$ in GPU and $\mathrm{H}_{2} / \mathrm{CO}_{2}$ selectivity of selected WFXPBI hollow fiber at $250^{\circ} \mathrm{C}$.

The fibers in Set 2 achieved a $\mathrm{H}_{2} / \mathrm{CO}_{2}$ selectivity of 15 with a $\mathrm{H}_{2}$ permeance of $250 \mathrm{GPU}$ at $250^{\circ} \mathrm{C}$. However, a significant variation in the fiber performances observed for multiple fibers 
that were coated using the same procedure. This problem was identified and WFX took steps to improve the quality control. The porous substrate (WFX-00) was stabilized by heat treatment ranging from $250^{\circ}$ and $300^{\circ} \mathrm{C}$ to remove the solvent and enhance the cross-linking to reduce swelling.

Set 4: The Set 3 fibers tested include WFX-39 through WFX-50. Fibers WFX-39, WFX-40 and WFX-41 that were prepared by coating untreated (without heat treatment) substrate fibers and they had a single selective coating layer. Fibers WFX-44 through WFX-50 were prepared from heat treated substrate fibers and they had either a single a double coating layer. In selected cases, prepared fibers were subjected to a post heat treatment at $250^{\circ}$ and $300^{\circ} \mathrm{C}$ prior to applying the second coating. (WFX-46 and WFX-50). Fibers, WFX-46, WFX-49 and WFX-50 have seen $300^{\circ} \mathrm{C}$ either during pretreatment of the substrate fiber or during the post-treatment prior to applying a second coating. SRI characterized the morphology and determined the $\mathrm{H}_{2} / \mathrm{CO}_{2}$ selectivity and $\mathrm{H}_{2}$ permeance (Table II-2).

Table II-2. $\mathrm{H}_{2}$ permeance and $\mathrm{H}_{2} / \mathrm{CO}_{2}$ selectivity of the fibers at $250^{\circ} \mathrm{C}$.

\begin{tabular}{|c|c|c|c|c|c|}
\hline Fiber ID & Testing Reriod & H2 Permeance & Selectivity & No. of Coatings & Treatment \\
\hline & & (GPU) & (H2/CO2) & & \\
\hline WFX-35 & $8 \mathrm{hr}$ testing & 424 & 9 & single & No Pretreatment \\
\hline WFX-35 & $36 \mathrm{hr}$ testing & 587 & 8 & single & No Pretreatment \\
\hline WFX-36 & $8 \mathrm{hr}$ testing & 420 & 5 & single & No Pretreatment \\
\hline WFX-34 & $8 \mathrm{hr}$ testing & 545 & 6 & single & No Pretreatment \\
\hline WFX-37a & $8 \mathrm{hr}$ testing & 408 & 9 & single & No Pretreatment \\
\hline WFX-38 & $8 \mathrm{hr}$ testing & 257 & 14 & single & No Pretreatment \\
\hline WFX-39 & $8 \mathrm{hr}$ testing & 500 & 6 & single & No Pretreatment \\
\hline WFX-40 & $36 \mathrm{hr}$ testing & 517 & 5 & single & No Pretreatment \\
\hline WFX-41 & $8 \mathrm{hr}$ testing & 68 & 8 & single & No Pretreatment \\
\hline WFX-44 & 36 hr testing & 211 & 11 & single & Pre-treated \\
\hline WFX-45 & $8 \mathrm{hr}$ testing & 183 & 38 & double & Pre-treated \\
\hline WFX-45 & $36 \mathrm{hr}$ testing & 160 & 23 & double & Pre-treated \\
\hline WFX-46 & $36 \mathrm{hr}$ testing & 214 & 10 & double & Pre-treated \\
\hline WFX-50 & $36 \mathrm{hr}$ testing & 148 & 8 & double & Pre-treated \\
\hline WFX-49 & $4 \mathrm{hr}$ testing & 277 & 4 & double & Pre-treated \\
\hline WFX-43b & $4 \mathrm{hr}$ testing & 333 & 19 & No Coating & pre-treated \\
\hline
\end{tabular}

In summary, we evaluated several approaches for fabricating PBI hollow fibers for gas separation. One approach was to coat a dense layer on asymmetric fibers from Whitefox ( $1 \mathrm{~mm}$ OD) to increase the selectivity. In another approach, PBI porous substrate fibers (0.6 mm OD) were coated with a dense PBI layer. In asymmetric membranes, the porosity changes from one 
surface of the membrane to the other, with the highest density part being the functional separation layer. In the WFX membranes, the separation layer was not sufficiently uniform decrease the $\mathrm{H}_{2} / \mathrm{CO}_{2}$ selectivity. Applying a dense PBI layer minimized the defective regions and increased the selectivity. But the extra-thick dense layer decreased the $\mathrm{H}_{2}$ permeance. In coated porous substrates, the gas separation function is provided by the applied secondary dense layer coating. The porous substrate provides the mechanical support with negligible gas transport resistance as in the asymmetric fiber. The initial performance evaluation at SRI had indicated $\mathrm{H}_{2} / \mathrm{CO}_{2}$ selectivities in the range 15 to 40 with $\mathrm{H}_{2}$ permeance of 150 to $200 \mathrm{GPU}$ at $250^{\circ}$. However, a significant variation in the fiber performances observed for multiple fibers that were coated using the same procedure (Figure II-13). These variations are due to a difficult quality control in applying the dense layer on the porous substrate fiber.

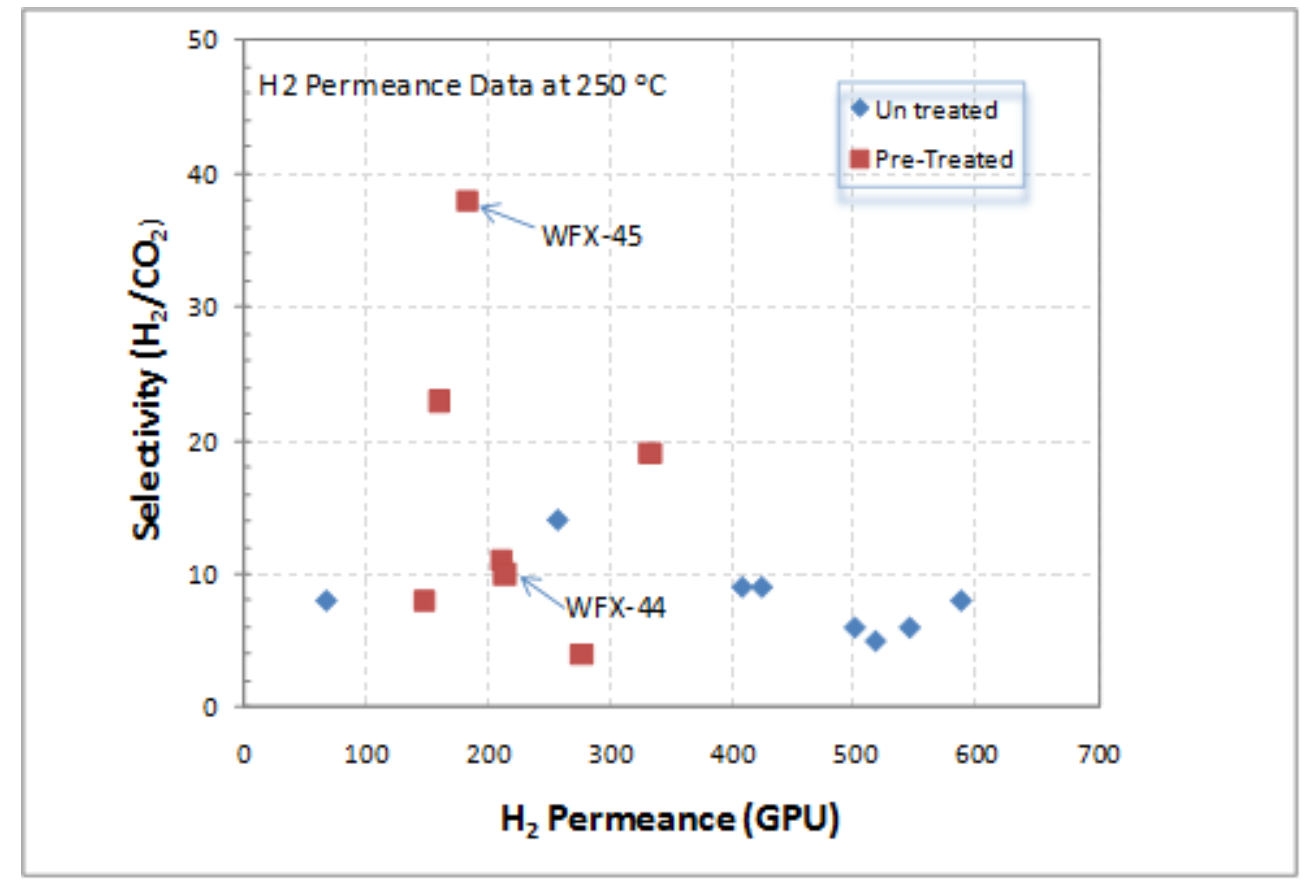

Figure II-13. The measured permeance of $\mathrm{H}_{2}$ in GPU and $\mathrm{H}_{2} / \mathrm{CO}_{2}$ selectivity of selected WFXPBI hollow fiber at $250^{\circ} \mathrm{C}$. 


\section{PBI HOLLOW-FIBER FABRICATION AT SRI}

Hollow Fiber Spinning Procedure: The coating procedure used at WFX resulted in relatively short length of fibers ( $\sim 1$ meter) with variable quality. The unavailability of the required fiber lengths ( 2 to 5 kilometer) and poor quality control became the barriers in progressing to module fabrication. In our laboratories, we undertook a program in which a porous substrate and dense layer were fabricated in a single step in the form of spinning an asymmetric membrane from a PBI polymer solution (PBI dope). This approach expedited the process to fabricate fibers in large quantities with minimal defects.

Figure II-14 is a schematic diagram of the bench-scale spinning line. Figure II-15 is a photograph of the fiber spinning set-up for continuous spinning with reasonable quality control. The fiber spinning line includes a custom designed spinneret, coagulation bath, washing bath, draw rollers, stretch rollers and a fiber take up system. Dope solution and the bore solvent were delivered to the spinneret using high pressure pumps with $\pm 0.01 \mathrm{~cm}^{3} / \mathrm{min}$ accuracy. The spinning line is equipped with manual speed controllers, although automated speed controllers with feedback system may be included in the future. Figure II-16 shows a photograph of SRI PBI hollow fiber bundles with about $3 \mathrm{~km}$ length of fibers. These fibers are cut to 24-in length for post-fiber processing and easy handling. Figure II-17 shows the sequential steps in fabricating hollow fiber modules.

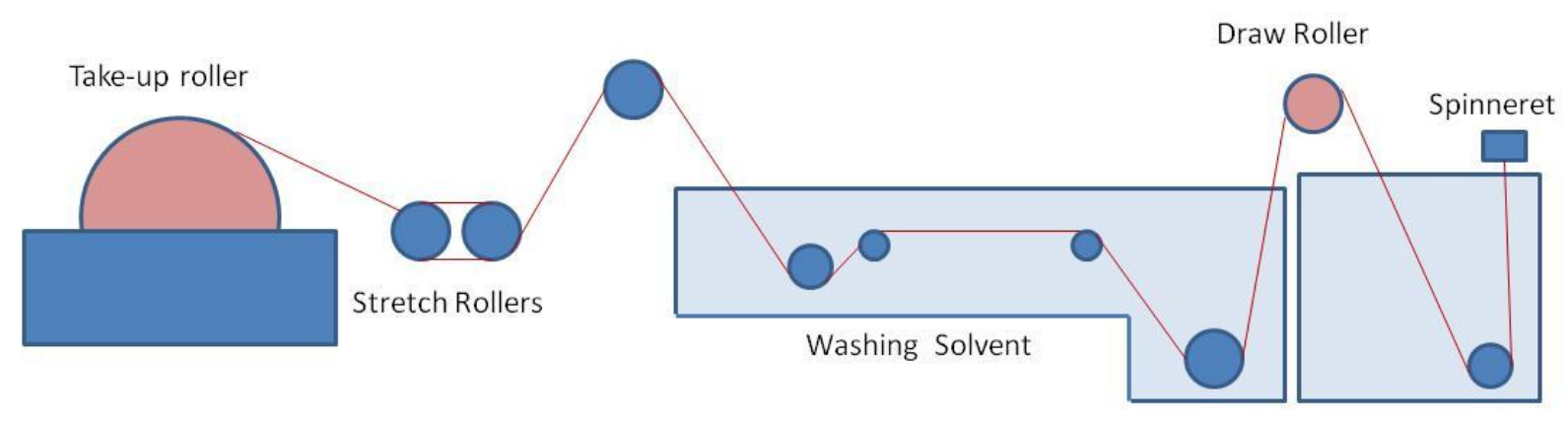

Figure II-14. Schematic of the SRI bench Scale spinning line. 


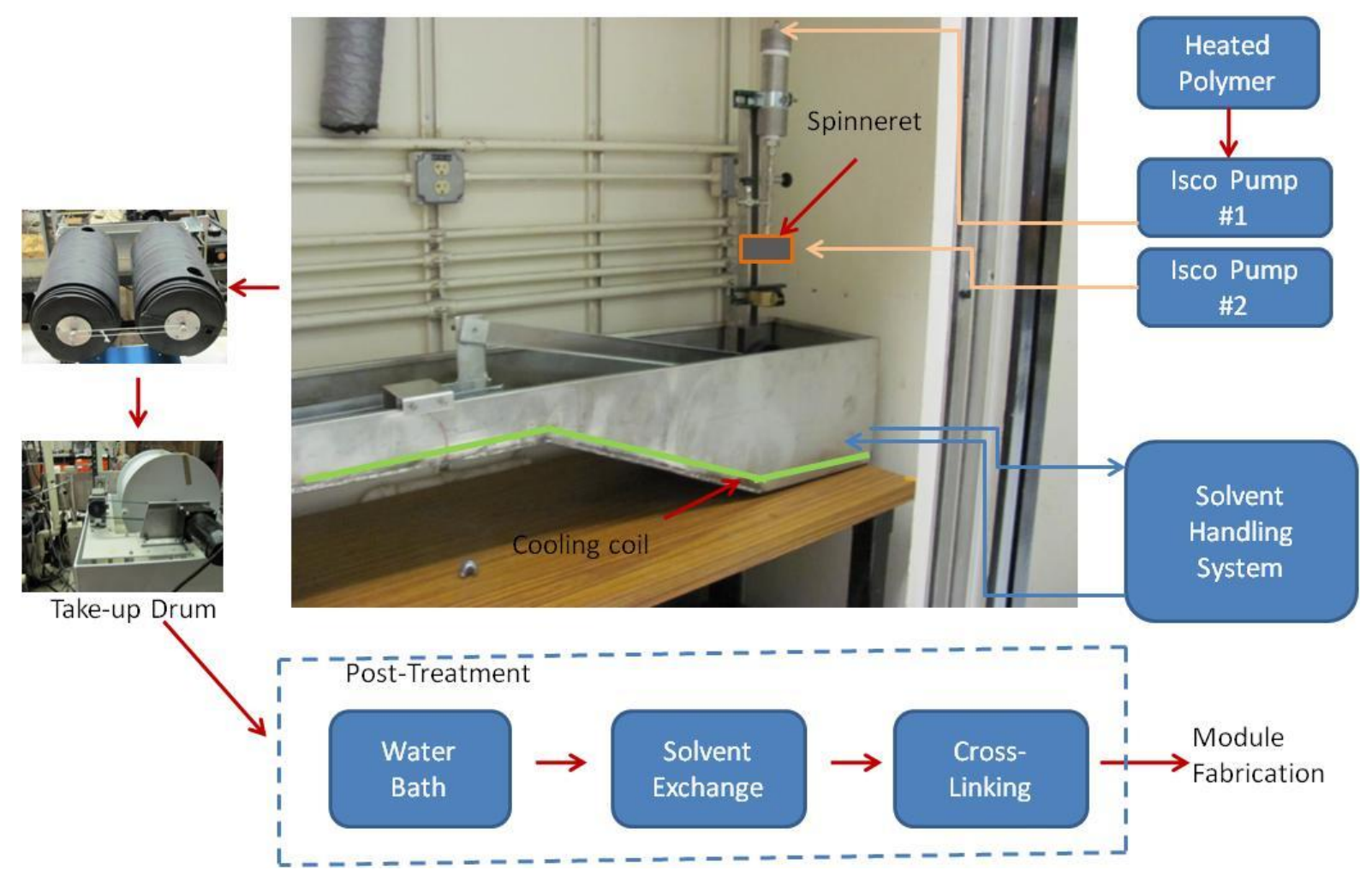

Figure II-15. SRI bench Scale spinning line.

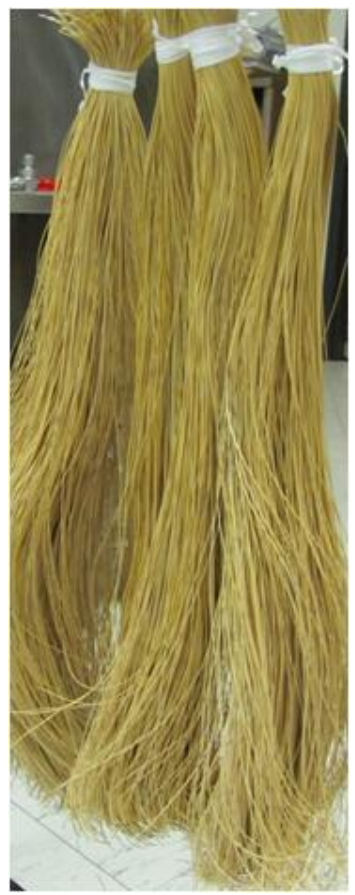

Figure II-16. A photograph of PBI hollow fiber bundles fabricated at SRI series B fiber. 


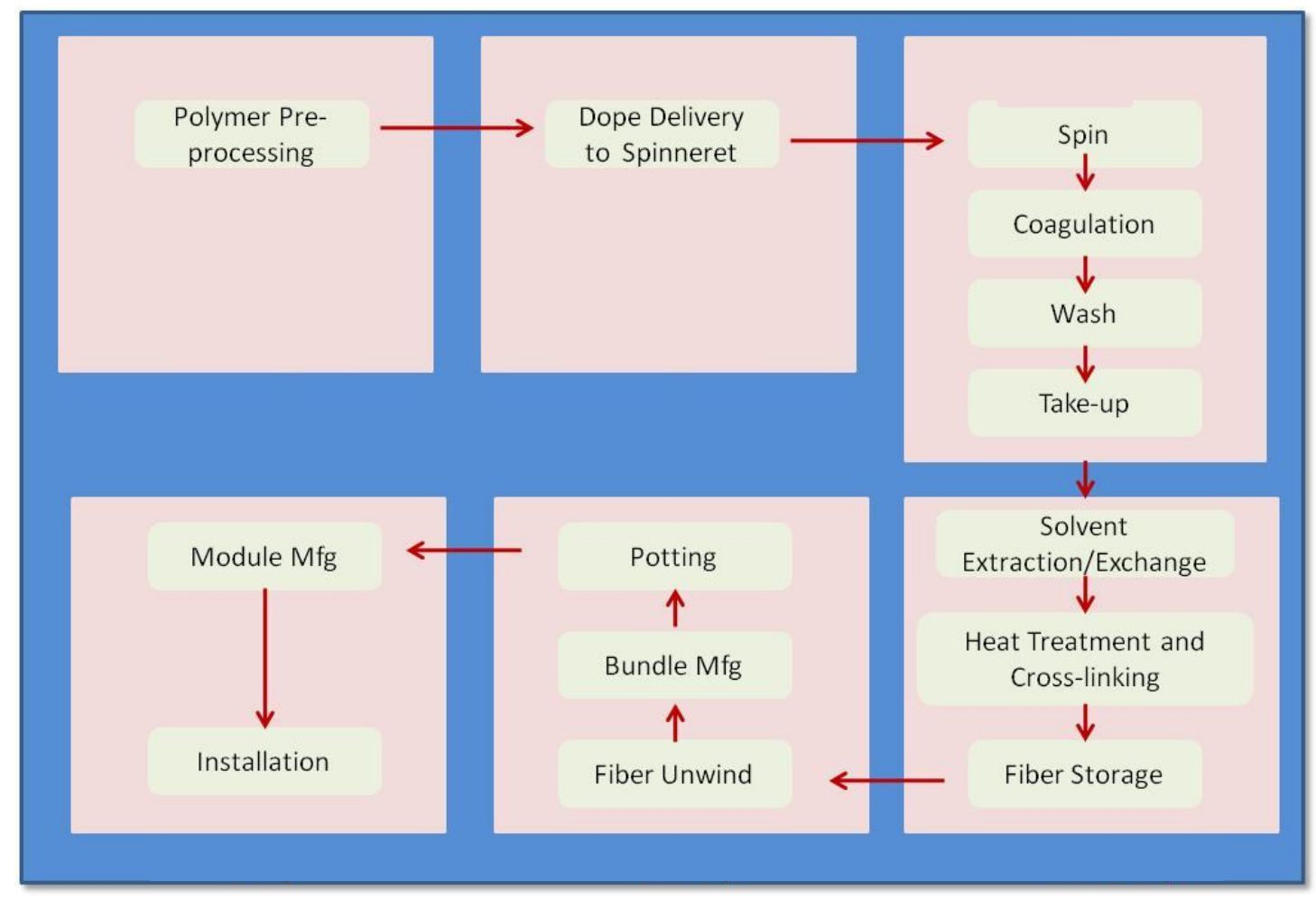

Figure II-17. Processing steps in fabricating hollow fiber modules.

To identify the critical process parameters in the fiber spinning, we used a generic design of experiment (DOE) approach with two level-factorial design to quickly identify the controllable input factors that can be modified to optimize the quality of the hollow fiber. As an example, the relationship between controllable input factors, uncontrollable input factors and responses is shown in Figure II-18 and the details of the factors that are related to fiber spinning process are given in Table II-3.

In our evaluation, we reduced the number of controllable parameters to investigate by downselecting the most sensitive parameters conducting a series of small scale tests to identify the dominant process variables. Table II-4 shows the preliminary guide to controlling macroscopic properties for a given dope composition based on our initial investigation. The properties listed in bold letters in Table II-4 identify the dominant process variables controlling a given macroscopic property. 


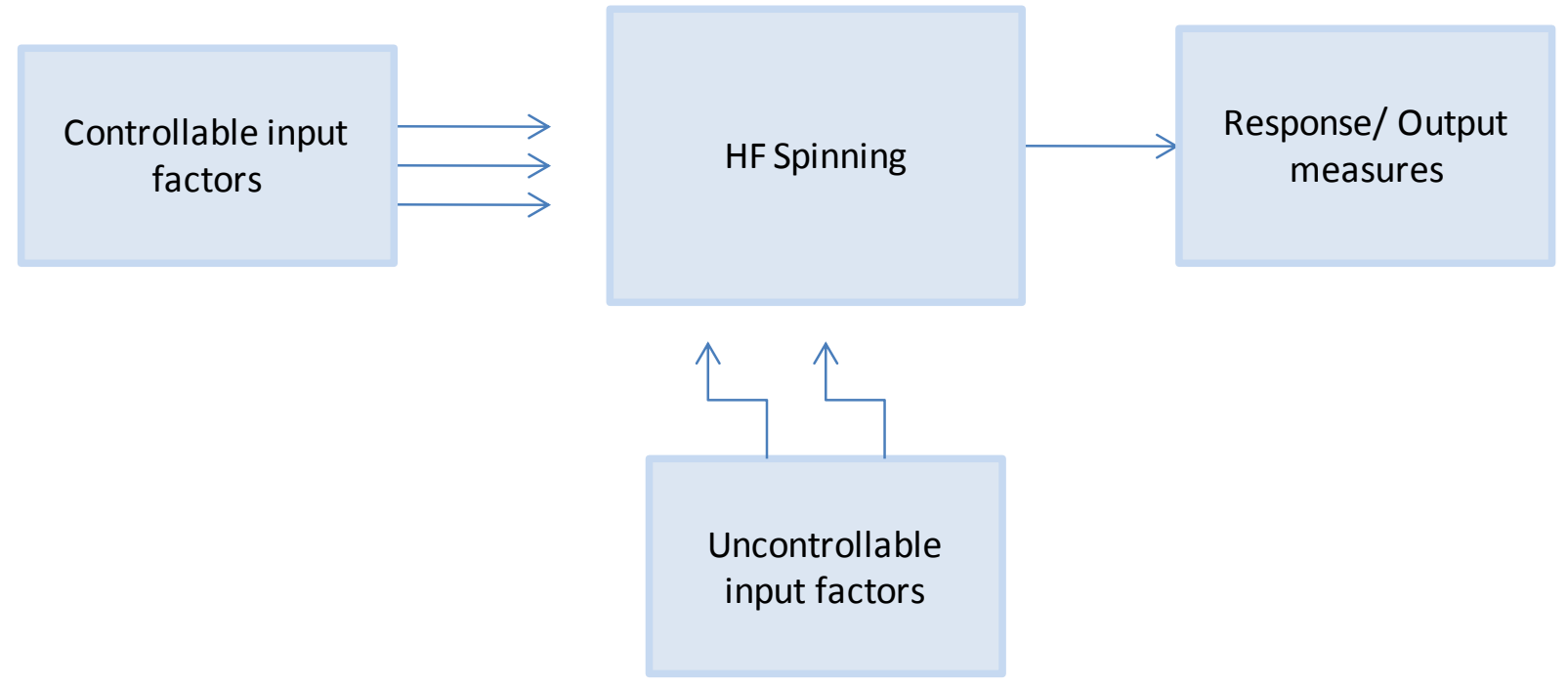

Figure II-18. Fiber spinning process factors and responses flow chart.

Table II-3. Hollow Fiber Spinning Parameters

\begin{tabular}{|c|c|}
\hline Parameter & Notes \\
\hline $\begin{array}{l}\text { Controllable parameters } \\
\text { 1. Spinneret Design } \\
\text { 2. Dope solution (composition, flow rate, and } \\
\text { temperature) } \\
\text { 3. Bore solution (flow rate, composition and } \\
\text { temperature) } \\
\text { 4. Coagulant ( flow rate, composition and } \\
\text { temperature ) } \\
\text { 5. Additives }\end{array}$ & -Spinneret design is fixed \\
\hline 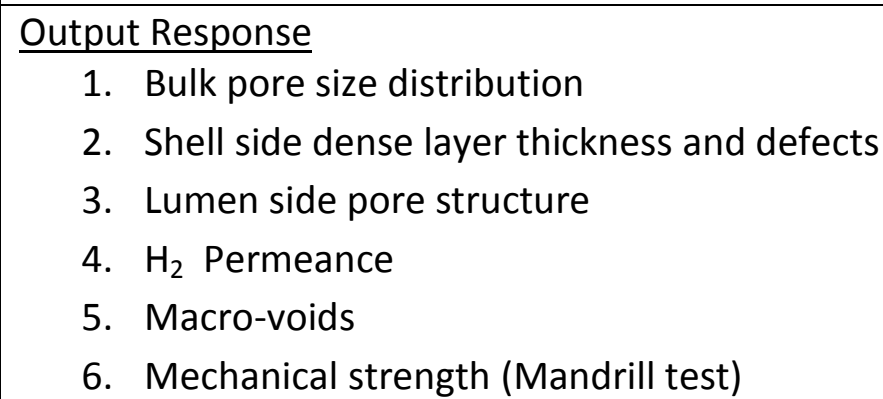 & $\begin{array}{l}\text { - Key screening parameters are } \\
\text { density of macro-voids, dense layer } \\
\text { thickness and the } \mathrm{H}_{2} \text { permeance }\end{array}$ \\
\hline
\end{tabular}


Table II-4. Relationship Between Process Parameters and Fiber Properties

\begin{tabular}{|c|c|c|c|c|c|}
\hline & \multicolumn{5}{|c|}{ Macroscopic Properties } \\
\hline Parameter & Fiber OD & Finer ID & $\begin{array}{c}\text { Diameter } \\
\text { Variance, DV }\end{array}$ & Ovality, OV & $\begin{array}{c}\text { Irregular Bores, } \\
\text { IB }\end{array}$ \\
\hline $\begin{array}{l}\text { Spinneret } \\
\text { Design, SD }\end{array}$ & $\begin{array}{l}\text { Second order to } \\
\text { DR }\end{array}$ & $\begin{array}{l}\text { Second order } \\
\text { to } F_{D}\end{array}$ & & & \\
\hline $\begin{array}{l}\text { Dope Flow } \\
\text { Rate, } \mathrm{F}_{\mathrm{D}}\end{array}$ & $\begin{array}{l}\text { OD decrease } \\
\text { with decrease in } \\
\mathrm{F}_{\mathrm{D}} \text { at a constant } \\
\text { draw rate }\end{array}$ & & & & $\begin{array}{l}\text { Fiber breaks as } \mathrm{F}_{\mathrm{D}} \\
\text { increases when } \mathrm{Dr} \\
\text { is held constant due } \\
\text { to dope elasticity }\end{array}$ \\
\hline Draw Ratio, DR & $\begin{array}{l}\text { OD decreases as } \\
\text { DR increases }\end{array}$ & $\begin{array}{l}\text { ID is } \\
\text { controlled by } \\
F_{B} \text { once } O D \text { is } \\
\text { fixed with } \\
\text { constant } D R \\
\text { and } F_{D}\end{array}$ & $\begin{array}{l}\text { Highly dope } \\
\text { specific }\end{array}$ & & \\
\hline $\begin{array}{l}\text { Air Gap Height, } \\
\text { AG }\end{array}$ & & & $\begin{array}{l}\text { DV depends on } \\
\text { AG, but highly } \\
\text { dope specific }\end{array}$ & $\begin{array}{l}\text { Second order to } \\
\text { VK in the quench } \\
\text { bath }\end{array}$ & \\
\hline $\begin{array}{l}\text { Bore Flow Rate, } \\
F_{B}\end{array}$ & $\begin{array}{l}\text { Second order to } \\
\text { DR }\end{array}$ & $\begin{array}{l}\text { ID decreases } \\
\text { as } \mathrm{F}_{\mathrm{B}} \\
\text { decreases }\end{array}$ & & $\begin{array}{l}\text { OV tends to } \\
\text { decrease as } \mathrm{F}_{\mathrm{B}} \\
\text { increases since } \\
\text { increasing } \mathrm{OD} / \mathrm{ID} \\
\text { increases } \mathrm{VK}\end{array}$ & \\
\hline $\begin{array}{l}\text { Solvent } \\
\text { Concentration } \\
\text { in Bore } \\
\text { Solution, Sc }\end{array}$ & & & & & $\begin{array}{l}\text { IB decreases as SC } \\
\text { increases. Low SC } \\
\text { can increase fiber } \\
\text { break }\end{array}$ \\
\hline $\begin{array}{l}\text { Vitrification } \\
\text { Kinetics, VK }\end{array}$ & $\begin{array}{l}\text { Fiber shrinkage } \\
\text { is second order } \\
\text { to } D R\end{array}$ & $\begin{array}{l}\text { Second order } \\
\text { to } F_{B}\end{array}$ & $\begin{array}{l}\text { Highly dope } \\
\text { specific, DV } \\
\text { decrease as VK } \\
\text { increase }\end{array}$ & $\begin{array}{l}\text { OV decreases as } \\
\text { VK increases }\end{array}$ & $\begin{array}{l}\text { IB decreases as VK } \\
\text { at fiber ID decreases } \\
\text { (e.g., increase SC) }\end{array}$ \\
\hline
\end{tabular}


Based on this work, we selected two possible dope formulations that will produce asymmetric hollow fiber membranes with $<0.5 \mu \mathrm{m}$ selective dense layer membrane. The $\mathrm{OD}$ and ID of the membrane are $0.6 \mathrm{~mm}$ and $0.3 \mathrm{~mm}$, respectively.

A macroscopic parameter that is not shown above is the presence of macro-voids. Presence of macro-voids is highly dope-specific and is dependent strongly on the non-solvent and solvent exchange rate during coagulation. Figure II-19 shows a PBI hollow fiber with macroscopic voids. Both the fiber cross section and the magnified photograph of morphology of the bulk porous structure are also shown. The measured $\mathrm{H}_{2}$ permeance for his fiber was in the range 100 to $200 \mathrm{GPU}$ at room temperature but the $\mathrm{H}_{2} / \mathrm{CO}_{2}$ selectivity was only 5 .

The presence of macro-voids reduces the mechanical strength of the fiber. Once the hollow fiber spinning conditions to produce a fiber with required dense layer thickness is selected, the next step in process optimization is to identify the process parameters that affect the macro-void formation. Table II-5 shows the approach for identifying dominant parameters and to spin fibers with improved quality control. The response measured will be the gas permeation rate and the density of macro-voids.

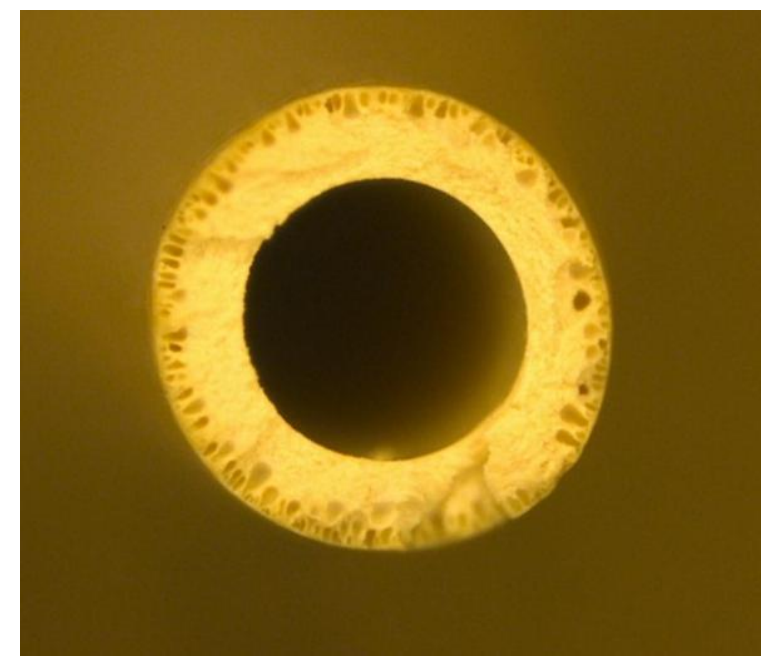

Figure II-19. A photograph of a cross section of an asymmetric PBI hollow fiber membrane. 
Table II-5. Parameters Affecting Macro-Voids and their Associated Levels to be tested

\begin{tabular}{|l|c|c|}
\hline \multicolumn{1}{|c|}{ Name } & Lower Level & Upper Level \\
\hline 1. $\begin{array}{l}\text { Bore fluid solvent } \\
\text { concentration (wt\%) }\end{array}$ & 5 & 50 \\
2. Non solvent in dope (wt\%) & 0 & 25 \\
3. Non-solvent diffusion rate & $\begin{array}{c}\text { Slow diffusing } \\
\text { coagulant }\end{array}$ & Highly diffusive coagulant \\
\hline
\end{tabular}

Figure II-19 shows the pictures of sections of PBI fibers using four different coagulations solvents that boarder the conditions given in Table II-5. Bottom right-hand shows the fiber coagulated from the solvent combination optimized to form minimum macro-voids in the lumen side of the fiber. Figure II-20 illustrates the fibers without macro-defects fabricated after optimizing the spinning process parameters.

The production of these hollow fibers with desired geometry represents a significant milestone of this project. As described above, previous experimental work on WFX fibersfocused on coating a dense PBI layer on to porous hollow fibers produced in a separate step. Although this two-step procedure resulted in the fabrication of short sections of fibers with a suitable dense-porous geometry, the quality control necessary to produce long lengths of the fibers was found to be difficult. The SRI developed fiber spinning procedure produced the asymmetric fibers in a single step by controlling the dope composition and optimizing the spinning parameters during the fabrication of PBI hollow fibers.
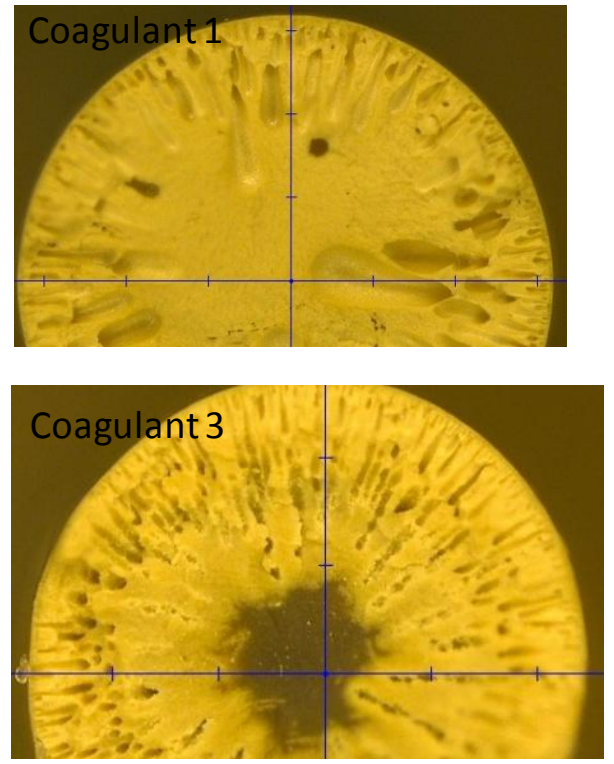
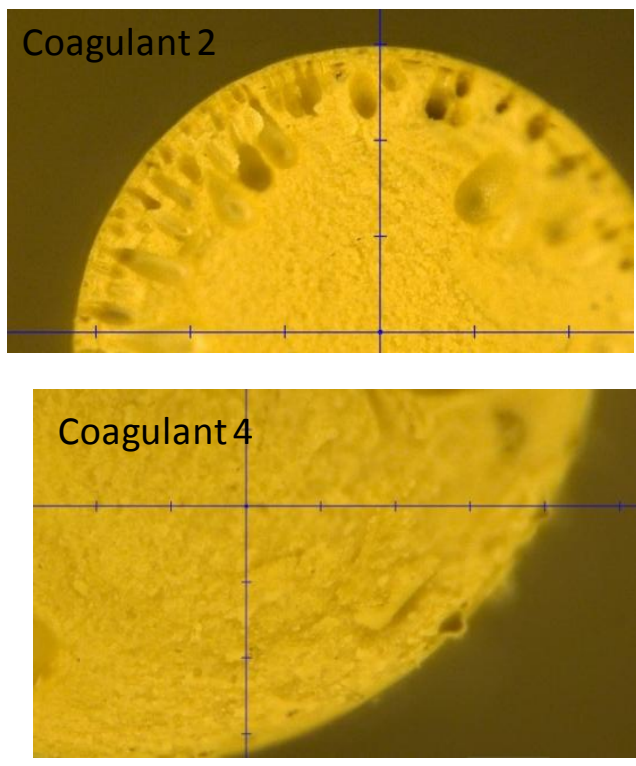

Figure II-19a. Photographs of the cross section of bulk porous sections of PBI fibers drawn from four different coagulation solvent combinations. 

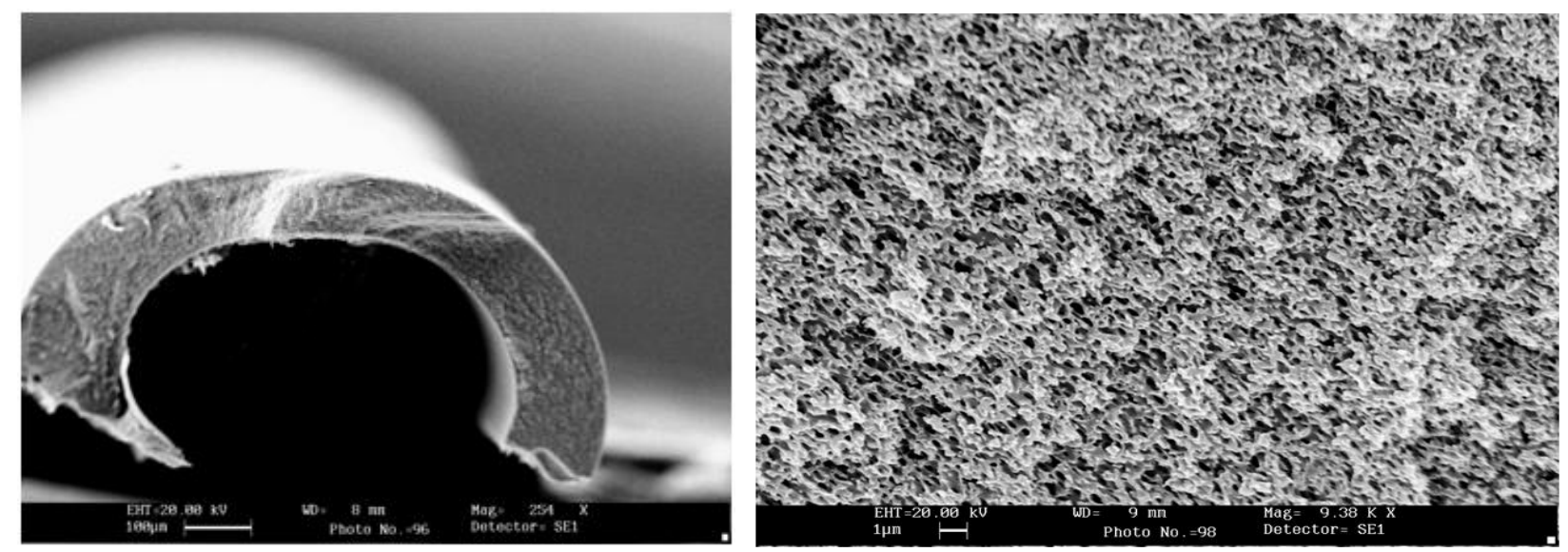

Figure II-20. Photographs of a fiber without macro-defects and the cross section illustrating the porous substrate.

Based on the spinning optimization work at SRI, we selected two possible dope formulations (PBI Dope A and PBI Dope B) to produce asymmetric hollow fiber membranes with $<1 \mu \mathrm{m}$ selective dense layer. The fibers from Dope A and Dope B are identified as SRI Fiber Series- A and $-B$, respectively. Initially, we fabricated about 500 meter length of fibers (SRI Fiber Series A) for long term performance evaluation. The dimensions of this hollow fiber membrane are $0.6 \mathrm{~mm}$ OD and $0.3 \mathrm{~mm}$ ID. Figure II-21 shows a cross section of a PBI hollow fiber with no noticeable finger voids. Figure II-22 below shows a fiber bundle with $0.6 \mathrm{~mm}$ diameter fibers from Series A fibers. Figure II-23 is a photograph of coils of the fibers produced by the spinning process. Figure II-24 shows the high magnification photographs of fiber cross-sections near dense shell surface and porous lumen surface for SRI Series B fibers. The main difference between Series A and Series B is the thickness of the dense layer. Series B fibers have a thinner dense layer than Series A fibers. In both cases, the exterior of the hollow fibers were dense with an extremely porous inner layer. The dense layer provides the separation between the highly permeating $\mathrm{H}_{2}$ and low-permeating $\mathrm{CO}_{2}$ whereas the porous layer provides mechanical strength with low pressure drop for the passage of the permeating gas. Based on the initial tests, Series A fibers were found to be superior and further development focused only on Series A. 


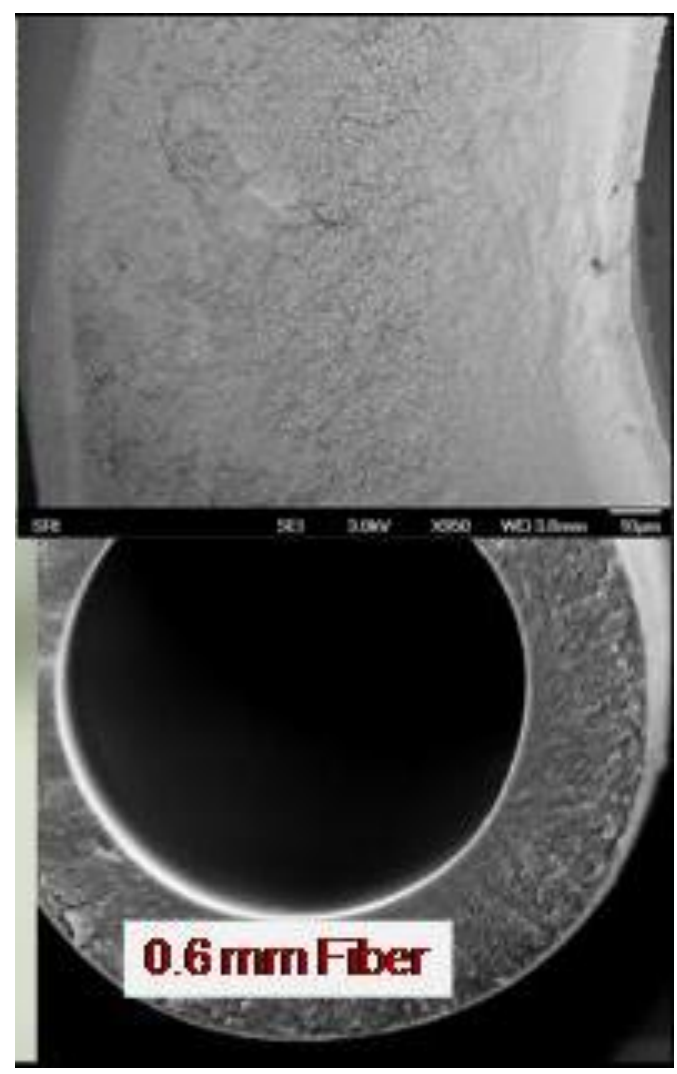

Figure II-21. A cross section of the PBI asymmetric hollow fiber made at SRI with no finger voids.

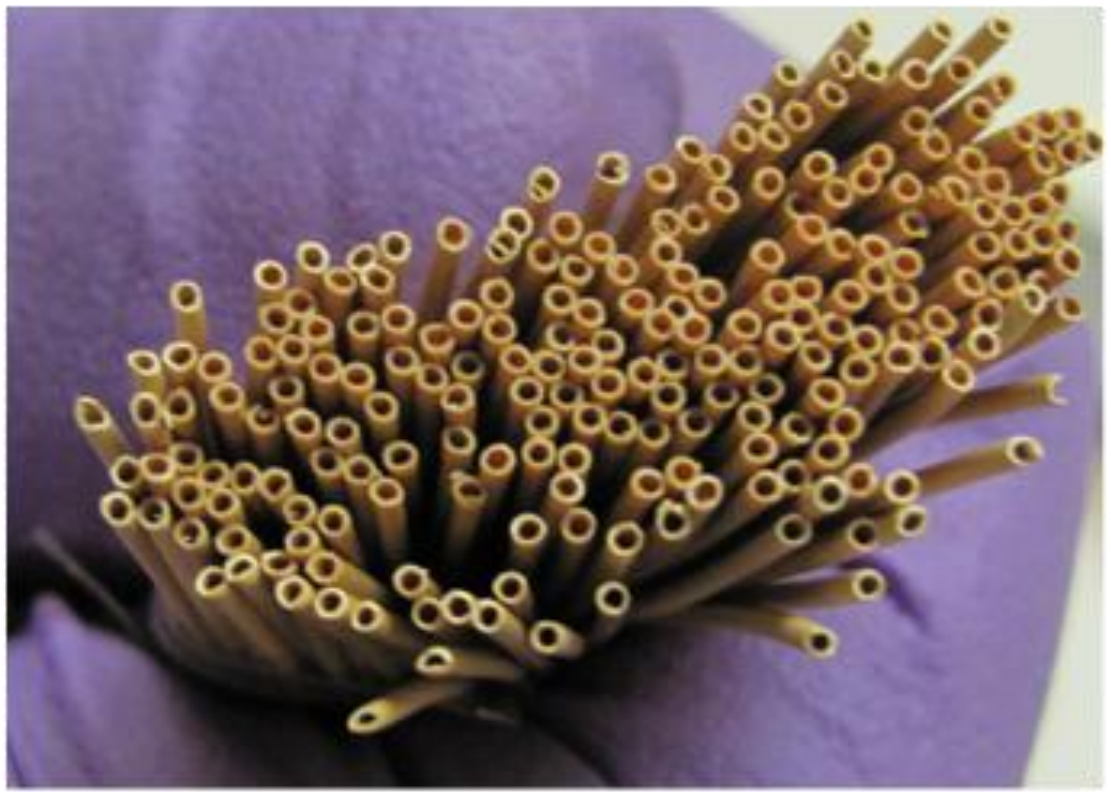

Figure II-22. Image of a bundle of PBI-based, asymmetric hollow fibers made at SRI. 


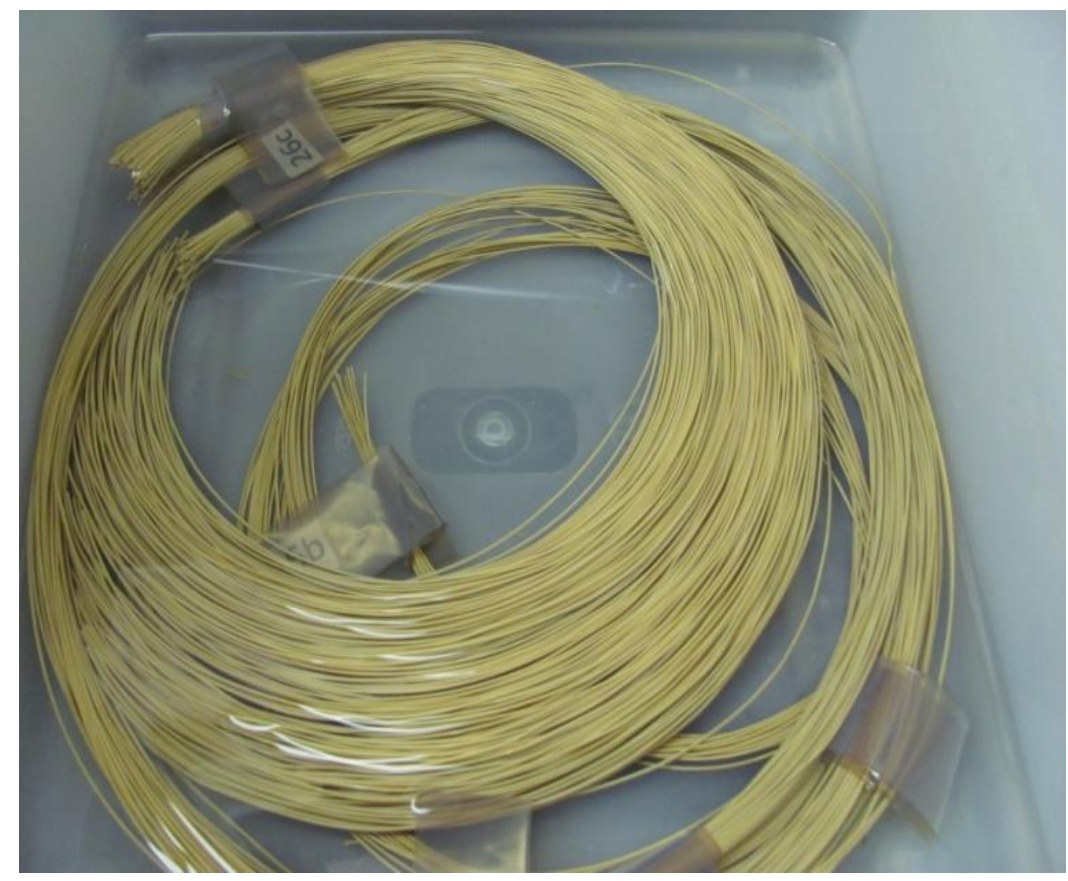

Figure II-23. Photograph of coils of $0.6 \mathrm{~mm}$ diameter PBI hollow fibers fabricated at SRI.

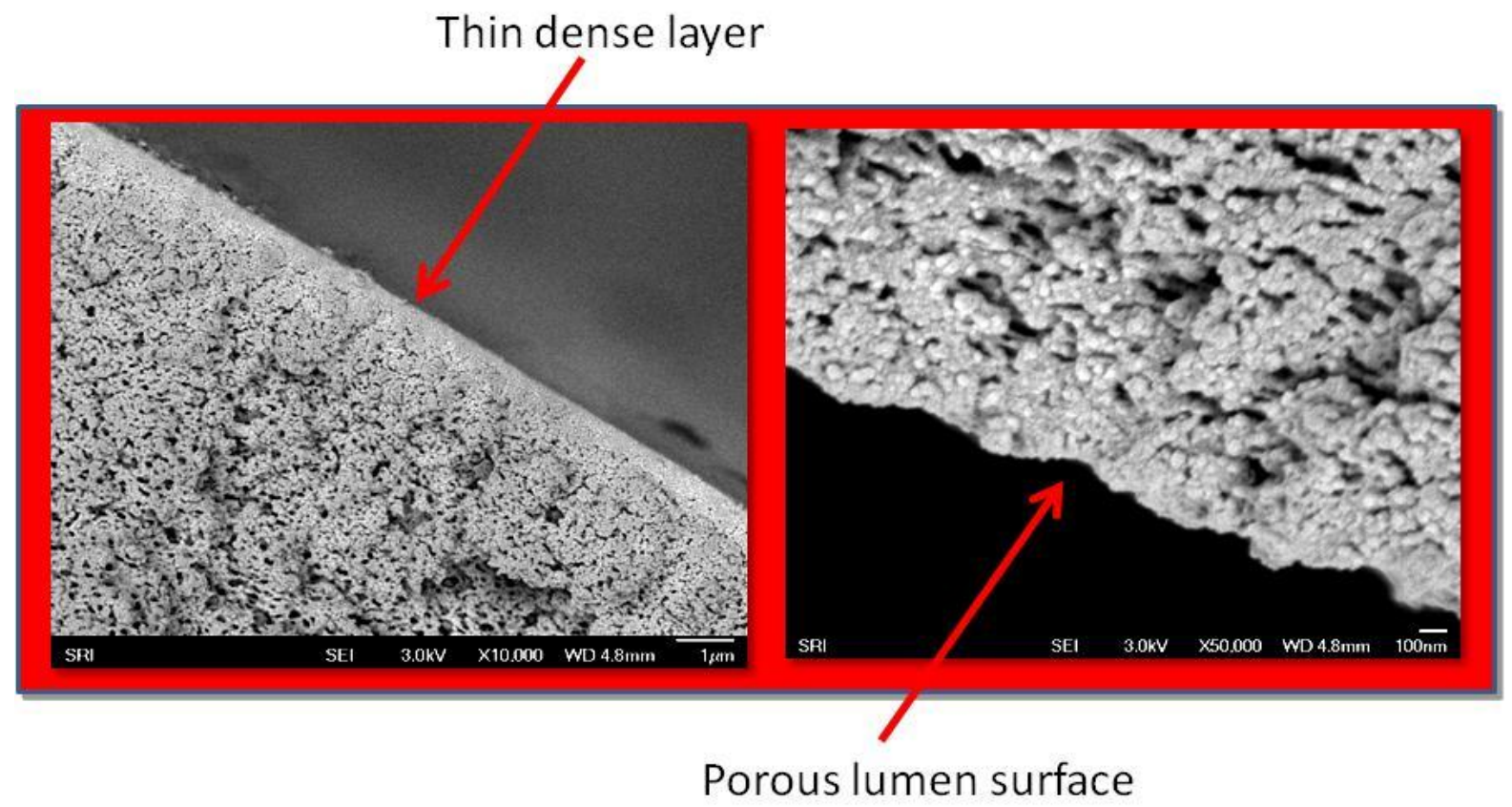

Figure II-24. High magnification photographs of cross-sections near shell and lumen sides of SRI Series A fiber. 
Potting of Fibers into a Bundle. We used a commercial high temperature epoxy material (Loctite) to bond the fibers in a bundle. It has high temperature stability was sufficient for the single fiber experiments test of about 100-hour durations. The epoxy was also found to be acceptable in a hydrothermal environment at $250 \mathrm{C}$ for $1000 \mathrm{~h}$. We also tested seals made with the PBI polymer that could be durable for long periods of time. Figure II- 25 shows the $1 / 2$ inch diameter hollow fiber bundle potted using PBI as potting material.

In our module fabrication, the fibers were potted with the high temperature epoxy and cured at $150^{\circ} \mathrm{C}$. Figures II-26 and II-27 shows the pictures of selected potted hollow fiber bundles used for potting and performance evaluation. These were made with varying fiber packing densities (10 to $30 \%$ ), each element contained fiber area up to $30 \mathrm{~m}^{2}$. The average fiber diameter and the wall thickness were $0.6 \mathrm{~mm}$ and $0.15 \mathrm{~mm}$, respectively.

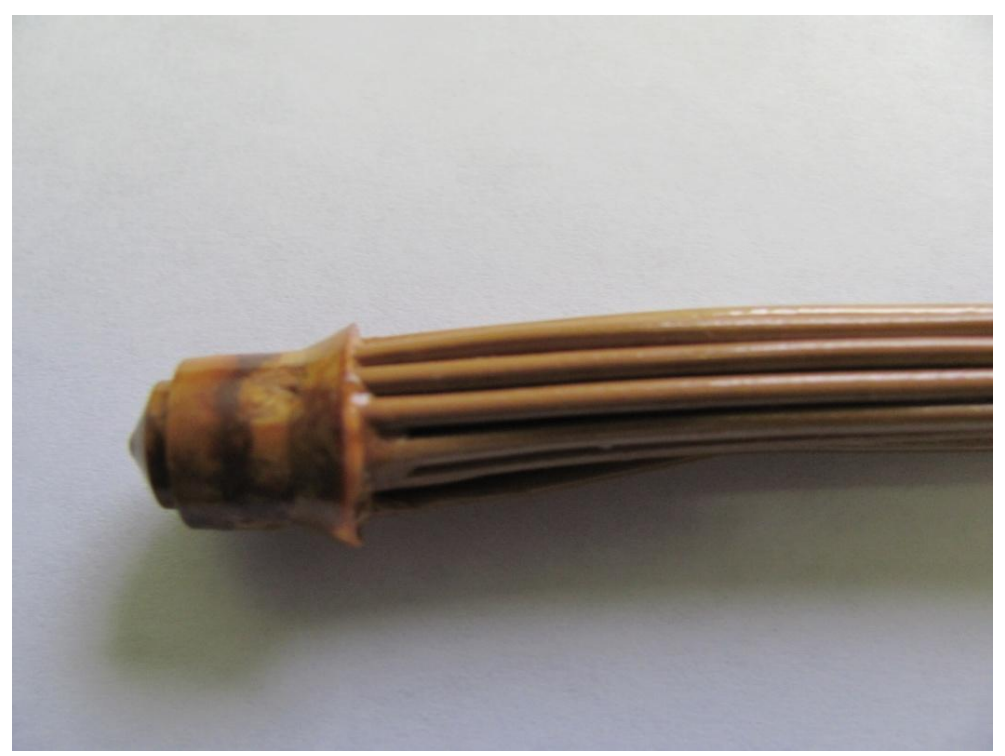

Figure II-25. Fiber bundle potted with PBI sealant. 


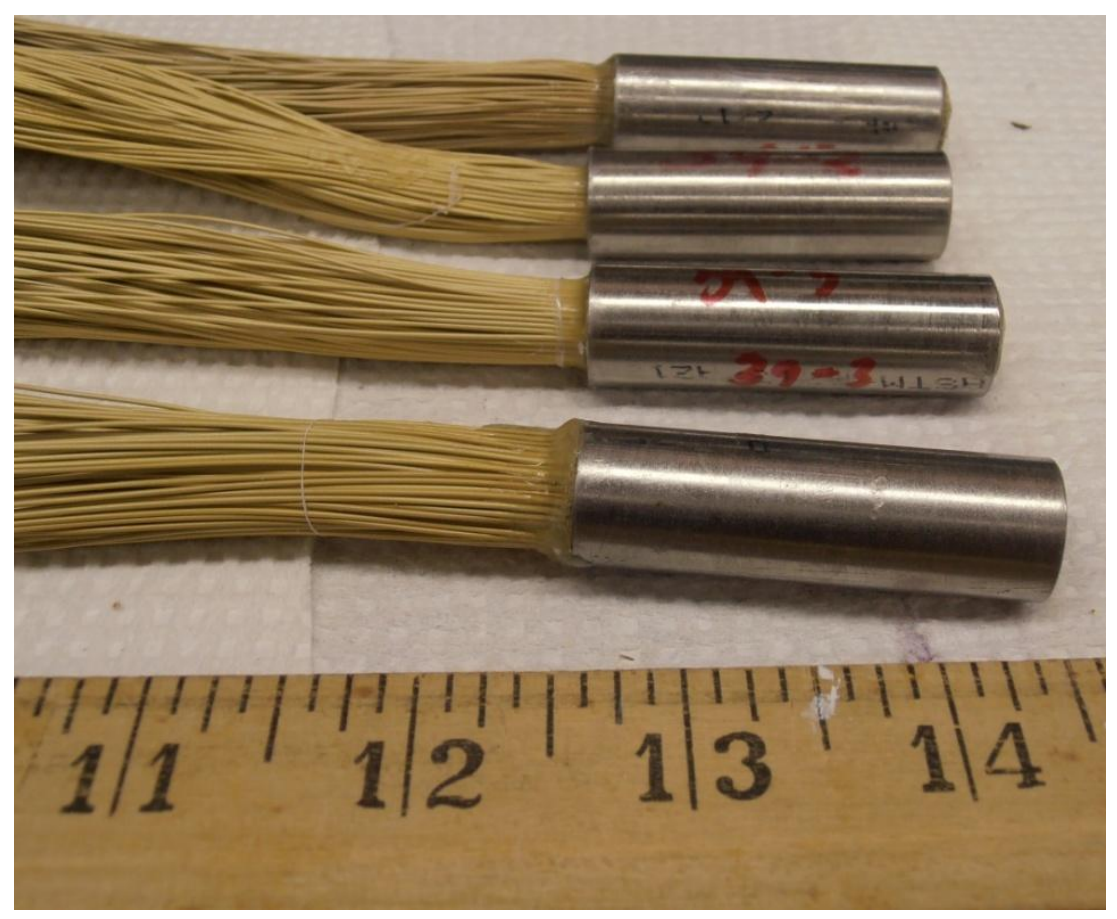

Figure II-26. Potted hollow fiber membrane elements, 1-in x 14-in size

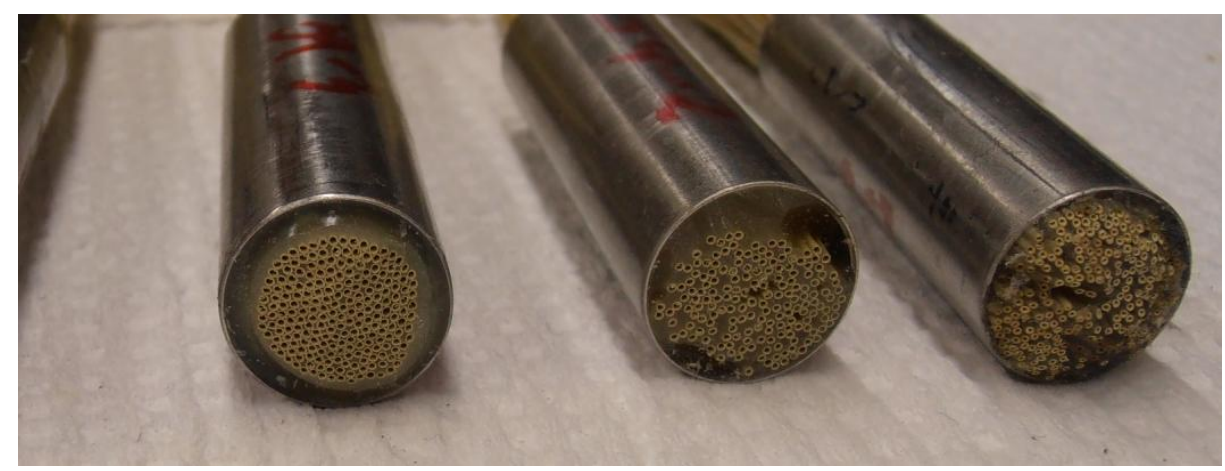

Figure II-27. Potted Fiber bundles assembled with varying packing densities to assess the potting performance

Gas Permeation Testing: Gas permeation testing was performed with SRI fiber series A. The selected fibers had $0.6 \mathrm{~mm}$ outer diameter and $0.3 \mathrm{~mm}$ inner diameter with 0.5 to $0.8 \mu \mathrm{m}$ dense layer thickness. $\mathrm{CO}_{2}$ and $\mathrm{H}_{2}$ peremances were measured in the temperature range at $150^{\circ}$ to $225^{\circ} \mathrm{C}$. Figure II- 28 shows the measured peremance values for $\mathrm{H}_{2}$ and $\mathrm{CO}_{2}$ as a function of applied pressure difference. The data shows that the $\mathrm{H}_{2}$ permeates more rapidly than $\mathrm{CO}_{2}$ 
through the membrane, as expected. The permeance of $\mathrm{H}_{2}$ increases with increasing temperature whereas the permeance of $\mathrm{CO}_{2}$ is relatively insensitive to the temperature.

Figure II-29 shows the measured selectivity for $\mathrm{H}_{2} / \mathrm{CO}_{2}$ as a function of $\mathrm{H}_{2}$ permeance in GPU units at $150^{\circ}, 200^{\circ}, 225^{\circ}$ and $250^{\circ} \mathrm{C}$. Both the $\mathrm{H}_{2} / \mathrm{CO}_{2}$ selectivity and $\mathrm{H}_{2}$ permeance increase with the increasing temperature up to a temperature of $225^{\circ} \mathrm{C}$. The ratio of $\mathrm{H}_{2} / \mathrm{CO}_{2}$ increases whereas the $\mathrm{H}_{2}$ permeance decreases at $250^{\circ} \mathrm{C}$. This observation may suggest a slight increase in the thickness of the dense layer.

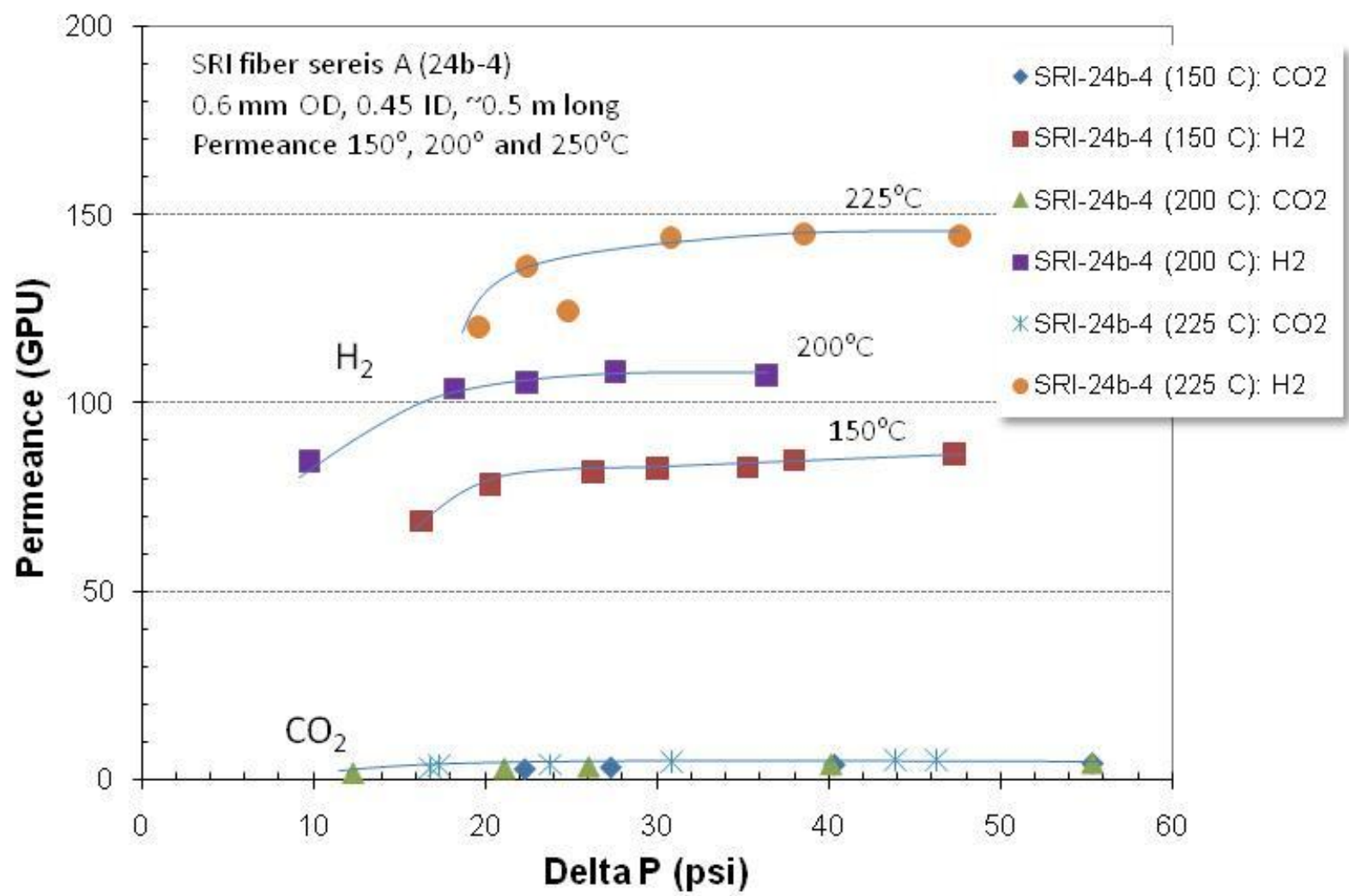

Figure II-28. Measured permeance values for $\mathrm{H}_{2}$ and $\mathrm{CO}_{2}$ at $150^{\circ}$ to $225^{\circ} \mathrm{C}$ as a function of applied pressure difference across the hollow fiber membrane. 


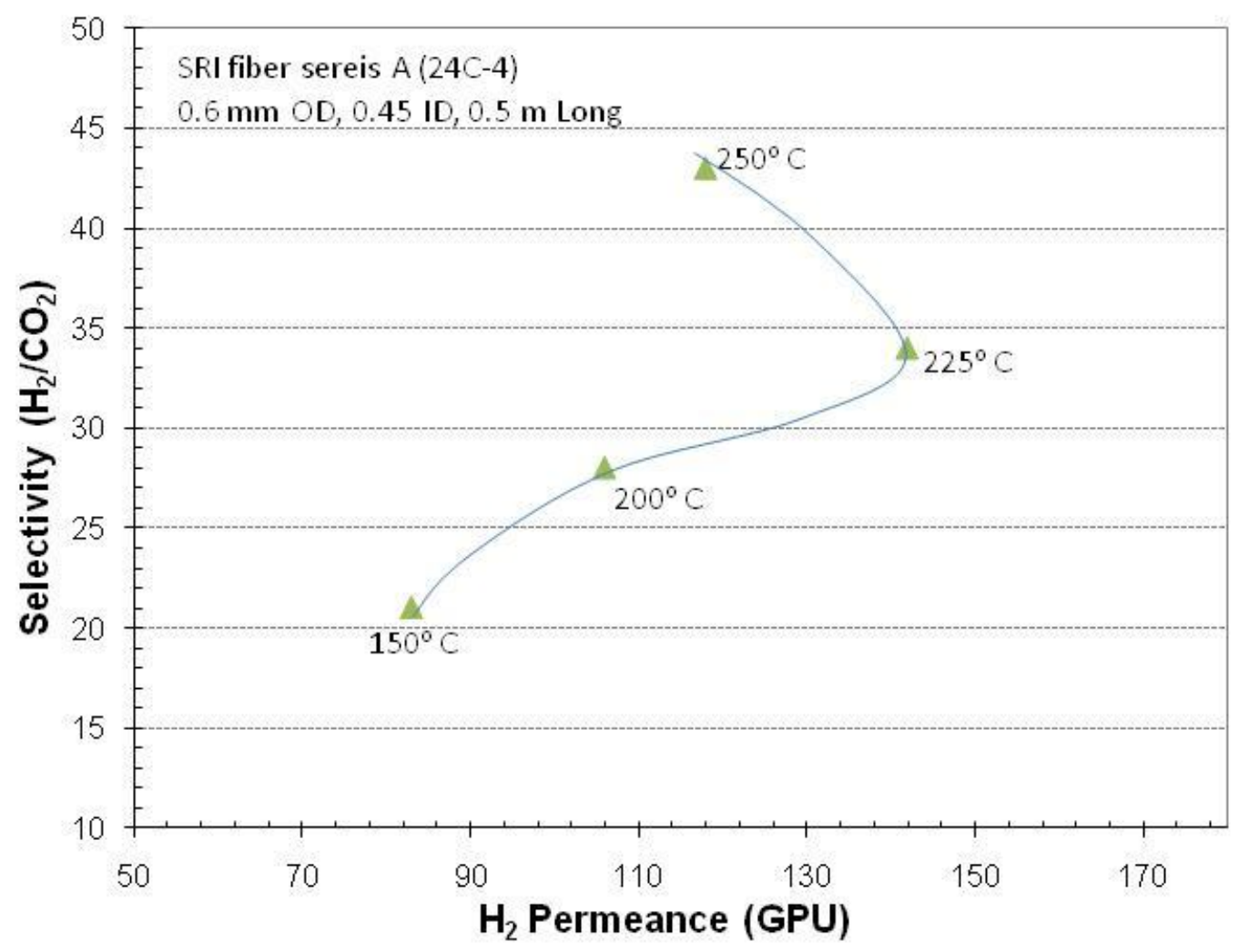

Figure II-29. Measured selectivity for $\mathrm{H}_{2} / \mathrm{CO}_{2}$ as a function of $\mathrm{H}_{2}$ permeance in GPU units at temperatures from $150^{\circ}$ to $250^{\circ} \mathrm{C}$.

The performance of SRI fiber series A was evaluated over 50 days, representing the performance over 1000 hours. The selectivity for $\mathrm{H}_{2} / \mathrm{CO}_{2}$ improved with time increasing from 35 to 50 , exceeding the design target of 40. Long term performance evaluation data are shown in Figure II-30. The $\mathrm{H}_{2}$ permeance value remained at about $80 \mathrm{GPU}$ throughout the test period and this value is above the target value. At the end of the 1000-h test period, the $\mathrm{H}_{2}$ permeance was measured to be $130 \mathrm{GPU}$ at $250^{\circ} \mathrm{C}$.

Figure II-31 summarizes the interplay between the $\mathrm{H}_{2} / \mathrm{CO}_{2}$ selectivity and the $\mathrm{H}_{2}$ permeance at $250^{\circ} \mathrm{C}$ for the $\mathrm{PBI}$ hollow fiber membranes. As expected, the permeance increases as the selectivity decreases. Figure II-32 illustrates the improvement in the selectivity and permeance characteristics as we decreased the dense layer thickness from $10 \mu \mathrm{m}$ to $1 \mu \mathrm{m}$. In the future, we expect to decrease the dense layer thickness even further to $0.1 \mu \mathrm{m}$, as more experience is gained in the fiber spinning. Such quality increases have been experienced in the industry with the spinning of other polymer fibers. 
Figure II-32 compares the $\mathrm{H}_{2} / \mathrm{CO}_{2}$ with $\mathrm{H}_{2}$ permeability using the well-known Robeson plot. It shows clearly, the hollow fibers produced at SRI have higher selectivities and permeance than other polymers and approach the values observed at Los Alamos National Laboratory with PBI dense layer deposited on a porous stainless steel substrate. The PBI hollow fiber geometry represents an order-of-magnitude decrease in the module size over the stainless steel substrate.

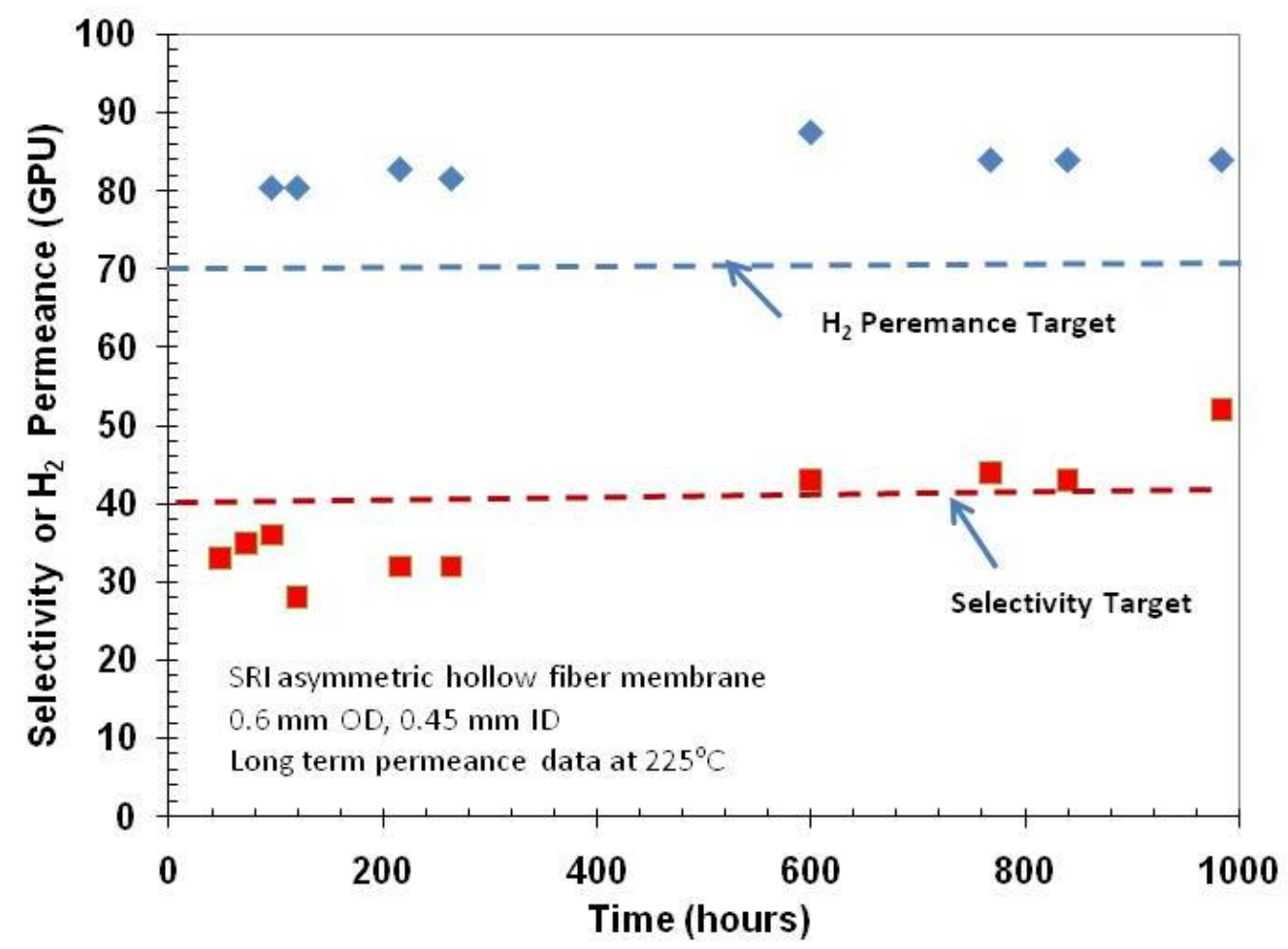

Figure II-30. Measured selectivity for $\mathrm{H}_{2} / \mathrm{CO}_{2}$ and $\mathrm{H}_{2}$ permeance at $225^{\circ} \mathrm{C}$ measured over $1000 \mathrm{~h}$. 


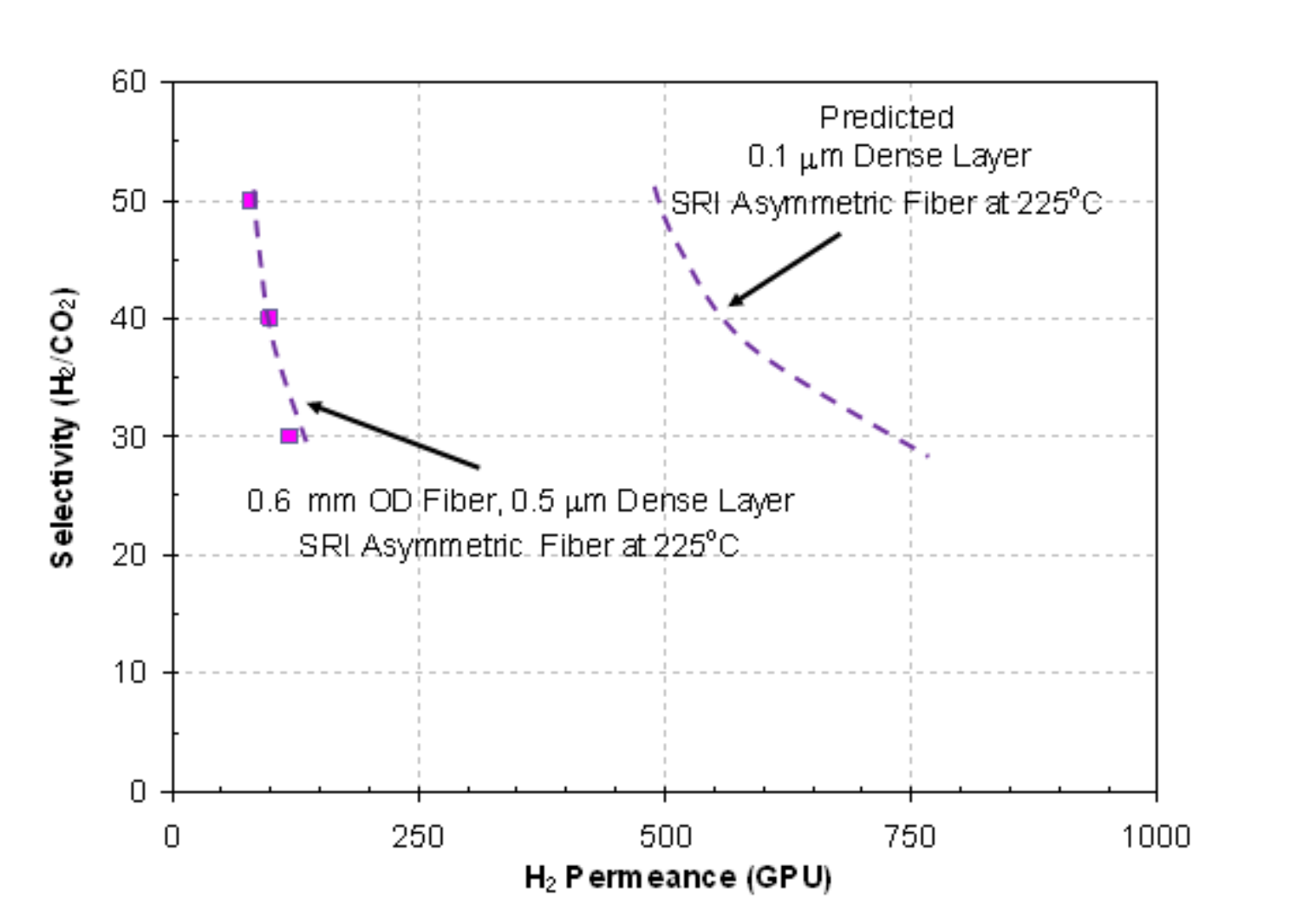

Figure II-31. Relationship between selectivity for $\mathrm{H}_{2} / \mathrm{CO}_{2}$ and $\mathrm{H}_{2}$ permeance at $250^{\circ} \mathrm{C}$ as a function of the dense layer thickness.

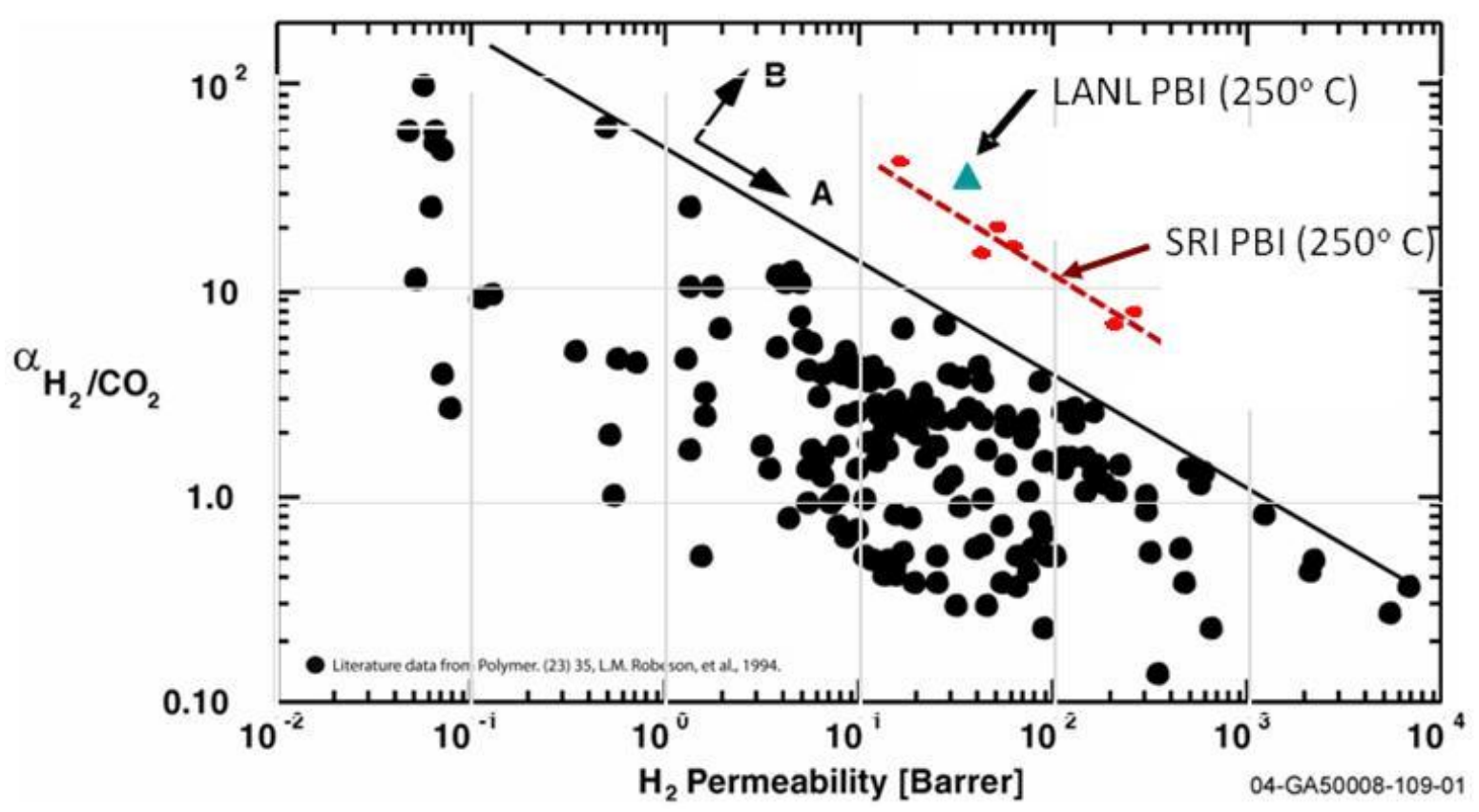


Figure II-32. Comparison of $\mathrm{H}_{2} / \mathrm{CO}_{2}$ selectivity and $\mathrm{H}_{2}$ permeability in polymers.

We calculated single stage membrane performance using the given permeance and selectivity data was simulated for $90 \% \mathrm{CO}_{2}$ capture using the PBI membrane having a dense layer thickness of $0.5 \mu \mathrm{m}$. This membrane would have a $\mathrm{H}_{2} / \mathrm{CO}_{2}$ selectivity of 43 and a $\mathrm{H}_{2}$ permeance of 175 GPU. $\mathrm{A} \mathrm{N}_{2}$ permeate sweep equal to $48 \%$ of the total permeate flow was assumed. Feed composition was set at a typical shifted coal-fired syngas: $\mathrm{H}_{2}=54.2 \%, \mathrm{CO}_{2}=38.8 \%, \mathrm{H}_{2} \mathrm{O}=$ $3.7 \%, \mathrm{~N}_{2}=1.5 \%, \mathrm{CO}=1.1 \%, \mathrm{H}_{2} \mathrm{~S}=0.6 \%$ and $\mathrm{CH}_{4}=0.1 \%$. Under these conditions, we can obtain a $\mathrm{H}_{2}$ recovery of $98.3 \%$ and $90 \%$ capture $95.5 \%$ of the heating value of the fuel. In contrast to other polymer membranes having a $\mathrm{H}_{2} / \mathrm{CO}_{2}$ selectivity of 15 and $\mathrm{H}_{2}$ permeance of 240 GPU, the PBI membrane recovers $43 \%$ more feed $\mathrm{H}_{2}$ and correspondingly $43 \%$ more thermal energy from the feed in a single stage. The PBI membrane achieves its goals of $98.3 \%$ $\mathrm{H}_{2}$ recovery and $90 \% \mathrm{CO}_{2}$ capture without requiring multiple stages, multiple recycle streams, and multiple rotating machinery with substantial parasitic power.

Sub-scale Module Testing: Several 1-inch PBI hollow fiber modules were prepared for testing the fiber sealing procedures and performance reproducibility testing. Figure II-32a shows a photograph of the assembled 0.75-in module ready for testing. The fibers used in these modules are fabricated using conditions similar to those used for $1000 \mathrm{~h}$ testing shown previously. The total fiber length in this module was $\sim 21$ meter with effective fiber surface area is $340 \mathrm{~cm}^{2}$. In the initial testing, measured at $200^{\circ} \mathrm{C}, \mathrm{H}_{2}$ permeance was in the range 90 to 100 GPU with $\mathrm{H}_{2} / \mathrm{CO}_{2}$ selectivity was in the range 20 to 25 (see Figure II-33). We believe that some of the fibers were damaged during the module fabrication. Other fiber modules ( $4 \mathrm{~m}$ long with a fiber surface area is $0.16 \mathrm{~m}^{2}$ ) exhibited a $\mathrm{H}_{2} / \mathrm{CO}_{2}$ selectivity of 25-to 40 and $\mathrm{H}_{2}$ permeance of 100 to $125 \mathrm{GPU}$ at $200^{\circ}$ to $225^{\circ} \mathrm{C}$.

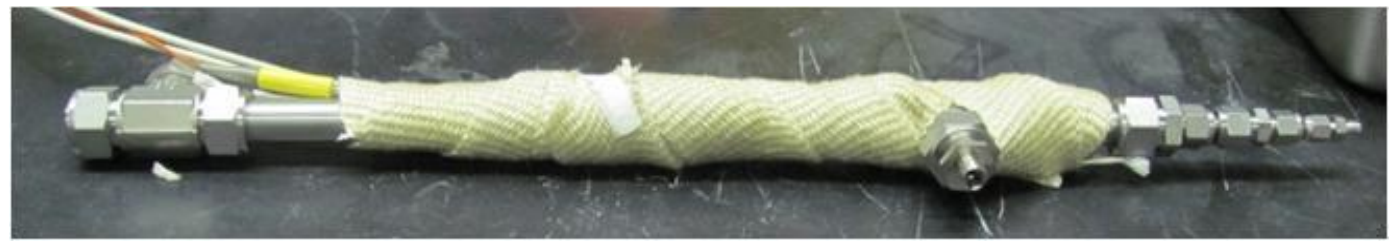

Figure II-32a. A photograph of assembled sub-scale 1-in module with SRI PBI hollow fiber membrane. 


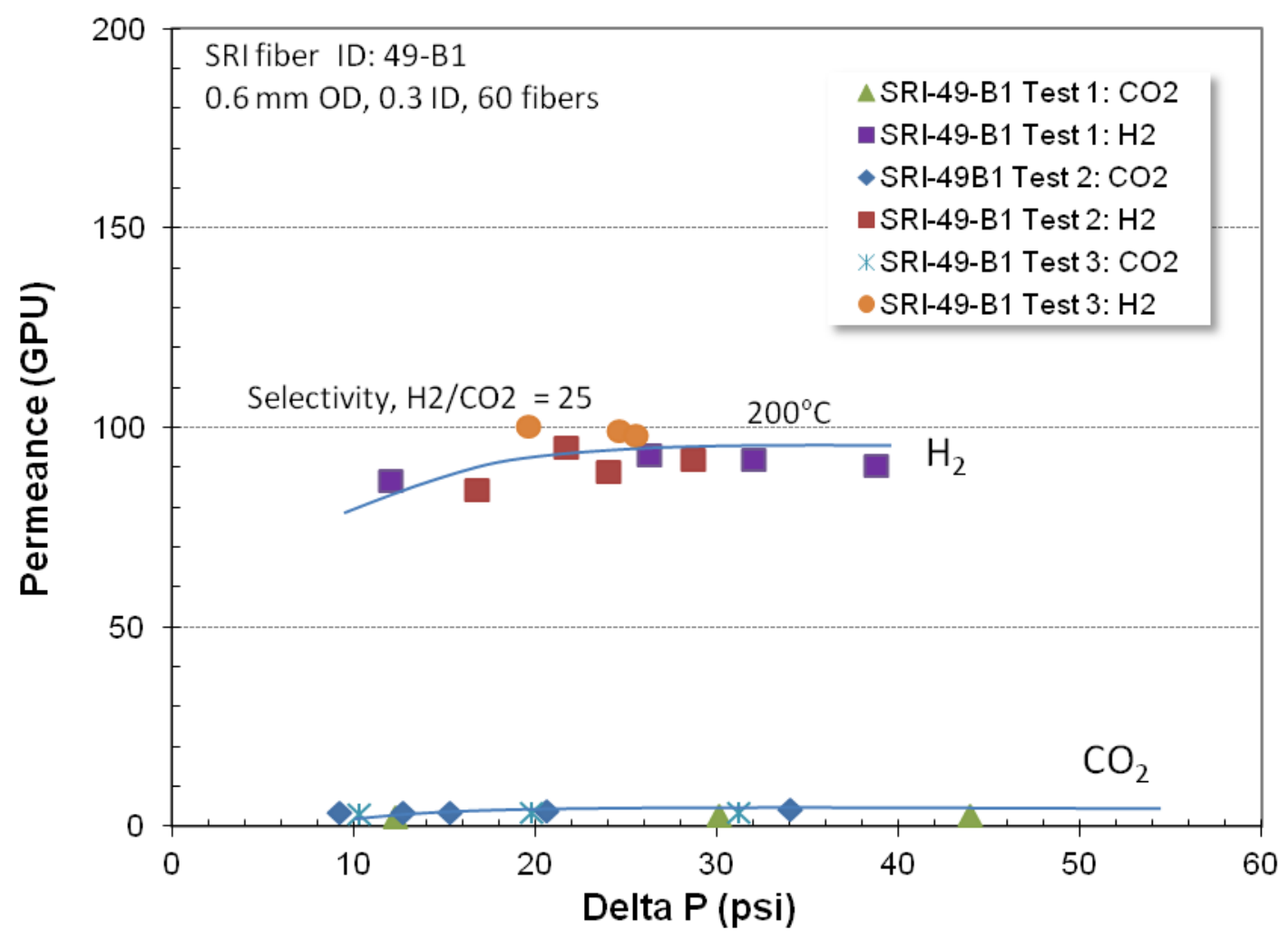

Figure II-33. Performance data for large hollow fiber membrane module at $200^{\circ} \mathrm{C}$.

\section{MEMBRANE MODULE (50 KW $\mathrm{KH}_{\text {TH }}$ FABRICATION AND TESTING}

Table II-6 shows a module specification based on the currently fabricated asymmetric PBI hollow fibers. These fibers have a $0.6 \mathrm{~mm}$ ID and $0.45 \mathrm{~mm}$ OD with a $0.5 \mu \mathrm{m}$ thick dense layer. A membrane area of $3 \mathrm{~m}^{2}$ is needed for each $25 \mathrm{~kW}_{\text {th }}$ element.

A membrane system model was used to calculate the performance of a module that will process a fuel gas stream from GE-type oxygen-blown gasifier. The module will operate at a temperature of $225^{\circ} \mathrm{C}$ with a trans-membrane pressure of 200 psi. Representative experimental values at $225^{\circ} \mathrm{C}$ of the $\mathrm{H}_{2} / \mathrm{CO}_{2}$ selectivity of 200 and a $\mathrm{H}_{2}$ permeance of $100 \mathrm{GPU}$, and a fiber packing density of $63 \%$ were assumed in the simulation. Modeling data shows that $95 \% \mathrm{H}_{2}$ recovery and $90 \% \mathrm{CO}_{2}$ capture can be achieved by using two 3"x1' fiber elements with $63 \%$ fiber packing density (Table II-6). Table II-7 shows the main gas stream compositions for $\mathrm{H}_{2}$, $\mathrm{CO}_{2}, \mathrm{H}_{2} \mathrm{~S}$ and $\mathrm{H}_{2} \mathrm{O}$ equivalent to $50 \mathrm{~kW}$ th feed stream. Figure II-34 shows the mass balances for a test skid with a feed processing capacity of $50 \mathrm{MWh}_{\text {th }}$ with gas compositions as given in Table II-8. 
Table II-6. Module Specification for 0.6 mm O.D. fiber with a $0.45 \mu \mathrm{m}$ Thick Dense Layer

\begin{tabular}{|l|c|}
\hline \multicolumn{2}{|c|}{ 3.0" $\times$ 12" Fiber Element } \\
\hline Fiber O.D/I.D. & $600 \mu \mathrm{m} / 450 \mu \mathrm{m}$ \\
\hline Fiber packing & $50-60 \%$ \\
\hline Total fiber length per element, $\mathrm{km}$ & 1.86 \\
\hline Number of fibers per element & 5,586 \\
\hline Module membrane area, $\mathrm{m}^{2}$ & 3 \\
\hline Module membrane area, $\mathrm{ft}^{2}$ & 32.3 \\
\hline Element Volume, $\mathrm{m}^{3}$ & 0.00139 \\
\hline Specific membrane area, $\mathrm{m}^{2} / \mathrm{m}^{3}$ & 2,159 \\
\hline $\mathrm{kWth}^{2}$ (feed)/element & 25 \\
\hline $\mathrm{H}_{2}$ recovery & $95.0 \%$ \\
\hline $\mathrm{CO}_{2}$ recovery & $90.0 \%$ \\
\hline
\end{tabular}

Table II-7. The Simulation of a Membrane Module with for a $50 \mathrm{kWth}$ System

\begin{tabular}{|l|c|c|c|c|}
\hline \multicolumn{1}{|c|}{ Stream } & Feed & Retentate & Sweep & Permeate \\
\hline $\mathrm{CO}_{2}$, fraction & 0.388 & 0.8524 & 0 & 0.0344 \\
\hline $\mathrm{CO}$, fraction & 0.0114 & 0.0272 & 0 & 0.0002 \\
\hline $\mathrm{CH}_{4}$,fraction & 0.0008 & 0.0019 & 0 & 0.00001 \\
\hline $\mathrm{N}_{2}$, fraction & 0.015 & 0.0363 & 1 & 0.4785 \\
\hline $\mathrm{H}_{2}$, fraction & 0.542 & 0.0659 & 0 & 0.4548 \\
\hline $\mathrm{H}_{2} \mathrm{~S}$, fraction & 0.0058 & 0.0141 & 0 & 0.00001 \\
\hline $\mathrm{H}_{2} \mathrm{O}$, fraction & 0.037 & 0.0022 & 0 & 0.0319 \\
\hline $\mathrm{CO}_{2}$, recovery & - & $90.00 \%$ & - & - \\
\hline $\mathrm{H}_{2}$, recovery & - & - & - & $95.00 \%$ \\
\hline scfh & 931.3 & 381.4 & 504.6 & 549.9 \\
\hline $\mathrm{LPM}$ & 440 & 180 & 238 & 260 \\
\hline pressure, psia & 215 & 200 & 15 & 15 \\
\hline $\mathrm{Btu} / \mathrm{cf} \mathrm{LHV}$ & 153.4 & 28.9 & 0 & 125 \\
\hline $\mathrm{Btu} / \mathrm{h} \mathrm{LHV}$ & 142,847 & 11,008 & 0 & 131,839 \\
\hline $\mathrm{kWth}$ & 41.866 & 3.226 & 0 & 38.64 \\
\hline kWe & 25.12 & 1.936 & 0 & 23.184 \\
\hline
\end{tabular}


Table II-8. Gas Flow Rates in Feed, Retentate and Permeate streams for a 50 KWth System

\begin{tabular}{|c|r|r|r|}
\hline Stream & $\begin{array}{c}\text { Feed } \\
\text { SLPM }\end{array}$ & $\begin{array}{c}\text { Retentate } \\
\text { SLPM }\end{array}$ & $\begin{array}{c}\text { Permeate } \\
\text { SLPM }\end{array}$ \\
\hline $\mathrm{CO}_{2}$, fraction & 171 & 153 & 17 \\
\hline $\mathrm{CO}$, fraction & 5 & 5 & 0 \\
\hline $\mathrm{CH}_{4}$, fraction & 0 & 0 & 0 \\
$\mathrm{~N}_{2}$, fraction & 7 & 7 & 238 \\
\hline $\mathrm{H}_{2}$, fraction & 238 & 12 & 226 \\
\hline $\mathrm{H}_{2} \mathrm{~S}$, fraction & 3 & 3 & 0 \\
\hline $\mathrm{H}_{2} \mathrm{O}$, fraction & 16 & 0 & 16 \\
\hline $\mathrm{N}_{2}$, Sweep & 238 & & \\
\hline
\end{tabular}

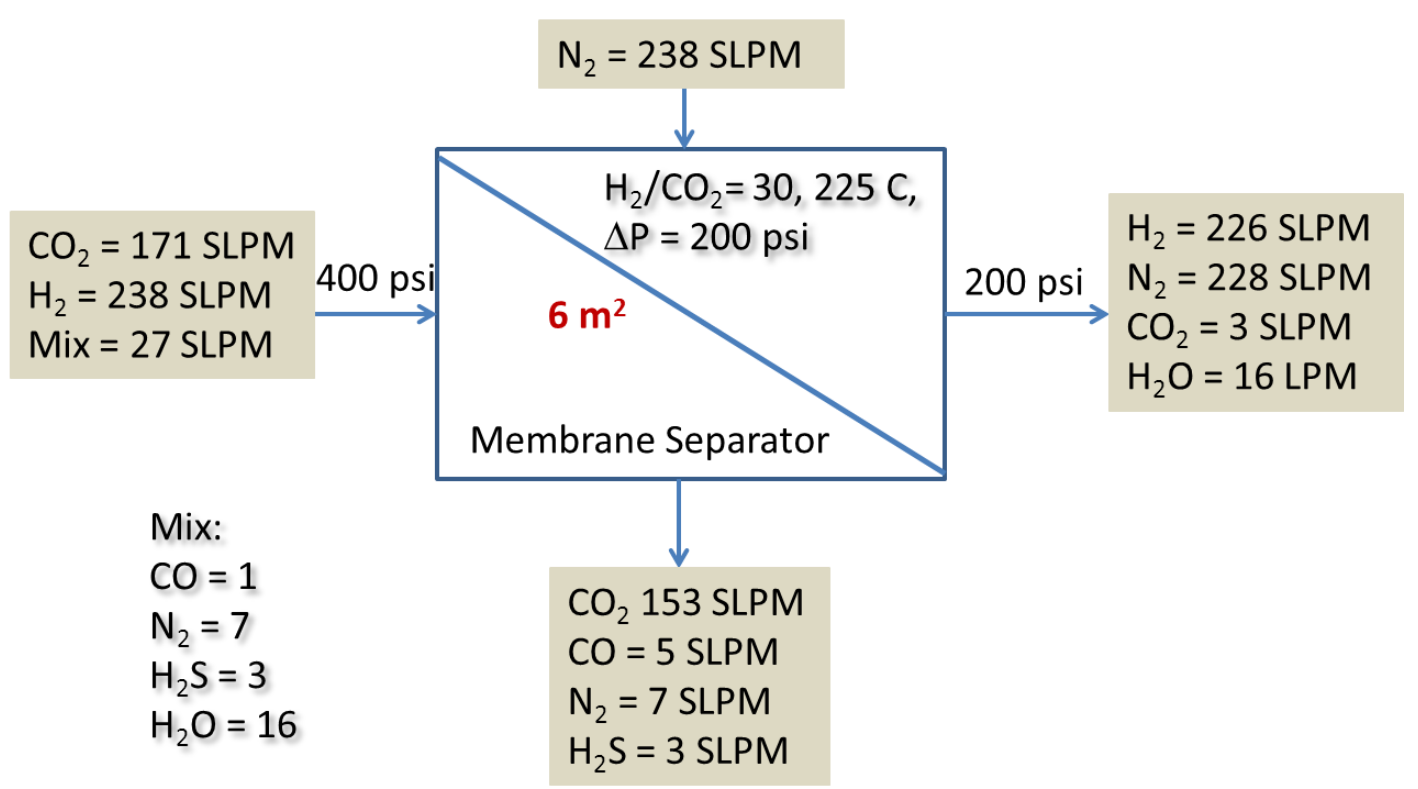

Figure II-34. A block diagram showing mass balances for the test skid with a feed gas processing capacity of $50 \mathrm{~kW}_{\text {th }}$.

The $50 \mathrm{~kW}_{\text {th }}$ test skid consisted of two membrane modules. We selected 4-in ID pressure vessels for installation of the hollow fiber (HF) elements (Figure II-35). SRI fabricated about $10 \mathrm{~km}$ of asymmetric hollow fiber membranes made of PBI polymer. 


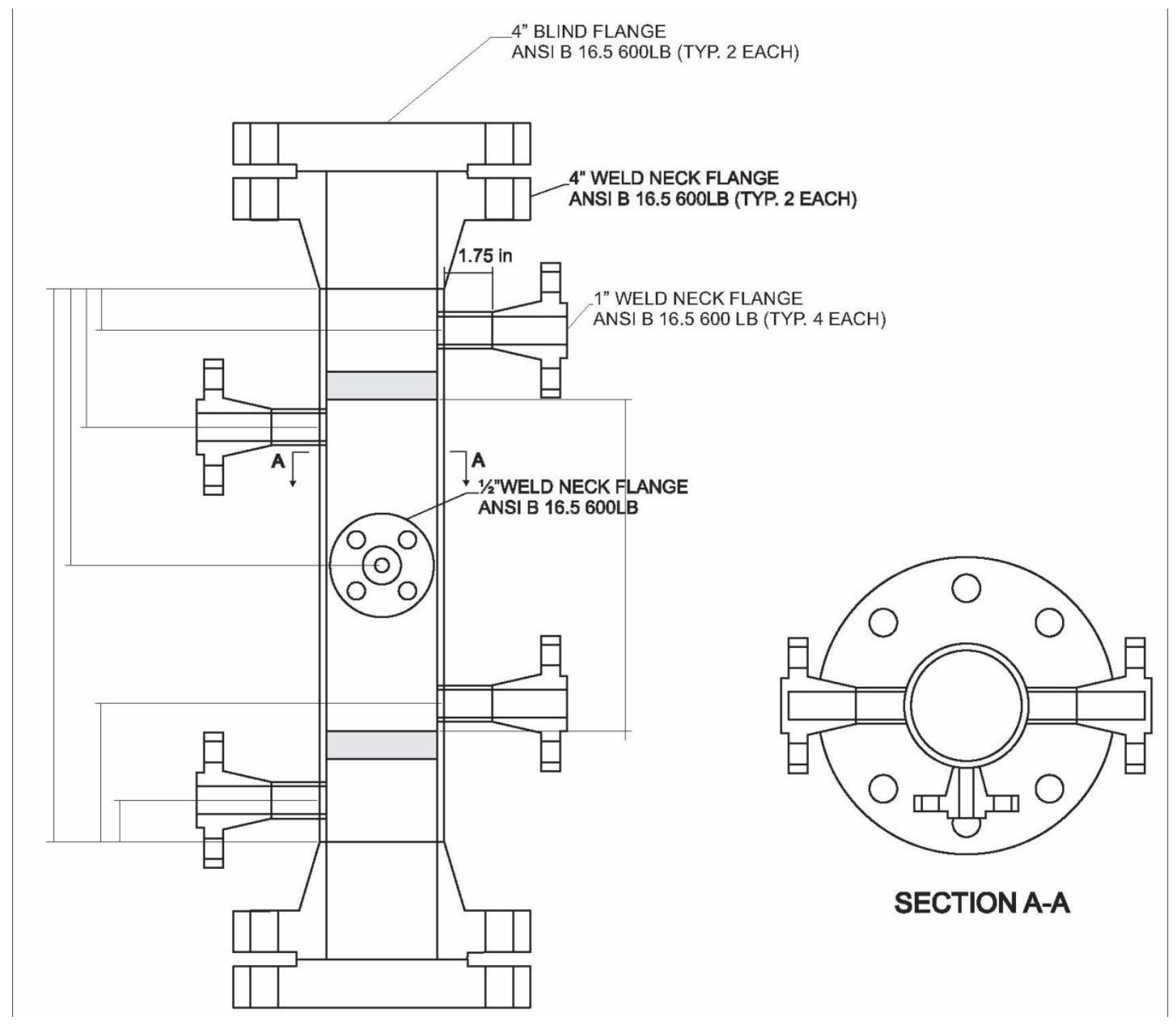

Figure II-35. Schematic diagram of the nominal 4 inch shell side feed test module

The test skid consisted of two 4" x 1' pressure vessels for housing the hollow fiber (Figure II-36). The pressure vessels are rated for operation at $600 \mathrm{psi}$ and $250^{\circ} \mathrm{C}$. When installing the skid system for HF element testing, commercial off the shelf (COTS) control systems and connecters were used. A process flow diagram (PFD) showing the stream flows is shown in Figure II-37. The feed flows in parallel through the HF modules. The skid were fitted isolation valves, blow down pressure relief valve, mass flow meters, sample ports, $\mathrm{CO}_{2}$ and $\mathrm{H}_{2}$ detectors, and pressure and temperature indicators. Figure II-38 is a photograph of a 3"x1' of hollow fiber element sized for 4-inch diameter HF module. Figure II-39 is a photograph of the completed skid with valves and instrumentation. 


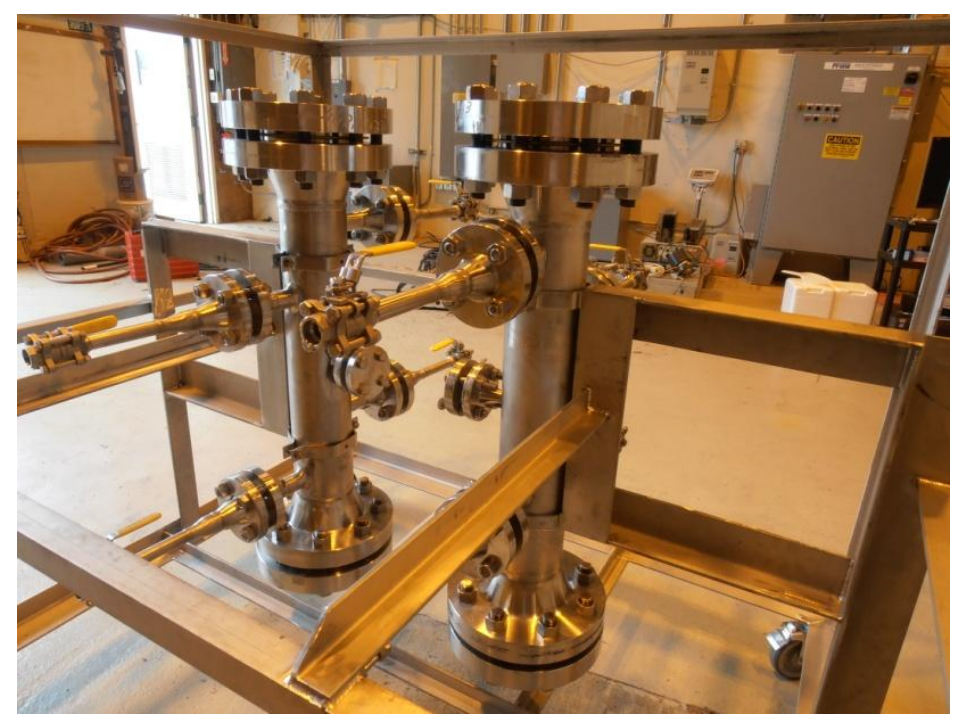

Figure II-36. The skid containing two pressure vessels in as-fabricated stage.

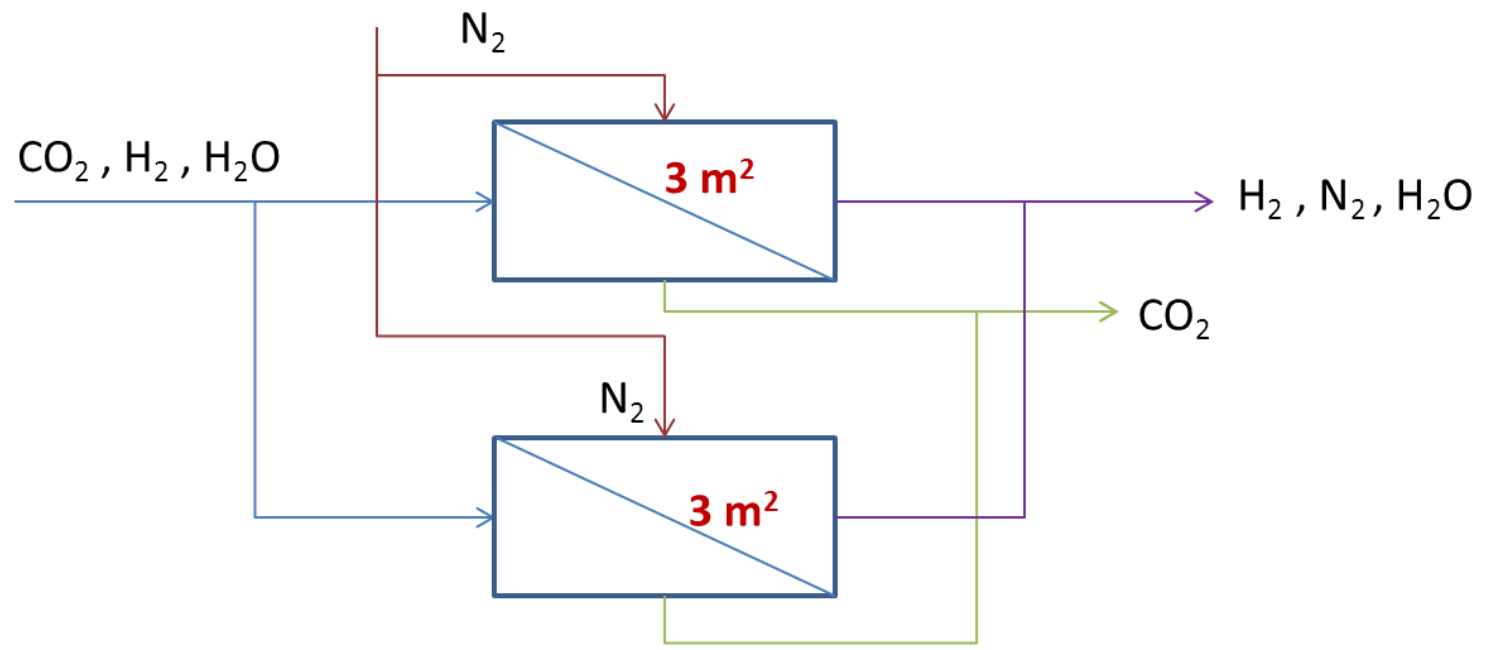

Figure II-37. Gas flow diagram for the test skid 


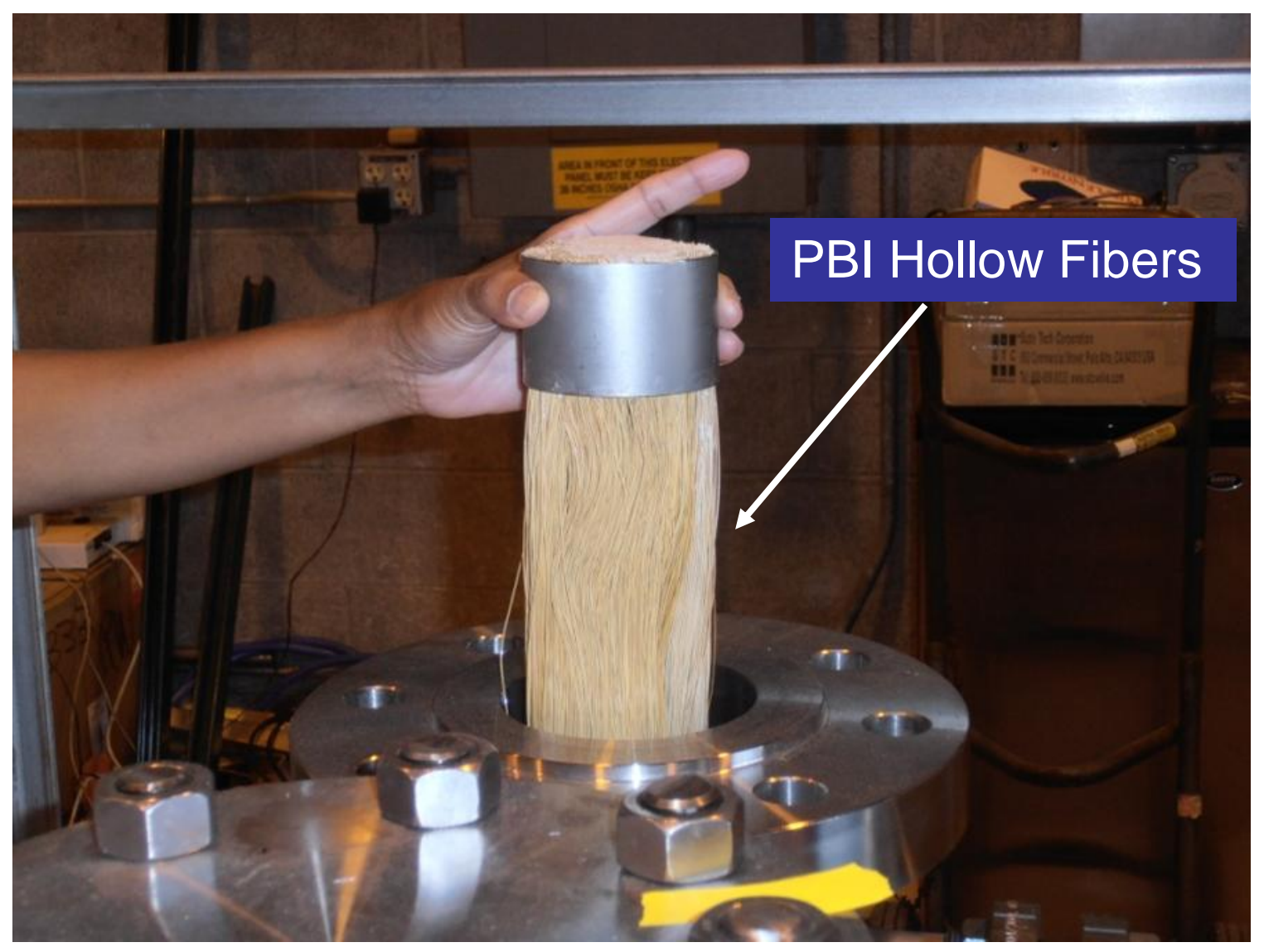

Figure II-38. A photograph of 3-in diameter x1-ft long HF element for insertion in the pressure vessel.

The prototype skid mounted system was targeted to test, for a minimum of 100 hours, using a feed stream consisting of $\mathrm{CO}_{2}$ and helium. However, we decided to use $\mathrm{CO}_{2}$ and $\mathrm{H}_{2}$ as it would provide more realistic data. The long term performance of the HF element is shown in Figure II40. The selectivity for $\mathrm{H}_{2} / \mathrm{CO}_{2}$ remained constant with time at 29 , only slightly below the design target of 30. The $\mathrm{H}_{2}$ permeance value remained at about 85 to 96 GPU throughout the test period and these values are well above the target value of 75 . At the end of the 120 -h test period, the $\mathrm{H}_{2}$ permeance was measured to be $92 \mathrm{GPU}$ at $225^{\circ} \mathrm{C}$. This data agrees well with our initial long term (1000 hour) fiber performance testing with small modules. 


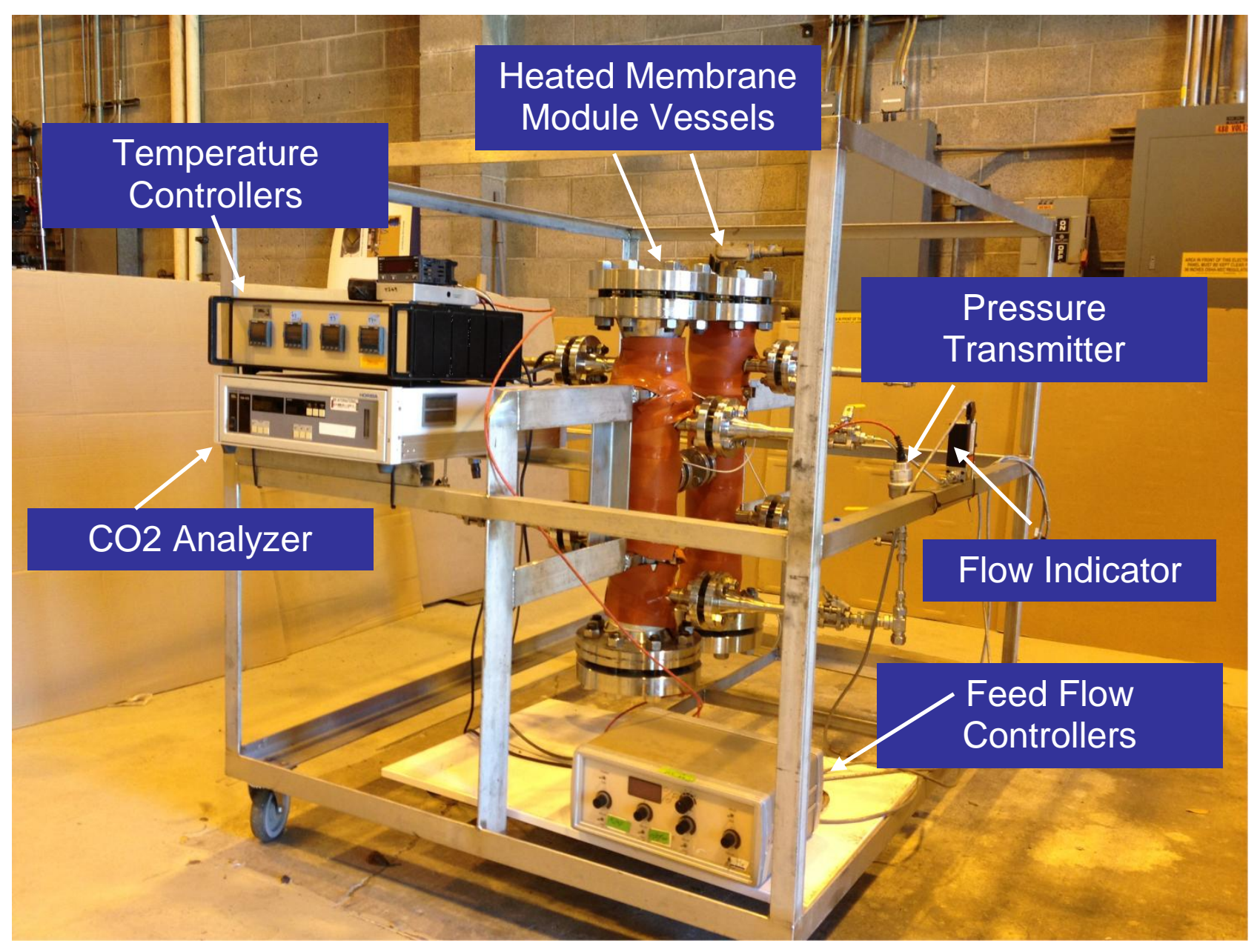

Figure II-39. A photograph showing the installed skid with instrumentation.

The measured $\mathrm{H}_{2}$ permeance was higher than expected for operation at $225^{\circ} \mathrm{C}$ with $\Delta \mathrm{P}$ of 200 psi for $6 \mathrm{~m}^{2}$ fiber surface area. We believe that this higher than expected permeance may be due to slightly lower than the selectivity used in the simulation. In addition, the actual fiber surface area may have been slightly higher because we did not count the number of the fibers in the module and it was estimated from the weight of the fibers. The $\mathrm{H}_{2} / \mathrm{CO}_{2}$ selectivity and the $\mathrm{H}_{2}$ permeance of the membrane elements were evaluated over 120 hours. 


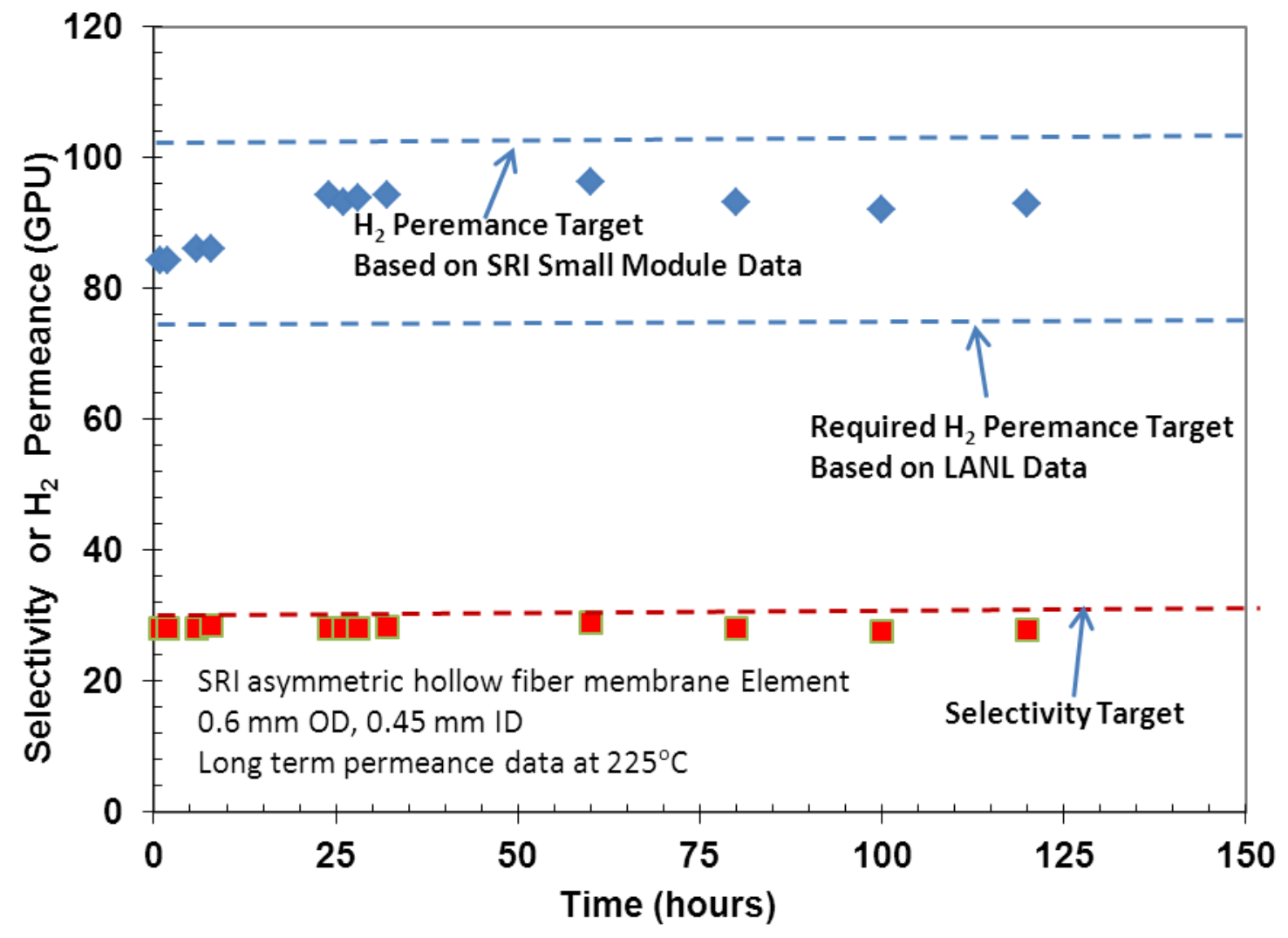

Figure 11-40. The selectivity of $\mathrm{H}_{2} / \mathrm{CO}_{2}$ and $\mathrm{H}_{2}$ permeance of fibers at $225^{\circ} \mathrm{C}$ measured over a period of $120 \mathrm{~h}$. 


\section{MEMBRANE PERFORMANCE SIMULATION AND ECONOMIC ANALYSIS}

Enerfex Inc., located in Williston, Vermont, designs and evaluates membrane processes that separate and capture gases to reduce pollution and save energy. In collaboration with Dresser Rand, Enerfex Inc. designed a system based on conventional membranes to capture $\mathrm{CO}_{2}$ for Statoil's natural gas platforms in the North Sea. The company has also designed systems for onsite industrial gas $\mathrm{CO}_{2}$ recovery, natural gas nitrogen reduction, and industrial refrigeration $\mathrm{NH}_{3}$ recycle. Enerfex has a proprietary model to simulate the performance of a membrane module. The model has been validated using the data from industrial processes. The model was used to simulate the performance of PBI hollow fiber membrane modules.

\section{COMPARISON OF POROUS PBI SUBSTRATE VS METAL SUBSTRATE}

An analysis was performed to determine the size of a membrane module if a PBI hollow fiber was used as compared with applying a dense PBI coating on a porous stainless steel tube. This calculation was critical in determining the selection of a substrate material for future scale-up.

LANL provided the permeation data for a system in which a dense PBI layer was deposited on a porous stainless steel substrate manufactured by Pall Corporation. The membrane tested was a $12 \mu \mathrm{m}$ thick dense PBI separation layer coated on sintered stainless steel 0.25 in. diameter tube. Normalized permeability values in Barrer units were calculated from the LANL data and then used to simulate projected performance of an asymmetric hollow fiber PBI membrane having a $0.5 \mu \mathrm{m}$ thick dense PBI separation layer.

An asymmetric PBI hollow fiber was made totally from PBI polymer and comprised a microporous supporting hollow fiber with a thin dense separating layer formed in situ on either the inside bore or the outside shell of the porous hollow fiber wall. A typical hollow fiber membrane has an OD of $500 \mu \mathrm{m}$, a dense separating layer thickness of 0.1 to $0.5 \mu \mathrm{m}$ and a supporting microporous substrate wall thickness of about $100 \mu \mathrm{m}$.

Compared with the metal tube support system, the asymmetric hollow fiber configuration can achieve a substantially thinner 0.1 to $0.5 \mu \mathrm{m}$ separation layer and a much higher area per volume ratio. The area and volume reductions possible with a hollow fiber membrane recommend it as the membrane design of choice. Size comparisons between a hollow fiber and a tubular design are presented in Table III- 1 . In both cases, it is assumed that $\mathrm{CO}_{2}$ capture is $90 \%$ with a feed temperature of $250^{\circ} \mathrm{C}$, a feed pressure of $750 \mathrm{psia}$, and a permeate pressure of 250 psia. Table 24 demonstrates that for the same size $\mathrm{CO}_{2}$ capture plant, the metal tube design requires 24 times more membrane area and 305 times more membrane volume. Note the substantially better areato-volume ratio with a hollow fiber design. 
Table III-1. PBI -Hollow Fiber vs PBI coated on a Metal Substrate ${ }^{1}$

\begin{tabular}{|c|c|c|}
\hline Parameter & $\begin{array}{c}\text { 0. } 12 \mu \mathrm{m} \text { Layer on } 0.64 \\
\text { cm OD Porous Metal tube }\end{array}$ & $\begin{array}{c}0.5 \mu \mathrm{m} \text {. layer on } 0.05 \mathrm{~cm} \\
\text { O.D. PBI hollow fiber }\end{array}$ \\
\hline Membrane Area, $\mathrm{m}^{2}$ & $1,759,317$ & 73,232 \\
\hline Membrane Volume, $\mathrm{m}^{3}$ & $1,675,750$ & 5,492 \\
\hline $\begin{array}{l}\text { Membrane Bundle } \\
\text { Volume, } \mathrm{m}^{3 *}\end{array}$ & $2,234,333$ & 7,323 \\
\hline \multicolumn{2}{|c|}{ * $75 \%$ membrane volumetric packing density } & \\
\hline
\end{tabular}

\section{SIMULATION OF PBI HOLLOW FIBER MEMBRANE SYSTEMS}

The data from LANL was used to simulate the performance PBI hollow fiber modules as a function of temperature and pressure. Figure III-1 shows LANL's $\mathrm{PBI}_{2} / \mathrm{CO}_{2}$ selectivity and $\mathrm{H}_{2}$ permeability data points at $400^{\circ} \mathrm{C}$ and $250^{\circ} \mathrm{C}$; selectivity increases and permeability decreases as the feed temperature is lowered. To simulate increased $\mathrm{H}_{2}$ and $\mathrm{CO}_{2}$ recovery with higher selectivity, the data in Figure III- 2 were extrapolated to $215^{\circ} \mathrm{C}$ and $170^{\circ} \mathrm{C}$ to estimate the selectivity and permeability values shown in Table III-3.

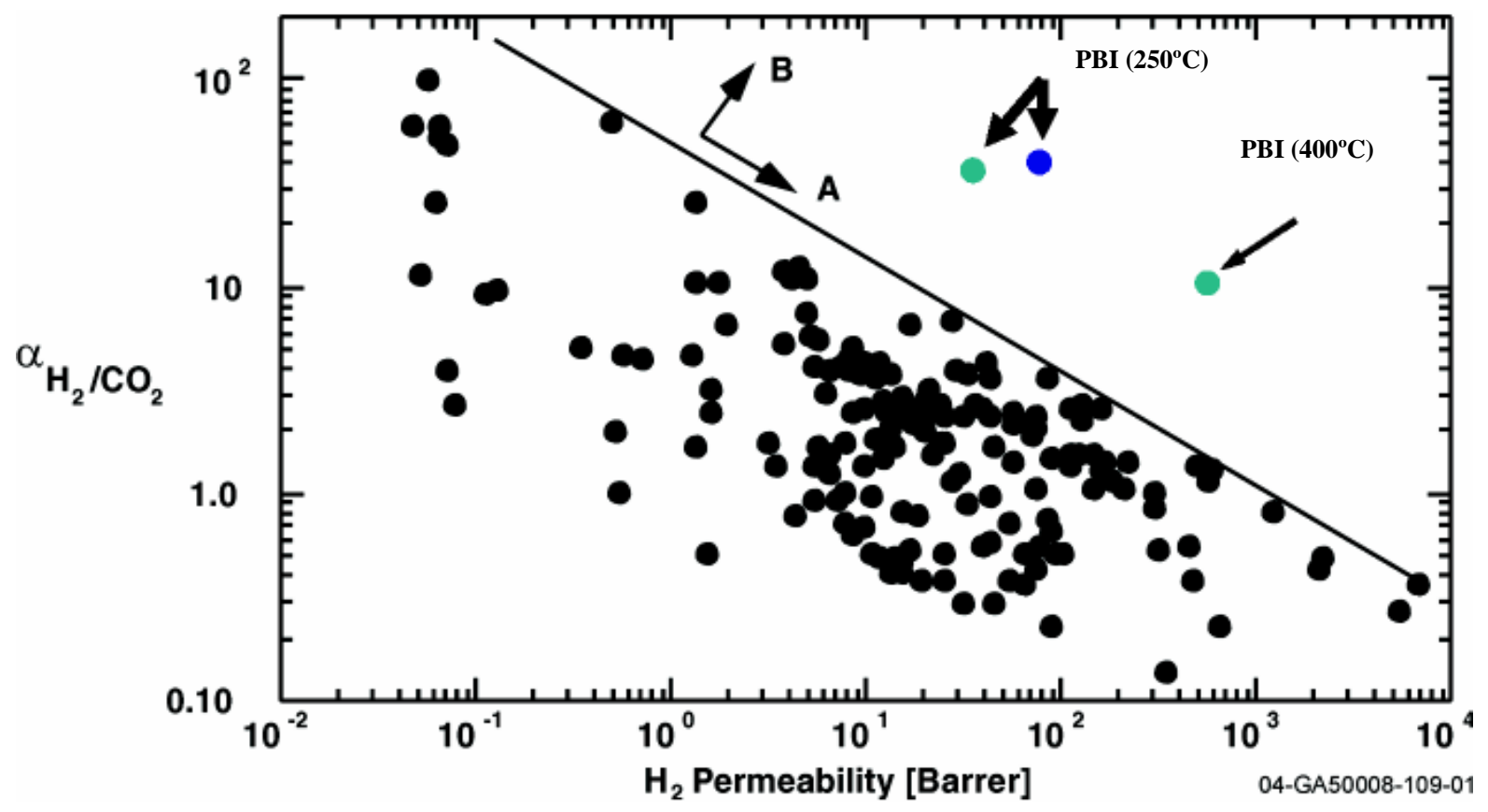

Figure III-1. Plot of LANL PBI $\mathrm{H}_{2} / \mathrm{CO}_{2}$ selectivity vs. $\mathrm{H}_{2}$ permeability at two temperatures. 
Table III-2. LANL PBI Data Extrapolated to $170^{\circ} \mathrm{C}$ and $215^{\circ} \mathrm{C}$

\begin{tabular}{|c|c|c|c|c|}
\hline $\begin{array}{c}\text { Feed } \mathbf{H}_{\mathbf{2}} \mathbf{O}, \\
\mathbf{\%}\end{array}$ & $\begin{array}{c}\text { Sat. } \mathbf{H}_{\mathbf{2}} \mathbf{O}, \\
\boldsymbol{\%}^{\prime}\end{array}$ & $\mathbf{T}^{\mathbf{}}{ }^{\mathbf{O}} \mathbf{C}$ & $\boldsymbol{\alpha}_{\mathbf{H} 2 / \mathbf{C O} 2}$ & $\begin{array}{c}\mathbf{H}_{2} \text { permeance, } \\
\text { Barrer }\end{array}$ \\
\hline 23 & 75 & 250 & 43 & 88 \\
\hline 23 & 41 & $215^{*}$ & 60 & 50 \\
\hline 16 & 16 & $170^{*}$ & 90 & 20 \\
\hline \multicolumn{2}{|c|}{ *Extrapolated } & & & \\
\hline
\end{tabular}

The selectivity and permeability values estimated by extrapolation of the PBI data points in Table III- 2 were simulated for $98 \% \mathrm{H}_{2}$ recovery, 250 psia and 450 psia permeate pressure, and a $0.5 \mu \mathrm{m}$ separation layer; the results are summarized in Table III-3. For comparison, selectivity and permeability data at $250^{\circ} \mathrm{C}$ were also simulated for $98 \% \mathrm{H}_{2}$ recovery at the same permeate pressures.

Table III-3. Hollow Fiber Membrane performance at $98 \% \mathrm{H}_{2}$ Recovery at Different Temperatures and Permeate Pressures ${ }^{1}$

\begin{tabular}{|c|c|c|c|c|c|}
\hline $\begin{array}{c}\text { Feed } \\
\text { temperature, } \\
{ }^{\circ} \mathrm{C}\end{array}$ & $\begin{array}{c}\text { Permeate, } \\
\text { psia }\end{array}$ & $\begin{array}{c}\mathrm{H}_{2} / \mathrm{CO}_{2} \\
\text { selectivity }\end{array}$ & $\begin{array}{c}\mathrm{CO}_{2} \\
\text { recovery }\end{array}$ & $\mathrm{CO}_{2}$ purity & $\begin{array}{c}\text { Membrane, } \\
\mathbf{m}^{2}\end{array}$ \\
\hline 250 & 250 & 43 & $83.8 \%$ & $88.1 \%$ & 107,446 \\
\hline 250 & 450 & 43 & $63.0 \%$ & $84.4 \%$ & 271,904 \\
\hline $215 *$ & 250 & 60 & $88.0 \%$ & $88.5 \%$ & 193,091 \\
\hline $215 *$ & 450 & 60 & $68.5 \%$ & $85.5 \%$ & 555,138 \\
\hline $170 *$ & 250 & 90 & $91.8 \%$ & $89.1 \%$ & 478,543 \\
\hline $170 *$ & 450 & 90 & $72.0 \%$ & $86.5 \%$ & $1,785,293$ \\
\hline
\end{tabular}

${ }^{1}$ Separation layer thickness: $0.5 \mathrm{~mm}, \mathrm{~N} 2$ sweep: $42 \%$;

${ }^{2}$ Extrapolated data

The best performance was at $170^{\circ} \mathrm{C}$ and 250 psia permeate pressure where $\mathrm{CO}_{2}$ recovery exceeded the NETL goal of $90 \% \mathrm{CO}_{2}$ capture with a $\mathrm{H}_{2}$ recovery of $98 \%$. However, because permeability decreases at $170^{\circ} \mathrm{C}$, the membrane area was substantially larger than at $250^{\circ} \mathrm{C}$.

Membrane module modeling was performed for the PBI membrane separation unit for inclusion in the overall simulation model for an IGCC with CCS. Focus parameters were:

- Feed rate.

- Feed pressure.

- Permeate pressure.

- $\mathrm{N}_{2}$ permeate sweep.

- Membrane separation layer thickness. 
In an earlier study, LANL tested a dense PBI membrane supported on a porous metal support using a gas mixture containing $\mathrm{H}_{2}, \mathrm{CO}, \mathrm{H}_{2} \mathrm{O}, \mathrm{CO}_{2}, \mathrm{~N}_{2}, \mathrm{CH}_{4}$, and $\mathrm{H}_{2} \mathrm{~S}$. LANL obtained gas permeability data for the mixture with a PBI separation layer thickness of $12 \mu \mathrm{m}$ and pressure of $260 \mathrm{~cm} \mathrm{Hg}$. The data from the tests provided the permeability and component selectivities (with respect to $\mathrm{H}_{2}$ ) for the various gases through the PBI membrane (Table III-4).

Table III-4. LANL Permeation Data for Gas Mixtures

\begin{tabular}{|l|c|c|c|}
\hline \multicolumn{4}{|c|}{$\begin{array}{c}\text { Separation Layer }=\mathbf{1 2} \boldsymbol{\mu m} \\
\text { Mixed Gas GPU } \\
\mathbf{1 0}^{-\mathbf{6}} \mathbf{c m}^{\mathbf{3}} / \mathbf{s} / \mathbf{c m}^{2} / \mathbf{c m ~ H g}\end{array}$} \\
\hline $\mathrm{H}_{2}$ & 7.30 & 1.00 & Barrer \\
\hline $\mathrm{CO}_{2}$ & 0.17 & 42.94 & $8.76 \mathrm{E}-09$ \\
\hline $\mathrm{CO}$ & 0.06 & 121.67 & $2.04 \mathrm{E}-10$ \\
\hline $\mathrm{N}_{2}$ & 0.020 & 365.00 & $7.20 \mathrm{E}-11$ \\
\hline $\mathrm{CH}_{4}$ & 0.030 & 243.33 & $2.40 \mathrm{E}-11$ \\
\hline $\mathrm{H}_{2} \mathrm{~S}$ & 0.004 & 1825.00 & $3.60 \mathrm{E}-11$ \\
\hline
\end{tabular}

The membrane area was calculated as a function of the membrane thickness, pressure difference across the membrane, purge gas flow rate, temperature, and other parameters. The membrane areas are also reported as the number of equivalent 4 in. $\times 5 \mathrm{ft}$ membrane hollow fiber bundle elements (standard module size) required per megawatt. The number of elements for a given power output is calculated by multiplying the megawatt output by the number of membrane elements simulated. The simulated membrane feed rate was set to $32,250 \mathrm{scf} / \mathrm{h}$. This flow is the equivalent shift gas feed rate for a $1.0 \mathrm{MW}$ power output assuming $44 \%$ thermal efficiency.

The simulated membrane permeate pressure was 250 psia. The permeate will be compressed to 450 psia for feed to the gas turbine combustor. We also calculated the required membrane in which both the permeate pressure and the feed pressure to the gas turbine combustor were kept at 290 psia to eliminate the need for recompression and improve process economics.

Table III-5 lists the permeability of a membrane with a targeted thickness of $0.5 \mu \mathrm{m}$ and a targeted pressure of 750 psia. 
Table III-5. Extrapolated LANL Data for a Separation Layer of $0.5 \mu \mathrm{m}$

\begin{tabular}{|c|c|c|c|}
\hline & $\begin{array}{c}\text { Separation Layer }=0.5 \mu \mathrm{m} \\
\text { Mixed Gas GPU } \\
10^{-6} \mathrm{~cm}^{3} / \mathrm{s} / \mathrm{cm}^{2} / \mathrm{cm} \mathrm{Hg}\end{array}$ & $\mathbf{H}_{2} \boldsymbol{\alpha}$ & Barrer \\
\hline $\mathrm{H}_{2}$ & 175.20 & 1.00 & 8.76E-09 \\
\hline $\mathrm{CO}_{2}$ & 4.08 & 42.94 & $2.04 \mathrm{E}-10$ \\
\hline $\mathrm{CO}$ & 1.44 & 121.67 & $7.20 \mathrm{E}-11$ \\
\hline $\mathrm{N}_{2}$ & 0.48 & 365.00 & $2.40 \mathrm{E}-11$ \\
\hline $\mathrm{CH}_{4}$ & 0.72 & 243.33 & $3.60 \mathrm{E}-11$ \\
\hline $\mathrm{H}_{2} \mathrm{~S}$ & 0.10 & 1825.00 & $4.80 \mathrm{E}-12$ \\
\hline
\end{tabular}

The gas permeation unit (GPU) varies inversely with the separation layer thickness (i.e., $12.0 / 0.5 \times 7.3=175.2$.) The permeability values are the intrinsic permeation property of the membrane. Permeability values may be somewhat different because of changes in polymer morphology or mixed gas effects in a thinner membrane at higher pressure. Nonetheless, for a first approximation, we performed a simulation at the targeted thickness of a $0.5 \mu \mathrm{m}$ separation layer and a 750 psia feed pressure with a gas composition representative of the gas downstream of the WGSRs. The results for a $600 \mathrm{MW}$ power plant are summarized in Table III-6.

Table III-6. Simulation Projection of a Membrane With $0.5 \mu \mathrm{m}$ Separation Layer

\begin{tabular}{|c|c|c|c|c|c|c|c|}
\hline $\begin{array}{c}\text { Feed } \\
\text { Pressure }\end{array}$ & $\begin{array}{c}\text { Permeate } \\
\text { Pressure }\end{array}$ & $\begin{array}{c}\text { Membrane } \\
\text { Layer }\end{array}$ & $\mathrm{N}_{2}$ Sweep & Permeate & $\begin{array}{c}\mathrm{CO}_{2} \\
\text { Recovery }\end{array}$ & $\begin{array}{c}\text { Membrane } \\
\text { Area }\end{array}$ & $\begin{array}{c}4 \text { in. } \times 5 \mathrm{ft} \\
\text { elements }\end{array}$ \\
\hline psia & psia & $\mu \mathrm{m}$ & $\%$ & $\mathrm{Btu} / \mathrm{ft}^{3}$ & $\%$ & $\mathrm{~m}^{2}$ & Number \\
\hline 750 & 250 & 0.5 & 61.5 & 115.5 & 88.6 & 70,906 & 1,156 \\
\hline
\end{tabular}

A $0.5 \mu \mathrm{m}$ separation thickness is a reasonable target in view of the typical $0.1 \mu \mathrm{m}$ thickness available in commercial gas separation membranes.

$\mathbf{N}_{2}$ Permeate Sweep - One of the major goals of the permeate sweep is to substantially reduce membrane area by lowering $\mathrm{H}_{2}$ backpressure in the permeate stream. In addition, the sweep lowers the fuel heating value of the permeate stream to a 115 to $130 \mathrm{Btu} / \mathrm{ft}^{3}$ value similar to that for an IGCC syngas that has not undergone $\mathrm{CO}_{2}$ separation. Thus, the operating parameters and the efficiency of the combustion turbine are similar. The amount of area reduction is shown in Table III-7. The $\mathrm{N}_{2}$ sweep reduces the membrane area required to recover $98 \%$ of the $\mathrm{H}_{2}$ four fold. Fortunately the required permeate fuel dilution will also reduce membrane cost. 
Table III-7. Effect of $\mathrm{N}_{2}$ Permeate Sweep Gas ${ }^{1}$

\begin{tabular}{|c|c|c|c|c|c|c|}
\hline $\begin{array}{c}\text { Raffinate } \\
\mathrm{CO}_{2} \\
\text { Recovery } \\
\end{array}$ & $\begin{array}{l}\text { Permeate } \\
\mathrm{H}_{2} \text { purity } \\
\end{array}$ & $\begin{array}{c}\text { Raffinate } \\
\mathrm{CO}_{2} \\
\text { purity } \\
\end{array}$ & $\begin{array}{c}\text { Sweep } \mathbf{N}_{2} \\
\% \\
\end{array}$ & $\begin{array}{c}\text { Feed } \\
\mathrm{ft}^{3} / \mathrm{ft}^{2}-\mathrm{h}\end{array}$ & $\begin{array}{c}\text { Membrane } \\
\mathbf{f t}^{2} / \mathrm{MW}\end{array}$ & $\begin{array}{c}\text { Permeate } \\
\text { Btu/ft }\end{array}$ \\
\hline $58.9 \%$ & $76.0 \%$ & $81.1 \%$ & $0 \%$ & 6.0 & 5,364 & 251.7 \\
\hline $88.6 \%$ & $35.4 \%$ & $85.6 \%$ & $61.5 \%$ & 25.3 & 1,274 & 115.3 \\
\hline
\end{tabular}

${ }^{1} 98 \% \mathrm{H}_{2}$ recovery, Feed at 750 psia, Permeate at 250 psia, and $0.5 \mu \mathrm{m}$ separation layer thickness.

Effect of $\mathrm{H}_{2} \mathrm{O}$ in the Feed on Percent $\mathrm{N}_{2}$ Sweep - The presence of $\mathrm{H}_{2} \mathrm{O}$ in the membrane feed has significant value for the membrane operation with respect to membrane area and $\mathrm{N}_{2}$ permeate sweep gas demand. Table III- 8 presents the simulated effect of $\mathrm{H}_{2} \mathrm{O}$ in the feeds. For the simulation, the permeability of $\mathrm{H}_{2} \mathrm{O}$ is taken to be higher than $\mathrm{H}_{2}$ because $\mathrm{H}_{2} \mathrm{O}$ in general has a higher permeability than $\mathrm{H}_{2}$ in commercial membranes and, in fact, is typically the most permeable gas represented in published literature. As a consequence, the simulation shows that $\mathrm{H}_{2} \mathrm{O}$ in the permeate reduced the $\mathrm{N}_{2}$ sweep fraction needed from $61.5 \%$ to $42 \%$ to yield a specified $115 \mathrm{Btu} / \mathrm{scf}$ fuel heating value, while maintaining the reduced membrane area achieved with the higher percent $\mathrm{N}_{2}$ sweep. Reducing $\mathrm{N}_{2}$ sweep in this way is also appropriate because it is expected that the amount of available $\mathrm{N}_{2}$ from the ASU for permeate sweep will be limited to about $42 \%$ because the ASU will be sized to provide only sufficient $\mathrm{O}_{2}$ to run the gasifier and Claus units.

Table III-8. Effect of $\mathrm{H}_{2} \mathrm{O}$ on Percent $\mathrm{N}_{2}$ Permeate Sweep Gas ${ }^{1}$

\begin{tabular}{|c|c|c|c|c|c|c|}
\hline Sweep N & $\begin{array}{c}\text { Feed } \\
\text { flux }\end{array}$ & Permeate & Raffinate & Raffinate & $\begin{array}{c}\text { Membrane } \\
\text { Area }\end{array}$ & $\begin{array}{c}\text { Permeate } \\
\text { Fuel }\end{array}$ \\
\hline$\%$ & $\mathrm{ft}^{3} / \mathrm{ft}^{2}-\mathrm{h}$ & $\mathrm{H}_{2}$ purity & $\begin{array}{c}\mathrm{CO}_{2} \\
\text { purity }\end{array}$ & $\begin{array}{c}\mathrm{CO}_{2} \\
\text { recovery }\end{array}$ & $\mathrm{ft}^{2} / \mathrm{MW}$ & $\mathrm{Btu} / \mathrm{ft}^{3}$ \\
\hline $61.5 \%$ & 29.5 & $35.7 \%$ & $83.9 \% *$ & $90.0 \%$ & 1,093 & 116.2 \\
\hline $42.0 \%$ & 33.8 & $35.7 \%$ & $80.4 \% *$ & $90.0 \%$ & 1,251 & 115.6 \\
\hline
\end{tabular}

${ }^{\mathrm{I}} 98 \% \mathrm{H}_{2}$ recovery, Feed at 750 psia, Permeate at 250 psia, and $0.5 \mu \mathrm{m}$ separation layer thickness.

Effect of $\mathrm{CH}_{4}$ Percentage on the Membrane Energy Balance - The $\mathrm{CH}_{4}$ content in the membrane feed is a function of a gasifier's operating temperature and pressure. The amount of $\mathrm{CH}_{4}$ present in the membrane feed can have a significant effect on energy recovery in the permeate fuel because heating value in the feed is split between the permeate fuel and the raffinate capture gas according to the selectivity of the respective gases over $\mathrm{CO}_{2} \cdot \mathrm{CH}_{4}$ and $\mathrm{CO}$ have heating values of 1,012 Btu/scf and $320 \mathrm{Btu} / \mathrm{scf}$, respectively, and each has a negative selectivity over $\mathrm{CO}_{2}$; that is, $\mathrm{CO}_{2}$ is marginally selective over $\mathrm{CH}_{4}$ and $\mathrm{CO}$. Accordingly, the two 
gases have $97.8 \%$ and $95.7 \%$ recovery rates, respectively, in the raffinate capture gas, substantially higher than the $90 \% \mathrm{CO}_{2}$ recovery rate.

Table III-9 shows an energy balance for $3 \% \mathrm{CH}_{4}$ in the feed based on the feed composition from LANL data, where about 1.0 MWe is generated from the permeate fuel. In this case about $83 \%$ of the energy in the feed is recovered in the permeate fuel and about $17 \%$ in the raffinate capture gas. Of the $1,173,055 \mathrm{Btu} / \mathrm{hr}$ in the raffinate capture gas, $81.7 \%$ is due to $\mathrm{CH}_{4}, 9.9 \%$ to $\mathrm{H}_{2}$, and $8.4 \%$ to $\mathrm{CO}$.

Table III-9. Energy Balance Based on "Plot To Enerfex From LANL" Data

\begin{tabular}{|l|c|c|c|l|l|}
\hline \multicolumn{1}{|c|}{ Energy balance } & Btu/hr & Btu/scf & \% & MWg & MWe \\
\hline Permeate fuel gas & $5,656,550$ & 115.21 & 82.82 & 1.66 & 0.99 \\
\hline Raffinate capture gas & $1,173,055$ & 87.77 & 17.18 & 0.34 & 0.21 \\
\hline Feed gas & $6,829,605$ & 211.76 & 100.00 & 2.00 & 1.20 \\
\hline
\end{tabular}

Table III-10 presents an energy balance for about 1.0 MWe to the permeate fuel at a substantially lower $\mathrm{CH}_{4}$ feed percentage based on a dry basis* of the feed composition of the Scenario 4 containing $0.1 \% \mathrm{CH}_{4}$. In this case, about $96 \%$ of the feed heating value is recovered in the permeate fuel and about $4 \%$ in the raffinate capture gas. Of the $267,051 \mathrm{Btu} / \mathrm{hr}$ in the raffinate capture gas, $13.1 \%$ is due to $\mathrm{CH}_{4}, 43.8 \%$ to $\mathrm{H}_{2}$, and $43.1 \%$ to $\mathrm{CO}$. $\mathrm{CH}_{4}$ production in the gasifier must be minimized to maximize energy recovery in the permeate fuel and to minimize energy loss in the raffinate capture gas.

Table III-10. Energy Balance Based on “Plot To Enerfex From LANL" Data for a Low $\mathrm{CH}_{4}$ Concentration*

\begin{tabular}{|l|l|l|c|l|l|}
\hline \multicolumn{1}{|c|}{ Energy balance } & \multicolumn{1}{c|}{ Btu/hr } & Btu/cf & \% & MWg & MWe \\
\hline Permeate fuel gas & $5,851,496$ & 115.23 & 95.64 & 1.71 & 1.03 \\
\hline Raffinate capture gas & 267,051 & 21.21 & 4.36 & 0.08 & 0.05 \\
\hline Feed gas & $6,118,547$ & 190.28 & 100.00 & 1.79 & 1.08 \\
\hline
\end{tabular}

\section{Effect of Gasifier Pressure and Consequently of Membrane Feed Pressure on}

Membrane Area - Gasifier outlet pressure in the current Aspen model is 815 psia.

Consequently, the WGSR outlet pressure, which is also the membrane feed pressure, is 777 psia. BP's experience with quench-style gasifiers puts the operating pressure higher, providing 977 psia downstream of the syngas scrubbers. The membrane feed pressures in our simulation analyses have ranged from 715 to 1,015 psia. Table III-11 illustrates the difference in membrane area between 750 and 1,015 psia feed pressure. Membrane area decreases with increasing feed pressure because the pressure difference across a membrane increases permeation flux while actual gas volume is reduced. Increasing membrane feed pressure from 750 to 1,015 psia reduces the membrane area by $39 \%$ while maintaining $\mathrm{CO}_{2}$ recovery at approximately $90 \%$. 
Table III-11. Membrane Performance at 750 psia and 1,015 psia Feed Pressure.

\begin{tabular}{|c|c|c|c|c|}
\hline Feed, psia & $\begin{array}{c}\text { Permeate, } \\
\text { psia }\end{array}$ & $\begin{array}{c}\text { Permeate, } \\
\text { Btu/cf }\end{array}$ & $\begin{array}{c}\mathbf{C O}_{\mathbf{2}} \text { recovery } \\
\text { \% }\end{array}$ & $\begin{array}{c}\text { Membrane area/ } \\
\text { MWe, } \mathbf{~ m}^{\mathbf{2}}\end{array}$ \\
\hline 1,015 & 250 & 115.2 & 90.5 & 72.5 \\
\hline 750 & 250 & 115.5 & 88.6 & 118.2 \\
\hline
\end{tabular}

Note: $0.5 \mu \mathrm{m}$ separation layer and $98 \% \mathrm{H}_{2}$ recovery

The above engineering membrane performance simulations and designs have used empirical performance data provided by LANL. LANL single gas data for $\mathrm{H}_{2}$ and $\mathrm{CO}_{2}$ from testing using a $12 \mu \mathrm{m}$ dense PBI layer coated onto a 0.5 inch O.D. Pall Accusep ${ }^{\mathrm{TM}} \mathrm{s} / \mathrm{s}$ porous tube are presented in Table III-12 below.

Table III-12. LANL Empirical Data

\begin{tabular}{|c|c|c|c|}
\hline & Single Gas GPU Units & & Single Gas Barrer Units \\
\hline Gas & $\mathbf{1 0}^{-\mathbf{6}} \mathbf{c m}^{\mathbf{3}} / \mathbf{s} / \mathbf{c m}^{2} / \mathbf{c m ~ H g}$ & $\mathbf{H}_{\mathbf{2}} \boldsymbol{\alpha}$ & $\mathbf{1 0}^{-10} \mathbf{c m}^{\mathbf{3}} \times \mathbf{c m} / \mathbf{s} / \mathbf{c m}^{2} / \mathbf{c m ~} \mathbf{H g}$ \\
\hline $\mathrm{H}_{2}$ & 5.20 & 1.00 & 62.4 \\
\hline $\mathrm{CO}_{2}$ & 0.12 & 43.33 & 1.44 \\
\hline
\end{tabular}

Note: $12 \mu \mathrm{m}$ shell side dense separation layer; Feed presssure $=260 \mathrm{~cm} \mathrm{Hg}$; Permeate pressure $=$ $76 \mathrm{~cm} \mathrm{Hg}$; Temperature $=250^{\circ} \mathrm{C}$; Pall Accusep ${ }^{\mathrm{TM}}$ tube $=0.5$ in. O.D

The data from SRI's PBI asymmetric hollow fiber $24 \mathrm{~b}-4$ which was tested at $250^{\circ} \mathrm{C}$ had a measured $\mathrm{H}_{2}$ GPU of about 115 and a $\mathrm{H}_{2} / \mathrm{CO}_{2}$ selectivity of about 43. The average effective dense separation layer thickness observed by SEM is estimated to be about $0.5 \mu \mathrm{m}$ after heat treatment. As of this date the performance has been sustained at test conditions for 500 hours. The SRI test data is presented in Table III-13 below.

Table III-13 - SRI Empirical Data for PBI Asymmetric Hollow Fiber 24b-4

\begin{tabular}{|c|c|c|c|}
\hline & Single Gas GPU Units & & Single Gas Barrer Units \\
\hline Gas & $\mathbf{1 0}^{-\mathbf{6}} \mathbf{c m}^{\mathbf{3}} / \mathbf{s} / \mathbf{c m}^{2} / \mathbf{c m ~ H g}$ & $\mathbf{H}_{\mathbf{2}} \boldsymbol{\alpha}$ & $\mathbf{1 0}^{-10} \mathbf{c m}^{\mathbf{3}} \times \mathbf{c m} / \mathbf{s} / \mathbf{c m}^{2} / \mathbf{c m ~} \mathbf{H g}$ \\
\hline $\mathrm{H}_{2}$ & 115 & 1.00 & 57.5 \\
\hline $\mathrm{CO}_{2}$ & 2.67 & 43 & 1.38 \\
\hline
\end{tabular}

Note: Feed Pressure $=260 \mathrm{~cm} \mathrm{Hg}$; Permeate pressure $=76 \mathrm{~cm} \mathrm{Hg}$; Temperature $=250^{\circ} \mathrm{C}$; Asymmetric hollow fiber $=0.6 \mathrm{~mm}$ OD; separation layer thickness $=0.5 \mu \mathrm{m}$

The above results confirm that intrinsic PBI permeation properties in Barrer at the same test conditions would be about the same for both a PBI hollow fiber membrane and the LANL PBI deposited on an Accusep ${ }^{\mathrm{TM}}$ tube membrane.

The data from these simulations was used in an ASPEN program to calculate heat and mass balances, as described below. 


\section{PROCESS MODELING AND COST OF $\mathrm{CO}_{2}$ CAPTURE}

Aspen modeling was used to evaluate the location and performance effects that the PBI membrane system will have on the overall power plant performance. LANL provided the project team with the PBI performance data for incorporation into the Aspen development work. To optimize the overall plant to take advantage of the beneficial characteristics of the membrane system, we considered six scenarios:

- Scenario 1: Base case IGCC plant with no $\mathrm{CO}_{2}$ capture: In this base case scenario, the gas stream from the gasifier is cooled, and $\mathrm{NH}_{3}$ and $\mathrm{Hg}$ vapor are removed before $\mathrm{H}_{2} \mathrm{~S}$ is removed using Selexol solvent. The clean fuel gas stream is sent to the gas turbine.

The following scenarios are IGCC plants equipped with $\mathrm{CO}_{2}$ capture. In these scenarios, WGSRs are used to convert $\mathrm{CO}$ in the fuel gas to $\mathrm{CO}_{2}$ (sour gas shift). The major components of the gas leaving the shift reactors are $\mathrm{H}_{2}, \mathrm{CO}_{2}$, and steam with minor levels of $\mathrm{H}_{2} \mathrm{~S}$ and $\mathrm{NH}_{3}$.

- Scenario 2: Selexol units are used to separate $\mathrm{CO}_{2}$ and $\mathrm{H}_{2} \mathrm{~S}$ from $\mathrm{H}_{2}$. Most of the steam is condensed out during the cool-down of the gas to the operating temperature of the Selexol unit.

- Scenario 3: The PBI membrane is used to separate the $\mathrm{H}_{2}$ and steam from the $\mathrm{CO}_{2}$. The $\mathrm{H}_{2} \mathrm{~S}$ is in the retentate stream, separated from the $\mathrm{CO}_{2}$ using Selexol and sent to a Claus unit for $\mathrm{S}$ recovery.

- Scenario 4: The PBI membrane is used to separate the $\mathrm{H}_{2}$ and steam from the $\mathrm{CO}_{2}$. The $\mathrm{H}_{2} \mathrm{~S}$ in the retentate stream and is not separated from the $\mathrm{CO}_{2}$

- Scenario 5: The PBI membrane is used to separate the $\mathrm{H}_{2}$ and steam from the $\mathrm{CO}_{2}$. The $\mathrm{H}_{2} \mathrm{~S}$ permeates with the $\mathrm{H}_{2}$ and is separated with Selexol and sent to a Claus unit.

In our simulation, the process conditions were made as consistent as possible with the NETL results presented in 2007 [Klara, 2007\}

An Aspen/GT-Pro model was used to simulate the various IGCC scenarios. In all scenarios, the IGCC plant uses a GEE (Texaco) radiant only gasifier and two GE F-class gas turbines, each of which produces $232 \mathrm{MW}$. The two gas turbines dictate the sizing of the entire IGCC plant because, depending on the fuel's composition, they can require a specific amount of fuel. For this reason, both the total power output and the coal feed rate vary on the basis of the parameters of each scenario. The syngas fuel composition found in Aspen was entered into the GT-Pro model. Both GT-Pro and Aspen calculated a required syngas fuel flow rate to the gas turbines. Once both programs were in agreement, heat integration was performed with the heating and cooling streams required in the Aspen model accounted for in the GT-Pro model. Given these heating 
and cooling inputs along with the syngas composition, GT-Pro calculated the steam turbine power output.

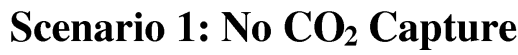

III-2 provides a block flow diagram of the Scenario 1 IGCC process with no $\mathrm{CO}_{2}$ capturethe baseline for performance. A bituminous coal is gasified in an $\mathrm{O}_{2}$-blown, slagging gasifier at about $2400^{\circ} \mathrm{F}$. An ASU supplies the necessary $\mathrm{O}_{2}$ to the gasifier and to the Claus unit combustor. $\mathrm{N}_{2}$ from the ASU is used in the gas turbine as a diluent. The syngas leaving the gasifier is cooled, and the $\mathrm{COS}$ in the gas stream is hydrolyzed to $\mathrm{H}_{2} \mathrm{~S}$ to assist the capture of $\mathrm{S}$ compounds. A Selexol solvent absorber is used to capture the $\mathrm{H}_{2} \mathrm{~S}$ in the coal gas, and the captured $\mathrm{H}_{2} \mathrm{~S}$ is sent to a Claus unit for producing elemental $\mathrm{S}$. The clean syngas is combusted in a gas turbine to generate electricity. Additional electricity is produced in the bottoming steam cycle. The gas and steam turbines produce about 464 and $303 \mathrm{MW}$ of electricity, respectively. The total auxiliary power requirement is $144 \mathrm{MW}$, resulting in a net power output of $629 \mathrm{MW}$. Table III-14 lists the temperatures, pressures, and mass flows at the various steps in the IGCC process.

Figure III-3 provides a summary of the GT-Pro simulation for Scenario 1. The input parameters to GT-Pro include the composition of the fuel gas, the particular gas turbine, flow rate and composition of diluents, and any inputs or bleeds of steam or hot water. The program then designs an optimal energy recovery system. In Scenario 1, low-pressure steam is drawn from the first low-pressure superheater to provide heating in several unit operations. There are also three large energy inputs to the steam cycle that are generated by cooling processes from the gasifier portion of the plant. High-pressure $\mathrm{H}_{2} \mathrm{O}$ is drawn from the final high-pressure economizer and used to provide steam cooling, predominately in the radiant cooler. This highpressure $\mathrm{H}_{2} \mathrm{O}$ is vaporized and returned to the first high-pressure super-heater. Water is also removed from the low-pressure boiler and the low-temperature economizer to provide cooling to successively cooler unit operations. 


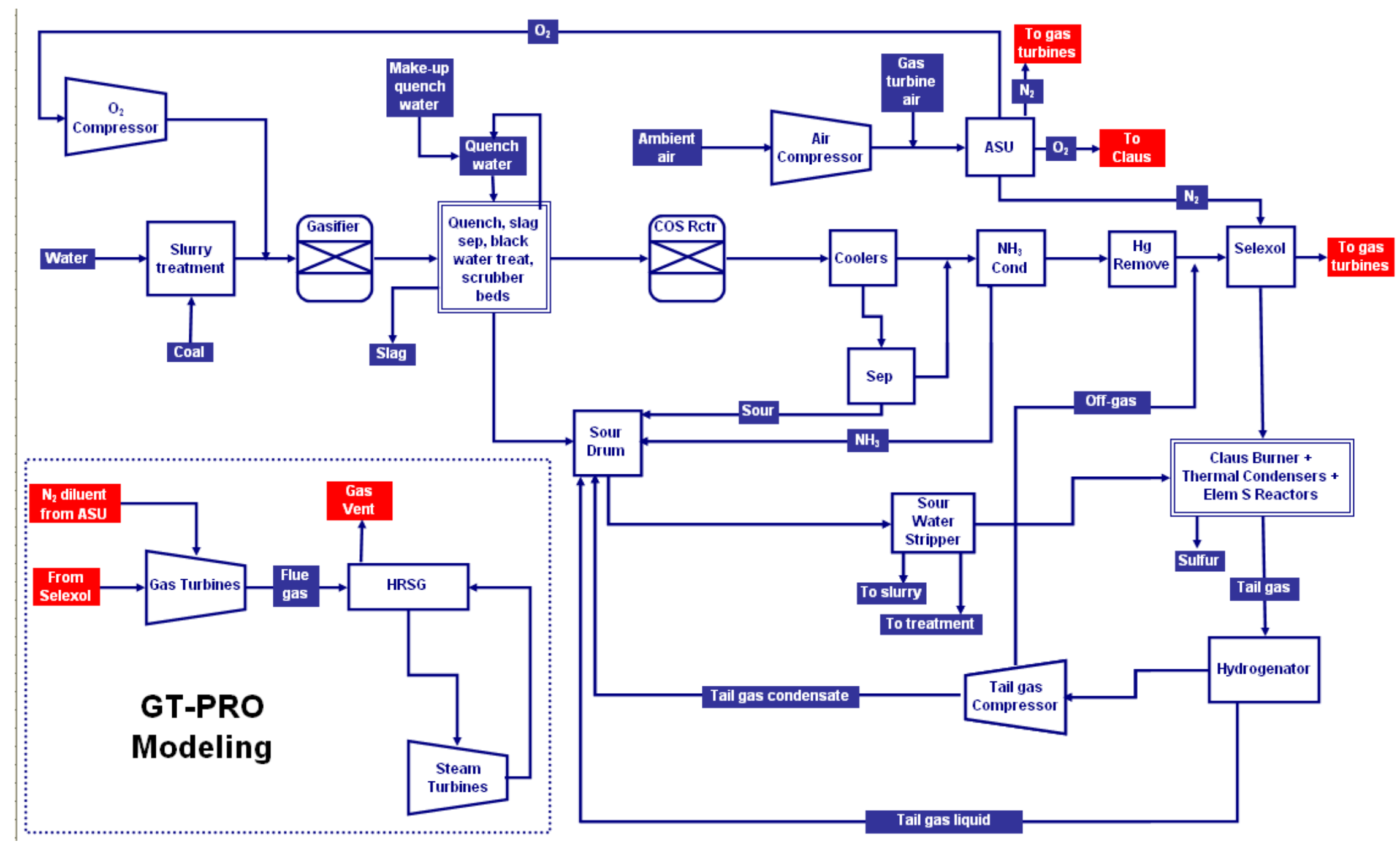

Figure III-2. Block flow diagram for Scenario 1. 
Table III-14. Characteristics of Temperatures, Pressures, and Gas Flows for Scenario 1

\begin{tabular}{|c|c|c|c|c|c|c|c|c|c|c|}
\hline & Gasifier In & Gasifier Out & COS-Rxtr In & COS-Rxtr Out & Selexol In & To Comb & To Claus & Comb In & Comb Out & To HRSG \\
\hline Temperature C & 1113 & 1316 & 210 & 204 & 37 & 38 & 49 & 361 & 1377 & 560 \\
\hline Pressure psia & 980 & 815 & 798 & 788 & 738 & 667 & 31 & 235 & 212 & 15 \\
\hline Vapor Frac & 1 & 1 & 1 & 1 & 1 & 1 & 1 & 1 & 1 & 1 \\
\hline Mole Flow scfm & 244900 & 318503 & 404693 & 404693 & 276979 & 273859 & 10077 & 1603371 & 1497989 & 1882929 \\
\hline Mass Flow $\mathrm{lb} / \mathrm{hr}$ & 719728 & 1024852 & 1269434 & 1269434 & 934472 & 904000 & 61286 & 6938118.04 & 6938118.04 & 8694000 \\
\hline Volume Flow cuft/hr & 1072180 & 1896936 & 748620 & 720759 & 355224 & 389901 & 324967 & 13196806 & 35665050 & 314398937 \\
\hline Dew Temp C & 226 & 175 & 209 & 208 & 38 & 4 & 35 & 50 & 104 & 39 \\
\hline \multicolumn{11}{|l|}{ Mass Flow $\mathrm{lb} / \mathrm{hr}$} \\
\hline $\mathrm{H} 2 \mathrm{O}$ & 265883 & 140092 & 386270 & 386111 & 895 & 134 & 761 & 33545 & 340820 & 352672 \\
\hline AR & 15616 & 15616 & 15616 & 15616 & 15942 & 15942 & 0 & 83985 & 83985 & 106829 \\
\hline $\mathrm{CO} 2$ & 0 & 344779 & 343293 & 343681 & 389837 & 347805 & 42032 & 350032 & 1077111 & 1077901 \\
\hline $\mathrm{O} 2$ & 403686 & 0 & 0 & 0 & 0 & 0 & 0 & 1146251 & 607686 & 1011943 \\
\hline N2 & 13422 & 12268 & 12268 & 12268 & 20477 & 44327 & 6965 & 4828513 & 4828513 & 6144652 \\
\hline O2S & 0 & 0 & 0 & 0 & 0 & 0 & 0 & 0 & 3 & 3 \\
\hline $\mathrm{CH} 4$ & 0 & 707 & 707 & 707 & 1352 & 1352 & 0 & 1352 & 0 & 0 \\
\hline $\mathrm{CO}$ & 0 & 463197 & 463197 & 463197 & 460441 & 460395 & 46 & 460395 & 0 & 0 \\
\hline $\cos$ & 0 & 533 & 533 & 3 & 5 & 0 & 5 & 0 & 0 & 0 \\
\hline $\mathrm{H} 2$ & 21121 & 34047 & 34047 & 34047 & 34047 & 34044 & 3 & 34044 & 0 & 0 \\
\hline $\mathrm{H} 2 \mathrm{~S}$ & 0 & 12208 & 12110 & 12411 & 11227 & 1 & 11225 & 1 & 0 & 0 \\
\hline NH3 & 0 & 1404 & 1392 & 1392 & 248 & 0 & 248 & 0 & 0 & 0 \\
\hline \multicolumn{11}{|l|}{ Mole Frac } \\
\hline $\mathrm{H} 2 \mathrm{O}$ & 0.3811 & 0.1544 & 0.3351 & 0.3350 & 0.0011 & 0.0002 & 0.0265 & 0.0073 & 0.0799 & 0.0658 \\
\hline$A R$ & 0.0101 & 0.0078 & 0.0061 & 0.0061 & 0.0091 & 0.0092 & 0.0000 & 0.0083 & 0.0089 & 0.0090 \\
\hline $\mathrm{CO} 2$ & 0.0000 & 0.1556 & 0.1219 & 0.1220 & 0.2023 & 0.1825 & 0.5994 & 0.0314 & 0.1033 & 0.0823 \\
\hline $\mathrm{O} 2$ & 0.3258 & 0.0000 & 0.0000 & 0.0000 & 0.0000 & 0.0000 & 0.0000 & 0.1413 & 0.0802 & 0.1062 \\
\hline N2 & 0.0124 & 0.0087 & 0.0068 & 0.0068 & 0.0167 & 0.0365 & 0.1561 & 0.6799 & 0.7277 & 0.7368 \\
\hline O2S & 0.0000 & 0.0000 & 0.0000 & 0.0000 & 0.0000 & 0.0000 & 0.0000 & 0.0000 & 0.0000 & 0.0000 \\
\hline $\mathrm{CH} 4$ & 0.0000 & 0.0009 & 0.0007 & 0.0007 & 0.0019 & 0.0019 & 0.0000 & 0.0003 & 0.0000 & 0.0000 \\
\hline $\mathrm{CO}$ & 0.0000 & 0.3284 & 0.2584 & 0.2584 & 0.3754 & 0.3796 & 0.0010 & 0.0648 & 0.0000 & 0.0000 \\
\hline $\cos$ & 0.0000 & 0.0002 & 0.0001 & 0.0000 & 0.0000 & 0.0000 & 0.0000 & 0.0000 & 0.0000 & 0.0000 \\
\hline $\mathrm{H} 2$ & 0.2706 & 0.3354 & 0.2640 & 0.2640 & 0.3857 & 0.3900 & 0.0011 & 0.0666 & 0.0000 & 0.0000 \\
\hline $\mathrm{H} 2 \mathrm{~S}$ & 0.0000 & 0.0071 & 0.0056 & 0.0057 & 0.0075 & 0.0000 & 0.2067 & 0.0000 & 0.0000 & 0.0000 \\
\hline $\mathrm{NH} 3$ & 0.0000 & 0.0016 & 0.0013 & 0.0013 & 0.0003 & 0.0000 & 0.0092 & 0.0000 & 0.0000 & 0.0000 \\
\hline
\end{tabular}




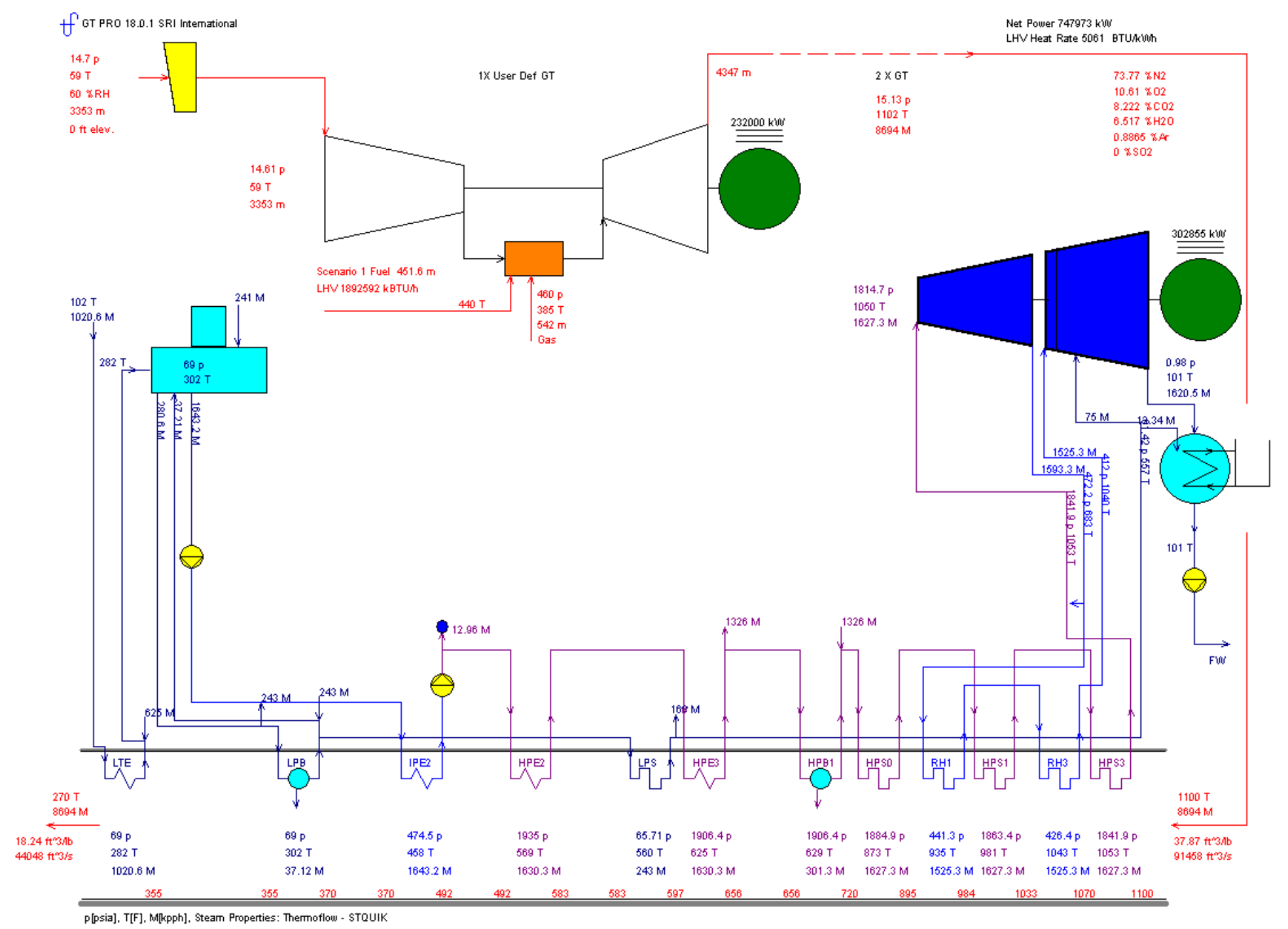

Figure III-3. GT-Pro diagram for Scenario 1. 


\section{Scenario 2: $\mathrm{CO}_{2}$ Capture Using Selexol}

Figure III-4 is the block flow diagram of Scenario 2, in which Selexol units are used to separate $\mathrm{CO}_{2}$ from $\mathrm{H}_{2}$ and also to remove $\mathrm{H}_{2} \mathrm{~S}$ from the $\mathrm{CO}_{2}$ stream. The $\mathrm{CO}$ in the syngas is converted to $\mathrm{H}_{2}$ and $\mathrm{CO}_{2}$ using two WGSRs in series. To convert the desired amount of $\mathrm{CO}$, it is necessary to feed steam into the syngas before the first WGSR. We have assumed that the water gas shift reaction will take place in the presence of $\mathrm{H}_{2} \mathrm{~S}$ (sour gas shift) using a sulfur-tolerant catalyst at an inlet temperature of $450^{\circ} \mathrm{F}$ for both reactors. The gas stream leaving the second WGSR contains about $\sim 1 \mathrm{wt} \% \mathrm{CO}$ and passes through a series of coolers and separators that remove $\mathrm{H}_{2} \mathrm{O}, \mathrm{NH}_{3}$, and $\mathrm{Hg}$. The syngas then enters the two-stage Selexol unit, which separates the feed gas into three streams. The $\mathrm{H}_{2} \mathrm{~S}$-rich stream is sent to the Claus unit as in Scenario 1. The $\mathrm{CO}_{2}$-rich stream is sent to a series of compressors and compressed to 2215 psia for sequestration. The syngas leaves the Selexol unit and is expanded in a turbine before being mixed with diluent $\mathrm{N}_{2}$ before being combusted in the gas turbines. Table III-15 lists the temperatures, pressures, and mass flows at the various steps in the IGCC process.

The firing temperature of the gas turbines is reduced from that in Scenario 1 to maintain the life of the parts in the gas turbines, given that the steam content of the fuel gas increases significantly in the $\mathrm{CO}_{2}$ capture cases. The higher steam content also reduces the temperature of the flue gas fed to the heat recovery steam generator (HRSG) and therefore the temperature of the steam fed to the steam turbines.

The net plant output in Scenario 2 is significantly smaller than the output in Scenario 1. The gas turbines still have an output of $464 \mathrm{MW}$, but the steam turbine output is $277 \mathrm{MW}$, and the auxiliary power requirements are $231 \mathrm{MW}$. The net power output for the plant is 516 MW, which is approximately $18 \%$ less than Scenario 1. Additionally, the Scenario 2 plant requires about $6 \%$ more coal. The largest parasitic losses related to the capture of $\mathrm{CO}_{2}$ are associated with the compression of the $\mathrm{CO}_{2}$ from approximately 30 to 2215 psia and the additional pumping, chilling, and compressing requirements of operating the Selexol unit. The heat produced by the water gas shift reaction can be recovered, but a large portion of it is used to produce the steam that is added to the WGSRs to improve the equilibrium of the reaction.

Figure III-5 provides a summary of the GT-Pro simulation for Scenario 2. In Scenario 2, high-pressure steam is drawn from the first high-pressure superheater to be mixed into the gasifier product stream just before the WGSRs. A saturated high-pressure steam is drawn from the stream leaving the high-pressure steam turbine to provide the required heating to the 
Selexol unit. A final heating stream is withdrawn from the low-pressure superheater to provide heating to various unit operations throughout the plant. There are also three large energy inputs to the steam cycle that are generated by cooling processes from the gasifier portion of the plant. High-pressure $\mathrm{H}_{2} \mathrm{O}$ is drawn from the final high-pressure economizer and used to provide steam cooling, predominately in the radiant cooler. This high-pressure $\mathrm{H}_{2} \mathrm{O}$ is vaporized and returned to the first high-pressure superheater. $\mathrm{H}_{2} \mathrm{O}$ is also removed from the low-pressure boiler and the low temperature economizer to provide cooling to successively cooler unit operations. 


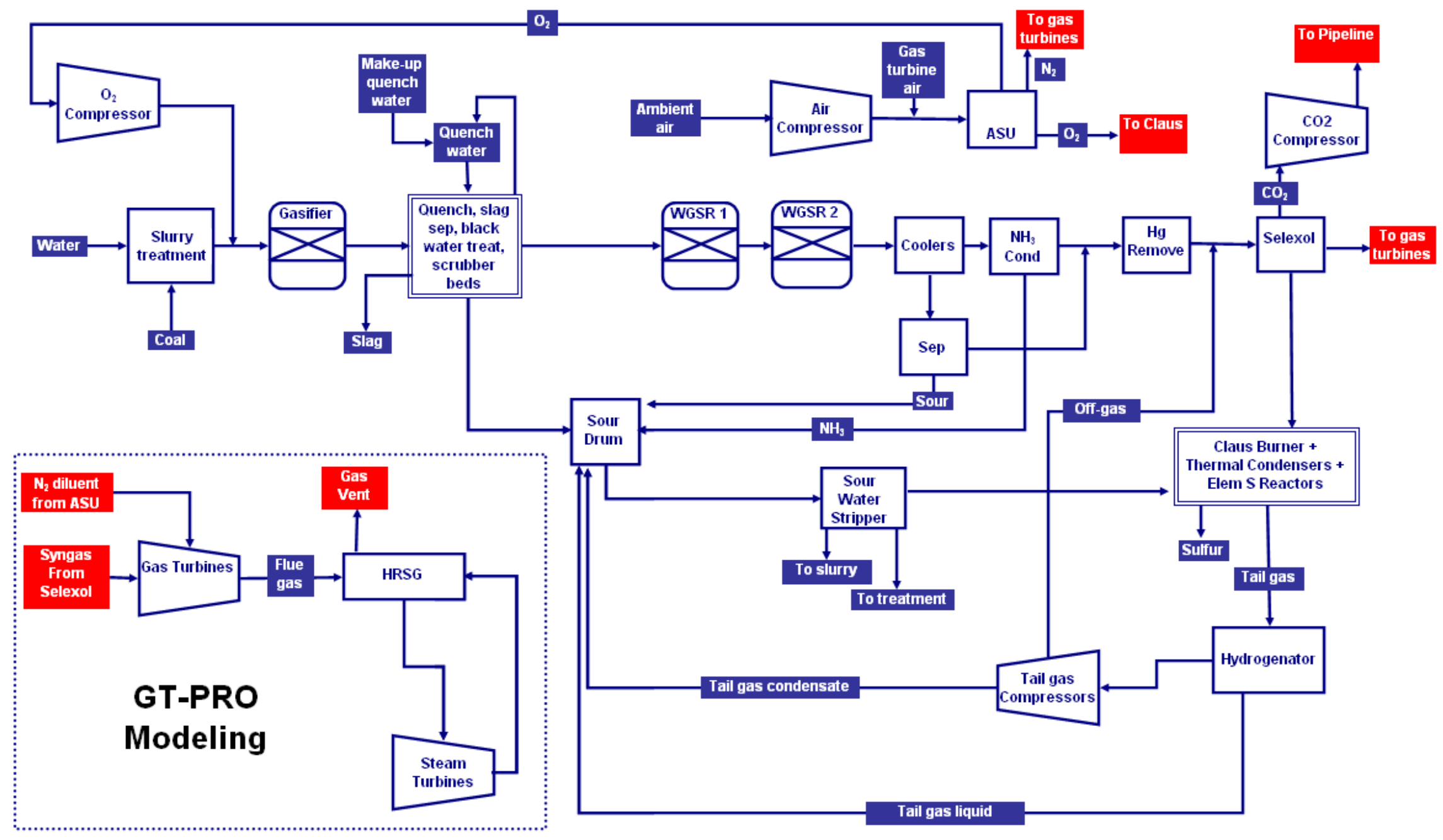

Figure III-4. Block Flow Diagram for scenario 2. 
Table III-15. Characteristics of Temperatures, Pressures, and Gas Flows for Scenario 2

\begin{tabular}{|c|c|c|c|c|c|c|c|c|c|}
\hline & Gasifier In & Gasifier Out & WGSR Feed & WGSR Exit & Selexol In & To Claus & To CO2 Comp & To Gas Turb & To HRSG \\
\hline Temperature C & 1128 & 1316 & 229 & 270 & 36 & 43 & 10 & 27 & 567 \\
\hline Pressure psia & 980 & 815 & 798 & 777 & 727 & 25 & 17 & 695 & 15 \\
\hline Vapor Frac & 1 & 1 & 1 & 1 & 1 & 1 & 1 & 1 & 1 \\
\hline Mole Flow scfm & 254904 & 332812 & 507801 & 507801 & 409517 & 20706 & 149463 & 239349 & 1941483 \\
\hline Mass Flow $\mathrm{lb} / \mathrm{hr}$ & 749525 & 1072618 & 1570228 & 1570228 & 1365699 & 139344.973 & 1023937 & 202417 & 8438000 \\
\hline Volume Flow cuft/hr & 1113196 & 1982160 & 976954 & 1084332 & 532707 & 810279 & 7739767 & 315352 & 326904708 \\
\hline Enthalpy MMBtu/hr & -889 & -1992 & -5801 & -6048 & -4867 & -503 & -4017 & -360 & -2100 \\
\hline Dew Temp F & 436 & 344 & 434 & 375 & 103 & 59 & -27 & 80 & 123 \\
\hline \multicolumn{10}{|l|}{ Mass Flow $\mathrm{lb} / \mathrm{hr}$} \\
\hline $\mathrm{H} 2 \mathrm{O}$ & 268958 & 140141 & 639191 & 332467 & 1233 & 586 & 154 & 493 & 668537 \\
\hline AR & 16535 & 16535 & 16535 & 16535 & 16878 & 0 & 0 & 16878 & 112732 \\
\hline $\mathrm{CO} 2$ & 0 & 354486 & 353150 & 1102449 & 1229830 & 126673 & 1020759 & 82399 & 117481 \\
\hline $\mathrm{O} 2$ & 427455 & 0 & 0 & 0 & 0 & 0 & 0 & 0 & 1070185 \\
\hline N2 & 14213 & 12999 & 12999 & 12999 & 14305 & 0 & 286 & 14019 & 6469035 \\
\hline O2S & 0 & 0 & 0 & 0 & 0 & 0 & 0 & 0 & 29 \\
\hline $\mathrm{CH} 4$ & 0 & 792 & 792 & 792 & 1111 & 0 & 0 & 1111 & 0 \\
\hline $\mathrm{CO}$ & 0 & 497137 & 497137 & 20488 & 20393 & 0 & 2039 & 18354 & 0 \\
\hline cos & 0 & 580 & 580 & 46 & 49 & 25 & 0 & 25 & 0 \\
\hline $\mathrm{H} 2$ & 22365 & 35554 & 35554 & 69858 & 69836 & 0 & 698 & 69137 & 0 \\
\hline $\mathrm{H} 2 \mathrm{~S}$ & 0 & 12919 & 12826 & 13129 & 11768 & 11767 & 0 & 2 & 0 \\
\hline $\mathrm{NH} 3$ & 0 & 1476 & 1465 & 1465 & 296 & 296 & 0 & 0 & 0 \\
\hline \multicolumn{10}{|l|}{ Mole Frac } \\
\hline $\mathrm{H} 2 \mathrm{O}$ & 0.3704 & 0.1478 & 0.4419 & 0.2299 & 0.0011 & 0.0099 & 0.0004 & 0.0007 & 0.1209 \\
\hline $\mathrm{AR}$ & 0.0103 & 0.0079 & 0.0052 & 0.0052 & 0.0065 & 0.0000 & 0.0000 & 0.0112 & 0.0092 \\
\hline $\mathrm{CO} 2$ & 0.0000 & 0.1531 & 0.0999 & 0.3120 & 0.4316 & 0.8792 & 0.9815 & 0.0495 & 0.0087 \\
\hline $\mathrm{O} 2$ & 0.3314 & 0.0000 & 0.0000 & 0.0000 & 0.0000 & 0.0000 & 0.0000 & 0.0000 & 0.1089 \\
\hline N2 & 0.0126 & 0.0088 & 0.0058 & 0.0058 & 0.0079 & 0.0000 & 0.0004 & 0.0132 & 0.7523 \\
\hline O2S & 0.0000 & 0.0000 & 0.0000 & 0.0000 & 0.0000 & 0.0000 & 0.0000 & 0.0000 & 0.0000 \\
\hline $\mathrm{CH} 4$ & 0.0000 & 0.0009 & 0.0006 & 0.0006 & 0.0011 & 0.0000 & 0.0000 & 0.0018 & 0.0000 \\
\hline $\mathrm{CO}$ & 0.0000 & 0.3373 & 0.2211 & 0.0091 & 0.0112 & 0.0000 & 0.0031 & 0.0173 & 0.0000 \\
\hline cos & 0.0000 & 0.0002 & 0.0001 & 0.0000 & 0.0000 & 0.0001 & 0.0000 & 0.0000 & 0.0000 \\
\hline $\mathrm{H} 2$ & 0.2753 & 0.3352 & 0.2197 & 0.4316 & 0.5350 & 0.0000 & 0.0147 & 0.9063 & 0.0000 \\
\hline $\mathrm{H} 2 \mathrm{~S}$ & 0.0000 & 0.0072 & 0.0047 & 0.0048 & 0.0053 & 0.1055 & 0.0000 & 0.0000 & 0.0000 \\
\hline $\mathrm{NH} 3$ & 0.0000 & 0.0016 & 0.0011 & 0.0011 & 0.0003 & 0.0053 & 0.0000 & 0.0000 & 0.0000 \\
\hline
\end{tabular}




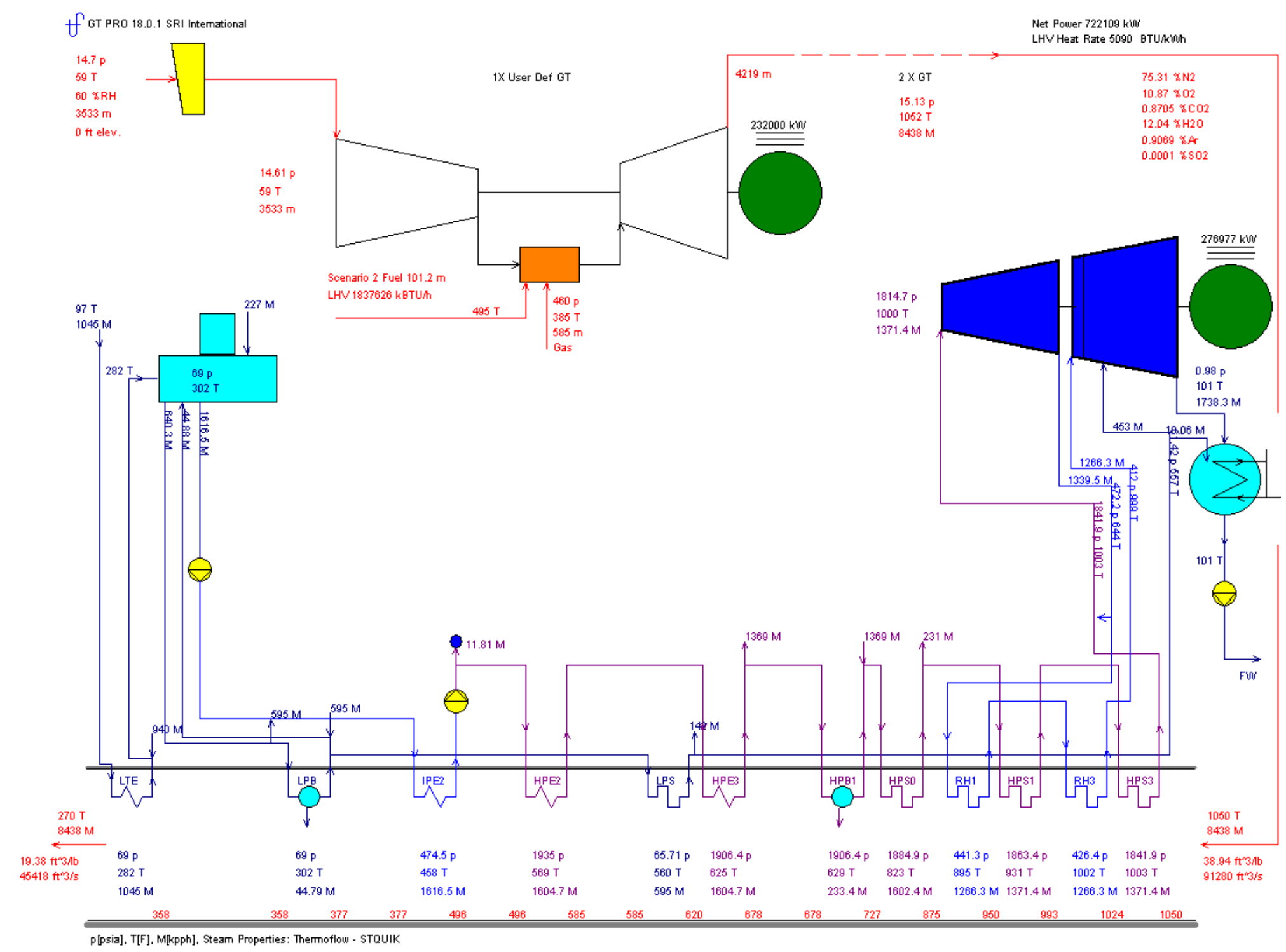

Figure III-5. GT-Pro diagram for scenario 2. 


\section{Scenario 3: $\mathrm{CO}_{2}$ Capture Using a High-Temperature PBI Membrane}

In this scenario a PBI membrane is used to separate the $\mathrm{H}_{2}$ from the $\mathrm{CO}_{2}$. The $\mathrm{H}_{2} \mathrm{~S}$ remains in the retentate and is removed from the $\mathrm{CO}_{2}$ using Selexol. The $\mathrm{H}_{2} \mathrm{~S}$ is then sent to a Claus unit. III-6 is the block flow diagram for Scenario 3. The CO in the syngas is converted to $\mathrm{H}_{2}$ and $\mathrm{CO}_{2}$ using two $\mathrm{H}_{2} \mathrm{O}$ WGSRs in series. To convert the desired amount of $\mathrm{CO}$, it is necessary to feed steam into the syngas before the first WGSR. We have assumed that the water gas shift reaction will take place in the presence of $\mathrm{H}_{2} \mathrm{~S}$ (sour gas shift) using a sulfurtolerant catalyst at an inlet temperature of $450^{\circ} \mathrm{F}$ for both reactors. The gas stream leaving the second WGSR contains about $\sim 1 \mathrm{wt} \% \mathrm{CO}$ and then enters the high-temperature membrane separator.

The membrane simulation model was used to calculate the required membrane area and gas compositions of permeate and retentate streams. We assumed a membrane separation layer thickness of $0.5 \mu \mathrm{m}$, permeate pressure of $250 \mathrm{psia}$, and $90 \% \mathrm{CO}_{2}$ recovery. We have assumed that in the membrane separator most of the steam and $\mathrm{H}_{2}$ permeates through the membrane whereas $\mathrm{CO}, \mathrm{H}_{2} \mathrm{~S}$, and $\mathrm{CO}_{2}$ remain mainly in the retentate. After the $\mathrm{H}_{2} \mathrm{O}, \mathrm{NH}_{3}$, and $\mathrm{Hg}$ have been removed, the retentate stream enters the Selexol unit where the $\mathrm{H}_{2} \mathrm{~S}$ is captured and sent to the Claus unit. The $\mathrm{CO}_{2}$ is compressed to 2215 psia. The permeate and sweep gas are compressed from 250 to 455 psia to meet the gas turbine design specifications. Table III-16 lists the temperatures, pressures, and mass flows at the various steps in the IGCC process.

The gross plant output in Scenario 3 is slightly smaller than the output in Scenario 2, whereas the coal feed rate is $11 \%$ higher. The gas turbines still have an output of $464 \mathrm{MW}$, but the steam turbine output is $272 \mathrm{MW}$ and the auxiliary power requirements are $215 \mathrm{MW}$. The net power output for the plant is $521 \mathrm{MW}$, which is approximately $1 \%$ greater than that in Scenario 2. Scenario 3 has an HHV efficiency of $27.57 \%$, whereas Scenario 2 has an HHV efficiency of $30.35 \%$.

Figure III-7 provides a summary of the GT-Pro simulation for Scenario 3. In Scenario 3, high-pressure steam is drawn from the first high-pressure superheater to be mixed into the gasifier product stream just before the WGSRs. Saturated high-pressure steam is drawn from the stream leaving the high-pressure steam turbine to provide the required heating to the Selexol unit. A final heating stream is withdrawn from the low-pressure superheater to provide heating to various unit operations throughout the plant. There are also three large energy inputs to the steam cycle, which are generated by cooling processes from the gasifier portion of the plant. High-pressure $\mathrm{H}_{2} \mathrm{O}$ is drawn from the final high-pressure economizer 
and used to provide steam cooling, predominately in the radiant cooler. This high-pressure $\mathrm{H}_{2} \mathrm{O}$ is vaporized and returned to the first high-pressure superheater. $\mathrm{H}_{2} \mathrm{O}$ is also removed from the low-pressure boiler and the low-temperature economizer to provide cooling to successively cooler unit operations 


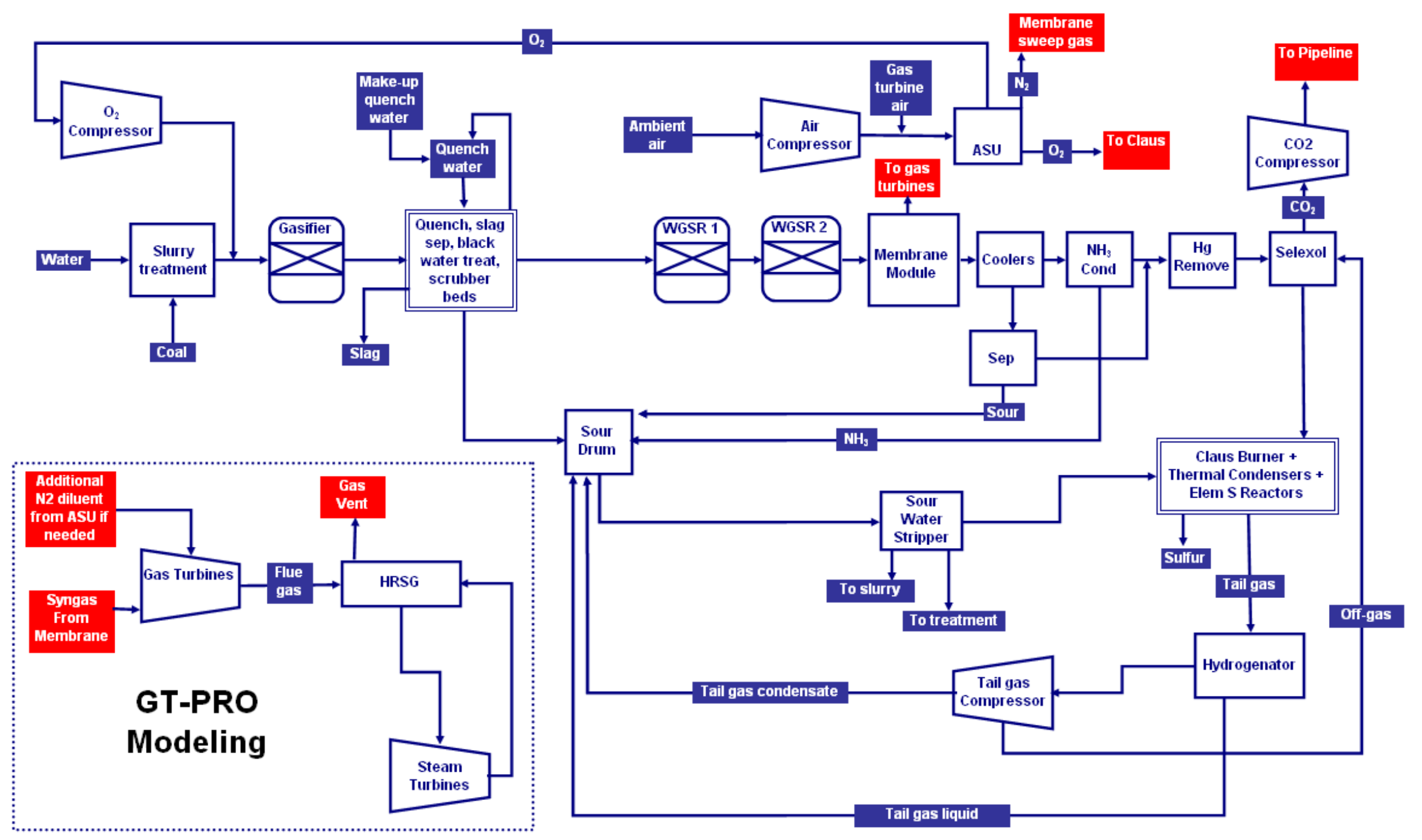

Figure III-6. Block flow diagram for scenario 3. 
Table III-16. Characteristics of Temperatures, Pressures, and Gas Flows for Scenario 3

\begin{tabular}{|c|c|c|c|c|c|c|c|c|c|}
\hline & WGSR Feed & WGSR Exit & Membrane In & Retentate & Permeate & To Selexol & To Claus & To CO2 Comp & To HRSG \\
\hline Temperature $\mathrm{C}$ & 230 & $\overline{271}$ & $\overline{232}$ & 232 & $\overline{246}$ & $\overline{36}$ & $\overline{38}$ & 38 & $\overline{568}$ \\
\hline Pressure psia & 798 & 777 & 777 & 757 & 250 & 707 & 31 & 667 & 15 \\
\hline Vapor Frac & 1 & 1 & 1 & 1 & 1 & 1 & 1 & 1 & 1 \\
\hline Mole Flow scfm & 565764 & 565764 & 565764 & 203043 & 630320 & 201372 & 10041 & 191331 & 1989406 \\
\hline Mass Flow Ib/hr & 1749330 & 1749330 & 1749330 & 1206556 & 1730101 & 1232199 & 65511 & 1166688 & 8438003 \\
\hline Volume Flow cuft/hr & 1089697 & 1208803 & 1124313 & 635637 & 3727296 & 268896 & 312621 & 272403 & 335126883 \\
\hline Enthalpy MMBtu/hr & -6344 & -6620 & -6673 & -4362 & -2242 & -4484 & -205 & -4278 & -4130 \\
\hline Dew Temp F & 434 & 375 & 375 & & & 102 & 71 & 30 & 138 \\
\hline \multicolumn{10}{|l|}{ Mass Flow lb/hr } \\
\hline $\mathrm{H} 2 \mathrm{O}$ & 717891 & 373312 & 373312 & 25796 & 347516 & 418 & 355 & 63 & 1027389 \\
\hline$A R$ & 18379 & 18379 & 18379 & 18128 & 4161 & 18451 & 0 & 18451 & 91431 \\
\hline $\mathrm{CO} 2$ & 383912 & 1225689 & 1225689 & 1102752 & 122937 & 1154596 & 51957 & 1102639 & 127354 \\
\hline $\mathrm{O} 2$ & 0 & 0 & 0 & 0 & 7169 & 0 & 0 & 0 & 987410 \\
\hline N2 & 14457 & 14457 & 14457 & 14259 & 1176445 & 15396 & 0 & 15396 & 6204420 \\
\hline O2S & 0 & 0 & 0 & 0 & 0 & 0 & 0 & 0 & 0 \\
\hline $\mathrm{CH} 4$ & 917 & 917 & 917 & 890 & 27 & 1343 & 0 & 1343 & 0 \\
\hline $\mathrm{CO}$ & 558133 & 22661 & 22661 & 21818 & 843 & 21741 & 0 & 21741 & 0 \\
\hline cos & 658 & 50 & 50 & 50 & 0 & 53 & 0 & 53 & 0 \\
\hline $\mathrm{H} 2$ & 39104 & 77642 & 77642 & 6638 & 71003 & 6655 & 0 & 6655 & 0 \\
\hline $\mathrm{H} 2 \mathrm{~S}$ & 14260 & 14604 & 14604 & 14604 & 0 & 13202 & 13199 & 3 & 0 \\
\hline $\mathrm{NH} 3$ & 1620 & 1620 & 1620 & 1620 & 0 & 346 & 0 & 346 & 0 \\
\hline \multicolumn{10}{|l|}{ Mole Frac } \\
\hline $\mathrm{H} 2 \mathrm{O}$ & 0.4455 & 0.2316 & 0.2316 & 0.0446 & 0.1936 & 0.0007 & 0.0124 & 0.0001 & 0.1813 \\
\hline$A R$ & 0.0051 & 0.0051 & 0.0051 & 0.0141 & 0.0010 & 0.0145 & 0.0000 & 0.0153 & 0.0073 \\
\hline $\mathrm{CO} 2$ & 0.0975 & 0.3113 & 0.3113 & 0.7805 & 0.0280 & 0.8240 & 0.7436 & 0.8282 & 0.0092 \\
\hline $\mathrm{O} 2$ & 0.0000 & 0.0000 & 0.0000 & 0.0000 & 0.0022 & 0.0000 & 0.0000 & 0.0000 & 0.0981 \\
\hline N2 & 0.0058 & 0.0058 & 0.0058 & 0.0159 & 0.4214 & 0.0173 & 0.0000 & 0.0182 & 0.7041 \\
\hline O2S & 0.0000 & 0.0000 & 0.0000 & 0.0000 & 0.0000 & 0.0000 & 0.0000 & 0.0000 & 0.0000 \\
\hline $\mathrm{CH} 4$ & 0.0006 & 0.0006 & 0.0006 & 0.0017 & 0.0000 & 0.0026 & 0.0000 & 0.0028 & 0.0000 \\
\hline $\mathrm{CO}$ & 0.2228 & 0.0090 & 0.0090 & 0.0243 & 0.0003 & 0.0244 & 0.0000 & 0.0257 & 0.0000 \\
\hline cos & 0.0001 & 0.0000 & 0.0000 & 0.0000 & 0.0000 & 0.0000 & 0.0000 & 0.0000 & 0.0000 \\
\hline $\mathrm{H} 2$ & 0.2168 & 0.4306 & 0.4306 & 0.1026 & 0.3534 & 0.1037 & 0.0000 & 0.1091 & 0.0000 \\
\hline $\mathrm{H} 2 \mathrm{~S}$ & 0.0047 & 0.0048 & 0.0048 & 0.0133 & 0.0000 & 0.0122 & 0.2439 & 0.0000 & 0.0000 \\
\hline $\mathrm{NH3}$ & 0.0011 & 0.0011 & 0.0011 & 0.0030 & 0.0000 & 0.0006 & 0.0000 & 0.0007 & 0.0000 \\
\hline
\end{tabular}




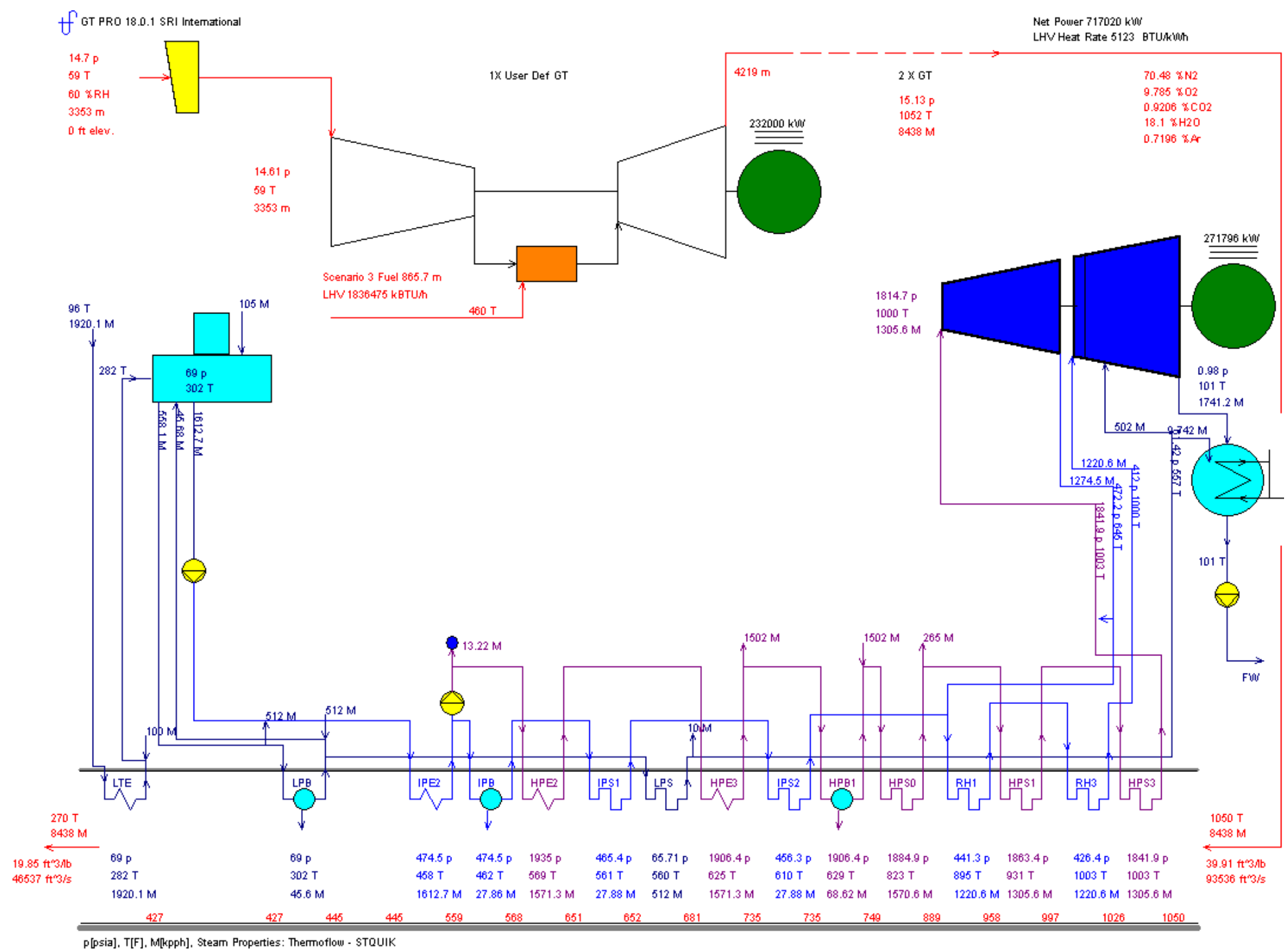

Figure III-7. GT-Pro diagram for scenario 3. 


\section{Scenario 4: $\mathrm{CO}_{2}$ and $\mathrm{H}_{2} \mathrm{~S}$ Capture Using a High-Temperature PBI Membrane}

In this scenario a PBI membrane is used to separate the $\mathrm{H}_{2}$ from the $\mathrm{CO}_{2}$. The $\mathrm{H}_{2} \mathrm{~S}$ in the retentate stream and is not separated from the $\mathrm{CO}_{2}$. III- 8 is the block flow diagram for Scenario 4. The $\mathrm{CO}$ in the syngas is converted to $\mathrm{H}_{2}$ and $\mathrm{CO}_{2}$ using two WGSRs in series. To convert the desired amount of $\mathrm{CO}$, it is necessary to feed steam into the syngas before the first WGSR. We have assumed a sour gas shift using a sulfur-tolerant catalyst at an inlet temperature of $450^{\circ} \mathrm{F}$ for both reactors. The gas stream leaving the second WGSR contains about $\sim 1 \mathrm{wt} \% \mathrm{CO}$ and enters the high-temperature membrane separator.

The membrane simulation model was used to calculate the required membrane area and gas compositions of permeate and retentate streams. We assumed a membrane separation layer thickness of $0.5 \mu \mathrm{m}$, permeate pressure of $250 \mathrm{psia}$, and $90 \% \mathrm{CO}_{2}$ recovery. We assumed most of the steam and $\mathrm{H}_{2}$ permeates through the membrane, whereas $\mathrm{CO}, \mathrm{H}_{2} \mathrm{~S}$, and $\mathrm{CO}_{2}$ remain mainly in the retentate. After the $\mathrm{H}_{2} \mathrm{O}, \mathrm{NH}_{3}$, and $\mathrm{Hg}$ have been removed, the retentate stream is pressurized to 2215 psia. The permeate and sweep gas are compressed from 250 to 455 psia to meet the gas turbine design specifications. Table III-17 lists the temperatures, pressures, and mass flows at the various steps in the IGCC process.

The gross plant output in Scenario 4 is slightly smaller than the output in Scenario 2, whereas the coal feed rate is $16 \%$ higher. The gas turbines still have an output of $464 \mathrm{MW}$, but the steam turbine output is $273 \mathrm{MW}$ and the auxiliary power requirements are $194 \mathrm{MW}$. The net power output for the plant is $543 \mathrm{MW}$, which is approximately $5 \%$ greater than that in Scenario 2. The net efficiencies of the plants are similar, with Scenario 4 having a HHV efficiency of $29.03 \%$ whereas Scenario 2 has an HHV efficiency of $30.35 \%$.

Figure III-9 provides a summary of the GT-Pro simulation for Scenario 4. In Scenario 4, high-pressure steam is drawn from the first high-pressure superheater to be mixed into the gasifier product stream just before the WGSRs. A second heating stream is withdrawn from the low-pressure super-heater to provide heating to various unit operations throughout the plant. There are also three large energy inputs to the steam cycle, which are generated by cooling processes from the gasifier portion of the plant. High-pressure $\mathrm{H}_{2} \mathrm{O}$ is drawn from the final high-pressure economizer and used to provide steam cooling, predominately in the radiant cooler. This high-pressure $\mathrm{H}_{2} \mathrm{O}$ is vaporized and returned to the first high-pressure superheater. $\mathrm{H}_{2} \mathrm{O}$ is also removed from the low-pressure boiler and the low temperature economizer to provide cooling to successively cooler unit operations. 


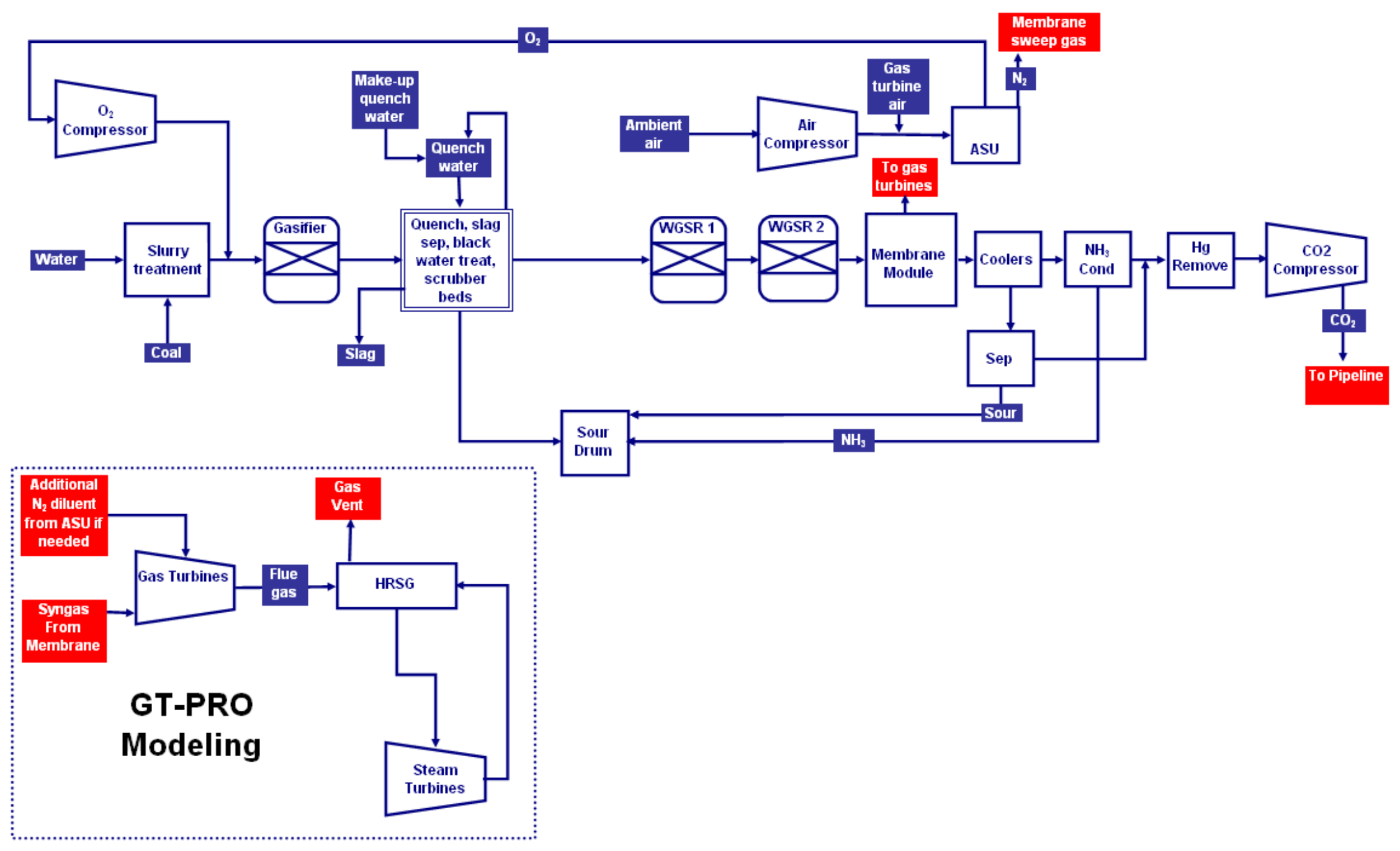

Figure III-8. Block flow diagram for scenario 4. 
Table III-17. Characteristics of Temperatures, Pressures, and Gas Flows for Scenario 4

\begin{tabular}{|c|c|c|c|c|c|c|c|c|c|}
\hline & Gasifier In & Gasifier Out & WGSR Feed & WGSR Exit & Membrane In & Retentate & Permeate & To CO2 Comp & To HRSG \\
\hline Temperature $\mathbf{C}$ & 1123 & 1316 & 231 & 271 & 232 & 232 & 246 & 41 & 567 \\
\hline Pressure psia & 980 & 815 & 798 & 777 & 777 & 750 & 250 & 650 & 15 \\
\hline Vapor Frac & 1 & 1 & 1 & 1 & 1 & 1 & 1 & 1 & 1 \\
\hline Mole Flow scfm & 272846 & 358469 & 561039 & 561039 & 561039 & 200998 & 628162 & 192123 & 1988446 \\
\hline Mass Flow $\mathrm{lb} / \mathrm{hr}$ & 802970 & 1158287 & 1734614 & 1734614 & 1734614 & $1.19 \mathrm{E}+06$ & 1730134 & 1169540 & 8438000 \\
\hline Volume Flow cuft/hr & 1186791 & 2134969 & 1081903 & 1199555 & 1114924 & 629236 & 3715257 & 238638 & 334725805 \\
\hline Enthalpy MMBtu/hr & -882 & -2072 & -6305 & -6579 & -6632 & -4337 & -2236 & -4257 & -4094 \\
\hline Dew Temp F & 432 & 338 & 435 & 376 & 376 & & & 32 & 138 \\
\hline \multicolumn{10}{|l|}{ Mass Flow $\mathrm{lb} / \mathrm{hr}$} \\
\hline $\mathrm{H} 2 \mathrm{O}$ & 274473 & 140496 & 718000 & 373049 & 373049 & 25778 & 347271 & 0 & 1020286 \\
\hline$A R$ & 18184 & 18184 & 18184 & 18184 & 18184 & 17936 & 4193 & 17936 & 91462 \\
\hline $\mathrm{CO} 2$ & 0 & 371279 & 370192 & 1212879 & 1212879 & 1091215 & 121664 & 1092302 & 126066 \\
\hline $\mathrm{O} 2$ & 470088 & 0 & 0 & 0 & 0 & 0 & 7233 & 0 & 993560 \\
\hline N2 & 15630 & 14312 & 14312 & 14312 & 14312 & 14117 & 1178678 & 14117 & 6206627 \\
\hline O2S & 0 & 0 & 0 & 0 & 0 & 0 & 0 & 0 & 0 \\
\hline $\mathrm{CH} 4$ & 0 & 950 & 950 & 950 & 950 & 922 & 28 & 922 & 0 \\
\hline $\mathrm{CO}$ & 0 & 558382 & 558382 & 22334 & 22334 & 21503 & 832 & 21503 & 0 \\
\hline cos & 0 & 665 & 665 & 50 & 50 & 50 & 0 & 50 & 0 \\
\hline $\mathrm{H} 2$ & 24595 & 38224 & 38224 & 76803 & 76803 & 6567 & 70236 & 6567 & 0 \\
\hline $\mathrm{H} 2 \mathrm{~S}$ & 0 & 14191 & 14111 & 14460 & 14460 & 14460 & 0 & 14541 & 0 \\
\hline $\mathrm{NH3}$ & 0 & 1603 & 1593 & 1593 & 1593 & 1593 & 0 & 1603 & 0 \\
\hline \multicolumn{10}{|l|}{ Mole Frac } \\
\hline $\mathrm{H} 2 \mathrm{O}$ & 0.3532 & 0.1376 & 0.4493 & 0.2334 & 0.2334 & 0.0450 & 0.1941 & 0.0000 & 0.1801 \\
\hline $\mathrm{AR}$ & 0.0106 & 0.0080 & 0.0051 & 0.0051 & 0.0051 & 0.0141 & 0.0011 & 0.0148 & 0.0073 \\
\hline $\mathrm{CO} 2$ & 0.0000 & 0.1488 & 0.0948 & 0.3107 & 0.3107 & 0.7802 & 0.0278 & 0.8171 & 0.0091 \\
\hline $\mathrm{O} 2$ & 0.3405 & 0.0000 & 0.0000 & 0.0000 & 0.0000 & 0.0000 & 0.0023 & 0.0000 & 0.0988 \\
\hline N2 & 0.0129 & 0.0090 & 0.0058 & 0.0058 & 0.0058 & 0.0159 & 0.4236 & 0.0166 & 0.7047 \\
\hline O2S & 0.0000 & 0.0000 & 0.0000 & 0.0000 & 0.0000 & 0.0000 & 0.0000 & 0.0000 & 0.0000 \\
\hline $\mathrm{CH} 4$ & 0.0000 & 0.0010 & 0.0007 & 0.0007 & 0.0007 & 0.0018 & 0.0000 & 0.0019 & 0.0000 \\
\hline $\mathrm{CO}$ & 0.0000 & 0.3517 & 0.2247 & 0.0090 & 0.0090 & 0.0242 & 0.0003 & 0.0253 & 0.0000 \\
\hline $\cos$ & 0.0000 & 0.0002 & 0.0001 & 0.0000 & 0.0000 & 0.0000 & 0.0000 & 0.0000 & 0.0000 \\
\hline $\mathrm{H} 2$ & 0.2828 & 0.3345 & 0.2138 & 0.4295 & 0.4295 & 0.1025 & 0.3508 & 0.1072 & 0.0000 \\
\hline $\mathrm{H} 2 \mathrm{~S}$ & 0.0000 & 0.0073 & 0.0047 & 0.0048 & 0.0048 & 0.0134 & 0.0000 & 0.0140 & 0.0000 \\
\hline $\mathrm{NH} 3$ & 0.0000 & 0.0017 & 0.0011 & 0.0011 & 0.0011 & 0.0029 & 0.0000 & 0.0031 & 0.0000 \\
\hline
\end{tabular}




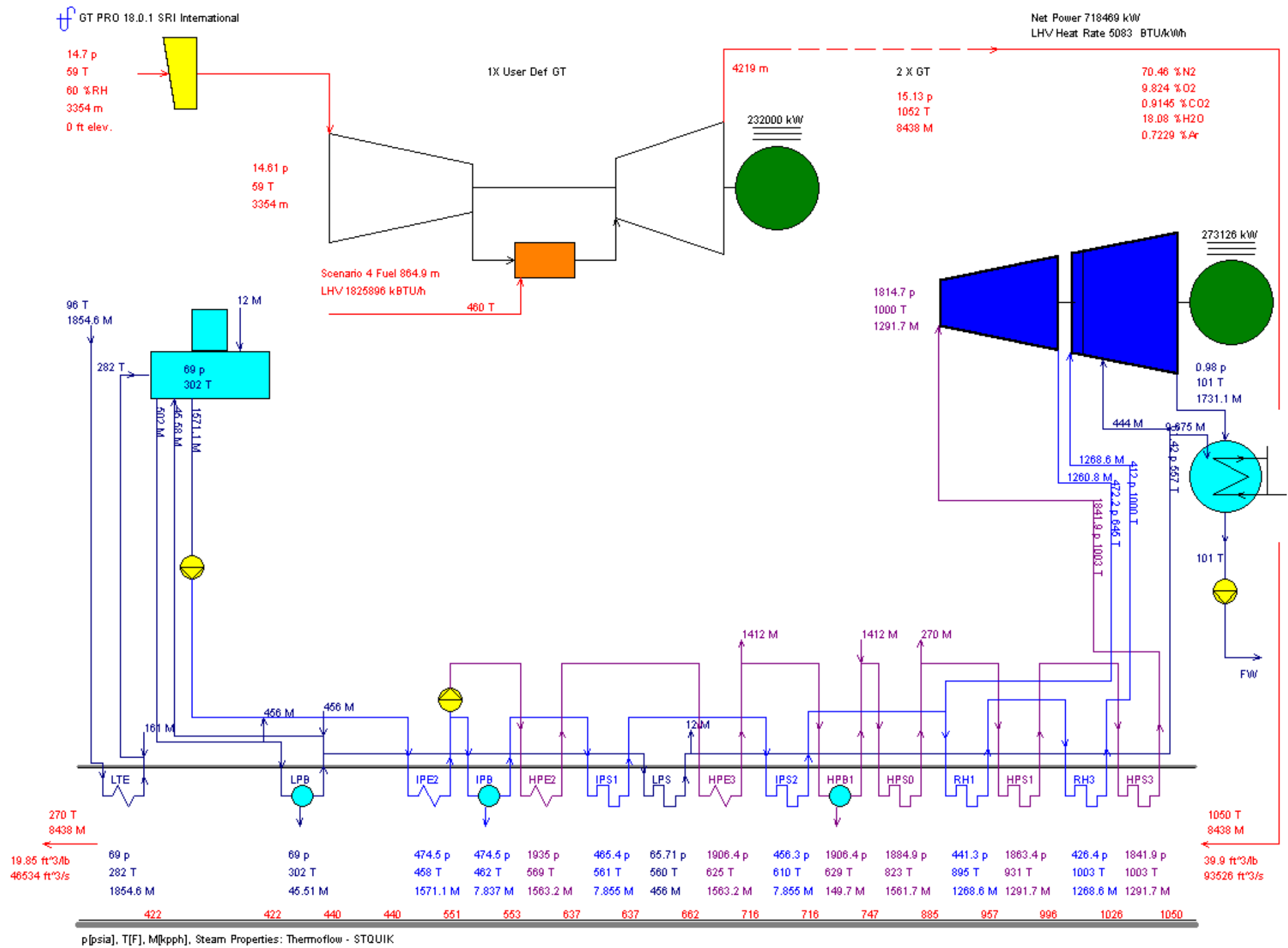

Figure III-9. GT-Pro diagram for scenario 4. 


\section{Scenario 5: $\mathrm{CO}_{2}$ Capture Using a High-Temperature PBI Membrane}

In this scenario a PBI membrane is used to separate the $\mathrm{H}_{2}$ from the $\mathrm{CO}_{2}$ as in Scenario 3 . However, in an effort to better understand the effect of $\mathrm{H}_{2} \mathrm{~S}$ permeability on $\mathrm{COE}$ we have assumed that the $\mathrm{H}_{2} \mathrm{~S}$ permeates with the $\mathrm{H}_{2}$. This $\mathrm{H}_{2}$-rich stream is fed to a Selexol unit where the $\mathrm{H}_{2} \mathrm{~S}$ is removed and sent to a Claus unit. The $\mathrm{H}_{2}$ fuel is then fed to the gas turbine as in Scenario 3.

Figure III-10 is the block flow diagram for Scenario 5. The $\mathrm{CO}$ in the syngas is converted to $\mathrm{H}_{2}$ and $\mathrm{CO}_{2}$ using two WGSRs in series. To convert the desired amount of $\mathrm{CO}$, it is necessary to feed the steam into the syngas before the first WGSR. We have assumed that the water gas shift reaction will take place in the presence of $\mathrm{H}_{2} \mathrm{~S}$ (sour gas shift) using a sulfurtolerant catalyst at an inlet temperature of $450^{\circ} \mathrm{F}$ for both reactors. The gas stream leaving the second WGSR contains about $\sim 1 \mathrm{wt} \% \mathrm{CO}$ and then enters the high-temperature membrane separator.

The membrane simulation model was used to calculate the required membrane area and gas compositions of permeate and retentate streams. We assumed a membrane separation layer thickness of $0.5 \mu \mathrm{m}$, permeate pressure of $250 \mathrm{psia}$, and $90 \% \mathrm{CO}_{2}$ recovery. We have assumed that in the membrane separator most of the steam and $\mathrm{H}_{2}$ permeate through the membrane, whereas $\mathrm{CO}$ and $\mathrm{CO}_{2}$ remain mainly in the retentate. After the $\mathrm{H}_{2} \mathrm{O}, \mathrm{NH}_{3}$, and $\mathrm{Hg}$ have been removed, the retentate stream is compressed to 2215 psia. The permeate and sweep gases blend and are compressed from 250 to 455 psia to meet the gas turbine design specifications. The gas turbine fuel is then cooled to condense out the remaining $\mathrm{H}_{2} \mathrm{O}$ from the water gas shift reaction. The dry gas is then fed to the Selexol unit, where the $\mathrm{H}_{2} \mathrm{~S}$ is removed. Because the Selexol unit operates at low temperatures, the fuel gas must be reheated before being introduced into the gas turbine combustor. Table III-18 lists the temperatures, pressures, and mass flows at the various steps in the IGCC process.

The gross plant output in Scenario 5 is smaller than the output in Scenario 2, whereas the coal feed rate is $12 \%$ higher. The gas turbines still have an output of $464 \mathrm{MW}$, but the steam turbine output is $260 \mathrm{MW}$ and the auxiliary power requirements are $208 \mathrm{MW}$. The net power output for the plant is $516 \mathrm{MW}$, which is approximately the same as Scenario 2. Scenario 5 has an HHV efficiency of $27.06 \%$, whereas Scenario 2 has an HHV efficiency of $30.35 \%$.

Figure III-11 provides a summary of the GT-Pro simulation for Scenario 5. In Scenario 5, high-pressure steam is drawn from the first high-pressure superheater to be mixed into the gasifier product stream just before the WGSRs. A saturated high-pressure steam is drawn from the stream leaving the high-pressure steam turbine to provide the required heating to the 
Selexol unit. A final heating stream is withdrawn from the low-pressure superheater to provide heating to various unit operations throughout the plant. There are also three large energy inputs to the steam cycle, which are generated by cooling processes from the gasifier portion of the plant. High-pressure $\mathrm{H}_{2} \mathrm{O}$ is drawn from the final high-pressure economizer and used to provide steam cooling, predominately in the radiant cooler. This high-pressure $\mathrm{H}_{2} \mathrm{O}$ is vaporized and returned to the first high-pressure superheater. $\mathrm{H}_{2} \mathrm{O}$ is also removed from the low-pressure boiler and the low-temperature economizer to provide cooling to successively cooler unit operations. 


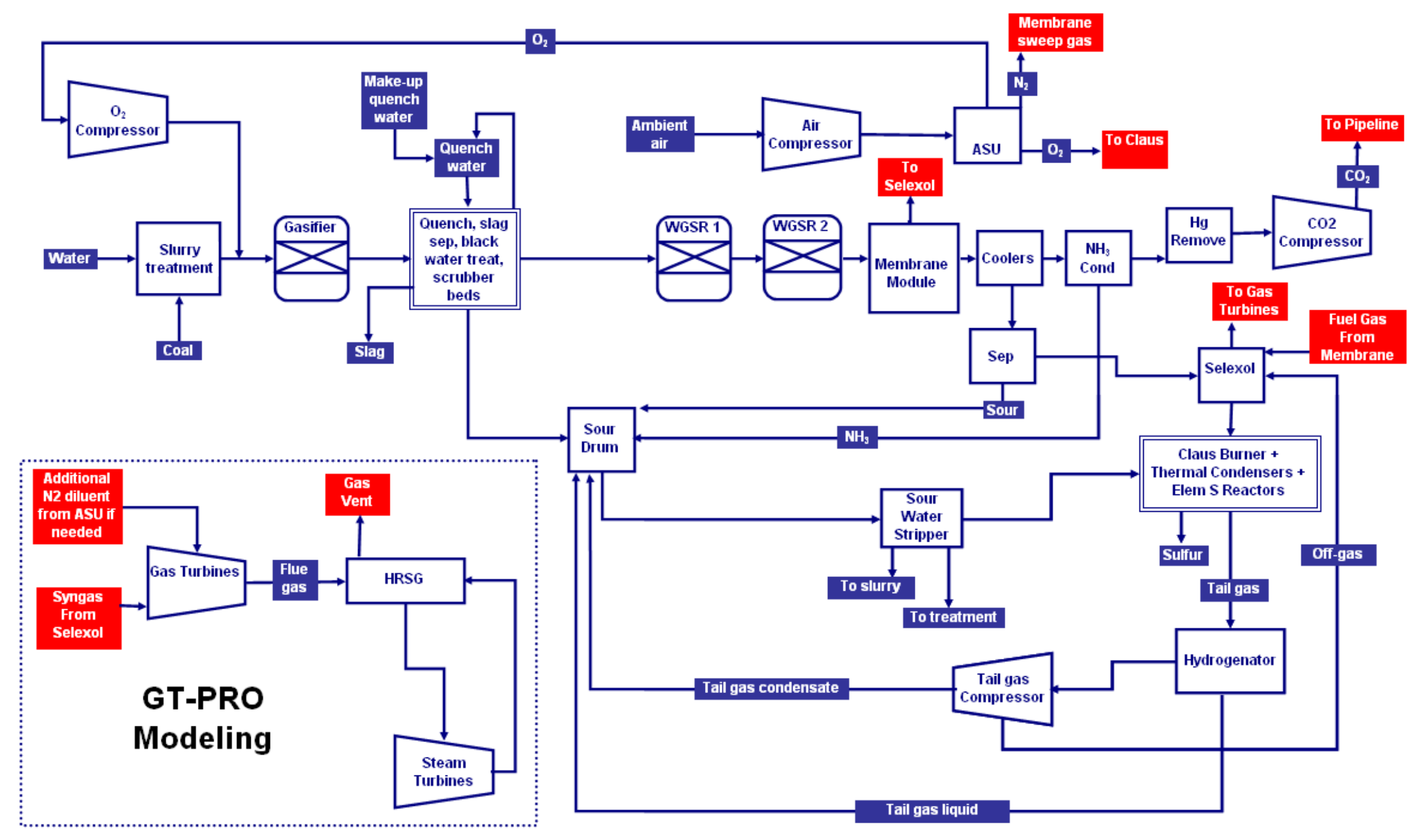

Figure III-10. Block flow diagram for scenario 5. 
Table III-18. Characteristics of Temperatures, Pressures, and Gas Flows for Scenario 5

\begin{tabular}{|c|c|c|c|c|c|c|c|c|c|c|}
\hline & WGSR Feed & WGSR Exit & Membrane In & Retentate & To CO2 Comp & Permeate & To Selexol & To Claus & To Turbine & To HRSG \\
\hline Temperature $\mathbf{C}$ & 231 & 271 & 232 & 232 & 40 & 232 & 40 & 38 & $\overline{241}$ & $\overline{567}$ \\
\hline Pressure psia & 798 & 777 & 777 & 757 & 707 & 250 & 465 & 31 & 450 & 15 \\
\hline Vapor Frac & 1 & 1 & 1 & 1 & 1 & 1 & 1 & 1 & 1 & 1 \\
\hline Mole Flow scfm & 572530 & 572530 & 572530 & 202328 & 192527 & 370203 & 516670 & 6920 & 509750 & 1943550 \\
\hline Mass Flow Ib/hr & 1770071 & 1770071 & 1770071 & 1203531 & 1175604 & 566540 & 1414409 & 24499 & 1389910 & 8437965 \\
\hline Volume Flow cuft/hr & 1104602 & 1224390 & 1137759 & 633397 & 215925 & 2110648 & 1061215 & 188112 & 1777267 & 327298730 \\
\hline Enthalpy MMBtu/hr & -6395 & -6674 & -6728 & -4396 & -4332 & -2401 & -509 & -46 & -258 & -2210 \\
\hline Dew Temp F & 436 & 376 & 376 & & 36 & & 107 & 160 & 49 & 124 \\
\hline \multicolumn{11}{|l|}{ Mass Flow $\mathrm{lb} / \mathrm{hr}$} \\
\hline $\mathrm{H} 2 \mathrm{O}$ & 735190 & 382011 & 382011 & 26397 & 0 & 355614 & 3576 & 3039 & 536 & 682809 \\
\hline$A R$ & 18537 & 18537 & 18537 & 18283 & 18204 & 253 & 4839 & 0 & 4839 & 96534 \\
\hline $\mathrm{CO} 2$ & 373744 & 1236530 & 1236530 & 1113124 & 1113124 & 123406 & 129301 & 5819 & 123483 & 129183 \\
\hline $\mathrm{O} 2$ & 0 & 0 & 0 & 0 & 0 & 0 & 7169 & 0 & 7169 & 1064808 \\
\hline N2 & 14593 & 14593 & 14593 & 14394 & 14340 & 199 & 1181684 & 0 & 1181684 & 6464624 \\
\hline O2S & 0 & 0 & 0 & 0 & 0 & 0 & 0 & 0 & 0 & 6 \\
\hline $\mathrm{CH} 4$ & 985 & 985 & 985 & 956 & 947 & 29 & 437 & 0 & 437 & 0 \\
\hline $\mathrm{CO}$ & 571541 & 22709 & 22709 & 21864 & 21778 & 845 & 846 & 0 & 846 & 0 \\
\hline cos & 684 & 51 & 51 & 51 & 51 & 0 & 0 & 0 & 0 & 0 \\
\hline $\mathrm{H} 2$ & 38791 & 78290 & 78290 & 6694 & 6692 & 71596 & 71628 & 716 & 70912 & 0 \\
\hline $\mathrm{H} 2 \mathrm{~S}$ & 14386 & 14745 & 14745 & 147 & 130 & 14598 & 14928 & 14925 & 3 & 0 \\
\hline $\mathrm{NH3}$ & 1620 & 1620 & 1620 & 1620 & 338 & 0 & 0 & 0 & 0 & 0 \\
\hline \multicolumn{11}{|l|}{ Mole Frac } \\
\hline $\mathrm{H} 2 \mathrm{O}$ & 0.4508 & 0.2342 & 0.2342 & 0.0458 & 0.0000 & 0.3372 & 0.0024 & 0.1542 & 0.0004 & 0.1233 \\
\hline$A R$ & 0.0051 & 0.0051 & 0.0051 & 0.0143 & 0.0150 & 0.0001 & 0.0015 & 0.0000 & 0.0015 & 0.0079 \\
\hline $\mathrm{CO} 2$ & 0.0938 & 0.3104 & 0.3104 & 0.7906 & 0.8309 & 0.0479 & 0.0360 & 0.1208 & 0.0348 & 0.0096 \\
\hline $\mathrm{O} 2$ & 0.0000 & 0.0000 & 0.0000 & 0.0000 & 0.0000 & 0.0000 & 0.0027 & 0.0000 & 0.0028 & 0.1083 \\
\hline N2 & 0.0058 & 0.0058 & 0.0058 & 0.0161 & 0.0168 & 0.0001 & 0.5164 & 0.0000 & 0.5234 & 0.7510 \\
\hline O2S & 0.0000 & 0.0000 & 0.0000 & 0.0000 & 0.0000 & 0.0000 & 0.0000 & 0.0000 & 0.0000 & 0.0000 \\
\hline $\mathrm{CH} 4$ & 0.0007 & 0.0007 & 0.0007 & 0.0019 & 0.0019 & 0.0000 & 0.0003 & 0.0000 & 0.0003 & 0.0000 \\
\hline $\mathrm{CO}$ & 0.2254 & 0.0090 & 0.0090 & 0.0244 & 0.0255 & 0.0005 & 0.0004 & 0.0000 & 0.0004 & 0.0000 \\
\hline $\cos$ & 0.0001 & 0.0000 & 0.0000 & 0.0000 & 0.0000 & 0.0000 & 0.0000 & 0.0000 & 0.0000 & 0.0000 \\
\hline $\mathrm{H} 2$ & 0.2126 & 0.4290 & 0.4290 & 0.1038 & 0.1090 & 0.6068 & 0.4350 & 0.3247 & 0.4364 & 0.0000 \\
\hline $\mathrm{H} 2 \mathrm{~S}$ & 0.0047 & 0.0048 & 0.0048 & 0.0001 & 0.0001 & 0.0073 & 0.0054 & 0.4002 & 0.0000 & 0.0000 \\
\hline $\mathrm{NH3}$ & 0.0011 & 0.0011 & 0.0011 & 0.0030 & 0.0007 & 0.0000 & 0.0000 & 0.0000 & 0.0000 & 0.0000 \\
\hline
\end{tabular}




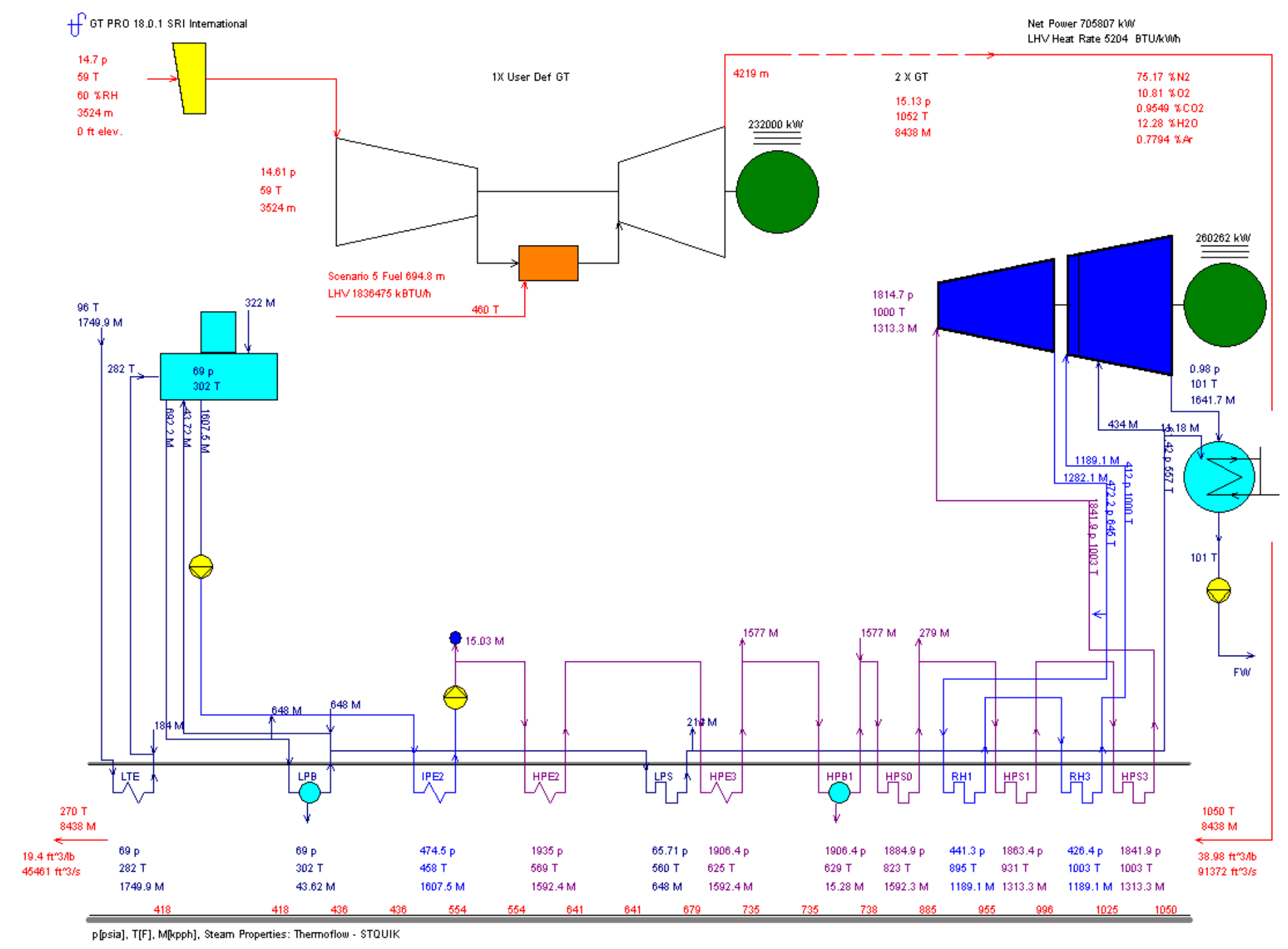

Figure III-11. The Gt-Pro diagram for scenario 5. 


\section{Plant Performance Summary}

The plant performance summary data are shown in Table III-19. Both the NETL Case 1 and Scenario 1 correspond to IGCC plants with no $\mathrm{CO}_{2}$ capture. NETL Case 2 and Scenario 2 are both IGCC plants with $\mathrm{CO}_{2}$ capture using Selexol.

A more detailed comparison of no $\mathrm{CO}_{2}$ capture plants is shown in Table III-20. Many of the auxiliary power loads are estimated by GT-Pro and totaled into a single value labeled as "GT-PRO Auxiliaries." The other major deviation is the use of ASU main air compressor. In Case 1, NETL used "air integration" in which part of the required compression for the ASU is provided by the gas turbine compressor. This optimization was not incorporated into Scenario 1.

A more detailed comparison of $\mathrm{CO}_{2}$ capture plants using Selexol is shown in Table III21. In this case, NETL did not use "air integration" and therefore the ASU main air compressor loads are very similar between NETL Case 2 and Scenario 2, after accounting for the difference in coal feed rates. However, other significant deviations are related to the operation and separation assumptions pertaining to the Selexol unit. The information that we believe to be relevant with respect to the Selexol process appears to differ significantly from the information NETL used. First, the NETL model assumes $100 \%$ recovery of $\mathrm{H}_{2}$ in the syngas stream, in contrast to our assumption of $99 \%$ recovery. Second, the NETL Selexol model has several $\mathrm{CO}_{2}$ bleeds that occur well above atmospheric pressure (150 to $300 \mathrm{psia}$ ) and make up approximately $65 \%$ of the captured $\mathrm{CO}_{2}$. We assumed that the $\mathrm{CO} 2$ will ber released at 30 psia. Third, the capture efficiency of the Selexol with regard to $\mathrm{CO}_{2}$ used by NETL is significantly higher than indicated in the data provided to SRI. Finally, the auxiliary load to operate the Selexol unit is significantly lower in the NETL Case 2 than in Scenario 2. The result is that the NETL Case 2 has a $7 \%$ greater net output and a net HHV efficiency that is $2.2 \%$ higher than Scenario 2.

To reconcile the Selexol capture model developed by the project team with NETL's Selexol capture case, SRI developed an additional scenario entitled Scenario 2 (NETL Selexol). This model is identical to Scenario 2, except that certain assumptions concerning the Selexol operation are those of NETL instead of those from SRI's source. This scenario is based on the assumption of $100 \% \mathrm{H}_{2}$ recovery, multiple flash recovery of $\mathrm{CO}_{2}$, higher firstpass recovery of $\mathrm{CO}_{2}$, and a reduced auxiliary load requirement. A detailed power summary comparing results from Scenario 2 (NETL Selexol), Scenario 2, and NETL Case 2 is shown 
in Table III-22. Using NETL's assumptions regarding the Selexol operation, the results of the SRI simulation is virtually identical to the results reported by NETL. Although an approximate 5\% difference in the COE occurs between Scenario 2 and NETL's Case 2, that difference between Scenario 2 (NETL Selexol) and NETL's Case 2 is less than 1\%. This suggests that the underlying model correlates well with NETL's efforts. 
Table III-19. Summary of Plant Performance for Various Scenarios

\section{Plant Performance}

Gas Turbine Gross Power

Sweet Gas Expander Gross Powe kWe

Steam Turbine Gross Power

Gross Power Total

Auxiliary Load

\section{Net Plant Power}

Net Plant Efficiency (HHV)

Net Plant Heat Rate (HHV)

Coal Feed Flowrate

Thermal Input

Oxygen Flowrate

$\mathrm{CO} 2$ Captured

CO2 Removal

$\begin{array}{rr}\text { NETL Case 1 } & \text { NETL Case 2 } \\ 464,300 & 464,010 \\ 7,130 & 6,260 \\ 298,920 & 274,690 \\ 770,350 & \mathbf{7 4 4 , 9 6 0} \\ 130,100 & 189,285 \\ 640,250 & 555,675 \\ 38.2 \% & 32.5 \% \\ 8,922 & 10,505 \\ 489,634 & 500,379 \\ 1,674,044 & 1,710,780 \\ 418,795 & 425,751 \\ 0 & 1,033,930 \\ 0 \% & 90 \%\end{array}$

\section{Scenario 1}

464,000

6,600

302,855

773,455

144,193

629,262

$39.2 \%$

8,707

469,630

$1,605,650$

400,438

0

$0 \%$
Scenario 2

464,000

6,440

276,977

$\mathbf{7 4 7 , 4 1 7}$

231,766

$\mathbf{5 1 5 , 6 5 1}$

$30.3 \%$

11,251

497,286

$1,700,204$

423,938

$1,023,964$

$90 \%$
Scenario 3

464,000

271,796

$\mathbf{7 3 5 , 7 9 6}$

214,603

521,193

$27.6 \%$

12,372

552,757

$1,889,857$

469,915

$1,136,804$

$90 \%$
Scenario 4

464,000

273,126

737,126

194,327

542,799

$29.0 \%$

11,754

546,883

$1,869,776$

457,774

$1,126,092$

$90 \%$
Scenario 5

464,000

260,282

724,282

208,459

515,823

$27.1 \%$

12,608

557,495

$1,906,056$

480,010

$1,147,346$

$90 \%$ 
Table III-20. Comparison of $\mathrm{No}-\mathrm{CO}_{2}$ Capture IGCC Plants

Gross Plant Power Output

Gas Turbine Gross Power

Sweet Gas Expander Gross Power

Steam Turbine Gross Power

GT-PRO Steam Turbine Gross Power $\mathrm{kW}_{\mathrm{e}}$

Total Gross Power kW

$\mathrm{kW}_{\mathrm{e}}$
Scenario 1 NETL Case 1

464,000

464,300

$\mathrm{kW}_{\mathrm{e}}$

6,600

7,130

298,920

302,855

773,455

770,350

\section{Auxiliary Load}

Coal Handling

$\mathrm{kW}_{\mathrm{e}}$

432

450

Coal Milling

$\mathrm{kW}_{\mathrm{e}}$

Coal Slurry Pumps

$\mathrm{kW}_{\mathrm{e}}$

2,187

2,280

$\mathrm{kW}_{\mathrm{e}}$

$\mathrm{kW}_{\mathrm{e}}$

$\mathrm{kW}_{\mathrm{e}}$

$\mathrm{kW}_{\mathrm{e}}$

$\mathrm{kW}_{\mathrm{e}}$

$\mathrm{kW}_{\mathrm{e}}$

$\mathrm{kW}_{\mathrm{e}}$

$\mathrm{kW}_{\mathrm{e}}$

$\mathrm{kW}_{\mathrm{e}}$

$\mathrm{kW}_{\mathrm{e}}$

$\mathrm{kW}_{\mathrm{e}}$

$\mathrm{kW}_{\mathrm{e}}$

$\mathrm{kW}_{\mathrm{e}}$

$\mathrm{kW}_{\mathrm{e}}$

Transformer Losses

Total Auxiliaries $\mathbf{k W}_{\mathrm{e}}$

Net Plant Power $\mathbf{k W}_{\mathrm{e}}$

Net Plant Efficiency (HHV)

Net Plant Heat Rate (HHV)

Coal Feed

Thermal Input
Btu/kWhr

$\mathrm{lb} / \mathrm{hr}$

$\mathrm{kWt}$
713

1,126

1,000

68,180

10,810

31,897

2,350

740

1,170

1,000

60,070

11,270

30,560

1,230

4,590

250

200

200

3,710

1,910

420

300

3,420

1,000

18,782

100

200

200

3,000

3,000

2,650

144,193

629,262

$39.2 \%$

8,707

469,630

$1,605,650$
130,100

640,250

$38.2 \%$

8,922

489,634

$1,674,044$ 
Table III-21. Comparison of Selexol $\mathrm{CO}_{2}$ Capture IGCC plants

Gross Plant Power Output

Gas Turbine Gross Power

Sweet Gas Expander Gross Power

Steam Turbine Gross Power

GT-PRO Steam Turbine Gross Power

Total Gross Power kW

Auxiliary Load

Coal Handling

Coal Milling

Coal Slurry Pumps

Slag Handling and Dewatering

Air Separation Unit Auxiliaries

ASU Main Air Compressor

Oxygen Compressor

Nitrogen Compressor

Tail Gas Recycle Compressor

CO2 Compressor

Boiler Feedwater Pumps

Condensate Pumps

Flash Bottoms Pump

Circulating Water Pump

Cooling Tower Fans

Scrubber Pumps

Double Stage Selexol Unit Auxiliaries

Gas Turbine Auxiliaries

GT-PRO Auxiliaries

Steam Turbine Auxiliaries

Claus Plant Auxiliaries

Miscellaneous Balance-of-Plant

Transformer Losses
$\mathrm{kW}_{\mathrm{e}}$

$\mathrm{kW}_{\mathrm{e}}$

$\mathrm{kW}_{\mathrm{e}}$

$\mathrm{kW}_{\mathrm{e}}$

$\mathrm{kW}_{\mathrm{e}}$

$\mathrm{kW}_{\mathrm{e}}$

$\mathrm{kW}_{\mathrm{e}}$

$\mathrm{kW}_{\mathrm{e}}$

$\mathrm{kW}_{\mathrm{e}}$

$\mathrm{kW}_{\mathrm{e}}$

$\mathrm{kW}_{\mathrm{e}}$

$\mathrm{kW}_{\mathrm{e}}$

$\mathrm{kW}_{\mathrm{e}}$

$\mathrm{kW}_{\mathrm{e}}$

$\mathrm{kW}_{\mathrm{e}}$

$\mathrm{kW}_{\mathrm{e}}$

$\mathrm{kW}_{\mathrm{e}}$

$\mathrm{kW}_{\mathrm{e}}$

$\mathrm{kW}_{\mathrm{e}}$

$\mathrm{kW}_{\mathrm{e}}$

$\mathrm{kW}_{\mathrm{e}}$

$\mathrm{kW}_{\mathrm{e}}$

$\mathrm{kW}_{\mathrm{e}}$
Scenario 2 NETL Case 2

464,000

6,440

6,260

274,690

276,977

$\mathbf{7 4 7 , 4 1 7}$

744,960

457

460

2,316

755

1,193

1,000

72,190

11,440

34,271

5,490

32,484

27,400

4,580

265

200

3,580

1,850

420

420

47,339

17,320

1,000

18,686

100

200

3,000

2,760

189,285

555,675

$32.5 \%$

10,505

Btu/kWhr $\quad 11,243$

$\mathrm{lb} / \mathrm{hr}$

497,286

500,379

$\mathrm{kW}_{\mathrm{e}} \quad 1,700,204$

$1,710,780$ 
Table III-22. Comparison of Scenario 2 (NETL Selexol) with NETL and SRI Selexol $\mathrm{CO}_{2}$ Capture IGCC Plants

\begin{tabular}{|c|c|c|c|}
\hline Gross Plant Power Output & & Scenario 2 (NETL Selexol) & NETL Case 2 \\
\hline Gas Turbine Gross Power & $\mathrm{kW}_{\mathrm{e}}$ & 464,000 & 464,010 \\
\hline Sweet Gas Expander Gross Power & $\mathrm{kW}_{\mathrm{e}}$ & 6,432 & 6,260 \\
\hline Steam Turbine Gross Power & $\mathrm{kW}_{\mathrm{e}}$ & - & 274,690 \\
\hline GT-PRO Steam Turbine Gross Power & $\mathrm{kW}_{\mathrm{e}}$ & 277,212 & \\
\hline \multicolumn{2}{|c|}{ Total Gross Power kW $\mathrm{e}$} & 747,644 & 744,960 \\
\hline \multicolumn{4}{|l|}{ Auxiliary Load } \\
\hline Coal Handling & $\mathrm{kW}_{\mathrm{e}}$ & 451 & 460 \\
\hline Coal Milling & $\mathrm{kW}_{\mathrm{e}}$ & 2,286 & 2,330 \\
\hline Coal Slurry Pumps & $\mathrm{kW}_{\mathrm{e}}$ & 746 & 760 \\
\hline Slag Handling and Dewatering & $\mathrm{kW}_{\mathrm{e}}$ & 1,177 & 1,200 \\
\hline Air Separation Unit Auxiliaries & $\mathrm{kW}_{\mathrm{e}}$ & 1,000 & 1,000 \\
\hline ASU Main Air Compressor & $\mathrm{kW}_{\mathrm{e}}$ & 71,130 & 72,480 \\
\hline Oxygen Compressor & $\mathrm{kW}_{\mathrm{e}}$ & 11,300 & 11,520 \\
\hline Nitrogen Compressor & $\mathrm{kW}_{\mathrm{e}}$ & 34,531 & 35,870 \\
\hline Tail Gas Recycle Compressor & $\mathrm{kW}_{\mathrm{e}}$ & 1,310 & 990 \\
\hline CO2 Compressor & $\mathrm{kW}_{\mathrm{e}}$ & 30,593 & 27,400 \\
\hline Boiler Feedwater Pumps & $\mathrm{kW}_{\mathrm{e}}$ & - & 4,580 \\
\hline Condensate Pumps & $\mathrm{kW}_{\mathrm{e}}$ & - & 265 \\
\hline Flash Bottoms Pump & $\mathrm{kW}_{\mathrm{e}}$ & 200 & 200 \\
\hline Circulating Water Pump & $\mathrm{kW}_{\mathrm{e}}$ & - & 3,580 \\
\hline Cooling Tower Fans & $\mathrm{kW}_{\mathrm{e}}$ & - & 1,850 \\
\hline Scrubber Pumps & $\mathrm{kW}_{\mathrm{e}}$ & 420 & 420 \\
\hline Double Stage Selexol Unit Auxiliaries & $\mathrm{kW}_{\mathrm{e}}$ & 17,430 & 17,320 \\
\hline Gas Turbine Auxiliaries & $\mathrm{kW}_{\mathrm{e}}$ & - & 1,000 \\
\hline GT-PRO Auxiliaries & $\mathrm{kW}_{\mathrm{e}}$ & 18,859 & - \\
\hline Steam Turbine Auxiliaries & $\mathrm{kW}_{\mathrm{e}}$ & - & 100 \\
\hline Claus Plant Auxiliaries & $\mathrm{kW}_{\mathrm{e}}$ & 200 & 200 \\
\hline Miscellaneous Balance-of-Plant & $\mathrm{kW}_{\mathrm{e}}$ & 3,000 & 3,000 \\
\hline Transformer Losses & $\mathrm{kW}_{\mathrm{e}}$ & - & 2,760 \\
\hline \multicolumn{2}{|c|}{ Total Auxiliaries $\mathrm{kW}_{\mathrm{e}}$} & 194,634 & 189,285 \\
\hline \multicolumn{2}{|c|}{ Net Plant Power $\mathbf{k W}_{\mathrm{e}}$} & 553,010 & 555,675 \\
\hline Net Plant Efficiency (HHV) & & $32.9 \%$ & $32.5 \%$ \\
\hline Net Plant Heat Rate (HHV) & Btu/kWhr & 10,358 & 10,505 \\
\hline Coal Feed Flowrate & $\mathrm{lb} / \mathrm{hr}$ & 490,983 & 500,379 \\
\hline Thermal Input & $\mathrm{kW}_{\mathrm{e}}$ & $1,678,654$ & $1,710,780$ \\
\hline
\end{tabular}




\section{Plant Economic Summary}

The economic summaries by scenario are shown in Tables III-23. The two NETL cases are included to provide a basis for comparison. Because the NETL cost estimates were used as guidelines to generate the costs for the official scenarios, although the models may differ, the costs should be equivalent for equivalent plants. The data show that Scenario 1 and NETL Case 1 have only a $0.2 \%$ deviation in the total COE. On the other hand, Scenario 2 and NETL Case 2 have a deviation of 5.2\% for the reasons cited above. The PBI scenarios shown in Table III-23 are based on conservative estimates concerning both the PBI membrane $(0.5 \mu \mathrm{m}$ thick separation layer) and the operation parameters (fuel gas inlet pressure: 450 psia) of the gas turbine. The cost of electricity (COE) in each scenario is significantly higher than the DOE's goal of a $10 \%$ increase. However, the scenarios are very competitive with a Selexol capture scenario.

Table III-24 describes the effect of changing various process parameters on the cost of $\mathrm{CO} 2$ capture (sensitivity analysis). Changing the membrane module cost from $\$ 10$ to $\$ 30 / \mathrm{m} 2$ changed the cost of electricity (COE) from 10.85 to $10.95 \phi / \mathrm{kWh}$ only. However, changing the gas turbine fuel pressure from 450 to 290 psia had a dramatic effect on the COE from 10.87 to $10.31 \notin / \mathrm{kWh}$.

Table III-25 contains PBI scenarios that rely on achievable characteristics of the PBI membrane and the operation of the gas turbine. Specifically, the separation layer of the membrane has been decreased from 0.5 to $0.1 \mu \mathrm{m}$. In addition, the fuel pressure for the gas turbine is assumed to be $290 \mathrm{psia}$ instead of $450 \mathrm{psia}$. We also assumed that the $\mathrm{H}_{2} \mathrm{~S}$ present in the $\mathrm{CO}_{2}$ retentate stream will not be converted to elemental sulfur using Selexol solvent and Claus process. Separation of $\mathrm{H}_{2} \mathrm{~S}$ and $\mathrm{CO}_{2}$ can be achieved by an alternative process that is currently being tested by SRI in the National Carbon Capture Center. The Bechtel High Pressure Swing Claus Process (BHTS) converts $\mathrm{H}_{2} \mathrm{~S}$ under elevated pressure without the need to separate $\mathrm{H}_{2} \mathrm{~S}$ from $\mathrm{CO}_{2}$. The resulting decrease in cost is dramatic. In the case of Scenario 4, the $\mathrm{COE}$ increase required for the capture and compression of $\mathrm{CO}_{2}$ is under $10 \%$. However, when the cost of transporting, storing, and monitoring the $\mathrm{CO}_{2}$ is accounted for, the increase in the COE is $14.4 \%$, approaching the DoE goal. 
Table III-23. Summary of Preliminary Economic Estimates For Various Scenarios

Project Cases (Conservative Estimates)

\begin{tabular}{|c|c|c|c|c|c|c|c|c|}
\hline & Units & $\begin{array}{l}\text { No Capture } \\
\text { NETL Case } 1\end{array}$ & $\begin{array}{c}\text { Selexol Capture } \\
\text { NETL Case } 2\end{array}$ & $\begin{array}{l}\text { No Capture } \\
\text { Scenario } 1\end{array}$ & $\begin{array}{c}\text { Selexol } \\
\text { Capture } \\
\text { Scenario } 2\end{array}$ & $\begin{array}{c}\mathrm{PBI} \text { Capture, } \\
\mathrm{H}_{2} \mathrm{~S} \text { removal } \\
\text { from } \mathrm{CO}_{2} \\
\text { Scenario } 3\end{array}$ & $\begin{array}{l}\text { PBI Capture, } \\
\mathrm{No}_{2} \mathrm{~S} \\
\text { removal from } \\
\mathrm{CO}_{2} \\
\text { Scenario } 4\end{array}$ & $\begin{array}{c}\mathrm{PBI} \text { Capture, } \\
\mathrm{H}_{2} \mathrm{~S} \text { removal } \\
\text { from } \mathrm{H}_{2} \\
\text { Scenario } 5\end{array}$ \\
\hline Power Production @ 100\% Capacity & GWh/yr & 5609 & 4868 & 5,455 & 4,460 & 4,566 & 4,755 & 4,519 \\
\hline Power Plant Capital & $\mathrm{c} / \mathrm{kWh}$ & 4.53 & 5.97 & 4.50 & 6.19 & 6.24 & 5.43 & 6.35 \\
\hline Power Plant Fuel & $\mathrm{c} / \mathrm{kWh}$ & 1.94 & 2.28 & 1.90 & 2.47 & 2.68 & 2.54 & 2.73 \\
\hline Variable Plant O\&M & $\mathrm{c} / \mathrm{kWh}$ & 0.75 & 0.94 & 0.78 & 1.00 & 0.98 & 0.95 & 0.99 \\
\hline Fixed Plant O\&M & $\mathrm{c} / \mathrm{kWh}$ & 0.58 & 0.72 & 0.60 & 0.79 & 0.77 & 0.74 & 0.78 \\
\hline Cost of Electricity (COE) $)^{*}$ & $\mathrm{c} / \mathrm{kWh}$ & 7.80 & 9.91 & 7.78 & 10.44 & 10.67 & 9.66 & 10.85 \\
\hline Cost of Electricity (COE) & $\mathrm{c} / \mathrm{kWh}$ & 7.80 & 10.33 & 7.78 & 10.86 & 11.09 & 10.06 & 11.27 \\
\hline Increase in $\mathrm{COE}^{\star}$ & $\%$ & $\mathrm{n} / \mathrm{a}$ & $27.3 \%$ & $\mathrm{n} / \mathrm{a}$ & $34.2 \%$ & $37.1 \%$ & $24.1 \%$ & $39.3 \%$ \\
\hline Increase in COE & $\%$ & $\mathrm{n} / \mathrm{a}$ & $32.7 \%$ & $\mathrm{n} / \mathrm{a}$ & $39.5 \%$ & $42.5 \%$ & $29.2 \%$ & $44.8 \%$ \\
\hline
\end{tabular}


Table III-24. Sensitivity Analysis of the $\mathrm{CO}_{2}$ Capture

\begin{tabular}{|c|c|c|c|c|c|c|c|c|c|}
\hline & Units & Base Case & $\begin{array}{c}\text { Module } \\
\text { Cost }\end{array}$ & $\begin{array}{c}\text { Module } \\
\text { Cost }\end{array}$ & $\begin{array}{l}\text { Membrane } \\
\text { Thickness }\end{array}$ & $\begin{array}{l}\text { GT Fuel } \\
\text { Pressure }\end{array}$ & \begin{tabular}{c|} 
Module \\
Temperature \\
\end{tabular} & $\begin{array}{l}\mathrm{No}_{2} \mathrm{~S} \\
\text { removal }\end{array}$ & $\begin{array}{c}\text { Temperature, } \\
\text { Thickness, Pressure }\end{array}$ \\
\hline Membrane Temperature & C & 250 & 250 & 250 & 250 & 250 & 170 & 250 & 170 \\
\hline Separation Layer Thickness & $\mu \mathrm{m}$ & 0.5 & 0.5 & 0.5 & 0.1 & 0.5 & 0.5 & 0.5 & 0.1 \\
\hline Gas Turbine Fuel Pressure & psia & 450 & 450 & 450 & 450 & 290 & 450 & 450 & 290 \\
\hline Membrane Permeate Pressure & psia & 250 & 250 & 250 & 250 & 250 & 290 & 250 & 290 \\
\hline H2S Capture & & Yes & Yes & Yes & Yes & Yes & Yes & No & Yes \\
\hline Membrane Module Cost & $\$ / \mathrm{ft}^{2}$ & 15 & 30 & 10 & 15 & 15 & 15 & 15 & 15 \\
\hline Hydrogen Recovery & $\%$ & 91.4 & 91.4 & 91.4 & 90.8 & 91.4 & 98.6 & 91.4 & 98.6 \\
\hline Membrane Area & $1000 \mathrm{~m}^{2}$ & 93.6 & 94 & 94 & 19 & 94 & 708 & 94 & 137 \\
\hline Power Production @ 100\% Capacity & GWh/yr & 4,642 & 4,642 & 4,642 & 4,596 & 4,902 & 4,847 & 4,735 & 4,980 \\
\hline Power Plant Capital & $\mathrm{c} / \mathbf{k W h}$ & 6.12 & 6.19 & 6.10 & 6.14 & 5.80 & 5.95 & 5.45 & 5.39 \\
\hline Power Plant Fuel & $\mathrm{c} / \mathrm{kWh}$ & 2.62 & 2.62 & 2.62 & 2.67 & 2.48 & 2.32 & 2.55 & 2.30 \\
\hline Variable Plant O\&M & $\mathrm{c} / \mathbf{k W h}$ & 0.97 & 0.97 & 0.97 & 0.97 & 0.93 & 0.93 & 0.95 & 0.91 \\
\hline Fixed Plant O\&M & $\mathrm{c} / \mathbf{k W h}$ & 0.76 & 0.76 & 0.76 & 0.77 & 0.72 & 0.72 & 0.74 & 0.71 \\
\hline Cost of Electricity (COE)* & $\mathrm{c} / \mathbf{k W h}$ & 10.47 & 10.54 & 10.44 & 10.55 & 9.92 & 9.92 & 9.70 & 9.30 \\
\hline Cost of Electricity (COE) & $\mathrm{c} / \mathbf{k W h}$ & 10.87 & 10.95 & 10.85 & 10.96 & 10.31 & 10.30 & 10.10 & 9.68 \\
\hline Increase in $\mathrm{COE}^{*}$ & $\%$ & $34.2 \%$ & $35.4 \%$ & $34.2 \%$ & $35.2 \%$ & $27.5 \%$ & $27.2 \%$ & $24.6 \%$ & $19.5 \%$ \\
\hline Increase in COE & $\%$ & $39.7 \%$ & $40.6 \%$ & $39.4 \%$ & $40.6 \%$ & $32.5 \%$ & $32.1 \%$ & $29.8 \%$ & $24.4 \%$ \\
\hline
\end{tabular}


Table III-25. Cost of $\mathrm{CO}_{2}$ Capture with Removal and Non-Removal of $\mathrm{H}_{2} \mathrm{~S}$

\begin{tabular}{|c|c|c|c|c|}
\hline & & $\begin{array}{l}\mathrm{PBI} \text { Capture, } \\
\mathrm{H}_{2} \mathrm{~S} \text { removal } \\
\text { from } \mathrm{CO}_{2}\end{array}$ & $\begin{array}{c}\text { PBI Capture, } \\
\mathrm{No} \mathrm{H}_{2} \mathrm{~S} \\
\text { removal from } \\
\mathrm{CO}_{2}\end{array}$ & $\begin{array}{l}\mathrm{PBI} \text { Capture, } \\
\mathrm{H}_{2} \mathrm{~S} \text { removal } \\
\text { from } \mathrm{H}_{2}\end{array}$ \\
\hline & Units & Scenario 3 & Scenario 4 & Scenario 5 \\
\hline Power Production @ 100\% Capacity & GWh/yr & 4,980 & 5,152 & 4,944 \\
\hline Power Plant Capital & c/kWh & 5.39 & 4.75 & 5.45 \\
\hline Power Plant Fuel & c/kWh & 2.30 & 2.22 & 2.31 \\
\hline Variable Plant O\&M & c/kWh & 0.91 & 0.89 & 0.92 \\
\hline Fixed Plant O\&M & c/kWh & 0.71 & 0.68 & 0.71 \\
\hline Cost of Electricity (COE)* & c/kWh & 9.30 & 8.54 & 9.39 \\
\hline Cost of Electricity (COE) & $\mathrm{c} / \mathrm{kWh}$ & 9.68 & 8.90 & 9.77 \\
\hline Increase in $\mathrm{COE}^{\star}$ & $\%$ & $19.5 \%$ & $9.7 \%$ & $20.6 \%$ \\
\hline Increase in COE & $\%$ & $24.4 \%$ & $14.4 \%$ & $25.5 \%$ \\
\hline
\end{tabular}




\section{STRATEGIC PLAN DEVELOPMENT}

U.S. Department of Energy and National Energy Technology Laboratory (NETL) are developing a technology portfolio of cost-effective, commercial-scale carbon capture, storage, and mitigation technologies through the Carbon Sequestration Program. The overall goal of this project is to develop a PBI-based capture system that is capable of operation under a broad range of conditions relevant to the power industry, while meeting the Carbon Sequestration Program goals $\left(90 \% \mathrm{CO}_{2}\right.$ capture at less than a $10 \%$ increase in the cost of energy services). The RD\&D that this project team is pursuing is aligned directly with these capture goals and utilizes a precombustion $\mathrm{CO}_{2}$ separation technology and capture system focused on the integration of hightemperature polymer-based membranes into an advanced IGCC process.

To support this overall program goal, the project team has used a commercialization approach to infuse the business perspective and acumen into the technology development process to ensure that the needs and requirements of stakeholders with a vested interest in the success of the technology are taken into account during the research and development phase. We prepared a topical report on the strategic development plan and submitted to NETL. The report is attached as Appendix C.

The PBI project team, comprised of the following members and their associated stakeholder identifications, ensures that the research is focused on the actual needs of the end-user while meeting the requirements of the regulatory and business stakeholders (Table IV-1).

Table IV-1. PBI Team Stakeholder Classification

\begin{tabular}{|l|l|}
\hline \multicolumn{1}{|c|}{ PBI Project Team Member } & \multicolumn{1}{c|}{ Stakeholder Classification } \\
\hline \hline SRI International & Technology Developer \\
\hline Los Alamos National Laboratory & Technology Developer \\
\hline Whitefox Technologies & OEM \& Suppliers \\
\hline Enerfex & OEM \& Suppliers \\
\hline BP Alternative Energy & Utilities \\
\hline Southern Company & Utilities \\
\hline Visage Energy & Business/Financial \\
\hline $\begin{array}{l}\text { US DOE National Energy Technology } \\
\text { Laboratory }\end{array}$ & Government \\
\hline
\end{tabular}

This commercialization effort was designed to meet the following objectives: 
- Validate the potential of the technologies under development to meet the Sequestration Program Capture focus area goals, which are:

- Capture at least $90 \%$ of the carbon dioxide from the effluent gas of a power generation plant.

- Cost less than a $10 \%$ increase in the cost of electricity.

- Considerably increase the likelihood of commercializing the polybenzimidazolebased (PBI-based) membrane technology for pre-combustion carbon dioxide capture.

- Expedite the development of the technical and commercial potential of the technology.

Accelerated deployment of CCS technologies hinges not only on the economics of the process, but also on the ability to create a regulatory environment that encourages investment in these technologies and rewards early technology adopters. The CCS technology learning curve could be decreased by the timely and coordinated deployment of utility-scale state-of-the-art technologies enabling the sharing of best practices concerning the permitting process, design, construction, startup, and operation of power generation facilities with CCS within each of the different technology pathways.

The Visage Energy/SRI Partnership commercialization effort for the PBI project is designed to establish commercialization pathway(s) for novel technologies by aligning multiorganizational teams and focusing on end-user needs within the context of the Statement of Project Objectives (SOPO).

A commercialization pathway schedule was developed based on the on the technical progress and expected time line for availability of modules for pilot testing. Several factors were considered when establishing this schedule:

- Upstream factors such as gasifier type and characteristics of fuel source may cause variation in the performance of capture systems

- Non-technical factors such as regulatory changes and public opinion could impact timelines for pilot, demonstration, and deployment of new capture systems

- Commercialization of PBI capture systems will impact supply chains such as the global supply of PBI hollow fibers and PBI polymer

- Mitigating these risks was important in order to rapidly transition PBI capture systems from pilot to demonstration to deployment

\section{FUTURE OF COAL GASIFICATION TECHNOLOGY}

The report summarized the U.S. and global market for IGCC (pre-combustion) technology. According to the Gasification Technologies Council, in 2007 there were 144 gasification plants 
and 427 gasifiers in operation worldwide, with a thermal capacity of some 56 GWth. Specifically, coal gasification accounted for approximately $31 \mathrm{GW}$ th of that amount with the remainder from petroleum, gas, pet coke, biomass, and waste. [Emerging Energy Research] China has become the global test case for large-scale coal conversion activities. In 2008, China held licenses for the installation of 18 coal gasification plants; among these, 11 commercial size coal gasification plants were already in operation, most of them for the industrial production of methanol or ammonia.

Project momentum slowed dramatically since 2007 according to a new study by Emerging Energy Research with considerable delays and cancellations of several prominent IGCC projects in the past two years. The primary cause of the decline is the difficult market environment facing all new coal builds outside of China and India.

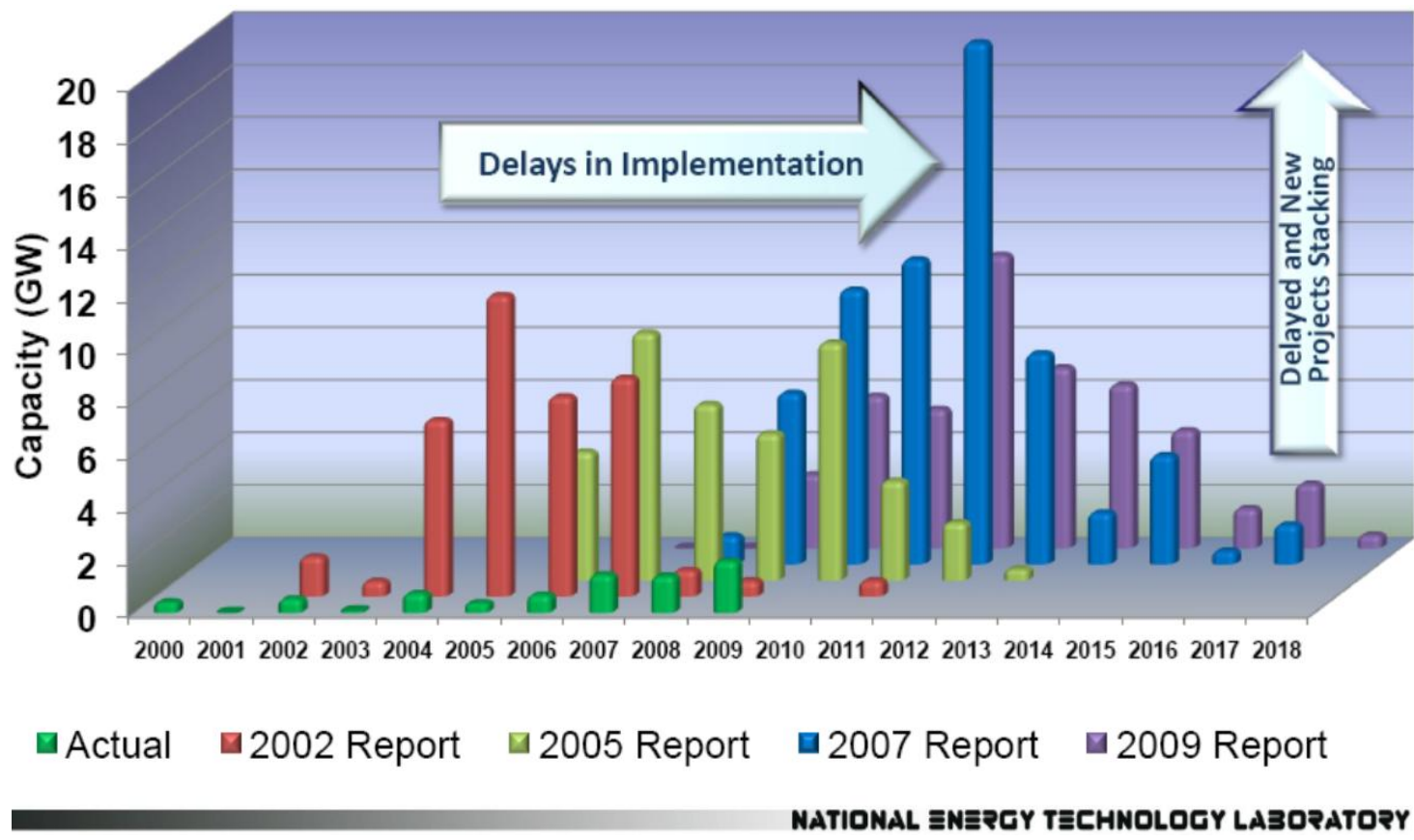

Figure IV-1. Past capacity announcements vs. actual [Ventys 2007]

However, as a testament to the IGCC market and proof that overall confidence in IGCC, as a commercial technology has improved, there are still a considerable number of plants in the development pipeline as can be seen by the green line on the graph.

Within the global IGCC market, there are projects under development in 10 countries with the overwhelming concentration within the US, accounting for $60 \%$ of current coal and/or pet coke IGCC plants under consideration. 
- The US is currently leading the commercialization efforts of IGCC globally with 26 projects at some stage of development in 17 states with a combined capacity of 15,000 MW.

- Australia is next, given strong state and federal policies targeting clean coal technologies while Canada is driven primarily by early EOR opportunities.

- China's interest is growing due to air quality regulations becoming a greater threat to economic development. On a worldwide basis, the main activity on coal gasification is centered in China due to strong support from the central government.

- In contrast, Europe is expected to see rather slow development of IGCC, at least until 2015 according to EER's study.

\section{FINANCIAL, INSURANCE, REGULATORY AND LEGAL ISSUES}

Financial institutions are reticent to invest in these facilities given the dependence of profitability on increasingly risky and uncertain long-term yields. Historically, the financial community has not invested resources in the environmental control technologies because they viewed legal compliance as being sufficient. The two most substantial barriers to project financing are utility industry inertia in novel technology deployment and the lack of sufficient business incentives to cover the cost of CCS. Thus, it is becoming clear to regulators that there will need to be substantial government and industrial financial support to encourage wide-scale deployment of CCS. There are a number of financing methods being proposed and developed such as technology mandates, utility mandates, electricity regulator approval of higher cost, and the creation of a dedicated CCS Trust Fund. In the past, governments assumed that the vehicle of public/private partnerships would effectively finance the early stage deployment necessary; however, in the last year numerous projects have been canceled due to a lack of sufficient resources to cover escalating costs. 


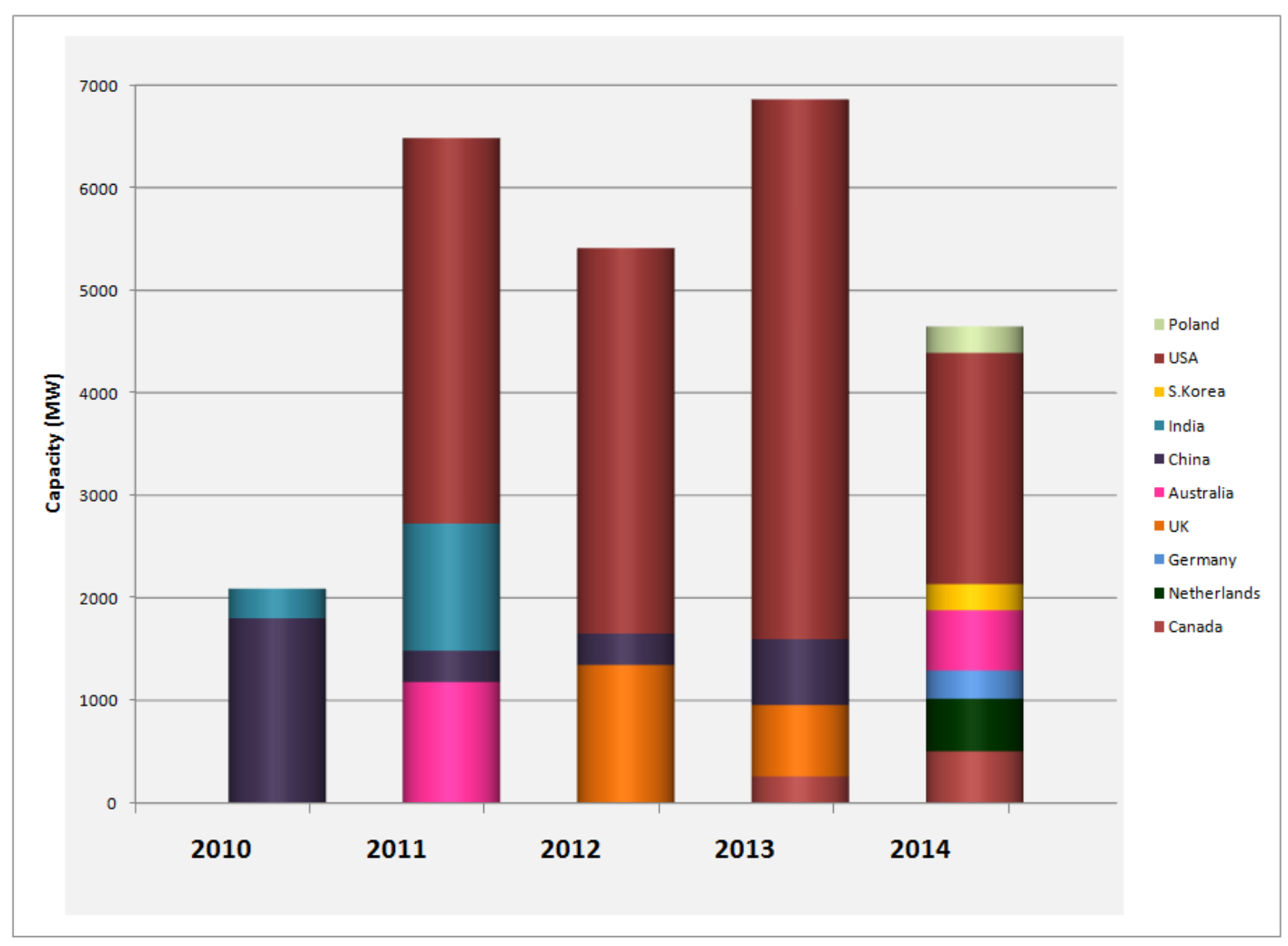

Figure IV-2. Global IGCC project pipeline [Emerging Energy Research]

The financial stakeholders concerns include:

- Concerned with the current lack of sufficient business incentives but encouraged by strong indication of an imminent carbon policy.

- CCS Financing Options: Emissions trading, Mandating CCS, Energy regulatory approval of the higher cost, and CCS Trust Fund.

- Adoption of Carbon Principles: More stringent requirements for investment in coal-based generating facilities. Provides a procedure to analyze the dispatch order of this additional coal-fired power generation and its economic performance under various scenarios.

- Approval of CCS project methodology under Clean Development Mechanism will be important.

Although international governments have made some progress in developing suitable CCS policy frameworks in an effort to promote early demonstration of CCS projects, there are still many issues that need to be fully addressed prior to wide-scale deployment of the CCS in the power generation and industrial sectors. On the transportation front, $\mathrm{CO}_{2}$ pipeline regulations will be required to increase coordination across state and national borders to eliminate the barrier of inconsistencies in pipeline access and $\mathrm{CO}_{2}$ purity requirements. Another deployment barrier 
is the lack of clarity of the property rights associated with $\mathrm{CO}_{2}$ storage, particularly including access rights and ownership of storage reservoirs. The insurance stakeholders concerns include:

- Long-term indemnification of storage liability has yet to be resolved.

- Need clarity on property rights associated with $\mathrm{CO}_{2}$ storage including access rights and pore space ownership.

Currently traditional insurance companies are not offering coverage in the event of storage catastrophe. The key issue with using traditional insurance products is the long-term position that would potentially be required. Insurance companies are unable to fix a long-term premium at the outset of a project given the lack of available data, such as an unexpected catastrophic loss of a carbon dioxide reservoir which could immediately impact the operating expenditures of all geological sequestration projects. [Engleman, 2004] However, without this critical issue resolved, the majority of the utility companies with whom Visage Energy has had extensive discussions are extremely reticent to become involved in large pilot projects deploying capture technologies.

- Ambiguities must be resolved regarding pore space ownership and the relation between the surface and mineral estate. A process for owners and project developers to transfer/lease the necessary subsurface pore space property rights for a CCS project is also an issue.

- The long-term ownership of and liability for the stored $\mathrm{CO}_{2}$ also are potential barriers for CCS development which may be addressed by transferring liability to the state or by federal or private indemnification schemes.

At the federal level, a bill has been introduced and referred to committee that would establish a carbon-storage-stewardship trust fund funded by fees from operators to ensure compensation for potential damages relating to the geologic storage of $\mathrm{CO}_{2}$. One private insurer is making short-term insurance policies available.

Successful deployment of CCS technologies hinges not only on the economics of the process but also on the ability to create a regulatory environment that encourages investment in technologies and rewards early adopters of the technologies. Visage Energy would assert that the technology development is not a major impediment to the wide-scale deployment of CCS in California.

- Without a price on carbon, investor interest in CCS worldwide has been limited to outside niche applications. Policies that place a price on GHG emissions, such as a cap and trade, would discourage investments in 
traditional fossil-fuel use and spur investments in a range of clean energy technologies, including CCS.

- Funding for Initial CCS Projects: To foster the initial, large-scale CCS projects needed to fully demonstrate the technology, the government can offer financial incentives for CCS. For example, the government could create a trust fund that could competitively award money to CCS projects to help them overcome financing hurdles. [Pena and Rubin 2008] A study prepared for the Pew Center found that coal power plant owners would require between $\$ 300$ million and $\$ 650$ million in funds to cover the investments in equipment and lost capacity necessary for the initial commercial-scale deployments of CCS, depending on the plant type and whether plants are newly built with CCS or retrofit.

- Mandating GHG Emission Rates: Policymakers could rely on performance standards to drive CCS deployment by enacting new regulations that require CCS via a new source performance standard for power plants or a low-carbon performance standard.

\section{PBI COMMERCIALIZATION PATHWAY SCHEDULE}

The maturation of new technologies for energy applications is different than the process for other technologies, i.e., software. Energy-related technologies are required to be highly reliable. They have traditionally transitioned through a series of discrete steps as depicted in Table IV-2.

This development process is crucial since often heat, thermal, and mass transport considerations can change dramatically during scale-up of the unit. Pilot-scale testing is a crucial step since it is the first time the system is exposed to an actual power-plant environment.

It is important that researchers consider the needs of end-users early in the development process, e.g., Proof-of-Concept Stage, since many designs made at this early phase could impact the ability of the system to operate successfully in a power plant environment (Pilot-scale and beyond). This project has specifically included representatives from utilities and other end-users (e.g., Southern Company and BP) in order to ensure that their needs are included in the design of the PBI Membrane, module, and skid. This should facilitate and hasten the transition of the technology to Pilot-scale and beyond.

The PBI project is currently in the Proof-of-Concept (Applied) Research Stage. During this stage the PBI module and skid will be tested in a simulated syngas environment on-site at SRI. Successful completion of this stage will enable the module and skid to be ready for pilot testing. 
Table IV-2. Typical Stages of Maturation for Energy Technologies

\begin{tabular}{|c|c|c|c|c|}
\hline & $\begin{array}{c}\text { Proof-of-Concept } \\
\text { (Fundamental) Research }\end{array}$ & $\begin{array}{c}\text { Post Proof-of-Concept } \\
\text { Research } \\
\text { (Current PBI Stage) }\end{array}$ & Pilot-scale & Demonstration \\
\hline $\begin{array}{l}\text { Type of Work } \\
\text { performed }\end{array}$ & $\begin{array}{l}\text { Bench scale batch-type } \\
\text { experimentation and } \\
\text { conceptual studies at the } \\
\text { fundamental science level }\end{array}$ & Bench/Laboratory Scale & Field testing & $\begin{array}{l}\text { Construction of a to } \\
\text { scale carbon control } \\
\text { plant }\end{array}$ \\
\hline Study Size & No working model & $0.01-0.1 \mathrm{MW}$ & $1-5 \mathrm{MW}$ & $100-250 \mathrm{MW}$ \\
\hline $\begin{array}{l}\text { Required } \\
\text { Funding }\end{array}$ & $\$ 0.3-\$ 1 \mathrm{MM}$ & $\$ 1-\$ 5$ MM & $\$ 15-\$ 40 \mathrm{MM}$ & $+\$ 100 \mathrm{MM}$ \\
\hline $\begin{array}{l}\text { Funding } \\
\text { Period }\end{array}$ & $6-7$ years & 3 - 5 years & $3-4$ years & $3-7$ years \\
\hline
\end{tabular}

The National Carbon Capture Center (NCCC) has been targeted as a potential site for pilotscale testing [National Carbon Capture Center website]. Southern Company is the contractor for this DOE center and is a member of the PBI research team. The test would focus only on the capture of $\mathrm{CO}_{2}$ (i.e., no storage or use for enhanced oil recovery) and would use a slipstream for input into the module. It is especially important that the NCCC has the capability to utilize a variety of fuel sources, e.g., biomass and bituminous, subbituminous, and lignite coals. It is anticipated that multiple modules would be produced in order to evaluate in parallel a variety of different types of coal, i.e., bituminous, subbituminous, and lignite coal.

Because of their expertise and geographic location relative to bituminous sources, NETL and its university partners (West Virginia University, University of Pittsburgh, Carnegie Mellon University, Virginia Polytechnic Institute and State University, and Penn State University) would be included in the pilot-scale evaluation. The University of Montana and the Energy and Environmental Research Center [Undeerc website] would be engaged in the evaluation of subbituminous and lignite coals. Of special interest would be subbituminous coal sourced from the Powder River Basin. Petroleum coke ("Pet Coke") would also be tested since it is one of the fuel sources BP has expressed interest in evaluating. Pet Coke is one of the fuel sources for the Hydrogen Energy Project in California [Hydrogen Energy website]. 
It is also critical that PBI systems be evaluated internationally as well. These tests should also be conducted in parallel with tests in the US. Some candidate sites are in Canada, Australia, China, and Europe. The province of Alberta would be an important test site due to the near-zero emission plant being designed by EPCOR and Siemens. [Carbon Capture center website]. The Alberta Energy Research Institute and National Resources Canada would be research partners for this effort. The Wandoan Project is a joint effort between Queensland and GE is planned to be an IGCC plant equipped with $90 \%$ carbon capture [Reliable Plant website]. In addition, the ZeroGen project offers another IGCC capture plant in Australia [MHI website]. CSIRO could be a research partner to evaluate a PBI system in conjunction with this effort. The existing cooperation between NETL, PNNL, and the Chinese Academy of Sciences could form a platform for a pilot-scale evaluation at the Research Center for Energy and Power at Lianyungang [West Virginia University website]. Potential sites in Europe include the Hatfield Plant in Stainforth, UK. This plant, being developed by Powerfuel Power, UK, has been selected as a CCS demonstration plant for funding under the EU Energy Recovery Programme [H2 to IGCC website].

This parallel approach at the pilot-scale leads to the ability to rapidly create a worldwide knowledge base for the PBI technology and should hasten the transition from Pilot to Demonstration (Demo), to Deployment. One potential schedule is depicted in IV-3. Pilot studies begin in the US. The information from this initial study enables the implementation of a series of simultaneous pilots in all the major markets. As part of this international effort, A Design of Experiments Approach is developed in 2011 to ensure that the information collected can be shared and statistically evaluated. Existing international relationships developed by the Department of Energy and NETL facilitate the international cooperation. 
Table IV-3. Potential Commercialization Pathway Schedule

\begin{tabular}{|c|c|c|c|c|c|c|c|c|c|c|}
\hline China & & & & e & e & py & py & py & py & py \\
\hline Europe & & & & & e & e & e & py & py & py \\
\hline Australia & & & & & e & e & e & py & py & py \\
\hline Canada & & & & e & e & e & py & py & py \\
\hline US & & & & e & e & e & py & py & py & py \\
\hline & 2011 & 2012 & 2013 & 2014 & 2015 & 2016 & 2017 & 2018 & 2019 & 2020 \\
\hline & & & & & & & & & & \\
\hline
\end{tabular}

P=Pilot, De=Demo, Dpy=Deployment

The results from the multivariable study are evaluated in 2013 and enable the initiation of a demonstration study in both the US and China in 2014. Demonstration studies are again coordinated on an international basis and designed so that performance and statistics can be shared and analyzed. The experience gained in the US and China will enable the initiation of demonstrations in the other regions by 2015. Full deployment of the technology begins in 2016 in China, 2017 in the US. By 2018 the PBI technology has been deployed global for $\mathrm{CO}_{2}$ capture from IGCC plants.

\section{RISK MITIGATION FOR COMMERCIALIZATION PATHWAY}

There are a number of risks technical/business risks that could impact the aggressive commercialization pathway discussed earlier. The risks and actions that need to be taken to mitigate these risks are outlined in Table IV-4. 
Table IV-4. Risks to the Implementation of the Commercialization Pathway and Actions to Mitigate Risks

\begin{tabular}{|l|l|}
\hline \multicolumn{1}{|c|}{ Risk } & \multicolumn{1}{|c|}{ Mitigation } \\
\hline $\begin{array}{l}\text { Limited worldwide PBI production } \\
\text { capacity requires new PBI production } \\
\text { plants }\end{array}$ & $\begin{array}{l}\text { PBI supplier becomes member of } \\
\text { development team and provides input on } \\
\text { commercialization pathway. PBI supplier } \\
\text { provides plan to support pathway. }\end{array}$ \\
\hline $\begin{array}{l}\text { PBI hollow fiber production capacity } \\
\text { requires significant increase in capacity }\end{array}$ & $\begin{array}{l}\text { PBI hollow fiber supplier is currently team } \\
\text { member. Supplier provides feedback on } \\
\text { pathway and plan for capacity increase to } \\
\text { support pathway. }\end{array}$ \\
\hline $\begin{array}{l}\text { Geographic variations in fuel supply result } \\
\text { in large variations in system performance. }\end{array}$ & $\begin{array}{l}\text { Parallel pilot testing and a Design of } \\
\text { Experiment Approach provide a means to } \\
\text { quickly identify sources of variation and } \\
\text { potential solutions. International } \\
\text { cooperation provides the intellectual capital } \\
\text { to solve issues. }\end{array}$ \\
\hline $\begin{array}{l}\text { Regulatory requirements and/or public } \\
\text { opinion extend approval times and hence } \\
\text { project time lines }\end{array}$ & $\begin{array}{l}\text { Parallel testing in a variety of international } \\
\text { markets with a range of regulatory and } \\
\text { public opinion processes increases } \\
\text { probability that projects move forward in at } \\
\text { least one region. }\end{array}$ \\
\hline $\begin{array}{l}\text { Increase in worldwide demand for ancillary } \\
\text { membrane equipment drives up capital } \\
\text { costs }\end{array}$ & $\begin{array}{l}\text { Increase in production capacity of PBI } \\
\text { polymer and hollow fiber should help } \\
\text { reduce cost of fiber and provide some } \\
\text { offset to other potential cost increases. } \\
\text { Competition from other technologies will } \\
\text { also limit increases in costs to the end-user. } \\
\text { parallel evaluations provide a means to } \\
\text { identify and resolve issues. }\end{array}$ \\
\hline
\end{tabular}

PBI was invented in late 1940's and is manufactured for the last 30 years. The initial patents have expired. One of the risks of a large-scale demand for the PBI capture system is the limited worldwide supply of the PBI polymer. PBI polymer is currently produced in any significant commercial quantities by one supplier--PBI Performance Products. PBI Performance Products is located in Charlotte, North Carolina and reported to have 70 employees and have annual sales of approximately $\$ 9,400,000$. [Manta website]. Using the targeted performance (GPU and selectivity) and current design for the membrane module, it is estimated that for a $250 \mathrm{MW}$ 
IGCC plant approximately 1,440 modules would be required. Fabrication of these modules would require nearly 54,000 pounds of PBI polymer.

This amount of polymer, while insignificant for most polymers, is estimated to represent $30 \%$ of the current production capacity. Despite this fact, the polymer industry typically constructs plants that can produce in excess of 1 million pounds per year. Therefore, it is predicted that the required increase in capacity of polymer production as the PBI system transitions through the commercialization pathway is possible. With this increase in PBI demand, it is reasonable to deduce that many companies would be interested in entering the PBI production industry. It does highlight the importance of coordinating the commercialization pathway and timeline with the polymer supplier so that they plan capacity increases in order to meet the projected increases in demand.

A similar risk involves the supply of PBI hollow fiber. There is one supplier of PBI hollow fiber--Whitefox Technologies. Using the targeted performance (GPU and selectivity) and current design for the membrane module, it is estimated that for a $250 \mathrm{MW} \mathrm{IGCC} \mathrm{plant,}$ approximately $29,000 \mathrm{~km}$ of fiber would be required (1440 modules). This requires a significant scale-up in capacity for the supplier. Whitefox Technologies is currently a member of the team and is engaged in the planning for the commercialization of the PBI membrane system.

It is expected that the fuel source will vary based on the geographic location of the plant. In other systems, process performance has been shown to be impacted by variations in the fuel source. Similarly differences in gasifier design may also impact the capture process. In order to mitigate these risks, a Design of Experiments Approach should facilitate identifying any variations in performances that could be due to fuel source. Statistical analysis, pooling of data, and international cooperation will assist in identifying and resolving issues.

Other factors that could impact the timeline are regulatory and political in nature. For example, delays in permitting or changes in public opinion could impede the progression of projects. This risk is mitigated due to the fact that the regulatory environment and the stance and impact of public opinion vary across these regions.

Rapidly deployment could also result in a rapid rise in the cost of ancillary equipment. Compressors, fittings, valves, and other related items could rise in cost due to increased demand. It is expected that this rise would be transitory in nature and would be limited by the fact that other technology options would still be available to the designer. It is expected that some of these increases might at least be partially offset by a reduction in cost of the raw polymer and hollow fibers as volume increases. 
The technical progress in the development of the substrate and selective layer has resulted in hollow fibers that have performance (GPU and selectivity) close to the target goals. The process simulation has demonstrated that achieving the target membrane performance goals enables the overall process economics to approach the DOE target of less than $10 \%$ increase in COE. Preliminary work has begun to outline the membrane module configuration, skid, and control system.

The global nature of carbon capture coupled with the international relationships developed by the Department of Energy and NETL have created an environment that facilitates international cooperation. This enables pilot and demonstration projects to be performed in parallel. Preplanning on a global scale between research institutes coupled with experimental design and data sharing should accelerate the commercialization process. This approach mitigates the risks listed below and enables an efficient and effective method to enable PBI capture systems to be transitioned into full deployment.

Job creation and increased regional economic development will also be additional advantages of the deployment of PBI capture systems. The PBI polymer production industry, located in the southeastern US, is predicted to undergo explosive growth with the need to increase its capacity by over $7 \mathrm{x}$ by 2020 . This growth could result in nearly 400 new jobs being created. PBI hollow fiber production will also undergo a similar expansion. In addition, the Gulf Coast region of the US should be positively impacted due to the need for EDC firms to fabricate and install PBI membrane modules and control systems. 


\section{CONCLUSIONS AND RECOMMENDATIONS}

Based on the experimental and analytical results obtained in this project, we reach the following conclusions:

- PBI-based hollow fibers have been fabricated at kilometer lengths and bundled as modules at a bench-scale level for the separation of $\mathrm{CO}_{2}$ from $\mathrm{H}_{2}$ at high temperatures and pressures.

- Long term stability of these fibers has been demonstrated with a relatively high $\mathrm{H}_{2} / \mathrm{CO}_{2}$ selectivity (35 to 50 ) and $\mathrm{H}_{2}$ permeance ( $80 \mathrm{GPU}$ ) at temperatures exceeding $225^{\circ} \mathrm{C}$.

- The experience gained in this project is ready for transfer to the industry to demonstrate the separation process at pilot- and commercial-scale levels.

- Membrane performance simulations and systems analysis of an IGCC system incorporating a PBI hollow fiber membrane modules have demonstrated that the cost of electricity for $\mathrm{CO}_{2}$ capture $(<10 \%)$ using such a high temperature separator. When the cost of transporting, storing, and monitoring the $\mathrm{CO}_{2}$ is accounted for, the increase in the COE is only $14.4 \%$, approaching the DoE goal.

- A commercialization pathway schedule was developed based on the on the technical progress and expected time line for availability of modules for pilot testing.

The following recommendations are made:

- The development of the PBI hollow fiber fabrication should be continued at a pilotscale level using commercially appropriate equipment.

- The PBI hollow fibers shall be assembled into modules and made into a system that is capable of handling gas streams equivalent of a 0.25 MWe IGCC system.

- The system should be tested using the gas stream from an operating gasifier for extended period of time to validate the long-term stability of PBI membranes.

- System level studies should be continued to update the cost of $\mathrm{CO}_{2}$ capture using the PBI membrane systems. 


\section{REFERENCES}

Anand, M.; Langsam, M.; Rao, M. B.; Sircar, S., Journal of Membrane Science 1997, 123, 17-25.

Armor, J. N., Journal of Membrane Science 1998, 147, 217-233.

B.D. Freeman, Macromolecules 1999, 32(2), 375-380.

Berchtold, K.A.; J.S. Young; K.W. Dudeck; J. Acquaviva; F. Onorato; S.D. Hopkins, Novel PolymericMetallic Composite Membranes for $\mathrm{CO}_{2}$ Separations at Elevated Temperatures, Fifth Annual Conference on Carbon Capture \& Sequestration, May 2006.

Carbon capture journal web edition

http://www.carboncapturejournal.com/displaynews.php?NewsID=263\&PHPSESSID=hn7lh6bj98j17ktcjd $\underline{1 \text { lpavn06 }}$

Chiou , J.S, J.W. Barlow, D.R. Paul, Journal of Applied Polymer Science 1985, 30, 2633-2642.

Ciferno, Jared; Howard McIIverid, Gary Stiegel, Carbon Sequestration Systems Analysis Technical Note, No. 5, National Energy Technology Laboratory, July 2005.

D.W. Breck, Zeolite Molecular Sieves: Structure, Chemistry, and Use; John Wiley and Sons: New York, 1974; pp 593-724.

Emerging Energy Research Gasification Market Analysis

Greenberg, A.R., S. Brahmandam, K.A. Berchtold, J.S. Young; et al., "Mechanical and Transport Behavior of Polybenzimidazole (PBI) Dense Films Used for Elevated-Temperature Gas Separation," Proceedings of the 5th Annual Carbon Sequestration Meeting, NETL (2006).

H2-IGCC website www.h2-igcc.eu/Pdf/ICEPAG-Final.pdf

Hagg, M.-B., Separation and Purification Methods 1998, 27, 51-168.

Hydrogen energy website http://www.hydrogenenergycalifornia.com/

Khare, Vivek P. and Alan R. Greenberg, North American Membrane Society Annual Meeting Proceedings 2004.

Kita, H.; Inada, T.; Tanaka, K.; Okamoto, K., Journal of Membrane Science 1994, 87, 139-147

Klara, Julianne, et al. Cost and Performance Baseline for Fossil Energy Plants, DOE/NETL-2007/1281.

Koros, W. J.; Fleming, G. K., Journal of Membrane Science 1993, 83, 1-80.

Koros, W. J.; Mahajan, R., Journal of Membrane Science 2000, 175, 181-196.

L.M. Robeson, W.F. Burgoyne, M. Langsam, A.C. Savoca, C.F. Tien, Polymer 1994, 35(23), 4970-4978.

Larbot, A.; Fabre, J. P.; Guizard, C.; Cot, L., Journal of Membrane Science 1988, 39, 203-212.

Lawson, K.W., M.S. Hall, D.R. Lloyd, Journal of Membrane Science 1995, 101, 99-108.

Lee, D., Journal of Membrane Science 2002, 210, 291.

Lin, Y. S., Separation and Purification Technology 2001, 25, 39-55.

Liu, Y.; Pan, C.; Ding, M.; Xu, J., European Polymer Journal 1999, 35, 1739-1741.

Mahajan, R.; Koros, W. J., Polymer Engineering and Science 2002, 42, 1420-143

Manta website http://www.manta.com/c/mm750v6/pbi-performance-produst-inc 
Marano, John; Jared Ciferno, Membrane Selection and Placement for Optimal $\mathrm{CO}_{2}$ Capture from IGCC Power Plants, Fifth Annual Conference on Carbon Capture \& Sequestration, May 2006.

MHI website http://www.mhi.co.jp/en/news/story/090622english.html

National Carbon Capture website http://www.nationalcarboncapturecenter.com/

Pena, N. and E. Rubin. A Trust Fund Approach to Accelerating Deployment of CCS: Options and Considerations. Prepared for the Pew Center on Global Climate Change, 2008

Prabhu, A.; Oyama, S., Journal of Membrane Science 2000, 176, 233-248.

R. Engleman, Geological Carbon Dioxide Sequestration: Insurance and Legal Perspectives on Liability, September 2004

R.C. Reid, J.M. Prausnitz, B.E. Poling, The Properties of Gases and Liquids, 4th ed.; McGraw-Hill: New York, 1987; pp 29-73, 656-732.

Rao, M. B.; Sircar, S., Gas Separation and Purification 1993, 7.

Rao, M. B.; Sircar, S., Journal of Membrane Science 1993, 85, 253-264.

Reliable plant website http://www.reliableplant.com/Read/19145/ge-energy-proposes-world-leading-igcc-plantfor-australia

Rezac, M. E.; Koros, W. J., Journal of Applied Polymer Science 1992, 46, 1927-1938.

Robeson, L. M., Journal of Membrane Science 1991, 62, 165-185.

Staudt-Bickel, C.; Koros, W. J., Journal of Membrane Science 1999, 155, 145-154.

Tuan, V. A.; Falconer, J. L.; Noble, R. D., Microporous and Mesoporous Materials 2000, 41, 269-280.

Undeerc website http://www.undeerc.org/

Ventyx- Velocity Suite and 2002-2005 data- Previous NETL Tracking New Coal-Fired Power Plants Reports2007 \& 2009 data

Vu, D. Q.; Koros, W. J., Industrial and Engineering Chemistry Research 2002, 41, 367-380.

Wang, Sam, Alberta Research Council, Report to Asia Pacific Economic Cooperation)

West Virginia website www.nrcce.wvu.edu/cleanenergy/docs/20-Xiao.pdf 


\title{
APPENDIX A
}

\section{INITIAL PBI HOLLOW FIBER DEVELOPMENT}

\author{
Hollow Fiber Development at WhiteFox Technologies
}

Morphology and Permeation Characterization at Los Alamos National Laboratories

Morphology and Permeation Characterization at SRI International 


\section{INTRODUCTION}

WhiteFox Technologies Ltd. (WFX), located in Oregon, Canada, and the United Kingdom, has expertise in the fabrication of membranes for ethanol dehydration. WFX was launching new products for the purification and dehydration of ethanol. Since its incorporation, WFX has expertise in the following areas:

- Dehydrated ethanol-water mixtures to produce industrial and high grade ethanol;

- Formed strategic alliances with research organizations, suppliers, engineering firms and ethanol producers;

- Identified new membrane applications in the solvents market; and

- Optimized its technology to reduce solvent production costs.

WFX has independent verification that its membrane technology is more effective than the current industry standard, both from continuous industrial-scale production of potable ethanol and through sophisticated computer simulations in which its membrane modules have been substituted for molecular sieves in existing ethanol production plants. WFX licensed a technology that was originally developed by Bend Research for the production of PBI-based hollow fibers. They also have the capability to fabricate membrane modules. The initial development of the PBI hollow fibers was made at the WFX facilities.

The fibers produced at the WFX were characterized for its morphology and permeation characteristics. Morphology characterization using scanning electron microscopy (SEM) and Xray micro-tomography were performed at Los Alamos National Laboratory (LANL). In addition to morphology characterization using SEM, permeation characteristics were performed at SRI.

Early attempts at the WFX in the spinning of PBI fibers produced fibers that were largely homogeneous in morphology but consisted primarily of spherical agglomerates that were unstable to thermal fluctuations (Figure A-1a). Through the course of executing designed changes in the process parameters, a more stable underlying morphology that is hexagonal in nature was achieved (Figure A-1b) although structural homogeneity and integrity throughout the substrate fiber need to be optimized. Some examples of early substrate "homogeneity" issues are presented in Figure A-2. 


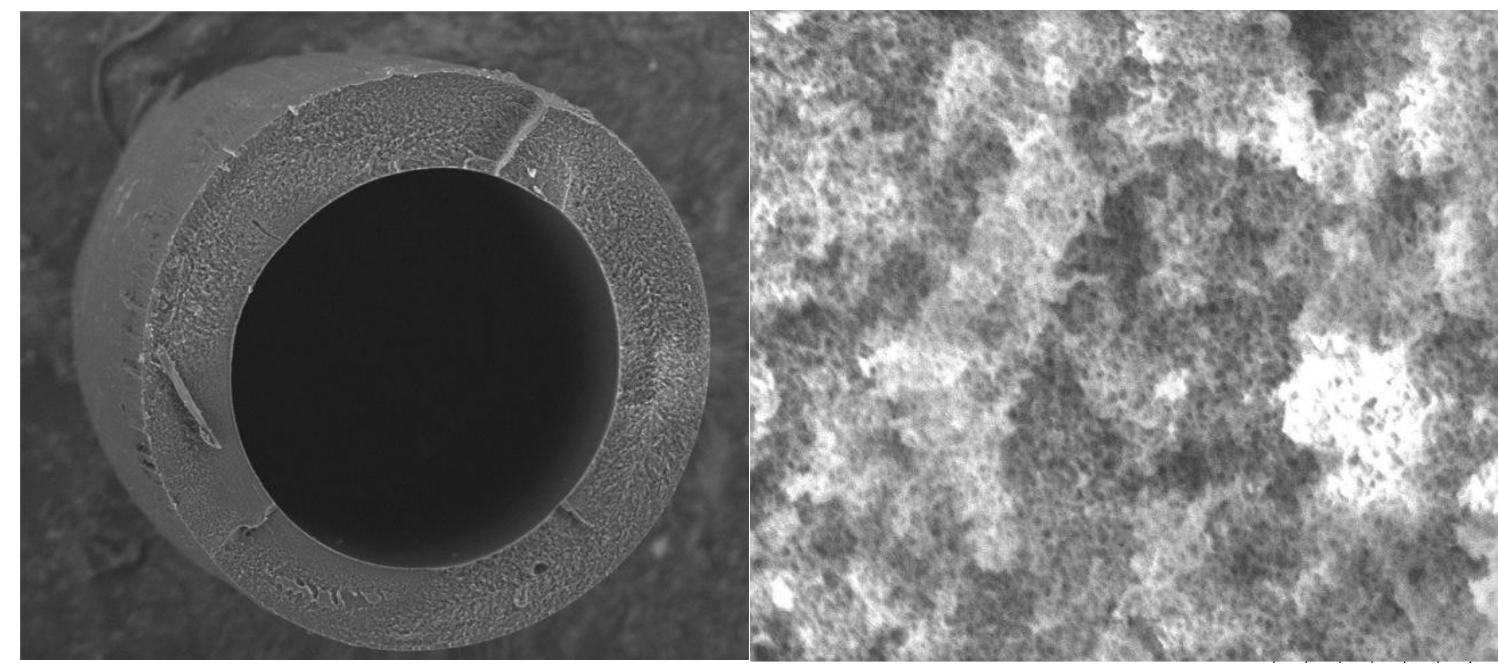

(a)

(b)

Figure A-1. SEM of early stage fiber morphologies.

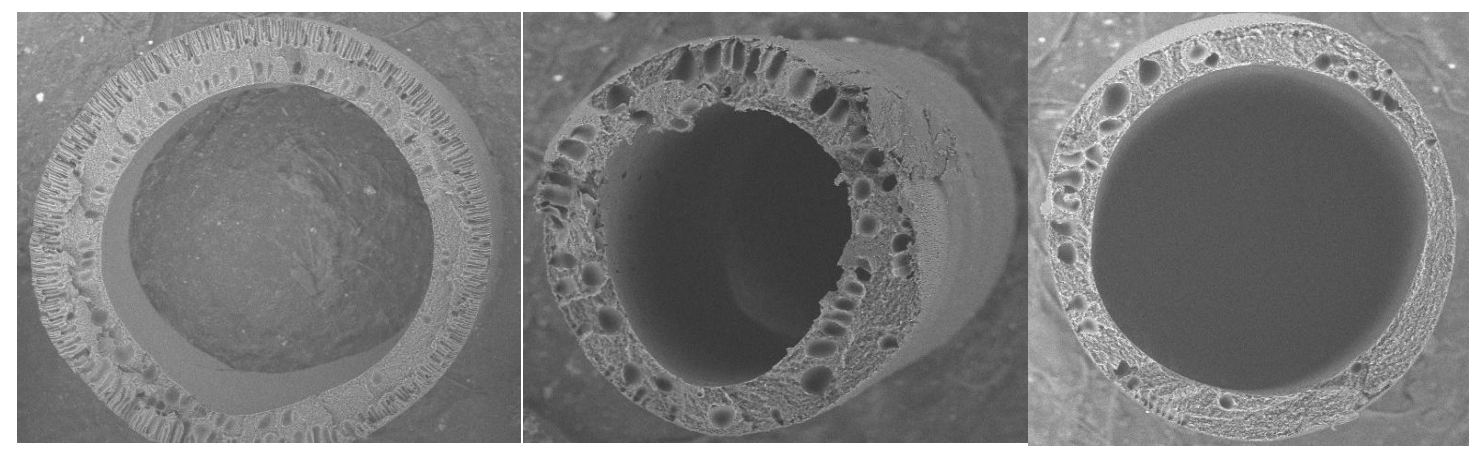

Figure A-2. SEM of examples of early substrate "homogeneity" issues.

\section{MULTI-BORE HOLLOW FIBER FABRICATION}

Initially, WFX focused on the fabrication multi-bore fibers. The multi-bore configuration provides an increase in the selective layer area density over that of single-bore fiber for given fiber diameter. As an approximation, for an equivalent fiber outer diameter and length, the selective area is more than doubled by transitioning from a single- to a multi-bore ( 7 bore) configuration. The multi-bore configuration also provides a platform with enhanced mechanical stability and durability. This configuration also reduces the extent of potting (sealing) area per fiber reducing the probability of gas leakage through seal. Figure A-3 shows the cross section of two multi-bore fibers with 2 and $4 \mathrm{~mm}$ OD each. 


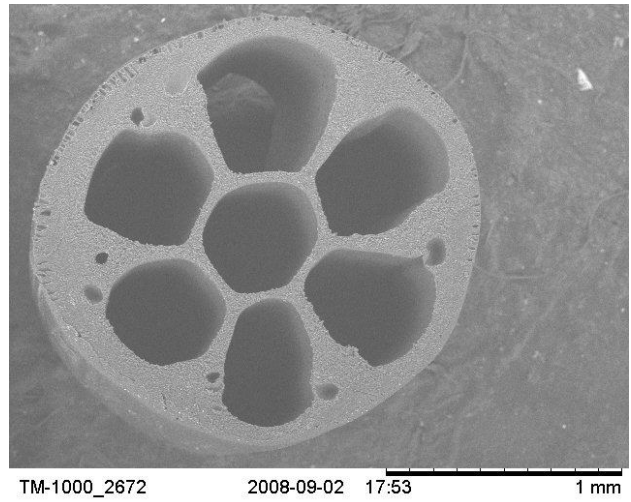

(a)

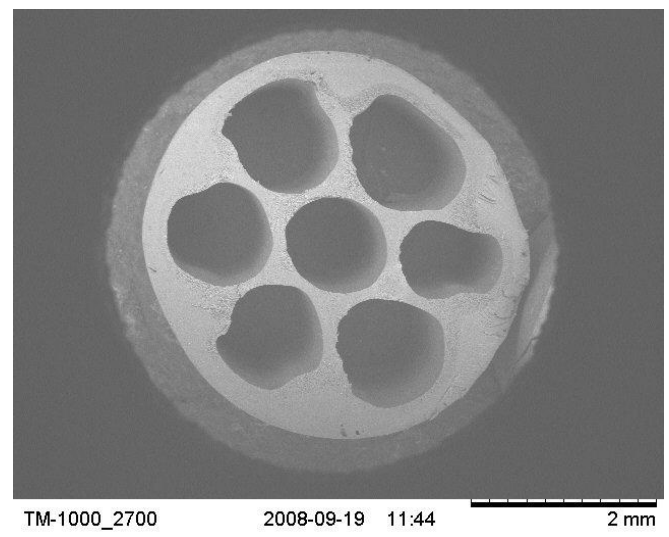

(b)

Figure A-3. SEMs of PBI-based multi-bore hollow fibers with varied outer diameters and bore diameters: (A) 7-bore, OD: $2 \mathrm{~mm}$ (B) 7-bore, OD: $4.2 \mathrm{~mm}$.

Morphology of the Multi-bore Hollow Fibers: LANL examined the integrity of the interlumen walls using optical microscopy, SEM, and 3D X-ray-computed micro-tomography. These evaluations indicated the presence of continuous, porous inter-lumen walls. The characterized fiber morphology features include the presence of macro voids, inhomogeneities in the graded porous structure, pore interconnectivity of the support, continuity of the selective layer, and continuity of the support structure at the outer fiber. Examples of some these features are presented in Figures A-4 and A-5.

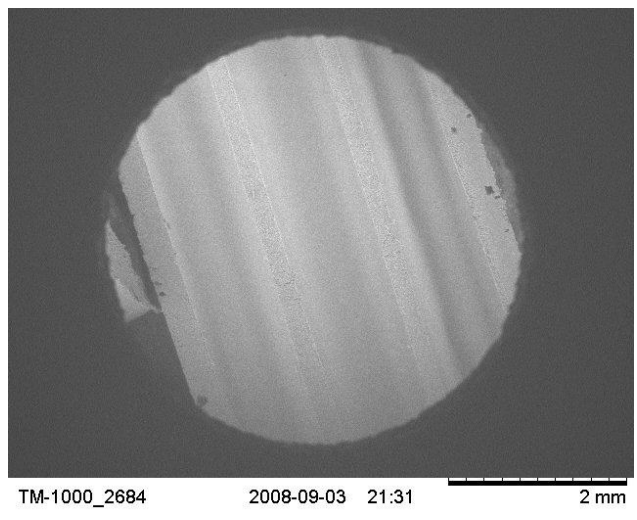

(a)

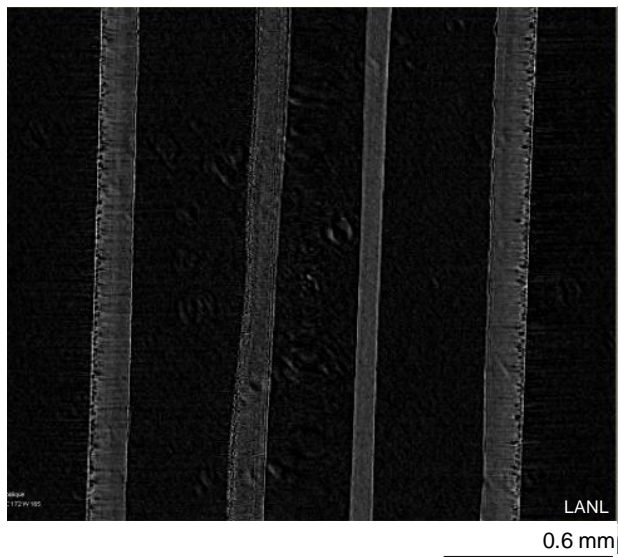

(b)

Figure A-4. SEM (A) and 3D x-ray-computed micro-tomography (B)cross-sections of interlumen walls. 


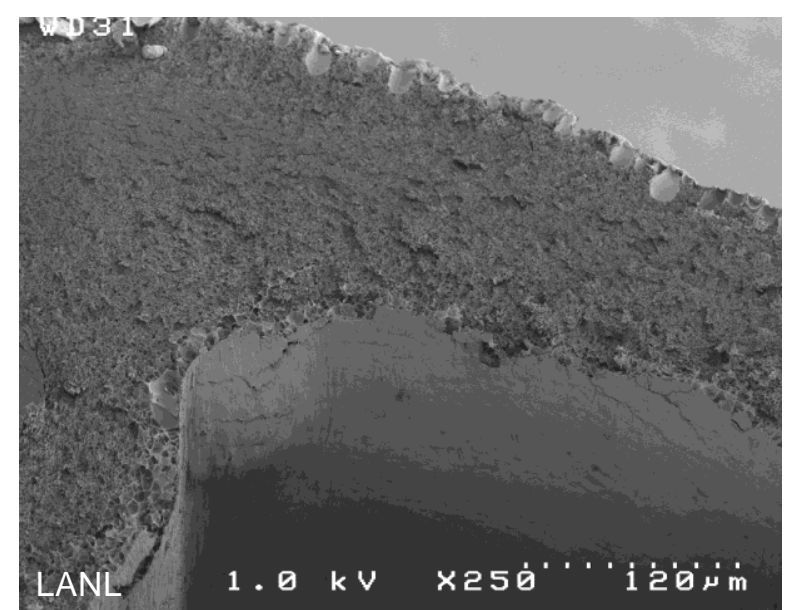

Figure A-5. Porous structure leading to a non-optimized "dense" layer at the inner (lumen) surface of the multi-bore fiber.

SRI performed additional characterization using SEM on a set of multi-bore hollow fibers received from Whitefox in October 2008. Since these fibers are from the initial attempts at fabricating a multi-bore geometry and many process parameters were not yet optimized. The separation layer area was not well defined, and the gas may have to diffuse through a number of dense walls. The fibers were tested to be water-tight at the factory. At SRI, the as-received fibers were washed with ethanol to remove any polyvinyl pyrrolidone (PVP) remaining from the fiber spinning operation.

The fibers had a nominal OD of $1.5 \mathrm{~mm}$ and had 7 internal bores, six on the periphery and one in the center (Figure A-6). The internal bores were generally circular, although the shape was distorted in some cases. The internal bore diameters were in the range 0.2 to $0.3 \mathrm{~mm}$. The wall thickness between the bore also varied from $\sim 0.1$ to $\sim 0.2 \mathrm{~mm}$. The average length of each fiber, as-received, was $25 \mathrm{~cm}$. The fibers were examined with SEM, surface area and pore size analysis using the BET technique, and with gas flow measurements. The results of these tests are described below.

The physical morphology of both the surface and cross section of the fibers were examined using SEM. A magnified image of the cross section showed that the walls were porous with an apparently dense skin at the outer and inner surfaces (Figures A-7 and A-8). Several oblong voids ( 5 to $10 \mu \mathrm{m}$ in size) were also observed beneath both the external and internal skin layers.

High magnification examination showed that the interior walls shows were highly porous and that the pores were generally 1 to $5 \mu \mathrm{m}$ in size (A-9). In the areas that we examined, it appeared that the pores may not have been interconnected. However, it is possible that the nanometer-size necks may connect the micron-size pores, thereby providing a path for gas flow. 


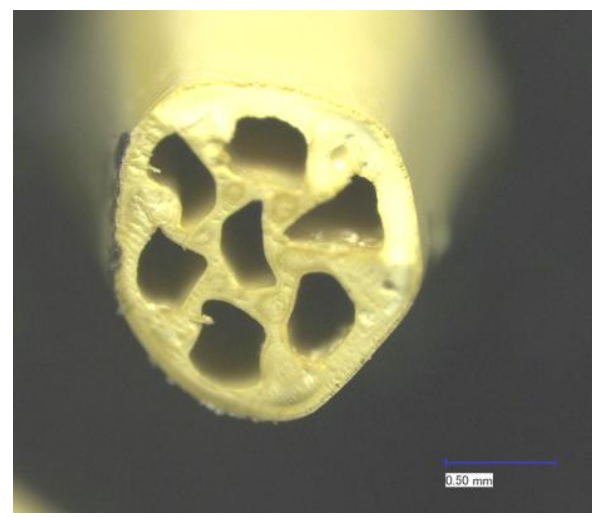

Figure A-6. The cross section of PBI multi-bore fiber WF-MB-102208.

The external skin of the membrane was also examined with SEM. The SEM images also showed that the external skin layer was very thin $(<1 \mu \mathrm{m})$ and contained many micro-cracks. At a relatively moderate magnification $(500 \mathrm{X})$, the surface appeared to be covered with many depressions (Figure A-10). These depressions did not appear to be open pores. Figure A-11 illustrates that, at a very high magnification $(100,000 \mathrm{X})$, the surface had a mud-crack appearance, and the cracks may allow the gas to penetrate the skin layer. The width of the crack appeared to be about 10 to $20 \mathrm{~nm}$.

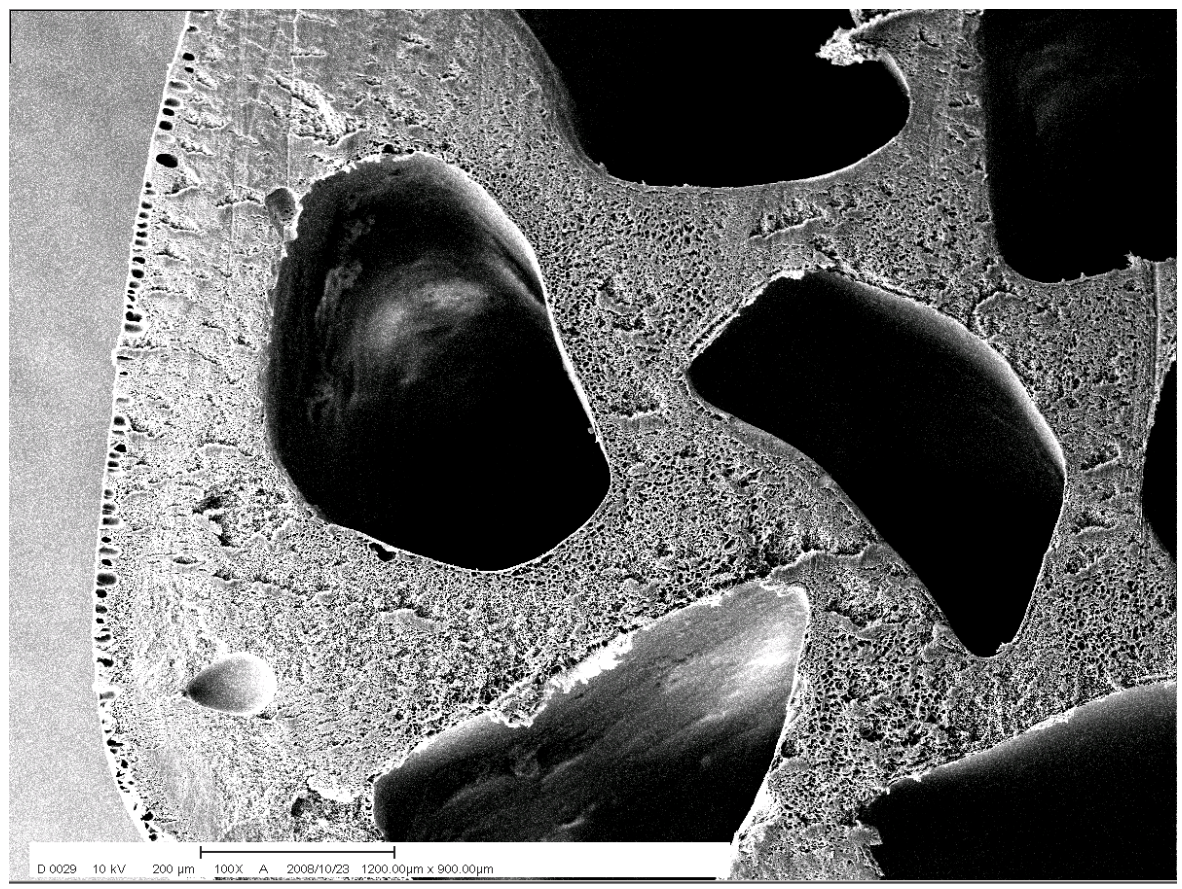

Figure A-7. The cross section of the PBI fiber illustrating the porous walls. 


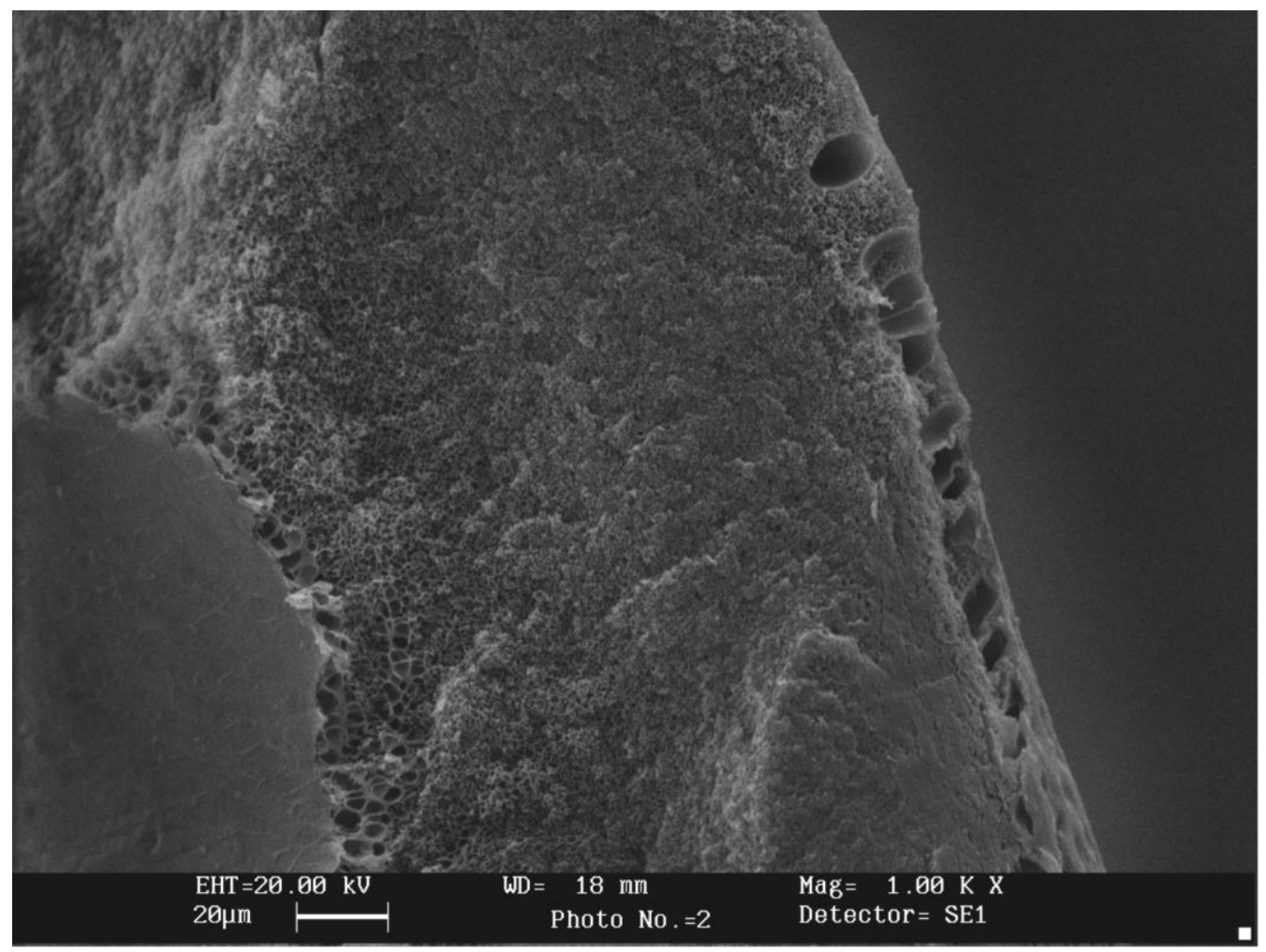

Figure A-8. The cross section of a PBI fiber illustrating porous walls and external skin layer.

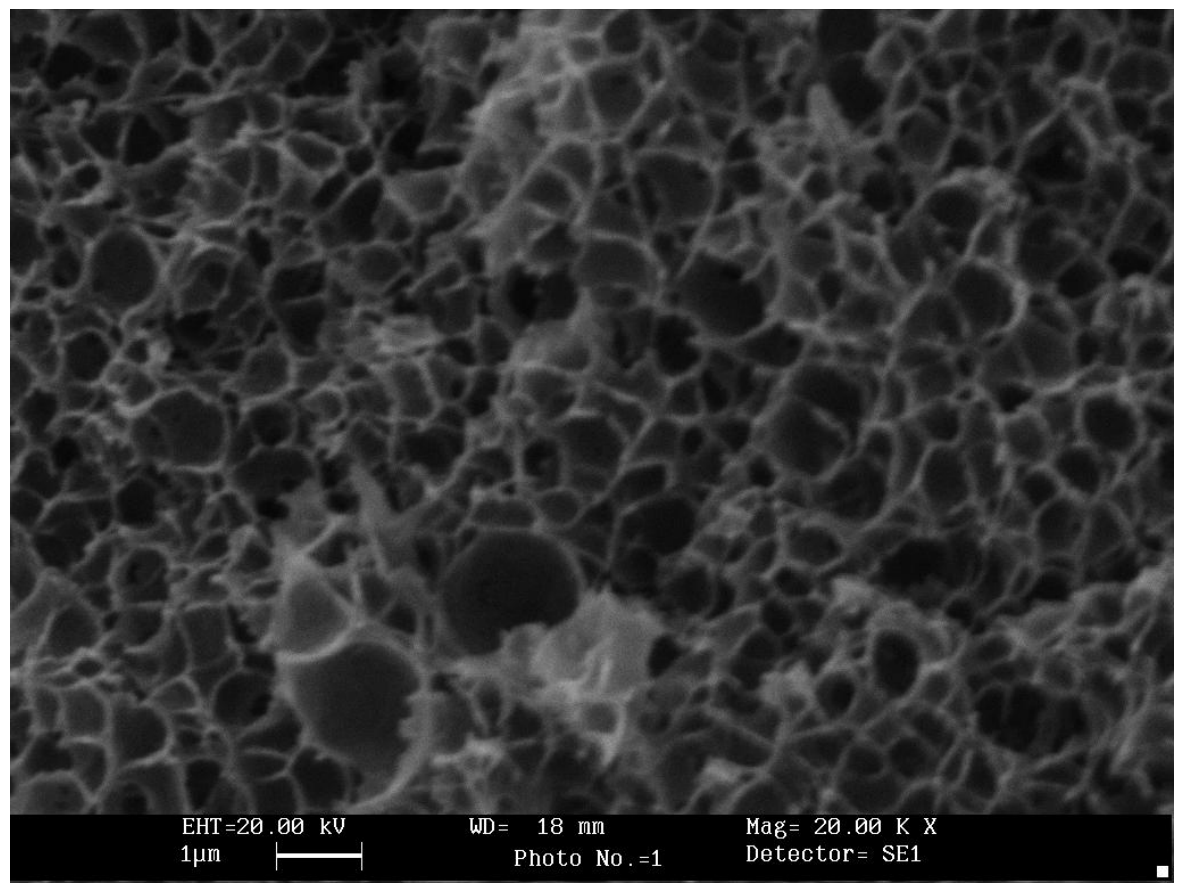

Figure A-9. High magnification image of the interior walls of the membrane. 


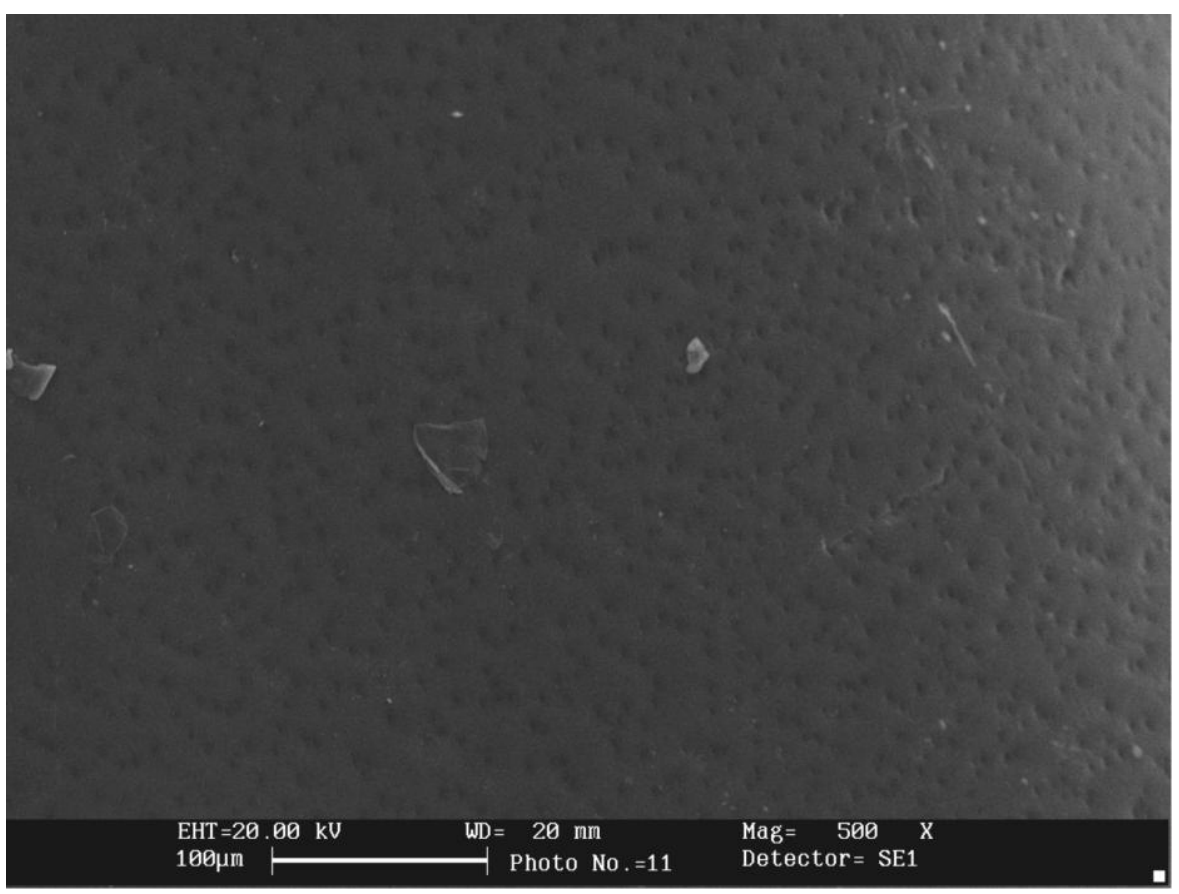

Figure A-10. The surface of a membrane at a magnification of 500X.

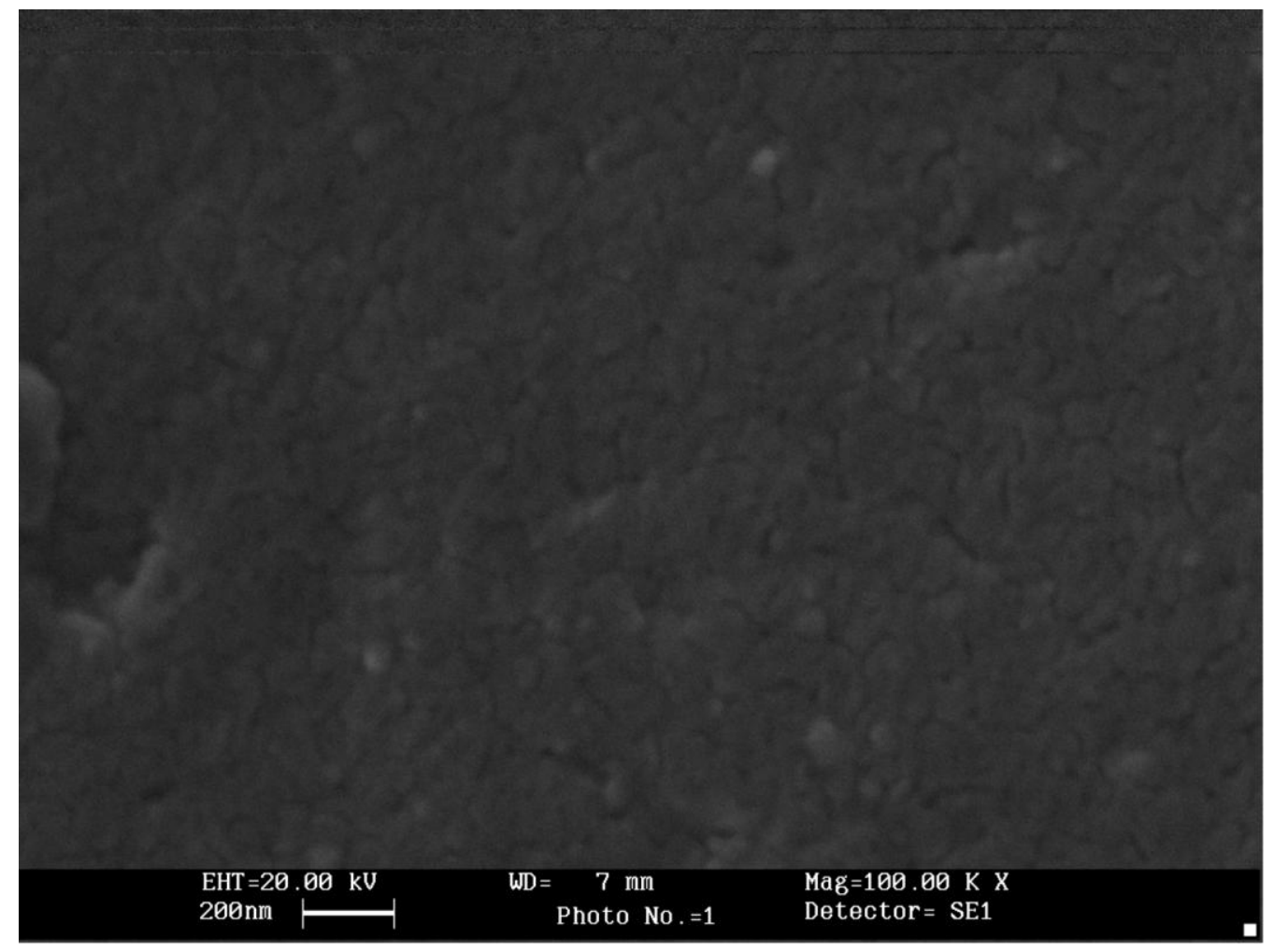

Figure A-11. The surface of a membrane at a magnification of 100,000X. 
Surface Area and Pore Size Distribution Analysis: The surface area and pore size distribution were determined from $\mathrm{N}_{2}$ gas adsorption and desorption isotherms at liquid $\mathrm{N}_{2}$ temperature. Initially, the fiber was heated at $150^{\circ} \mathrm{C}$ under vacuum to remove any residual adsorbed gases. Then the sample was cooled to liquid nitrogen temperature $(78 \mathrm{~K})$ and the uptake of $\mathrm{N}_{2}$ gas was determined as a function of $\mathrm{N}_{2}$ gas pressure from $\sim 0.01$ to $1 \mathrm{~atm}$. The surface area of the membrane was calculated using the well-known BET theory of multilayer adsorption. The meso-pore size distribution in the range 1 to $100 \mathrm{~nm}$ was calculated using the BJH method.

The data from the BET analysis are shown in Table A-1. The membrane had a surface area of $10 \mathrm{~m}^{2} / \mathrm{g}$. If the pores are assumed to be spherical in shape and if the polymer density is assumed to be $1.3 \mathrm{~g} / \mathrm{cm}^{3}$, the average pore diameter is calculated to be $0.5 \mu \mathrm{m}$. This value is approximately similar to the size of the pores observed in the interior walls of the membrane.

Table A-1. BET Analysis of the Data for PBI Fiber WF-MB-102208

\begin{tabular}{|l|l|}
\hline BET Surface Area $\left(\mathrm{m}^{2} / \mathrm{g}\right)$ & $9.9 \pm 0.2$ \\
\hline Slope $\left(\mathrm{g} / \mathrm{cm}^{3} \mathrm{STP}\right)$ & $0.4469 \pm 0.009$ \\
\hline Y-Intercept $\left(\mathrm{g} / \mathrm{cm}^{3} \mathrm{STP}\right)$ & $-0.0012 \pm 0.001$ \\
\hline Monlayer capacity $\left(\mathrm{g} / \mathrm{cm}^{3} \mathrm{STP}\right)$ & $2.249 \mathrm{~cm}^{3} / \mathrm{g} \mathrm{STP}$ \\
\hline Correlation Coefficient & 0.999 \\
\hline
\end{tabular}

The pore size distribution of the meso-pores was calculated with the BJH method using both adsorption and desorption isotherms. This technique uses the Kelvin equation, which defines the relation between the pore radius and the vapor pressure of a liquid film on the surface. Basically, the relation states that on a concave surface, the vapor pressure of a liquid is less than that on a flat surface. In a highly curved surface such as a meso-pore surface kept at boiling point temperature, the vapor condenses at a lower partial pressure than on a macro-pore surface. The $\mathrm{BJH}$ method also includes a correction term for the multilayer gas adsorption film. The method is applicable only in the range 2 to $200 \mathrm{~nm}$. 
The calculated pore size distribution is shown in Figure A-12, which indicates pores in the 5 to $200 \mathrm{~nm}$ range and the differential pore volume peaks at pores of about $20 \mathrm{~nm}$ in size. The calculated pore volume for pores in this range is $0.04 \mathrm{~cm}^{3} / \mathrm{g}$. The surface area calculated from this pore size distribution was $6 \mathrm{~m}^{2} / \mathrm{g}$, less than the value calculated by the BET theory indicating that pores less than $5 \mathrm{~nm}$ were present and that they contributed to the total surface area.

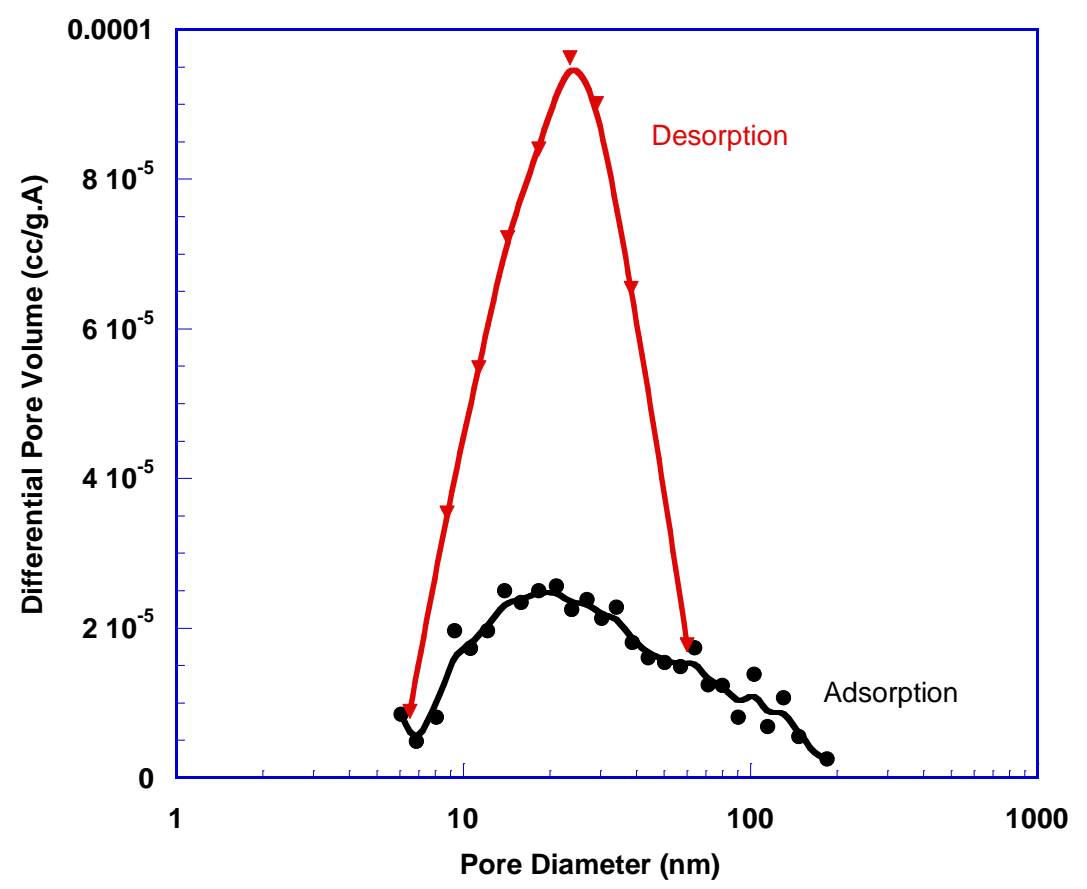

Figure A-12. The size distribution of meso-pores in the PBI membrane.

\section{Permeation Characterization of Multi-Bore Fibers}

Cotronics high-temperature epoxy (Durapot 865) was used to seal the ends of a fiber to a 0.125 inch OD stainless steel tubing. The assembly was cured at $120^{\circ} \mathrm{C}$ for $2 \mathrm{~h}$. After curing, the permeation rate of gases through the membrane was measured by applying gas pressure to the outside of the membrane. The inner bores were kept at near atmospheric pressure. The permeate flow was measured using a precise, electronic mass flow meter that has an accuracy of $0.1 \mathrm{~cm}^{3} / \mathrm{min}$. The gas flow rates of $\mathrm{H}_{2}, \mathrm{CO}_{2}$, and $\mathrm{N}_{2}$ were measured at various temperatures in the range $25^{\circ}$ to $250^{\circ} \mathrm{C}$ and pressures in the range 15 to 65 psi.

Figure A-13 illustrates the measured gas flow as a function of applied pressure differential at $25^{\circ} \mathrm{C}$ for $\mathrm{H}_{2}$ and $\mathrm{CO}_{2}$. The gas flow rates increased linearly with the pressure difference, indicating that the gas transport was in the molecular flow (Knudsen flow) range. For $\mathrm{H}_{2}$ at $25^{\circ} \mathrm{C}$ 
and $1 \mathrm{~atm}$, molecular flow dominated when the pore size was less than $80 \mathrm{~nm}$. The data also indicate that no large cracks or pores were present.

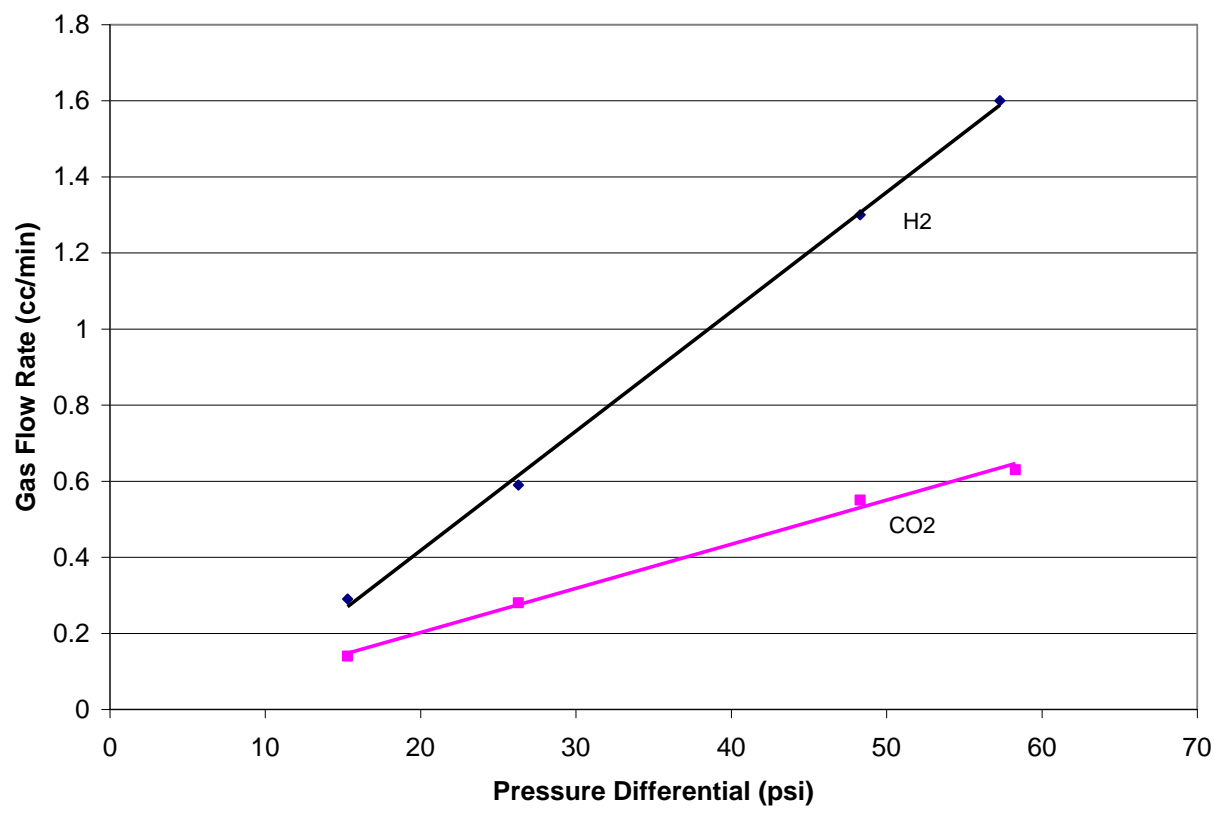

Figure A-13. The Flow rate of $\mathrm{H}_{2}$ and $\mathrm{CO}_{2}$ as a function of pressure difference at $25^{\circ} \mathrm{C}$.

The permeance for $\mathrm{H}_{2}$ and $\mathrm{CO}_{2}$ normalized to the membrane area (external area: $10 \mathrm{~cm}^{2}$ ) and the pressure differential are shown in Figure A-14 and A-15, respectively. The permeance of the membrane for $\mathrm{H}_{2}$ increased slightly with the applied pressure differential up to 60 psi and it remained nearly constant above that. As expected, the permeance of $\mathrm{H}_{2}$ increased with temperature. However, the permeance for $\mathrm{CO}_{2}$ was found to be relatively insensitive to both temperature and pressure differential.

We found that the gas permeance and selectivity varied among different fibers. Such variation was not unexpected because the fiber spinning process has not been optimized for the multi-bore geometry. We tested 3 fibers from the same batch to ascertain the variability in the fiber characteristics and the results from these tests are described below.

The dense PBI membrane is relatively impermeable to $\mathrm{H}_{2}$ or $\mathrm{CO}_{2}$ at $25^{\circ} \mathrm{C}$, and the gas transport at this temperature observed was through the cracks or pores in the walls. As the temperature increased, additional $\mathrm{H}_{2}$ diffused through the dense walls, increasing the total permeance for $\mathrm{H}_{2}$. 


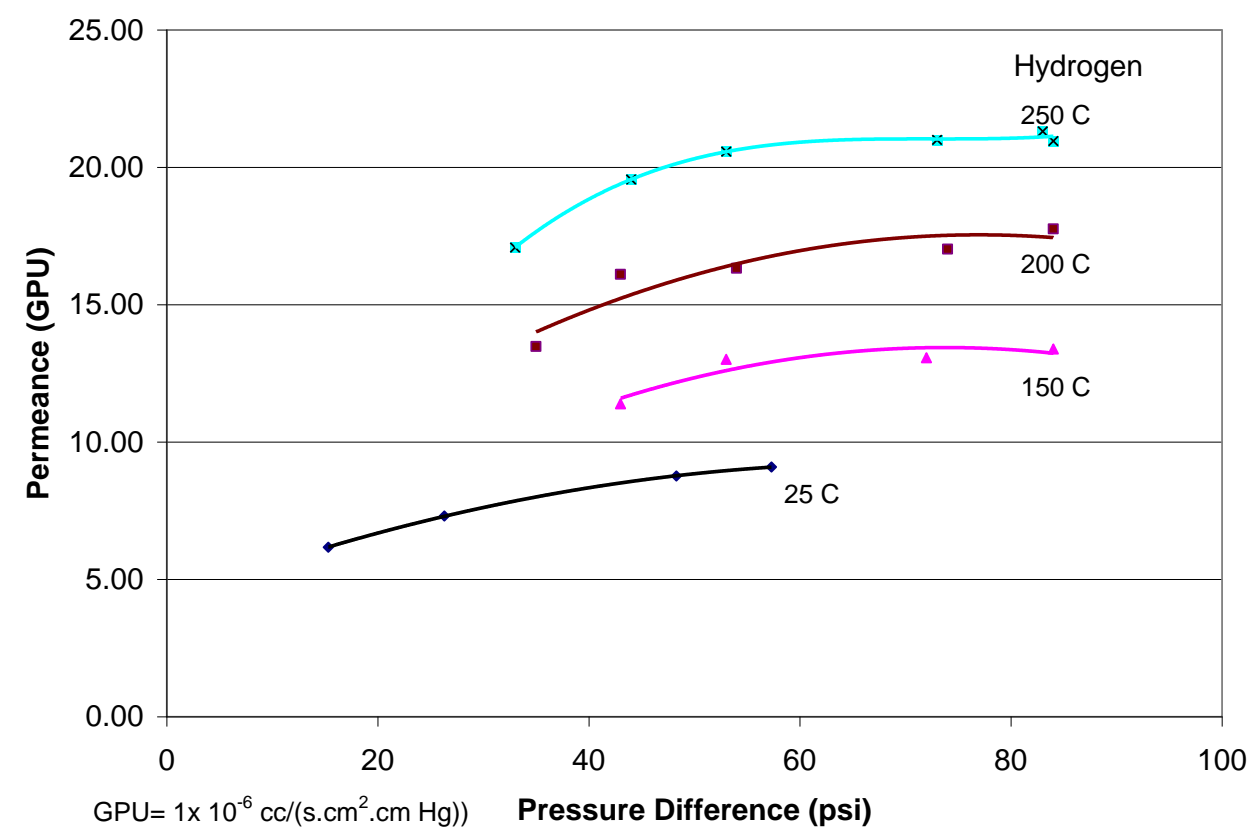

Figure A-14. The permeance of membrane for $\mathrm{H}_{2}$ as a function of temperature and pressure.

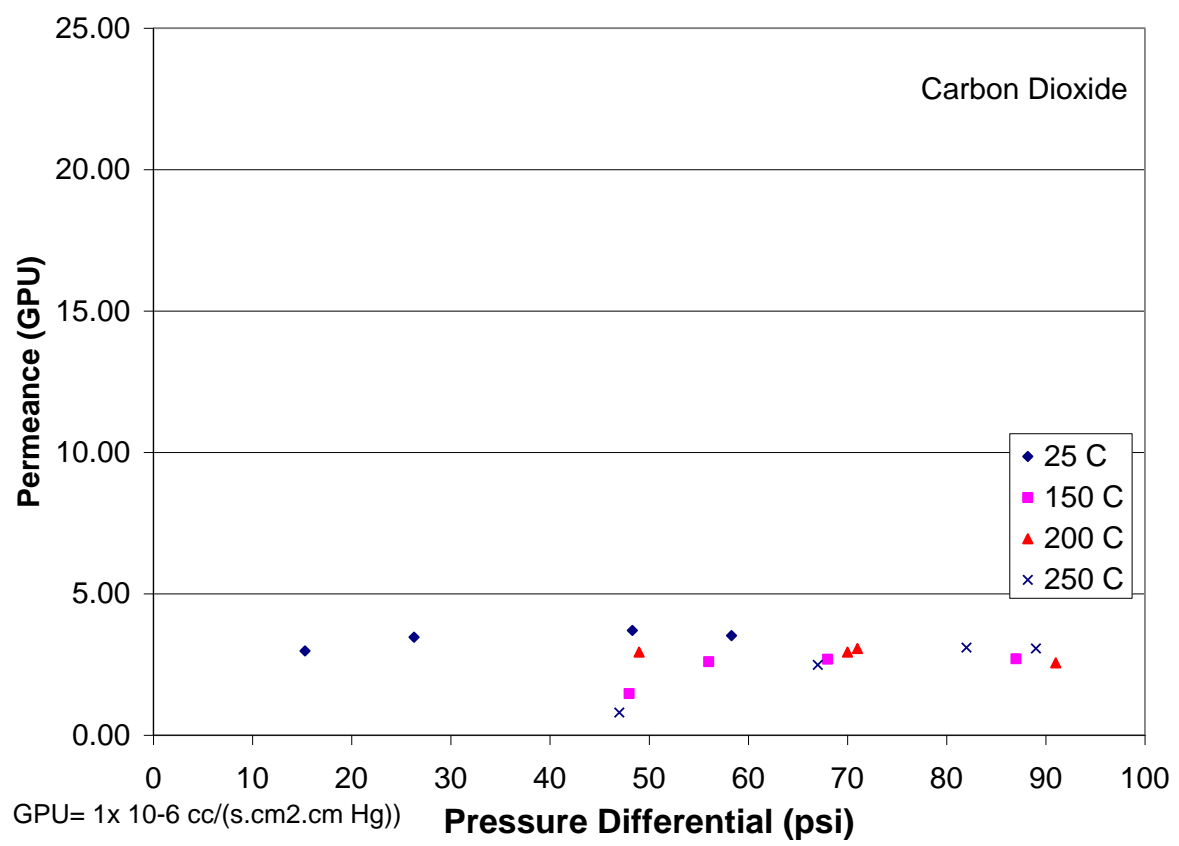

Figure A-15. The permeance of membrane for $\mathrm{CO}_{2}$ as a function of temperature and pressure. 
Table A-2 summarizes the observed $\mathrm{H}_{2}$ permeance and the $\mathrm{H}_{2} / \mathrm{CO}_{2}$ selectivity as a function of temperature for the three fibers tested. Fibers 1 and 3 had similar characteristics, whereas fiber 2 had increased $\mathrm{H}_{2} / \mathrm{CO}_{2}$ selectivity but with a reduced permeance at $250^{\circ} \mathrm{C}$. These data were collected at a pressure differential of 65 to $75 \mathrm{psi}$.

Table A-2. $\mathrm{H}_{2}$ Permeability and $\mathrm{H}_{2} / \mathrm{CO}_{2}$ Selectivity of the WF-MB-102208 PBI Fibers

\begin{tabular}{|c|c|c|c|c|c|c|}
\hline $\begin{array}{c}\text { Temperature } \\
\left({ }^{\circ} \mathbf{C}\right)\end{array}$ & \multicolumn{2}{|c|}{ Fiber 1 } & \multicolumn{2}{c|}{ Fiber 2 } & \multicolumn{2}{c|}{ Fiber 3 } \\
\hline & $\begin{array}{c}\mathbf{H}_{2} \\
\mathbf{G P U}\end{array}$ & $\begin{array}{c}\mathbf{H}_{2} / \mathbf{C O}_{2} \\
\text { Selectivity }\end{array}$ & $\begin{array}{c}\mathbf{H}_{2} \\
\mathbf{G P U}\end{array}$ & $\begin{array}{c}\mathbf{H}_{2} / \mathbf{C O}_{2} \\
\text { Selectivity }\end{array}$ & $\mathbf{H}_{2}$ GPU & $\begin{array}{c}\mathbf{H}_{2} / \mathbf{C O}_{2} \\
\text { Selectivity }\end{array}$ \\
\hline 25 & 9.0 & 2.5 & - & - & - & - \\
\hline 150 & 13.2 & 5.0 & 6.0 & - & 14.3 & 7.7 \\
\hline 200 & 17.8 & 6.9 & - & - & - & - \\
\hline 250 & 21.0 & 8.2 & 12.0 & 13.8 & 18.8 & 7.2 \\
\hline 300 & & & 16.0 & 16.0 & - & - \\
\hline
\end{tabular}

The calculated selectivity ratio for $\mathrm{H}_{2}$ to $\mathrm{CO}_{2}$ for Fiber 1 increased with temperature from 2.5 at $25^{\circ} \mathrm{C}$ to 8.2 at $250^{\circ} \mathrm{C}$ (Table A-2). In the molecular flow range, the selectivity, proportional to the square root of the molecular weight ratio which is calculated to be 4.7. The observed room temperature selectivity was somewhat lower than this value, and the discrepancy may have been due to an error in measuring the low permeance of $\mathrm{CO}_{2}$ accurately. Above $200^{\circ} \mathrm{C}$, selectivity was higher than expected, indicating that an additional, selective path is available for $\mathrm{H}_{2}$ transport, possibly because of diffusion through the dense membrane walls.

As seen from Table A-2, fiber 2 exhibited a higher selectivity than did the other fibers. We heated fiber 2 to $300^{\circ} \mathrm{C}$ for $5 \mathrm{~h}$ to anneal the defects that may have been present so that selectivity could be increased. Table A-3 summarizes the observed $\mathrm{H}_{2}$ permeance and the $\mathrm{H}_{2} / \mathrm{CO}_{2}$ selectivity as a function of temperature after the high-temperature treatment. An improvement in the selectivity was observed after the treatment, but with a reduced $\mathrm{H}_{2}$ permeance. 
Table A-3. $\mathrm{H}_{2} / \mathrm{CO}_{2}$ Selectivity of the PBI Fiber WF-MB-102208 after Heating to $300^{\circ} \mathrm{C}$

\begin{tabular}{|c|c|c|}
\hline Temperature $\left({ }^{\circ} \mathbf{C}\right)$ & $\mathbf{H}_{2}$ Permeance (GPU) & $\mathbf{H}_{2} / \mathbf{C O}_{2}$ Selectivity \\
\hline 250 & 8.0 & 14.4 \\
\hline 260 & 8.5 & 15.3 \\
\hline 280 & 9.2 & 16.8 \\
\hline 300 & 11.2 & 17.8 \\
\hline
\end{tabular}

The activation energy calculated from the permeance of $\mathrm{H}_{2}$ as a function of temperature is about $3 \mathrm{~kJ} / \mathrm{mole}$ below $130^{\circ} \mathrm{C}$ (Figure A-16). Such an activation energy value can be expected for gas transport by molecular flow. But, for high temperature $\mathrm{H}_{2}$ permeation, the activation energy appeared to be higher, at $9 \mathrm{~kJ} / \mathrm{mole}$. This activation energy was significantly lower than the $16 \mathrm{~kJ} /$ mole observed in dense PBI membranes. These observations again confirmed that the gas transport consisted both of diffusion through solid walls and molecular flow through cracks or holes, and that the relative magnitude of these two transport mechanisms depended on temperature.

We also calculated the apparent thickness of the separation layer for this membrane from the observed $\mathrm{H}_{2}$ permeation at $250^{\circ} \mathrm{C}$ and the reported permeance of $14 \times 10^{-10} \mathrm{~cm}^{3}-\mathrm{cm} /\left(\mathrm{s} . \mathrm{cm}^{2} . \mathrm{cm}\right.$ $\mathrm{Hg}$ ) for the dense PBI membrane. In the calculation, we subtracted the gas flow through the micropores by extrapolating the low-temperature data shown in Figure. The calculated apparent thickness of $2 \mu \mathrm{m}$ was only a small fraction of the 100 to $200 \mu \mathrm{m}$ thick wall between the outer surface and inner bores, indicating that the walls are highly porous. Alternatively, many of the pores were interconnected, but only a small fraction required the gas to permeate through dense walls. 


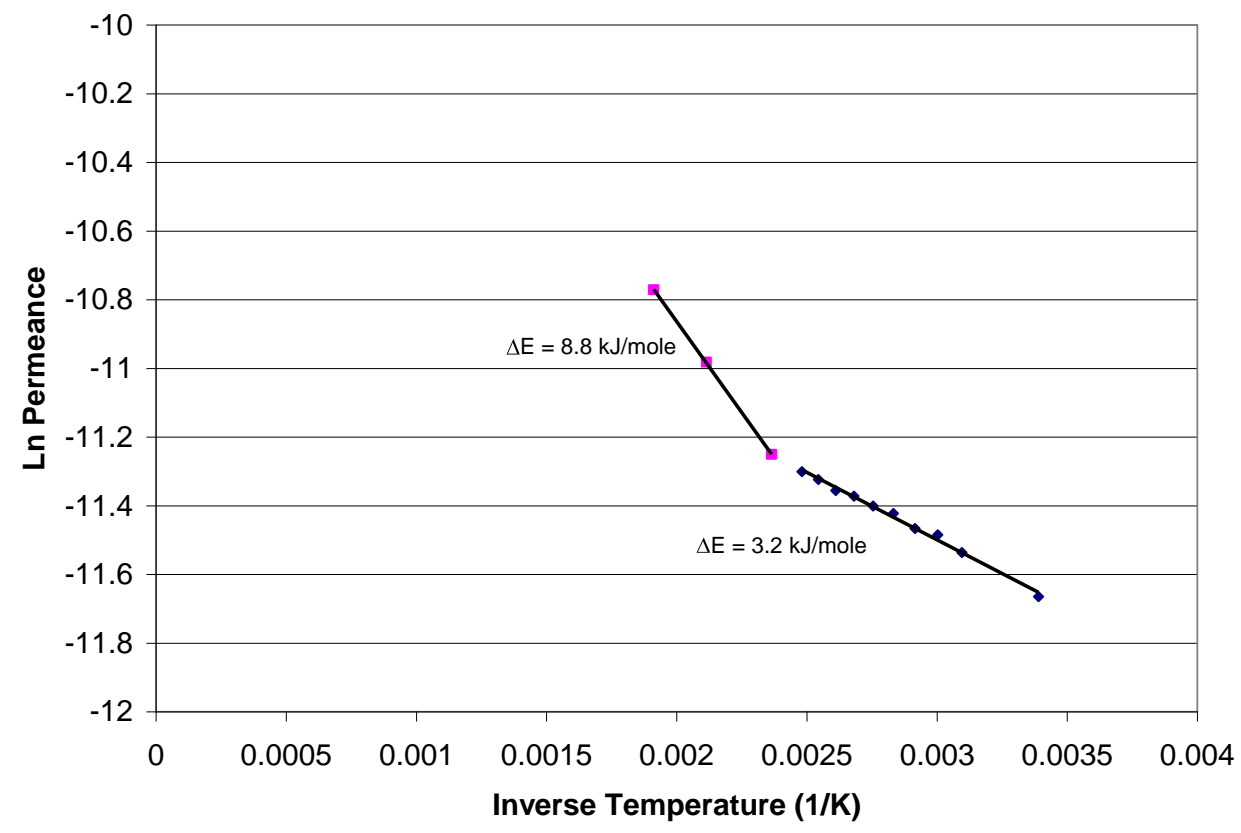

Figure A-16. The activation energy for transport of $\mathrm{H}_{2}$ through the membrane.

A second batch of multi-bore fibers was provided also by WFX. Batch WF-MB-010609 consisted of seven-bore PBI hollow fibers which were produced at the Whitefox facilities at the beginning of January 2009. Four fiber samples from this batch (WF-MB-010609-F1 to -F4), each with the same characteristics and each with a membrane area $A=40 \mathrm{~cm}^{2}$, were tested under flows of two different individual gases: carbon dioxide $\left(\mathrm{CO}_{2}\right)$ and hydrogen $\left(\mathrm{H}_{2}\right)$, in order to determine individual gas component trans-membrane (permeate) flow rates and permeance at varying temperatures: $25,150,200,250$ and $300{ }^{\circ} \mathrm{C}$. Trans-membrane pressure difference was kept constant at $\Delta \mathrm{P}=65$ psi. A heating rate $\Delta \mathrm{T} / \Delta \mathrm{t}=2 \mathrm{~K} / \mathrm{min}$ was applied for the variation of temperature. Since both the area of the hollow fibers and $\Delta \mathrm{P}$ were constant parameters, permeance was then directly proportional to flow rate. Figure A-17 shows the measured membrane permeance in each fiber for each gas compound as a function of temperature.

As can be seen from the Figure, permeance of the membrane for $\mathrm{H}_{2}$ increased with temperature up to $250^{\circ} \mathrm{C}$. Permeance for $\mathrm{H}_{2}$ at $300^{\circ} \mathrm{C}$ appeared to reduce with time when the membrane was kept at that temperature. The points in Figure A-17 at $300^{\circ} \mathrm{C}$ were taken within 10 min of reaching $300^{\circ} \mathrm{C}$. However, in a separate test performed with Fiber 1F4 it was observed that permeance finally stabilized after $1 \mathrm{~h}$ at $300^{\circ} \mathrm{C}$. On the other side, permeance of the membrane for $\mathrm{CO}_{2}$ increased only very slightly with temperature and was in average almost independent of $\mathrm{T}$. $\mathrm{A} \mathrm{H}_{2} / \mathrm{CO}_{2}$ selectivity in the range of 9.5 to 10 was thus obtained. 
Additionally, the four fibers were tested under a flow of nitrogen $\mathrm{N}_{2}$ and at the same temperature varying conditions as before; permeance for $\mathrm{N}_{2}$ was shown here also to be more or less insensitive to $\mathrm{T}$.

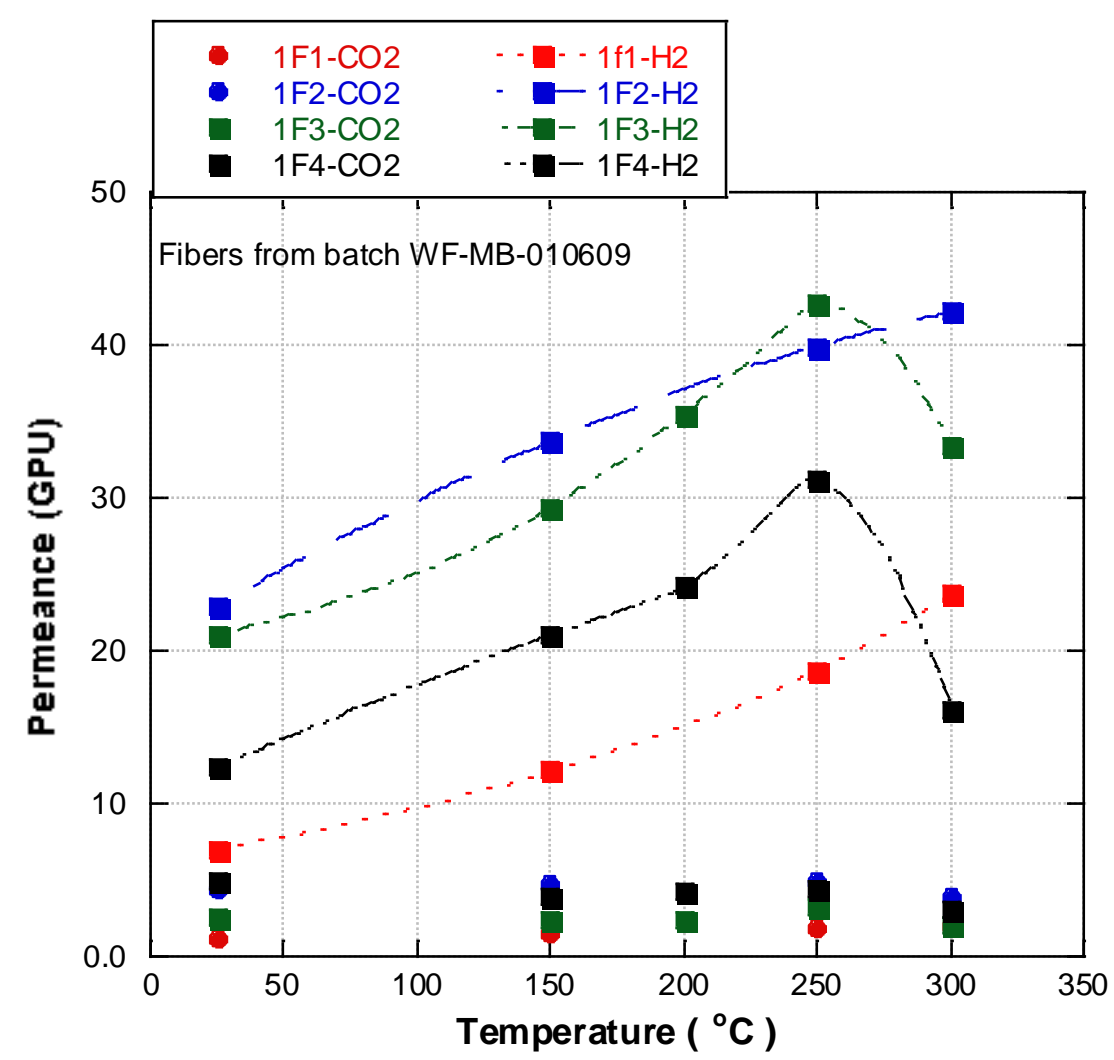

Figure A-17. Permeance of membrane $1 \mathrm{Fx}(\mathrm{x}=1 . .4)$ for $\mathrm{CO}_{2}$ and $\mathrm{H}_{2}$ as a function of temperature, at $\Delta \mathrm{P}=65 \mathrm{psi}$.

Mixed gas permeabilities were measured at LANL. With the purpose of studying the PBI fiber membrane under conditions closer to reality, Fibers 1F3 and 1F4 were tested in selectivity under a pressurized system and under a continuous gas mixture flow. The results can be seen in Tables A-4 and A-5.

As can be seen from Table A-4, a selectivity $\mathrm{S}_{\mathrm{H} 2 / \mathrm{CO} 2}$ as high as 18 was obtained under the binary gas mixture flow (at $\mathrm{T}=250^{\circ} \mathrm{C}$ and $\Delta \mathrm{P}=65 \mathrm{psi}$ ). Also, apparently a higher transmembrane pressure difference contributes to a higher value of $\mathrm{S}_{\mathrm{H} 2 / \mathrm{CO} 2}$ (see Table A-5). Interestingly, the presence of $\mathrm{H}_{2} \mathrm{O}$ (steam) in the gas mixture -for a constant ratio $\mathrm{H}_{2} / \mathrm{CO}_{2}$ - also had a noticeable effect on the increase of selectivity (again from Table A-5). 
Table A-4. Permeation Characteristics of 7-Bore Fiber (PBI 1F3) in Binary Gas Mixtures

\begin{tabular}{|l|c|c|c|c|c|c|}
\hline $\begin{array}{l}\text { Gas, Rolume } \\
\text { Ratio }\end{array}$ & $\begin{array}{c}\text { Volume } \\
\text { ratio }\end{array}$ & $\begin{array}{c}\mathbf{F}_{\mathbf{P}, \mathbf{H} 2} \\
(\mathbf{m l} / \mathbf{m i n})\end{array}$ & $\begin{array}{c}\mathbf{F}_{\mathbf{P}, \mathbf{C O} 2} \\
(\mathbf{m l} / \mathbf{m i n})\end{array}$ & $\begin{array}{c}\mathbf{Q}_{\mathbf{H} 2} \\
(\mathbf{G P U})\end{array}$ & $\begin{array}{c}\mathbf{Q}_{\mathbf{C O} 2} \\
(\mathbf{G P U})\end{array}$ & $\begin{array}{c}\mathbf{S}_{\mathbf{H} 2 / \mathbf{C O}} \\
\mathbf{2}\end{array}$ \\
\hline $\mathrm{H}_{2} / \mathrm{CO}_{2}$ & $61: 39$ & 12.5 & 1.3 & 27 & 1.5 & 18 \\
\hline
\end{tabular}

$\Delta \mathrm{P}=65 \mathrm{psi}, \mathrm{T}=250^{\circ} \mathrm{C}$.

Table A-5. Permeation Characteristics of 7-bore Fiber (PBI 1F4) in Multi-Gas Mixtures

\begin{tabular}{|l|c|c|c|c|c|c|}
\hline $\begin{array}{l}\text { Gas, volume } \\
\text { Ratio }\end{array}$ & $\begin{array}{c}\text { Volume } \\
\text { Ratio }\end{array}$ & $\begin{array}{c}\mathbf{F}_{\mathbf{P}, \mathbf{H} 2} \\
(\mathbf{m l} / \mathbf{m i n})\end{array}$ & $\begin{array}{c}\mathbf{F}_{\mathbf{P}, \mathbf{C O} 2} \\
(\mathbf{m l} / \mathbf{m i n})\end{array}$ & $\begin{array}{c}\mathbf{Q}_{\mathbf{H} 2} \\
(\mathbf{G P U})\end{array}$ & $\begin{array}{c}\mathbf{Q}_{\mathbf{C O} 2} \\
(\mathbf{G P U})\end{array}$ & $\mathbf{S}_{\mathbf{H} 2 / \mathbf{C O} 2}$ \\
\hline $\mathrm{H}_{2} / \mathrm{CO}_{2}$ & $65: 35$ & 4.2 & 0.8 & 8.5 & 2.6 & 3.2 \\
\hline $\mathrm{H}_{2} / \mathrm{CO}_{2}$ & $65: 35$ & 4.5 & 0.6 & 9 & 1.8 & 5 \\
\hline $\mathrm{H}_{2} / \mathrm{CO}_{2}$ & $65: 35^{(*)}$ & 5.4 & 0.6 & 7.2 & 1.2 & 6 \\
\hline $\mathrm{H}_{2} / \mathrm{CO}_{2} / \mathrm{H}_{2} \mathrm{O}$ & $50: 27: 23$ & 7.2 & 0.8 & 19.3 & 2.4 & 8 \\
\hline
\end{tabular}

$\Delta \mathrm{P}=65 \mathrm{psi}, \mathrm{T}=250{ }^{\circ} \mathrm{C}$. ${ }^{(*)} \Delta \mathrm{P}=97 \mathrm{psi}$.

In summary, the multi-bore, hollow fiber PBI membrane WF-MB-102208 constituted a good start for making high-temperature polymer fibers for gas separation leading to the fabrication of compact modules. The $\mathrm{H}_{2} / \mathrm{CO}_{2}$ selectivity and permeability for $\mathrm{H}_{2}$ were lower than expected. Although the multi-bore system is indeed of great advantage, particularly in efficiency of area usage, it could not sustain a pressure difference higher than 6 bar, with feed from the lumen side.

In addition, WFX decided to discontinue the fabrication of the multi-bore PBI membranes for environmentally unacceptable processing methods. Instead they focused on coating a dense PBI layer on the surfaces of porous PBI hollow fiber tubing.

\section{SINGLE-BORE PBI HOLLOW FIBER MEMBRANE}

Whitefox Technologies established an experimental matrix consisting of several process variables in the fabrication of single bore PBI hollow fiber. They considered solvent, nonsolvent, doping mixture, cross-linking mechanisms, intermolecular interactions and the expected solvent versus non-solvent interactions that take place in the phase inversion process of hollow fiber membrane formation. 


\section{Initial Support layer Development}

The experimental work at WFX provided a scientific database from which a systematic optimization path can be followed to fabricate an appropriate support (substrate) layer. Among the several variables related to the manufacturing process of hollow fiber spinning, the focus was centered on the thermodynamics and kinetics of the phase inversion in a ternary system.

Whitefox Technologies fabricated a set of single-bore hollow PBI fiber membranes and sent to the facilities of SRI and LANL at for further testing on membrane characterization. During fabrication, cross-linking was performed as an additional step to add chemical and thermal stability. This cross-linking mechanism stabilized the polymeric matrix by means of a stable bridging of the long polymeric chains by bonding of radicals into the $\mathrm{H}$-groups of the $\mathrm{N}$-ring of the polymer. The resultant substrate fiber had an open pore structure necessary to function as a substrate. The average inner and outer diameters of the fibers are 1.2 and $1.4 \mathrm{~mm}$, respectively. Figures A-18 and A-19 are images of the cross section at low and high magnifications, respectively. The images show that the interior of the fiber is highly porous and has many interconnected pores with diameters in the order of $1 \mu \mathrm{m}$.

Although these substrate fibers were designed to be completely porous, the inner and outer walls were less porous with pores of less than $50 \mathrm{~nm}$ in size (Figures A-20 through A-22).

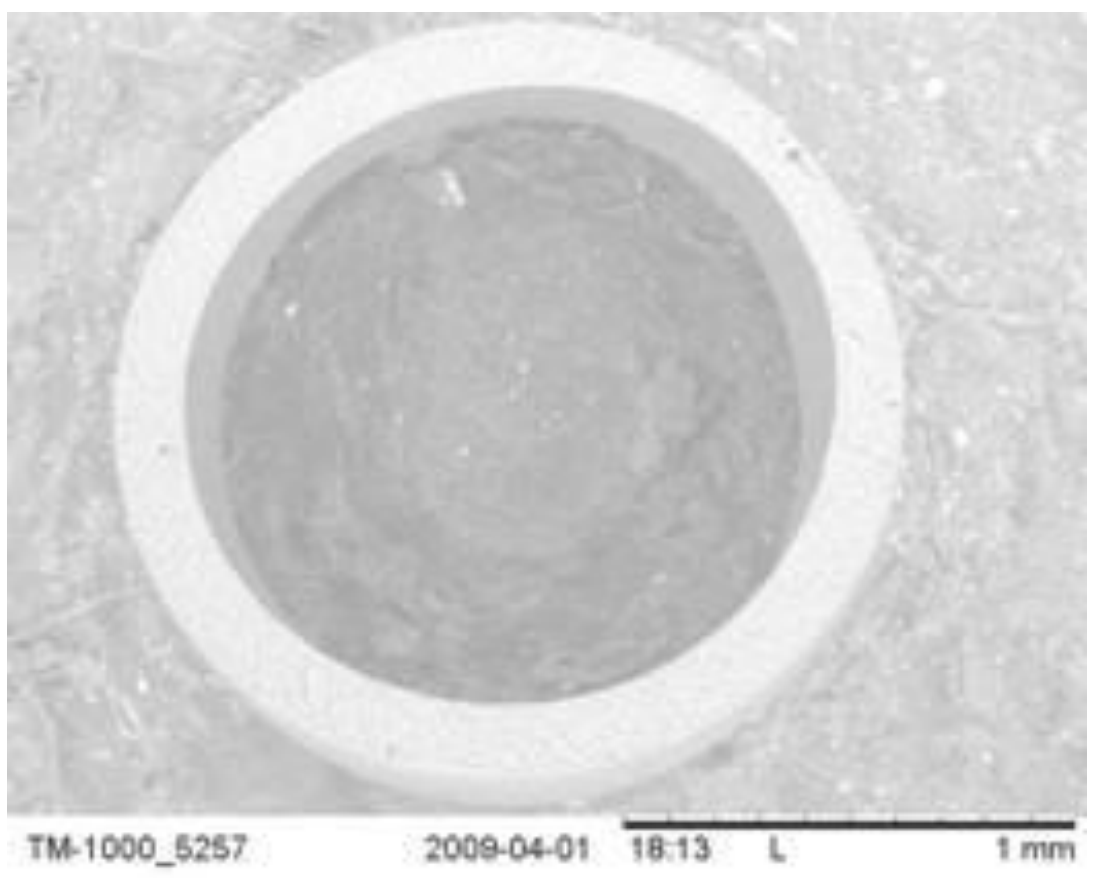

Figure A-18. A macroscopic image of the porous fiber substrate. 


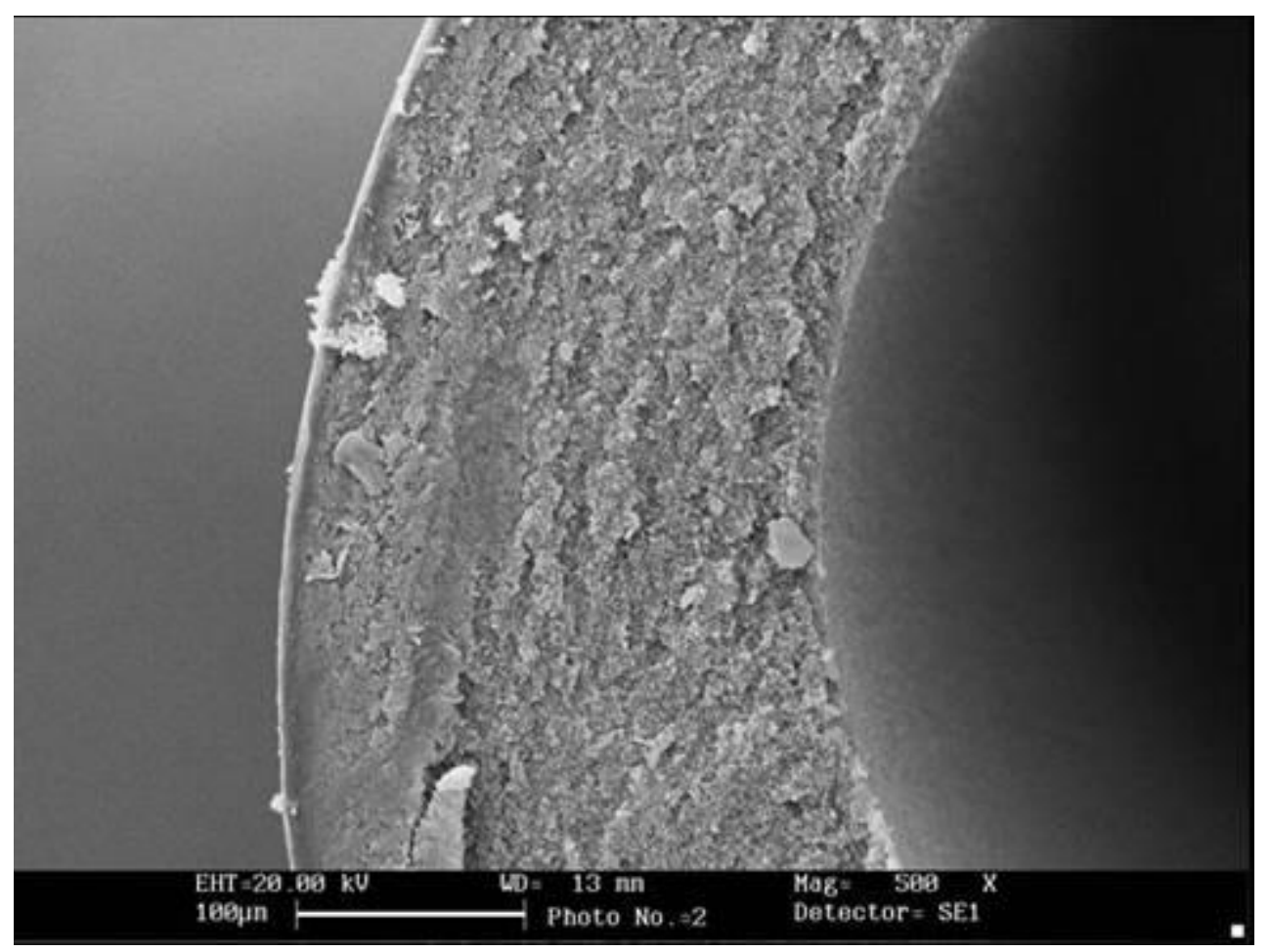

Figure A-19. SEM image of the cross section of the porous substrate fiber at a low magnification.

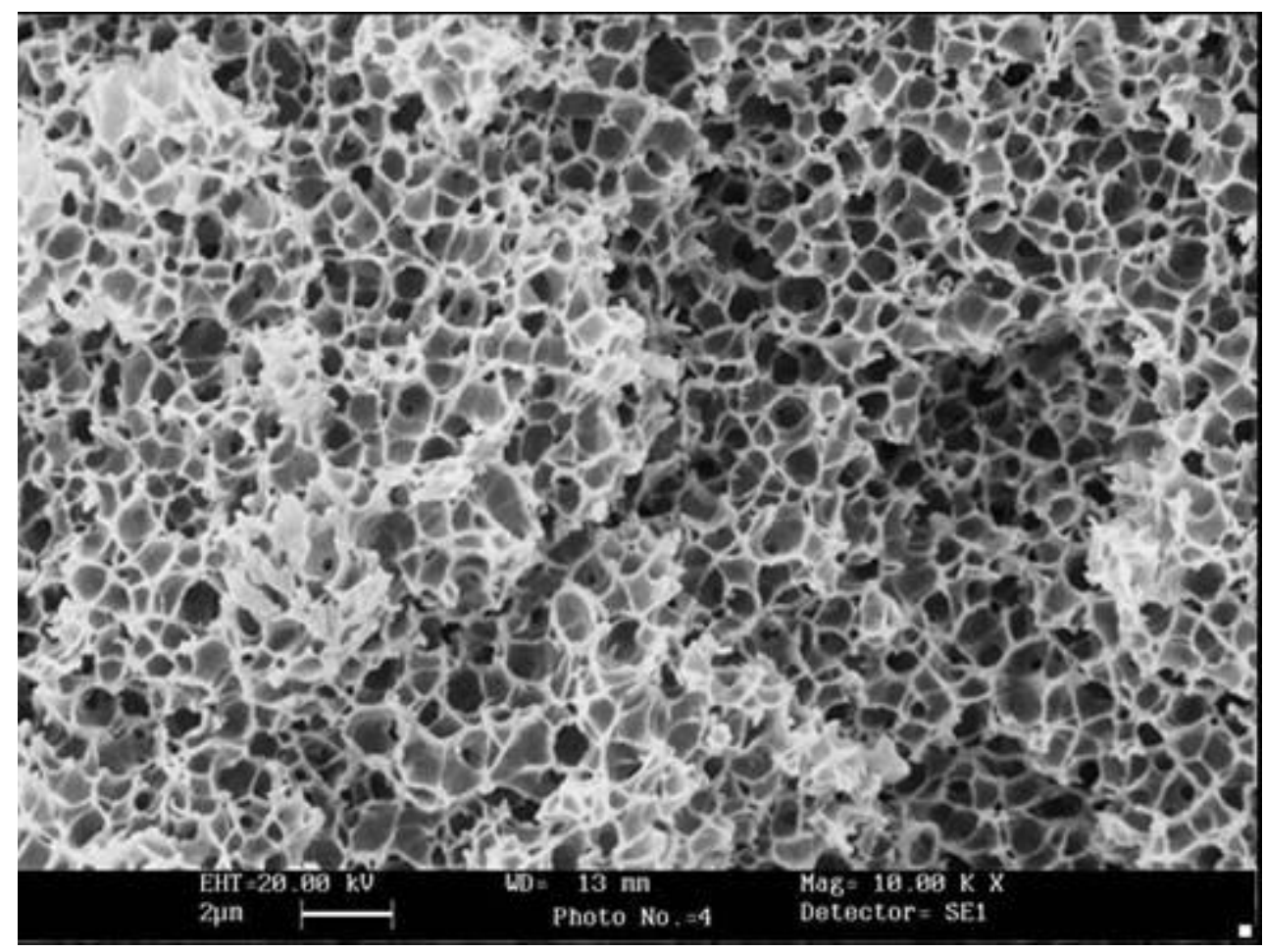

Figure A-20. SEM image of the cross section of the porous substrate fiber at a high magnification. 


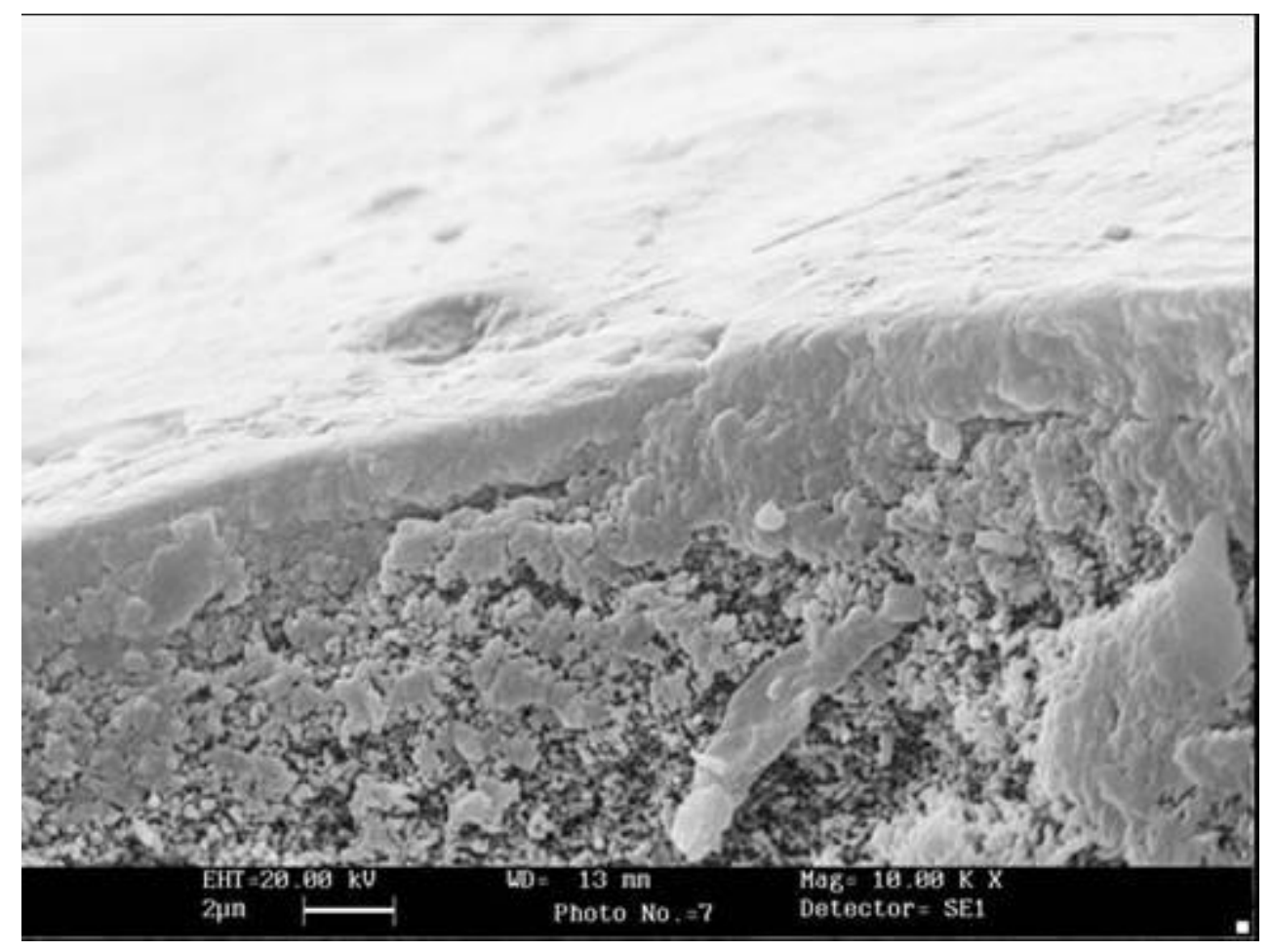

Figure A-21. SEM image of the cross section of the porous substrate fiber neat the outer edge.

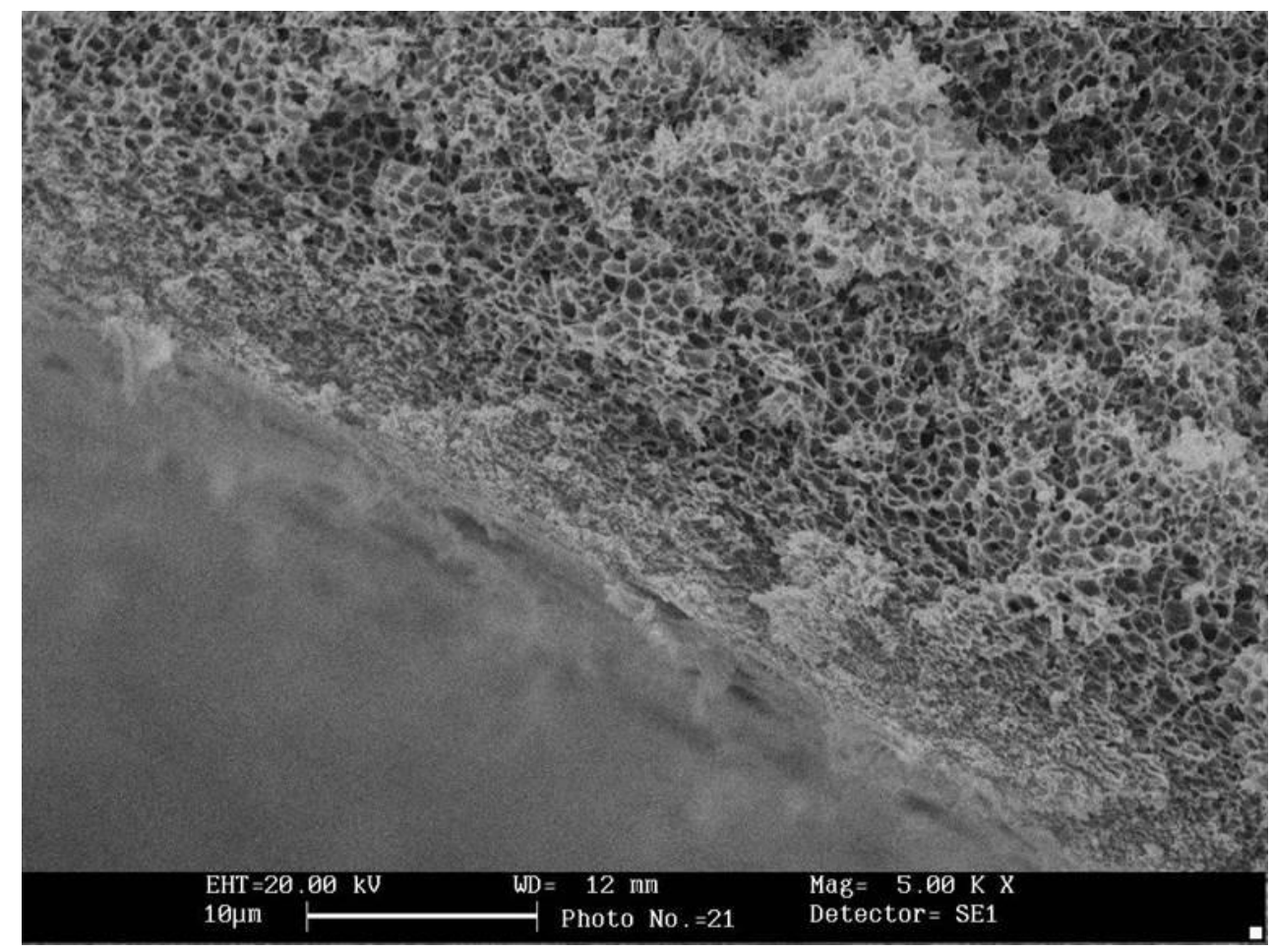

Figure A-22. SEM image of the cross section of the porous substrate fiber neat the inner edge. 
In addition to examining the physical morphology of the porous substrate fibers, we also conducted gas permeation tests at ambient conditions. The ends of a section of the fibers were sealed to a gas manifold and gases such as $\mathrm{H}_{2}, \mathrm{CO}_{2}$, and $\mathrm{N}_{2}$ were allowed to permeate from inside of the fiber to the outside. Figure A-23 illustrates the measured permeation rate of these gases as a function of the pressure difference between outside and lumen side. The permeation rate is linear with the pressure difference indicating that the flow is mainly of Knudsen (molecular flow) type. If the pores are large enough to allow viscous flow, the pressure difference will be proportional to the square of the flow rate.

Figure A-24 illustrates the calculated permeance for $\mathrm{H}_{2}, \mathrm{CO}_{2}$, and $\mathrm{N}_{2}$ as a function of the pressure difference. The calculated $\mathrm{H}_{2} / \mathrm{N}_{2}$ selectivity is $\sim 3.5$, which is in reasonable agreement with a value of 3.7 for the ratio of the inverse square root of the molecular weights of $\mathrm{H}_{2}$ to $\mathrm{N}_{2}$. The $\mathrm{H}_{2} / \mathrm{CO}_{2}$ permeance ratio is $\sim 2$, somewhat lower than the theoretical value for molecular flow indicating that additional permeation of $\mathrm{CO}_{2}$ also occurs by a different mechanism. Note that the permeance of $\mathrm{N}_{2}$ is independent of the pressure difference whereas a small non-linearity is observed in the case of $\mathrm{CO}_{2}$ and $\mathrm{H}_{2}$. These observations also confirm the presence of nanoporous layers, presumably at the walls as indicated in the SEM images. Even with the presence of nanoporous layer, the observed permeance for $\mathrm{H}_{2}$ was very high, at $1600 \mathrm{GPU}$.

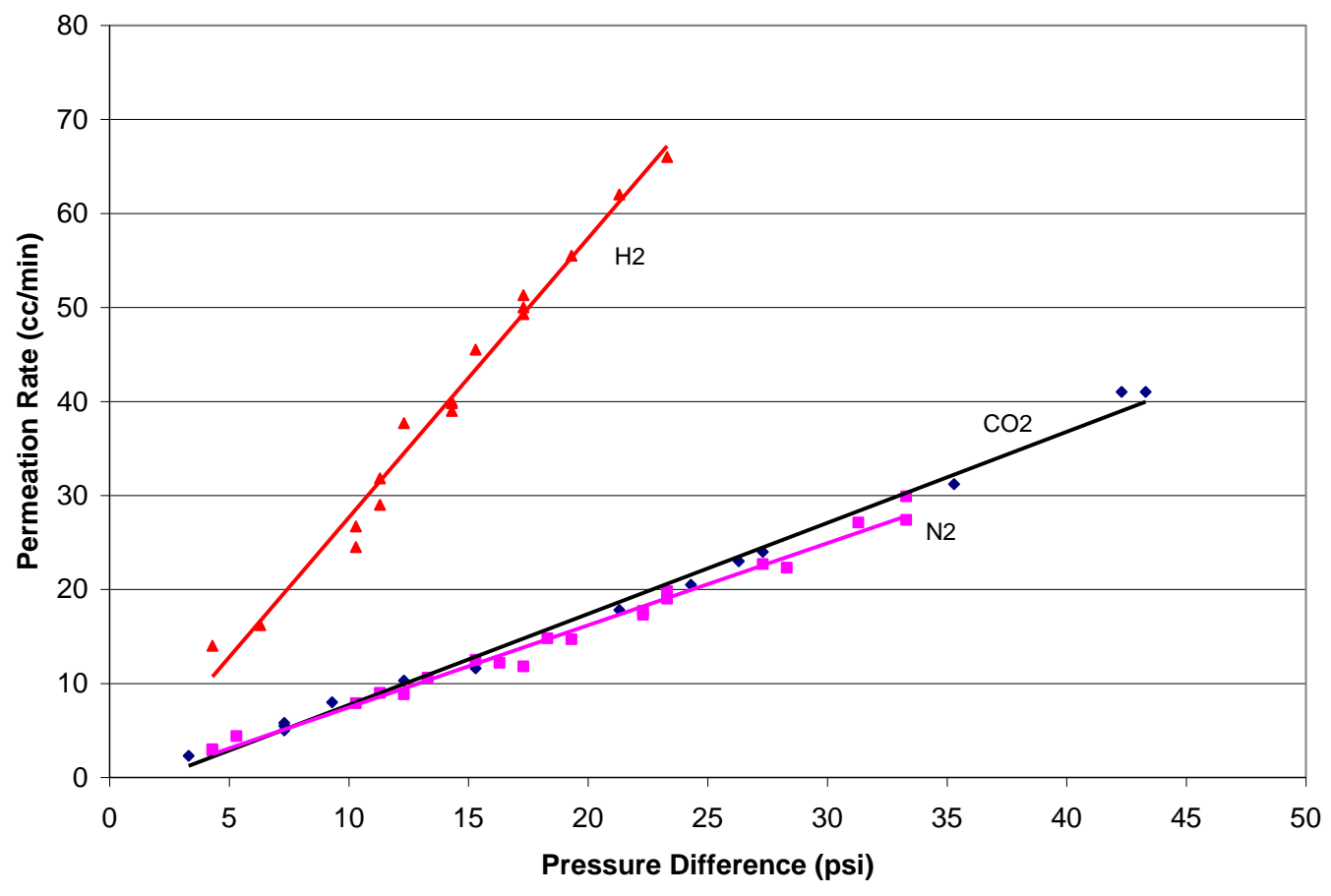

Figure A-23. The measured permeation rate of $\mathrm{H}_{2}, \mathrm{CO}_{2}$, and $\mathrm{N}_{2}$ through the porous substrate at $25^{\circ} \mathrm{C}$. 


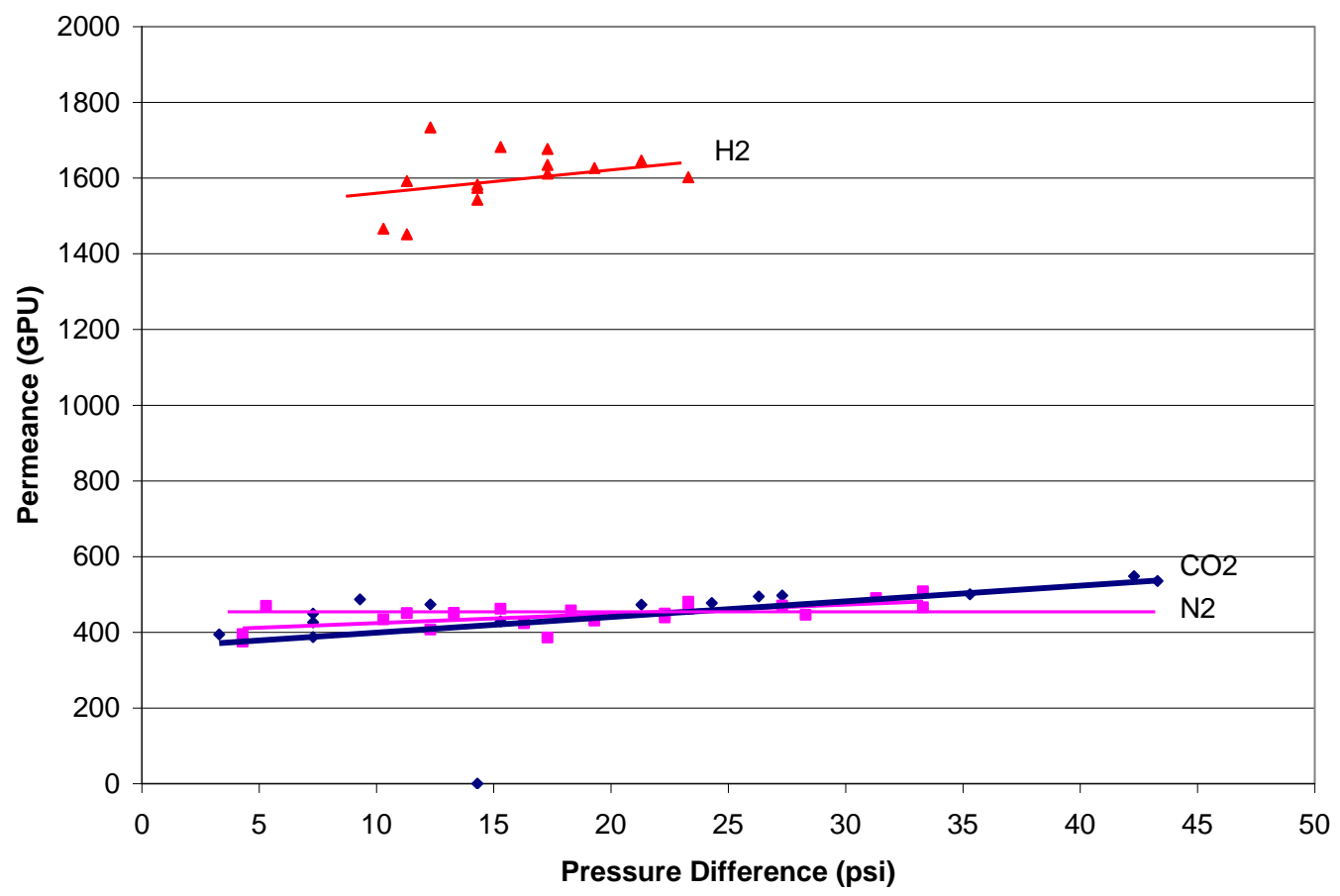

Figure A-24. The calculated permeance of $\mathrm{H}_{2}, \mathrm{CO}_{2}$, and $\mathrm{N}_{2}$ through the porous substrate at $25^{\circ} \mathrm{C}$.

\section{Deposition of a Selective Layer and Permselectivity Evaluation at LANL}

While Whitefox Technologies were optimizing the support layer structure and subsequent deposition of a dense layer on a wall, LANL deposited a dense layer on the outer walls of porous, single fibers fabricated last year using a secondary process (Figures A-25 through A-27). Relatively thick $(20-50 \mu \mathrm{m})$ selective layers have been added to the shell side of the fiber. Thick layers were required on these early generation fibers due to the defect content and type preexisting on the substrate fibers. Permselectivity testing was conducted from ambient to $270^{\circ} \mathrm{C}$ in $\mathrm{N}_{2}, \mathrm{CO}_{2}$, and $\mathrm{H}_{2}$ gas environments. The permeance of hydrogen and carbon dioxide as a function of temperature are presented in Figure A-28. The selectivity behavior as a function of temperature and thermal preconditioning status is presented in Figure A-29. After the second exposure to temperature the selectivity increases. Note that the diamonds and circles represent two separate sets of experiments on different hollow fiber samples/modules. This behavior is very similar to that which LANL observed in both free standing films and coated tubular supported membranes. It should be noted that the time-scales involved in observing the increased selectivity behavior vary for each platform. The marked increase in selectivity in the hollow fibers happens on much shorter time-scales than that which was observed for our earlier work with PBI coated ceramic-metallic tubular supports. 


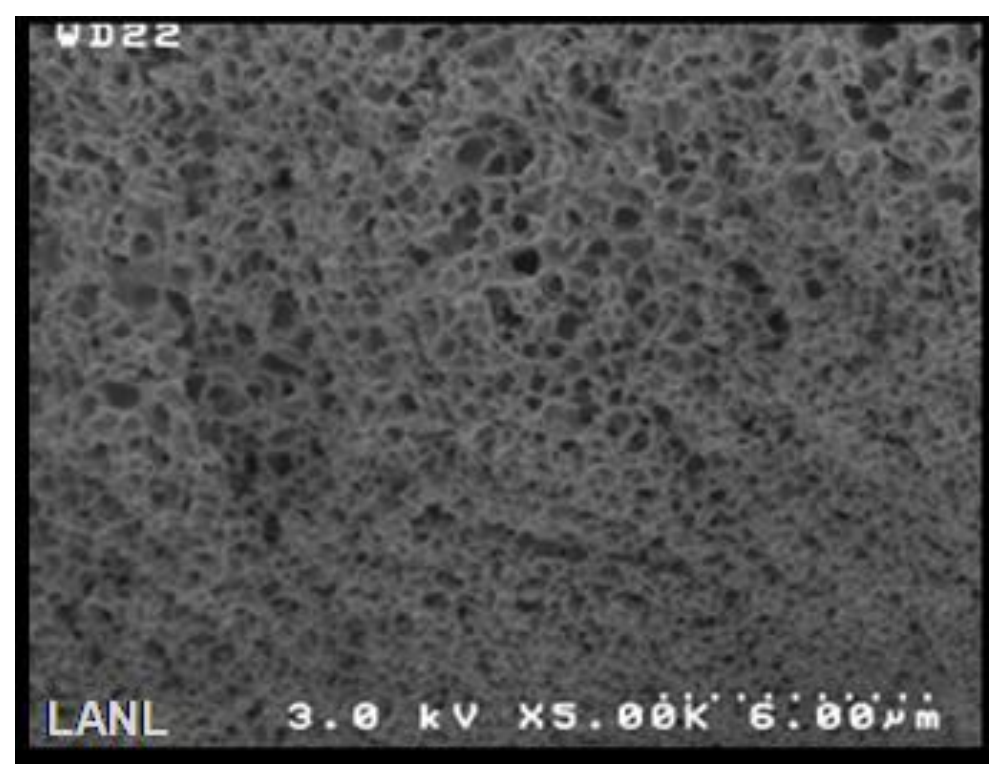

Figure A-25. SEM of a single bore fiber. Bulk morphology of the open cellular PBI-based porous support structure.

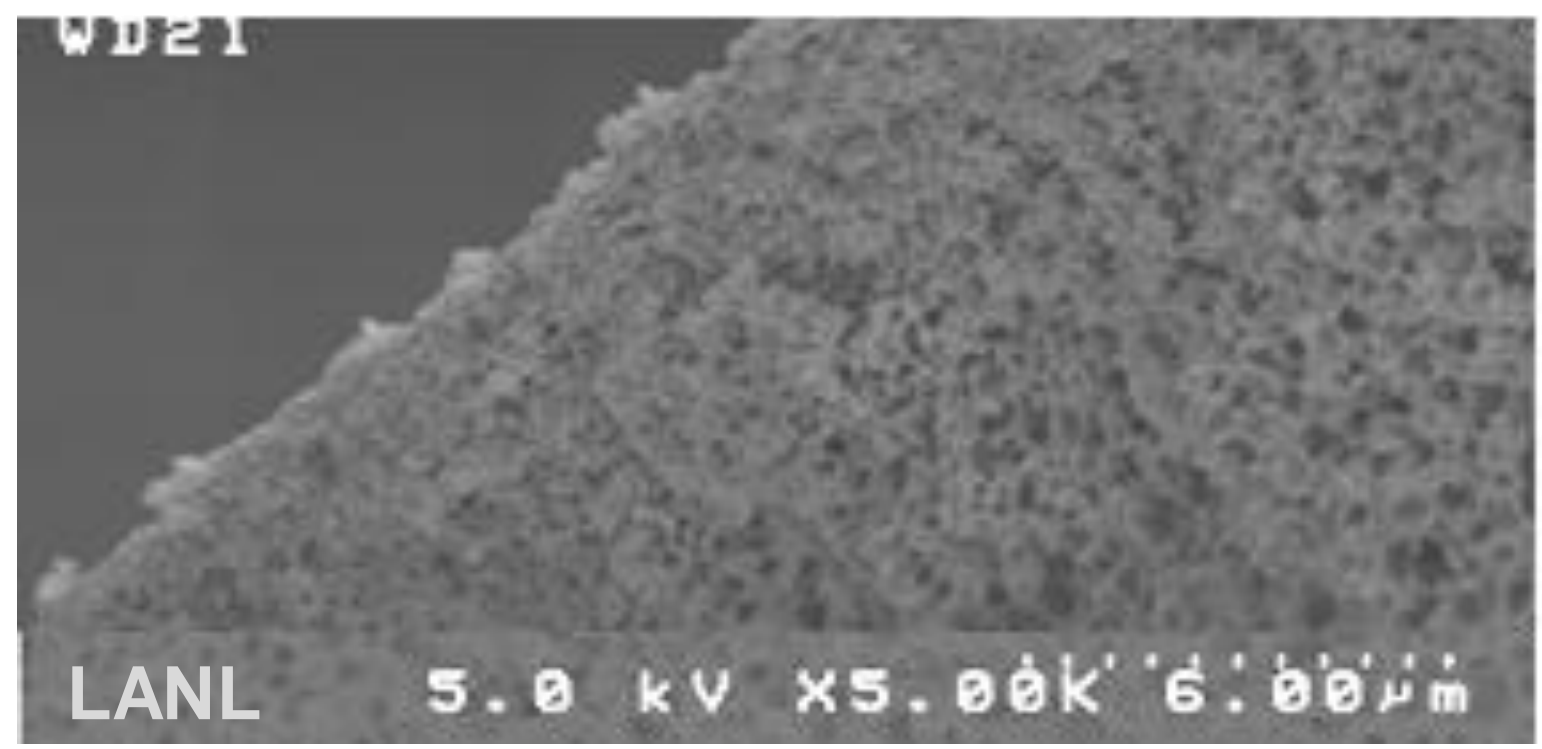

Figure A-26. Graded porous structure leading to a non optimized "dense" layer at the inner (lumen) surface of the fiber. 


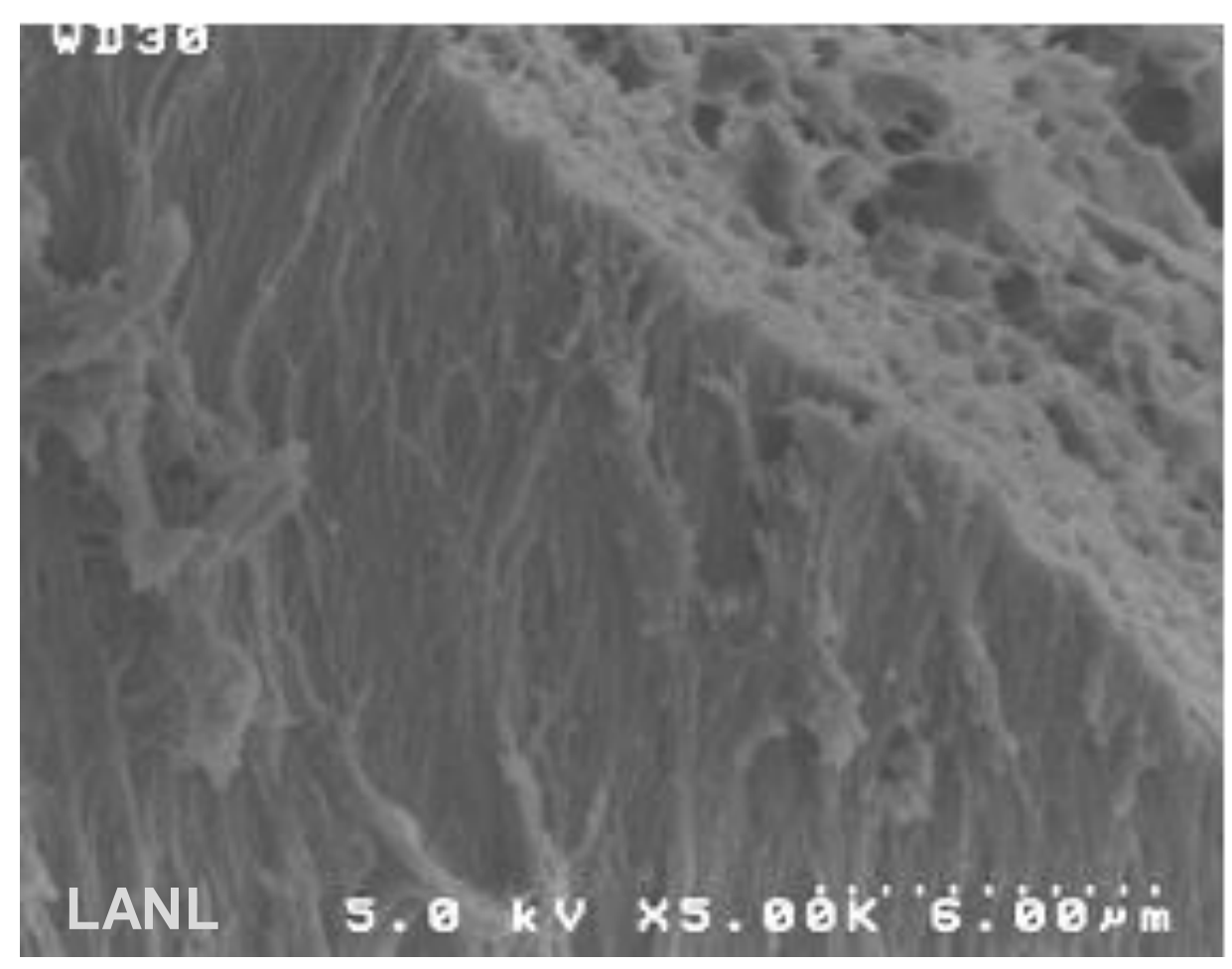

Figure A-27. Non-optimized "dense" layer at the inner (lumen) surface of the fiber with a view of the graded porous structure cross section.

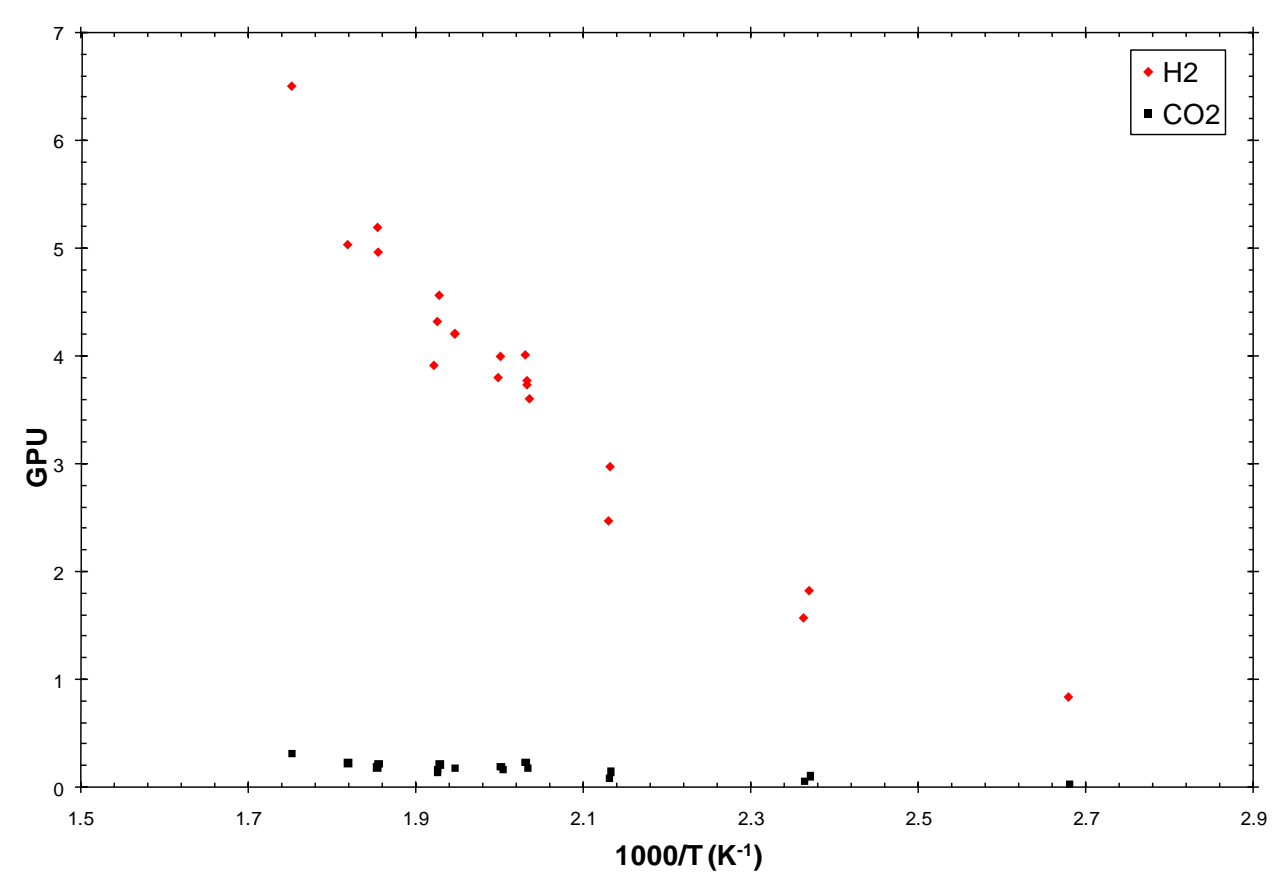

Figure A-28. Hydrogen and carbon dioxide permeance through a PBI coated PBI hollow fiber as a function of temperature. 


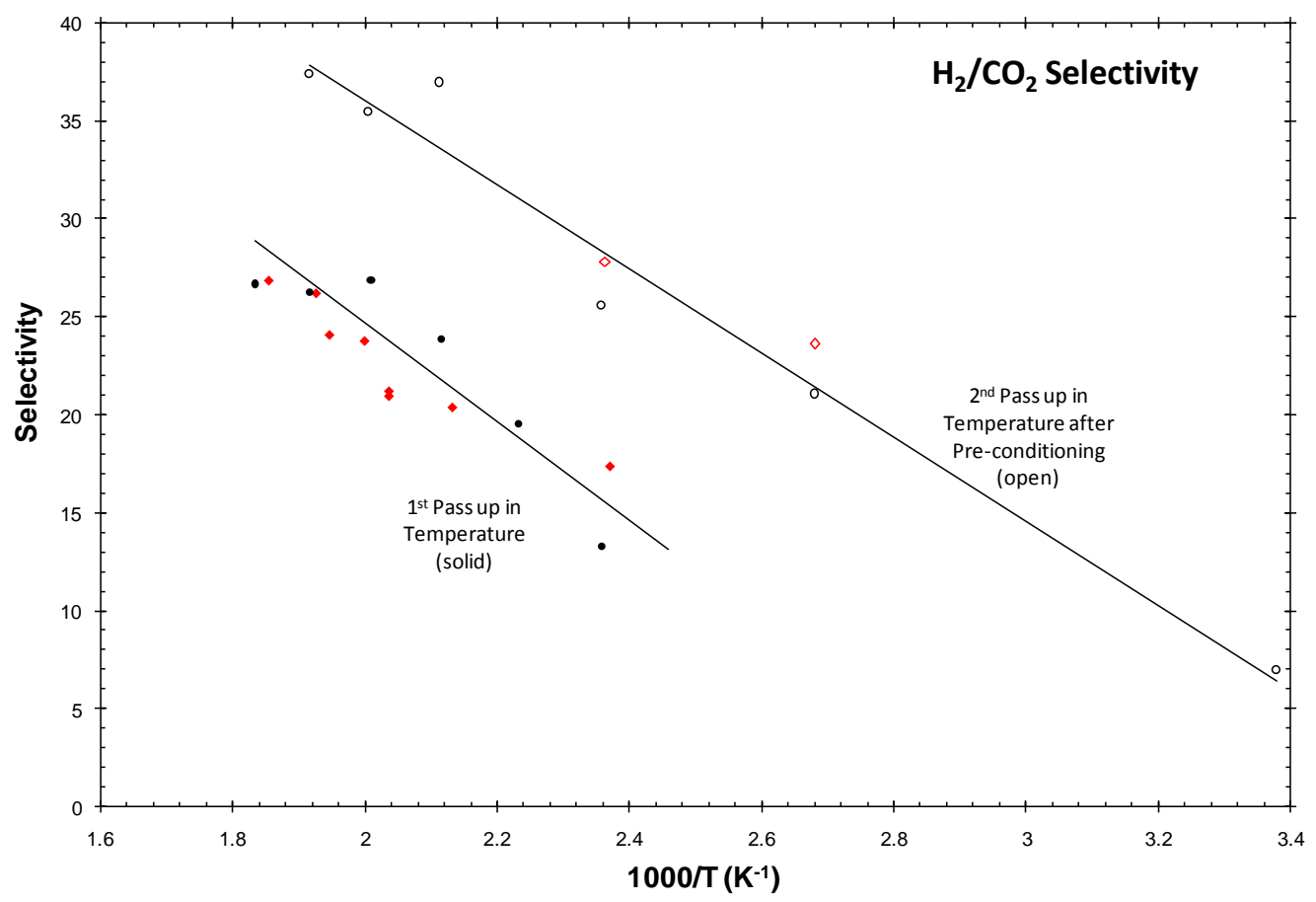

Figure A-29. Hydrogen/carbon dioxide selectivity as a function of temperature and thermal history/preconditioning for PBI coated PBI hollow fibers

A comparison of these secondarily coated $1^{\text {st }}$ generation single bore hollow fibers with our previously evaluated polymer-metallic tubular PBI-based membranes is presented in Table A-6. Additionally, the performance is further compared with the prior tubular platform PBI membranes as well as literature data in Figure A-30. There are a few points worthy of note with respect to the trade-off plot shown in Figure A-30: (1) the literature data presented in the plot is not updated since 2006. However, it is important to reiterate that even the best polymeric membrane data represented in the literature to-date for $\mathrm{H}_{2} / \mathrm{CO}_{2}$ separations and the best commercially available materials "hug" the upper bound line at best; (2) not only does the PBI break away from the traditional Robeson upper bound, but it does so even at temperatures well above the degradation temperatures of most of the other materials presented. All data points for PBI performance versus temperature are not presented here. However, a nearly linear relationship between the data points presented is observed. Nearly all of the previous work using the Trade-off or "Robeson" plots, this $\mathrm{H}_{2} / \mathrm{CO}_{2}$ plot included, is taken at or near ambient conditions. The data points for PBI reflect measurements made at "high temperature". PBI_A represents PBI coated on a tubular ceramic-metallic support. Gen1 PBI-HF represents the coated hollow fiber materials recently fabricated in this work. 
Table A-64. Performance of the Coated $1^{\text {st }}$ Generation Single Bore Hollow Fibers

\begin{tabular}{|c|c|c|c|c|}
\hline & $\begin{array}{c}\text { Temp, } \\
{ }^{\circ} \mathbf{C}\end{array}$ & $\begin{array}{c}\text { Trans- } \\
\text { Membrane } \\
\text { Pressure, psi }\end{array}$ & $\begin{array}{c}\mathrm{H}_{2} / \mathrm{CO}_{2} \\
\text { Selectivity }\end{array}$ & $\begin{array}{c}\text { Permeance, } \\
\text { GPU }\end{array}$ \\
\hline $\begin{array}{c}\text { Polymer-Metallic } \\
\text { PBI Membrane }\end{array}$ & 235 & 45 & 43.0 & 5.2 \\
\hline $\begin{array}{c}\text { Coated SB } \\
\text { Hollow Fibers, } \\
\text { 1.2mm OD }\end{array}$ & 248 & 45 & 37.4 & 6.2 \\
\hline
\end{tabular}

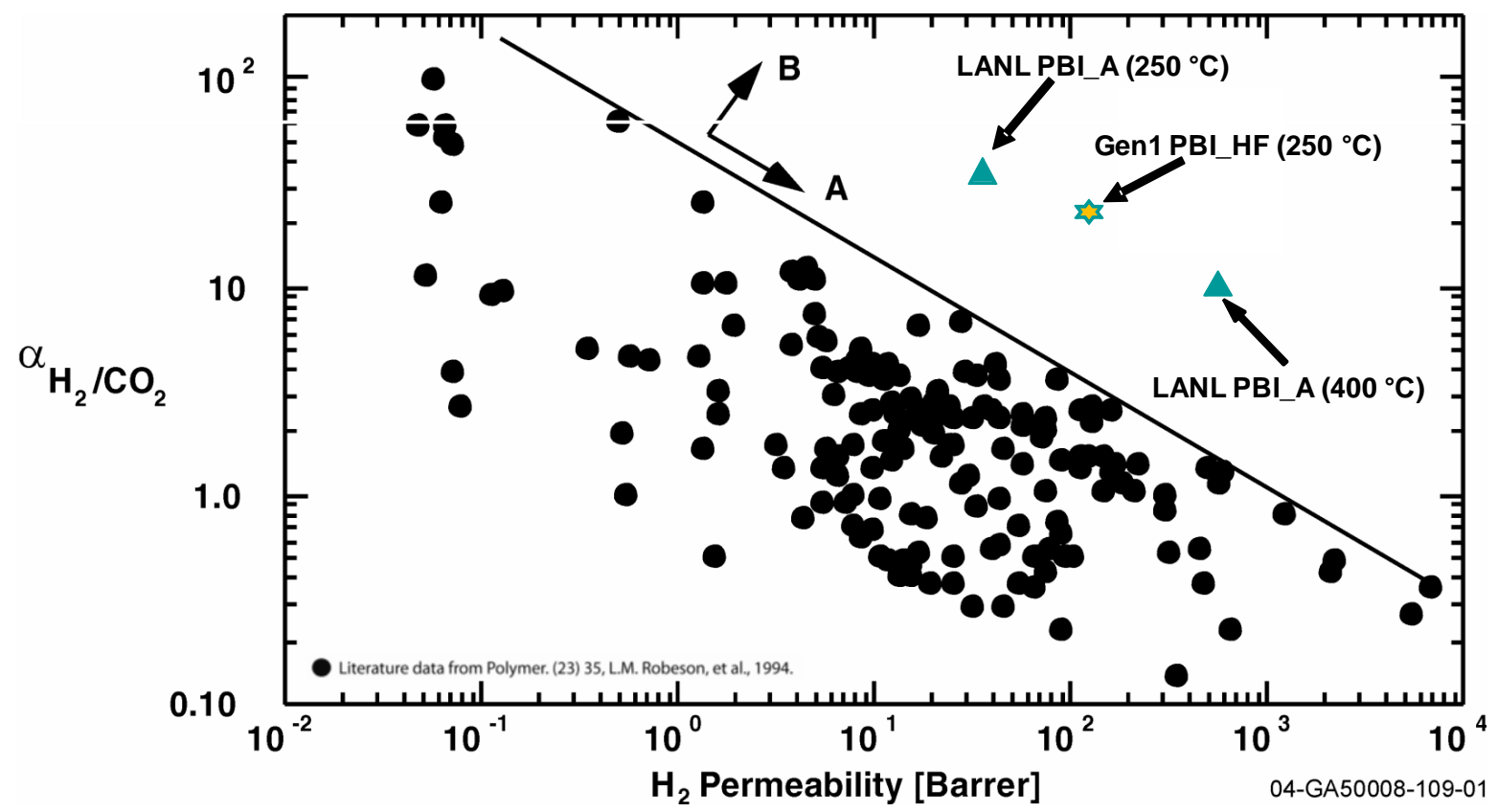

Figure A-30. Trade-off plot between $\mathrm{H}_{2}$ permeability and $\mathrm{H}_{2} / \mathrm{CO}_{2}$ selectivity in polymers.

\section{Development of Hollow Fiber Membrane at WFX (Set 1)}

Two preparation mixtures were developed at the Whitefox facilities and applied as chemically stable selective layers through a coating process of the inside surface (lumen side) of the membrane. These preparation mixtures included a particular curing procedure in each case. These single-bore hollow fiber membranes (selective coat layer + support layer) were characterized at SRI and LANL. 
Substrate (support) Layer Development: Single-bore hollow fibers consisting of a substrate layer of $0.60 \mathrm{~mm}$ and $0.75 \mathrm{~mm}$ internal diameter (designated as WFX-03a and WFX$03 \mathrm{~b}$, respectively) were manufactured at the WFX facilities. This substrate layer had a microporous morphology with numerous interconnecting pores (Figure A-31). The permeation testing performed at SRI showed that the $\mathrm{H}_{2}$ permeance values for these fibers were very high, at 3100 GPU at $30^{\circ} \mathrm{C}^{1}$ Note that a $\mathrm{H}_{2}$ permeance of $\sim 100$ only is needed for the present application. The fibers were mechanically strong because they were able to withstand a minimum of $150 \mathrm{psi}$ of pressure difference across the ID and OD of the membrane during the permeation testing. The $\mathrm{H}_{2} / \mathrm{CO}_{2}$ selectivity of this substrate-layer was higher than 4 at $150^{\circ} \mathrm{C}$ and $200^{\circ} \mathrm{C}$ indicating the substrate layer may contain small pores, presumably, near the surface that may provide a proper foundation on which the selective layer can be applied (Figures A-32 and A-33). Figure A-34 illustrates the progression of increased permeance with each subsequent batch of the fibers from WFX-1 through WFX 3 as the fabrication conditions are being optimized. Based on these results, WFX-3 morphology was chosen as the substrate layer for depositing a selective layer.

Selective Layer Development: $\mathrm{A}_{2}$ selective permeation layer on the surface of the membrane is needed to obtain the required $\mathrm{H}_{2} / \mathrm{CO}_{2}$ selectivity of the membrane. The selective layer must be dense to prevent excessive $\mathrm{CO}_{2}$ permeation of but thin enough to minimize resistance to $\mathrm{H}_{2}$ permeation. In depositing a dense, selective layer on the porous substrate, WFX took steps in to ensure an optimum mutual adherence between the substrate and selective layers. Figure A-35 illustrates the cross section of a substrate with a lumen-side selective layer. The picture shows a gradual decrease in microporosity from the bulk of the membrane toward the lumen side with a very thin $(2 \mu \mathrm{m})$ dense layer at the surface.

The measured permeance of a PBI fiber that contained a selective layer is shown in Figure A36. The $\mathrm{H}_{2}$ permeance of $\sim 40 \mathrm{GPU}$ and the $\mathrm{H}_{2} / \mathrm{CO}_{2}$ selectivity was 13 . The $\mathrm{H}_{2} / \mathrm{N}_{2}$ selectivity was reasonably high at 18 indicating that some $\mathrm{CO}_{2}$ permeation is occurring through the selective layer. This membrane is the first hollow fiber PBI membrane that has shown moderate $\mathrm{H}_{2}$ permeance and $\mathrm{H}_{2} / \mathrm{CO}_{2}$ selectivity higher than that can be achieved by molecular flow permeation. The moderate selectivity is due to the fact that the dense selective layer is not as dense as it needs to be and the moderate $\mathrm{H}_{2}$ permeance is because the selective layer is thicker than needed. Further optimization in the fiber manufacturing process will allow increases in both permeance and selectivity values.

\footnotetext{
${ }^{1} 1 \mathrm{GPU}: 10^{-6} \mathrm{~cm}^{3} / \mathrm{sec}$ of gas flow (STP) per $\mathrm{cm}^{2}$ membrane area per $\mathrm{cm}$ of $\mathrm{Hg}$ pressure drop.
} 


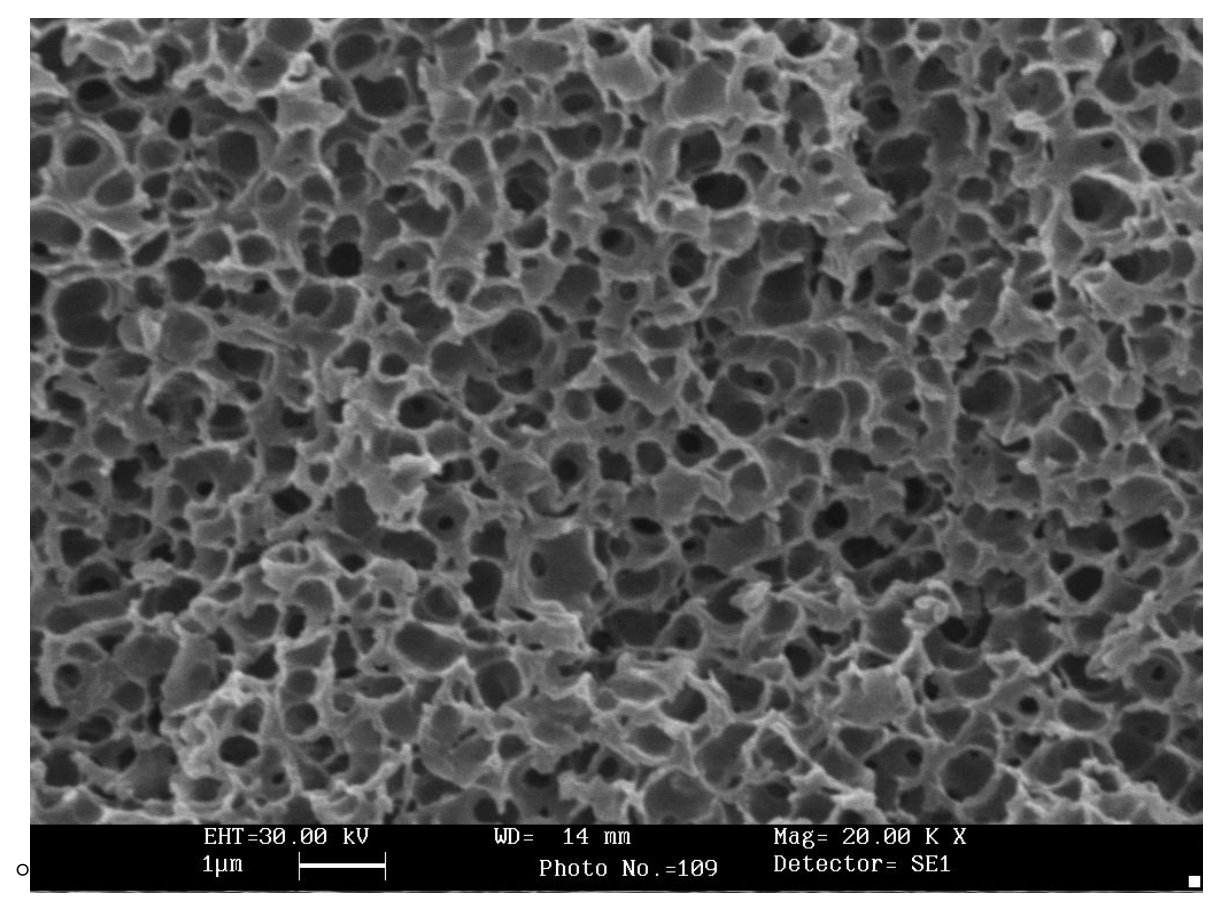

Figure A-31. Cross section of a $0.60 \mathrm{~mm}$ substrate layer (WFX-03a) with homogeneous microporous characteristics.

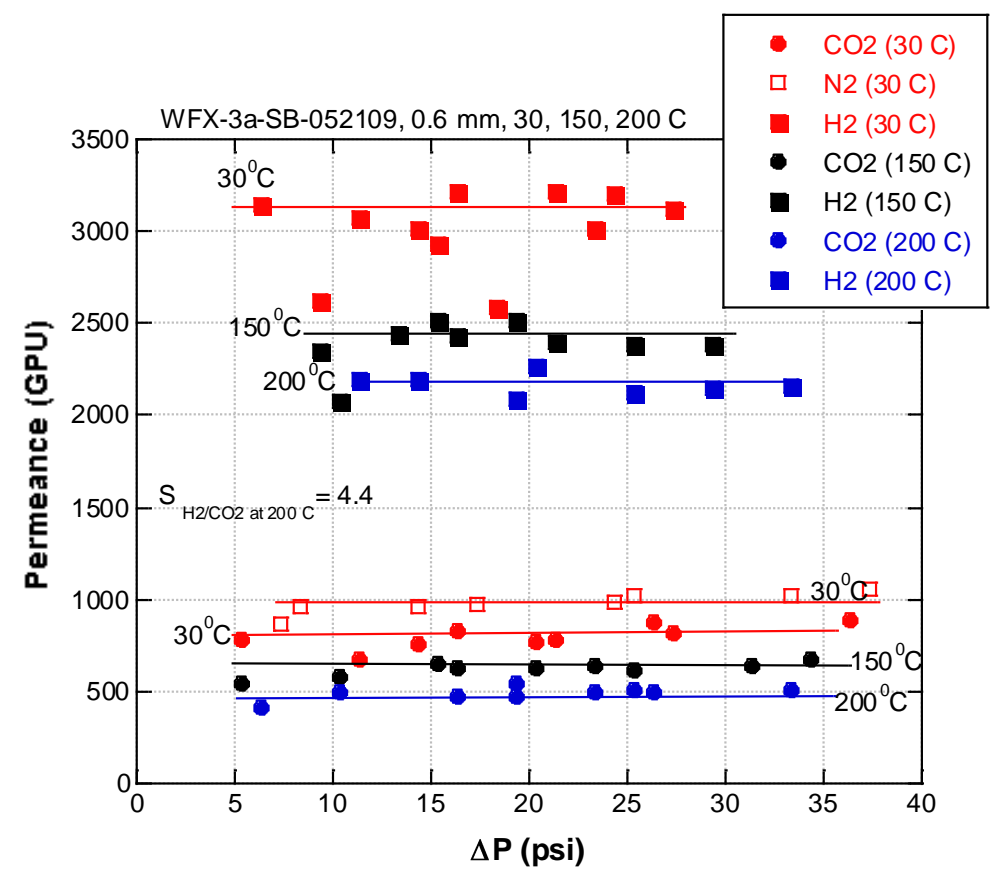

Figure A-32. The measured permeance of $\mathrm{CO}_{2}, \mathrm{~N}_{2}$ and $\mathrm{H}_{2}$ of WFX-3a PBI hollow fiber as a function of pressure difference at $30^{\circ}, 150^{\circ}$, and $200^{\circ} \mathrm{C}$. 


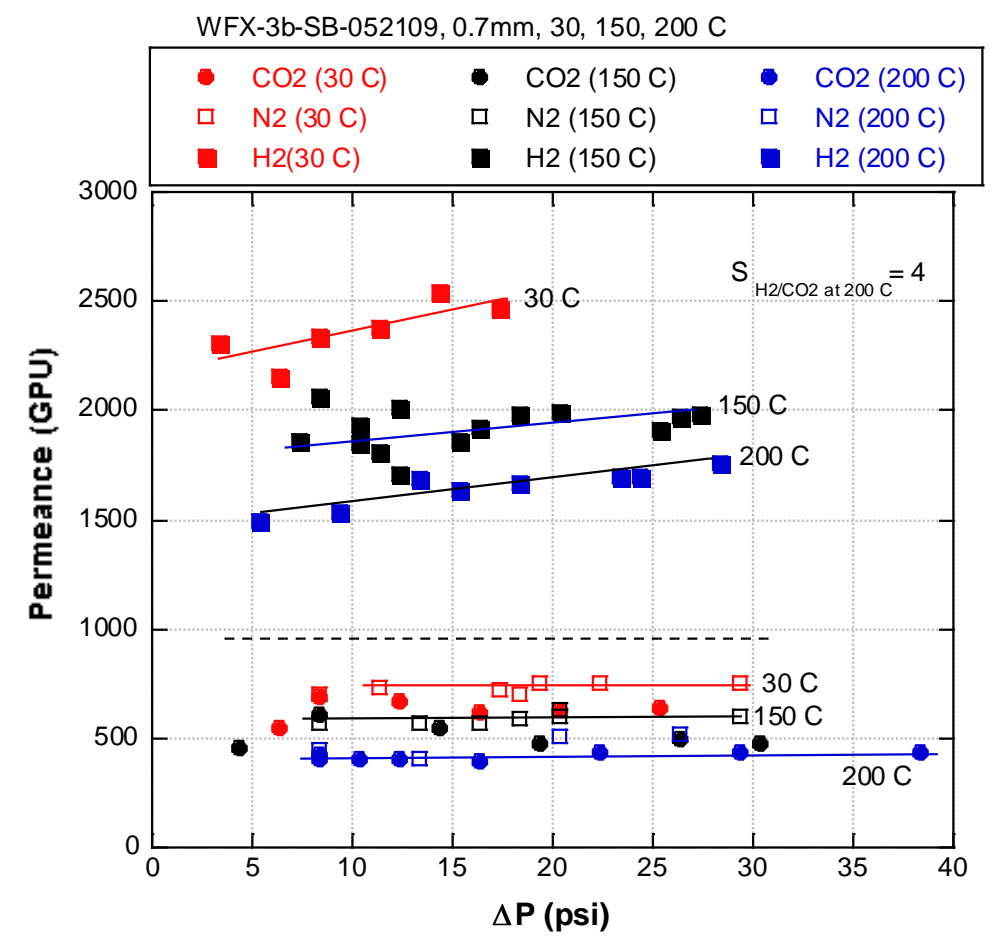

Figure A-33. The measured permeance of $\mathrm{CO}_{2}, \mathrm{~N}_{2}$ and $\mathrm{H}_{2}$ of WFX-3b PBI hollow fiber as a function of pressure difference at $30^{\circ}, 150^{\circ}$, and $200^{\circ} \mathrm{C}$.

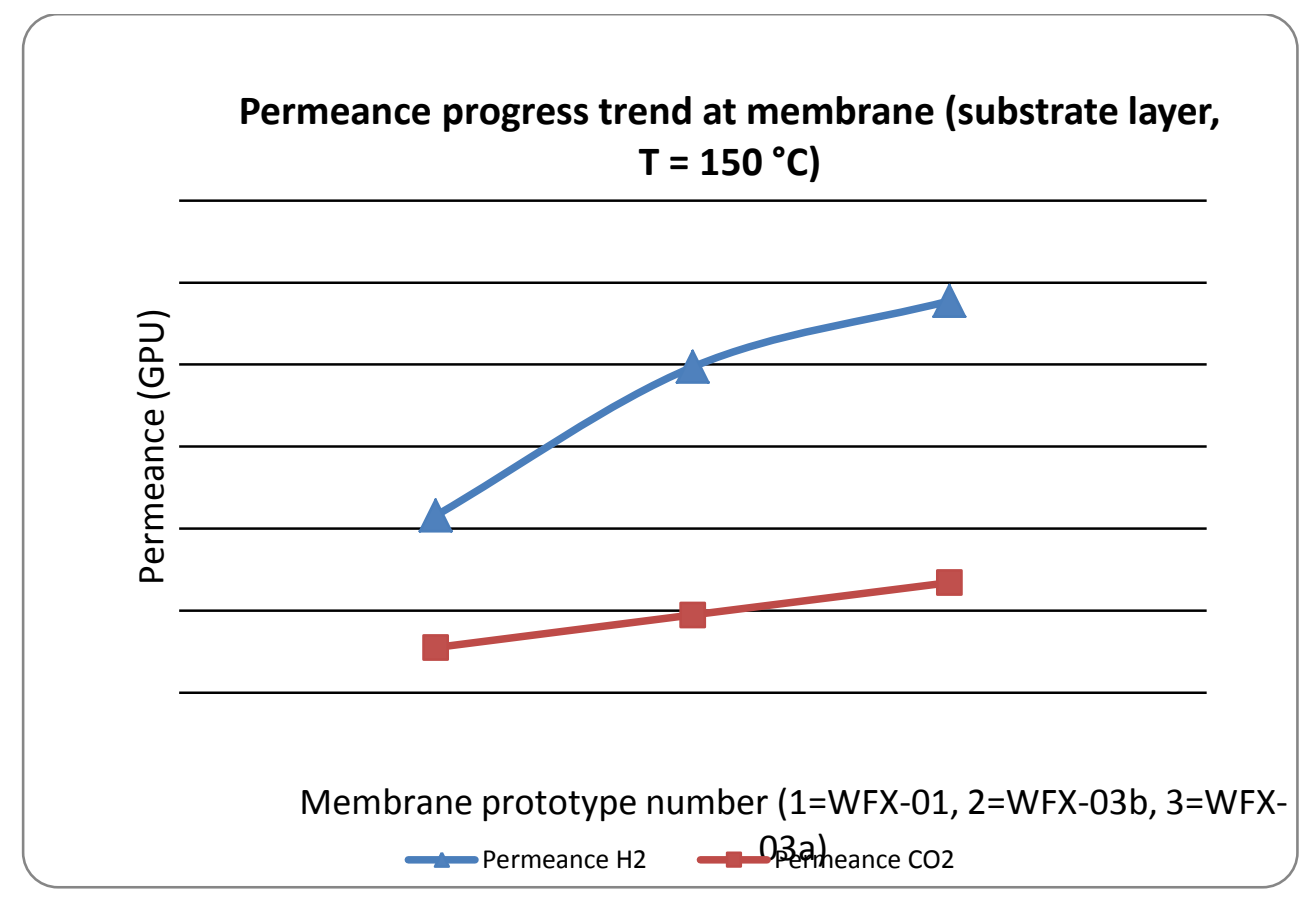

Figure A-34. Progress in the permeation characteristics of the Whitefox membrane substratelayer section. 


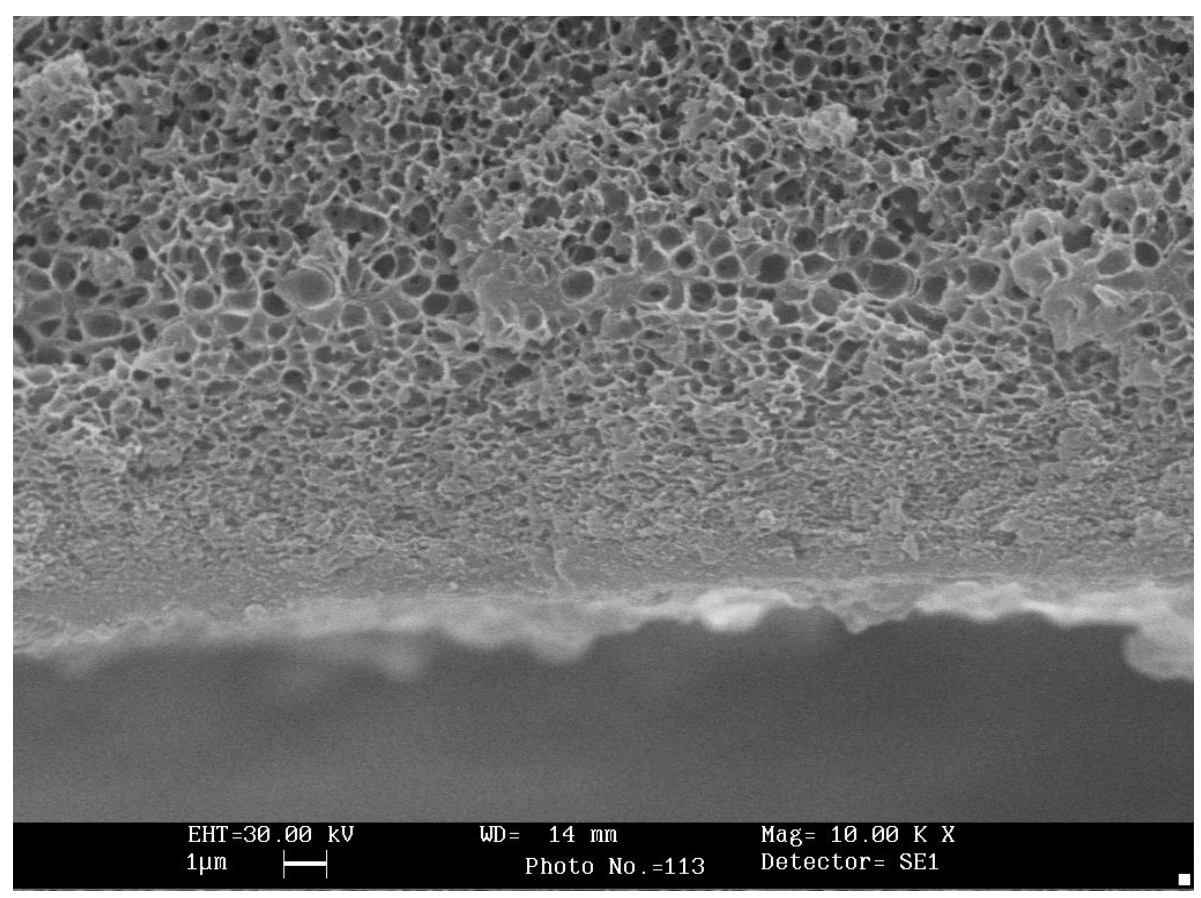

Figure A-35. Cross section of the WFX-07a membrane with a $0.60 \mathrm{~mm}$-substrate + lumen-side selective layer.

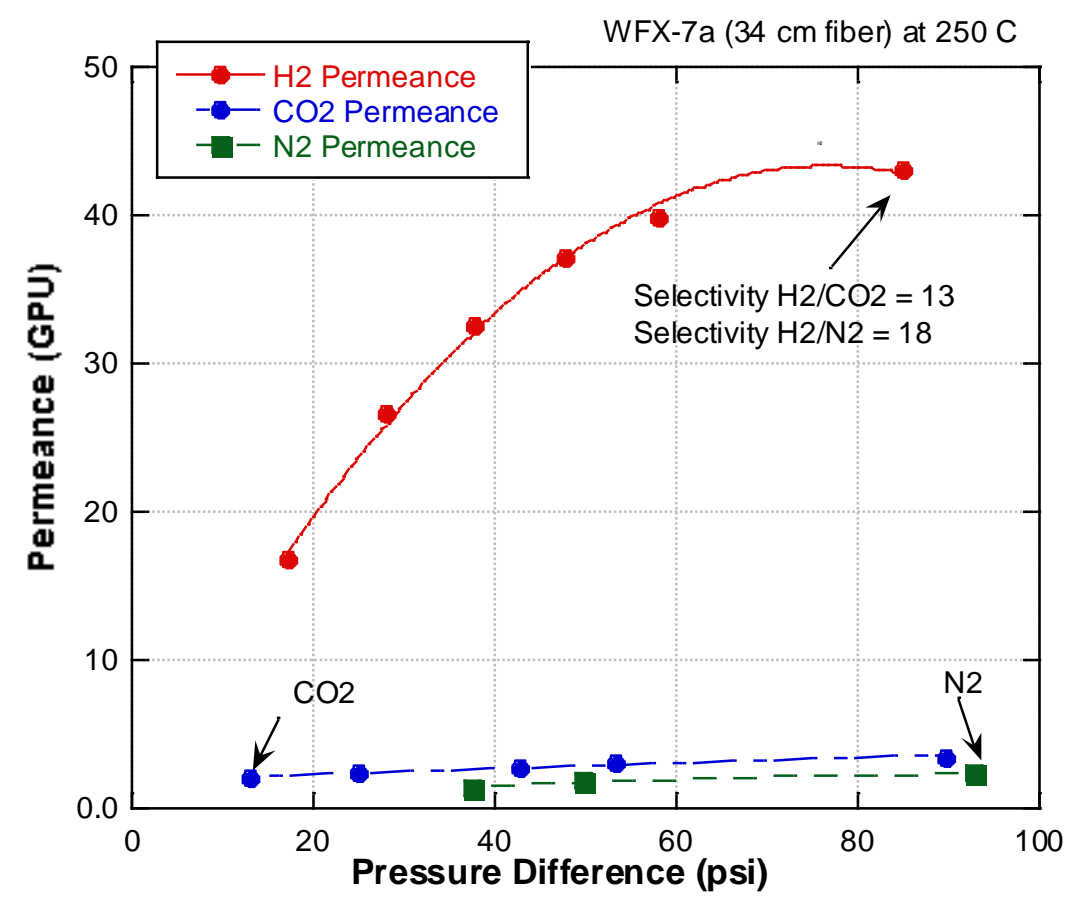

Figure A-36. The measured permeance for $\mathrm{H}_{2}, \mathrm{~N}_{2}$ and $\mathrm{CO}_{2}$ as a function of pressure difference at $250^{\circ} \mathrm{C}$. 
LANL used micro x-ray tomography of the WFX-3b fibers to evaluate the level of macro defects present in these fibers. The macro-voids at and near the lumen surface were of particular interest, as they would have a potential impact on the ability to successfully use a multistep support-selective layer deposition process where a thin selective layer is ultimately desired. Such macro-voids and the resulting defects at the lumen surface would present as large gaps/pores at the lumen surface that are difficult to span using a selective layer coating process designed to produce thin, less than $1 \mu \mathrm{m}$ thick, selective layers.

The WFX-3b support fibers had significantly fewer macro-voids than the previous generation fibers. As shown previously, the substrate fibers have an interconnected porous structure throughout the majority of the fiber that lends itself to minimal flow resistance. Despite the overall decrease in voids throughout the fiber, the WFX-3b fibers still exhibited a statistically significant number of lumen surface and near-lumen surface voids, a quantity that will make realization of a thin, defect-free selective layer at that surface unlikely. Representative slices of lumen surface voids/defects captured by tomography are presented in Figure A-37 below. On average, approximately 25 macro defects per cm of fiber length were detected in the WFX-3b fibers. It is worthy to note that there was some positional influence of the voids there was still a substantial seemingly "random" distribution around the fiber circumference. Additionally, it is clear that the wall thickness of the fibers varies substantially over both the circumference and the length of the fiber (Figures A-37 and A-38). This non-uniformity is likely to be an influential factor in the fiber and defect formation during the multiphase spinning process.

Additionally, SEM and confocal microscopy were used to investigate the roughness of the lumen surface, another factor that could potentially inhibit the deposition of a thin, defect-free selective layer at that surface (Figures A-39 and A-40). These data indicate significant 3D surface features with average peak to valley heights in excess of $1 \mu \mathrm{m}$, significantly larger than the desired selective layer thickness.

This analysis of the surface and the interior of the fiber indicates that while significant progress has been made, additional improvements must be achieved to the hollow fiber support structure before a thin $(<1 \mu \mathrm{m})$, defect free, homogeneous selective layer and correspondingly industrially applicable membrane is realized. 

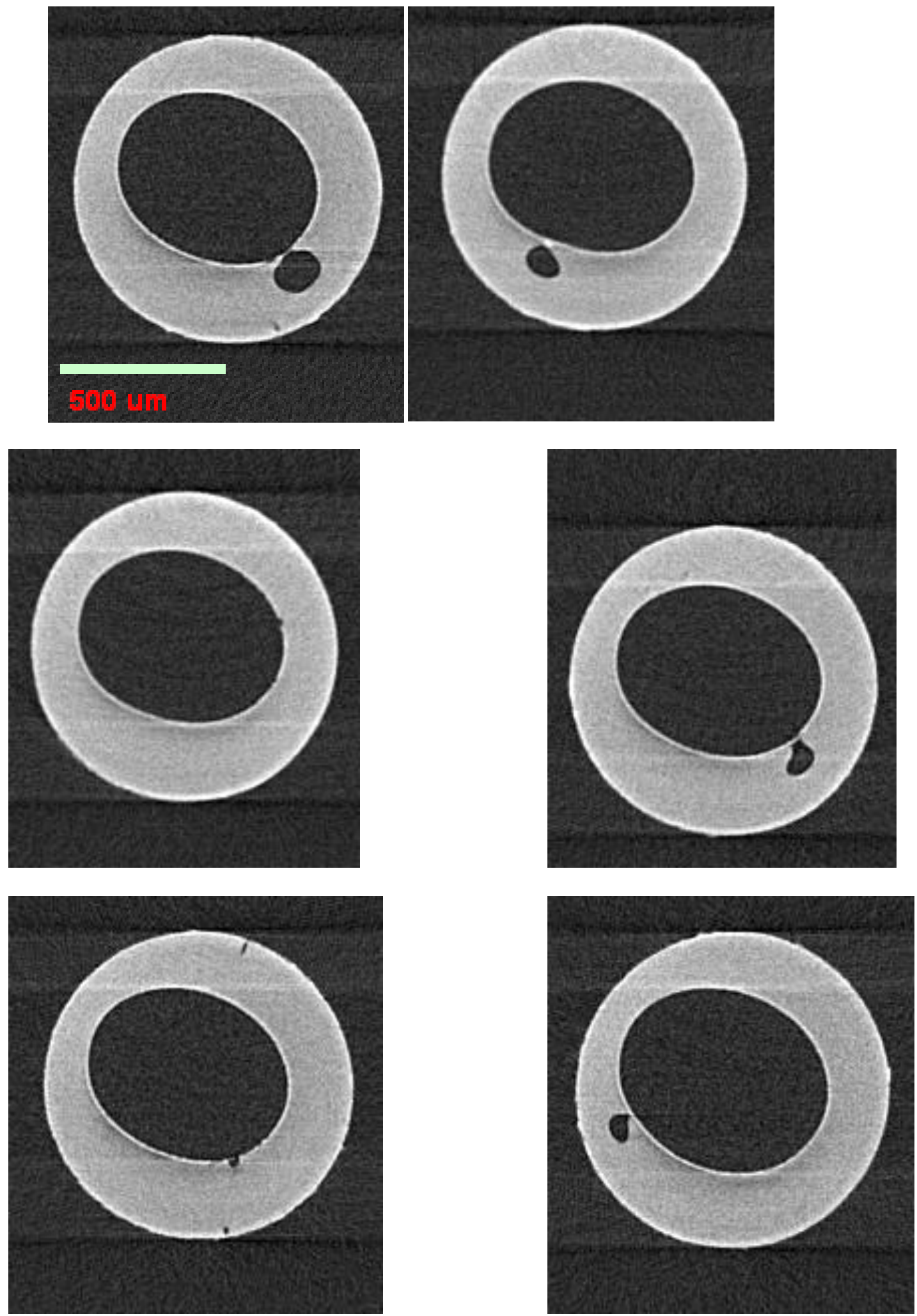

Figure A-37. Micro x-ray tomography of the cross section of the WFX-3b fiber. Note: Each picture represents a slice through the fiber. Data was taken using a $4 \mathrm{X}$ objective where $\sim 0.6 \mathrm{~cm}$ of fiber length comprises 1000 slices. 


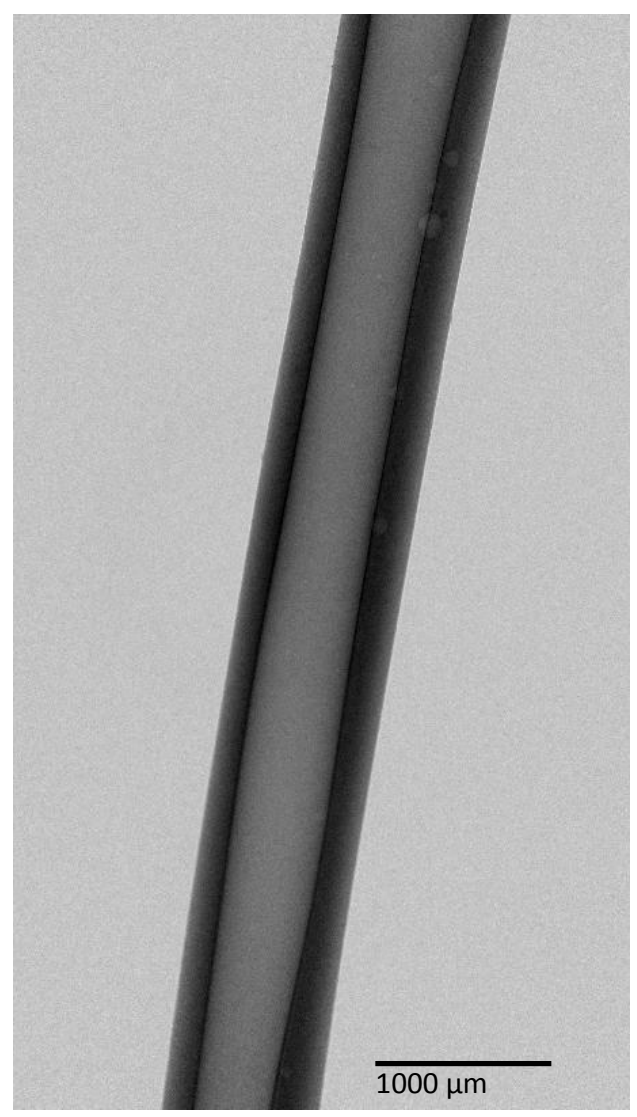

Figure A-38. Micro X-ray tomography along the length of the WFX-3b fiber. Note: Low resolution image of a fiber section illustrative of the varied wall thickness over the fiber length and circumference.
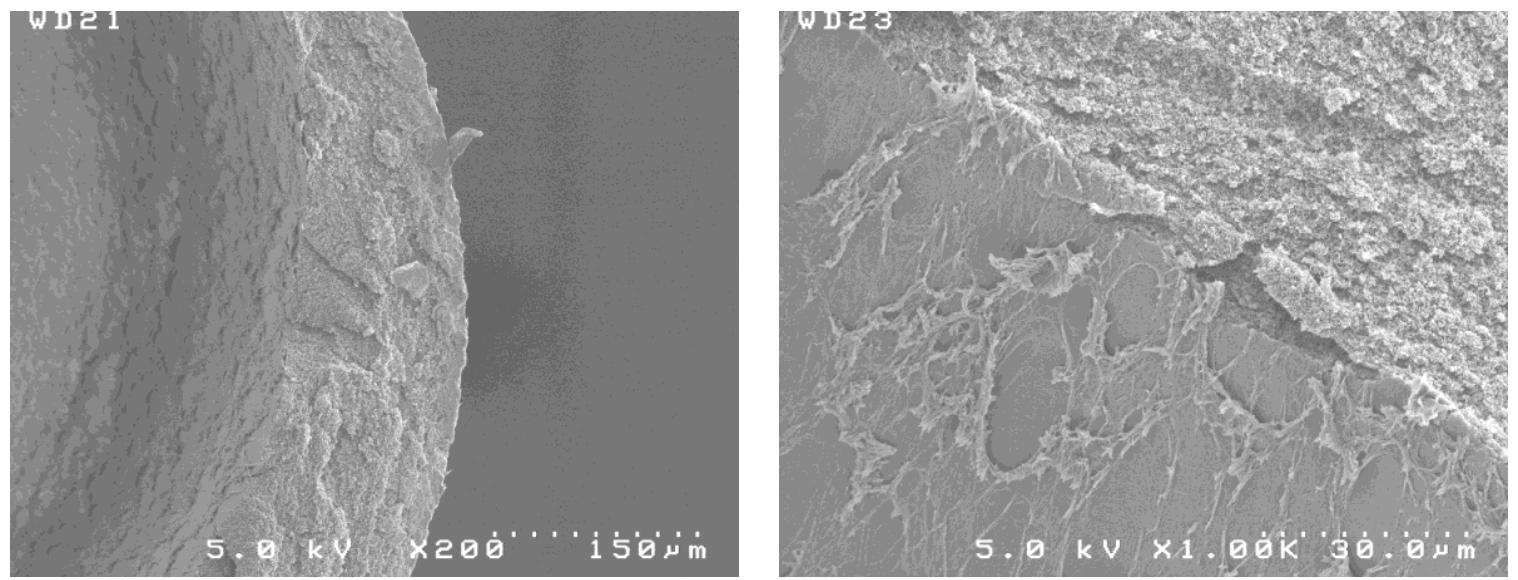

Figure A-39. SEM picture of the cross section of the WFX-3b fiber. 


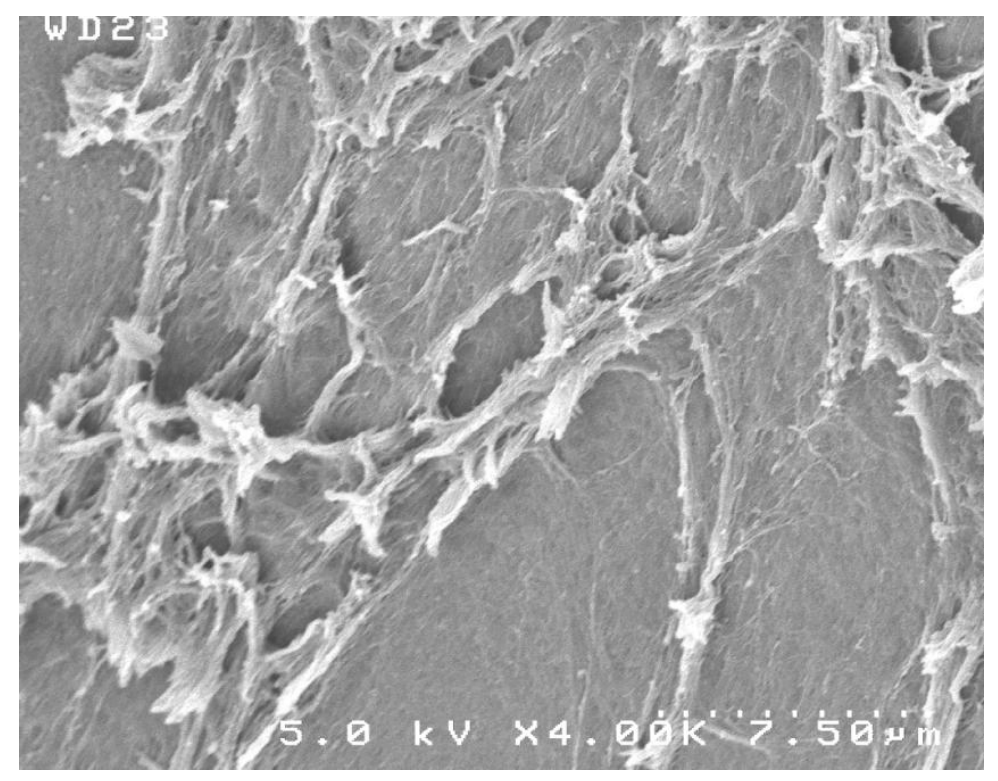

Figure A-40. SEM of the WFX-3b fiber lumen surface.

\section{Development of Hollow Fiber Membrane at WFX (Set 2)}

In fabricating the hollow fiber membrane set 2 , modified procedures were implemented at WFX to deposit selective layers of about 1 to $2 \mu \mathrm{m}$ in thickness with different polymer densities. The following fibers WFX-8b, WFX-9, WFX-10, WFX-16, WFX-23, WFX-27 and WFX-29 were tested at SRI. Among these fibers, WFX-9 had the highest polymer density at the lumen surface while WFX-28 had the least polymer density. All these fibers had apparent selective layer thickness about $2 \mu \mathrm{m}$. Figure A-41 illustrates the cross sections of WFX-27 and WFX-9. The picture shows a gradual decrease in microporosity from the bulk of the membrane toward the lumen side with a very thin dense layer at the surface.

Figure A-42 compares the SEM images of the inner surfaces of WFX-9 and WFX-27. As can be noted from these images, WFX-9 has a reduced surface roughness while WFX- has a high surface roughness. These observations indicate that to obtain a thin and dense layer at the surface, the polymer density near the surface must be high. 

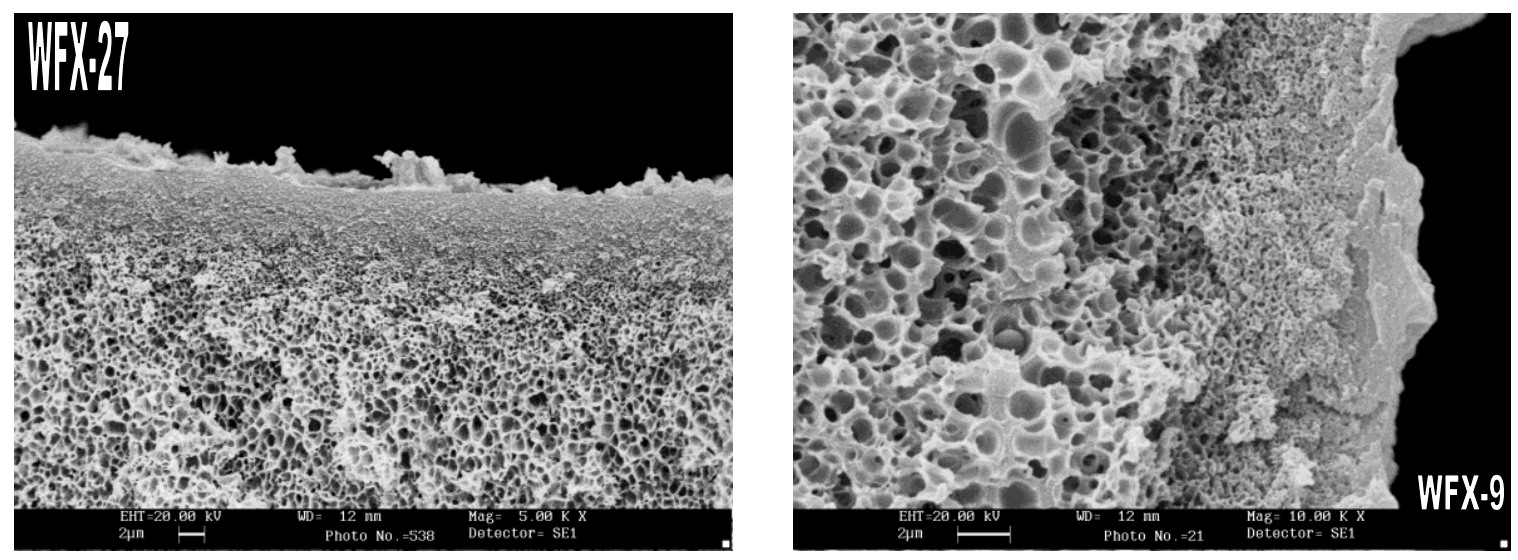

Figure A-41. SEM images of the cross section of the porous substrate fiber with selective layer near the inner edge and the inner surface of the fibers WFX-27 and WFX-9.
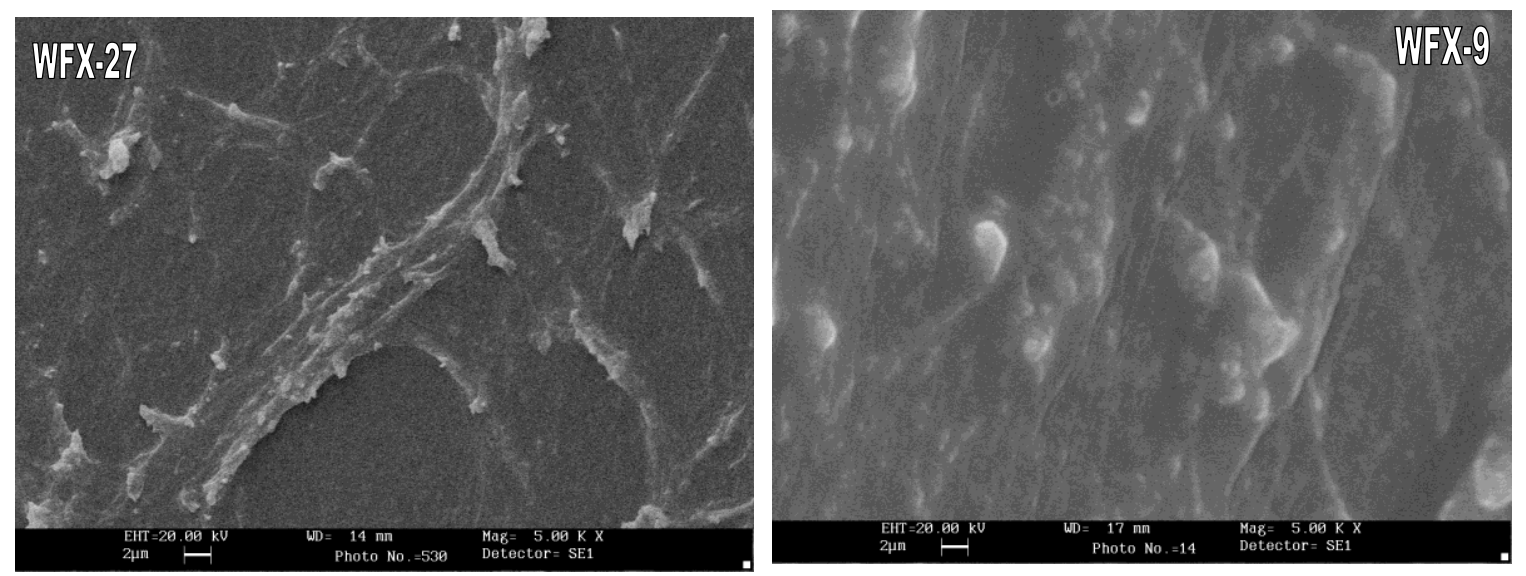

Figure A-42. SEM images of the inner surfaces of the porous substrate fiber of the fiber identified as WFX-9 and WFX-27.

The measured permeation data for fibers WFX-16b, WFX-8b, WFX-9b, WFX-10b, WFX23, WFX-27, and WFX-28 are depicted in Figure A-43. The $\mathrm{H}_{2}$ permeance values were in the range 5 to $125 \mathrm{GPU}$ and the corresponding $\mathrm{H}_{2} / \mathrm{CO}_{2}$ selectivities were in the range 6 to 40 . Most of the tested fibers showed the $\mathrm{H}_{2}$ permeance and $\mathrm{H}_{2} / \mathrm{CO}_{2}$ selectivity higher than that can be achieved by molecular flow permeation. The moderate selectivity in WFX- 28, WFX-23 and WFX-16 is due to the fact that the dense selective layer is not as dense as it needs to be while it had the desired $\mathrm{H}_{2}$ permeance. The moderate permeance in WFX-8, WFX-9, WFX-10, and WFX-27 is due to very high density of the dense layer than it needs to be. 
To evaluate the performance comparison between current series of WFX fibers with other commercial fibers and the first generation fibers from LANL, the corresponding Barrer values need to be used. A comparison of these secondarily coated WFX single bore hollow fibers with LANL previously evaluated polymer-metallic tubular PBI-based membranes and the literature data is presented in a Robeson plot format in Figure A-44. A point worthy of note is that the data for all the tested WFX fibers lies above the upper bound line of the traditional Robeson plot. Additionally, the data for WFX fibers shows a linear relationship. When calculating the corresponding Barrer values for WFX fibers were assumed to have a nominal thickness of $2 \mu \mathrm{m}$ for the dense layer of the asymmetric fibers. Note that a permeance of 1 GPU is corresponds to a membrane exhibiting an intrinsic permeability of 1 barrer and having a layer thickness of $1 \mu \mathrm{m}$.

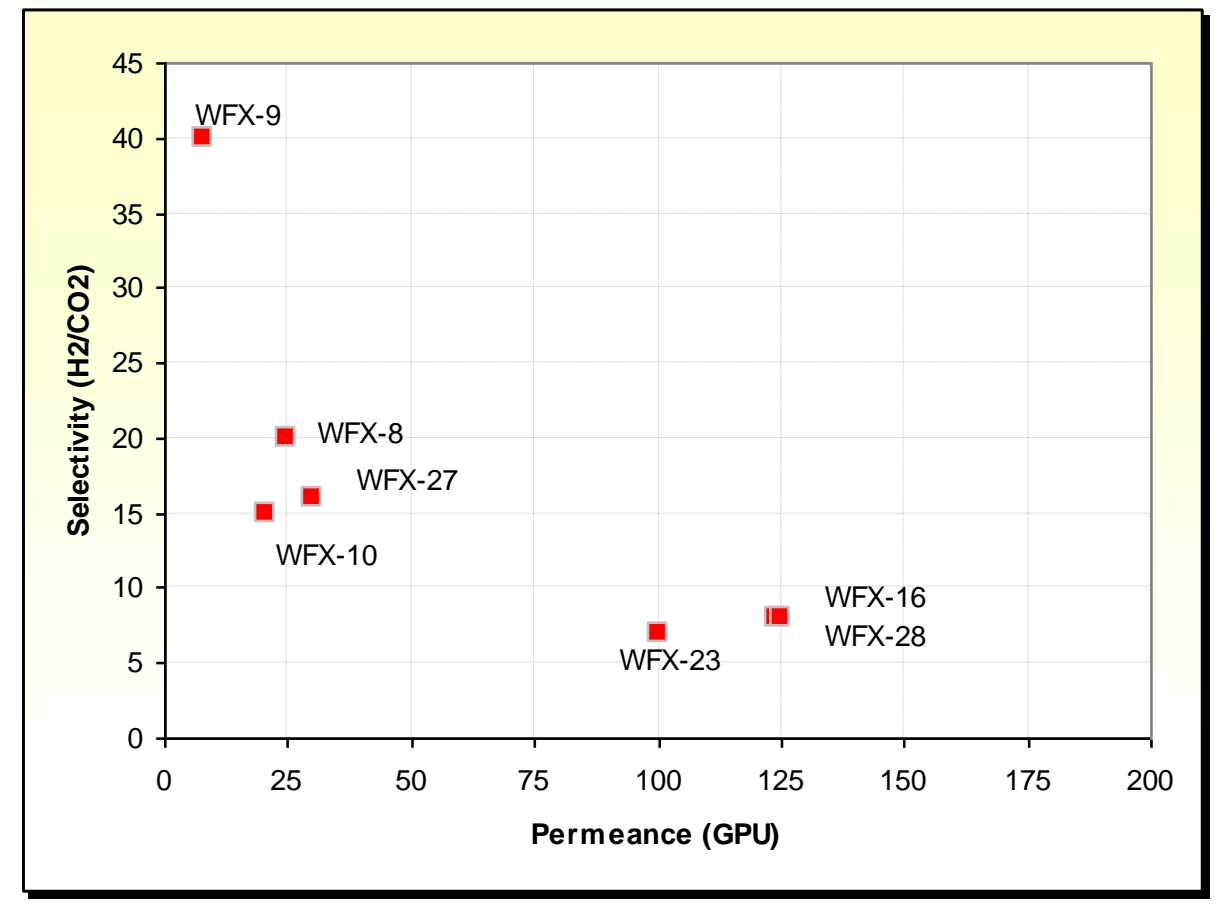

Figure A-43. The measured permeance of $\mathrm{H}_{2}$ in GPU and $\mathrm{H}_{2} / \mathrm{CO}_{2}$ selectivity of selected WFXPBI hollow fiber set 2 at $250^{\circ} \mathrm{C}$. 


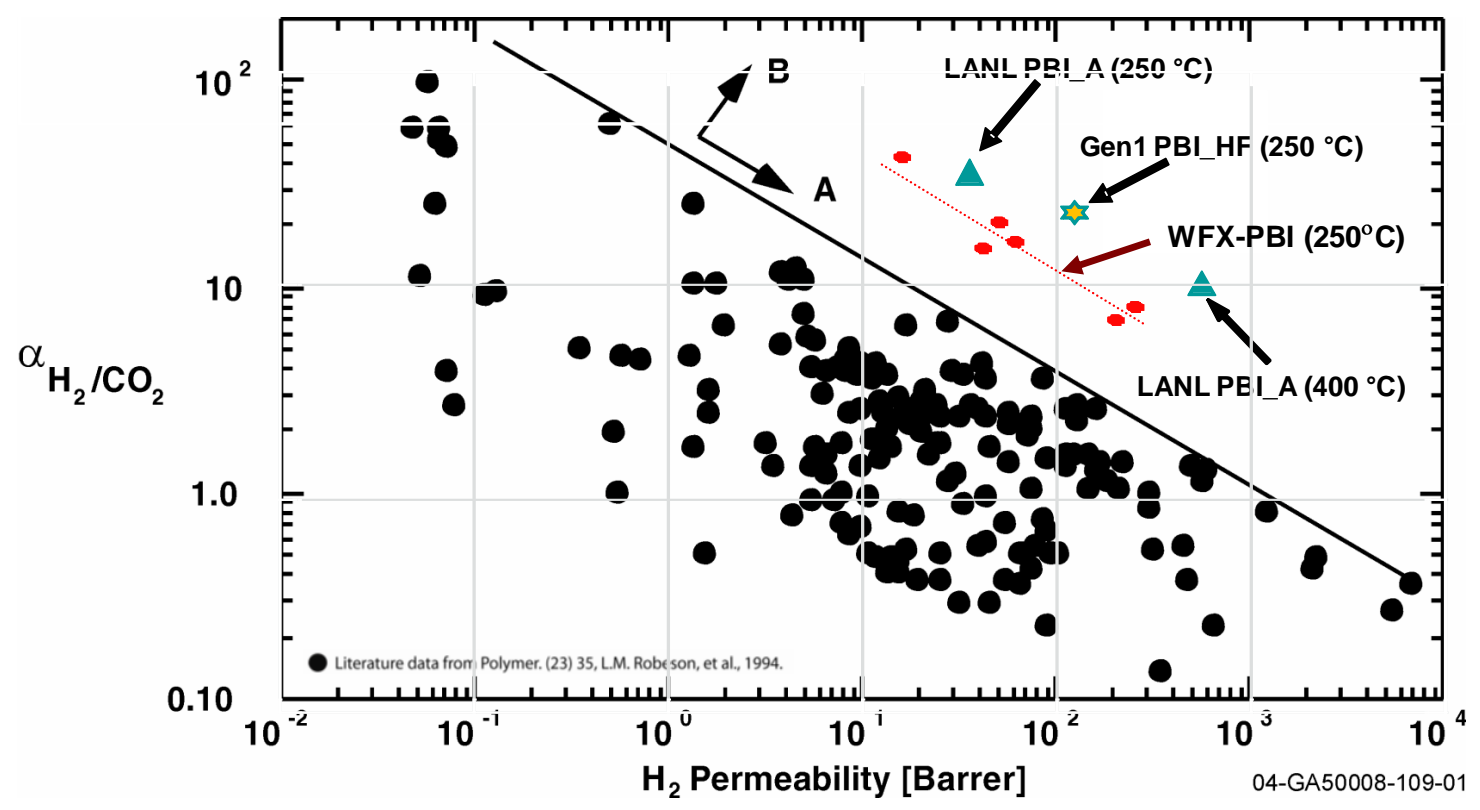

Figure A-44. Trade-off plot between $\mathrm{H}_{2}$ permeability and $\mathrm{H}_{2} / \mathrm{CO}_{2}$ selectivity in polymers.

The next step in optimization process is to reduce the surface roughness of the substrate fiber. Further optimization in the substrate fiber manufacturing process will allow increases in both permeance and selectivity values.

\section{Development of Hollow Fiber Membrane at WFX (Set 3)}

Although the $\mathrm{H}_{2} / \mathrm{CO}_{2}$ selectivity of WFX-9 and WFX-27 were relatively high, the $\mathrm{H}_{2}$ permeance was not at the required level. The relatively high surface roughness of the substrate fiber prevented deposition of a thin and defect-free dense layer that is necessary to obtain both high selectivity and permeance. Hence, WFX used a new substrate fiber with a $0.6 \mathrm{~mm}$ OD and $0.4 \mathrm{~mm}$ ID that had a much reduced surface roughness compared to the earlier tested WFX-3b based fibers. Figure A-45 compares the lumen surface roughness of the old (WFX-3b) and the new fibers series (WFX-00). Since the new fiber has reduced surface roughness, it may be a suitable substrate for depositing an ultra-thin and defect-free dense coating. 

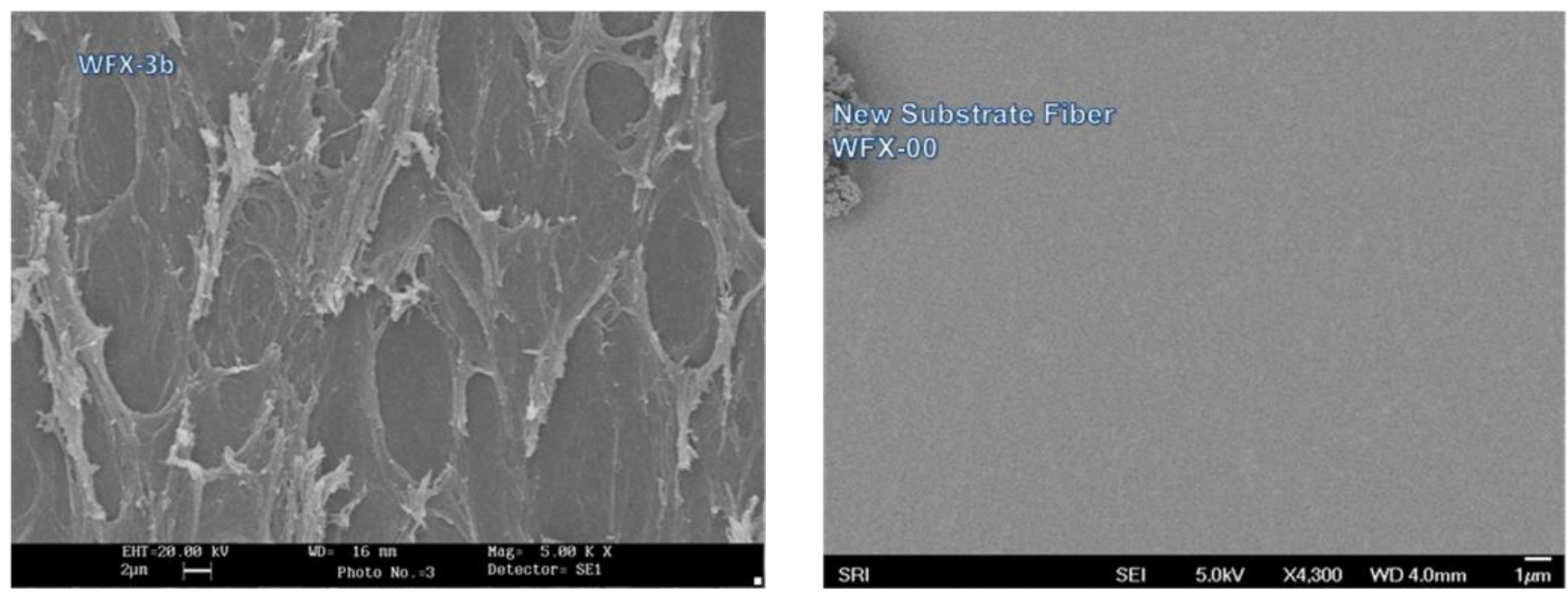

Figure A-45. SEM images of the lumen surfaces of the previous (WFX-3b) and new (WFX-00) porous substrate fiber.

The new substrate fiber (WFX-00) also has an open pore structure necessary to function as a substrate. Figure A-46 shows the images of the cross section of the new substrate fiber at low and high magnifications. The images show that the interior of the fiber is highly porous and has many inter-connected pores. The coating procedure was modified to accommodate the reduced diameter of and the wall thickness of the new fiber in comparison to earlier substrate fibers. The modifications involved identification of the optimum PBI concentration in the coating solution and the pressure at which the solution was injected inside the fiber. A series of fibers coated fibers based on this substrate fiber were prepared by Whitefox and tested at SRI. These fibers are identified as WFX-34 through WFX-38.
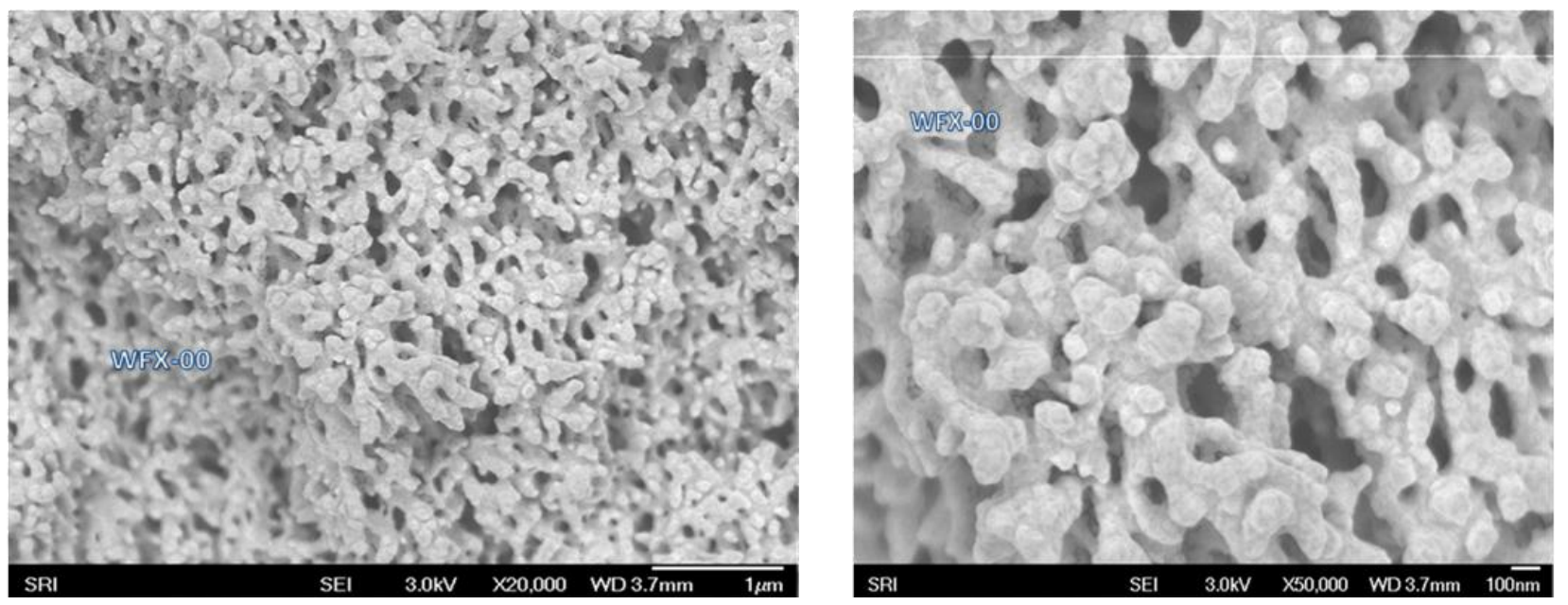

Figure A-46. SEM image of the cross section of the porous substrate fiber at low and high magnifications. 
Several fibers based on the new substrate (WFX-34, WFX-35, WFX-36, WFX-37 and WFX38) were tested at SRI to characterize its morphology and determine $\mathrm{H}_{2} / \mathrm{CO}_{2}$ selectivity and $\mathrm{H}_{2}$ permeance. These fibers had an apparent selective layer thickness less than $0.5 \mu \mathrm{m}$ on the lumen side of the fiber. Figure A-47 illustrates the cross sections of WFX-00 (substrate fiber without coating) and WFX-35 (a coated fiber). Unlike in WFX-3b substrate which had a gradual decrease in the porosity from the bulk of the membrane toward the lumen side, this new fiber had a continuum of open porosity area with little gradation. In addition the new coating formed a very thin, dense, and adherent layer $(0.1 \mu \mathrm{m})$ at the surface.
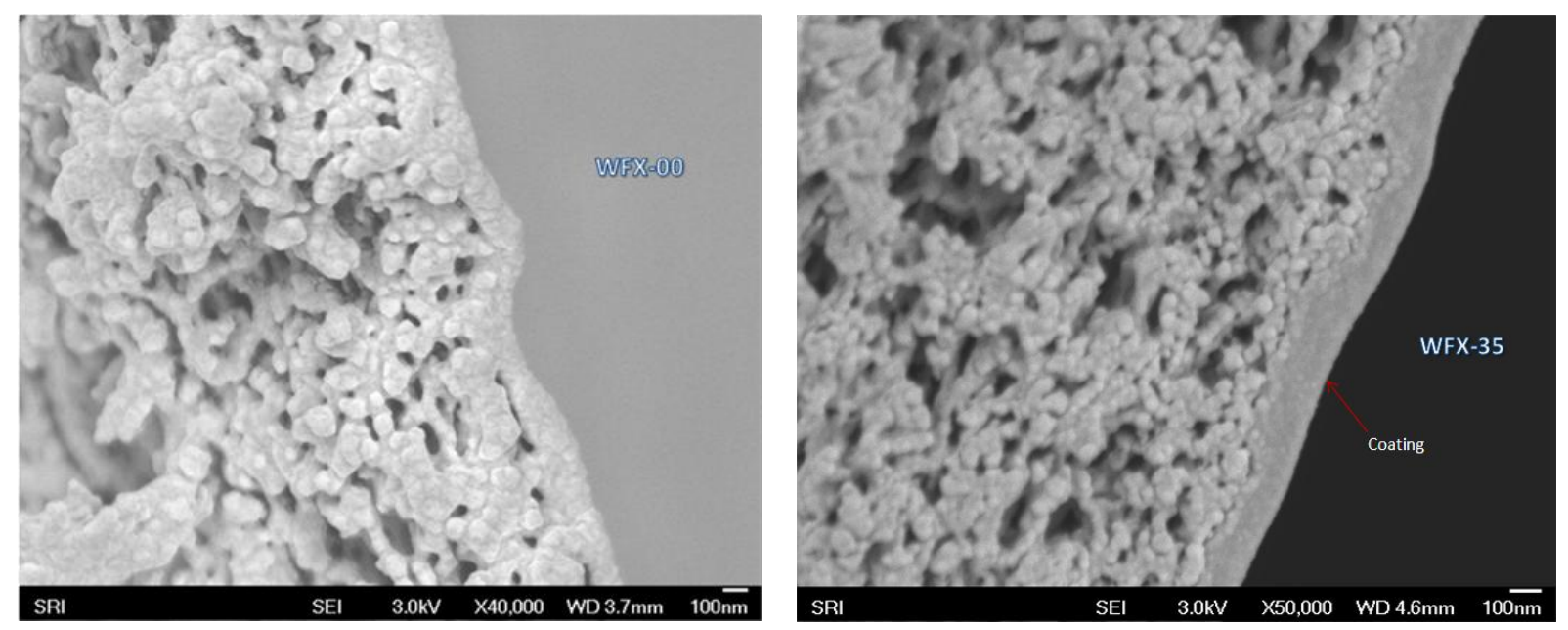

Figure A-47. SEM images of the inner surfaces of the porous substrate and coated fibers. Note: The left and right images correspond to substrate (WFX-00) and the coated fiber (WFX-35).

The SEM images of the cross section and the lumen surface of WFX-34, wFX-37, and WFX -38 are shown in Figure A-48. They indicate a progression in the thickness of the coating and a decrease in the defects on the lumen side of the fiber. 


\section{Cross section images}

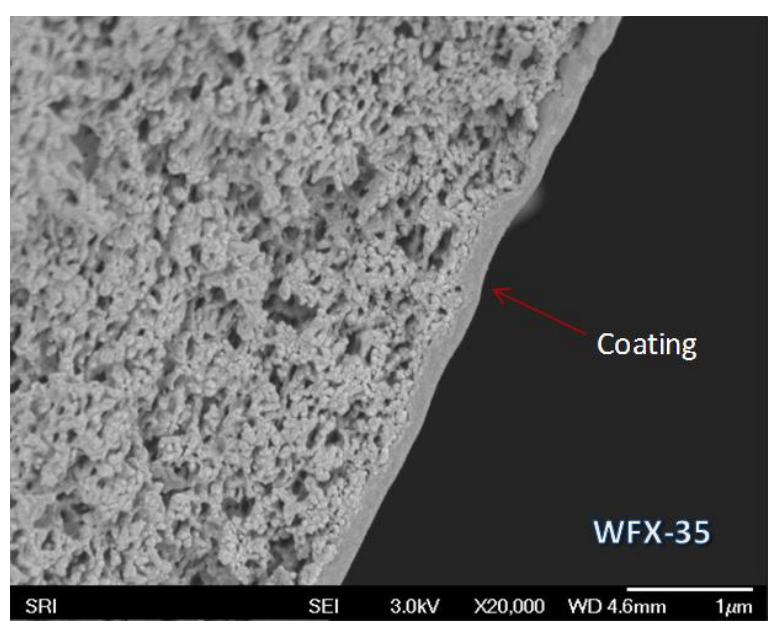

WFX-35

WFX-37

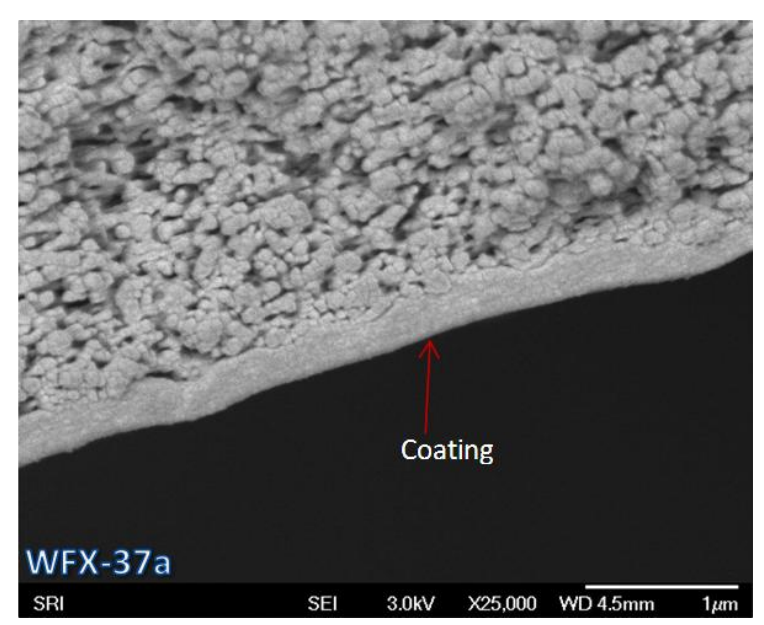

\section{Lumen Surface images}
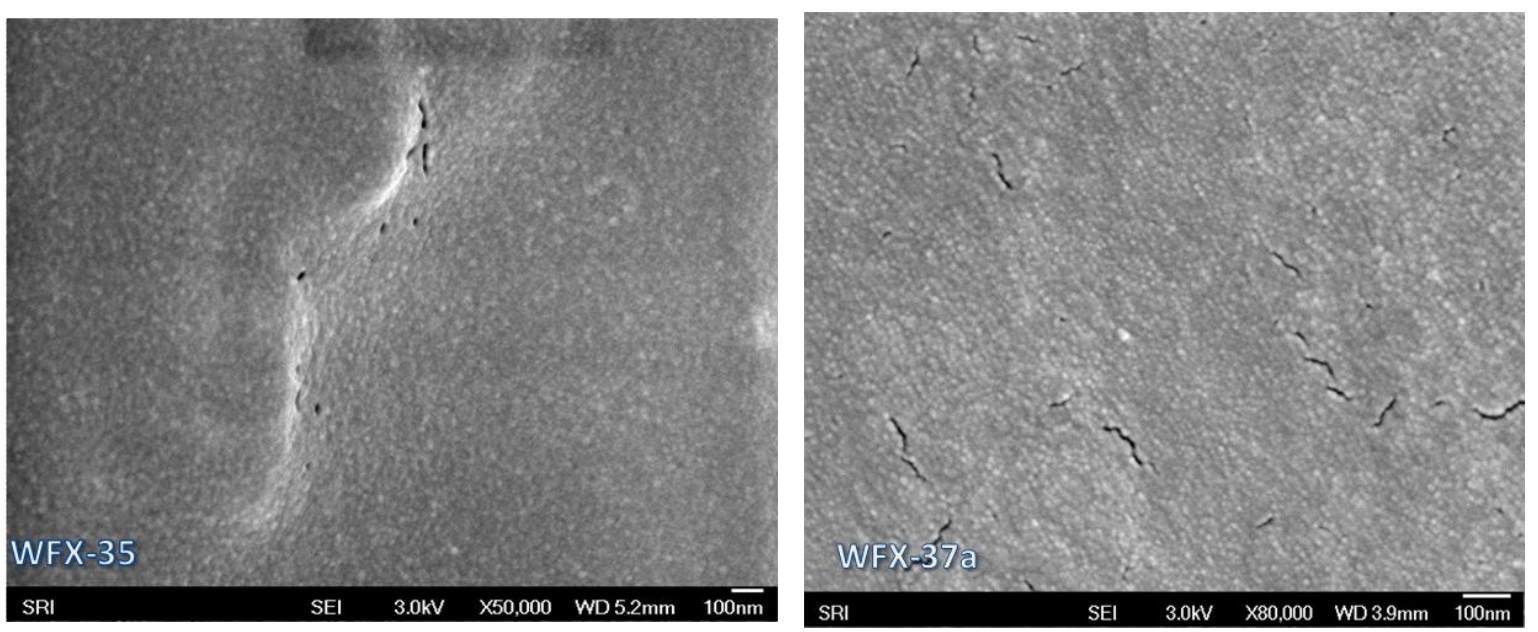

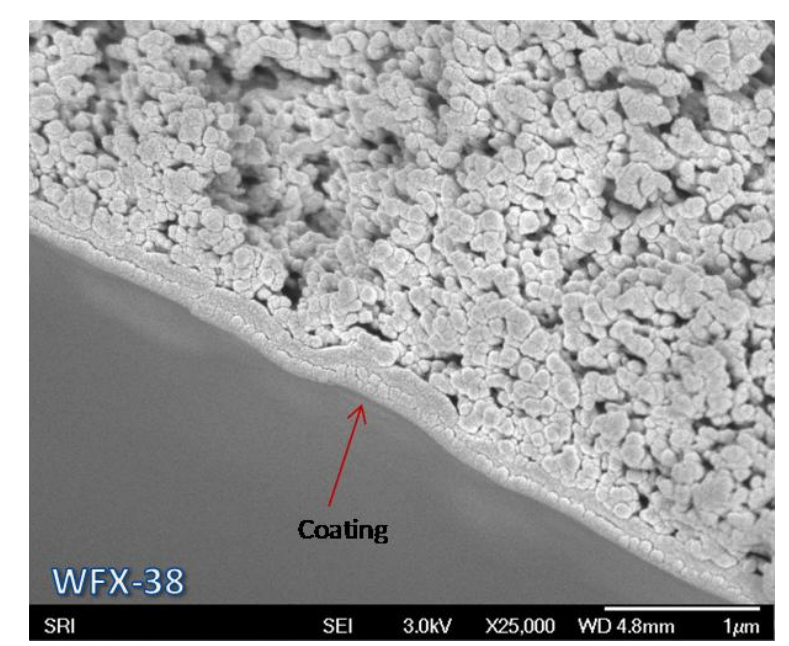

WFX-38

Figure A-48. SEM images of the cross section and lumen surface of coated fibers. 
The measured permeation data for coated fibers WFX-34, WFX-35, WFX-36, WFX37 and WFX-38 are depicted in Figures A-49 and A-50. In these plots, both measured $\mathrm{H}_{2}$ and $\mathrm{CO}_{2}$ permeances at $250^{\circ} \mathrm{C}$ are presented as a function of the pressure difference between lumen and the shell side of the fiber. In these tests, pressure was applied from the shell side. The observed $\mathrm{H}_{2}$ permeance values for coated fibers were in the range 250 to $600 \mathrm{GPU}$ and the corresponding $\mathrm{H}_{2} / \mathrm{CO}_{2}$ selectivities were in the range 5 to 14 (Table A-7). These PBI hollow fibers showed $\mathrm{H}_{2} / \mathrm{CO}_{2}$ selectivity higher than that can be achieved by molecular flow permeation. The moderate selectivity in these fibers and the relatively high $\mathrm{H}_{2}$ permeance are due to the fact that the ultra-thin dense selective layer $(0.1$ to $0.2 \mu \mathrm{m})$ is not as dense as it needs to be. However, the data indicate that in these ultra-thin layer coatings, small changes in the coating thickness can have a profound effect on both selectivity and permeability.

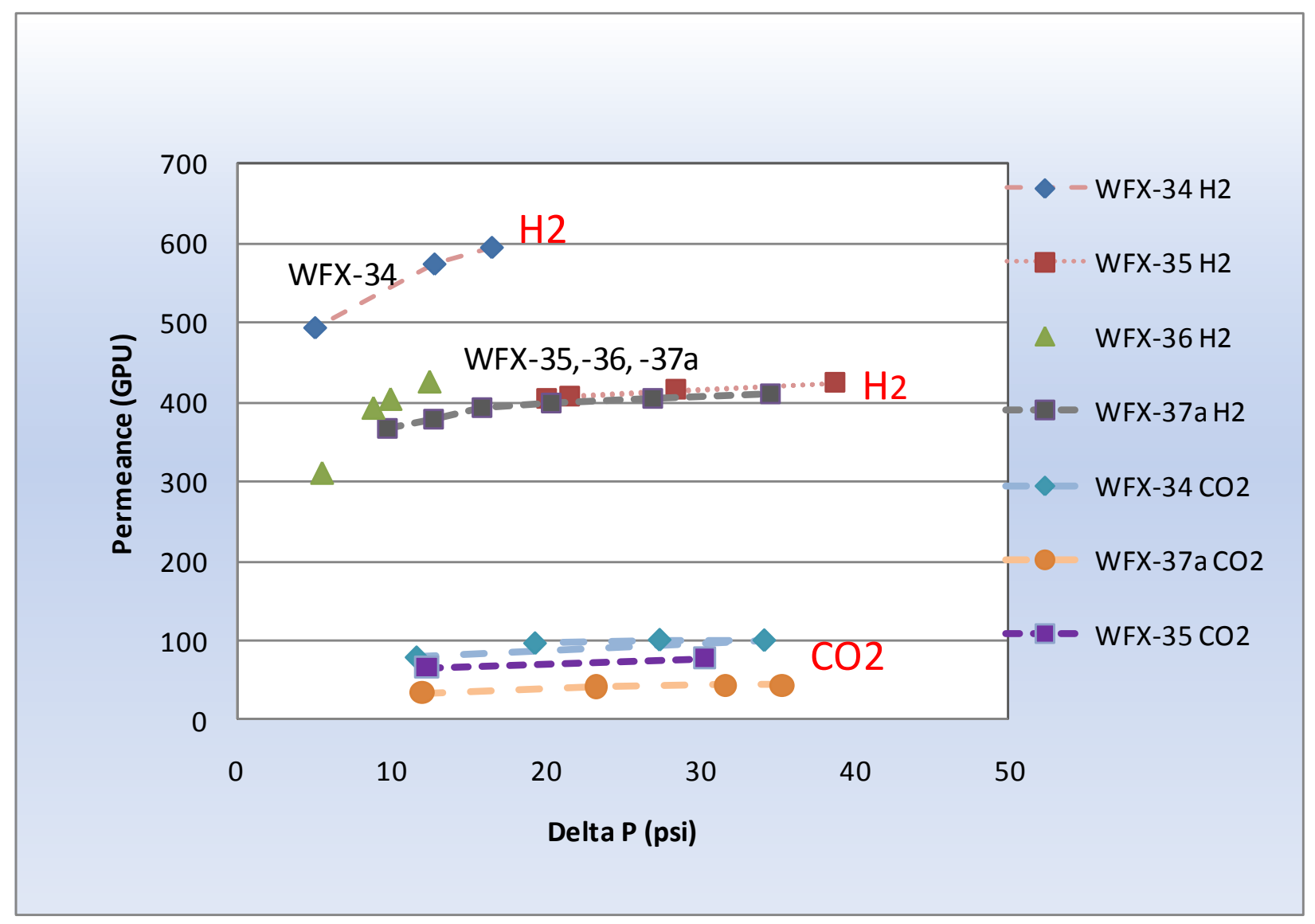

Figure A-49. The measured permeance of $\mathrm{H}_{2}$ and $\mathrm{CO}_{2}$ of WFX-34, WFX-35, WFX-36 and WFX -37 at $250^{\circ} \mathrm{C}$. 


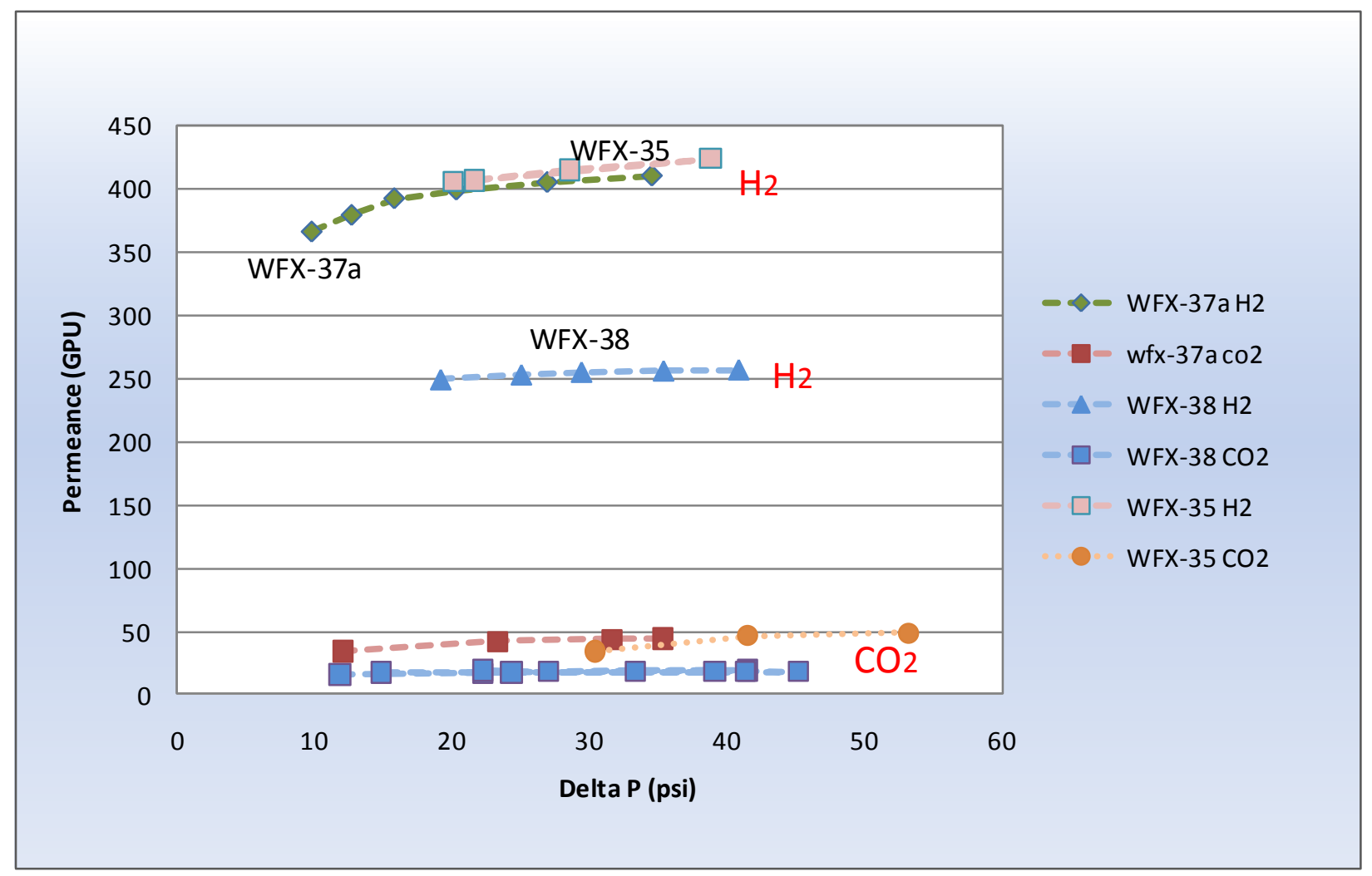

Figure A-50. Comparison of the measured permeance of $\mathrm{H}_{2}$ and $\mathrm{CO}_{2}$ of WFX-37 and WFX-38 at $250^{\circ} \mathrm{C}$.

Table A-7. The $\mathrm{H}_{2}$ permeance and $\mathrm{H}_{2} / \mathrm{CO}_{2}$ selectivity of the WFX fibers at $250^{\circ} \mathrm{C}$.

\begin{tabular}{|l|c|c|c|}
\hline \multicolumn{1}{|c|}{ Fiber ID } & $\begin{array}{c}\text { Coating Thickness } \\
(\boldsymbol{\mu} \mathbf{m})\end{array}$ & $\begin{array}{c}\mathbf{H}_{\mathbf{2}} \text { Permeance } \\
(\mathbf{G P U})\end{array}$ & $\begin{array}{c}\text { Selectivity } \\
\left(\mathbf{H}_{\mathbf{2}} / \mathbf{C O}_{\mathbf{2}}\right)\end{array}$ \\
\hline WFX-00 (Substrate) & No Coating & 2200 & 4 \\
\hline WFX-34 & $<0.1$ & 554 & 6 \\
\hline WFX-35 & $\sim 0.2$ & 425 & 9 \\
\hline WFX-36 & $\sim 0.2$ & 420 & 5 \\
\hline WFX-37a & $\sim 0.2$ & 408 & 14 \\
\hline WFX-38 & $\sim 0.3$ & 259 & \\
\hline
\end{tabular}


Figure A-51 compares the permeation data of the coated fibers based on new WFX00 substrates with those that were tested previously. The new set of fibers exhibited a higher $\mathrm{H}_{2}$ permeance and increased selectivity than the old set of fibers. The trend shown in Figure A-51 is a clear indication that the desired selectivity and permeance is achievable with current WFX-00 series fibers.

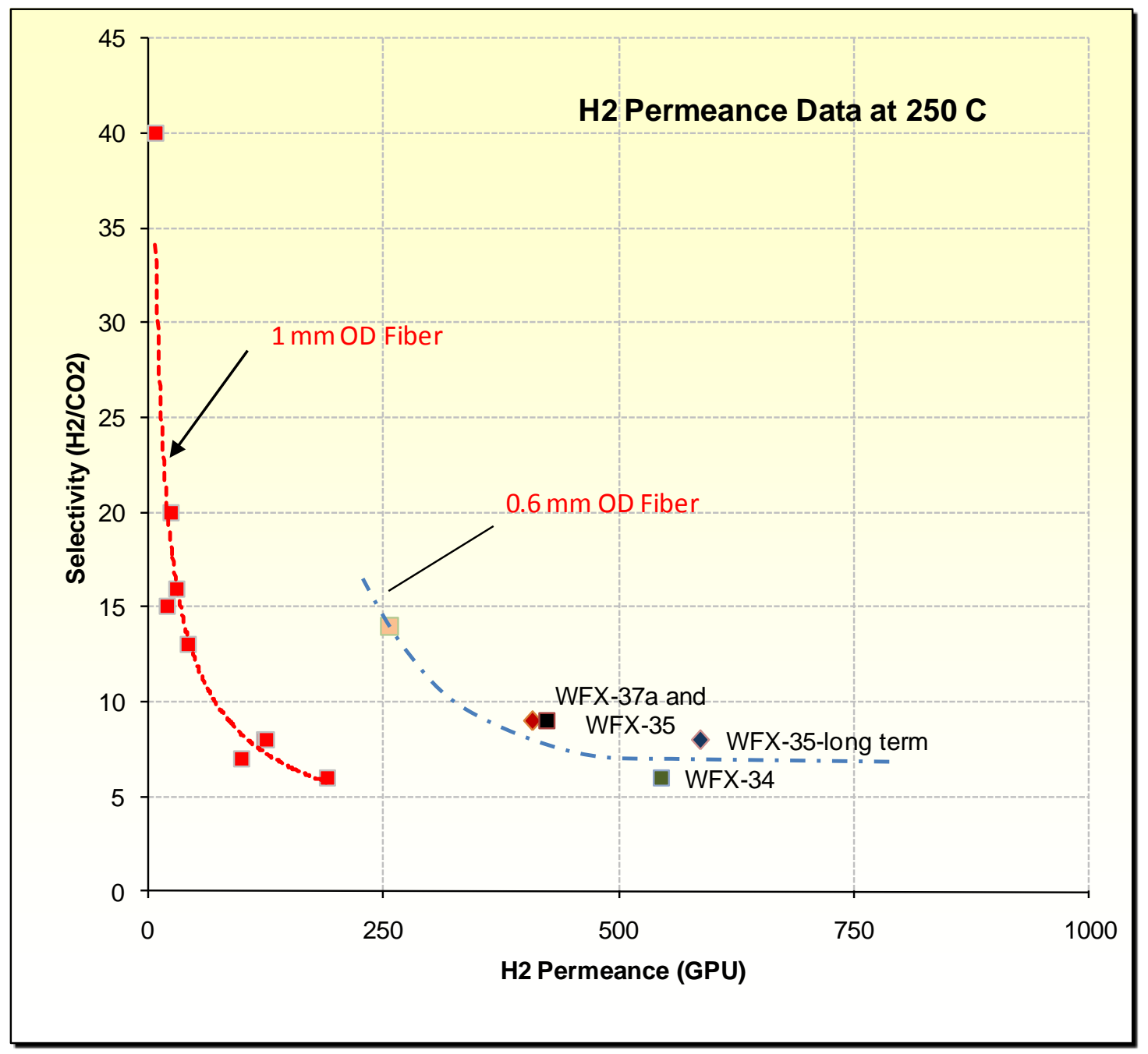

Figure A-51. The measured permeance of $\mathrm{H}_{2}$ in GPU and $\mathrm{H}_{2} / \mathrm{CO}_{2}$ selectivity of selected WFX-PBI hollow fiber at $250^{\circ} \mathrm{C}$. 


\section{Development of Hollow Fiber Membrane at WFX (Set 4)}

The previously described membrane Set 3 achieved a $\mathrm{H}_{2} / \mathrm{CO}_{2}$ selectivity with a $\mathrm{H}_{2}$ permeance of $250 \mathrm{GPU}$ at $250^{\circ} \mathrm{C}$. However, a significant variation in the fiber performances observed for multiple fibers that were coated using the same procedure. This problem was identified and WFX took steps to improve the quality control.

Figure A-52 illustrates the SEM images of the lumen surface of the untreated porous substrate fiber (WFX-00) at low and high magnifications. The image of the lumen surface of WFX-00 shows longitudinal narrow pores that of varying length. Unless stabilized, these pores could invariably affect the morphology of the selective coating. Therefore, the porous substrate (WFX-00) was stabilized by heat treatment ranging from $250^{\circ}$ and $300^{\circ} \mathrm{C}$ to remove the solvent and enhance the cross-linking to reduce swelling. A temperature ramp of $2^{\circ} \mathrm{C} / \mathrm{min}$ was used in both preheating and post heating tests. Figures A-53 and A-54 show the images of the cross section and the lumen surface of the heat treated porous substrate fiber that is identified as WFX-43b at low and high magnifications. The comparison of the SEM images of the lumen surfaces of the treated and untreated fibers indicates that the heat treatment had modified the morphology of the surface to reduce the longitudinal pores on the surface thereby making a better surface for applying a defect free coating. In addition, the current porous substrate has a continuum of open porosity area with little gradation towards the end of the lumen surface (unlike in purely asymmetric membranes), therefore, it is necessary to seal the surface in order to apply submicron thickness coatings.

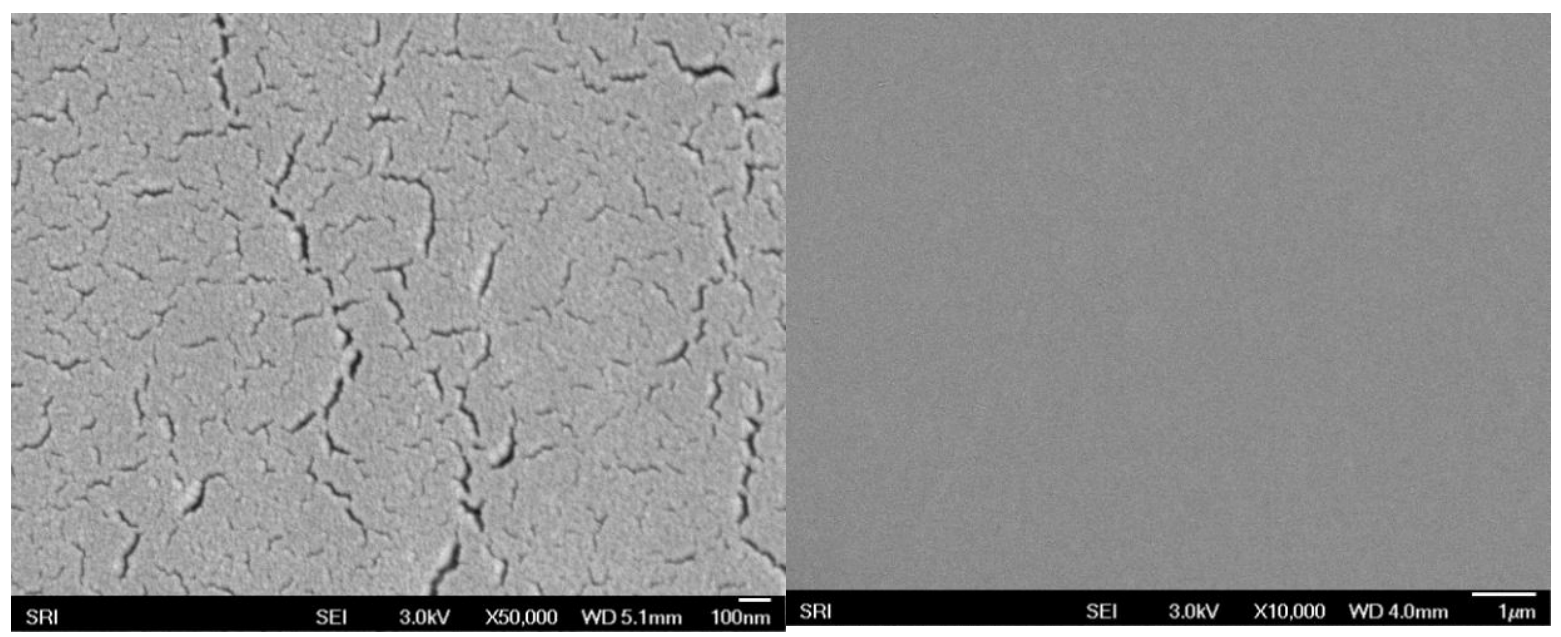

Figure A-52. SEM image of the lumen surface of the porous substrate fiber (WFX-00) at low and high magnifications. 

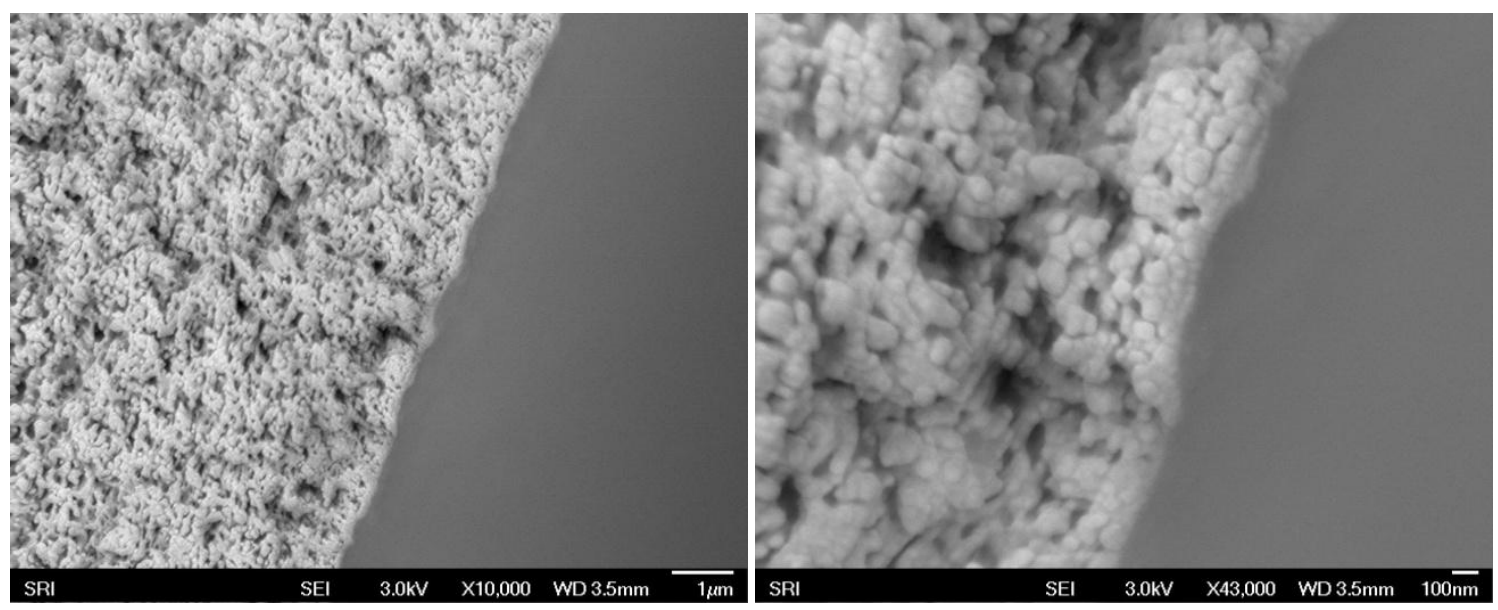

Figure A-53. SEM images of the cross section near the inner surfaces of the treated porous substrate (WFX-43b).
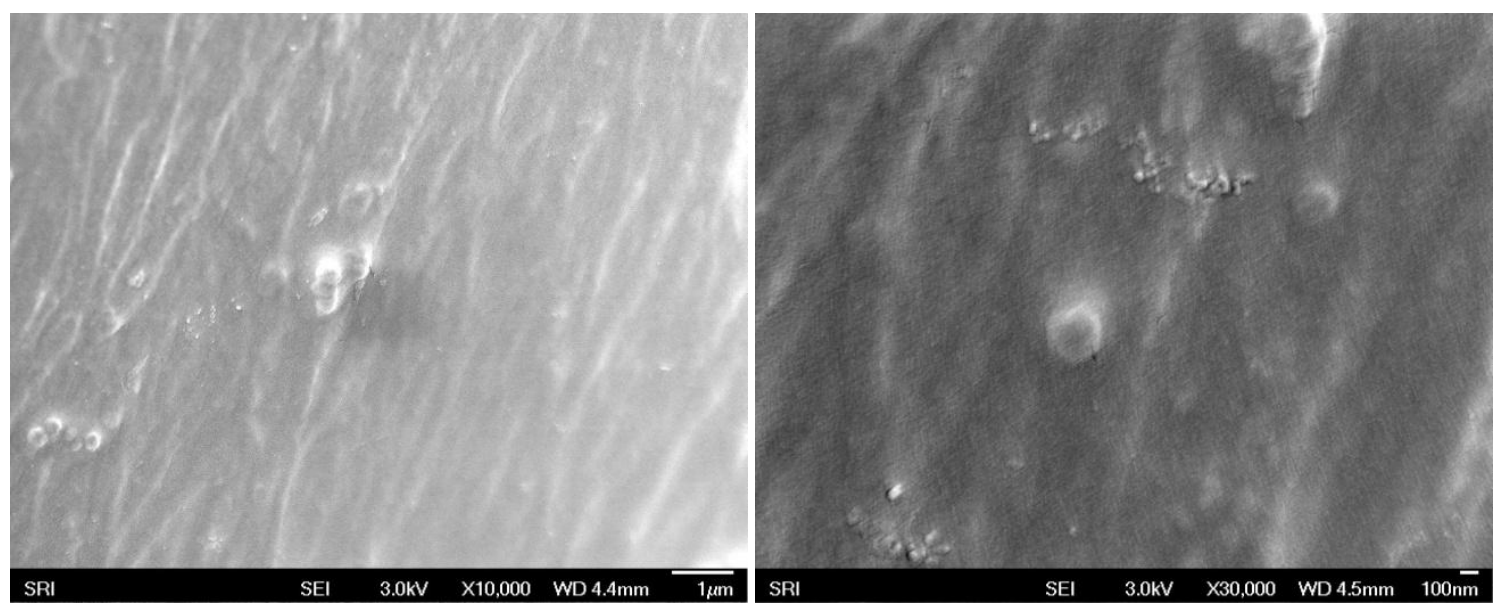

Figure A-54. SEM images of the inner surfaces of the treated porous substrate (WFX-43b).

The Set 4 fibers tested include WFX-39 through WFX-50. Fibers WFX-39, WFX-40 and WFX-41 that were prepared by coating untreated (without heat treatment) substrate fibers and they had a single selective coating layer. Fibers WFX-44 through WFX-50 were prepared from heat treated substrate fibers and they had either a single a double coating layer. In selected cases, prepared fibers were subjected to a post heat treatment at $250^{\circ}$ and $300^{\circ} \mathrm{C}$ prior to applying the second coating. (WFX-46 and WFX-50). Fibers, 
WFX-46, WFX-49 and WFX-50 have seen $300^{\circ} \mathrm{C}$ either during pretreatment of the substrate fiber or during the post-treatment prior to applying a second coating. SRI characterized the morphology and determined the $\mathrm{H}_{2} / \mathrm{CO}_{2}$ selectivity and $\mathrm{H}_{2}$ permeance. These fibers had an apparent selective layer thickness less than $0.3 \mu \mathrm{m}$ on the lumen side of the fiber. Figures A-55 and A-56 illustrate the SEM image of the cross section and the lumen surface of a coated fiber (WFX-45). They indicate a progression in the thickness of the coating and a decrease in the defects on the lumen side of the fiber with the pretreatment and post-treatment procedure.

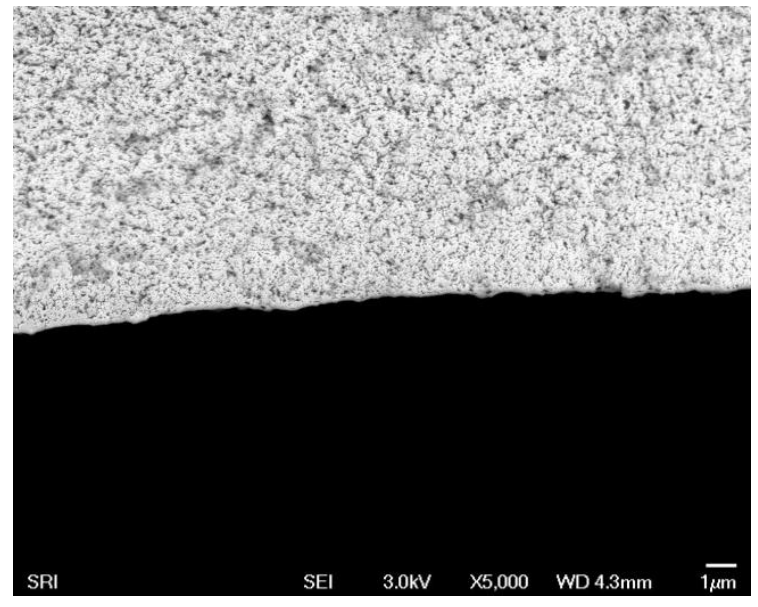

Cross-section lumen

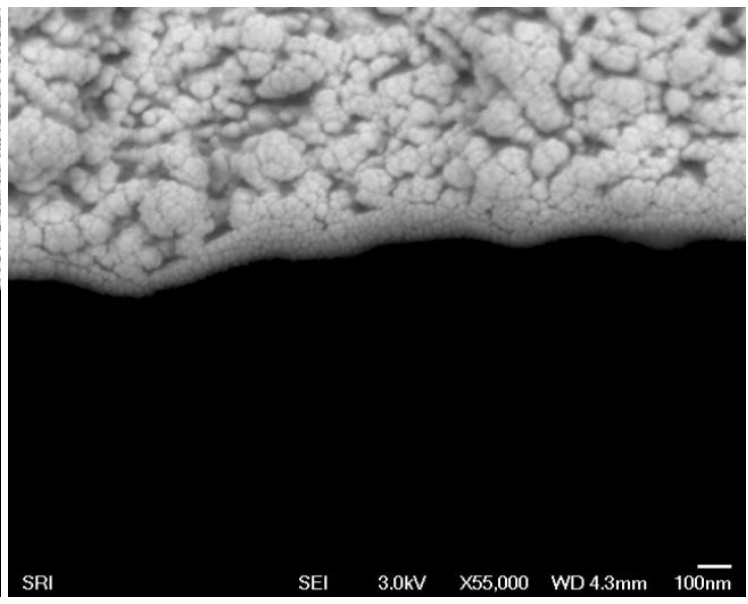

Cross-section lumen

Figure A-55. SEM images of the cross section of WFX-45 (coated fiber).

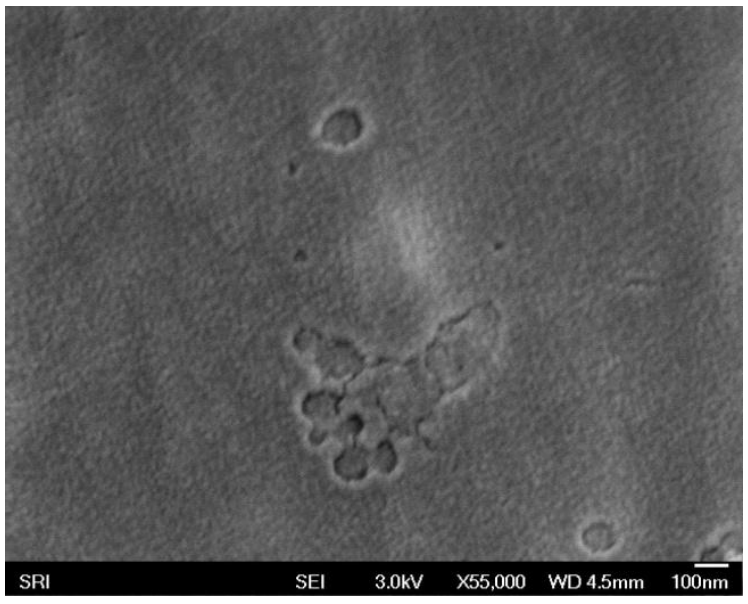

Lumen surface

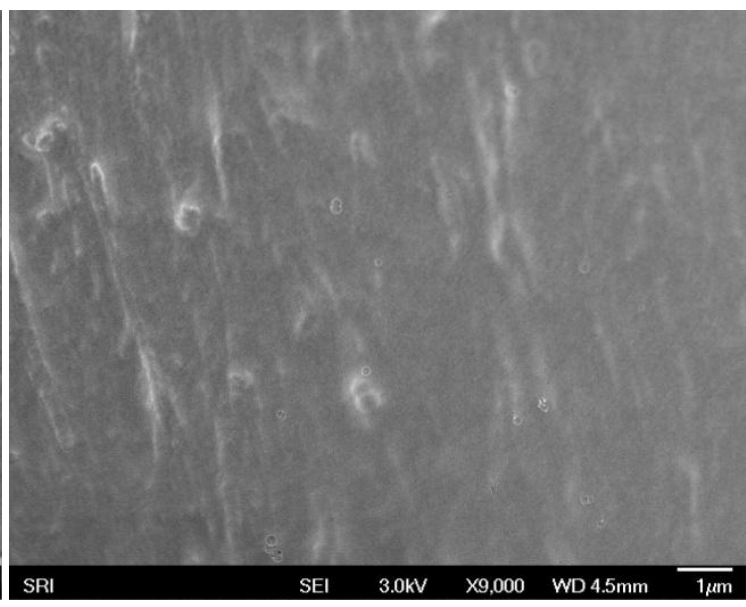

Lumen surface

Figure A-56. SEM images of the lumen surface of WFX-45 (coated fiber). 
The measured permeation data and other details for fibers WFX-39 through WFX-50 are given in Table A-8. Figure A-57 illustrates the permeation data for WFX-45 and WFX-44 as a comparison of the performance of fibers with a single and a double layer. In this plot, both measured $\mathrm{H}_{2}$ and $\mathrm{CO}_{2}$ permeances at $250^{\circ} \mathrm{C}$ are presented as a function of the pressure difference between lumen and the shell side of the fiber. In these tests, pressure was applied from the shell side. The observed $\mathrm{H}_{2}$ permeance values for coated fibers were in the range 68 to $517 \mathrm{GPU}$ and the corresponding $\mathrm{H}_{2} / \mathrm{CO}_{2}$ selectivities were in the range 4 to 38 ; the details of fibers coated with and without pretreated substrate fibers are given in Table A-8. These PBI hollow fibers showed $\mathrm{H}_{2} / \mathrm{CO}_{2}$ selectivity higher than that can be achieved by molecular flow permeation. The moderate selectivity in these fibers and the relatively high $\mathrm{H}_{2}$ permeance are due to the fact that the ultra-thin dense selective layer ( 0.1 to $0.2 \mu \mathrm{m}$ ) is not as dense as it needs to be. However, the data indicate that in these ultra-thin layer coatings, small changes in the coating thickness can have a profound effect on both selectivity and permeability. As an example, WFX-44 and WFX-46 were fabricated using the same coating procedure as WFX-45, but a presence of a small defect had yielded a lower selectivity in WFX-44 and WFX-46. WFX-49 and WFX-50 had micro-scale defects on the lumen surface thus reducing the selectivity.

Figure A-58 compares the permeation data of the coated fibers based on pre-treated prototype substrate (WFX-43b) substrates with those that were tested previously (coated on untreated prototype substrate). The new set of fibers with the pre-treatment exhibited a higher $\mathrm{H}_{2}$ permeance and increased selectivity than the untreated set of fibers. 
Table A-8. The $\mathrm{H}_{2}$ permeance and $\mathrm{H}_{2} / \mathrm{CO}_{2}$ selectivity of the fibers at $250^{\circ} \mathrm{C}$.

\begin{tabular}{|c|c|c|c|c|c|}
\hline Fiber ID & Testing Reriod & H2 Permeance & Selectivity & No. of Coatings & Treatment \\
\hline & & (GPU) & (H2/CO2) & & \\
\hline WFX-35 & $8 \mathrm{hr}$ testing & 424 & 9 & single & No Pretreatment \\
\hline WFX-35 & $36 \mathrm{hr}$ testing & 587 & 8 & single & No Pretreatment \\
\hline WFX-36 & $8 \mathrm{hr}$ testing & 420 & 5 & single & No Pretreatment \\
\hline WFX-34 & $8 \mathrm{hr}$ testing & 545 & 6 & single & No Pretreatment \\
\hline WFX-37a & $8 \mathrm{hr}$ testing & 408 & 9 & single & No Pretreatment \\
\hline WFX-38 & $8 \mathrm{hr}$ testing & 257 & 14 & single & No Pretreatment \\
\hline WFX-39 & $8 \mathrm{hr}$ testing & 500 & 6 & single & No Pretreatment \\
\hline WFX-40 & $36 \mathrm{hr}$ testing & 517 & 5 & single & No Pretreatment \\
\hline WFX-41 & $8 \mathrm{hr}$ testing & 68 & 8 & single & No Pretreatment \\
\hline WFX-44 & $36 \mathrm{hr}$ testing & 211 & 11 & single & Pre-treated \\
\hline WFX-45 & $8 \mathrm{hr}$ testing & 183 & 38 & double & Pre-treated \\
\hline WFX-45 & $36 \mathrm{hr}$ testing & 160 & 23 & double & Pre-treated \\
\hline WFX-46 & $36 \mathrm{hr}$ testing & 214 & 10 & double & Pre-treated \\
\hline WFX-50 & $36 \mathrm{hr}$ testing & 148 & 8 & double & Pre-treated \\
\hline WFX-49 & $4 \mathrm{hr}$ testing & 277 & 4 & double & Pre-treated \\
\hline WFX-43b & $4 \mathrm{hr}$ testing & 333 & 19 & No Coating & pre-treated \\
\hline
\end{tabular}

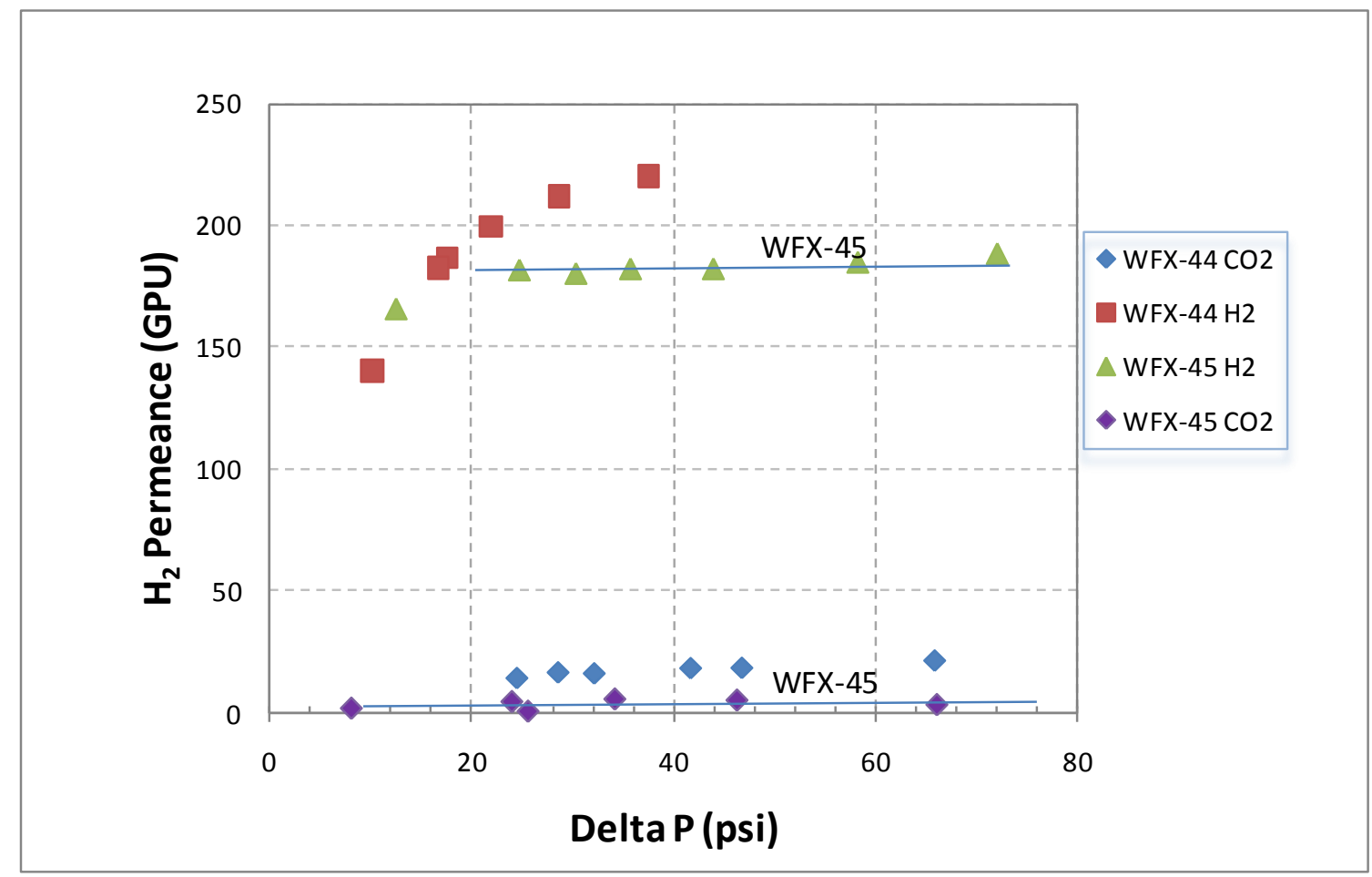

Figure A-57. Comparison of the measured permeance of $\mathrm{H}_{2}$ and $\mathrm{CO}_{2}$ of WFX-44 (single coating) and WFX-45 (double coating) at $250^{\circ} \mathrm{C}$. 


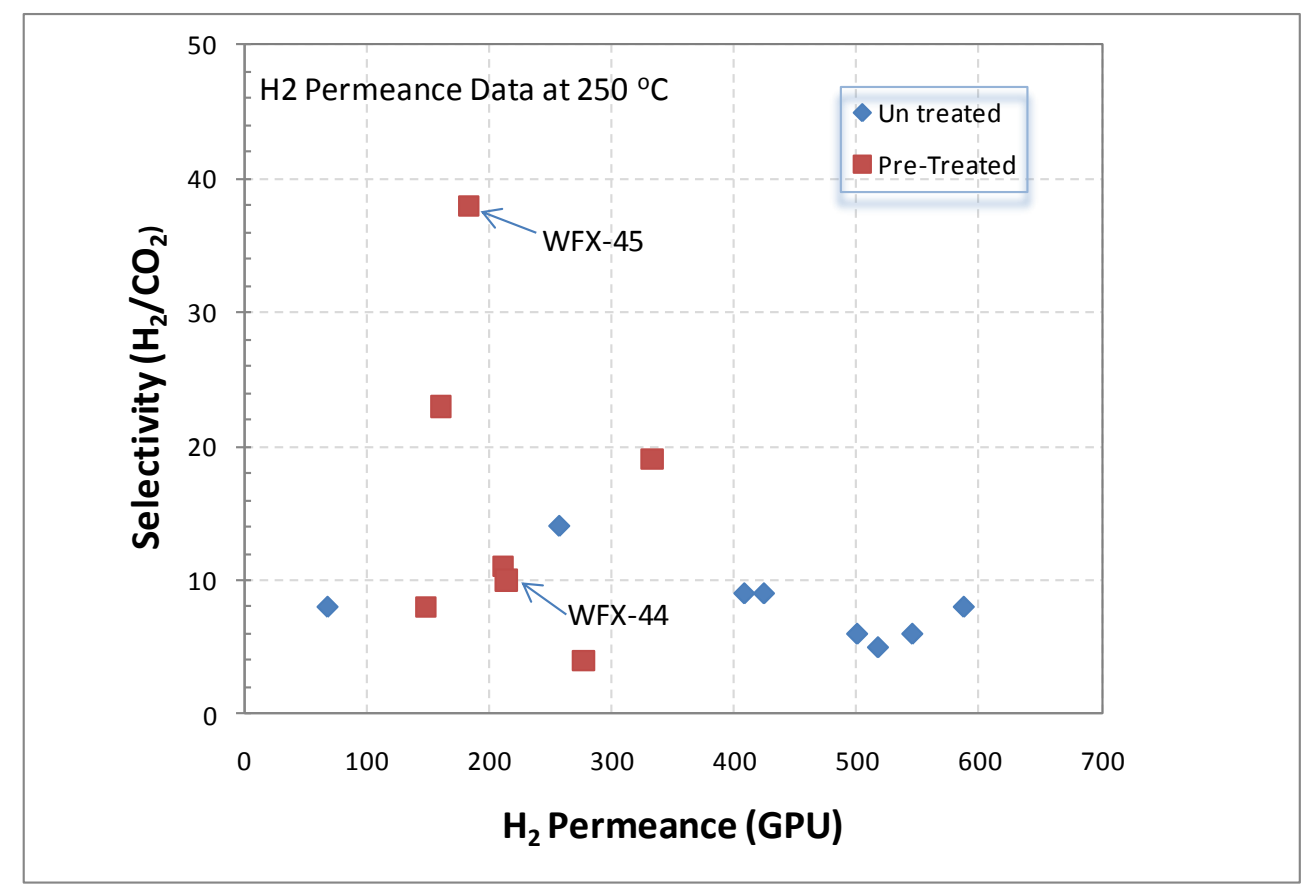

Figure A-58. The measured permeance of $\mathrm{H}_{2}$ in $\mathrm{GPU}$ and $\mathrm{H}_{2} / \mathrm{CO}_{2}$ selectivity of selected WFX-PBI hollow fiber at $250^{\circ} \mathrm{C}$.

In summary, we evaluated two approaches for fabricating PBI hollow fibers for gas separation. The first approach was to coat a dense layer on asymmetric fibers from Whitefox (1 mm OD) to increase the selectivity. In the second approach, PBI porous substrate fibers $(0.6 \mathrm{~mm}$ OD) were coated with a dense PBI layer. In asymmetric membranes, the porosity changes from one surface of the membrane to the other, with the highest density part being the functional separation layer. In the WFX membranes, the separation layer was not sufficiently uniform decrease the $\mathrm{H}_{2} / \mathrm{CO}_{2}$ selectivity. Applying a dense PBI layer minimized the defective regions and increased the selectivity. But the extra-thick dense layer decreased the $\mathrm{H}_{2}$ permeance. In coated porous substrates, the gas separation function is provided by the applied secondary dense layer coating. The porous substrate provides the mechanical support with negligible gas transport resistance as in the asymmetric fiber. Figure A-59 illustrates the summary results from two approaches. The high magnification pictures of both fibers are shown in Figures A-60 and A-61. The initial performance evaluation at SRI had indicated $\mathrm{H}_{2} / \mathrm{CO}_{2}$ selectivities in the range 15 to 40 with $\mathrm{H}_{2}$ permeance of 150 to $200 \mathrm{GPU}$ at $250^{\circ}$. However, a significant variation in the fiber performances observed for multiple fibers that were coated using the same 
procedure (Figure A-58). These variations are due to a difficult quality control in applying the dense layer on the porous substrate fiber.

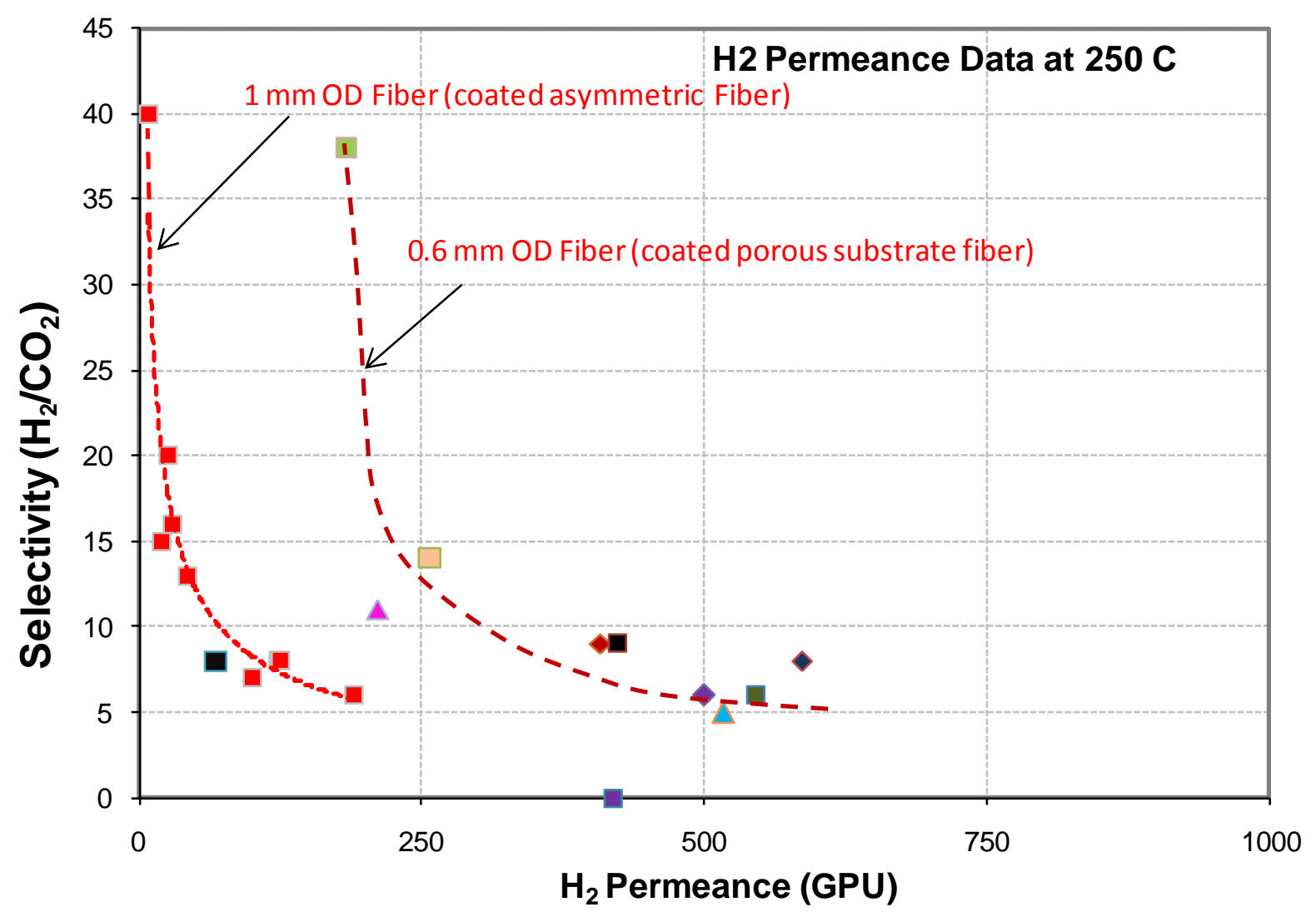

Figure A-59. $\mathrm{H}_{2}$ permeation results for coated asymmetric and porous substrate fibers.

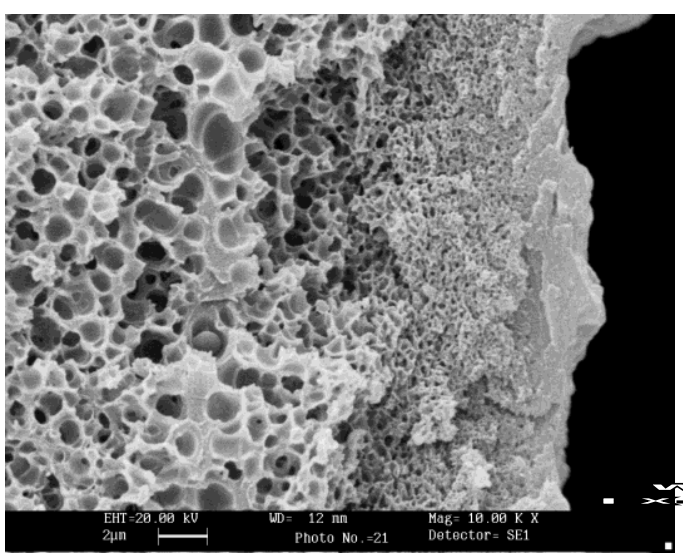

Cross Section

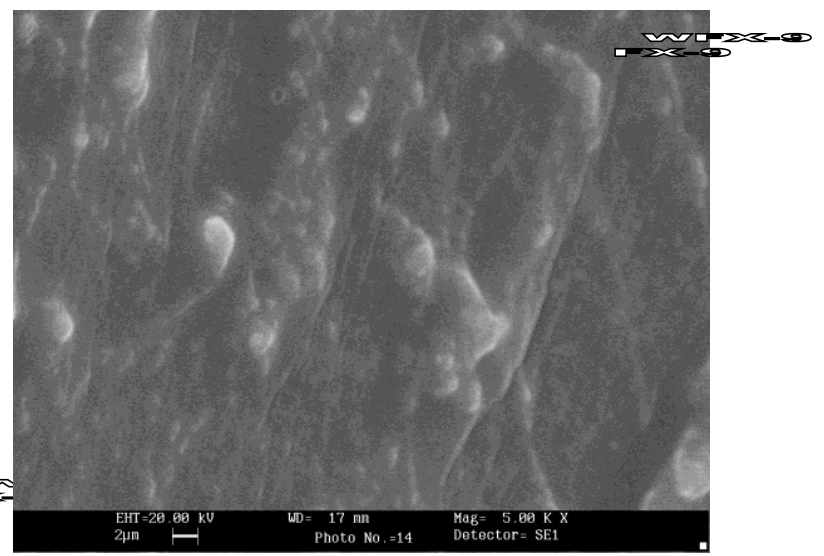

Coated Lumen Surface

Figure A-60. High magnification pictures of coated asymmetric fiber (ID = $1 \mathrm{~mm}$ ) 


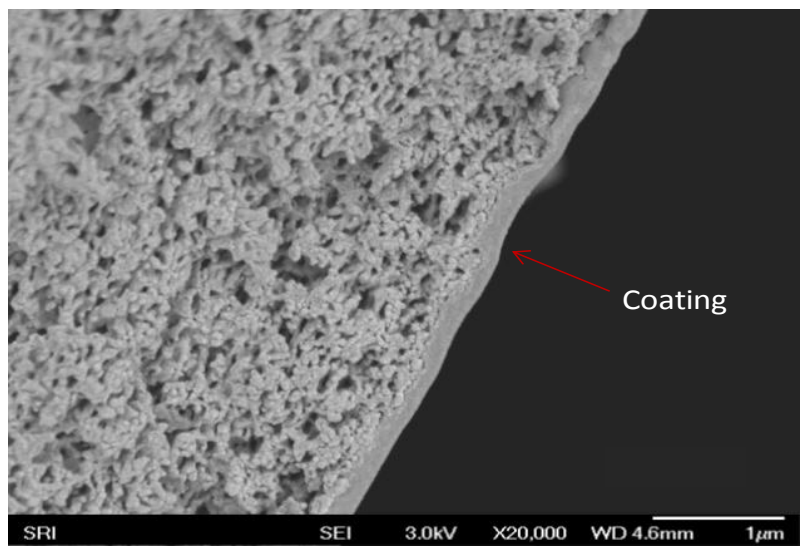

Cross Section

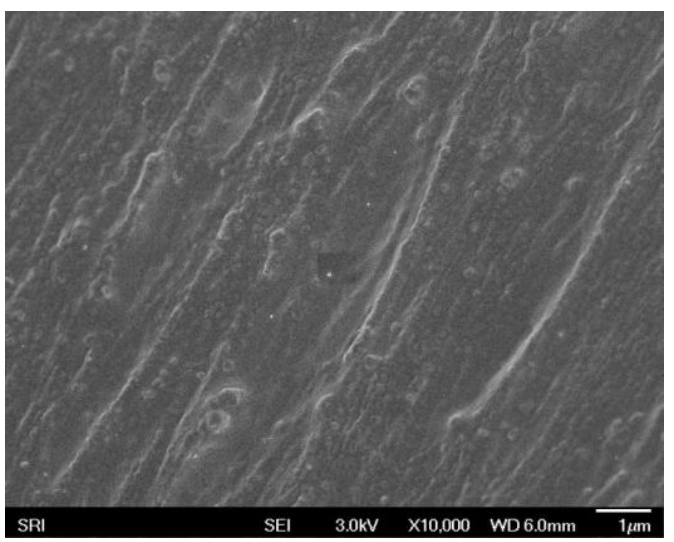

Coated Lumen Surface

Figure A-62. High magnification pictures of coated porous substrate fiber (ID $=0.6 \mathrm{~mm})$

\section{INITIAL MODULE DEVELOPMENT}

Regardless of the hollow fiber module design chosen there is a necessary requirement for potting of the hollow fibers. The most likely designs for a hollow fiber-based gas separation module for this application would incorporate open potting of the fibers on both ends. Such potting is common place in hollow fiber module design, as shown in Figure A-63. Unfortunately, the use temperatures of our selective materials and the temperatures of the target streams do not allow for use of commercially available potting materials as they would typically degrade or become ineffective as barrier materials at the operating temperatures of interest. Thus, potting materials and techniques compatible with our membrane materials and target process environments both thermal and chemical must be developed.

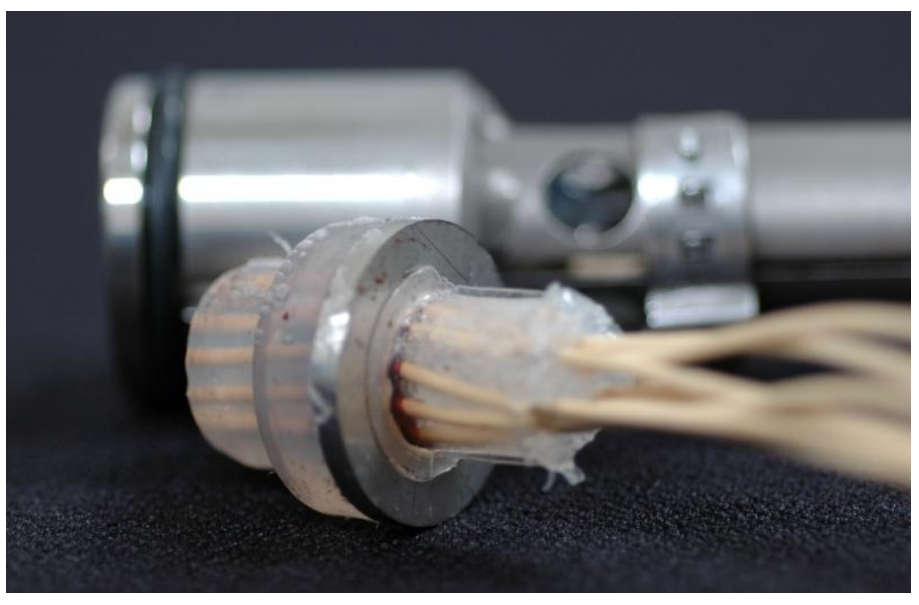

Figure A-63. Example of potted PBI-based hollow fibers. 
Figure 18 is schematic diagram of a module design that is in use at White Fox Technologies. The module, named the Whitefox Big Pen, consists of a membrane cartridge and housing. The current design uses elastomeric o-ring seals. The design allows transition to a higher temperature design when the fiber potting material allows for higher temperature testing. First generation hollow fiber modules that consist of single fibers and that utilize the potting materials discussed above were produced. These initial modules contain substrate/support fibers only.

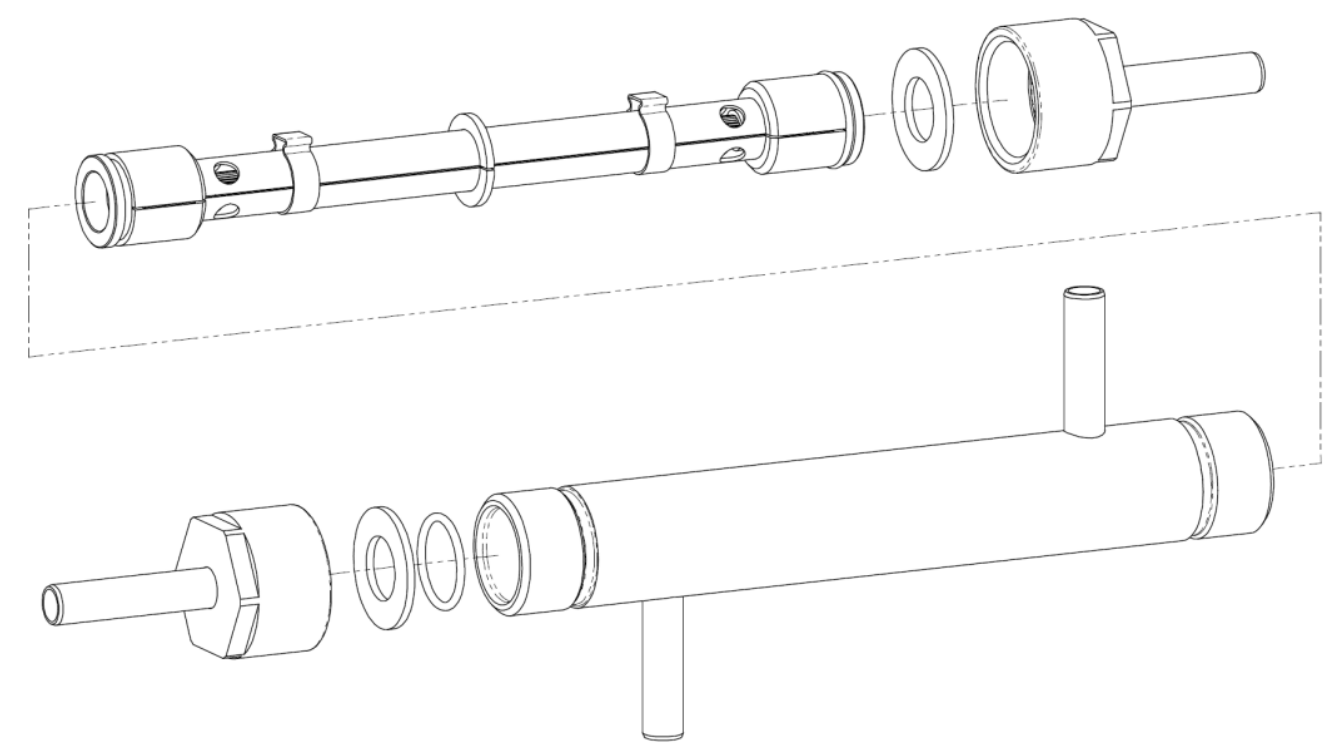

Figure A-64. A schematic diagram of the Whitefox Big Pen Module Design.

Photographs of a Big Pen multi-fiber cartridge and housing configuration (Figures A--65 and A-66) are shown below. 


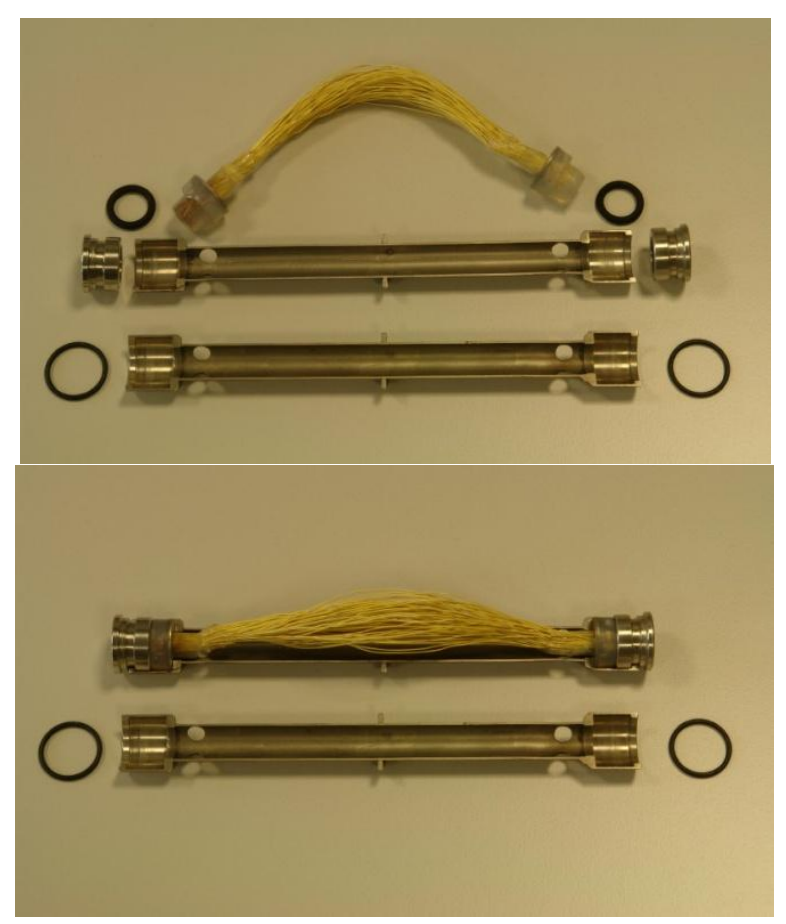

Figure A-65. Photograph of a disassembled Big Pen Fiber cartridge. (Note that the fibers shown are not PBI-based)

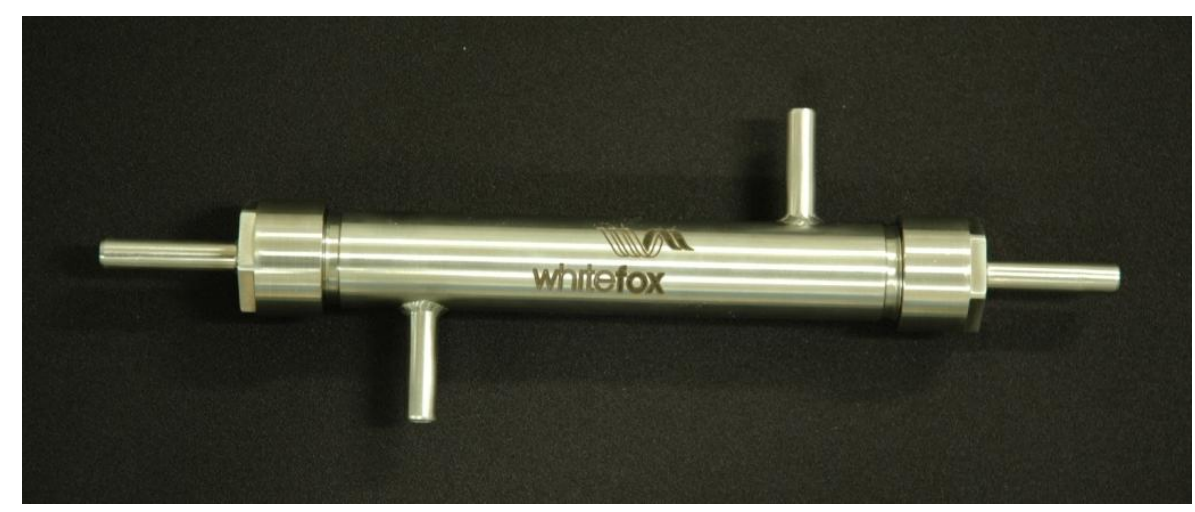

Figure A-66. Photograph of a Whitefox Big Pen Module Housing 


\section{APPENDIX B}

\section{POTTING MATERIAL DEVELOPMENT}

Thermal Stability of Adhesives Evaluated at Los Alamos National Laboratories 
The thermal stabilities of a wide variety of adhesives as candidate potting materials for the PBI hollow fiber membranes were investigated. The goals of these investigations are twofold. Over the long term, we aim to identify a material that would be appropriate for use in a high temperature, syngas environment on an industrial scale. In the short term, however, we need a material that is thermally and mechanically stable under less demanding laboratory conditions (i.e., temperatures of $250-350^{\circ} \mathrm{C}$ ). This short-term solution will allow us to test the fibers as Whitefox's production of them evolves and improves. To that end, several of materials classes are being explored as potential potting material candidates. The materials classes under primary investigation include high temperature epoxies, filled epoxies, silicones, filled silicones, filled silicates, PBI-based materials, and filled PBI based materials.

\section{Thermogravimetric Analysis (TGA)}

A TA Instruments Q500 TGA was used to evaluate the thermal stability of each candidate potting material. Three types of experiments were performed, in which the sample weight was measured as a function of temperature and / or time:

(1) Temperature Ramps - Temperature ramp from $25-500{ }^{\circ} \mathrm{C}$ at $2{ }^{\circ} \mathrm{C} /$ min under a nitrogen atmosphere

(2) Isothermal Holds - Isothermal holds at temperatures ranging from 200 to $450{ }^{\circ} \mathrm{C}$ under a nitrogen atmosphere

(3) Curing Profiles - Curing of the adhesives under nitrogen, using the curing profile recommended by the manufacturer for high temperature application

Temperature Ramps: Silicone materials were investigated as one class of likely candidate materials for fiber potting. Silicone materials are commonly used as potting agents in low temperature applications and generally have high thermal stabilities. In spite of the known high permeabilities of this material class, we believed these materials could still prove useful, given the long path lengths that could be used to encase the hollow fiber ends. Table B-1 summarizes the TGA results for two silicones and compares them to PBI. The WFX silicone shows no weight loss up to $400{ }^{\circ} \mathrm{C}$, and the Sylgard 184 (Dow Corning) loses little weight over the same temperature range. While these data appear promising, the mechanical stability of the WFX silicone begins to diminish around $185^{\circ} \mathrm{C}$, i.e., the material begins to flow. Clearly, this material does not meet our needs as a potting agent, even under our milder laboratory test conditions. The Sylgard 184 fares better, in that softening does not begin until $\sim 300{ }^{\circ} \mathrm{C}$. 
Table 1. Thermal And Mechanical Stability Of Silicone Samples And PBI

\begin{tabular}{|c|c|c|c|c|c|}
\hline \multirow[b]{2}{*}{ Adhesive } & \multicolumn{4}{|c|}{ Weight Retention in $\mathrm{N}_{2}$} & \multirow{2}{*}{$\begin{array}{l}\text { Mechanical stability limit } \\
\text { Flow temperature }\end{array}$} \\
\hline & $250^{\circ} \mathrm{C}$ & $300^{\circ} \mathrm{C}$ & $350^{\circ} \mathrm{C}$ & $400^{\circ} \mathrm{C}$ & \\
\hline WFX silicone & $100 \%$ & $100 \%$ & $100 \%$ & $100 \%$ & $\sim 185^{\circ} \mathrm{C}$ \\
\hline Sylgard 184 & $99 \%$ & $98 \%$ & $96 \%$ & $93 \%$ & $>300^{\circ} \mathrm{C}$ \\
\hline PBI & $100 \%$ & $99 \%$ & $97 \%$ & $95 \%$ & $>\mathrm{T}_{\mathrm{d}} \sim 500{ }^{\circ} \mathrm{C}$ (no flow) \\
\hline
\end{tabular}

As seen in Table B-1, PBI maintains mechanical stability up to its degradation temperature, ca. $500{ }^{\circ} \mathrm{C}$. Potentially, it could be used to pot the hollow fibers. For such an application, a cross-linked PBI may also be of interest. Table B-2 includes TGA results for $4 \mathrm{PBI}$ materials with varying levels of a sulfolane based cross-linking agent (0 $-15 \%$ ). Each of these maintains thermal and mechanical stability through at least $350^{\circ} \mathrm{C}$. PBI without an added cross-linking agent is thermally stable to much higher temperatures, i.e., until it degrades at $\sim 500^{\circ} \mathrm{C}$.

The use of commercial "high temperature" adhesives is also being investigated. These materials include: commercial grade JB Weld, Cotronics Duralco materials, and several Loctite materials. TGA results for a number of these materials are summarized in Table B-2. Of these, the Duralco epoxy based materials, $4460 \& 4700$, exhibit thermal stabilities adequate for laboratory tests up to $300^{\circ} \mathrm{C}$, while the Loctite samples appear stable up to $350^{\circ} \mathrm{C} \mathrm{(598} \mathrm{Black,} \mathrm{filled} \mathrm{silicone)} \mathrm{and} 400^{\circ} \mathrm{C}$ (2000 Putty, filled silicate and 5920 Copper, filled silicone). Figure B-1 compares the Duralco samples and clearly shows that significant degradation begins just above $300^{\circ} \mathrm{C}$. The Loctite data is given in Figure B-2 and shows the onset of degradation occurring at $\sim 370^{\circ}$ and $\sim 420^{\circ} \mathrm{C}$ for the 598 Black and 5920 Copper, respectively. The 2000 Putty shows no sign of significant degradation even at temperatures in excess of $500^{\circ} \mathrm{C}$.

Table B-2. TGA Results of candidate potting materials

\begin{tabular}{|l|c|c|c|c|}
\hline \multirow{2}{*}{ Adhesive } & \multicolumn{4}{|c|}{ Weight Retention in $\mathbf{~}_{\mathbf{2}}$} \\
\cline { 2 - 5 } & $\mathbf{2 5 0} \mathbf{}^{\circ} \mathbf{C}$ & $\mathbf{3 0 0}{ }^{\circ} \mathbf{C}$ & $\mathbf{3 5 0} \mathbf{C}$ & $\mathbf{4 0 0}{ }^{\circ} \mathbf{C}$ \\
\hline WFX silicone & $100 \%$ & $100 \%$ & $100 \%$ & $100 \%$ \\
\hline Sylgard 184 & $99 \%$ & $98 \%$ & $96 \%$ & $93 \%$ \\
\hline PBI & $100 \%$ & $99 \%$ & $97 \%$ & $95 \%$ \\
\hline PBI w/ 1\% Crosslinker & $100 \%$ & $99 \%$ & $96 \%$ & $91 \%$ \\
\hline PBI w/ 3\% Crosslinker & $100 \%$ & $99 \%$ & $96 \%$ & $92 \%$ \\
\hline PBI w/ 15\% Crosslinker & $100 \%$ & $99 \%$ & $95 \%$ & $90 \%$ \\
\hline JB Weld Industrial & $97 \%$ & $93 \%$ & $76 \%$ & $70 \%$ \\
\hline Duralco 4460 & $100 \%$ & $100 \%$ & $94 \%$ & $51 \%$ \\
\hline Duralco 4700 & $100 \%$ & $100 \%$ & $92 \%$ & $83 \%$ \\
\hline Duralco 4701 & $98 \%$ & $95 \%$ & $83 \%$ & $63 \%$ \\
\hline Loctite 2000 Putty & $98 \%$ & $98 \%$ & $98 \%$ & $97 \%$ \\
\hline Loctite 5920 Copper & $98 \%$ & $97 \%$ & $97 \%$ & $95 \%$ \\
\hline Loctite 598 Black & $99 \%$ & $98 \%$ & $97 \%$ & $86 \%$ \\
\hline
\end{tabular}




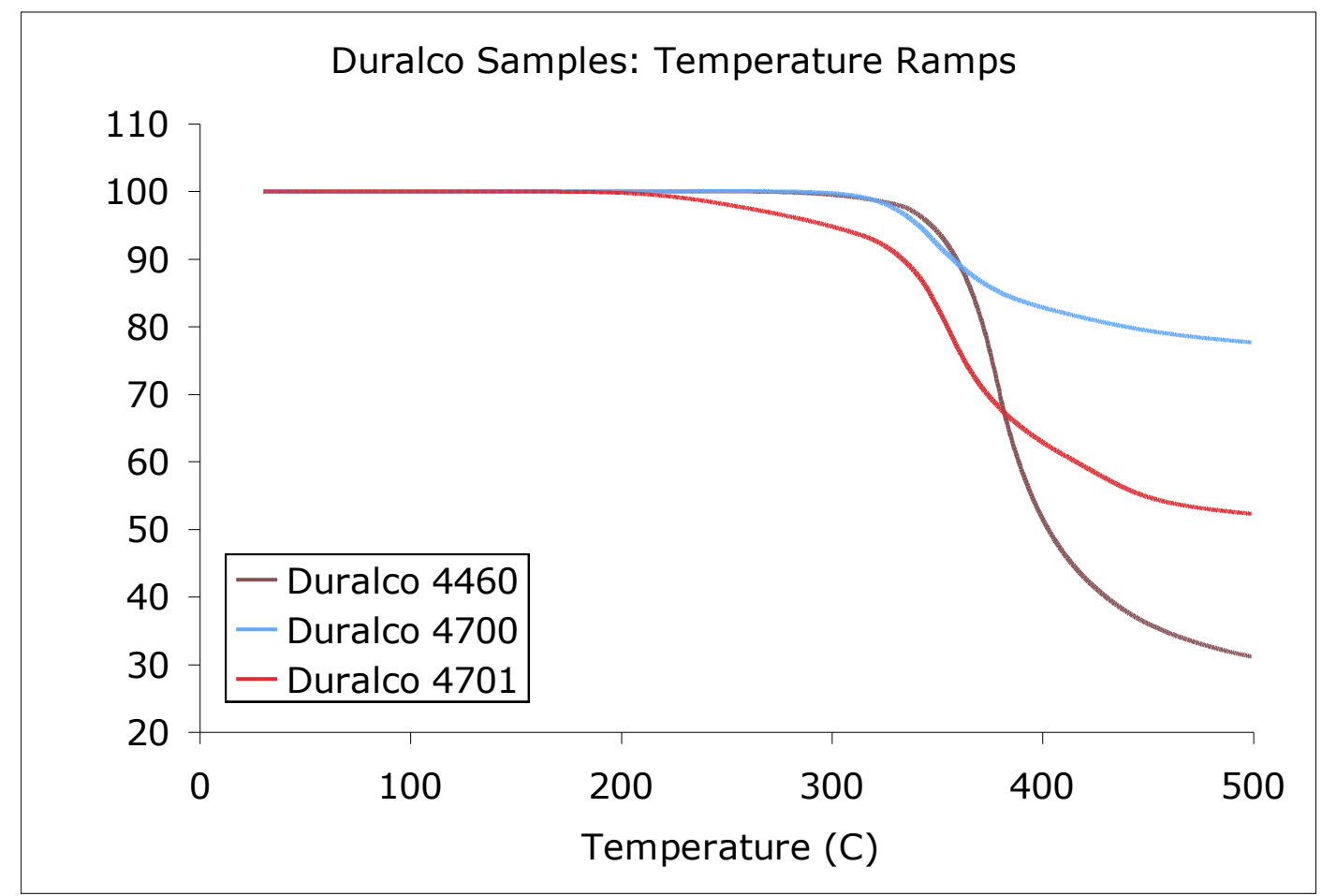

Figure B-1. TGA results for the three Cotronics Duralco epoxy samples.

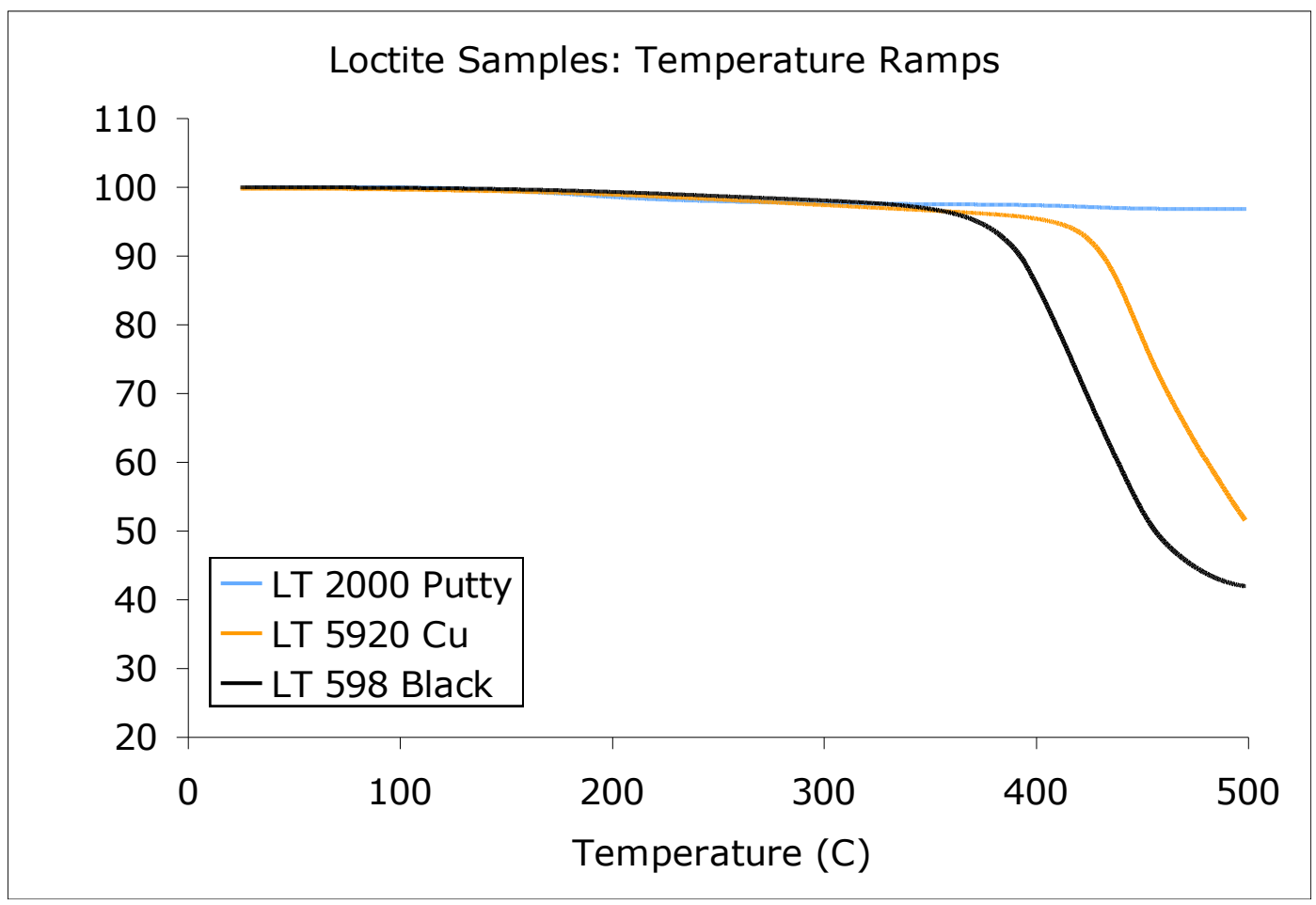

Figure B-2. TGA results for the three Loctite samples. 
Isothermal Holds: We investigated the thermal stability of some of the materials discussed above as a function of time for two reasons. First, both the end-use syngas environment and our laboratory test conditions require elevated temperatures for long periods of time. In addition, some adhesives may require a "break-in" period, during which weight loss occurs and after which the material is stable. Table 12 summarizes the TGA results of these experiments. The JB Weld sample experienced minimal weight loss when held at $200^{\circ} \mathrm{C}$, but degradation increased upon holding at $250^{\circ} \mathrm{C}$. The Loctite 5920 Copper shows promising results at $300^{\circ} \mathrm{C}$, with minimal weight loss $(0.7 \%)$ occurring over a 2-hour period. When this same sample was cooled to ambient, reheated to $300^{\circ} \mathrm{C}$ and held for another 2 hours, only an additional $0.3 \%$ weight was lost. Further, another cycle of cooling to ambient, heating to $300^{\circ} \mathrm{C}$ and holding for 2 hours resulted in only $0.1 \mathrm{wt} \%$ loss. Figure B-3 plots the $\%$ weight vs. time data for all 3 isothermal holds of this sample. The PBI samples with varying levels of a sulfolane based cross-linking agent were tested sequentially at 350,400 , and $450{ }^{\circ} \mathrm{C}$. Each of these experienced the greatest weight loss at $350^{\circ} \mathrm{C}$, but none lost more than $4.6 \%$ at any of the temperatures tested. For pure PBI, the weight loss experienced during each of these isothermal holds is likely due to water and or solvent evaporation. This is likely also a source of weight loss for the cross-linked PBI materials, though degradation of the crosslinks may also begin to occur at the higher test temperatures.

Table B-3. Summary Of TGA Isothermal Hold Experiments.

\begin{tabular}{|l|c|c|c|}
\hline Adhesive & $\begin{array}{c}\text { Hold } \\
\text { Temperature } \\
\left({ }^{\circ} \mathbf{C}\right)\end{array}$ & $\begin{array}{c}\text { Hold Time } \\
(\mathbf{h r})\end{array}$ & $\begin{array}{c}\text { Weight Loss } \\
\text { During Hold }\end{array}$ \\
\hline JB Weld & 200 & 1 & $0.3 \%$ \\
\hline JB Weld & 250 & 2 & $2.4 \%$ \\
\hline Loctite 5920 Copper & 300 & 2 & $0.7 \%$ \\
\hline PBI & 350 & 2 & $1.7 \%$ \\
\hline PBI w/ 1\% Crosslinker & 350 & 2 & $4.6 \%$ \\
\hline PBI w/ 3\% Crosslinker & 350 & 2 & $3.3 \%$ \\
\hline PBI w/ 15\% Crosslinker & 350 & 2 & $3.1 \%$ \\
\hline PBI & 400 & 2 & $0.4 \%$ \\
\hline PBI w/ 1\% Crosslinker & 400 & 2 & $0.6 \%$ \\
\hline PBI w/ 3\% Crosslinker & 400 & 2 & $0.7 \%$ \\
\hline PBI w/ 15\% Crosslinker & 400 & 2 & $2.7 \%$ \\
\hline PBI & 450 & 2 & $0.1 \%$ \\
\hline PBI w/ 1\% Crosslinker & 450 & 2 & $0.7 \%$ \\
\hline PBI w/ 3\% Crosslinker & 450 & 2 & $0.4 \%$ \\
\hline PBI w/ 15\% Crosslinker & 450 & 2 & $1.2 \%$ \\
\hline
\end{tabular}




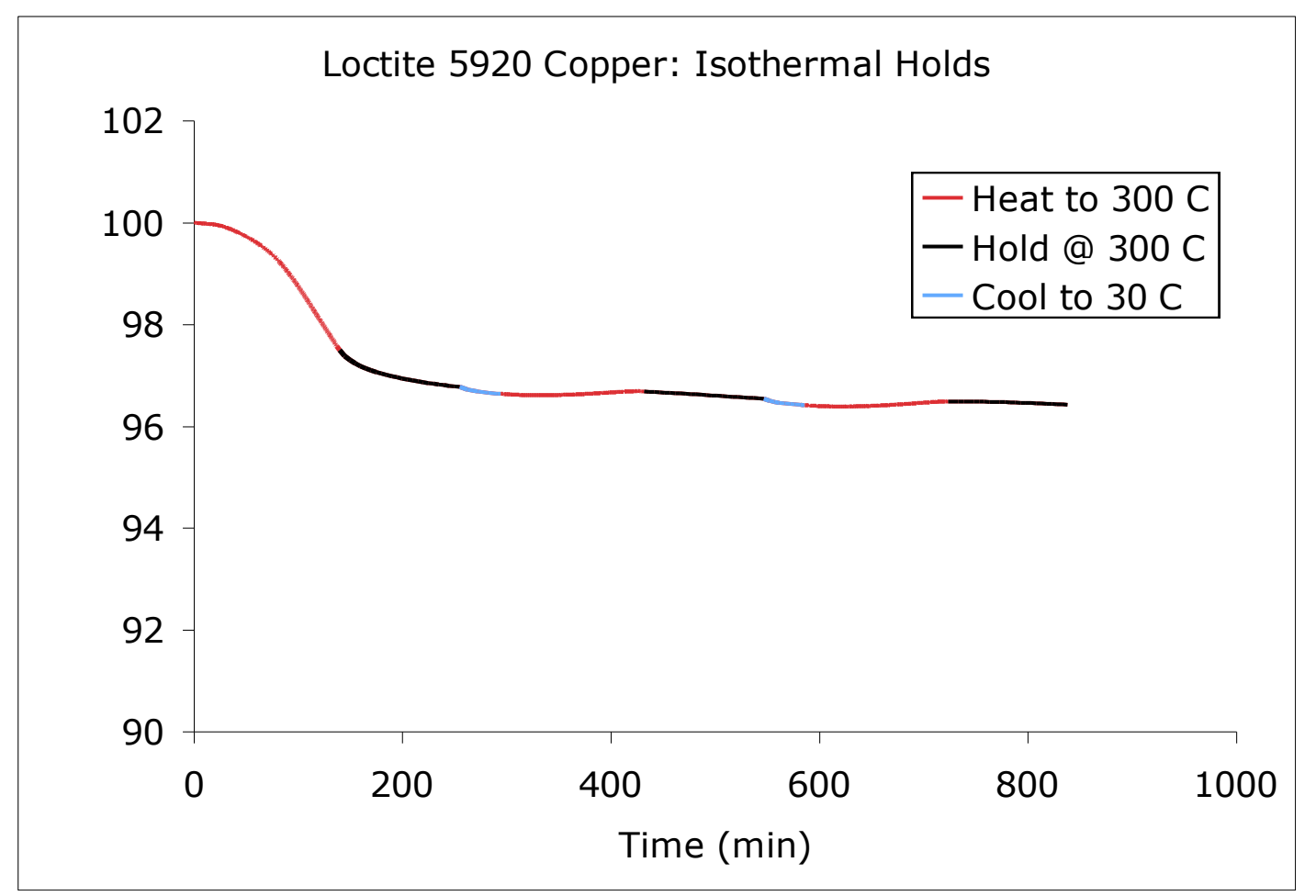

Figure B-3. TGA results for Loctite 5920 Copper during 3 isothermal holds at $300{ }^{\circ} \mathrm{C}$.

Curing Profiles: An excessive weight loss during cure could be detrimental for this potting application; therefore, we examined sample weight as a function of temperature and time for those materials whose curing conditions require elevated temperatures. Table B-4 gives the total weight loss during cure and a description of the cure conditions for the Duralco and Loctite materials. The Duralco epoxies all lose $\sim 10 \%$ during cure, while the Loctite 2000 Putty loses a much larger amount, 30\%. Figures B-4 and B-5 show the weight loss as a function of time for the Duralco samples and the Loctite 2000 Putty, respectively. Except for the Duralco 4701, the weight loss appears to plateau well before the end of the cure profile. 
Table B-4. Cure conditions for Duralco and Loctite samples.

\begin{tabular}{|l|c|l|}
\hline Adhesive & $\begin{array}{c}\text { Weight Loss Durin } \\
\text { Cure in N2 }\end{array}$ & \multicolumn{1}{|c|}{ Cure Conditions* } \\
\hline Duralco 4460 & $10 \%$ & $\begin{array}{l}(1) 120 \mathrm{C}, 4 \mathrm{hrs} \text { (2) } \\
175 \mathrm{C}, 2 \mathrm{hrs} \quad(3) 23 \\
\mathrm{C}, 16 \mathrm{hrs}\end{array}$ \\
\hline Duralco 4700 & $12 \%$ & $\begin{array}{l}(1) 120 \mathrm{C}, 4 \mathrm{hrs} \text { (2) } \\
175 \mathrm{C}, 2 \mathrm{hrs} \quad(3) 23 \\
\mathrm{C}, 16 \mathrm{hrs}\end{array}$ \\
\hline Duralco 4701 & $8 \%$ & $\begin{array}{l}(1) 135 \mathrm{C}, 2 \mathrm{hrs} \text { (2) } \\
175 \mathrm{C}, 2 \mathrm{hrs}\end{array}$ \\
\hline Loctite 2000 Putty & $30 \%$ & $93 \mathrm{C}, 3 \mathrm{hrs}$ \\
\hline Loctite 5920 Copper & not measured & ambient air, 24 hrs \\
\hline Loctite 598 Black & not measured & ambient air, 24 hrs \\
\hline
\end{tabular}

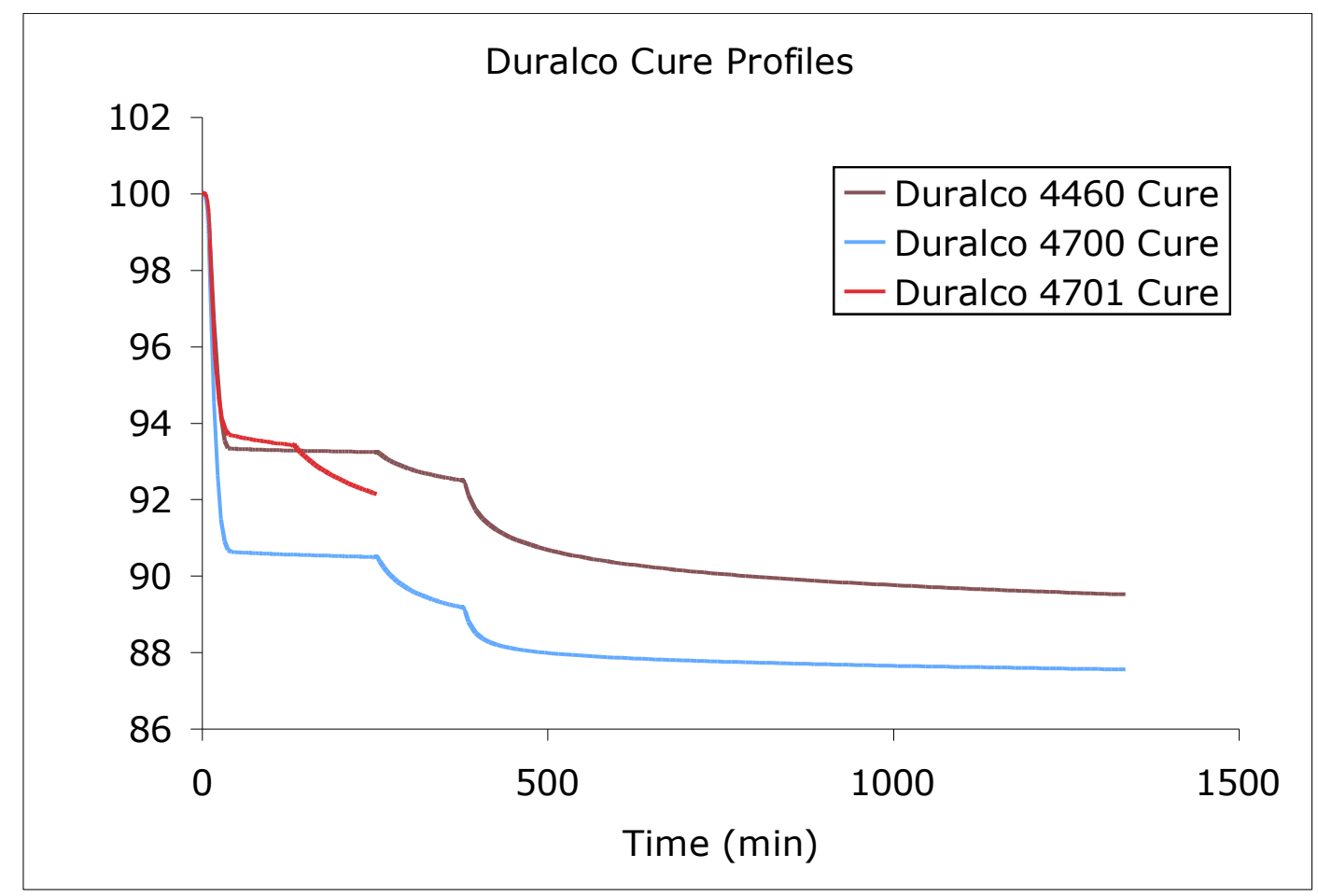

Figure B-4. TGA results for Duralco samples during cure. 


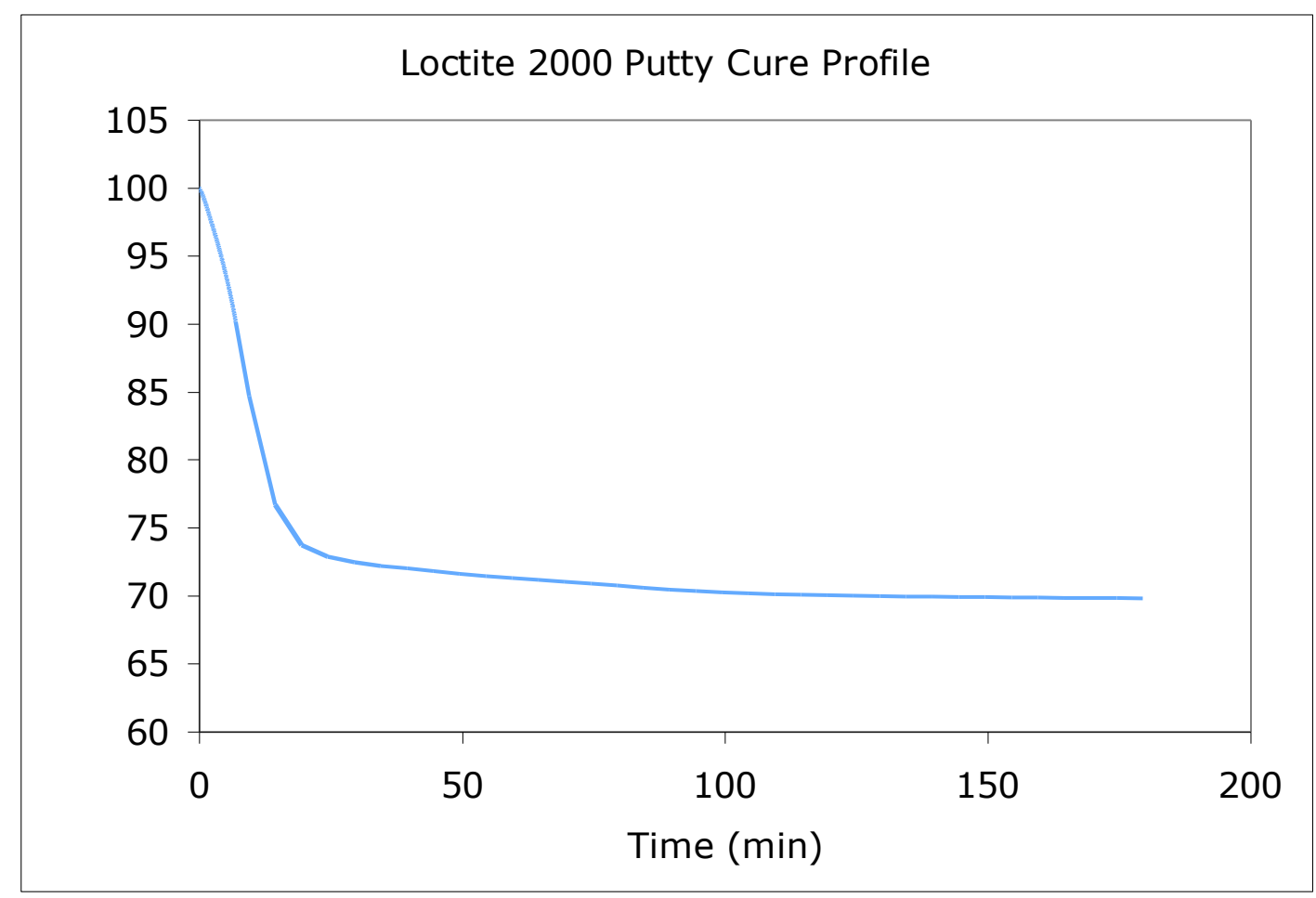

Figure B-5. TGA results for Loctite 2000 Putty during cure.

In summary, both commercial and non-commercial materials are being explored for their application as high temperature potting materials. These materials must ultimately demonstrate thermal, chemical, and mechanical stability and durability in the challenging syngas environments of an IGCC and must create a durable and non-permeable seal between the membrane fibers and the module cartridge/housing materials. Several candidate potting/adhesive materials and material classes have been identified. Several materials have been identified and demonstrated as suitable for use at temperatures up to ca. $300^{\circ} \mathrm{C}$. The Loctite 2000 Putty and 5920 Copper have demonstrated promise as potential sealants over a broader temperature range that is more conducive to extensive fiber evaluation at the laboratory scale. Not surprisingly, several PBI-based and filled PBI-based materials have also shown promise and are also likely candidates for larger pilot and industrial scale application. 


\title{
APPENDIX C
}

\section{STRATEGIC DEVELOPMENT PLAN}

\author{
Visage Energy, Inc. \\ Energy Commercialization \\ SRI International \\ Enerfex, Inc. \\ Los Alamos National Laboratory
}




\section{Strategic Development Plan Report:}

Fabrication and Scale-up of Polybenzimidazole (PBI) Membrane Based System for Pre-Combustion Based Capture of Carbon Dioxide

Cooperative Agreement No.: DE-FC26-07NE43090

\section{Prepared by:}

Gopala Krishnan and Indira Jayaweera, SRI International

Richard Callahan, Enerfex

Kathryn Berchtold, LANL

Will Johnson, Visage Energy

Kevin O'Brien, Energy Commercialization, LLC

\section{Prepared for:}

U.S. Department of Energy

National Energy Technology Laboratory

626 Cochran Mill Road

Pittsburgh, PA 15236 


\section{DISCLAIMER}

Strategic Development Plan • May 2010

This report was prepared as an account of work sponsored by an agency of the United States Government. Neither the United States Government nor any agency thereof, nor any of their employees, make any warranty, express or implied, or assumes any legal liability or responsibility for the accuracy, completeness, or usefulness of any information, apparatus, product, or process disclosed, or represents that its use would not infringe privately owned rights. Reference herein to any specific commercial product, process, or service by trade name, trademark, manufacturer, or otherwise does not necessarily constitute or imply endorsement, recommendation, or favoring by the United States Government or any agency thereof. The views and opinions of authors expressed herein do not necessarily state or reflect those of the United States Government or any agency thereof. 


\section{$\underline{\text { TABLE OF CONTENTS }}$}

Strategic Development Plan • May 2010

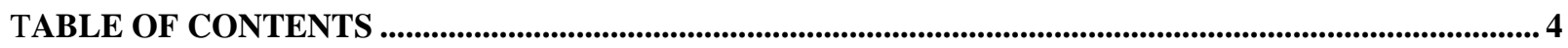

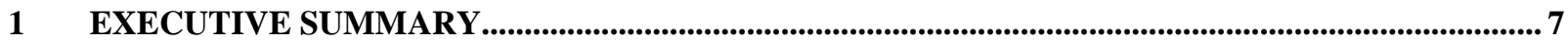

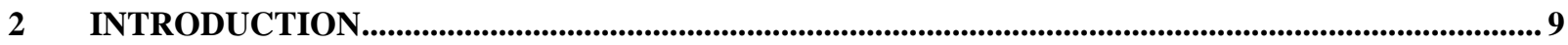

3 CARBON CAPTURE AND STORAGE MARKET ANALYSIS .............................................................. 12

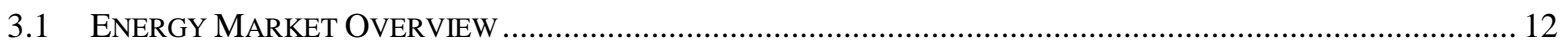

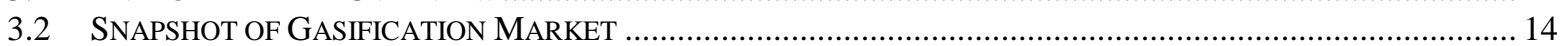

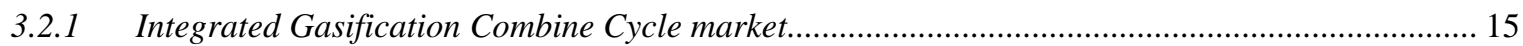

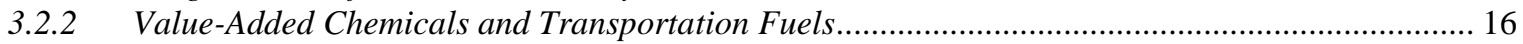

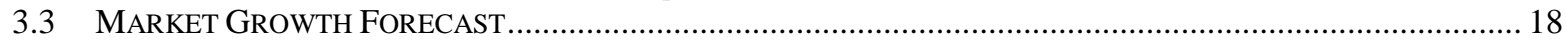

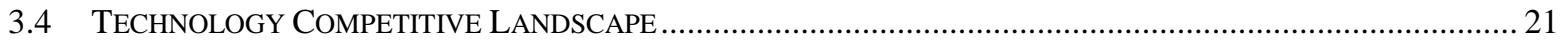

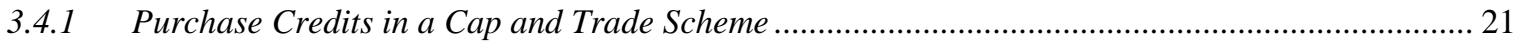

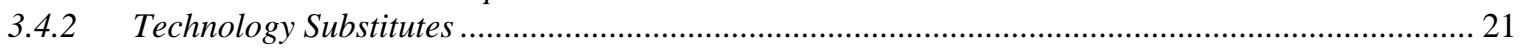

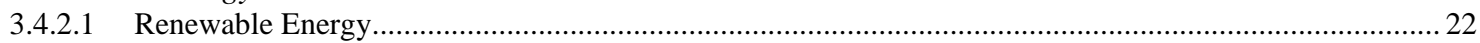

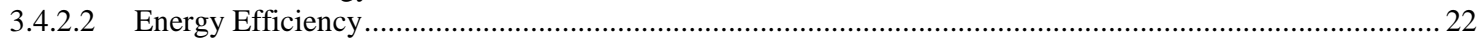

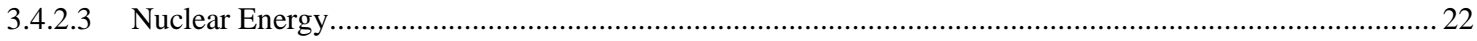

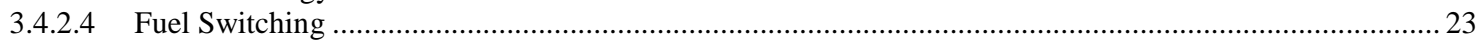

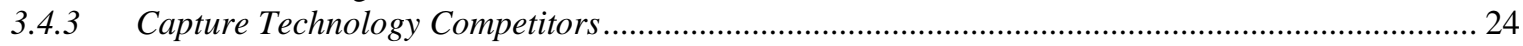

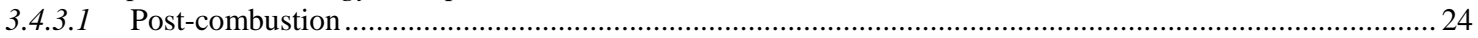

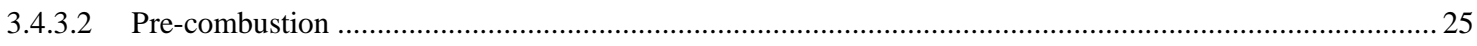

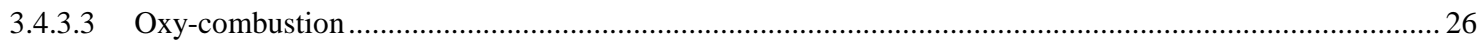

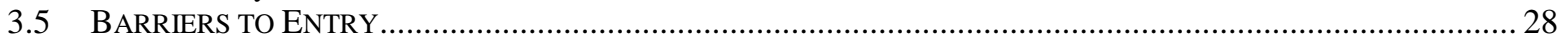

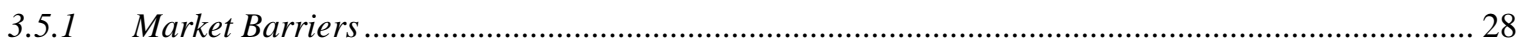

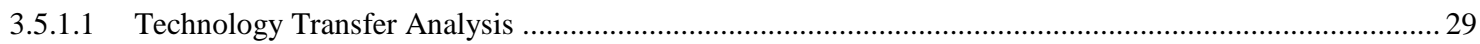

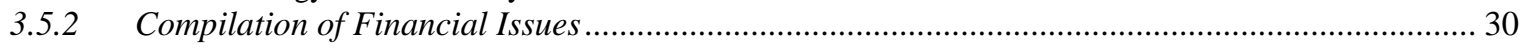

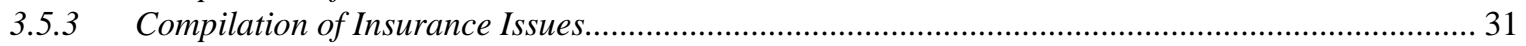

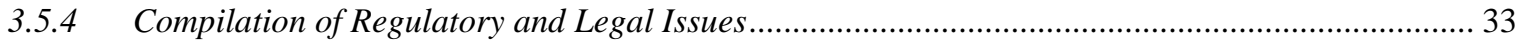

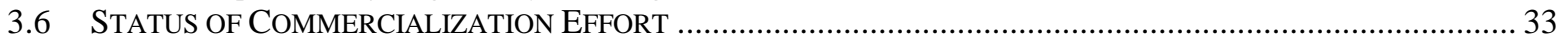

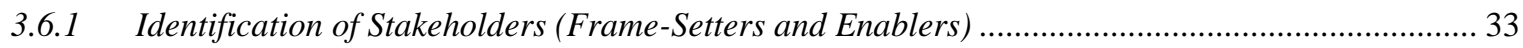

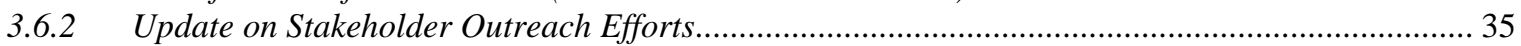

4 PBI TECHNOLOGY COMMERCIALIZATION PLAN ...............................................................................39

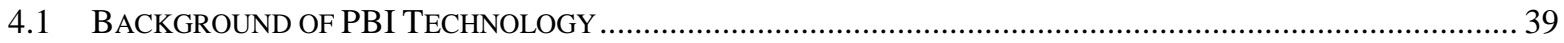

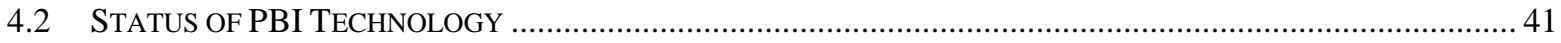

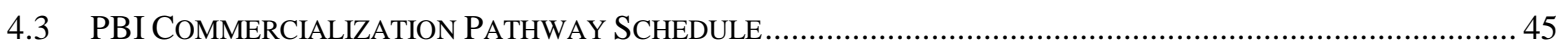

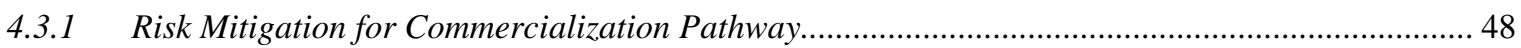

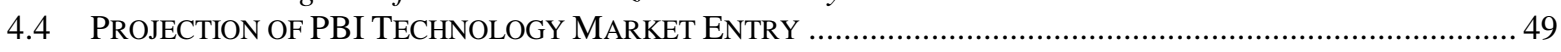

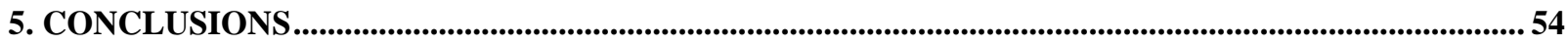




\section{LIST OF FIGURES}

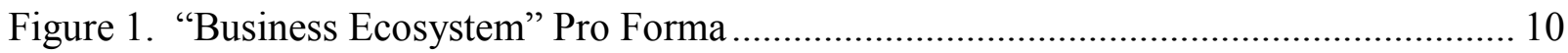

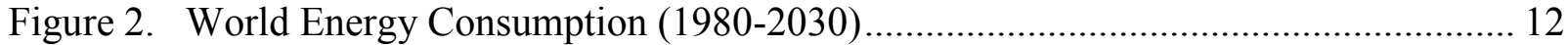

Figure 3. World Electricity Generation by Fuel, 2006-2030 ......................................... 13

Figure 4. Gasification Process ................................................................................... 14

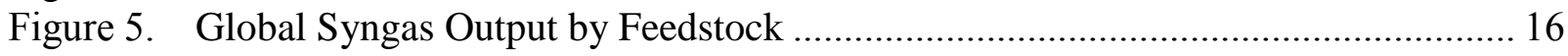

Figure 6. Past Capacity Announcements vs. Actual ....................................................... 18

Figure 7. Global IGCC Project Pipeline ....................................................................... 19

Figure 8. Potential for decarbonizing the U.S. electric sector - the full portfolio ................ 21

Figure 9. World Renewable Electricity Generation by Source, 2006-2030 ........................ 22

Figure 10. World Nuclear Generating Capacity by Region............................................... 23

Figure 11. NETL Fossil Energy $\mathrm{CO}_{2}$ Capture Solutions Commercialization ......................... 27

Figure 12. Technology Transfer Pathways ........................................................................ 29

Figure 13. Technology Commercialization Process ........................................................... 35

Figure 14. Symbiotic Relationship Between Energy Importing and Exporting States............ 37

Figure 15. Trade-Off Plot between $\mathrm{H}_{2}$ Permeability and $\mathrm{H}_{2} / \mathrm{CO}_{2}$ Selectivity in Polymers ....... 39

Figure 16. Role of Membrane and Process Simulation ..................................................... 40

Figure 17. SEM Images of the Cross Section Near the Inner Surfaces of the Porous Substrate

at Low and High Magnifications ........................................................................................ 42

Figure 18. The Measured Permeance of $\mathrm{H}_{2} \mathrm{In} \mathrm{GPU}$ and $\mathrm{H}_{2} / \mathrm{CO}_{2}$ Selectivity at $250^{\circ} \mathrm{C}$ for PBI

Membrane Samples Processed Using Different Conditions. The WFX-45 Sample Exhibited

Properties Close to the Target Values..................................................................... 43

Figure 19. SEM Images of the Cross Section of the Lumen Of WFX-45 (Coated Fiber)....... 43

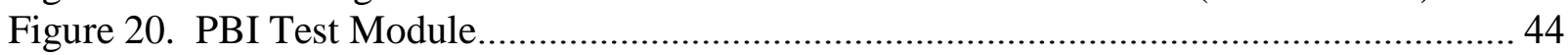

Figure 21. Schematic of Skid Used for Testing PBI Modules............................................. 45

Figure 22. Projected Mws from Which $\mathrm{CO}_{2}$ is Captured Using the PBI System Based on

Commercialization Pathway Schedule ......................................................................... 50

Figure 23. Number of Modules as a Function of Time Based on Commercialization Pathway

Schedule ................................................................................................................ 51

Figure 24. Pounds of PBI Polymer Required as a Function of Time Based on

Commercialization Pathway Schedule .......................................................................... 52

Figure 25. Kilometers of PBI Hollow Fiber Projected as a Function of Time Based on Commercialization Pathway Schedule ........................................................................... 53 


\section{TABLE OF TABLES}

Strategic Development Plan • May 2010

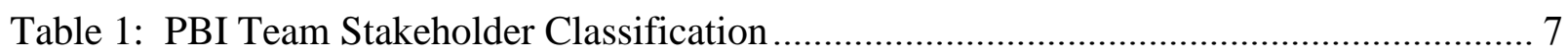

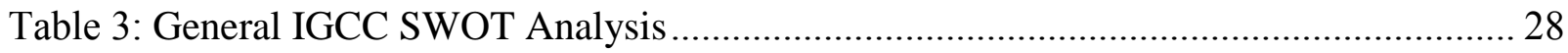

Table 4. Preliminary Process Economics Analysis Using Simulation ...................................... 41

Table 5: Typical Stages of Maturation for Energy Technologies .............................................. 45

Table 6. Potential Commercialization Pathway Schedule ..................................................... 47

Table 7. Risks to the Implementation of the Commercialization Pathway and Actions to

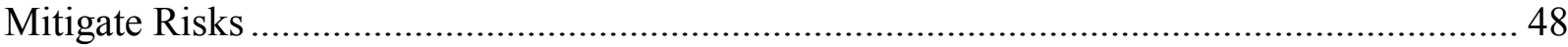




\section{Executive Summary}

Strategic Development Plan • May 2010

This report describes activities conducted to support the Department of Energy (DOE) National Energy Technology Laboratory (NETL) Carbon Sequestration Program's financial assistance for a research and development cooperative agreement, DE-FC26-07NE43090, to fabricate and scale-up polybenzimidazole (PBI)-based polymer membranes for the precombustion capture of carbon dioxide $\left(\mathrm{CO}_{2}\right)$. This $\mathrm{CO}_{2}$ separation and capture technology directly supports the DOE-NETL Carbon Sequestration Program goal of identification of two capture technologies that are ready for pilot-scale testing by 2012 by validating the scale-up of the PBI-based membranes to commercial size. To support this overall program goal, the project team is implementing a commercialization approach to infuse the business perspective and acumen into the technology development process to ensure that the needs and requirements of stakeholders with a vested interest in the success of the technology are taken into account during the research and development phase.

The PBI project team, comprised of the following members and their associated stakeholder identifications, ensures that the research is focused on the actual needs of the enduser while meeting the requirements of the regulatory and business stakeholders.

Table 1: PBI Team Stakeholder Classification

\begin{tabular}{|c|c||}
\hline PBI Project Team Member & Stakeholder Classification \\
\hline SRI International & Technology Developer \\
\hline Los Alamos National Laboratory & Technology Developer \\
\hline Whitefox Technologies & OEM \& Suppliers \\
\hline Enerfex & OEM \& Suppliers \\
\hline BP Alternative Energy & Utilities \\
\hline Southern Company & Busilities \\
\hline Visage Energy & Government \\
\hline US DOE National Energy Technology \\
Laboratory
\end{tabular}

This commercialization effort was designed to meet three NETL objectives:

- Validate the potential of the technologies under development to meet the Sequestration Program Capture focus area goals, which are:

○ Capture at least $90 \%$ of the carbon dioxide from the effluent gas of a power generation plant.

- Cost less than a $10 \%$ increase in the cost of electricity.

- Considerably increase the likelihood of commercializing the polybenzimidazole-based (PBI-based) membrane technology for precombustion carbon dioxide capture. 
Strategic Development Plan • May 2010

- $\quad$ Expedite the development of the technical and commercial potential of the technology.

Accelerated deployment of CCS technologies hinges not only on the economics of the process, but also on the ability to create a regulatory environment that encourages investment in these technologies and rewards early technology adopters. The CCS technology learning curve could be decreased by the timely and coordinated deployment of utility-scale state-ofthe-art technologies enabling the sharing of best practices concerning the permitting process, design, construction, startup, and operation of power generation facilities with CCS within each of the different technology pathways.

The Visage Energy/SRI Partnership commercialization effort for the PBI project is designed to establish commercialization pathway(s) for novel technologies by aligning multiorganizational teams and focusing on end-user needs within the context of the Statement of Project Objectives (SOPO). This is often challenging when multiple organizations are involved.

A commercialization pathway schedule was developed based on the on the technical progress and expected time line for availability of modules for pilot testing. There were a number of considerations when establishing this schedule:

- Upstream factors such as gasifier type and characteristics of fuel source may cause variation in the performance of capture systems

- Non-technical factors such as regulatory changes and public opinion could impact timelines for pilot, demonstration, and deployment of new capture systems

- Commercialization of PBI capture systems will impact supply chains such as the global supply of PBI hollow fibers and PBI polymer

- Mitigating these risks was important in order to rapidly transition PBI capture systems from pilot to demonstration to deployment 
Strategic Development Plan • May 2010

\section{INTRODUCTION}

The management of Greenhouse Gas emissions, in particular $\mathrm{CO}_{2}$, produced during the course of energy generation from coal is a critical factor to ensure that sufficient clean energy is available to continue to promote economic growth in the United States. This requires new investments in not only capital equipment, but also in research, development, and demonstration of new technologies to manage $\mathrm{CO}_{2}$ emissions [i.e., Carbon Capture and Storage (CCS) technologies]. Successful deployment of CCS technologies hinges not only on the economics of the process but also on the ability to create a regulatory environment that encourages investment in technologies and rewards early adopters of the technologies.

NETL is developing a technology portfolio of cost-effective, commercial-scale carbon capture, storage, and mitigation technologies through the Carbon Sequestration Program. The overall goal of this project is to develop a PBI-based capture system that is capable of operation under a broad range of conditions relevant to the power industry, while meeting the Carbon Sequestration Program goals $\left(90 \% \mathrm{CO}_{2}\right.$ capture at less than a $10 \%$ increase in the cost of energy services). The RD\&D that this project team is pursuing is aligned directly with these capture goals and utilizes a pre-combustion $\mathrm{CO}_{2}$ separation technology and capture system focused on the integration of high-temperature polymer-based membranes into an advanced IGCC process. Thus, one of the key milestones for the project will be to construct a capture system in a 3-year timeframe that can be field tested, in the next phase of development, at an end-user's facility.

Previous work has demonstrated that polybenzimidazole (PBI) shows promise as a membrane material for pre-combustion-based capture of $\mathrm{CO}_{2}$. The primary goals of this project are to demonstrate the performance and fabrication of a technically and economically viable pre-combustion-based $\mathrm{CO}_{2}$ capture system based on PBI. In addition, the optimization of that PBI-based capture system for integration into an IGCC plant will be addressed. To that end, larger scale/larger throughput membrane-based separation modules will be designed, fabricated, and evaluated during the course of the project. The project intends to develop a commercialization plan that addresses technical issues (e.g., a roadmap for the scale-up of production of PBI membrane modules) and business issues (e.g., identification and incorporation of multiple-stakeholder needs and requirements for a $\mathrm{CO}_{2}$ Capture technology and project management) to outline a clear path for technology transfer of the PBI membrane technology.

The commercialization effort for the PBI project, shown in Figure 1, is designed to establish pathway(s) for novel technologies by aligning the aforementioned multiorganizational teams to focus on end-user needs within the context of the Statement of Project Objectives (SOPO). As a result, the commercialization effort, which embodies macro and micro level perspectives to research and development projects like the PBI project, was included in the original application to NETL and is delineated in the current project's SOPO. The commercialization effort goal is to substantially reduce the technology development timeline and ensure seamless deployment of the technology by the end-user. Specifically, the commercialization process intends to:

- Infuse business perspective and acumen into technology development processes.

- $\quad$ Expedite development of the technical AND commercial potential of the technology. 
Strategic Development Plan • May 2010

- $\quad$ Expose the business community to the technology and highlight its functional and cost benefits over state-of-the-art.

- Incorporate feedback from potential customers, financial, and insurance communities.

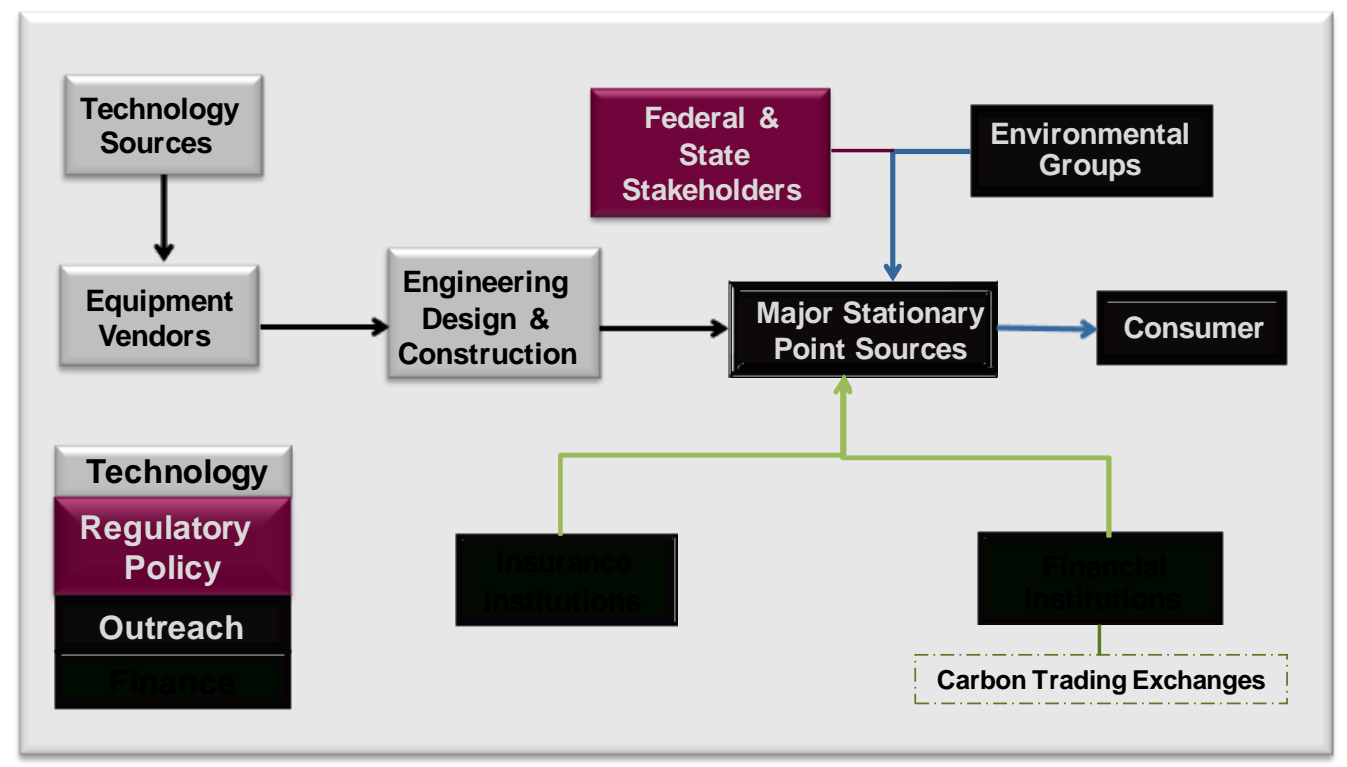

Figure 1 "Business Ecosystem" Pro Forma of Incorporating Members into Public/Private Partnerships

Insofar as CCS involves immature technologies and a high level of financial risk, close cooperation and collaboration will be required between the DOE/NETL, utilities, other major stationary $\mathrm{CO}_{2}$ point sources, and state regulatory agencies. State stakeholders should be engaged early in the process, providing a regulatory framework that supports the accelerated commercialization of CCS technologies due to their greater understanding of CCS technical and economic performance and potential.

While it is essential that Public Federal and State Stakeholders participate actively and constructively, it is also important that environmental groups and the business entities are actively included. The approach, illustrated in Figure 1 ensures that all aspects of the interested and affected parties and their needs are considered early in the technology development process by incorporating all members of the "business ecosystem." This is accomplished by developing partnerships that consist of not only the technology developers, but also organizations such as government entities and financial institutions which are critical to ensuring long-term acceptance of the technology by the marketplace. For example, endusers and potential equipment vendors are included to ensure that the emerging technologies can be manufactured in a cost-effective fashion and can be installed at the end-user's facility to meet their specific needs. Additionally, state and federal stakeholders are engaged early in the process, providing a regulatory framework that supports the commercialization of CCS technologies due to their greater understanding of CCS technical and economic performance capabilities. It is only through the exchange of information among stakeholders that a plausible approach to GHG management can be accelerated and timely realized.

Since $\mathrm{CO}_{2}$ capture will be regulatory-driven, the extent to which utilities will be required to remove $\mathrm{CO}_{2}$ from their exhaust stream will likely dictate the technology used to do 
Strategic Development Plan • May 2010 so. There may also be liability risk associated with sequestered $\mathrm{CO}_{2}$. These issues hamper the ability to finance pilot, demonstration, and full-scale projects. Insurance risks can also add to this issue in the form of uncertainty around ownership of the captured $\mathrm{CO}_{2}$.

The team determined that one of the key methods to mitigate these risks was to educate financial and insurance entities during the early development process and make them aware of progress of the project over time. It was also determined that future financial risks at the pilot, demonstration, and deployment phase could be mitigated through state incentives and financial backing from larger companies. The team also suggested that regulatory bodies, such as public utility commissions, be made aware of the project and briefed on its progress. This would mitigate the risk that the team might inadvertently design a system that would not comply with regulatory statutes. 


\section{Carbon Capture and Storage Market Analysis}

\subsection{Energy Market Overview}

In the International Energy Outlook 2009 projections, total world consumption of energy is projected to increase by 44 percent from 2006 to $2030 .{ }^{1}$ The largest projected increase in energy demand is for the non-Organization for Economic Co-operation and Development (OECD) economies. The current economic downturn dramatically impacted world demand for energy in the near term, as manufacturing and consumer demand for goods and services slowed. IEO-2009's forecast is that the majority of nations will begin to return to trend growth within the next 12 to 24 months (Figure 2).

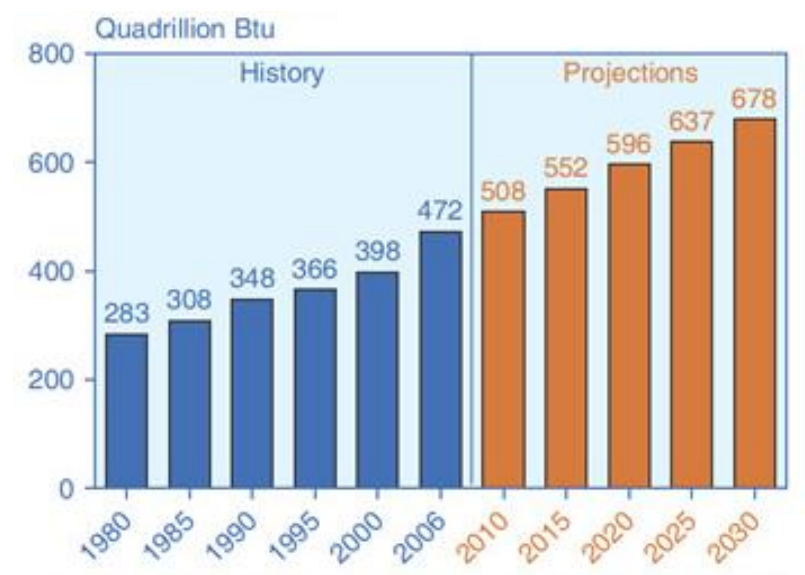

Figure 2. World Energy Consumption (1980-2030)

In 2009, US energy markets continued to be impacted by the economic downturn that began in late 2007. Power-sector investment is expected to be severely affected by financing difficulties, as well as by weak demand (i.e., availability of capital). ${ }^{3}$ In response, many ongoing energy projects have been delayed and others have been canceled all together. Specifically, electricity generation declined 1 percent in 2008 and an additional 3 percent in 2009,4 which was notably the first annual contraction since the end of the Second World War. The Energy Information Administration (EIA) presumes that in the short term, the key factors influencing worldwide energy markets will be the pace of the economic recovery, impact on capital-intensive energy projects from the turmoil in financial markets, and the potential enactment of legislation related to energy and the environment. 5 Thus, EIA predicts moderate energy consumption growth with energy intensity falling by 1.9 percent per year from 2008 to 2035.

It is unclear whether the full energy investment needed in the longer term to meet growing energy needs can be made available. The capital required to meet the projected

\footnotetext{
1 World Energy Outlook 2009 Fact Sheet, the impact of the financial crisis

2 International Energy Annual 2006 (June-December 2008), EIA World Energy Projections Plus (2009)

3 Ibid

4 US Energy Information Administration Annual Energy Outlook 2010

5 Ibid
} 
Strategic Development Plan • May 2010

energy demand through to 2030 is $\$ 26$ trillion (in year-2008 dollars) - equal to $\$ 1.1$ trillion (or $1.4 \%$ of global GDP) per year on average6. It is projected that financing energy investments will, in most cases, be more difficult and costly than prior to the crisis.

The highest growth in electricity generation is projected for the non-OECD countries where there is a forecasted increase of 3.5 percent per year in the reference case with the increase of standards of living. 7 In the OECD countries, much slower growth in generation is expected, averaging 1.2 percent per year from 2006 to 2030, given the well-established infrastructures and slower population growth.

It is anticipated that fossil fuels will continue to provide the majority of energy consumed in the US and worldwide over the next 25 years. Specifically, natural gas and coal combined account for the largest share of total world electricity generation, at more than 60 percent of global electricity supply. They will remain the world's most important sources of supply in 2030, with a 64 percent share of total generation (Figure 3). Additionally, it is anticipated that coal will continue to be a major fuel source for electricity generation over the next few decades. Moreover in non-OECD countries such as Asia and India, coal resources are ample and higher prices for oil and natural gas make coal a more economical source of energy for electricity generation. 8

However, EIA anticipates that the percentage of overall energy generated from fossil fuels will decline from 84 percent in 2008 to 78 percent in 2035. At the same time, renewable electricity generation is expected to grow exponentially as can be seen in Figure 3. However in the short term, investment in renewable-based power generation fell proportionately more than that in other types of generating capacity. Without the stimulus provided by government fiscal packages, it would have fallen by almost $30 \%$.

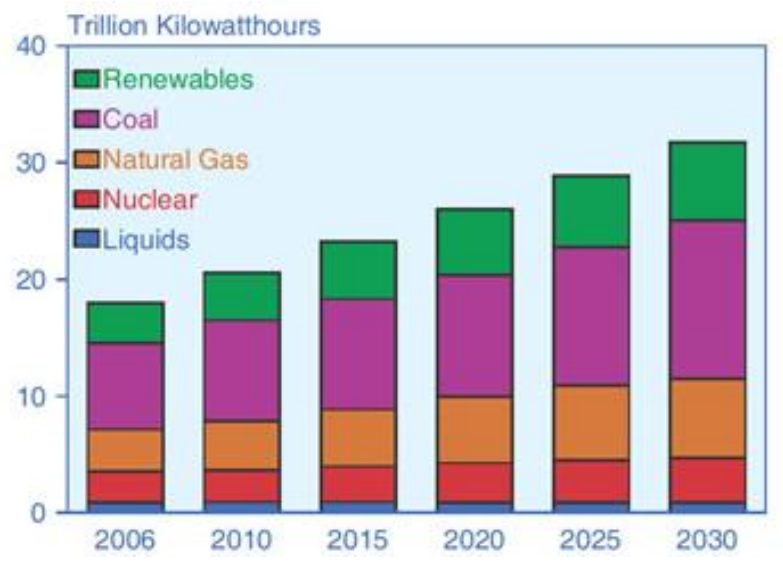

Figure 3. World Electricity Generation by Fuel, 2006-2030 ${ }^{9}$

\footnotetext{
6 Ibid

7 Ibid

8 Ibid

9 International Energy Annual 2006 (June-December 2008), EIA World Energy Projections Plus (2009)
} 


\subsection{Snapshot of Gasification Market}

Gasification has been used commercially around the world for more than 50 years by the chemical, refining, and fertilizer industries and for more than 35 years by the electric power industry. The gasification process, which was originally developed for and is widely deployed today in the production of chemical feedstock, is a partial oxidation reaction carried out in a continuous, high pressure reactor, in a reducing environment.10 A key advantage of the gasification process is the ability to convert undesirable, low value fuels (high in sulfur, heavy metals) to a clean burning synthesis gas. Subsequently, the fuel is then used in advanced technology combined cycle combustion turbines, as well as a feedstock for chemicals production.

\section{Advantages of $\mathrm{CO}_{2}$ capture from pre-combustion gases include:}

(1) The gas stream is at high pressure and high temperature providing a high reactivity for $\mathrm{CO}_{2}, \mathrm{H}_{2} \mathrm{~S}$, and other contaminants which leads to equipment with small foot prints

(2) The absence of combustion air keeps the volume of gas treated about 4 times less than that of post-combustion flue gas stream, and

(3) The $\mathrm{CO}_{2}$ gas can be retained at high pressures resulting in reduced electrical energy need for compressing that gas for pipe-line pressures.

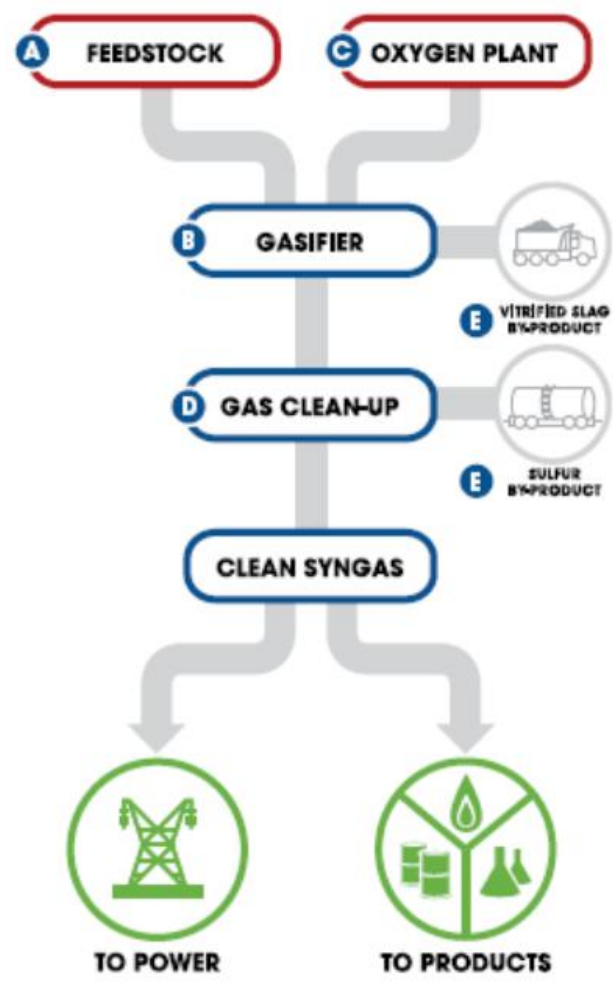

Figure 4. Gasification Process ${ }^{11}$

10 IGCC gathers pace, PowerGen Worldwide

11 Gasification Redefining Clean Energy, Gasification Technology Council 


\subsubsection{Integrated Gasification Combine Cycle market}

Strategic Development Plan • May 2010

Integrated Gasification Combined Cycle (IGCC) power generation allows the continued use of coal without equivalent high level air emissions associated with conventional coal combustion. In gasification power plants, the pollutants in the syngas are removed prior to combustion in the turbines. 12 In contrast, conventional coal combustion technologies capture the pollutants after the exhaust gas has passed through the boiler or steam generator.

Specifically plants have been commercialized over the past two decades demonstrating the technology's capability to meet stringent air emission standards. The first commercial scale IGCC projects were clean coal technology demonstrations in both the USA and Europe. Beginning in the mid 1980s, these included the Cool Water and TECO projects (using Texaco technology) and the Wabash River generating station (Dynergy/Destec technology) in the USA. European demonstrations of IGCC have included the Demkolec project in the Netherlands (Shell technology), and the Puertollano project in Spain (Prenflo/Uhde technology). 13

Commercial and near commercial sized plants using IGCC technologies have now accumulated several years of operating experience. Additional IGCC cost savings, resulting from technology advancements and improved construction techniques, have further reduced power generation costs and improved refiners' operating margins.

Faced with the reality of increasing global competition, excess capacity, and tightening environmental regulations, the refiners are taking new approaches to increase profitability including installation of independent power production (IPP). Many oil refineries have recognized that IGCC allows them to convert these unmarketable residues into valuable products. Using IGCC, the refineries are able to increase their overall profitability and improve their relative competitive position by: ${ }^{14}$

- $\quad$ Permitting more extensive upgrading of heavy materials to produce yields of lighter products and eliminating the need to dispose of increasingly unmarketable bottom products.

- Increasing the economic value of the produced residues through upgrading them to electric power and other products.

- $\quad$ Superior environmental performance, potentially reducing overall emissions for the refinery and eliminating or reducing the need for additional pollution control equipment.

- Destruction of refinery waste streams, eliminating tipping costs associated with their disposal, as well as deriving maximum fuel value from them.

- $\quad$ Easy integration with existing refinery equipment and infrastructure.

The main challenges with regard to the widespread adoption of this technology are:

- Demonstration of high availability equivalent to Pulverized Coal (PC) plants,

- $\quad$ Capital cost reduction to compete with state-of-the-art PC plants.

12 Ibid

13 Ibid

14 Holt, N., Wheeldon, J., Operating Experience, Risk, and Market Assessment of Clean Coal Technologies: 2006, EPRI 
Strategic Development Plan • May 2010

Specifically, the commercial deployment of IGCC technology has been inhibited over the last decade given the absence of a single entity responsibility for the supply of the IGCC technology from coal to kilowatts. Thus, within the industry there are no integrated IGCC power developers currently, but instead there are multiple "technology supporters".

These technology supporters include: ${ }^{15}$

- $\quad$ Air separation equipment technology and manufacturer firms.

- Gasification technology suppliers.

- $\quad$ Turbine technology and equipment manufacturers.

- $\quad$ Engineering, procurement, and construction (EPC) firms.

The main challenges with regard to the widespread adoption of this technology are: Unlike the NGCC industry, in which an investor deals mainly with the turbine and EPC firms, an IGCC investor must manage at least four constituencies, making the investment much more complex. In particular, the absence of an IGCC power developer increases the obstacles of achieving performance guarantee wraps and limiting liquidated damages. In response, three commercial teams were formed in 2004-2005 to offer reference turnkey IGCC plant designs to the US power industry with price, schedule, performance and emission guarantees. 16 The Gasification Technologies Council, a non-profit organization promoting technological advances and surveying the market, expects a further dynamic growth in gasification, reaching a worldwide equivalent thermal capacity of $73 \mathrm{GW}$ th by 2010 based upon planned projects. 17

\subsubsection{Value-Added Chemicals and Transportation Fuels}

In addition to generating power, the IGCC process can be modified to produce valueadded chemicals or transportation fuels from coal. For example, the Tennessee Eastman facility gasifies coal to produce chemicals.

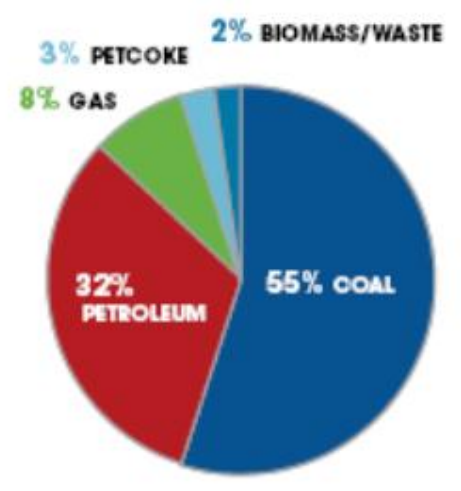

Figure 5. Global Syngas Output by Feedstock ${ }^{18}$

15 Coal-based IGCC: Market Penetration Recommendations and Strategies, Booz Allen Hamilton

16 Holt, N., Wheeldon, J., Operating Experience, Risk, and Market Assessment of Clean Coal Technologies: 2006, EPRI

17 Gasification Redefining Clean Energy, Gasification Technology Council

18 Ibid 
Strategic Development Plan • May 2010

It may be that the near-term market niche for IGCC lies not only in the production of electricity, but also in the generation of multiple products, where electricity, steam, and chemicals are economically bundled as products from a fully integrated complex. An IGCC poly-generation facility produces power and other products that conceivably could be varied in ratio depending on the market price and plant turndown ratio. In addition, poly-generation could provide energy storage potential, as plants produce electricity at peak demands and store synthetic fuel or other products at off-peak times ${ }^{19}$.

Forecasts from the International Fertilizer Industry Association suggest that demand should increase $4 \%$ in 2010 after falling nearly $7 \%$ in $2009 .^{20}$ High commodity prices experienced over recent years led to increased production and correspondingly greater fertilizer consumption as reflected in tight markets and higher fertilizer prices at the start of the outlook period. $^{21}$

The use of gasification technology for biomass and waste has become an application of interest with their use as partial feedstock to larger coal or petroleum coke based IGCC plants. ${ }^{22}$ Biomass/waste atmospheric gasifiers are also used adjacent to existing PC boilers supplying a raw gas to the boiler furnace. Gasification is also being developed for use in the forest products industry.

19 Coal-based IGCC: Market Penetration Recommendations and Strategies, Booz Allen Hamilton

20 Chemical News \& Intelligence, OUTLOOK 10: Fertilizer market back on track for growth

21 Current world fertilizer trends and outlook to 2011/12, FOOD AND AGRICULTURE ORGANIZATION OF THE UNITED NATIONS

22 Gasification Technology Status, Electric Power Research Institute 


\subsection{Market Growth Forecast}

Indications are that many new domestic gasification projects will be refinery-based, utilizing petroleum coke and other low-cost refinery by-products to produce power, steam, hydrogen, and chemicals for the refinery and additional power for internal use or export. 23 The maturation of gasification technologies through completion of several large-scale demonstration projects has made this technology a popular and viable alternative to conventional combustion technologies. There is significant market potential for coal gasification worldwide, as the technology allows generation of fuels for virtually all applications, i.e., transport, chemical products, and heat and power production. Escalating prices and limited availability of natural gas in regional consumer markets are driving factors for investments in gasification technology.

According to the Gasification Technologies Council, in 2007 there were 144 gasification plants and 427 gasifiers in operation worldwide, with a thermal capacity of some $56 \mathrm{GWth}$. Specifically, coal gasification accounted for approximately $31 \mathrm{GW}$ th of that amount with the remainder from petroleum, gas, pet coke, biomass, and waste. ${ }^{24}$ China has become the global test case for large-scale coal conversion activities. In 2008, China held licenses for the installation of 18 coal gasification plants; among these, 11 commercial size coal gasification plants were already in operation, most of them for the industrial production of methanol or ammonia.

Project momentum slowed dramatically since 2007 according to a new study by Emerging Energy Research with considerable delays and cancellations of several prominent IGCC projects in the past two years. The primary cause of the decline is the difficult market environment facing all new coal builds outside of China and India.

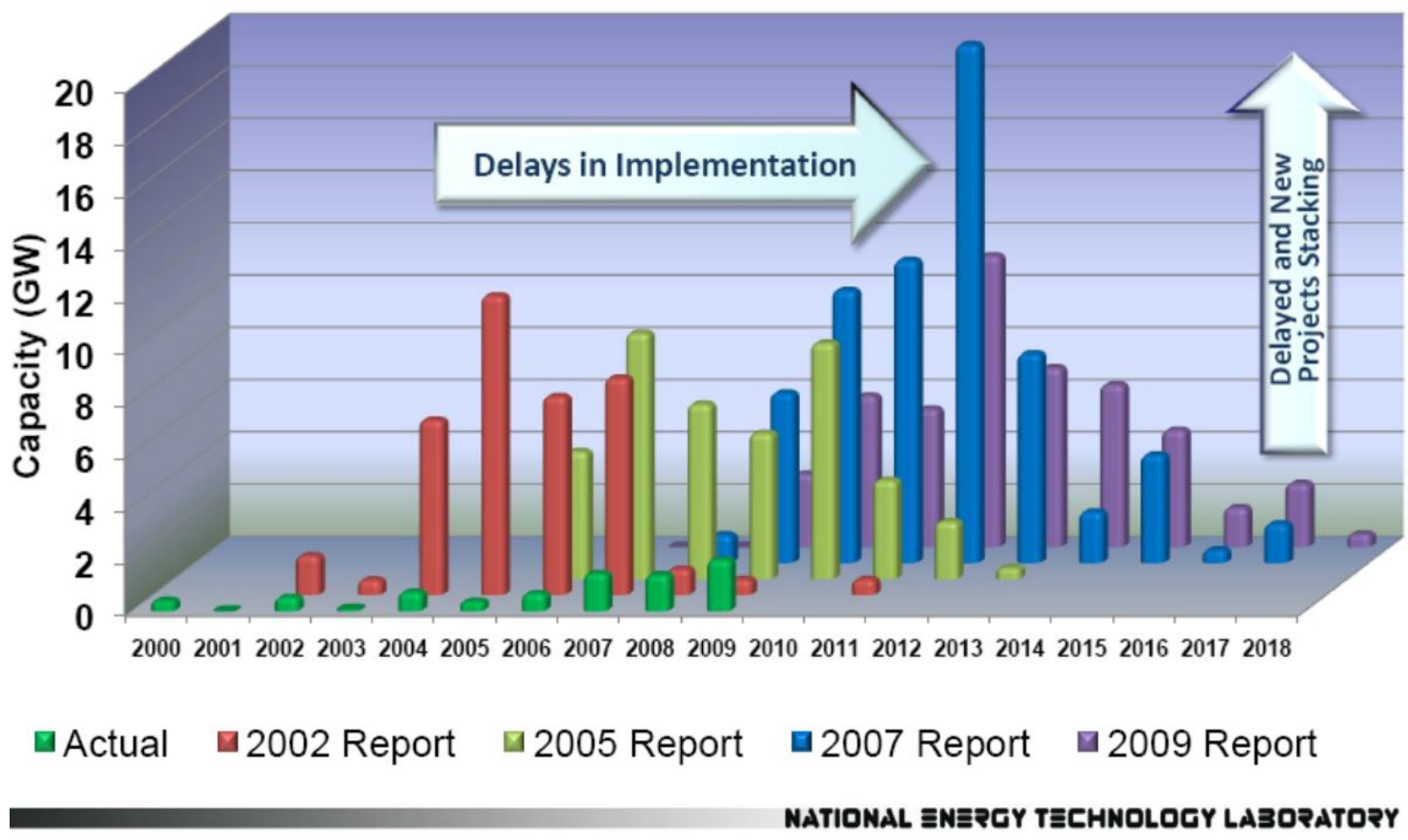

Figure 6. Past Capacity Announcements vs. Actual ${ }^{25}$

23 US Department of Energy National Energy Technology Laboratory, Wabash Report

${ }^{24}$ Gasification Market Analysis, Emerging Energy Research

252007 \& 2009 data Ventyx- Velocity Suite and 2002-2005 data- Previous NETL Tracking New Coal-Fired Power Plants Reports 
However, as a testament to the IGCC market and proof that overall confidence in IGCC, as a commercial technology has improved, there are still a considerable number of plants in the development pipeline as can be seen by the green line on the graph. Visage Energy also analyzed the potential advantages of a Capture Ready approach from a finance and insurance perspective.

Within the global IGCC market, there are projects under development in 10 countries with the overwhelming concentration within the US, accounting for $60 \%$ of current coal and/or pet coke IGCC plants under consideration.

- The US is currently leading the commercialization efforts of IGCC globally with 26 projects at some stage of development in 17 states with a combined capacity of 15,000 MW.

- Australia is next, given strong state and federal policies targeting clean coal technologies while Canada is driven primarily by early EOR opportunities.

- China's interest is growing due to air quality regulations becoming a greater threat to economic development. On a worldwide basis, the main activity on coal gasification is centered in China due to strong support from the central government.

- In contrast, Europe is expected to see rather slow development of IGCC, at least until 2015 according to EER's study.

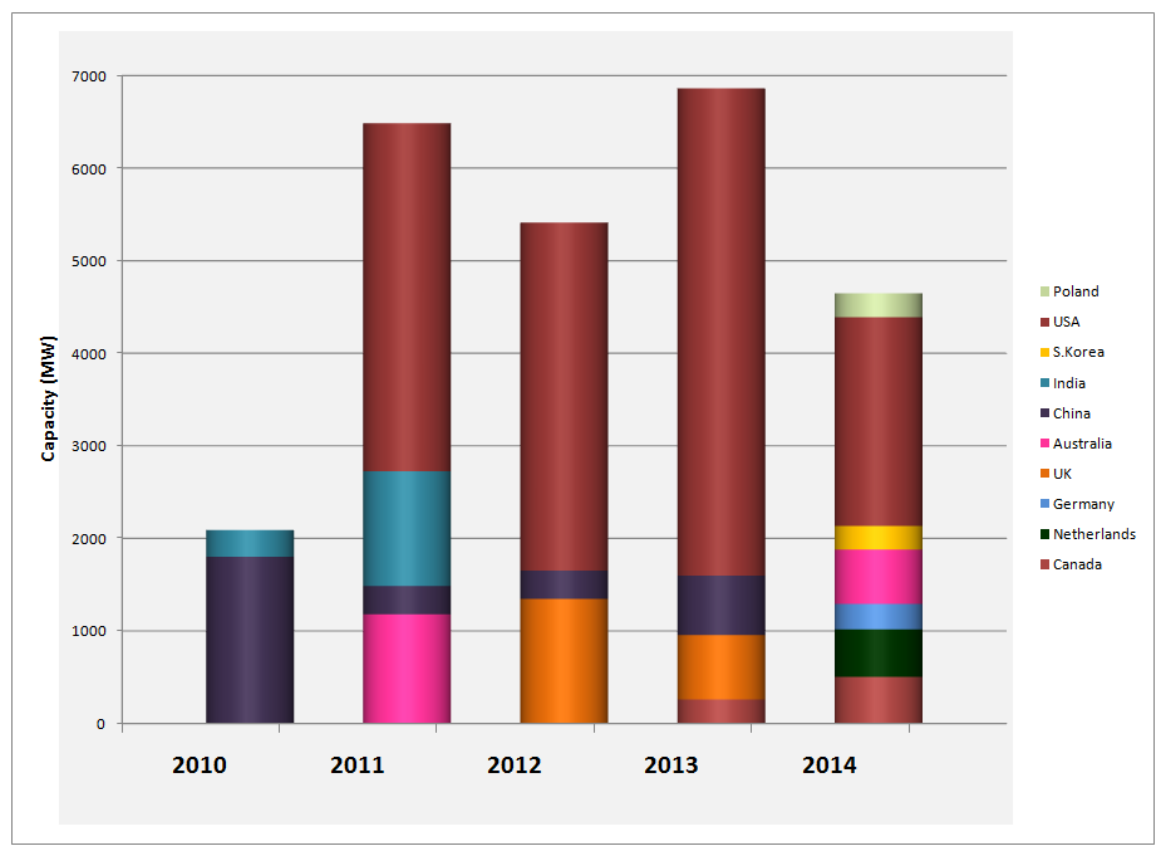

Figure 7. Global IGCC Project Pipeline

There are a number of potential market penetration options:27

i. Greenfield IGCC: building a new IGCC facility.

26 Gasification Market Analysis, Emerging Energy Research

27 Coal-based IGCC: Market Penetration Recommendations and Strategies, Booz Allen Hamilton 
Strategic Development Plan • May 2010

a. Advantage: Option most widely accepted in the market

b. Disadvantage: Lack of IGCC integrator and performance wrappers

ii. IGCC with Poly-generation: Building a Greenfield IGCC facility that also makes chemicals, synthetic gases, or synthetic fuels.

a. Advantage: Product diversification and flexible operating structure

b. Disadvantage: Added complexity of integrating a power facility with a chemical facility

iii. PC Repowering: Replacing existing PC facilities that are extremely inefficient or do not meet clean air requirements with IGCC.

a. Advantage: Owner capital cost resulting from pre-existing coal handling facility and steam turbines; existing permits and long-term contracts

b. Disadvantage: Disruptions to facility and added regulatory complexity

iv. NG Refueling with Syngas: Adding a gasification island in front of idle NGCC assets.

a. Advantage: Minimal disruption to facility; capability to withstand natural gas price volatility

b. Disadvantage: More capital intensive than a NGCC plant; plant loses its peaking capability

v. Brownfield Add-on: Adding an IGCC facility in parallel to an existing PC facility

a. $\quad$ Advantage: Reduced emissions per combined output; existing permits and long-term contracts

b. Disadvantage: Potential disruptions to facility; potential for physical siting constraints 


\subsection{Technology Competitive Landscape}

There are a number of carbon management strategies in development to address the growing concern that anthropogenic $\mathrm{CO}_{2}$ emissions are contributing to global climate changes. As indicated in Figure 8 to achieve emissions reduction targets the deployment of all technology options will be necessary.

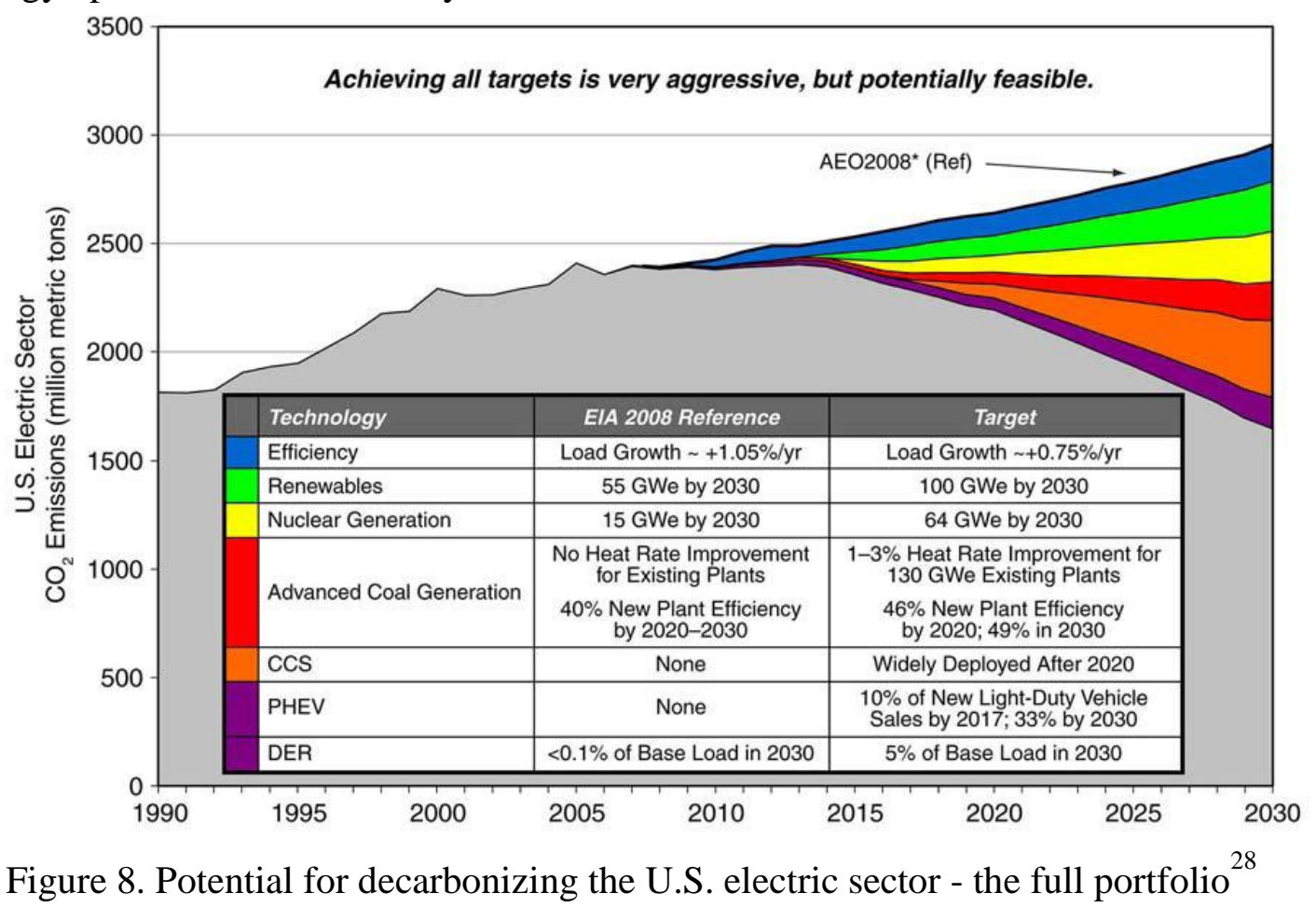

\subsubsection{Purchase Credits in a Cap and Trade Scheme}

One possible option to meet future regulations on carbon emission is emissions trading. The limit or cap is allocated or sold to firms in the form of emission permits representing the right to emit a specific volume of $\mathrm{CO}_{2}$. Firms are required to hold a number of credits equivalent to their emissions. Firms that need to increase their emission permits must buy permits from those who require fewer permits. 29 In essence, the buyer is paying a charge for polluting, while the seller is being rewarded for having reduced emissions.

\subsubsection{Technology Substitutes}

There are various options that can serve as substitutes to the deployment of CCS technologies. Specifically, an emitter can operate fossil fuel plants more efficiently, switch to $\mathrm{CO}_{2}$-free technologies such as nuclear and Renewables, or reduce electricity demanded by customers.

28 James, R., "The Power to Reduce CO2Emissions: the Full Portfolio" December 2008

29 Stavins, R.N., "Experience with Market-Based Environmental Policy Instruments" November 2001 


\subsubsection{Renewable Energy}

The role of renewable energy sources in the world energy generation landscape could become more substantial with the extension of current renewable energy policies. For example, in the IEA's reference case, there is the assumption that the Production Tax Credit (PTC) available for electricity generation from Renewables sunsets in 2012 (wind) or 2013 (other technologies) as specified in current law; however, in the past, this incentive has been renewed. IEA forecast that renewable generation will account for 45 percent of the increase in total generation from 2008 to 2035. In alternative cases assuming the PTC for renewable generation is extended through 2035, the share of growth in total generation accounted for by Renewables is between 61 and 65 percent.

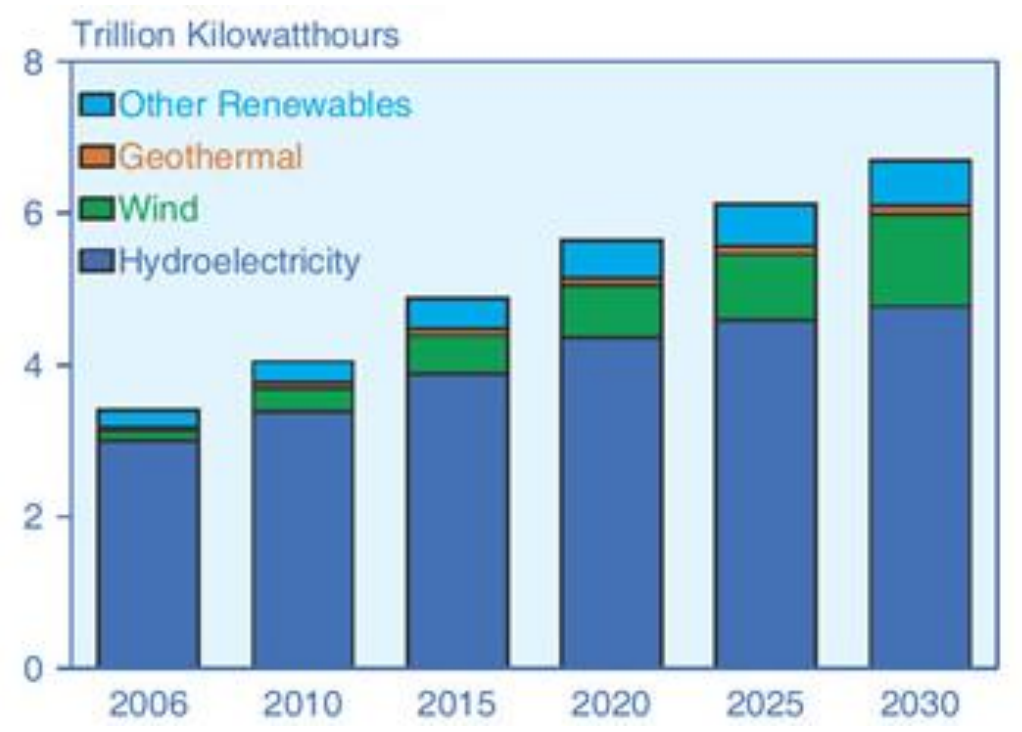

Figure 9. World Renewable Electricity Generation by Source, 2006-2030 ${ }^{30}$

\subsubsection{Energy Efficiency}

Energy efficiency is defined as utilizing less energy to provide the same level of energy service. Improvements in energy efficiency can reduce the need for investment in energy infrastructure, cut fuel costs, increase competitiveness, and improve consumer welfare. Energy security can also profit from improved energy efficiency by decreasing the reliance on imported fossil fuels. 31 Such measures could reduce the world's energy needs in 2050 by one third, and help control global emissions of greenhouse gases, according to the International Energy Agency (IEA). Energy efficiency and renewable energy have been defined as the pillars of sustainable energy policy.

\subsubsection{Nuclear Energy}

EIA forecast that electricity generation from nuclear power worldwide increases from 2.7 trillion kilowatt-hours in 2006 to 3.0 trillion kilowatt-hours in 2015 and 3.8 trillion kilowatt-hours in 2030 in the IEO2009 reference case. An increase in new nuclear generating

30 Energy Information Administration, International Energy Outlook 2009

31 The economics of transition in the power sector, International Energy Agency 
Strategic Development Plan • May 2010

capacity has been prompted by worldwide concerns with rising fossil fuel prices, energy security, and carbon emissions. Moreover, higher capacity utilization rates have been reported for many existing nuclear facilities, and it is expected that most of the existing facilities will be granted extensions to their operating lives.

However, there still exists considerable uncertainty about the future of nuclear powers such as plant safety, radioactive waste disposal, and the proliferation of nuclear weapons. Nevertheless, the IEO2009 projection for world nuclear electricity generation in 2025 is 25 percent higher than the projection in IEO2004. Most of the expansion of installed nuclear power capacity is expected in non-OECD countries. China, India, and Russia account for almost two-thirds of the projected net increment in world nuclear power capacity between 2006 and 2030 (Figure 9).

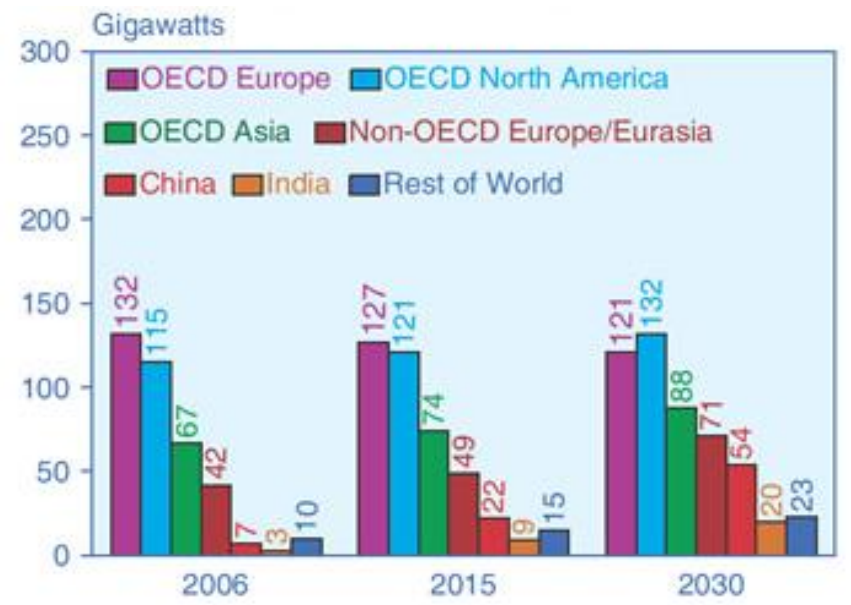

Figure 10. World Nuclear Generating Capacity by Region ${ }^{32}$

\subsubsection{Fuel Switching}

In the absence of a clear path forward for coal plants, US power companies are using natural gas combustion turbines and combined cycles to fill the power supply gap that cannot be satisfied by renewable energy, conservation, and end-use efficiency improvements. Natural gas remains an important fuel for electricity generation worldwide, given that it is more efficient and less carbon-intensive than other fossil fuels. In the IEO2009 reference case, total natural gas consumption increases by 1.6 percent per year on average, from 104 trillion cubic feet in 2006 to 153 trillion cubic feet in 2030, and its use in the electric power sector increases by 2.1 percent per year. With world oil prices assumed to rebound and rise through 2030 , consumers are expected to choose less expensive natural gas to meet their energy needs whenever possible. For example, in the industrial sector, newly constructed petrochemical plants are expected to rely more heavily on natural gas as a feedstock. Until the wide-scale deployment of CCS, the US and other OECD countries will become increasingly dependent on larger amounts of imported natural gas.

32 Energy Information Administration, International Energy Outlook 2009 


\subsubsection{Capture Technology Competitors}

Strategic Development Plan • May 2010

A key observation is that the growth of the pre-combustion capture technology market is typically contingent on the growth of the coal gasification market. In order to market the PBI membrane technology effectively, it is critical that technology developers see the benefits of coal gasification compared to the more developed coal combustion power system.

Several technological avenues for CCS are currently being explored. For power generation, these include pre-combustion, post-combustion, and oxy-fuel combustion.

\subsubsection{Post-combustion}

Flue gas typically contains up to $14 \% \mathrm{CO}_{2}$ that needs to be separated. For $\mathrm{CO}_{2}$ capture, chemical absorption with amines, such as mono-ethanolamine (MEA), is currently the state-of-art option. Post-combustion systems are positioned as a carbon mitigation solution for the existing fleet of coal-fired power plants. However, retrofitting a capture system to a power station requires major technical modifications. These alterations are quite costly and are accompanied by substantial decreases in generating efficiency (i.e., 33 percent reduction of net plant power output). ${ }^{33}$

\section{$\underline{\text { Post Combustion Emerging Technology Classes }}$}

Advanced Amines - Improvement to amine-based solutions include modified tower packing to reduce pressure drops and increased contacting, increased heat integration to reduce energy requirements, additives to reduce corrosion, and allow higher amine concentrations, and improved regeneration procedures.

Carbonated-based systems - Are based on the ability of a soluble carbonate to react with $\mathrm{CO}_{2}$ to form a bicarbonate that, when heated, releases $\mathrm{CO}_{2}$ and reverts to a carbonate.

- Advantages: Analysis indicates that the energy requirement is approximately 5 percent lower with a higher loading capacity of 40 percent compared to 30 percent for MEA. 34

Aqueous Ammonia - Works similar to amine-based systems. 35

- Advantages: Significantly lowers heat of reaction, potential for high $\mathrm{CO}_{2}$ capacity, lack of degradation during absorption/regeneration, potential for regeneration at high pressure.

○ Disadvantages: Hi Higher volatility of ammonia requires additional equipment to recover and recycle ammonia.

$>$ Membranes - Developing a variety of options for using membranes to recover $\mathrm{CO}_{2}$ from flue gas.

33 Figueroa, J.D., Carbon dioxide capture and sequestration potential and issues in US,

34 Rochelle G., Solvent and process enhancements for $\mathrm{CO}_{2}$,

35 Resnik, K.P. , Aqua ammonia process for simultaneous removal of $\mathrm{CO}_{2}$, 
Strategic Development Plan • May 2010

- Options: Flue gas is passed through a bundle of membrane tubes, as an amine solution flows through the shell side of the bundle. Novel thinfilm composite polymer membranes. 36

$\mathrm{CO}_{2}$ capture sorbents - Reaction of a solid with $\mathrm{CO}_{2}$ to form stable and then, at another set of conditions, allow for regeneration to liberate the absorbed $\mathrm{CO}_{2}$.

- Advantage: A number of solids can be used to perform the separation.

○ Disadvantage: Solids are inherently more difficult to work with than liquids, and no solid sorbent system for large scale recovery of $\mathrm{CO}_{2}$ from flue gas has yet been commercialized. 37

Metal organic frameworks - Are a class of hybrid material built from metal ions well-defined coordination geometry.

- Advantage: High storage capacity and minimal heat required for recovery.

○ Disadvantage: Very early laboratory scale research; manufacturing costs can be very high because of the high complexity. Unclear the effects of impurities at flue gas temperature and pressure and long-term stability. 38

Ionic liquids - Broad category of salts, containing organic cations and inorganic or organic anions.

- Advantage: Favorable temperature stability and little heat required for regeneration.

- Disadvantage: Most suitable ionic liquids are not commercially available. 39

Enzyme-based membranes - Achieves $\mathrm{CO}_{2}$ capture and release by mimicking the mechanism of the mammalian respiratory system.

- Advantage: Shown to have a very low heat of absorption that reduces the energy penalty of absorption processes.

- Disadvantage: Limitations include pore wetting, surface fouling, loss of enzyme activity, long-term operation, and scale-up. 40

\subsubsection{Pre-combustion}

Removal of $\mathrm{CO}_{2}$ is prior to combustion. Before combustion, the syngas is reacted with steam to produce $\mathrm{CO}_{2}$ that is subsequently scrubbed from the gas stream, usually by a physical absorption process. Acid gas removal processes that use physical solvents, such as Selexol and Rectisol, have such properties, but are energy intensive. Commercial applicability is more

\footnotetext{
36 Falk Pederson, O., Gas treating using membrane gas/liquid contactors.

37 Nelson T.O., Production of concentrated $\mathrm{CO}_{2}$ from flue gas using dry regenerable carbonate sorbents in a thermal-swing process,

38 Willis, R.R.Annual Report DE-FG26-04NT42121 National Energy Technology Laboratory,

39 Anderson, J.L., Measurement of $\mathrm{SO}_{2}$ solubility in ionic liquids,

40 Yang, W.C., Ciferno, J.Assessment of Carbozyme Enzyme-Based Membrane Technology for CO2 Capture
} 
Strategic Development Plan • May 2010

near-term until replaced with other technologies with higher performance and improved economics.

\section{$\underline{\text { Pre-Combustion Emerging Technology Classes }}$}

Other Membranes - Supported liquid membrane; dense metal alloy with high hydrogen permeability.

\section{Pre-combustion sorbents- Lithium silicate-based sorbent}

- $\quad$ Advantage: Ideal for high temperature environment and has shown excellent regeneration ability and attrition resistance in thermal cycling tests.

○ Disadvantage: Solids are inherently more difficult to work with than liquids, and no solid sorbent system for large-scale recovery of $\mathrm{CO}_{2}$ has yet been commercialized. ${ }^{42}$

Chemical looping gasification - Multiple solid particle loops are utilized to provide the oxygen necessary for gasification and carbon capture.

- Advantage: Provide greater driving force for water gas shift reaction and minimal increase in cost of electricity.

- Disadvantage: Early stages of development and handling of multiple solid streams.

\subsubsection{Oxy-combustion}

Oxy-combustion burns fossil fuels in 95 percent pure oxygen instead of air. This results in a flue gas with high $\mathrm{CO}_{2}$ concentrations (greater than 80 percent) that can be condensed and compressed for transport and storage. This method of $\mathrm{CO}_{2}$ capture is still in the demonstration phase and the key to commercialization is reduction in cost of oxygen production.

Oxygen production: The cryogenic air separation technology is current the only commercial option.

O Other Options: Ion transport membrane where oxygen diffuses through membrane as an oxygen ion, for use in $\mathrm{O}_{2} / \mathrm{N}_{2}$ separation. Oxygen transport membrane utilization in the boiler. ${ }^{44}$ Ceramic auto-thermal recovery uses perovskites to adsorb oxygen from

\footnotetext{
41 Figueroa, J., Plasynski, S., 2007Advances in $\mathrm{CO}_{2}$ capture technology- The US DOE's Carbon Sequestration Program $42 \mathrm{Li}$, W. , Gangwal, S.K. 2005Development of fluidizable lithium silicate-based sorbents for high temperature CO $\mathrm{O}_{2}$ removal

43 Lyngfelt, A., Kronberger, B., Development of oxygen carrier particles for chemical looping combustion, Seventh International Conference on GHG, Vancouver

${ }^{44}$ Acharya, D., Krishnamurthy, K.R., Development of a high temperature oxygen generation process, $22^{\text {nd }}$ Annual International Pittsburgh Coal Conference, Pittsburgh, PA.
} 
Strategic Development Plan • May 2010 air and then release the adsorbed oxygen into recycled flue gas to be vented.

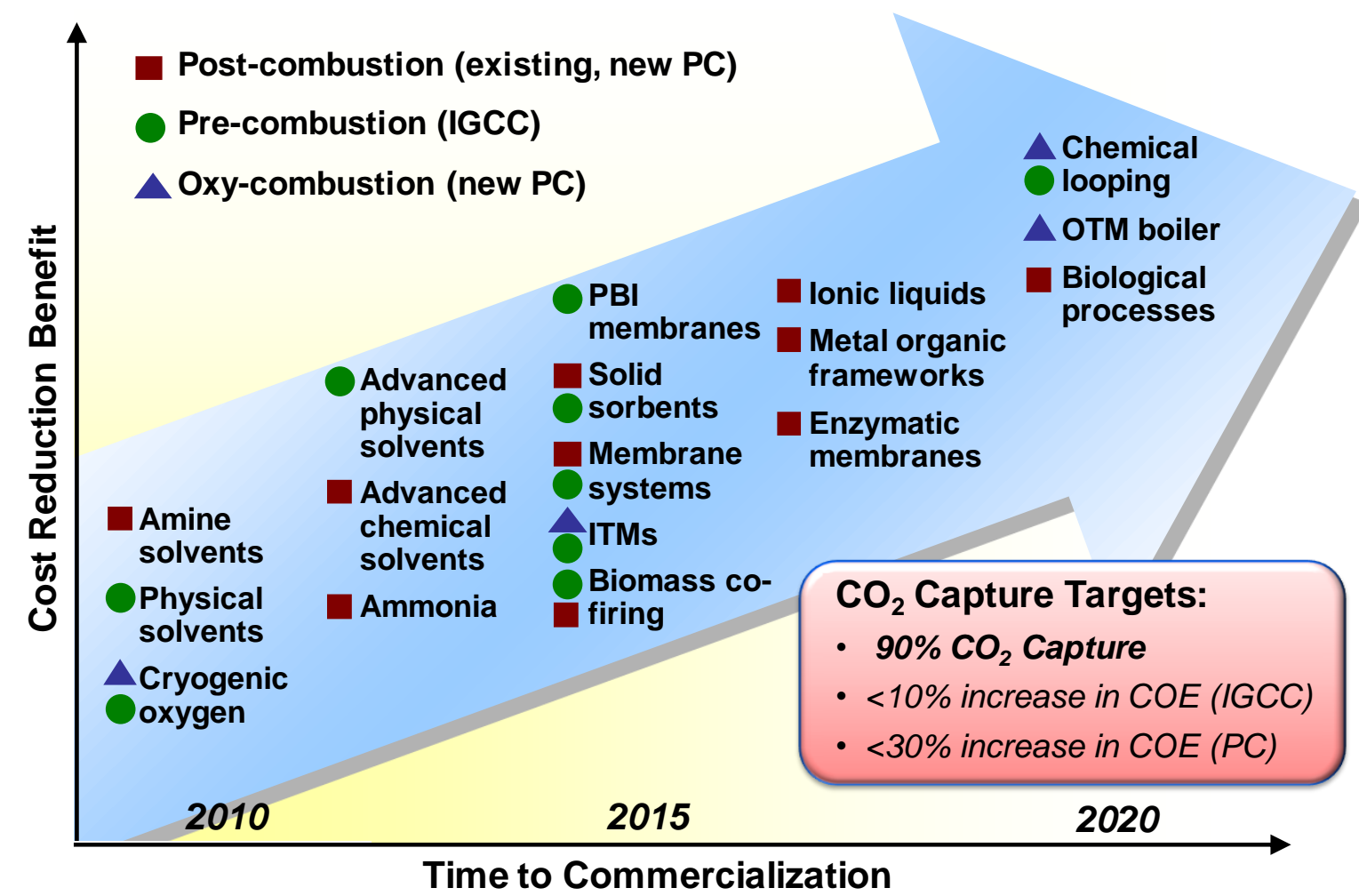

Figure 11. NETL Fossil Energy $\mathrm{CO}_{2}$ Capture Solutions Commercialization ${ }^{46}$

45 Shah, M., van Hassel, B., $\mathrm{CO}_{2}$ capture by membrane based oxy-fuel boiler, Proceedings of the 2006 Conference on CCS Alexandria, VA

46 National Energy Technology Laboratory Presentation - Reference Data 


\subsection{Barriers to Entry}

The most significant barrier to market penetration is pending $\mathrm{CO}_{2}$ capture and sequestration legislature. Specifically, many states are creating incentives for utility companies to invest in Renewable Energy Projects but have given no direction to the investment in the broader category of clean energy technologies generated by fossil fuel with near zero emissions. Thus, part of the commercialization effort has involved educating regulatory bodies on the role of CCS technologies as a complement to Renewable Energy technologies providing a portfolio of solutions to lower GHG emissions.

\subsubsection{Market Barriers}

The most significant barrier is the capital cost commitment needed for an IGCC plant. Even though an 850 to $1000 \mathrm{MW}$ plant is the most economical, current risk-averse financial markets are hesitant towards funding such a large investment, especially as power needs are trending towards incremental growth. The second main barrier to entry is investor perception that IGCC investments are novel and overly risky in a saturated market. Table 3 depicts a Strengths, Weaknesses, Opportunities, and Threats analysis for the IGCC market.

Table 2: General IGCC SWOT Analysis ${ }^{47}$

\begin{tabular}{|c|c|}
\hline Strengths & Weaknesses \\
\hline $\begin{array}{l}\text { - } \\
\text { - } \quad \text { A more proven technology format as } \\
\text { compared to other entry strategies } \\
\text { - } \quad \text { In short term, suppliers are in a weaker pricing } \\
\text { position } \\
\text { - } \quad \text { Most easily optimized of all options } \\
\text { - } \quad \text { Most easily replicated of all options } \\
\text { Future polygeneration potential }\end{array}$ & $\begin{array}{l}\text { Adversely viewed by investors because of } \\
\text { financial size } \\
\text { Regulatory handling of IGCC facilities } \\
\text { relative to NGCC } \\
\text { Reluctance to enter into long-term contracts } \\
\text { because of uncertainty over future demand, } \\
\text { natural gas prices, and regulatory framework }\end{array}$ \\
\hline Opportunities & Threats \\
\hline - Coal states that support IGCC as BACT & $\begin{array}{l}\text { - Anticipated technology advancements do not } \\
\text { occur in ASU and Gasification islands } \\
\text { - } \quad \text { NGCC capital costs decrease at a faster rate } \\
\text { - Permitting/siting difficult because of } \\
\text { environmental concerns and NIMBY }\end{array}$ \\
\hline
\end{tabular}

Utilities/End-user Stakeholders Issues

$>$ Require the ability to receive rate-base treatment for investment

$>$ Need for long-term stable carbon policies

$>$ Complexities in construction and operation of IGCC facilities

$\underline{\text { State Stakeholders Issues }}$

$>$ Renewables and natural gas generation preferred over coal + CCS

$>$ Some question viability of CCS as a climate-change mitigation tool

47 Coal-based Integrated Coal Gasification Combined Cycle: Market Penetration Recommendations and Strategies, Booz Allen Hamilton 
Strategic Development Plan • May 2010

$>$ Escalating construction costs and parasitic load associated with CCS

\subsubsection{Technology Transfer Analysis}

In subtask 9.2, Visage Energy was charged with evaluating the technology transfer opportunities associated with the PBI technology and, specifically, considering a broad spectrum of technology transfer options available for the technology. There are a number of possible options for technology transfer for the PBI technology. Each option was based on market conditions and the market potential addressed in Task 8.0. It is anticipated that the PBI technology will proceed from research and development, to deployment, to finally wide-scale adoption by the domestic market and the international market. Although it is possible for the spread of a technology to occur more rapidly to other countries, it does not appear that this will be the case with the PBI technology given the CCS leadership role that the United States has taken. Additionally, the transfer of technology outside of the US is generally more expensive given the export expenses and the higher barriers to penetration into those international markets. ${ }^{48}$ However, technology transfer domestically and abroad can occur simultaneously depending on the technology demand.

In general, there are five main opportunities for transferring technology into the marketplace: (1) Sale of Intellectual Property Rights, (2) Licensing technology to an end-user, (3) External Incubator, (4) Establishing a joint venture with an established company that has a channel to market and an established client base, and (5) the New Venture formation. The options are ordered with respect to least financial commitment to highest financial commitment required from the $\mathrm{PBI}$ technology development team.

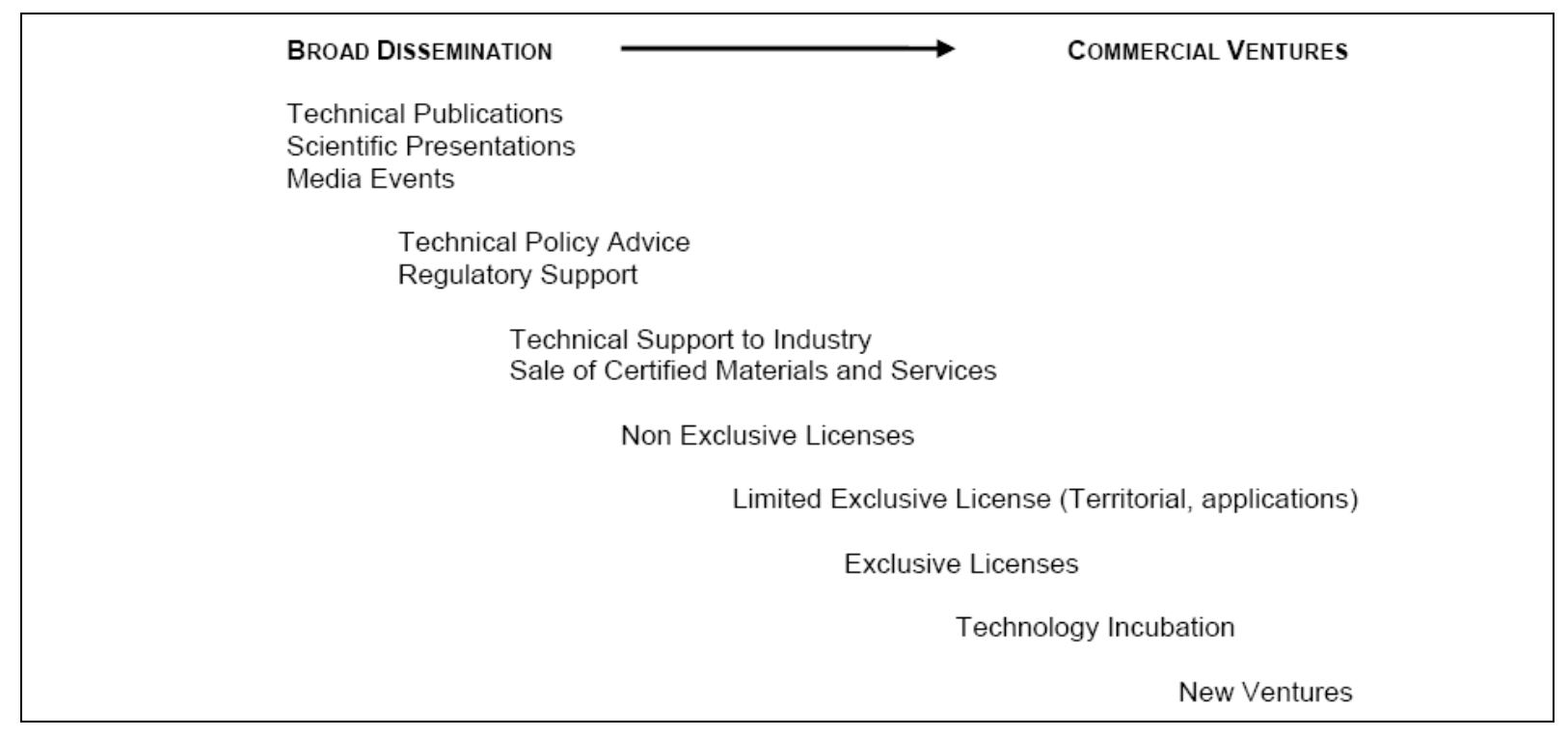

Figure 12. Technology Transfer Pathways ${ }^{49}$

Figure 11 presents another framework of the technology transfer pathways where there are three different variations on the licensing model option (Non Exclusive Licenses, Limited

\footnotetext{
48 Methodological and Technological issues in Technology Transfer, Intergovernmental Panel on Climate Change

49 Keith Belinko, “A Technology Transfer Decision Framework for Publicly Funded Research Organizations” May 2004
} 
Strategic Development Plan • May 2010

Exclusive Licenses, and Exclusive Licenses). Technology transfer does not occur at one single period, but instead is more of a continuum of activities leading to the application of a commercial technology. The optimal technology transfer pathway for the PBI technology will be based on the information available at the time of deployment. This decision will need to address not only the PBI technical specifications, but also the regulatory, legislative, market competition, and financial environments at that point in time. Given the decision's dependence on a number of technical and business issues, it is clear that the optimal technology pathway may change along the life of the technology development lifecycle. Thus, a snapshot is taken at a certain point to determine how best to transfer a particular technology. If another snapshot is taken along the technology transfer continuum as the technology evolves, more information may become available that could influence the outcome. For example, new applications for the technology may be found, market competition may increase, and new players may become involved.50 Currently, it appears that the PBI technology most likely should follow the Non Exclusive License technology transfer pathway. However, Visage Energy will continue to analyze the possible technology transfer options available as the PBI technology progresses.

\subsubsection{Compilation of Financial Issues}

Financial institutions are reticent to invest in these facilities given the dependence of profitability on increasingly risky and uncertain long-term yields. Historically, the financial community has not invested resources in the environmental control technologies because they viewed legal compliance as being sufficient. The two most substantial barriers to project financing are utility industry inertia in novel technology deployment and the lack of sufficient business incentives to cover the cost of CCS. Thus, it is becoming clear to regulators that there will need to be substantial government and industrial financial support to encourage wide-scale deployment of CCS. There are a number of financing methods being proposed and developed such as technology mandates, utility mandates, electricity regulator approval of higher cost, and the creation of a dedicated CCS Trust Fund. In the past, governments assumed that the vehicle of public/private partnerships would effectively finance the early stage deployment necessary; however, in the last year numerous projects have been canceled due to a lack of sufficient resources to cover escalating costs.

\section{Financial Stakeholders Concerns:}

$>\quad$ Concerned with the current lack of sufficient business incentives but encouraged by strong indication of an imminent carbon policy.

$>\quad$ CCS Financing Options: Emissions trading, Mandating CCS, Energy regulatory approval of the higher cost, and CCS Trust Fund.

Adoption of Carbon Principles: More stringent requirements for investment in coal-based generating facilities. Provides a procedure to analyze the dispatch order of this additional coal-fired power generation and its economic performance under various scenarios. 
Strategic Development Plan • May 2010 Approval of CCS project methodology under Clean Development Mechanism will be important.

Project Financing has been difficult for many project developers to obtain for coal projects and even IGCC projects because financiers are concerned with the carbon policy uncertainty. Many fear that without some form of additional support for CCS, a cap and trade policy will not be sufficient to cover cost. Many in the finance community feel that it is a missed opportunity that CCS is not included in the CDM and once it is included there will be a dramatic increase in projects in developing countries.

Due to the uncertainty of escalating cost associated with construction of new coal-fired plants, Public Utility Commissions are refusing to allow utility companies to recover the cost of new builds in their rate-base. At this time the majority of CCS projects in development are Enhanced Oil Recovery projects in which the $\mathrm{CO}_{2}$ originates from an industrial source typically not requiring deployment of a capture system. The major ramification of this delay in early deployment of CCS projects is that this experience needs to ultimately guide subsequent future commercial demonstrations in an effort to foster the learning necessary to proliferate CCS throughout the power generation and industrial sectors.

Thus, the financial community is looking to regulators to enact appropriate public policy to initially encourage the development of CCS pilots and later public support around capital cost and operating cost associated CCS. Currently, in the environmental community, there is a division on this issue and this will continue to be a major uncertainty for the financial community.

The IEA has urged the world's governments to invest $\$ 20$ billion in near-term, fullscale carbon capture and storage demonstrations. The organization argues that current spending is far from the level needed to achieve the necessary emissions reductions set forward by the G8. The IEA recommendation, which was endorsed at the 2008 Hokkaido Toyako summit, encourages the deployment of 20 CCS fully operational plants by 2020. "The technology must be proven within the next decade," IEA Executive Director Nobuo Tanaka was quoted as saying at a press conference in Paris. 52

McKinsey \& Co., in a study published in September of 2008, called for near-term investment in CCS demonstrations of $\$ 14.7$ billion, but concluded that after 2030, industry could cover its own capture and sequestration costs. 53 Interestingly, the report also states one of the less-mentioned drawbacks of CCS is that it will increase the amount of coal needed to produce a given electrical output given the decrease in plant efficiency.

\subsubsection{Compilation of Insurance Issues}

Although international governments have made some progress in developing suitable CCS policy frameworks in an effort to promote early demonstration of CCS projects, there are still many issues that need to be fully addressed prior to wide-scale deployment of the CCS in the power generation and industrial sectors. On the transportation front, $\mathrm{CO}_{2}$ pipeline

51 International Energy Agency, $\mathrm{CO}_{2}$ CAPTURE AND STORAGE: A key carbon abatement option, October 2008

52 Eduard Gismatullin, Bloomberg, Carbon-Capture Costs Delay Projects, Hamper CO2 Goals (Update1), October 20, 2008

http://www.bloomberg.com/apps/news? pid=20601072\&sid=aHbRYbAnIuMA\&refer $=$ energy

Earth2Tech, October 20, 2008 http://earth2tech.com/2008/10/20/iea-carbon-capture-needs-20b-now/\#more-12731 
Strategic Development Plan • May 2010

regulations will be required to increase coordination across state and national borders to eliminate the barrier of inconsistencies in pipeline access and $\mathrm{CO}_{2}$ purity requirements. Another deployment barrier is the lack of clarity of the property rights associated with $\mathrm{CO}_{2}$ storage, particularly including access rights and ownership of storage reservoirs.

\section{Insurance Stakeholders:}

Long-term indemnification of storage liability has yet to be resolved.

Need clarity on property rights associated with $\mathrm{CO}_{2}$ storage including access rights and pore space ownership.

The largest impediment is the indemnification of the long-term sequestration risk. The third-party and self-insurance instruments are best suited to the injection closure and postclosure periods because the risk profile of the project is clear while the site is active and the developer is best able to leverage the funds necessary to finance the instrument. Thus, the relative cost associated with closure and post-closure activities are reasonably quantifiable. On the other hand, long-term storage is much more difficult to estimate and the long-term risk profiles result in an uncertain probability of risk exposure making it difficult to define the cost of any necessary remediation activities. It is difficult to identify and monetize the damages that could result from long-term leakage. Public/Private pooling structure will be necessary given the inability to assign an upper limit of financial liability. Most insurance companies are waiting until some of the major impediments are handled.

Currently traditional insurance companies are not offering coverage in the event of storage catastrophe. The key issue with using traditional insurance products is the long-term position that would potentially be required. Insurance companies are unable to fix a long-term premium at the outset of a project given the lack of available data, such as an unexpected catastrophic loss of a carbon dioxide reservoir which could immediately impact the operating expenditures of all geological sequestration projects. ${ }^{54}$ However, without this critical issue resolved, the majority of the utility companies with whom Visage Energy has had extensive discussions are extremely reticent to become involved in large pilot projects deploying capture technologies.

$>$ Ambiguities must be resolved regarding pore space ownership and the relation between the surface and mineral estate. A process for owners and project developers to transfer/lease the necessary subsurface pore space property rights for a CCS project is also an issue.

$>$ The long-term ownership of and liability for the stored $\mathrm{CO}_{2}$ also are potential barriers for CCS development which may be addressed by transferring liability to the state or by federal or private indemnification schemes.

At the federal level, a bill has been introduced and referred to committee that would establish a carbon-storage-stewardship trust fund funded by fees from operators to ensure compensation for potential damages relating to the geologic storage of $\mathrm{CO}_{2}$. One private insurer is making short-term insurance policies available.

54 R. Engleman, Geological Carbon Dioxide Sequestration: Insurance and Legal Perspectives on Liability, September 2004 


\subsubsection{Compilation of Regulatory and Legal Issues}

Successful deployment of CCS technologies hinges not only on the economics of the process but also on the ability to create a regulatory environment that encourages investment in technologies and rewards early adopters of the technologies. Visage Energy would assert that the technology development is not a major impediment to the wide-scale deployment of CCS in California.

Without a price on carbon, investor interest in CCS worldwide has been limited to outside niche applications. Policies that place a price on GHG emissions, such as a cap and trade, would discourage investments in traditional fossil-fuel use and spur investments in a range of clean energy technologies, including CCS.

Example: Allocation of cap-and-trade allowances for carbon reductions from CCS deployment and potentially bonus allowances to early movers for the first selected number of gigawatts $(\mathrm{GW})$ of CCS capacity. At the federal level, the House legislation would allow EPA to issue the bonus allowances to early movers for the first six gigawatts (GW) of CCS capacity and, in a second phase, to distribute additional allowances for additional CCS deployment. The second phase would also be capped at $6 \mathrm{GW}$. The Senate bill, as introduced, would provide bonus allowances for up to $10 \mathrm{GW}$ of CCS in the initial phase, and another $10 \mathrm{GW}$ in a second phase

$>\quad$ Funding for Initial CCS Projects: To foster the initial, large-scale CCS projects needed to fully demonstrate the technology, the government can offer financial incentives for CCS. For example, the government could create a trust fund that could competitively award money to CCS projects to help them overcome financing hurdles. ${ }^{55}$ A study prepared for the Pew Center found that coal power plant owners would require between $\$ 300$ million and $\$ 650$ million in funds to cover the investments in equipment and lost capacity necessary for the initial commercial-scale deployments of CCS, depending on the plant type and whether plants are newly built with CCS or retrofit.

> Mandating GHG Emission Rates: Policymakers could rely on performance standards to drive CCS deployment by enacting new regulations that require CCS via a new source performance standard for power plants or a low-carbon performance standard.

\subsection{Status of Commercialization Effort}

\subsubsection{Identification of Stakeholders (Frame-Setters and Enablers)}

The Visage Energy/SRI Partnership commercialization effort for the PBI project is designed to establish a commercialization pathway(s) for novel technologies by aligning multiorganizational teams and focusing on end-user needs within the context of the Statement of Project Objectives (SOPO). This is often challenging when multiple organizations are

55 Pena, N. and E. Rubin. A Trust Fund Approach to Accelerating Deployment of CCS: Options and Considerations. Prepared for the Pew Center on Global Climate Change, 2008. 
Strategic Development Plan • May 2010 involved. A component of the Visage Energy/SRI commercialization effort is to create this alignment through the use of SRI's Disciplines of Innovation (DOI) approach, which is embedded throughout the performance of the research project (Figure 12). Visage initially identified the PBI technology stakeholders that would be involved in the entire value chain for that project, not only in the research area, but in all areas, straight through to commercialization. There are seven key stakeholders which will need to be brought into alignment to accelerate the demonstration and commercialization of CCS technologies:

- Federal Stakeholders

- Technology Developers

- State Stakeholders

- End-users,

- Environmental Groups

- Insurance Companies

- Financial Institutions

The end goal of successfully financing CCS projects cannot occur on a wide-scale level if any one of these seven stakeholders is unaligned or excluded. For example, Financial Institutions will be unwilling to finance CCS projects which have uninsurable and unlimited project risk. Insofar as traditional turn-key financing may not be available for decades, new and innovative financing methods will be required for the accelerated development and deployment of these facilities. Insurance companies will be unwilling to provide insurance coverage for CCS projects until state and federal regulators bound the liability by providing some form of federal backstop protection to assist in quantifying the risk associated with carbon sequestration. ${ }^{56}$

Visage Energy analyzed the market requirements of each of the stakeholders in an effort to begin incorporating those requirements into the technology-development process to target the design and development to those specifications. This step is critical and iterative, as the feedback gathered needs to be incorporated back into the technology process early. This should encourage seamless deployment of the PBI technology into the marketplace.

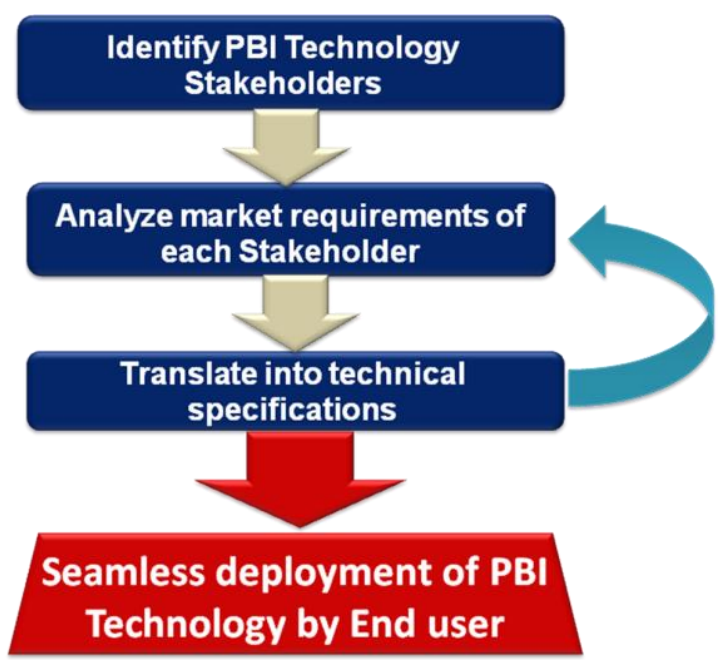

56 COMMERCIALIZATION OF CARBON CAPTURE AND STORAGE TECHNOLOGY THROUGH PUBLIC-PRIVATE PARTNERSHIPS, Kevin O’Brien, Will Johnson, Daryl-Lynn Roberts 2007 
Strategic Development Plan • May 2010

Figure 13. Technology Commercialization Process

In Task 8.0, Visage Energy performed a market analysis to further understand the market environment that the PBI technology will face upon completion. The anti-coal regulatory environment has somewhat hindered the growth of the IGCC market in the last 2 years. Many environmental groups have argued that the concept of "cleaning up coal" is a false notion that the power generation and coal industry have fabricated to enable the continued use of this fossil fuel. Additionally, many see investing in this industry as a distraction from the investment that is necessary in Renewable Energy and Energy Efficiency Initiatives. It is clear that additional education is necessary to demonstrate the true potential of CCS technologies as well as a demonstration of how CCS complements Renewable and Energy Efficiency Initiatives. Consequently, the success of Carbon Sequestration Partnership Projects will serve as critical examples of the viability of CCS.

\subsubsection{Update on Stakeholder Outreach Efforts}

The Executive Stakeholders' Collaborative (ESC) Initiative objective is to provide a forum to educate senior-level state regulators and end-users about the benefits of CCS technologies and their commercial viability. The Collaborative Initiative intends to work closely with the Carbon Sequestration Regional Partnerships to foster an environment that encourages and continues to accelerate the deployment of CCS as a carbon-management tool.

Insofar as CCS involves immature technologies and a high level of financial risk, close cooperation and collaboration will be required between the DOE/FE/NETL, utilities, and other major stationary $\mathrm{CO}_{2}$ point sources, and state regulatory agencies. State stakeholders should be engaged early in the process, providing a regulatory framework that supports the accelerated commercialization of CCS technologies due to the stakeholders' greater understanding of CCS technical and economic performance and potential.

The CCS/ESC Initiative will seek to foster Public/Private partnerships in an effort to develop a regulatory framework that encourages sharing deployment costs among electricimporting states and electric-exporting states within a region. Given the unique regulatory environment of each state, the CCS/ESC Initiative will combine a local-state approach and a regional approach to achieve the goal of accelerating the commercialization of CCS nationally.

\section{Expansion Strategy for CCS Executive Stakeholders' Collaborative Initiative}

1) Develop and apply a screening methodology to identify target states to initially serve as the focal point within each region using the following criteria:

$>\quad$ Total carbon footprint (including electric generation plants, cement manufactures, refineries, chemical manufactures, etc.).

$>\quad$ Availability of suitable sequestration resources.

$>\quad$ Active participation in RCSPs.

$>\quad$ Favorable carbon management regulatory environment .

$>\quad$ Collaborate with RCSPs to ensure that executive stakeholder outreach efforts are closely coordinated with the RCSPs' other public outreach efforts. 
2) Formulate a CCS/ESC Action Plan unique to each target state:

- $\quad$ Determine which state regulatory agency should be approached first as the host state agency executive stakeholder (most influential and/or most willing to be engaged).

- Determine subset of major stationary $\mathrm{CO}_{2}$ point sources that are prime candidates to join the CCS/ESC.

3) Implement the plan by establishing a CCS/ESC in each target state which will include the DOE/FE/NETL, state-agency principals, CEOs, and senior management of major stationary $\mathrm{CO}_{2}$ point sources. The composition of a target state CCS/ESC will expand with the inclusion of each relevant stakeholder and will evolve into a Regional CCS/ESC.

- Initiate and coordinate outreach forums to engage relevant executive stakeholders within each target state in an effort to expose and educate the regulatory community about the viability of CCS as a Carbon Mitigation Strategy and encourage its acceptance among the regulatory community.

- $\quad$ Coordinate a two-day visit to NETL to provide a primer on Carbon Capture and Storage and NETL's role in the development of CCS technologies for each target state.

- $\quad$ Additional regulatory agencies were invited to join each state's CCS/ESC.

$>\quad$ Relevant state agencies in each state may vary. Examples may include: Public Utilities Commission, Energy Commission, Air Resource Board, Department of Conservation, Department of Fish and Game, etc.

- $\quad$ Conduct follow-up meetings with Commissioners, staff, and utility company management to ensure that all questions/concerns have been adequately addressed and to solicit feedback to incorporate into upcoming forums.

4) Expand the target state's CCS/ESC to neighboring states:

- Cooperation and coordination is needed between the electric-importing and electric-exporting states in order to provide the proper environment for the acceleration of the deployment of CCS technologies.

Specifically, electric exporting states will likely be unwilling to approve the construction of CCS projects without support from the electric importing states by sharing in the total financing costs and risks associated with an accelerated deployment approach.

- Examples of regulatory activities that could foster interactions between electric-importing and electric-exporting states would include (Figure 13):

$>\quad$ Support of construction of new or retrofit of existing plants with CCS including out-of-state projects with assets dedicated to supplying electricity to importing states.

$>\quad$ Provide state regulatory support for ratepayer funds to be utilized for cost share in CCS technology projects. 
Strategic Development Plan • May 2010

$>\quad$ Encourage closer cooperation between major stationary $\mathrm{CO}_{2}$ point sources, financial and insurance entities, and technology sources focused on CCS development.

Construction subsidies and suspension of coal severance tax for initial CCS projects.

Joint guarantee from Public/Private partnerships provided by energy-importing states and energy-exporting states for indemnification of insurance liability in order to bound risk of $\mathrm{CO}_{2}$ sequestration for the first few projects, as currently there is no such indemnification available for $\mathrm{CO}_{2}$ sequestration (exception in the case of the indemnification of the FutureGen Alliance if FutureGen is sited in Texas or Illinois).

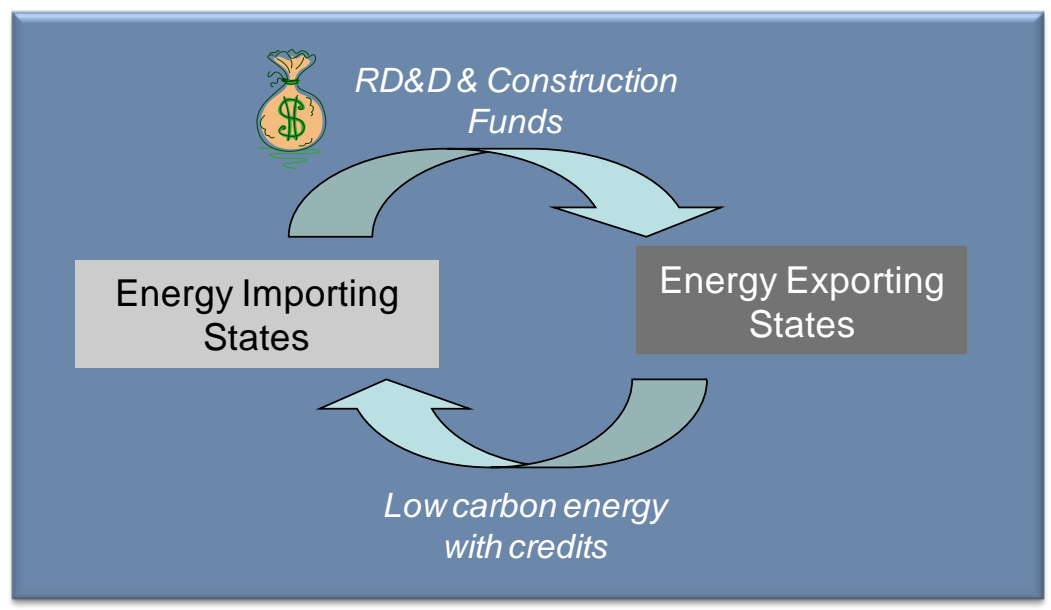

Figure 14. Symbiotic Relationship Between Energy Importing and Exporting States

5) Focus the existing CCS information source and database to assist all relevant executive stakeholders in gaining an understanding of the regional requirements for siting and permitting of CCS facilities, and technology procurement.

$>\quad$ The RCSPs are currently collecting and developing reports that address these key issues. Thus these libraries of information will be sourced to provide relevant decision-makers with executive-level synopses. Specifically, best practices concerning the permitting process, design, construction, startup, and operation of power generation facilities with CCS within each of the different technologies should be shared with executive stakeholders.

\section{CCS Executive Stakeholders' Collaborative Forums}

Each forum will include an educational session (i.e., presentations from NETL or other industry experts), a roundtable discussion session, and a next-steps session.

1) Industry experts from NETL, Regional Sequestration Partnerships, CCS Reg project, and project and technology developers will conduct sessions addressing issues such as capture technology status, sequestration potential, including opportunities for Enhanced Oil Recovery (EOR), status of current and pending 
projects in development, and state-specific regulatory and legal barriers to deployment.

2) The roundtable discussion session is the most valuable part of the forum as it provides an opportunity for executive stakeholders to engage in further discussion regarding the benefits and opportunity of CCS as a Carbon Management tool.

3) Additional Examples of Roundtable Discussion Topics:

$>$ The role of CCS technology in meeting the state's energy needs and carbon reduction goals.

$>$ The development of a comprehensive approach for a legal/regulatory framework for permitting proposed CCS projects that is consistent with the target state's energy and environmental policy objectives.

$>$ Develop and support current and emerging CCS opportunities within that region and address existing project development, legal, and regulatory barriers.

$>$ The roles of the target state agencies in the permitting and siting of CCS projects.

$>$ Coordinate and leverage current DOE CCS RD\&D activities within the target state to ensure that effective avenues of communication exist between researchers, decision-makers, and other executive stakeholders.

$>$ Complementary nature of CCS in providing low-carbon base-load generation to manage the intermittency of renewable energy.

4) Meeting frequency within each CCS/ESC is anticipated to be once per quarter for each target state. As the Collaborative expands to include surrounding states, meeting frequency will increase accordingly. A meeting summary and next-steps report will be provided to stakeholders following each meeting. 


\section{PBI Technology Commercialization Plan}

\subsection{Background of PBI Technology}

Polybenzimidazole (PBI) is a unique amorphous thermoplastic reported to have the highest $\mathrm{Tg}\left(427^{\circ} \mathrm{C}\right)$ and Heat Deformation Temperature $\left(435^{\circ} \mathrm{C}\right.$ at $\left.264 \mathrm{psi}\right)$ of any thermoplastic. It withstands brief exposure up to $760^{\circ} \mathrm{C}$ and also retains its properties down to $-196^{\circ} \mathrm{C}$. PBI does not burn and produces little or no smoke or off-gases at $1000 \mathrm{~F}$. It is highly resistant to acids, bases, and chemicals. At 58,000 psi, it boasts the highest compressive strength of any thermoplastic or thermoset ${ }^{57}$. The ground breaking research results at Los Alamos National Laboratory (LANL), shown in Figure 14, demonstrated that PBI exhibited $\mathrm{H}_{2}$ permeabilities and $\mathrm{H}_{2} / \mathrm{CO}_{2}$ selectivities far superior to other polymeric materials. This combination of excellent transport, thermal, and mechanical properties resulted in LANL fabricating membrane modules based on PBI for pre-combustion $\mathrm{CO}_{2}$ capture.

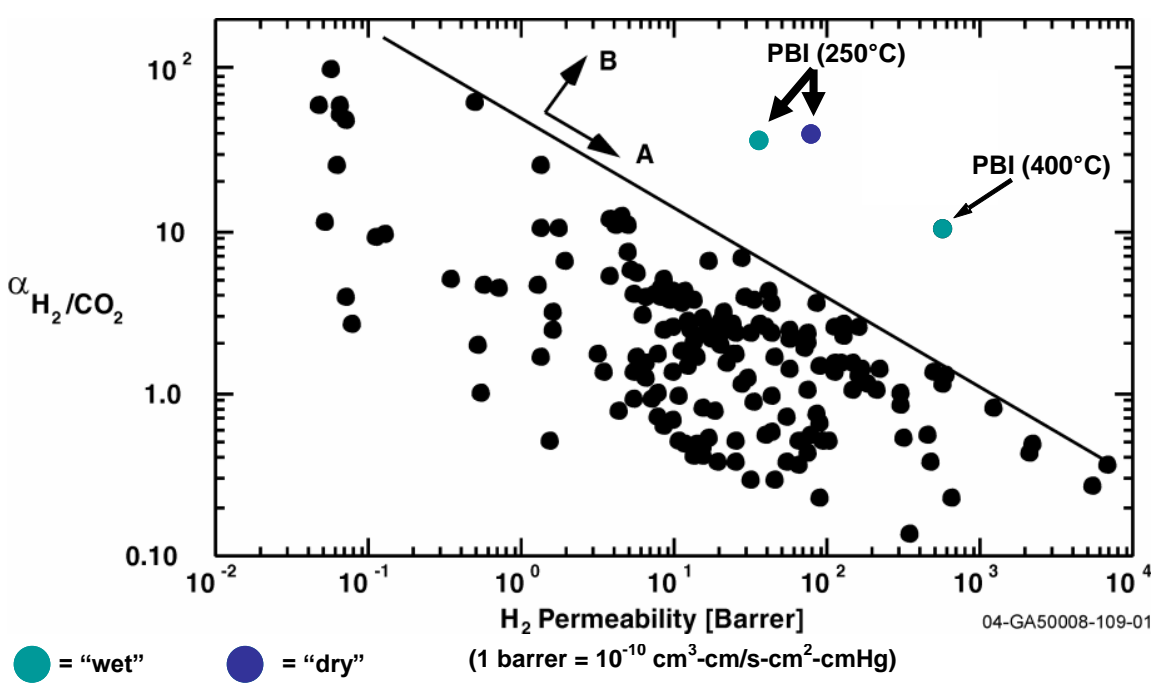

Figure 15. Trade-Off Plot between $\mathrm{H}_{2}$ Permeability and $\mathrm{H}_{2} / \mathrm{CO}_{2}$ Selectivity in Polymers

LANL's initial research focused on coating commercially available metallic substrates with a PBI selective layer. While the performance characteristics highlighted in Figure 14 met pre-combustion requirements, the projected process economics of the scaled-up metallic membrane system fell short of the Department of Energy's goal of less than $10 \%$ increase in cost of electricity. As a result, membrane systems based on a PBI selective layer on polymeric hollow fiber membranes were examined. Research indicated that the combination of a PBI selective layer onto a microporous PBI substrate (referred to now as the PBI Membrane) combined attractive process economics with the gas transport, thermal, and physical properties required for pre-combustion capture of $\mathrm{CO}_{2}{ }^{58}$.

\footnotetext{
57 Plastics Technology, "Extreme Plastics New Contenders Push Limits of Heat \& Chemical Resistance”, http://www.ptonline.com/articles/article_print1.cfm .
}

58 O’Brien, K.C.; G. Krishnan; K. Berchtold; S. Blum; R. Callahan; W. Johnson; D. Byard; T. Wu; J. Figueroa, "Towards a Pilot-Scale Membrane System for Pre-Combustion $\mathrm{CO}_{2}$ Separation”, GHGT-9, November 2008. 
Strategic Development Plan • May 2010

It was also important to establish a robust simulation to be able to model capture on an IGCC based system. This simulation was constructed using Aspen and GT-Pro and validated by comparison to results previously reported by NETL 59 . The membrane separation unit simulation portion was especially critical since it was used to establish performance targets for the PBI Membrane module as outlined in Figure 16.

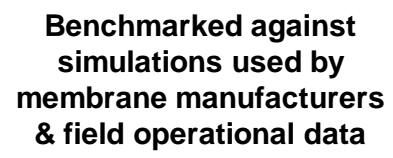

\section{Benchmarked against NETL simulations}

Metric of success in meeting program goals

Impacts Membrane and Process Development Strategy

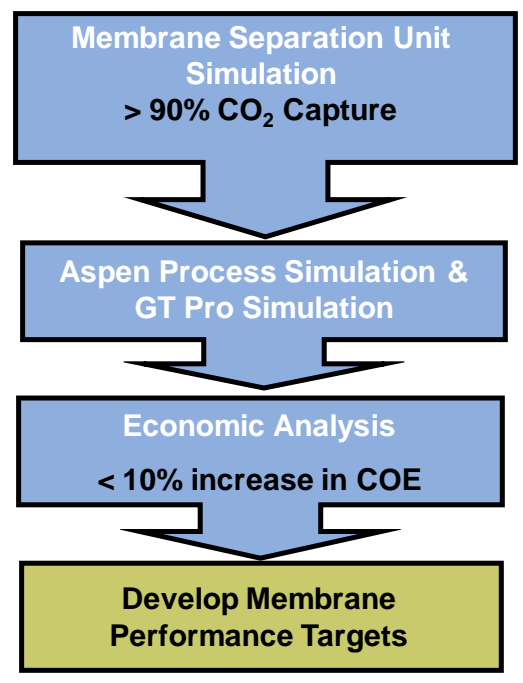

Figure 16. Role of Membrane and Process Simulation

The simulation was used to evaluate a number of different scenarios including a baseline with no capture, capture with Selexol, and capture with a PBI Membrane. The results, shown in Table 3, demonstrate that the PBI membrane-based capture system exhibits process economics that approach the DOE Program goal of less than $10 \%$ increase in COE. 
Strategic Development Plan • May 2010

Table 3. Preliminary Process Economics Analysis Using Simulation

\begin{tabular}{|c|c|c|c|c|c|}
\hline \multicolumn{2}{|c|}{ 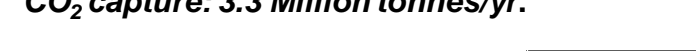 } & \multicolumn{4}{|c|}{ Project Cases } \\
\hline & Units & $\begin{array}{c}\text { No } \\
\text { Capture }\end{array}$ & $\begin{array}{c}\mathrm{CO}_{2} \text { and } \\
\mathrm{H}_{2} \mathrm{~S} \\
\text { Capture } \\
\text { w/Selexol }\end{array}$ & \begin{tabular}{|c|}
$\mathrm{CO}_{2}$ \\
Capture \\
w/PBI \& \\
$\mathrm{H}_{2} \mathrm{~S}$ \\
w/Selexol \\
\end{tabular} & $\begin{array}{c}\mathrm{CO}_{2} \\
\text { Capture } \\
\text { w/PBI no } \\
\mathrm{H}_{2} \mathrm{~S} \\
\text { removal }\end{array}$ \\
\hline Power Production @100\% Capacity & GWh/yr & 5,455 & 4,461 & 4,943 & 5,035 \\
\hline Power Plant Capacity & cents / kWh & 4.50 & 6.19 & 5.49 & 5.02 \\
\hline Power Plant Fuel & cents / kWh & 1.90 & 2.47 & 2.31 & 2.26 \\
\hline Variable Plant O\&M & cents / kWh & 0.78 & 1.00 & 0.92 & 0.91 \\
\hline Fixed Plant O\&M & cents / kWh & 0.60 & 0.79 & 0.71 & 0.70 \\
\hline Power Plant Total & cents / kWh & 7.78 & 10.45 & 9.43 & 8.89 \\
\hline Cost of Electricity* (COE) & cents / kWh & 7.78 & 10.45 & 9.43 & 8.89 \\
\hline Increase in COE (over no capture) & $\%$ & $n / a$ & $34 \%$ & $21 \%$ & $14 \%$ \\
\hline
\end{tabular}

Plant operating life: 30 years; Capacity Factor: $80 \%$; Capital charge factor: 17.5\%

\subsection{Status of PBI Technology}

The PBI Membrane hollow fiber is composed of two components: a substrate and the selective layer. The substrate needs to be microporous in nature and provide physical and mechanical stability. The selective layer needs to be continuous and defect free. During the course of the project it was determined that the best design was a PBI based selective layer applied over a PBI based substrate. ${ }^{60}$ Based on the previous work at LANL, combined with the simulation work, the target performance specifications for the PBI Membrane were set at $\mathrm{H}_{2} / \mathrm{CO}_{2}$ selectivities in the range of 25 to 40 with $\mathrm{H}_{2}$ permeance (i.e., throughput) of $200 \mathrm{GPU}$ at $250^{\circ} \mathrm{C}$.

The PBI Membrane manufacturer, Whitefox Technologies, has been systematically adjusting the membrane fabrication process in order to achieve fibers that meet or exceed these target specifications. Whitefox Technologies has made a significant effort to produce fibers within this range and also to enhance process controls in order to improve uniformity between batches of fibers. One of the first achievements was establishing a substrate which was consistent in nature and exhibited the proper microporous structure. Figure 17 depicts a Scanning Electron Microscope (SEM) image of the fiber at both low and high magnifications.

${ }^{60}$ Continuation application for : "Fabrication and Scale-up of Polybenzimidazole (PBI) Membrane Based System for Precombustion Based Capture of Carbon Dioxide”, December 2008. 
Strategic Development Plan • May 2010

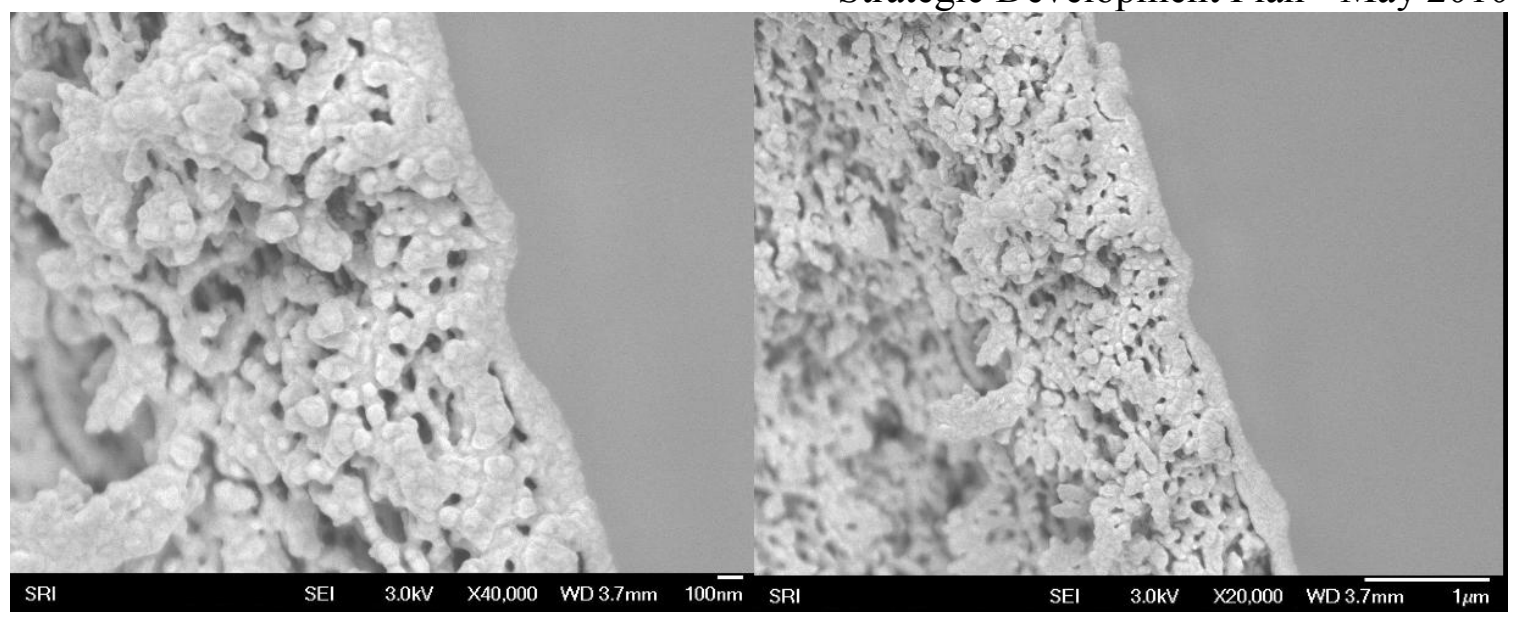

Figure 17. SEM Images of the Cross Section Near the Inner Surfaces of the Porous Substrate at Low and High Magnifications

A variety of samples were produced with PBI selective layers of different thicknesses, different outside diameters of fibers, and with different post-coating treatment conditions. The results are summarized in Figure 18. The batch labeled WFX-45 exhibited performance close to the target performance specifications. SEM images of the cross section of the lumen for these samples are shown in Figure 19. 


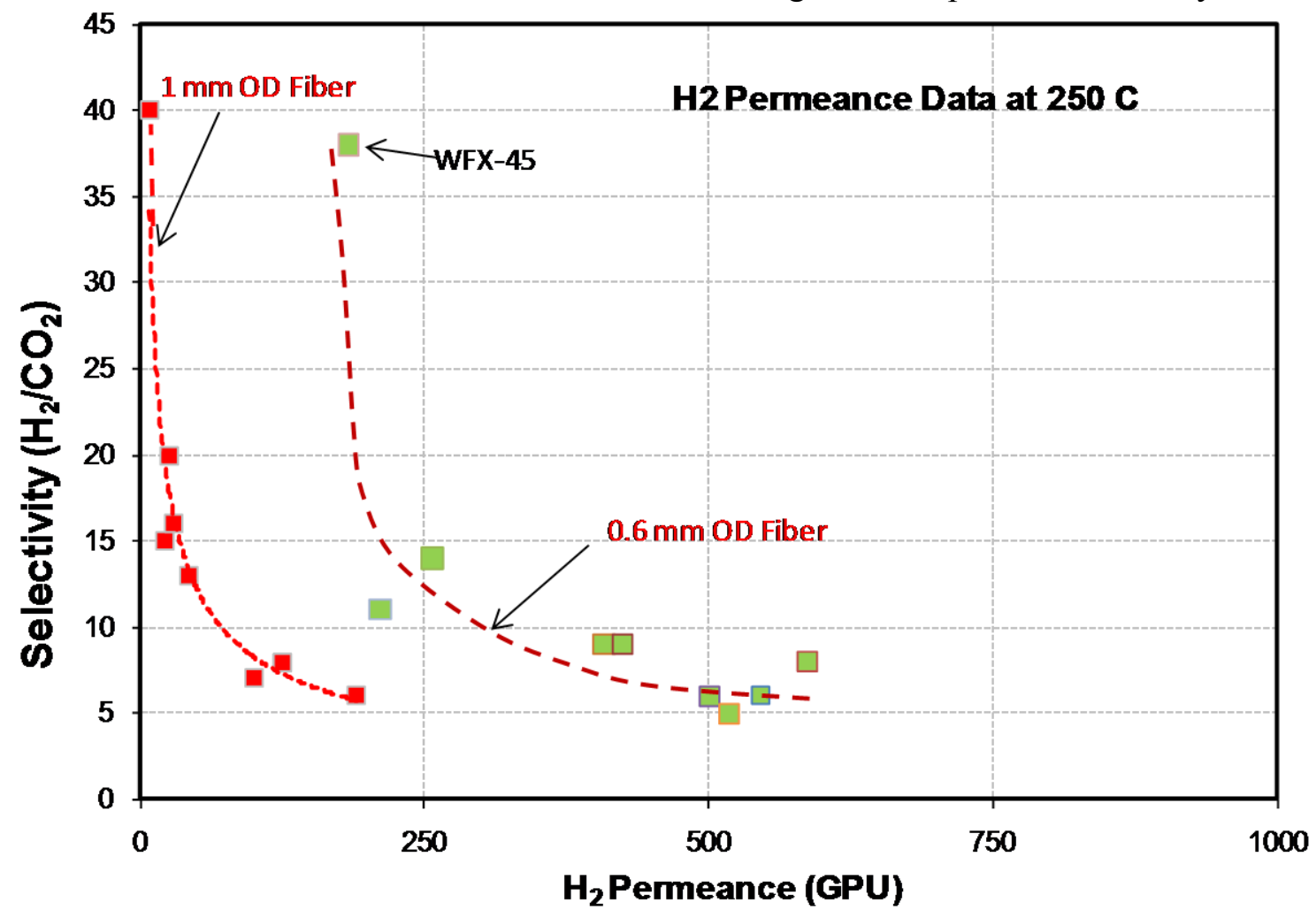

Figure 18. The Measured Permeance of $\mathrm{H}_{2}$ In GPU and $\mathrm{H}_{2} / \mathrm{CO}_{2}$ Selectivity at $250^{\circ} \mathrm{C}$ for PBI Membrane Samples Processed Using Different Conditions. The WFX-45 Sample Exhibited Properties Close to the Target Values

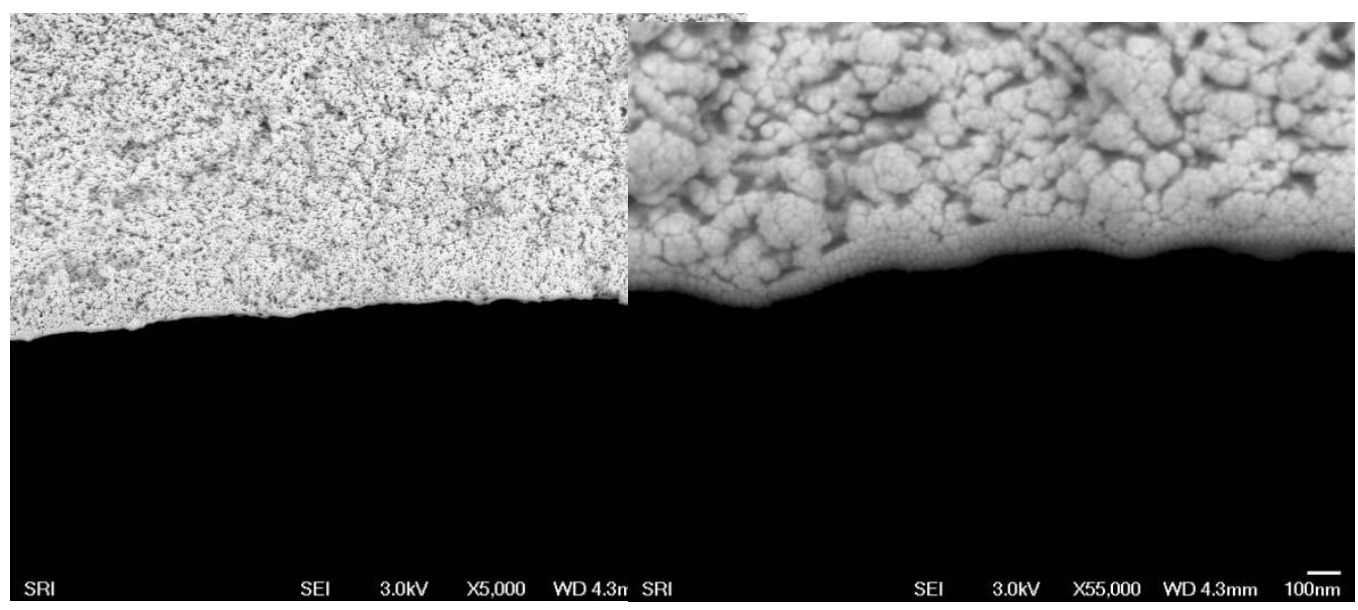

Figure 19. SEM Images of the Cross Section of the Lumen Of WFX-45 (Coated Fiber)

The latest results from the evaluation of PBI Membrane hollow fibers were used to develop preliminary design considerations for the membrane module and test skid. The test skid module will have a membrane fiber element similar in size to a commercial Air Products 
Strategic Development Plan • May 2010 PA3010 Prism membrane separator module. The PA3010 module has about $70 \mathrm{ft}^{2}$ of effective membrane area contained in a nominal 3 inch diameter by a 1 foot long fiber element containing $\sim 0.575 \mathrm{~mm}$ OD hollow fibers with about $63 \%$ fiber packing density. For this preliminary design analysis, we assumed that the PBI test module will have the same nominal element dimensions and fiber packing density as the PA3010 module. The test module housing mechanical hardware is shown in Figure 20. The test module will be fabricated from ANSI stainless steel pipe and flanges with all welded construction. All materials of construction will meet the specified test site pressure and temperature process conditions. All accessible high temperature surfaces will be adequately insulated and otherwise shielded to maintain personnel safety and to maintain the optimum membrane operating temperatures.

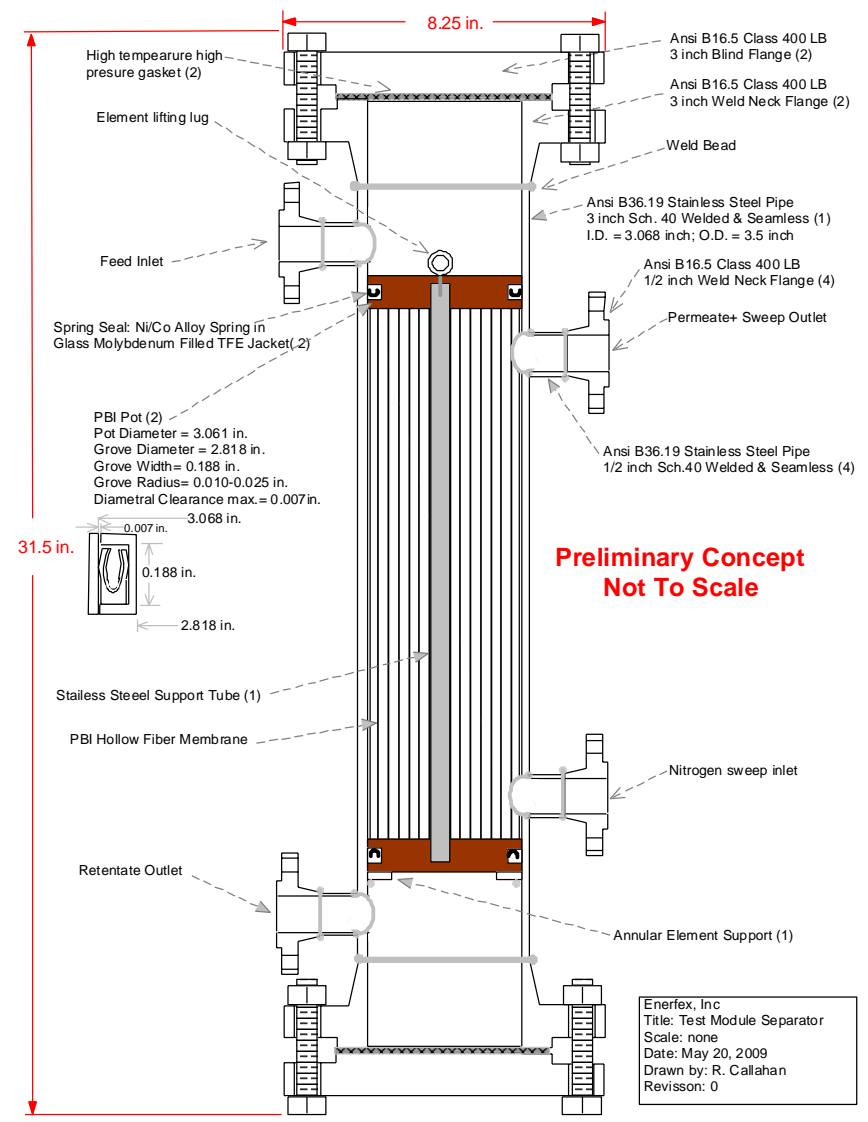

Figure 20. PBI Test Module

The PBI test module will be mounted in a test skid. The schematic for this skid is shown in Figure 21. The design and controls are similar to skids previously designed and constructed by Enerfex for pilot-scale testing. A separate control panel, not shown, will have switches to operate the butter-fly valves, labeled gauges or a display screen for all pressures, temperature indicators, turbine meters, and sample tubes connected to the appropriate ports. Appropriate safety designs will be included, such as insulation and shielding of all hot surfaces. 


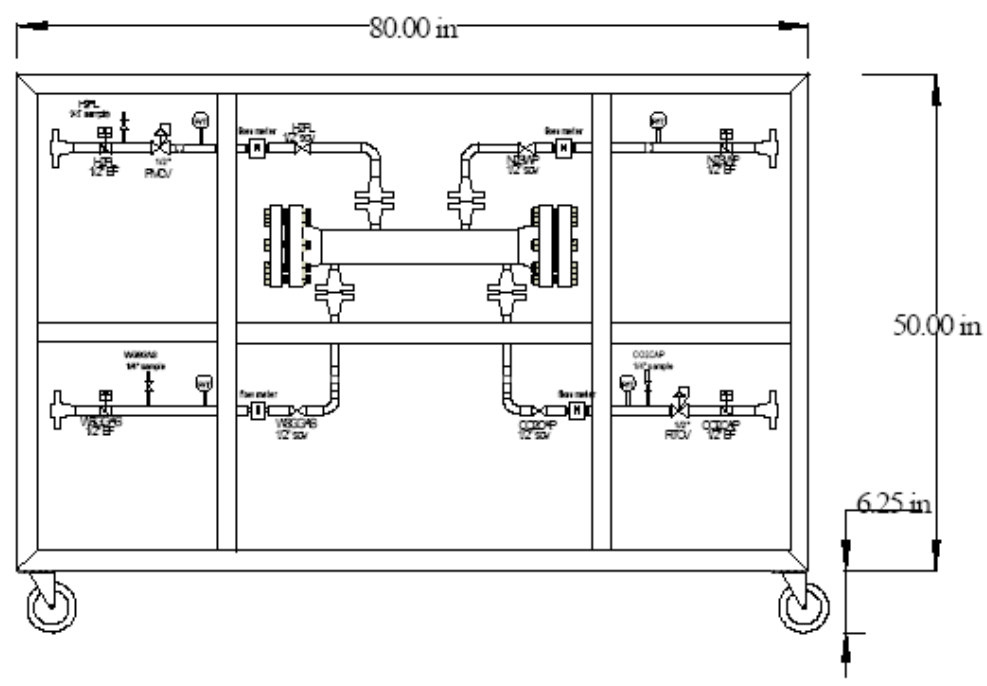

Figure 21. Schematic of Skid Used for Testing PBI Modules

\subsection{PBI Commercialization Pathway Schedule}

The maturation of new technologies for energy applications is different than the process for other technologies, i.e., software. Energy-related technologies are required to be highly reliable. They have traditionally transitioned through a series of discrete steps as depicted in Table 4.

Table 4. Typical Stages of Maturation for Energy Technologies

\begin{tabular}{|c|c|c|c|c|}
\hline & $\begin{array}{c}\text { Proof-of-Concept } \\
\text { (Fundamental) Research }\end{array}$ & $\begin{array}{c}\text { Post Proof-of-Concept } \\
\text { Research } \\
\text { (Current PBI Stage) }\end{array}$ & Pilot-scale & Demonstration \\
\hline $\begin{array}{l}\text { Type of Work } \\
\text { performed }\end{array}$ & $\begin{array}{l}\text { Bench scale batch-type } \\
\text { experimentation and } \\
\text { conceptual studies at the } \\
\text { fundamental science level }\end{array}$ & Bench/Laboratory Scale & Field testing & $\begin{array}{l}\text { Construction of a to } \\
\text { scale carbon control } \\
\text { plant }\end{array}$ \\
\hline Study Size & No working model & $0.01-0.1 \mathrm{MW}$ & $1-5 \mathrm{MW}$ & $100-250 \mathrm{MW}$ \\
\hline $\begin{array}{l}\text { Required } \\
\text { Funding }\end{array}$ & $\$ 0.3-\$ 1 \mathrm{MM}$ & $\$ 1$ - \$5 MM & $\$ 15-\$ 40 \mathrm{MM}$ & $+\$ 100 \mathrm{MM}$ \\
\hline $\begin{array}{l}\text { Funding } \\
\text { Period }\end{array}$ & $6-7$ years & 3 - 5 years & $3-4$ years & $3-7$ years \\
\hline
\end{tabular}


This development process is crucial since often heat, thermal, and mass transport considerations can change dramatically during scale-up of the unit. Pilot-scale testing is a crucial step since it is the first time the system is exposed to an actual power-plant environment.

It is important that researchers consider the needs of end-users early in the development process, e.g., Proof-of-Concept Stage, since many designs made at this early phase could impact the ability of the system to operate successfully in a power plant environment (Pilotscale and beyond). This project has specifically included representatives from utilities and other end-users (e.g., Southern Company and BP) in order to ensure that their needs are included in the design of the PBI Membrane, module, and skid. This should facilitate and hasten the transition of the technology to Pilot-scale and beyond.

The PBI project is currently in the Proof-of-Concept (Applied) Research Stage. During this stage the PBI module and skid will be tested in a simulated syngas environment on-site at SRI. Successful completion of this stage will enable the module and skid to be ready for pilot testing.

The National Carbon Capture Center ${ }^{61}$ (NCCC) has been targeted as a potential site for pilot-scale testing. Southern Company is the contractor for this DOE center and is a member of the PBI research team. The test would focus only on the capture of $\mathrm{CO}_{2}$ (i.e., no storage or use for enhanced oil recovery) and would use a slipstream for input into the module. It is especially important that the NCCC has the capability to utilize a variety of fuel sources, e.g., biomass and bituminous, subbituminous, and lignite coals. It is anticipated that multiple modules would be produced in order to evaluate in parallel a variety of different types of coal, i.e., bituminous, subbituminous, and lignite coal.

Because of their expertise and geographic location relative to bituminous sources, NETL and its university partners (University of West Virginia, University of Pittsburgh, Carnegie Mellon University, University of Virginia, and Penn State University) would be included in the pilotscale evaluation. The University of Montana and the Energy and Environmental Research Center $^{62}$ would be engaged in the evaluation of subbituminous and lignite coals. Of special interest would be subbituminous coal sourced from the Powder River Basin. Petroleum coke ("Pet Coke") would also be tested since it is one of the fuel sources BP has expressed interest in evaluating. Pet Coke is one of the fuel sources for the Hydrogen Energy Project in California. $^{63}$

It is also critical that PBI systems be evaluated internationally as well. These tests should also be conducted in parallel with tests in the US. Some candidate sites are in Canada, Australia, China, and Europe. The province of Alberta would be an important test site due to the near-zero emission plant being designed by EPCOR and Siemens. ${ }^{64}$ The Alberta Energy Research Institute and National Resources Canada would be research partners for this effort. The Wandoan Project is a joint effort between Queensland and GE is planned to be an IGCC plant equipped with $90 \%$ carbon capture. ${ }^{65}$ In addition, the ZeroGen project offers another

\footnotetext{
61 http://www.nationalcarboncapturecenter.com/

$62 \mathrm{http}: / / \mathrm{www}$. undeerc.org/

$63 \mathrm{http://www.hydrogenenergycalifornia.com/}$

64 http://www.carboncapturejournal.com/displaynews.php?NewsID=263\&PHPSESSID=hn7lh6bj98j17ktcjd1lpavn06

65 http://www.reliableplant.com/Read/19145/ge-energy-proposes-world-leading-igcc-plant-for-australia
} 
IGCC capture plant in Australia ${ }^{66}$. CSIRO could be a research partner to evaluate a PBI system in conjunction with this effort. The existing cooperation between NETL, PNNL, and the Chinese Academy of Sciences could form a platform for a pilot-scale evaluation at the Research Center for Energy and Power at Lianyungang. 67 Potential sites in Europe include the Hatfield Plant in Stainforth, UK. This plant, being developed by Powerfuel Power, UK, has been selected as a CCS demonstration plant for funding under the EU Energy Recovery Programme. 68

Table 5. Potential Commercialization Pathway Schedule $\mathrm{P}=$ Pilot, De=Demo, Dpy=Deployment

\begin{tabular}{|c|c|c|c|c|c|c|c|c|c|c|}
\hline China & & & & e & $\mathrm{e}$ & py & py & py & py & py \\
\hline Europe & & & & & e & e & e & py & py & py \\
\hline Australia & & & & & e & e & e & py & py & py \\
\hline Canada & & & & & e & e & e & py & py & py \\
\hline US & & & & e & e & e & py & py & py & py \\
\hline & 011 & 012 & 013 & 014 & 015 & 016 & 017 & 018 & 019 & 020 \\
\hline
\end{tabular}

This parallel approach at the pilot-scale leads to the ability to rapidly create a worldwide knowledge base for the PBI technology and should hasten the transition from Pilot to Demonstration (Demo), to Deployment. One potential schedule is depicted in Table 5. Pilot studies begin in the US. The information from this initial study enables the implementation of a series of simultaneous pilots in all the major markets. As part of this international effort, A Design of Experiments Approach is developed in 2011 to ensure that the information collected can be shared and statistically evaluated. Existing international relationships developed by the Department of Energy and NETL facilitate the international cooperation.

The results from the multivariable study are evaluated in 2013 and enable the initiation of a demonstration study in both the US and China in 2014. Demonstration studies are again coordinated on an international basis and designed so that performance and statistics can be shared and analyzed. The experience gained in the US and China enable the initiation of demonstrations in the other regions by 2015. Full deployment of the technology begins in 2016 in China, 2017 in the US. By 2018 the PBI technology has been deployed global for $\mathrm{CO}_{2}$ capture from IGCC plants.

\footnotetext{
66 http://www.mhi.co.jp/en/news/story/090622english.html

67 www.nrcce.wvu.edu/cleanenergy/docs/20-Xiao.pdf

68 www.h2-igcc.eu/Pdf/ICEPAG-Final.pdf
} 


\subsubsection{Risk Mitigation for Commercialization Pathway}

Strategic Development Plan • May 2010

There are a number of risks technical/business risks that could impact the aggressive commercialization pathway outlined in Table 5 . The risks and actions taken to mitigate these risks are outlined in Table 7.

Table 6. Risks to the Implementation of the Commercialization Pathway and Actions to Mitigate Risks

\begin{tabular}{|l|l|}
\hline \multicolumn{1}{|c|}{ Risk } & \multicolumn{1}{c|}{ Mitigation } \\
$\begin{array}{l}\text { Limited worldwide PBI production } \\
\text { capacity requires new PBI production } \\
\text { plants }\end{array}$ & $\begin{array}{l}\text { PBI supplier becomes member of } \\
\text { development team and provides input on } \\
\text { commercialization pathway. PBI supplier } \\
\text { provides plan to support pathway. }\end{array}$ \\
\hline $\begin{array}{l}\text { PBI hollow fiber production capacity } \\
\text { requires significant increase in capacity }\end{array}$ & $\begin{array}{l}\text { PBI hollow fiber supplier is currently team } \\
\text { member. Supplier provides feedback on } \\
\text { pathway and plan for capacity increase to } \\
\text { support pathway. }\end{array}$ \\
\hline $\begin{array}{l}\text { Geographic variations in fuel supply result } \\
\text { in large variations in system performance. }\end{array}$ & $\begin{array}{l}\text { Parallel pilot testing and a Design of } \\
\text { Experiment Approach provide a means to } \\
\text { quickly identify sources of variation and } \\
\text { potential solutions. International } \\
\text { cooperation provides the intellectual capital } \\
\text { to solve issues. }\end{array}$ \\
\hline $\begin{array}{l}\text { Regulatory requirements and/or public } \\
\text { opinion extend approval times and hence } \\
\text { project time lines }\end{array}$ & $\begin{array}{l}\text { Parallel testing in a variety of international } \\
\text { markets with a range of regulatory and } \\
\text { public opinion processes increases } \\
\text { probability that projects move forward in at } \\
\text { least one region. }\end{array}$ \\
\hline $\begin{array}{l}\text { Variation in gasifier types creates variation } \\
\text { in system performance }\end{array}$ & $\begin{array}{l}\text { Design of Experiment Approach and } \\
\text { parallel evaluations provide a means to } \\
\text { identify and resolve issues. }\end{array}$ \\
\hline $\begin{array}{l}\text { Increase in worldwide demand for ancillary } \\
\text { membrane equipment drives up capital } \\
\text { costs }\end{array}$ & $\begin{array}{l}\text { Increase in production capacity of PBI } \\
\text { polymer and hollow fiber should help } \\
\text { reduce cost of fiber and provide some } \\
\text { offset to other potential cost increases. } \\
\text { Competition from other technologies will } \\
\text { also limit increases in costs to the end-user. }\end{array}$ \\
\hline
\end{tabular}

PBI was invented in late 1940's and is manufactured for the last 30 years. The initial patents have expired. One of the risks of a large-scale demand for the PBI capture system is the limited worldwide supply of the PBI polymer. PBI polymer is currently produced in any significant commercial quantities by one supplier--PBI Performance Products. PBI Performance Products is located in Charlotte, North Carolina and reported to have 70 
Strategic Development Plan • May 2010

employees and have annual sales of approximately $\$ 9,400,000 .^{69}$ Using the targeted performance (GPU and selectivity) and current design for the membrane module, it is estimated that for a $250 \mathrm{MW}$ IGCC plant approximately 1,440 modules would be required. Fabrication of these modules would require nearly 54,000 pounds of PBI polymer.

This amount of polymer, while insignificant for most polymers, is estimated to represent $30 \%$ of the current production capacity. Despite this fact, the polymer industry typically constructs plants that can produce in excess of 1 million pounds per year. Therefore, it is predicted that the required increase in capacity of polymer production as the PBI system transitions through the commercialization pathway is possible. With this increase in PBI demand, it is reasonable to deduce that many companies would be interested in entering the PBI production industry. It does highlight the importance of coordinating the commercialization pathway and timeline with the polymer supplier so that they plan capacity increases in order to meet the projected increases in demand.

A similar risk involves the supply of PBI hollow fiber. There is one supplier of PBI hollow fiber--Whitefox Technologies. Using the targeted performance (GPU and selectivity) and current design for the membrane module, it is estimated that for a $250 \mathrm{MW}$ IGCC plant, approximately $29,000 \mathrm{~km}$ of fiber would be required (1440 modules). This requires a significant scale-up in capacity for the supplier. Whitefox Technologies is currently a member of the team and is engaged in the planning for the commercialization of the PBI membrane system.

It is expected that the fuel source will vary based on the geographic location of the plant. In other systems, process performance has been shown to be impacted by variations in the fuel source. Similarly differences in gasifier design may also impact the capture process. In order to mitigate these risks, a Design of Experiments Approach should facilitate identifying any variations in performances that could be due to fuel source. Statistic analysis, pooling of data, and international cooperation will assist in identifying and resolving issues.

Other factors that could impact the timeline are regulatory and political in nature. For example, delays in permitting or changes in public opinion could impede the progression of projects. This risk is mitigated due to the fact that the regulatory environment and the stance and impact of public opinion vary across these regions.

Rapidly deployment could also result in a rapid rise in the cost of ancillary equipment. Compressors, fittings, valves, and other related items could rise in cost due to increased demand. It is expected that this rise would be transitory in nature and would be limited by the fact that other technology options would still be available to the designer. It is expected that some of these increases might at least be partially offset by a reduction in cost of the raw polymer and hollow fibers as volume increases.

\subsection{Projection of PBI Technology Market Entry}

The commercialization pathway schedule outlined in Table 5 can be used to estimate the total number of modules, pounds of PBI polymer, and kilometers of PBI hollow fiber required as a function of time. The basis for these calculations will be the number of $\mathrm{MW}$ for which the PBI system is utilized for $\mathrm{CO}_{2}$ capture. Each pilot-scale test was assumed to be 1

69 http://www.manta.com/c/mm750v6/pbi-performance-produst-inc 
Strategic Development Plan • May 2010

MW, each demonstration test was assumed to be $100 \mathrm{MW}$, while each deployment was estimated to be $500 \mathrm{MW}$. It was assumed that there would be a minimum of three pilot-scale tests per region (e.g., in the US at least three pilot-scale tests). In comparison, demonstration tests would be two per region. The first deployment is assumed to occur in 2015. The number of deployments increases incrementally with each subsequent year (e.g., two deployments in 2016, three deployments in 2017, etc.).

The number of modules per MW, pounds of polymer of PBI per module, and kilometers of PBI hollow fiber per module were then used to project requirements as a function of time. These results are shown in Figures 21-24.

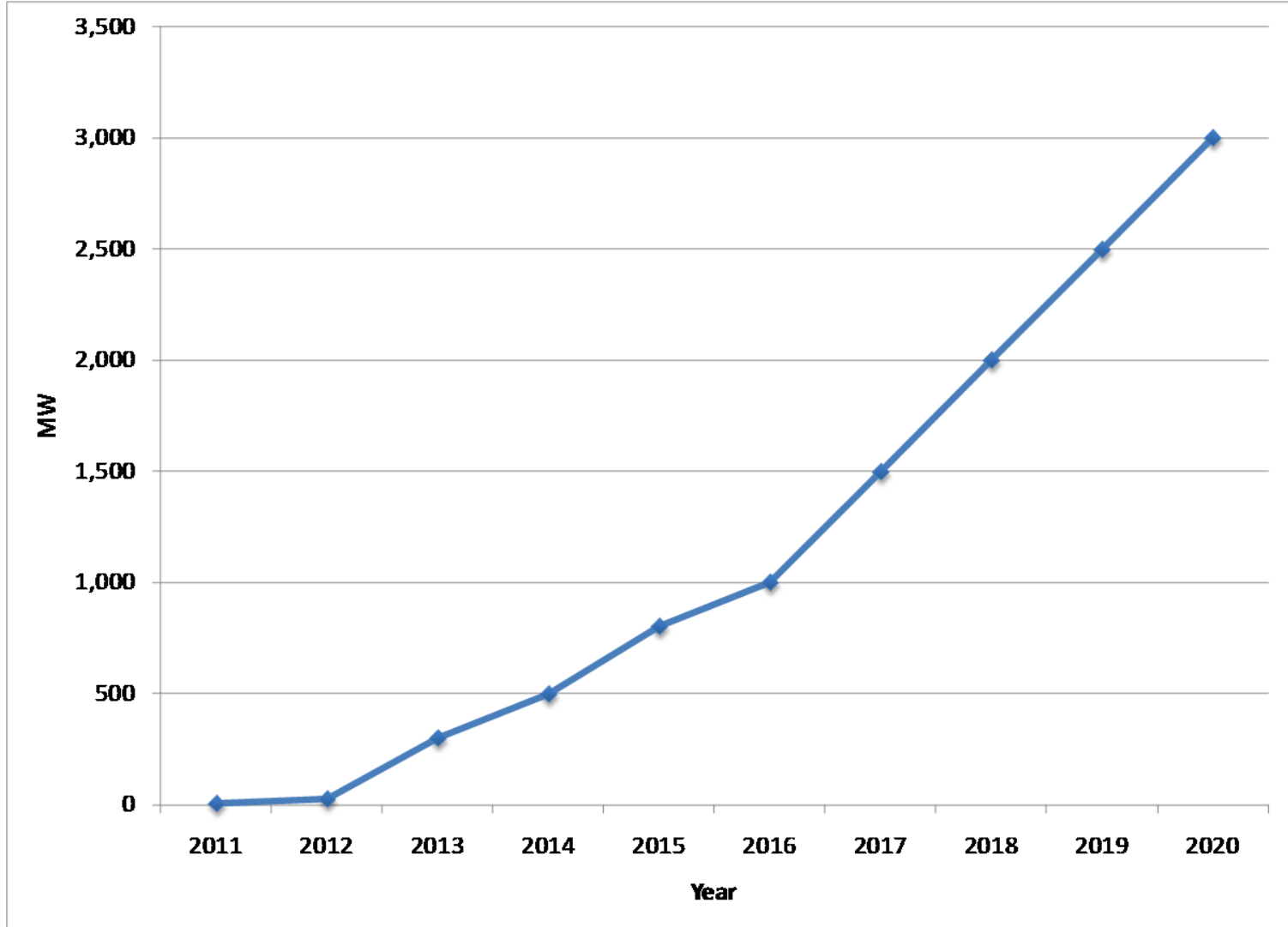

Figure 22. Projected Mws from Which $\mathrm{CO}_{2}$ is Captured Using the PBI System Based on Commercialization Pathway Schedule

Figure 22 illustrates the number of MWs from which $\mathrm{CO} 2$ is captured using the PBI system as a function of time. These calculations are based on the commercialization pathway schedule described in Table 5. It is useful to compare these values to the MW of new IGCC projects outlined earlier in this document Figure 6. The MWs predicted in Figure 7 correspond to overall market penetration rates of $0.1 \%, 0.2 \%, 1.6 \%$, and $2.1 \%$ in the 2011 to 2014 time frame. This demonstrates that the commercialization pathway projections are conservative and reasonable.

The number of modules, pounds of polymer, and kilometers of PBI hollow fiber were then projected for the 2011 to 2020 time frame. These results are shown in Figures 22-24. 


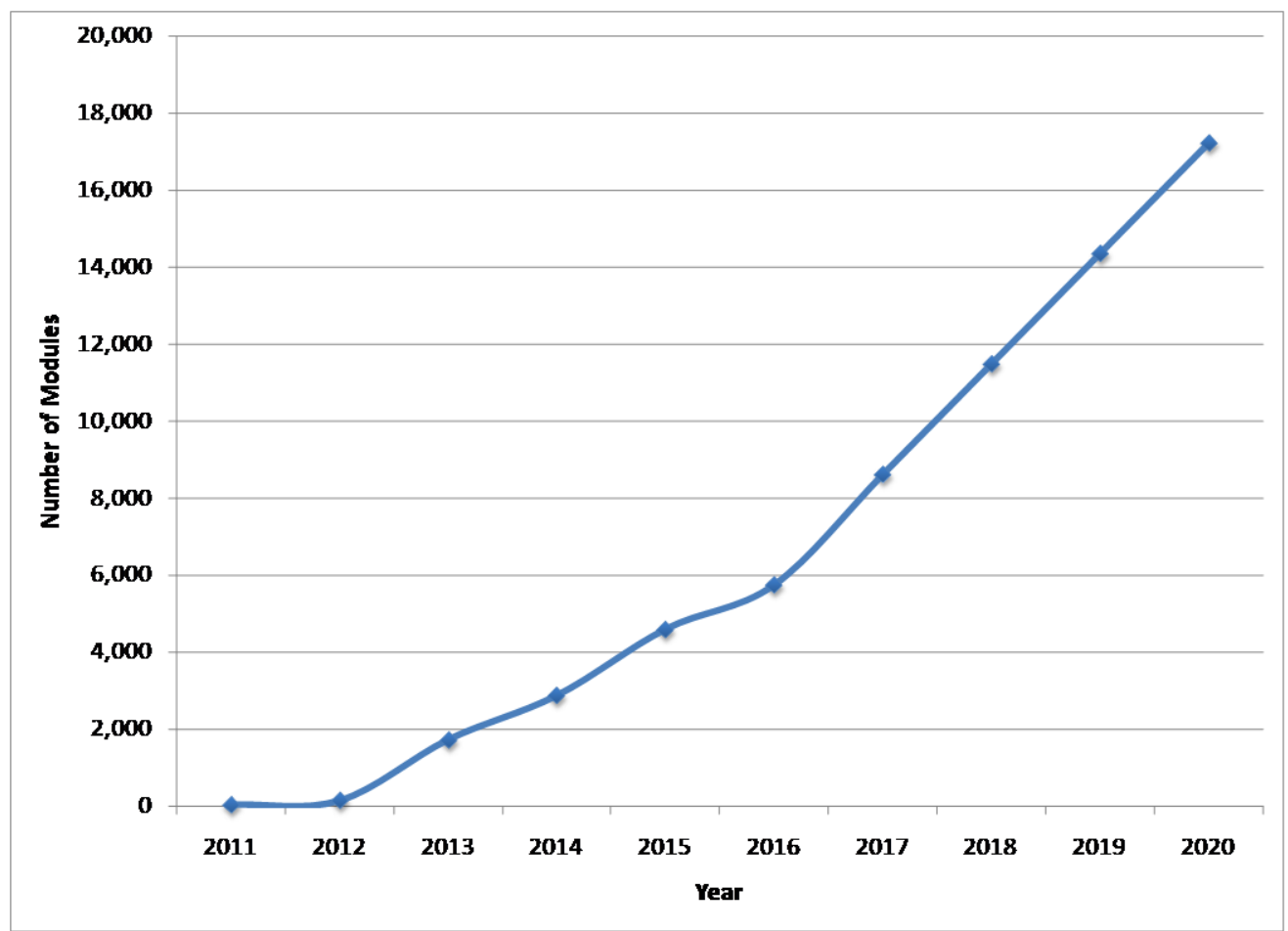

Figure 23. Number of Modules as a Function of Time Based on Commercialization Pathway Schedule 
Strategic Development Plan • May 2010

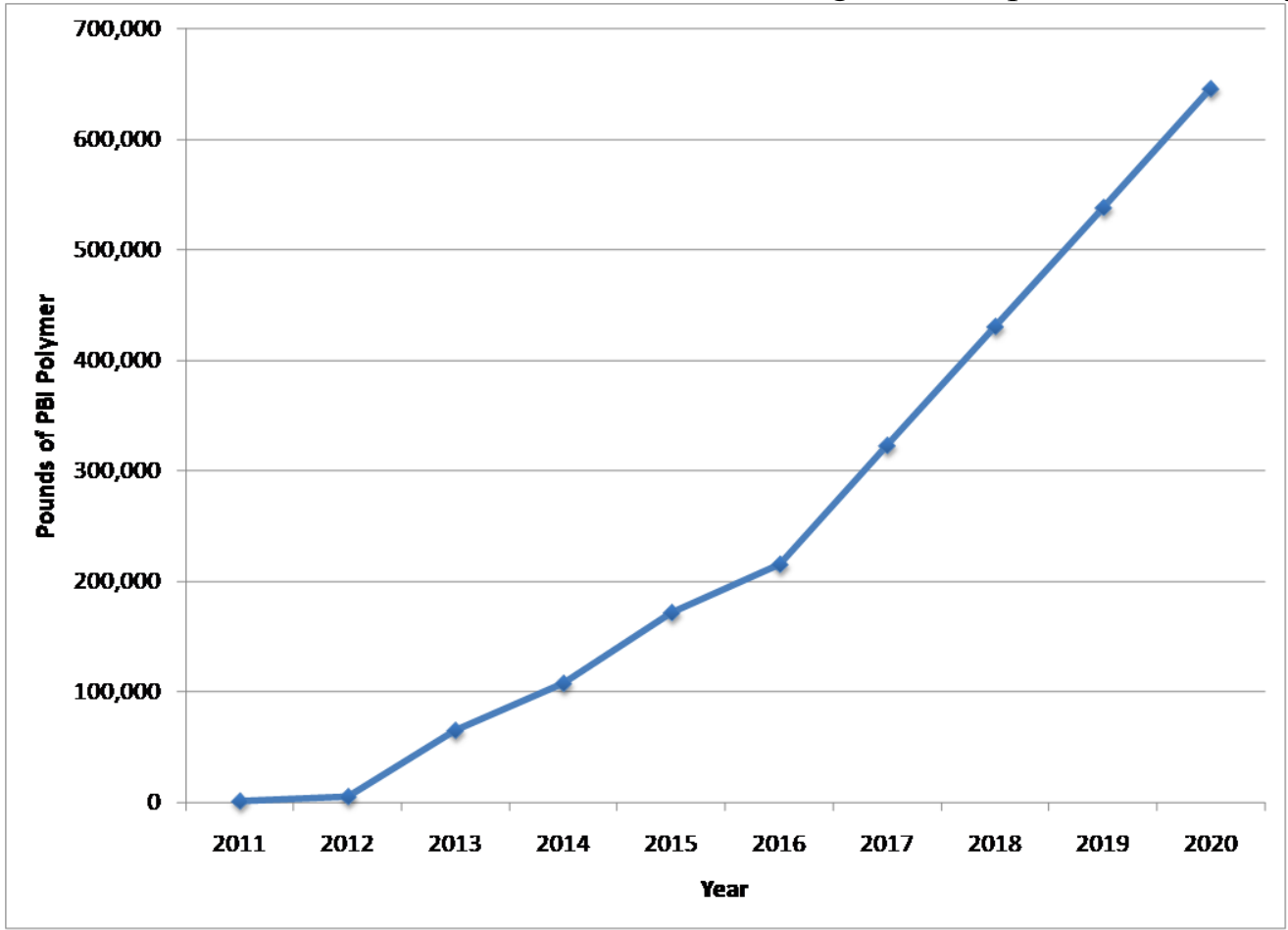

Figure 24. Pounds of PBI Polymer Required as a Function of Time Based on Commercialization Pathway Schedule 


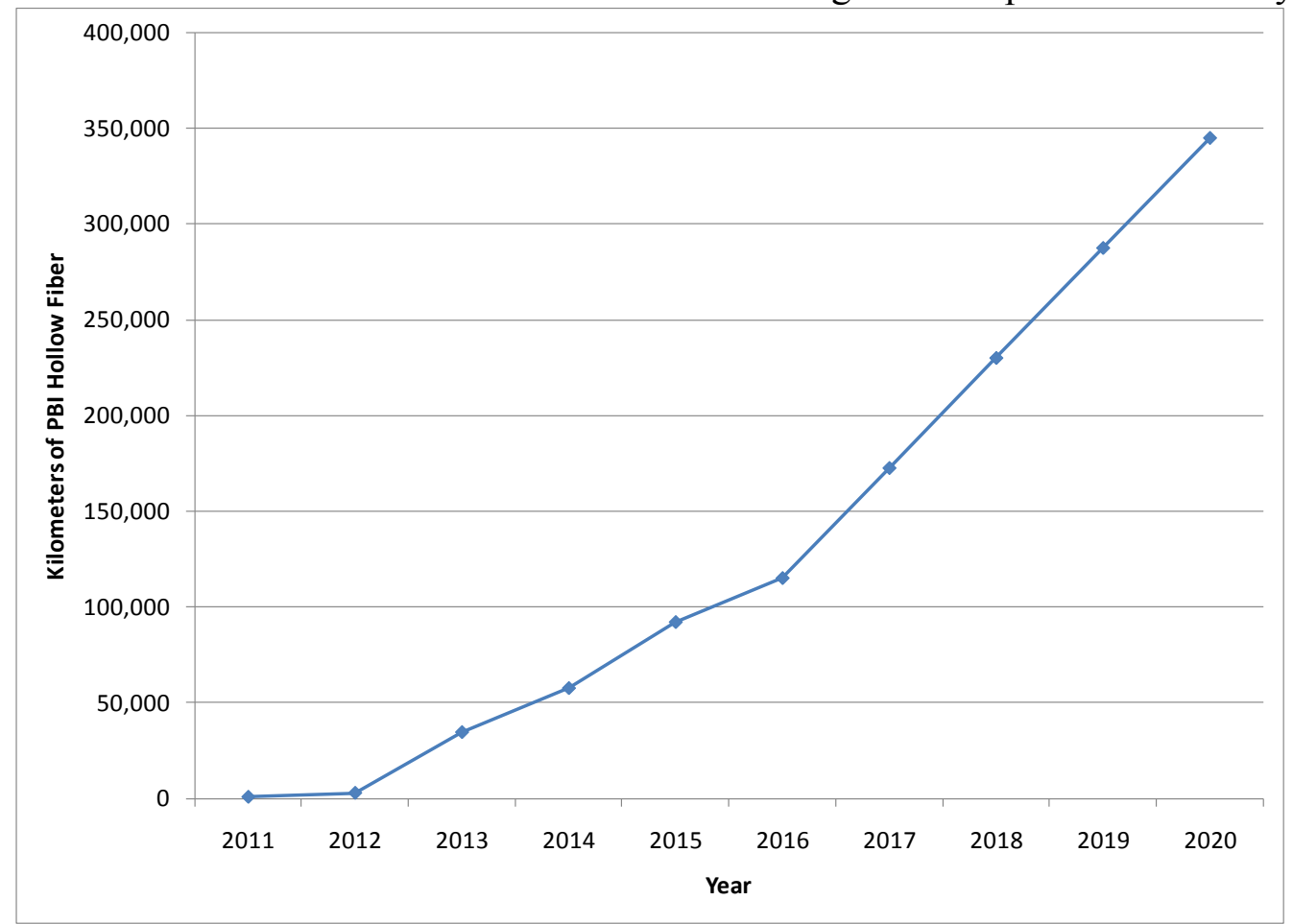

Figure 25. Kilometers of PBI Hollow Fiber Projected as a Function of Time Based on Commercialization Pathway Schedule

The significance of Figures 21-24 is that they demonstrate that successful transition of the PBI capture system from the pilot to demonstration to deployments will catalyze the growth of the PBI polymer production industry--an industry currently located in the southeast section of the US. Based on the current number of employees at the supplier of PBI polymer, the projected growth in the industry should create in excess of 400 new jobs by 2020 in order to support the increase in capacity of the industry. It will also create a huge PBI fiber industry and stimulate job growth for EDC firms. Many of the EDC firms that could provide this service have installations in the Gulf Coast. Growth of the PBI industry could also generate jobs in a region of the country that has suffered severe economic impacts. 
Strategic Development Plan • May 2010

\section{Conclusions}

The technical progress in the development of the substrate and selective layer has resulted in hollow fibers that have performance (GPU and selectivity) close to the target goals. The process simulation has demonstrated that achieving the target membrane performance goals enables the overall process economics to approach the DOE target of less than $10 \%$ increase in COE. Engineering work has begun to outline the membrane module configuration, skid, and control system.

A commercialization pathway schedule was developed based on the on the technical progress and expected time line for availability of modules for pilot testing. There were a number of considerations when establishing this schedule:

- Upstream factors such as gasifier type and characteristics of fuel source may cause variation in the performance of capture systems

- $\quad$ Non-technical factors such as regulatory changes and public opinion could impact timelines for pilot, demonstration, and deployment of new capture systems

- $\quad$ Commercialization of PBI capture systems will impact supply chains such as the global supply of PBI hollow fibers, and PBI polymer

- $\quad$ Mitigating these risks was important in order to rapidly transition PBI capture systems from pilot to demonstration to deployment

The global nature of carbon capture coupled with the international relationships developed by the Department of Energy and NETL have created an environment that facilitates international cooperation. This enables pilot and demonstration projects to be performed in parallel. Pre-planning on a global scale between research institutes coupled with experimental design and data sharing should accelerate the commercialization process. This approach mitigates the risks listed below and enables an efficient and effective method to enable PBI capture systems to be transitioned into full deployment.

Job creation and increased regional economic development will also be additional advantages of the deployment of PBI capture systems. The PBI polymer production industry, located in the southeastern US, is predicted to undergo explosive growth with the need to increase its capacity by over $7 x$ by 2020 . This growth could result in nearly 400 new jobs being created. PBI hollow fiber production will also undergo a similar expansion. In addition, the Gulf Coast region of the US should be positively impacted due to the need for EDC firms to fabricate and install PBI membrane modules and control systems. 


\title{
APPENDIX D
}

\section{MEMBRANE SIMULATION CALCULATIONS}

\author{
Enerfex, Inc.
}


Enerfex Inc., located in Williston, Vermont, designs and evaluates membrane processes that separate and capture gases to reduce pollution and save energy. In collaboration with Dresser Rand, Enerfex Inc. designed a system based on conventional membranes to capture $\mathrm{CO}_{2}$ for Statoil's natural gas platforms in the North Sea. The company has also designed systems for onsite industrial gas $\mathrm{CO}_{2}$ recovery, natural gas nitrogen reduction, and industrial refrigeration $\mathrm{NH}_{3}$ recycle. Enerfex has a proprietary model to simulate the performance of a membrane module. The model has been validated using the data from industrial processes. The model was used to simulate the performance of PBI hollow fiber membrane modules. Details of these calculations were provided by Enerfex as Memorandums and they are attached below. 


\section{D-1. PBI MEMBRANE SEPARATOR UNIT SIMULATION}

A first step is to initiate the PBI simulation model using available membrane separation data. Separation data was provided to Enerfex by LANL on November 27, 2007 in a single Excel chart entitled "Plot to Enerfex from LANL" shown below annotated in blue notation by Enerfex.

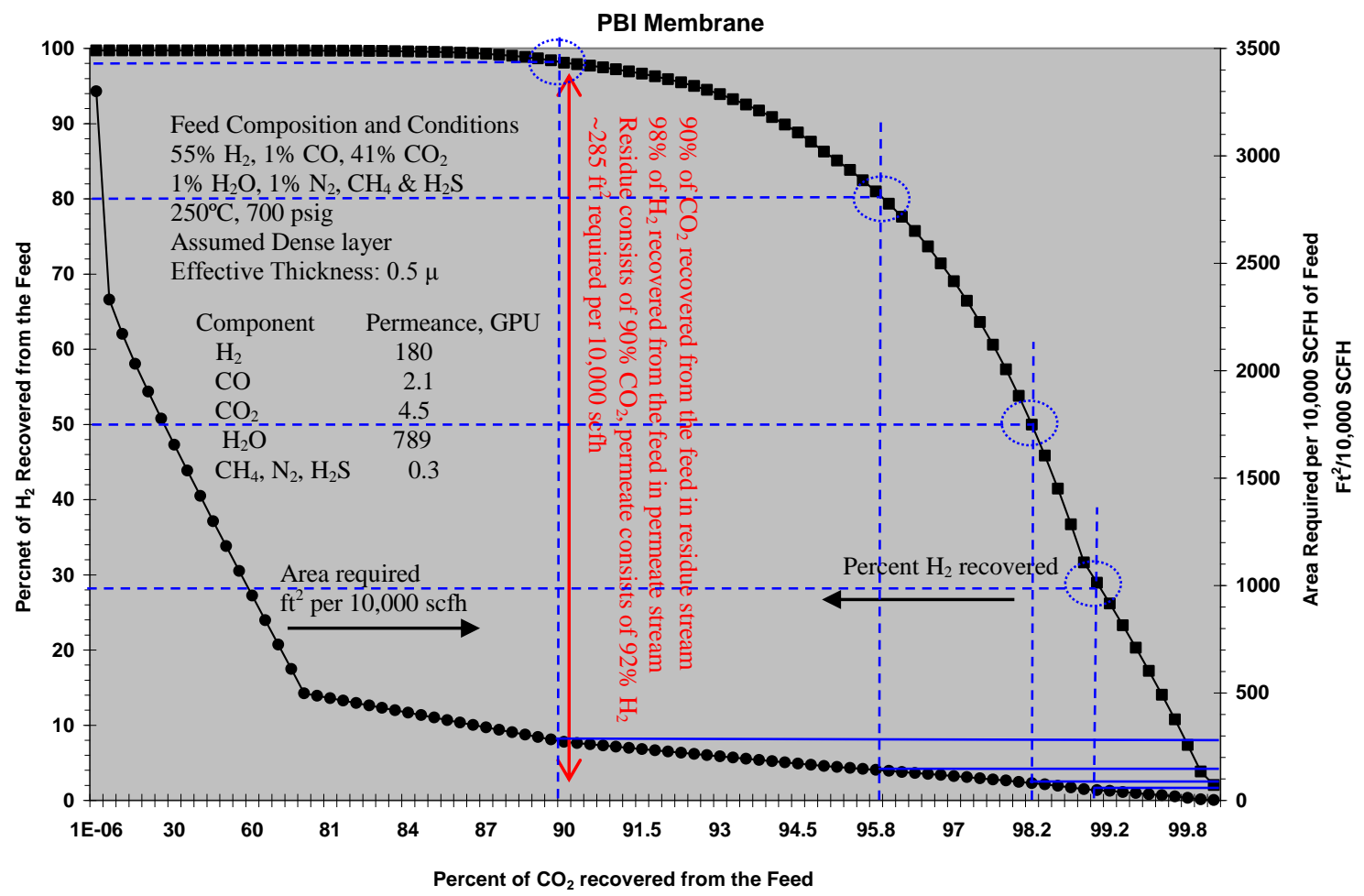

For the present simulation input data can be generated only if a binary mixture is assumed since purity and recovery values are given only for $\mathrm{H}_{2}$ and $\mathrm{CO}_{2}$. A mixture of $55 \% \mathrm{H}_{2}$ and $45 \% \mathrm{CO}_{2}$ shall be assumed. Thus as first approximations for the initial simulation it is assumed that $\mathrm{CO}$ and $\mathrm{CO}_{2}$ permeate similarly, that $\mathrm{CH}_{4}, \mathrm{~N}_{2}$ and $\mathrm{H}_{2} \mathrm{~S}$ are $100 \%$ recovered in the residue and that the $\mathrm{H}_{2} \mathrm{O}$ is $100 \%$ recovered in the permeate. Based on these assumptions the four chosen data points in the chart above give the following feed, residue and permeate mass balance:

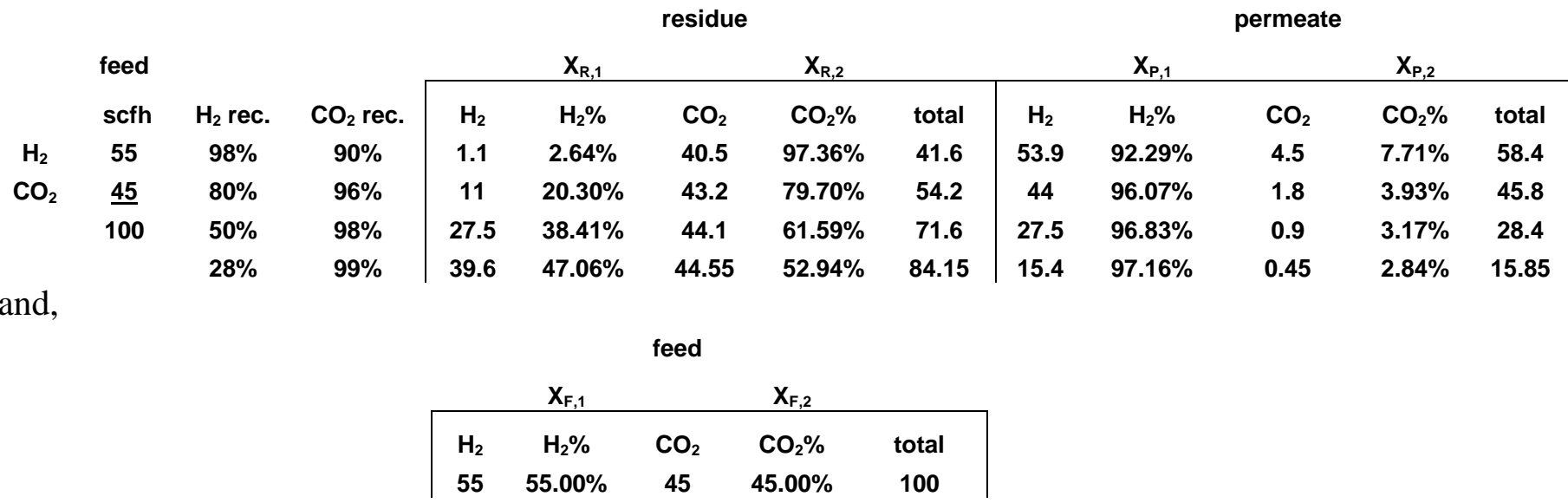


The $\mathrm{H}_{2}$ and $\mathrm{CO}_{2}$ permeate fluxes for each of the four chosen data points given in the table below are based on the corresponding feed fluxes indicated in the LANL chart above:

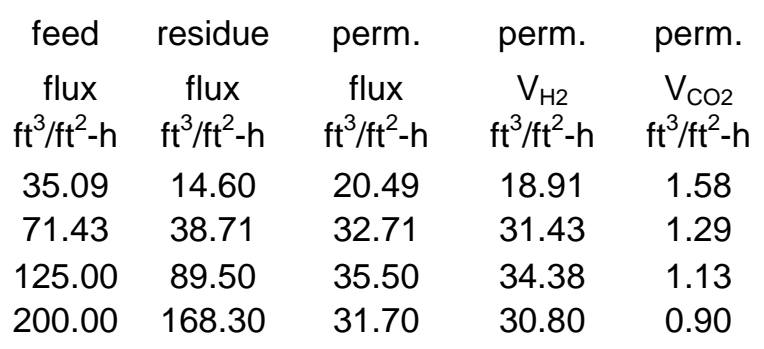

If feed pressure $=\mathrm{p}_{\mathrm{F}}=714.7 \mathrm{psia}$

and permeate pressure $=\mathrm{p}_{\mathrm{P}}=71.5 \mathrm{psia}$

then the pressure ratio $=\mathrm{p}_{\mathrm{F}} / \mathrm{p}_{\mathrm{P}}=0.1$ (equation 1$)$

And if,

$\mathrm{GPU}=\mathrm{P} / \mathrm{L}=\mathrm{V} /\left(\mathrm{p}_{\mathrm{F}}-\mathrm{p}_{\mathrm{P}}\right)$ (equation 2$)$ where:

$\mathrm{V}$ - Gas component flux (flow volume per unit area per unit volume)

$\mathrm{L}$ - Membrane thickness

$\mathrm{P}$ - Permeability equal to gas component flux normalized for pressure difference across the membrane and membrane thickness

$\mathrm{p}_{\mathrm{F}}-$ Gas component partial pressure in the higher pressure feed to retentate side of the membrane

$\mathrm{p}_{\mathrm{P}}-$ Gas component partial pressure in the lower pressure permeate side of the membrane

Then $\mathrm{H}_{2}$ and $\mathrm{CO}_{2}$ GPU in the present case are given by,

$\mathrm{P}_{\mathrm{H} 2} / \mathrm{L}=\mathrm{V}_{\mathrm{H} 2} /\left[\mathrm{p}_{\mathrm{F}} \times\left(\mathrm{X}_{\mathrm{F}, 1}+\mathrm{X}_{\mathrm{R}, 1}\right) / 2-\mathrm{p}_{\mathrm{P}} \times \mathrm{X}_{\mathrm{P}, 1]}\right.$ (equation $2 \mathrm{a}$ )

$\mathrm{P}_{\mathrm{CO} 2} / \mathrm{L}=\mathrm{V}_{\mathrm{CO} 2} /\left[\mathrm{p}_{\mathrm{F}} \times\left(\mathrm{X}_{\mathrm{F}, 2}+\mathrm{X}_{\mathrm{R}, 2}\right) / 2-\mathrm{p}_{\mathrm{P}} \times \mathrm{X}_{\mathrm{P}, 2}\right]$ (equation $2 \mathrm{~b}$ )

and therefore the $\mathrm{H}_{2}$ over $\mathrm{CO}_{2}$ selectivity $\alpha_{\mathrm{H} 2 / \mathrm{CO} 2}$ in the present case is given by, $\alpha_{\mathrm{H} 2 / \mathrm{CO} 2}=\left(\mathrm{P}_{\mathrm{H} 2} / \mathrm{L}\right) /\left(\mathrm{P}_{\mathrm{CO} 2} / \mathrm{L}\right)=\left[\mathrm{Xp}_{, 1} \times\left(\left(\mathrm{X}_{\mathrm{F}, 2}+\mathrm{X}_{\mathrm{R}, 2}\right) / 2-0.1 \times \mathrm{X}_{\mathrm{P}, 2}\right)\right] /\left[\mathrm{X}_{\mathrm{P}, 2} \times\left(\left(\mathrm{X}_{\mathrm{F}, 1}+\mathrm{X}_{\mathrm{R}, 1}\right) / 2-0.1 \times \mathrm{X}_{\mathrm{P}, 1}\right)\right]$ (equation 3)

Using the data in the tables at the bottom of page 1, calculates the following $\mathrm{H}_{2}$ GPU, $\mathrm{CO}_{2} \mathrm{GPU}, \alpha_{\mathrm{H} 2 / \mathrm{CO} 2}$ and relative $\mathrm{H}_{2}$ to $\mathrm{CO}_{2}$ partial pressure ratio in the feed to residue side of the membrane: 


\begin{tabular}{|c|c|c|c|}
\hline equation $2 a$ & equation $2 b$ & equation 3 & \\
\hline $\begin{array}{c}\mathrm{P}_{\mathrm{H} 2} / \mathrm{L} \\
\mathrm{ft}^{3} / \mathrm{ft}^{2} / \mathrm{h} / \text { psia }\end{array}$ & $\begin{array}{c}\mathrm{P}_{\mathrm{CO} 2} / \mathrm{L} \\
\mathrm{ft}^{3} / \mathrm{ft}^{2} / \mathrm{h} / \text { psia }\end{array}$ & $\begin{array}{c}\text { selectivity } \\
\alpha_{\mathrm{H} 2 / \mathrm{CO} 2}\end{array}$ & $\begin{array}{c}\text { avg. } \mathrm{H}_{2} / \mathrm{CO}_{2} \\
\text { rel. press }\end{array}$ \\
\hline 0.135086681 & 0.003137819 & 43.05 & 0.40 \\
\hline 0.156846847 & 0.002903453 & 54.02 & 0.60 \\
\hline 0.12993336 & 0.002971986 & 43.72 & 0.88 \\
\hline 0.104322906 & 0.002586483 & 40.33 & 1.04 \\
\hline
\end{tabular}

Converting the GPU units to $\mathrm{cm}^{3} / \mathrm{cm}^{2}-\mathrm{s}-\mathrm{cmHg} \times 10^{-6}$ and to permeability in Barrer for the given membrane thickness of $0.5 \mu$ gives the following:

"Plot to Enerfex from LANL" November 27, 2007:

$\begin{array}{cccc}\mathrm{P}_{\mathrm{H} 2} / \mathrm{L} \times 10^{-6} & \begin{array}{c}\mathrm{P}_{\mathrm{CO} 2} / \mathrm{L} \times 10^{-6} \\ \mathrm{~cm}^{3} / \mathrm{cm}^{2} / \mathrm{s} / \mathrm{cmHg}\end{array} & \begin{array}{c}\text { selectivty } \\ \mathrm{cm}^{3} / \mathrm{cm}^{2} / \mathrm{s} / \mathrm{cmHg}\end{array} & \begin{array}{c}\text { avg. } \\ \mathrm{H}_{2} / \mathrm{CO}_{2} / \mathrm{CO} 2\end{array} \\ \begin{array}{ccc}\text { rel. press } \\ 561.93\end{array} & 13.05 & 43.04 & 0.40 \\ 652.45 & 12.08 & 54.01 & 0.60 \\ 540.49 & 12.36 & 43.73 & 0.88 \\ 433.96 & 10.76 & 40.33 & 1.04\end{array}$

"Plot to Enerfex from LANL" November 27, 2007 :

$\begin{array}{cc}\mathrm{P}_{\mathrm{H} 2}{ }^{*} & \mathrm{P}_{\mathrm{CO} 2}{ }^{*} \\ \text { Barrer } & \text { Barrer } \\ 280.96 & 6.53 \\ 326.22 & 6.04 \\ 270.25 & 6.18 \\ 216.98 & 5.38 \\ { }^{*} \mathrm{~L}=0.5 \times 10^{-4} \mathrm{~cm} & \end{array}$

A plot of selectivity $\alpha_{\mathrm{H} 2 / \mathrm{CO} 2}$ versus average $\mathrm{H}_{2} / \mathrm{CO}_{2}$ partial pressure in the feed to residue side of the membrane is given in the following chart: 


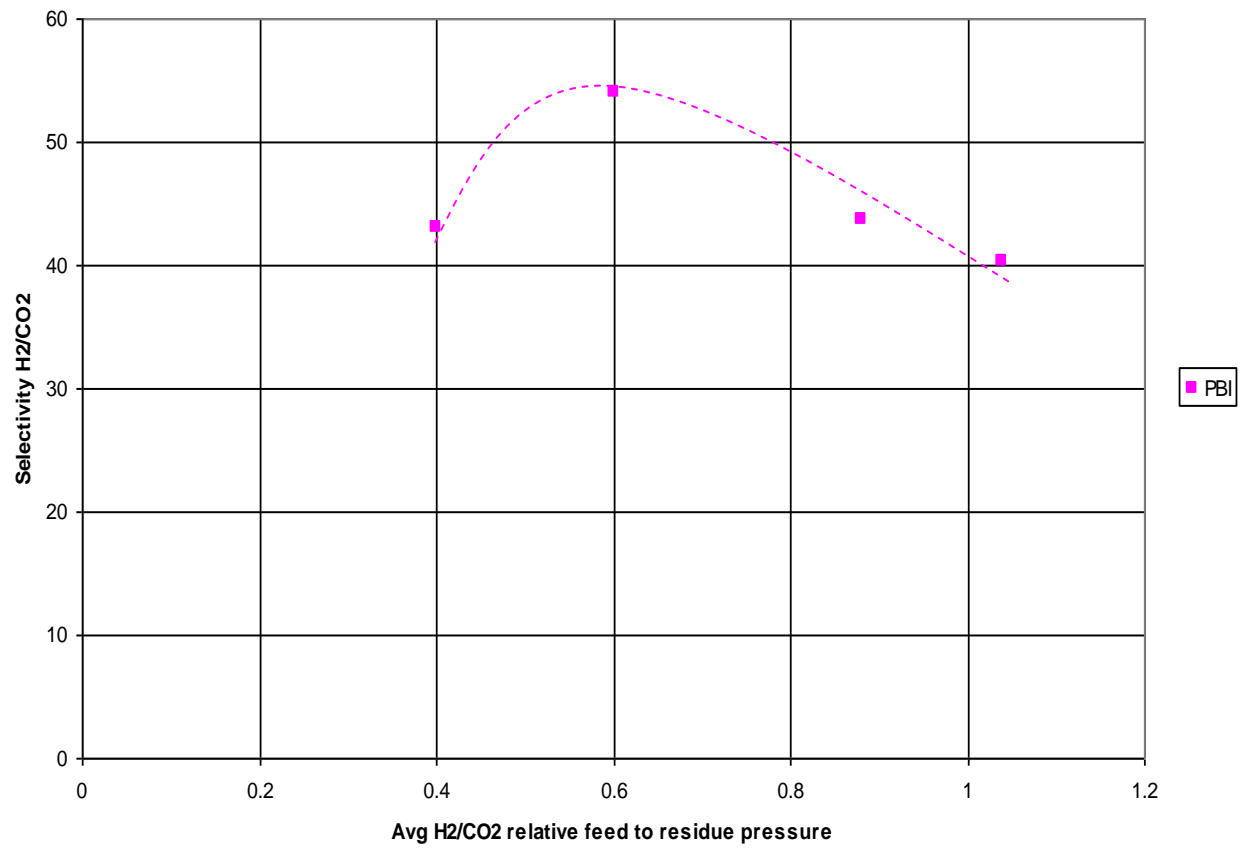

The difference between the GPU values listed in the "Plot to Enerfex from LANL" and those calculated in the table on the previous page were discussed by R. Callahan and K. Berchtold. The conclusion is that the plot and data listed was generated with Pall modeling data and the discrepancy in the listed GPU data and the plotted data is not understood. In the present simulation the calculated permeability data shown in the table on the previous page will be used. A subsequent Memorandum II will cover a simulation using estimated projected performance data provided by LANL on January 18, 2008 and shown in the table below:

\section{Projection Performance :}

$\begin{array}{cccc}\mathrm{P}_{\mathrm{H} 2} / \mathrm{L} \times 10^{-6} & \begin{array}{c}\mathrm{P}_{\mathrm{cO} 2} / \mathrm{L} \times 10^{-6} \\ \mathrm{~cm}^{3} / \mathrm{cm}^{2} / \mathrm{s} / \mathrm{cmHg}\end{array} & \begin{array}{c}\text { selectivty } \\ \mathrm{cm}^{3} / \mathrm{cm}^{2} / \mathrm{s} / \mathrm{cmHg}^{2}\end{array} & \begin{array}{c}\alpha_{\mathrm{H} 2 / \mathrm{CO} 2} \\ \text { avg. } \mathrm{H}_{2} / \mathrm{CO}_{2} \\ \text { rel. press }\end{array} \\ 100.00 & 2.32 & 43.04 & 0.40 \\ 116.11 & 2.15 & 54.01 & 0.60 \\ 96.19 & 2.20 & 43.73 & 0.88 \\ 77.23 & 1.91 & 40.33 & 1.04 \\ & & & \\ & & & \\ \mathrm{P}_{\mathrm{H} 2}{ }^{*} & \mathrm{P}_{\mathrm{co} 2}{ }^{*} & & \\ \text { Barrer } & \text { Barrer } & & \\ 700.00 & 16.26 & & \\ 812.76 & 15.05 & & \\ 673.30 & 15.40 & & \\ 540.59 & 13.40 & & \\ { }^{*} \mathrm{~L}=7.0 \times 10^{-4} \mathrm{~cm} & & & \end{array}$


The non-linear trend of $\alpha_{\mathrm{H} 2 / \mathrm{CO} 2}$ versus average $\mathrm{H}_{2} / \mathrm{CO}_{2}$ partial pressure shown in the chart at the bottom of page three is not understood. It is not clear that the data accurately represents what would happen in a PBI membrane at the conditions given. It has been Enerfex's experience with commercial membranes materials such as polyimide, polysulfone and cellulose acetate in the range of $40^{\circ}-50^{\circ} \mathrm{C}$ and the same range of relative partial pressure not to exhibit a maximum inflection but instead to have a directly proportional linear trend between selectivity and average partial pressure ratio.

Four single stage simulations for each of the four data points in the LANL Chart are presented in the table below. In order for the simulations to converge to the LANL Chart membrane area it was necessary to adjust the membrane thickness to $1.28 \mu$ in each case.

$\begin{array}{cccccc}\begin{array}{c}\text { permeate } \\ \text { LANL Chart }\end{array} & \begin{array}{c}\text { residue } \\ \text { LANL Chart }\end{array} & \begin{array}{c}\text { permeate } \\ \text { LANL Chart * }\end{array} & \begin{array}{c}\text { residue } \\ \text { LANL Chart * }\end{array} & \begin{array}{c}\text { permeate } \\ \text { Simulation }\end{array} & \begin{array}{c}\text { residue } \\ \text { Simulation }\end{array} \\ \mathrm{H}_{2} \text { Rec. } & \mathrm{CO}_{2} \text { Rec. } & \mathrm{H}_{2} \text { purity } & \mathrm{CO}_{2} \text { purity } & \mathrm{H}_{2} \text { purity } & \mathrm{CO}_{2} \text { purity } \\ 98.00 \% & 90.00 \% & 92.29 \% & 97.36 \% & 91.30 \% & 90.00 \% \\ 80.00 \% & 96.00 \% & 96.07 \% & 79.70 \% & 94.70 \% & 73.60 \% \\ 50.00 \% & 98.00 \% & 96.83 \% & 61.59 \% & 95.30 \% & 56.50 \% \\ 28.00 \% & 99.00 \% & 97.16 \% & 52.94 \% & 95.60 \% & 48.40 \%\end{array}$

The simulation result for $98 \% \mathrm{H}_{2}$ recovery based in the binary mixture mass balance generated permeability values are fairly close to the LANL Chart, i.e., $285 \mathrm{ft}^{2}$ of membrane area per 10,000 scfh of feed, $90 \% \mathrm{CO}_{2}$ recovery and $91.3 \% \mathrm{H}_{2}$ purity. The relatively high GPU and selectivity shows the membrane is able to achieve substantially high recovery and purity of $\mathrm{H}_{2}$ and $\mathrm{CO}_{2}$ at a substantially high feed and permeation flux. This would be a productive membrane with high separation efficiency.

The simulation on page 10 for the $98 \% \mathrm{H}_{2}$ recovery case shows that with a small adjustment to $\mathrm{H}_{2}$ and $\mathrm{CO}_{2}$ permeability values gives a simulation that matches the LANL Chart data, i.e., $\mathrm{H}_{2}$ permeability $=285.96$ Barrer instead of 280.96 Barrer, $\mathrm{CO} 2$ permeability $=6.2$ Barrer instead of 6.53 Barrer, and selectivity $=46.1$ instead of 43 gives $285 \mathrm{ft}^{2}$ of membrane area per 10,000 scfh of feed, $90 \% \mathrm{CO}_{2}$ recovery, $90 \% \mathrm{CO}_{2}$ purity and $92 \% \mathrm{H}_{2}$ purity. 


\section{D-2. PBI MEMBRANE SIMULATION: EFFECT OF PROCESS VARIABLES}

A PBI simulation model was done using data provided to Enerfex by LANL on November 27, 2007 in an Excel chart entitled "Plot to Enerfex from LANL" and is shown below annotated in blue by Enerfex.

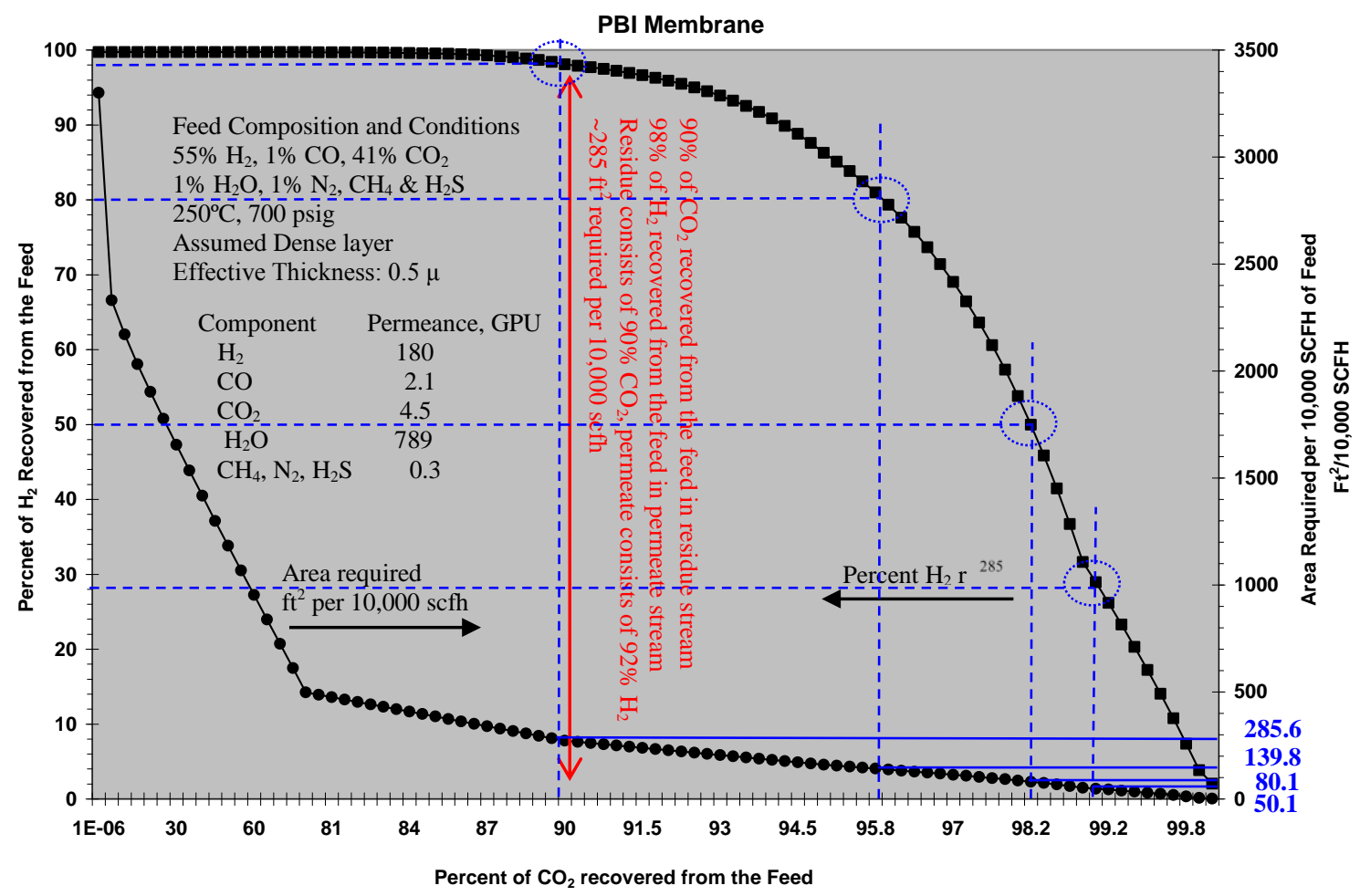

The LANL GPU data and performance provided are re-presented in the two tables below. Corresponding Barrer permeability values for $0.5 \mu$ are added:

\section{LANL GPU DATA}

Assumed dense layer effective thickness: $0.5 \mu$

Component

$\mathrm{H}_{2}$

$\mathrm{CO}$

$\mathrm{CO}_{2}$

$\mathrm{H}_{2} \mathrm{O}$

$\mathrm{CH}_{4}, \mathrm{~N}_{2}, \mathrm{H}_{2} \mathrm{~S}$
GPU Barrer

$180 \quad 90$

$2.1 \quad 1.05$

$4.5 \quad 2.25$

$789 \quad 394.5$

$0.3 \quad 0.15$
LANL PERFORMANCE

$\begin{array}{ccc} & \text { purity } & \text { recovery } \\ \text { permeate } \mathrm{H}_{2} & 92 \% & 98 \% \\ \text { residue } \mathrm{CO}_{2} & 90 \% & 90 \% \\ \text { ft2/10k scfh feed } & \sim 285 & \end{array}$

$\mathrm{ft} 2 / 10 \mathrm{k}$ scfh feed $\quad \sim 285$

The LANL GPU DATA was simulated and compared to the LANL PERFORMANCE.

The simulated membrane area needed to recover $98 \% \mathrm{H}_{2}$ in the permeate is $347 \mathrm{ft}^{2}$ per $10,000 \mathrm{scfh}$ of feed which is $21.8 \%$ more than the reported $285 \mathrm{ft}^{2}$. The residue $\mathrm{CO}_{2}$ purity is the same at $90 \%$ with marginally lower recovery at $89.2 \%$. The permeate $\mathrm{H}_{2}$ purity is marginally lower at $90.9 \%$. See four SIMULATED LANL DATA (sheets 1 to 
4) spreadsheets in the attached appendix. Note in the simulation that the $\mathrm{H}_{2} \mathrm{O}$ GPU is reduced to prevent calculation of negative mole or volume fractions.

The LANL performance and simulated performance based on the LANL GPU data at $98 \% \mathrm{H}_{2}$ recovery are compared in the table below:

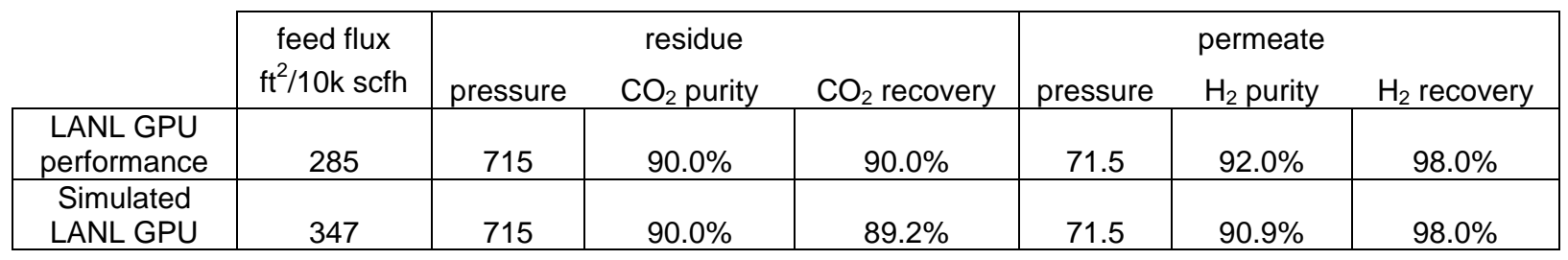

The two charts given below and on the following page summarize $\mathrm{H}_{2}$ and $\mathrm{CO}_{2}$ purity and recovery in the simulations of LANL GPU Data for the four data points annotated in the "Plot to Enerfex from LANL".

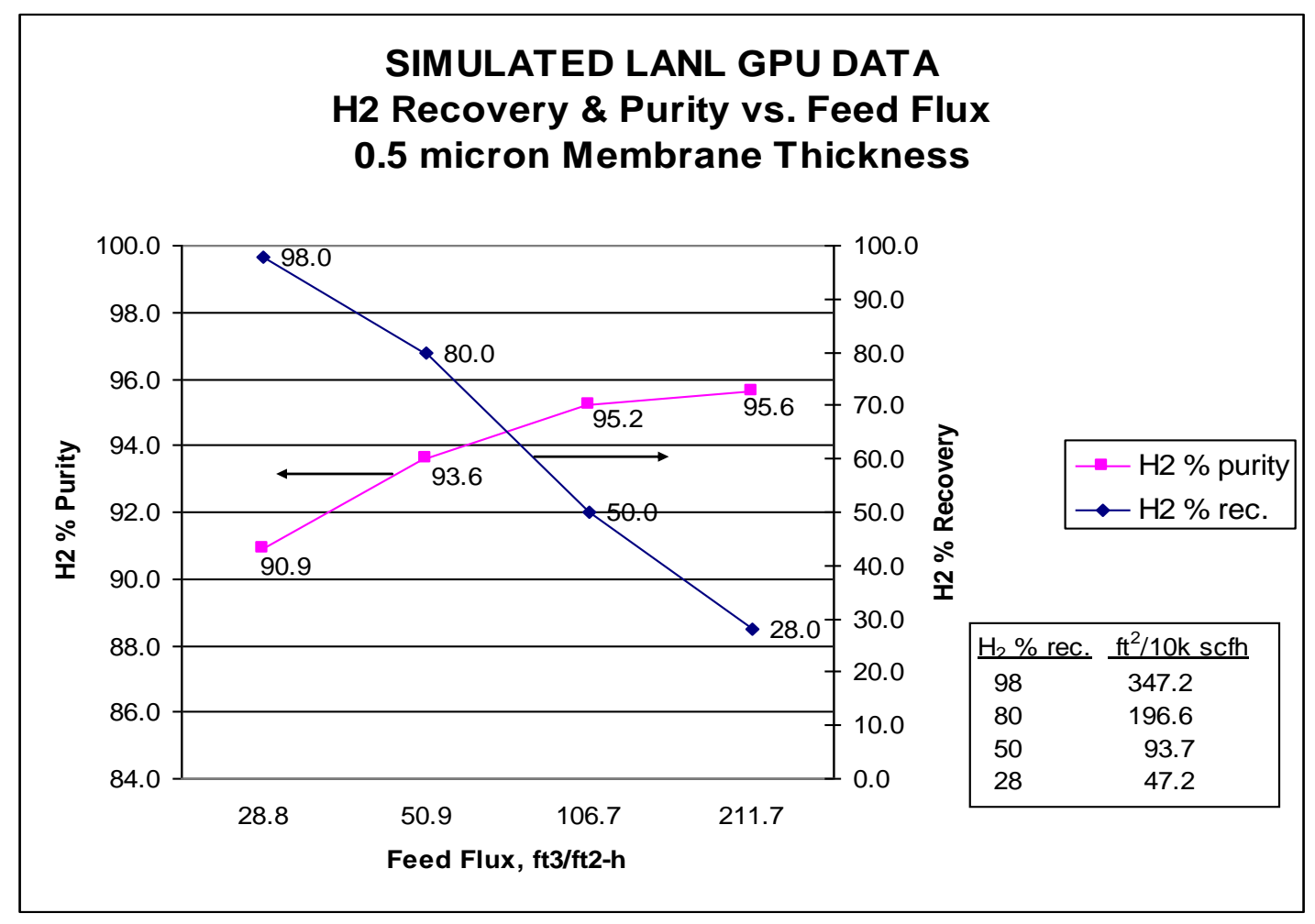




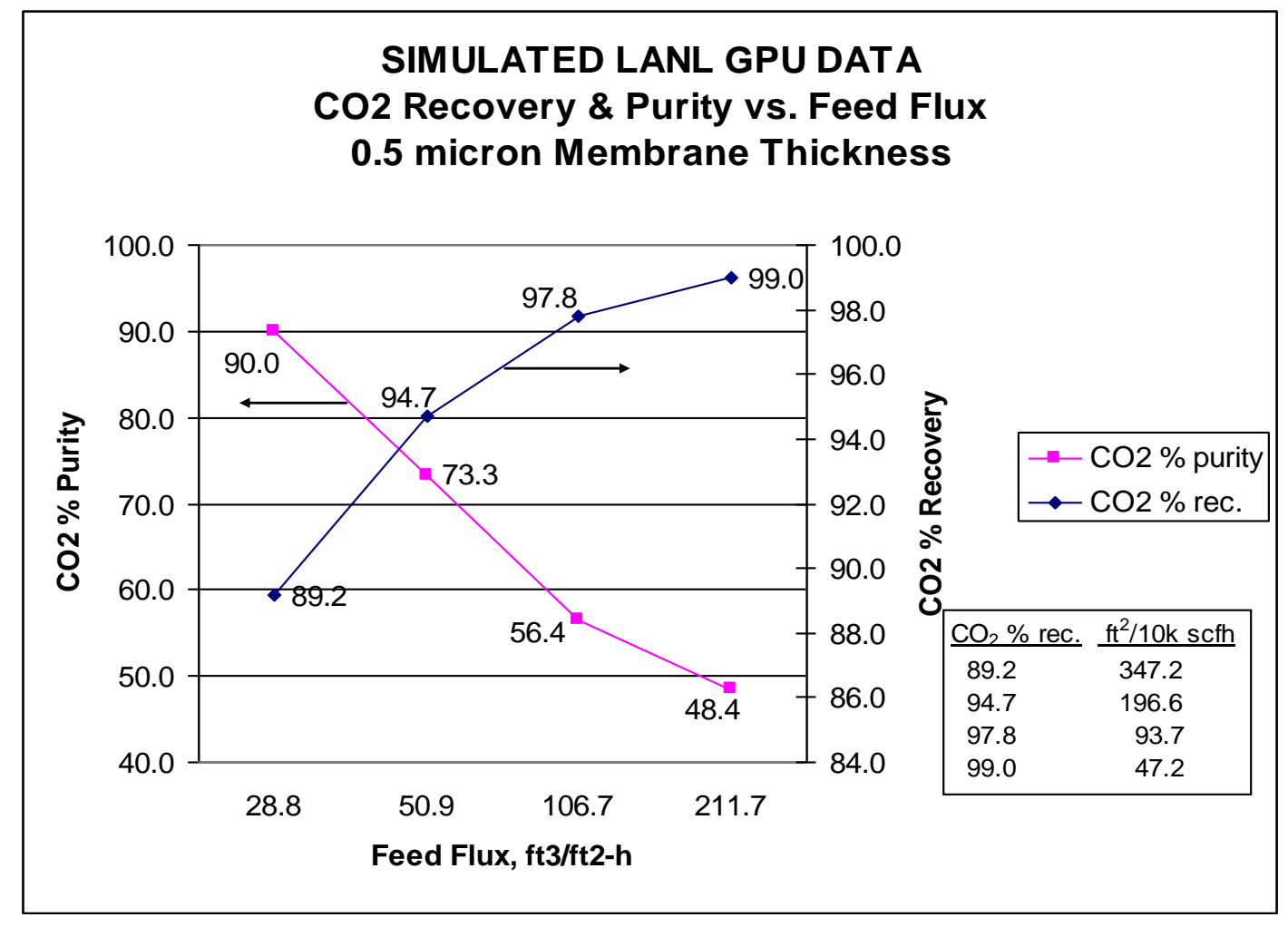

A simulation was done to calculate GPU parameters that yield a match to the LANL PERFORMANCE. The GPU parameters for $98 \% \mathrm{H}_{2}$ recovery are shown in the table below along with corresponding Barrer permeability for $0.5 \mu$ and $1.28 \mu$ membrane thickness. See the four SIMULATED LANL PERFORMANCE (sheets 5 to 8) spreadsheets in the attached appendix. Note in the simulation that the $\mathrm{H}_{2} \mathrm{O}$ GPU is reduced to prevent calculation of negative mole or volume fractions.

Simulated GPU values to match LANL performance

\begin{tabular}{lccc}
\multicolumn{1}{c}{ Component } & GPU & $\begin{array}{c}0.5 \mu \\
\text { Barrer }\end{array}$ & $1.28 \mu$ \\
$\mathrm{H}_{2}$ & 219.5 & 109.75 & 280.96 \\
$\mathrm{CO}$ & 2.1 & 1.05 & 2.687 \\
$\mathrm{CO}_{2}$ & 5.1 & 2.55 & 6.523 \\
$\mathrm{H}_{2} \mathrm{O}$ & 789 & 394.5 & 1009.92 \\
$\mathrm{CH}_{4}, \mathrm{~N}_{2}, \mathrm{H}_{2} \mathrm{~S}$ & 0.4 & 0.2 & 0.512
\end{tabular}


The LANL performance and simulated LANL performance at $98 \% \mathrm{H}_{2}$ recovery are compared in the table below:

\begin{tabular}{|c|c|c|c|c|c|c|c|}
\cline { 2 - 7 } \multicolumn{1}{c|}{} & $\begin{array}{c}\text { feed flux } \\
\mathrm{ft}^{2} / 10 \mathrm{k} \\
\text { scfh }\end{array}$ & \multicolumn{3}{c|}{ residue } & \multicolumn{3}{c|}{ permeate } \\
\hline $\begin{array}{c}\text { LANL GPU } \\
\text { performance }\end{array}$ & 285 & 715 & $90.0 \%$ & $90.0 \%$ & 71.5 & $92.0 \%$ & $98.0 \%$ \\
\hline $\begin{array}{c}\text { Simulated GPU } \\
\text { performance }\end{array}$ & 285.6 & 715 & $90.0 \%$ & $90.0 \%$ & 71.5 & $91.4 \%$ & $98.0 \%$ \\
\hline
\end{tabular}

The simulations of LANL performance for the four data points in the "Plot to Enerfex from LANL" for $\mathrm{H}_{2}$ and $\mathrm{CO}_{2}$ purity and recovery are summarized in the two charts below.

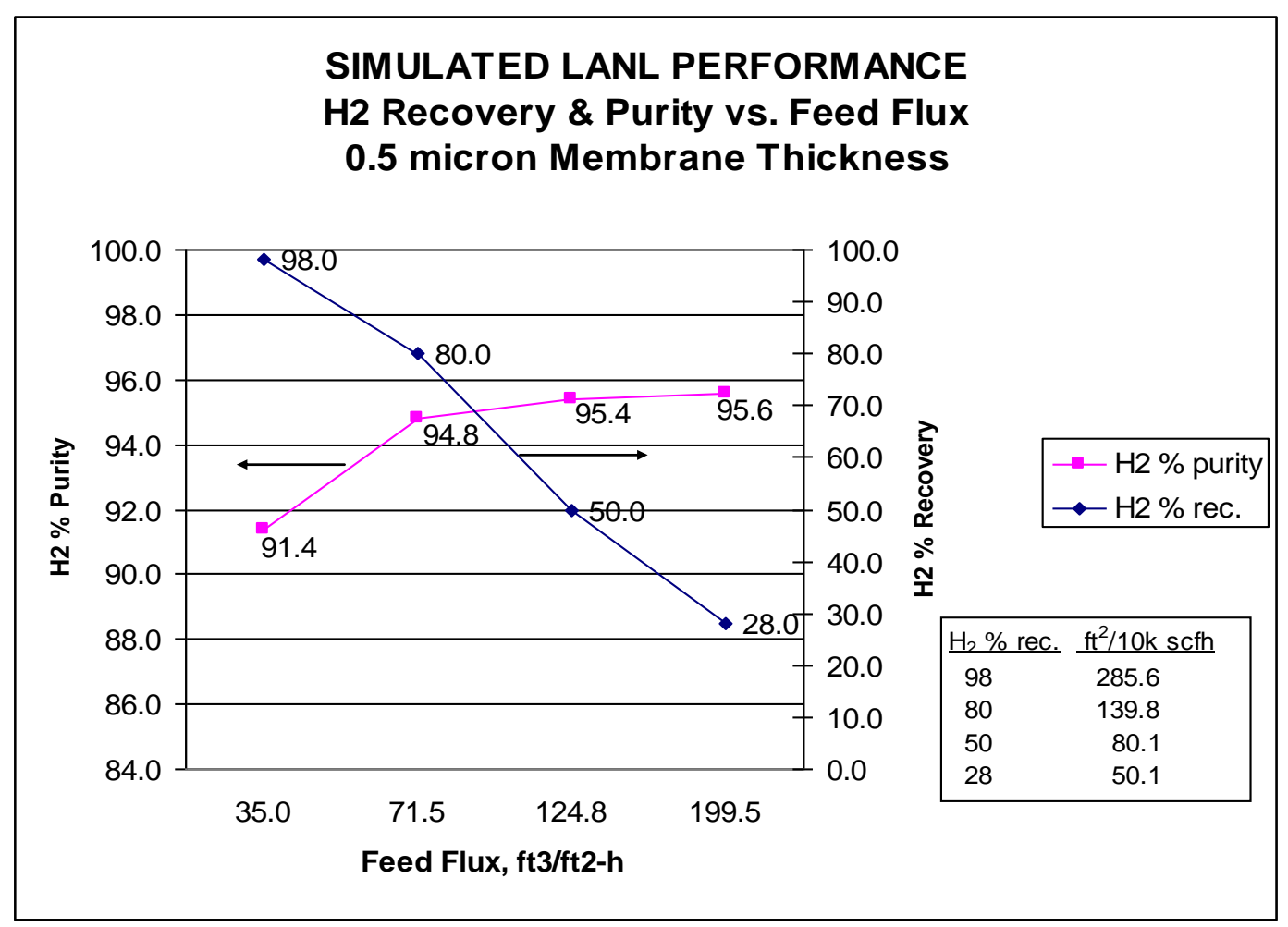




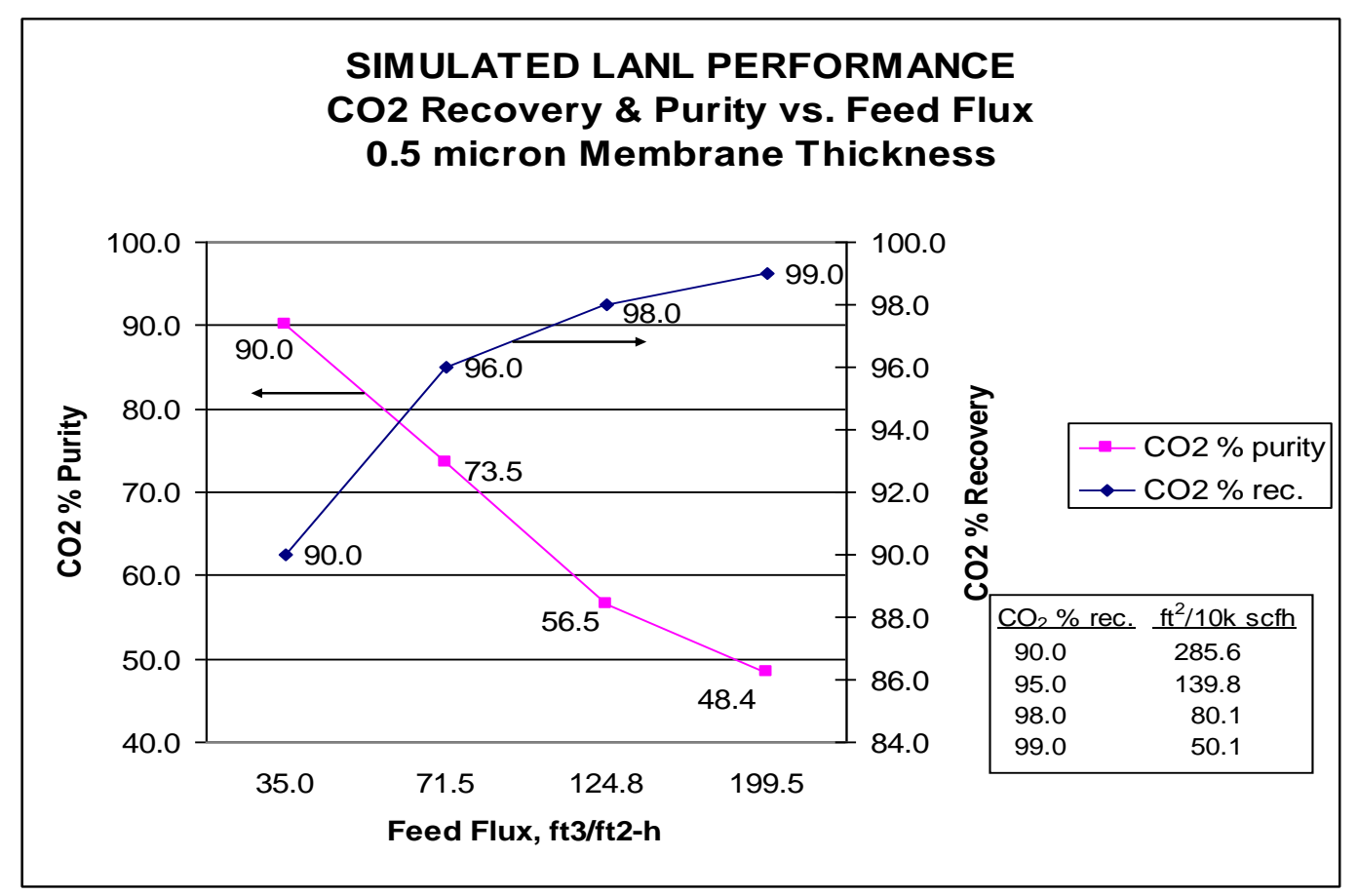

A plot of selectivity $\alpha_{\mathrm{H} 2 / \mathrm{CO} 2}$ versus average $\mathrm{H}_{2} / \mathrm{CO}_{2}$ partial pressure in the feed to residue side of the membrane for the four SIMULATED LANL PERFORMANCE spreadsheets is given in the chart below. The non-linear trend shown in the chart is unexpected. Typically commercial membranes such as polyimide, polysulfone and cellulose acetate with feed to residue mixtures of $\mathrm{CO}_{2}$ and $\mathrm{N}_{2}$ or $\mathrm{CH}_{4}$ with a temperature range of $40^{\circ}-50^{\circ} \mathrm{C}$ and within the same partial pressure ratio range do not exhibit a maximum inflection but instead show a proportional linear trend of $\alpha_{\mathrm{CO} / \mathrm{N} 2}$ selectivity increasing directly with average $\mathrm{CO}_{2} / \mathrm{N}_{2}$ partial pressure ratio.

The table below summarizes the simulated LANL performance.

$\begin{array}{lcccc}\mathrm{H}_{2} / \mathrm{CO}_{2} \text { avg. press. ratio } & 0.40 & 0.60 & 0.88 & 1.04 \\ \% \mathrm{H} 2 \text { recovery } & 98 \% & 80 \% & 50 \% & 28 \% \\ \% \mathrm{CO} 2 \text { recovery } & 90 \% & 96 \% & 98 \% & 99 \% \\ \mathrm{ft}^{2} / 10,000 \text { scfh of feed } & 285.6 & 139.8 & 80.1 & 50.1 \\ \mathrm{H}_{2} \mathrm{GPU} & 219.5 & 254.9 & 211.1 & 169.5 \\ \mathrm{CO}_{2} \mathrm{GPU} & 5.1 & 4.7 & 4.8 & 4.2 \\ \mathrm{\alpha}_{\mathrm{H} 2 / \mathrm{CO} 2} & 43.0 & 54.2 & 44.0 & 40.4\end{array}$


Selectivity correlation

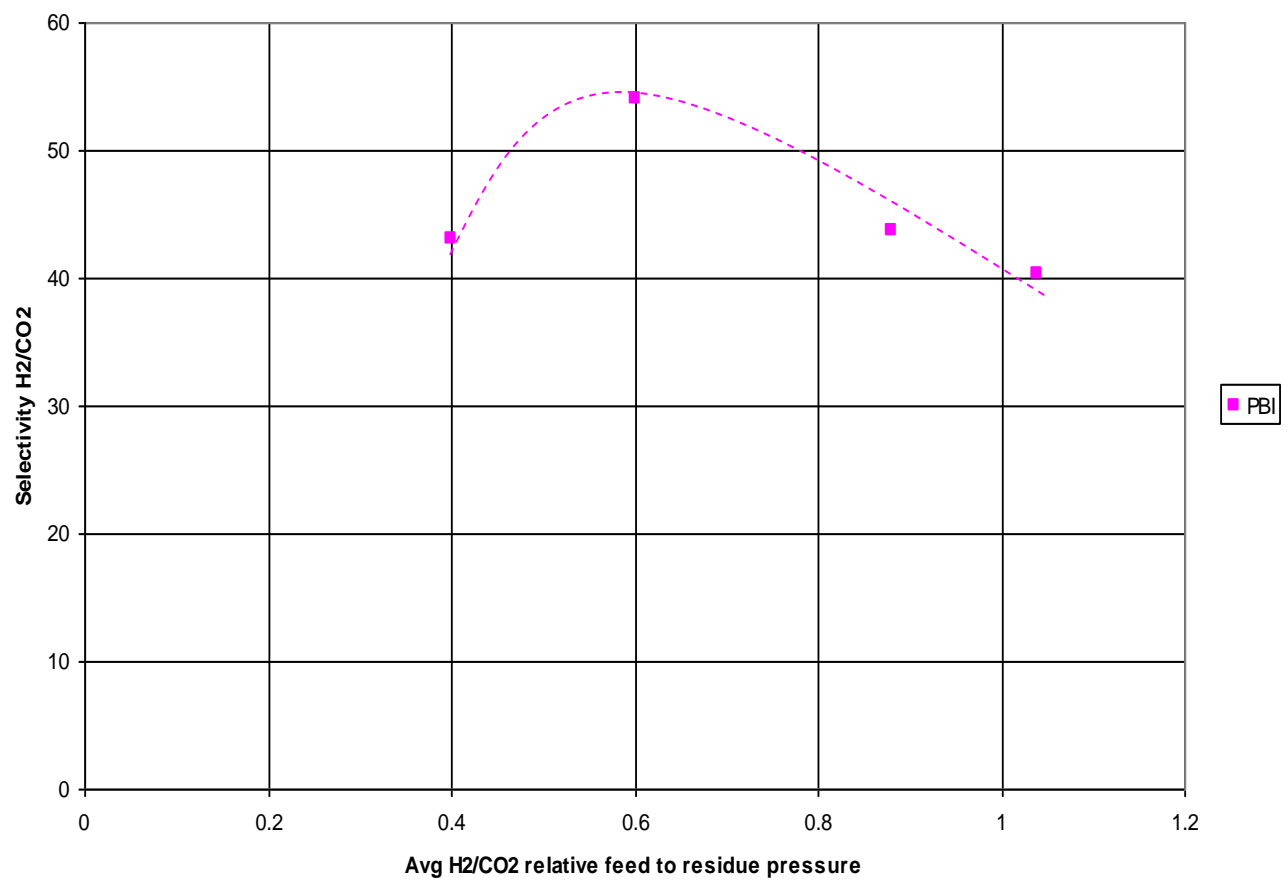

D - 13 


\section{D-3. PBI MEMBRANE SIMULATION - EFFECT OF SWEEP GAS}

LANL provided Projected PBI membrane data in addition to the LANL Performance simulated in Memorandums I and II. The Projected data are more conservative than the LANL Performance. The LANL Projected PBI membrane data is presented in Table 1 below.

\section{Table 1}

LANL Projected Data :

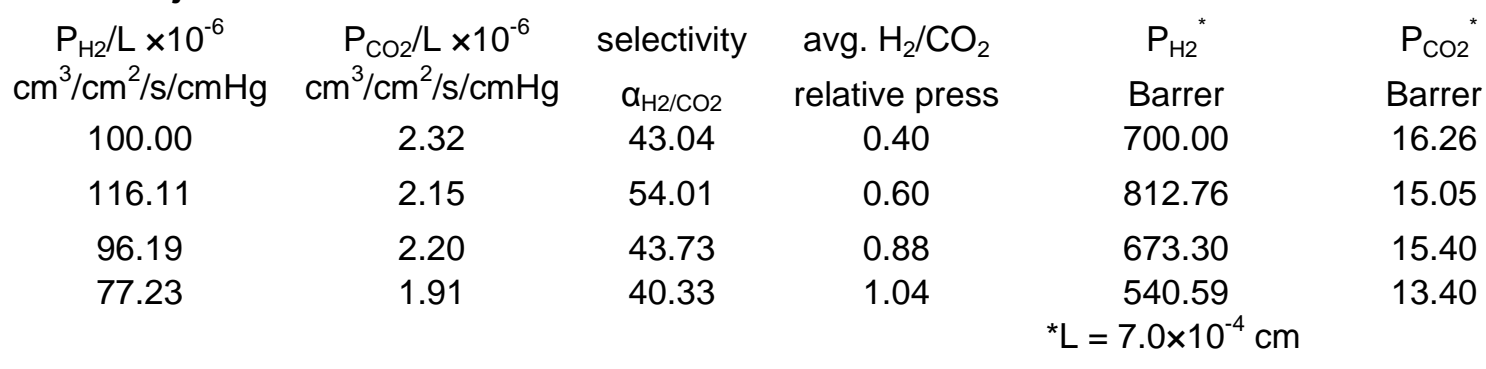

Projected membrane thickness is increased from $0.5 \mu$ to $7 \mu$ and Projected $\mathrm{H}_{2}$ GPU is reduced from 219 to 100. The Projected data assumes the $\mathrm{H}_{2} \mathrm{GPU}$ relative to the other components' GPU will be the same as the LANL Performance and, accordingly, the selectivity's will be the same. The respective residue and permeate component purities, recoveries and heating values will therefore be identical to the LANL Performance. However, membrane areas per 10,000 scfh of feed, which are compared in Table 2 below with the previously simulated LANL Performance, are about 2.2 times higher in each simulation case.

\begin{tabular}{ccccccc} 
simulation & \multicolumn{2}{c}{ Table 2 } & LANL Performance \& Projected Performance & \\
permeate & residue & permeate & residue & $\begin{array}{c}\text { performance } \\
\mathrm{ft}^{2} / 10 \mathrm{k} \text { scfh }\end{array}$ & $\begin{array}{c}\text { projected } \\
\mathrm{ft}^{2} / 10 \mathrm{k} \mathrm{scfh}\end{array}$ \\
$\#$ & $\mathrm{H}_{2}$ rec. & $\mathrm{CO}_{2}$ rec. & $\mathrm{H}_{2}$ purity & $\mathrm{CO}_{2}$ purity & feed. & feed. \\
1 & $98 \%$ & $90 \%$ & $91.4 \%$ & $87.8 \%$ & 285.6 & 627.1 \\
2 & $80 \%$ & $96 \%$ & $94.8 \%$ & $71.7 \%$ & 139.8 & 307.1 \\
3 & $50 \%$ & $98 \%$ & $95.3 \%$ & $55.1 \%$ & 80.1 & 175.8 \\
4 & $28 \%$ & $99 \%$ & $95.6 \%$ & $47.2 \%$ & 50.1 & 110.0
\end{tabular}

Therefore, the only change in performance is the increase in membrane area requirement. LANL Projected Performance Simulation spreadsheets titled "Simulated LANL Projected" numbered 1 to 4 are attached in the Appendix.

\section{Sweep Gas Simulations:}

It is generally understood that the $\mathrm{H}_{2}$ rich permeate fuel gas in order to fuel a gas turbine will need to be reduced in $\mathrm{Btu} / \mathrm{ft}^{3}$ heating value. The reduction can be accomplished by dilution with $\mathrm{N}_{2}$ which will be available from an ASU associated with an IGCC power plant. The exact lower heating value needed is not known. The dilution can be conveniently accomplished by means of a $\mathrm{N}_{2}$ sweep gas on the permeate side of the 
membrane which will at the same time reduce the membrane area requirement for the same degree of $\mathrm{H}_{2}$ and $\mathrm{CO}_{2}$ purity and recovery. Sweep Gas simulations for LANL Performance at sweep gas fractions of $0 \%, 25 \%, 50 \%$ and $75 \%$ with $98 \% \mathrm{H}_{2}$ recovery are summarized in Table 3 below.

\begin{tabular}{|c|c|c|c|c|c|c|c|}
\hline simulation & residue & permeate & residue & $\begin{array}{l}\text { sweep } \\
\text { fraction }\end{array}$ & $\begin{array}{l}\text { feed } \\
\text { flux }\end{array}$ & $\begin{array}{c}\text { membrane } \\
\text { area }\end{array}$ & $\begin{array}{l}\text { permeate } \\
\text { fuel }\end{array}$ \\
\hline \# & $\mathrm{CO}_{2} \mathrm{rec}$. & $\mathrm{H}_{2}$ purity & $\mathrm{CO}_{2}$ purity & $\%$ & $\mathrm{ft}^{3} / \mathrm{ft}^{2}-\mathrm{h}$ & $\mathrm{ft}^{2} / \mathrm{MW}^{*}$ & $\mathrm{Btu} / \mathrm{ft}^{3}$ \\
\hline 5 & $90.0 \%$ & $91.4 \%$ & $87.7 \%$ & $0 \%$ & 35.0 & 921.7 & 313.6 \\
\hline 6 & $90.9 \%$ & $69.0 \%$ & $87.8 \%$ & $25 \%$ & 39.0 & 827.8 & 236.7 \\
\hline 7 & $91.7 \%$ & $46.3 \%$ & $88.0 \%$ & $50 \%$ & 42.7 & 751.1 & 158.7 \\
\hline 8 & $92.4 \%$ & $23.3 \%$ & $88.0 \%$ & $75 \%$ & 47.0 & 685.4 & 79.9 \\
\hline
\end{tabular}

* One MW at $44 \%$ thermal efficiency equals 32,250 scfh of feed

A plot of the sweep gas effect on heating value and membrane requirement in LANL Performance over a range of Sweep gas fractions is illustrated in Chart 1 below.

\section{Chart 1 - LANL Performance Area and Heating Value vs. Sweep Gas Fraction}

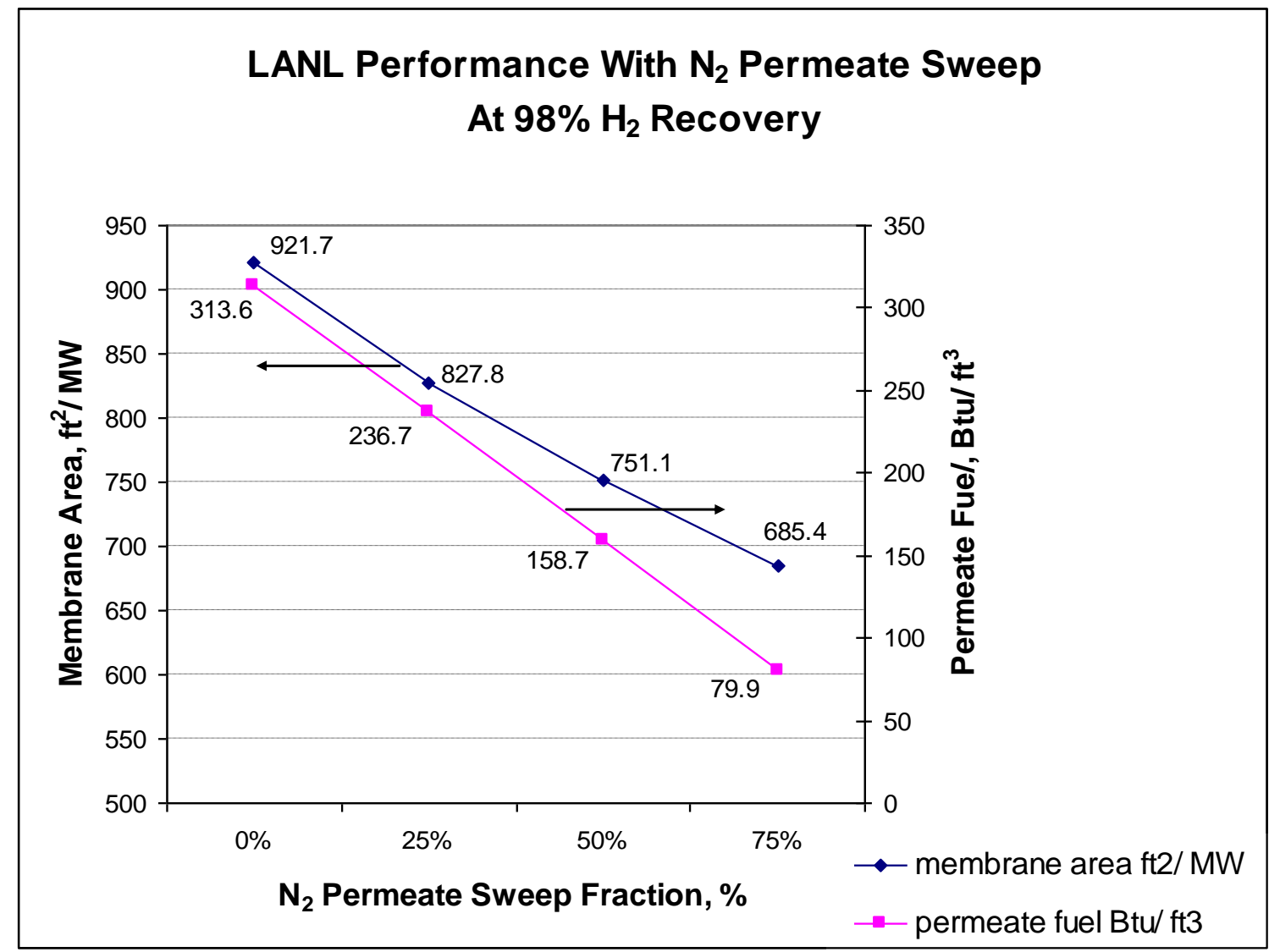

Sweep Gas simulations for LANL Projected at sweep gas fractions of 0\%, 25\%, 50\% and $75 \%$ with $98 \% \mathrm{H}_{2}$ recovery are summarized in Table 4 below. 


\begin{tabular}{|c|c|c|c|c|c|c|c|}
\hline simulation & residue & permeate & residue & $\begin{array}{l}\text { sweep } \\
\text { fraction }\end{array}$ & $\begin{array}{l}\text { feed } \\
\text { flux }\end{array}$ & $\begin{array}{c}\text { membrane } \\
\text { area }\end{array}$ & $\begin{array}{c}\text { permeate } \\
\text { fuel }\end{array}$ \\
\hline \# & $\mathrm{CO}_{2}$ rec. & $\mathrm{H}_{2}$ purity & $\mathrm{CO}_{2}$ purity & $\%$ & $\mathrm{ft}^{3} / \mathrm{ft}^{2}-\mathrm{h}$ & $\mathrm{ft}^{2} / \mathrm{MW}^{*}$ & $\mathrm{Btu} / \mathrm{ft}^{3}$ \\
\hline 9 & $90.0 \%$ & $91.4 \%$ & $87.7 \%$ & $0 \%$ & 15.9 & 2022.3 & 313.4 \\
\hline 10 & $90.9 \%$ & $69.0 \%$ & $87.9 \%$ & $25 \%$ & 17.7 & 1817.0 & 236.6 \\
\hline 11 & $91.8 \%$ & $46.2 \%$ & $87.9 \%$ & $50 \%$ & 19.6 & 1646.1 & 158.4 \\
\hline 12 & $92.4 \%$ & $23.3 \%$ & $88.0 \%$ & $75 \%$ & 21.4 & 1504.4 & 79.9 \\
\hline
\end{tabular}

* One MW at $44 \%$ thermal efficiency equals 32,250 scfh of feed

A plot of the sweep gas effect on heating value and membrane requirement in LANL Projected over a range of sweep gas fractions is illustrated in Chart 2 below.

\section{Chart 2 - LANL Projected Area and Heating Value vs. Sweep Gas Fraction}

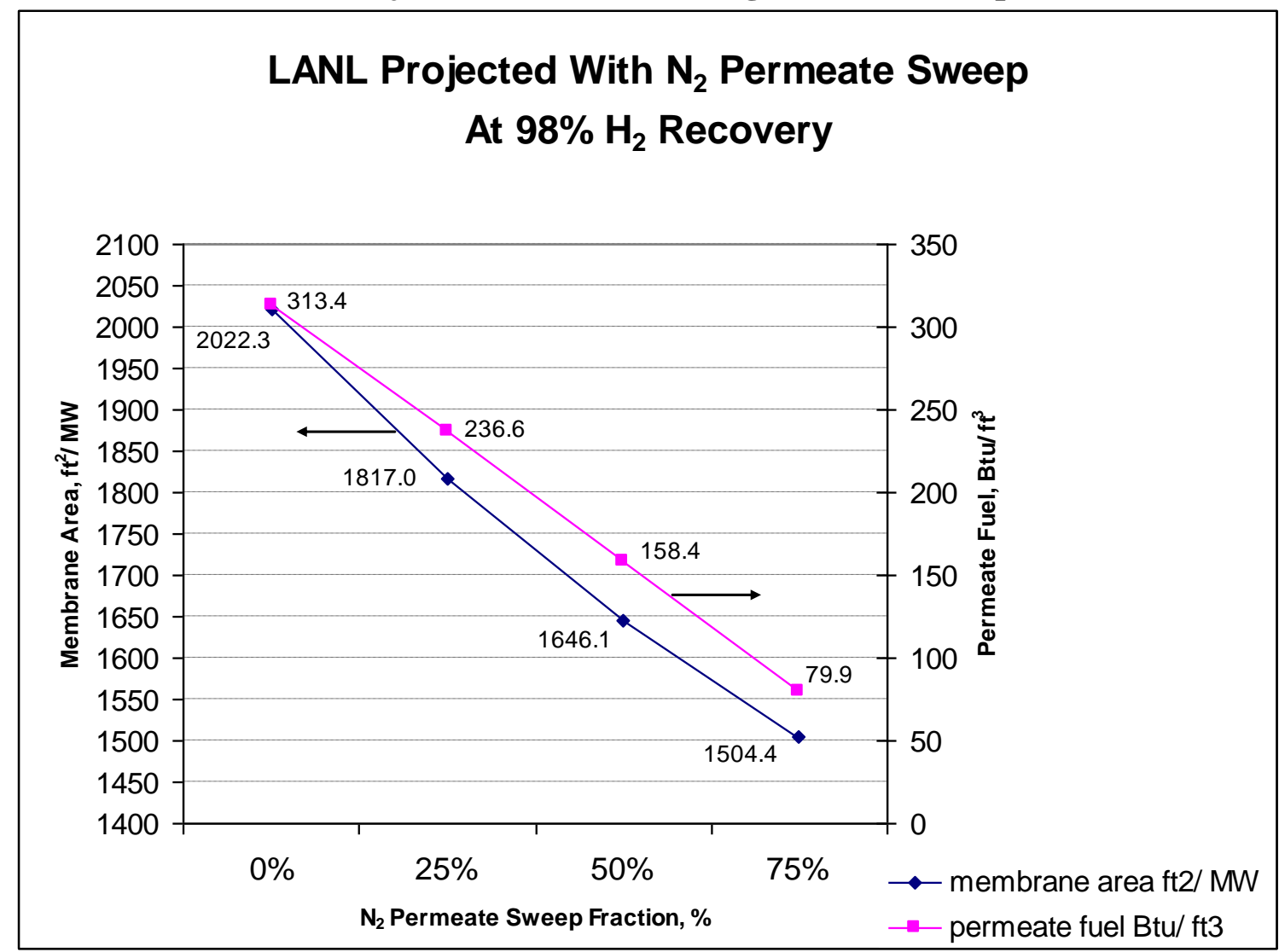

Tables 3 and 4 and Charts 1 and 2 above, show that progressively increasing the sweep gas fraction reduces both heating value and membrane area requirement while increasing $\mathrm{CO}_{2}$ recovery and purity by a small amount. LANL Performance simulation spreadsheets titled "Simulated LANL Performance with Sweep Gas" numbered 5 to 8 and LANL Projected simulation spreadsheets titled "Simulated LANL Projected Performance with Sweep Gas" numbered 9 to 12 are attached in the Appendix.

The lower $\mathrm{H}_{2}$ GPU and thicker effective membrane thickness in the LANL Projected data across the range of sweep gas fractions increases the membrane requirement compared to 
LANL Performance by a factor of about 2.2. Accordingly, the design goal for the PBI membrane should be an effective membrane thickness as close to as possible to the LANL Performance effective thickness of $0.5 \mu$ without a loss of operating membrane robustness or reduction in acceptable membrane economic life. 


\section{D-4. PBI SIMULATIONS WITH $\mathrm{N}_{2}$ PERMEATE SWEEP AND AN INCREASED PERMEATE PRESSURE OF 250 PSIA}

Simulations of LANL performance at 71.5 psia permeate pressure presented in Memorandum III are reviewed in Table 1. The green highlighted data was added after receiving information from $\mathrm{BP}$ that the heating value requirement of the gas turbine is $115 \mathrm{Btu} / \mathrm{ft}^{3}$.

\begin{tabular}{|c|c|c|c|c|c|c|}
\hline residue & permeate & residue & $\begin{array}{l}\text { sweep } \\
\text { fraction }\end{array}$ & $\begin{array}{l}\text { feed } \\
\text { flux }\end{array}$ & $\begin{array}{c}\text { membrane } \\
\text { area }\end{array}$ & $\begin{array}{l}\text { permeate } \\
\text { fuel }\end{array}$ \\
\hline $\mathrm{CO}_{2}$ rec. & $\mathrm{H}_{2}$ purity & $\mathrm{CO}_{2}$ purity & $\%$ & $\mathrm{ft}^{3} / \mathrm{ft}^{2}-\mathrm{h}$ & $\mathrm{ft}^{2} / \mathrm{MW}^{*}$ & $\mathrm{Btu} / \mathrm{ft}^{3}$ \\
\hline $90.0 \%$ & $91.4 \%$ & $87.7 \%$ & $0 \%$ & 35.0 & 921.7 & 313.6 \\
\hline $90.9 \%$ & $69.0 \%$ & $87.8 \%$ & $25 \%$ & 39.0 & 827.8 & 236.7 \\
\hline $91.7 \%$ & $46.3 \%$ & $88.0 \%$ & $50 \%$ & 42.7 & 751.1 & 158.7 \\
\hline $92.2 \%$ & $33.7 \%$ & $87.9 \%$ & $63.7 \%$ & 45.2 & 712.8 & 115.5 \\
\hline $92.4 \%$ & $23.3 \%$ & $88.0 \%$ & $75 \%$ & 47.0 & 685.4 & 79.9 \\
\hline
\end{tabular}

Increasing the $\mathrm{N}_{2}$ sweep fraction at 715 psia feed pressure and 71.5 psia permeate pressure lowered the membrane requirement with little or no effect on $\mathrm{H}_{2}$ and $\mathrm{CO}_{2}$ recovery. The sweep fraction and therefore the membrane requirement is now specified by the $115 \mathrm{Btu} / \mathrm{ft}^{3}$ permeate fuel heating value. However, 71.5 psia permeate pressure is not high enough pressure to fuel a gas turbine and will need to be increased to 250 psia.

Accordingly, a set of five simulations with a feed pressure of 715 psia, permeate pressure at 250 psia and nitrogen sweep fractions of $0 \%, 50 \%, 60 \%, 62.9 \%$ and $70 \%$ were completed. A sweep gas fraction of $62.9 \%$ gives a permeate fuel heating value of 115 $\mathrm{Btu} / \mathrm{ft}^{3}$. The results are summarized in Table 2 below.

Table 2 - $\mathrm{N}_{2}$ Permeate Sweep Gas At $98 \% \mathrm{H}_{2}$ Recovery, 715 psia Feed

\begin{tabular}{|c|c|c|c|c|c|c|c|}
\hline simulation & residue & permeate & $\begin{array}{l}\text { \& } 250 \text { psi } \\
\text { residue }\end{array}$ & $\begin{array}{l}\text { Permeat } \\
\text { sweep } \\
\text { fraction }\end{array}$ & $\begin{array}{l}\text { feed } \\
\text { flux }\end{array}$ & $\begin{array}{c}\text { membrane } \\
\text { area }\end{array}$ & $\begin{array}{l}\text { permeate } \\
\text { fuel }\end{array}$ \\
\hline \# & $\mathrm{CO}_{2}$ rec. & $\mathrm{H}_{2}$ purity & $\mathrm{CO}_{2}$ purity & $\%$ & $\mathrm{ft}^{3} / \mathrm{ft}^{2}-\mathrm{h}$ & $\mathrm{ft}^{2} / \mathrm{MW}^{*}$ & $\mathrm{Btu} / \mathrm{ft}^{3}$ \\
\hline 1 & $56.1 \%$ & $73.9 \%$ & $82.5 \%$ & $0 \%$ & 6.7 & $4,811.2$ & 253.6 \\
\hline 2 & $85.6 \%$ & $44.4 \%$ & $87.2 \%$ & $50 \%$ & 23.9 & $1,348.3$ & 152.1 \\
\hline 3 & $87.9 \%$ & $36.0 \%$ & $87.6 \%$ & $60 \%$ & 28.8 & $1,119.1$ & 123.6 \\
\hline 4 & $88.5 \%$ & $33.6 \%$ & $87.6 \%$ & $62.9 \%$ & 30.4 & $1,059.8$ & 115.3 \\
\hline 5 & $89.8 \%$ & $27.3 \%$ & $87.7 \%$ & $70 \%$ & 34.3 & 940.8 & 93.7 \\
\hline
\end{tabular}

\footnotetext{
${ }^{1}$ Subsequently added
} 
At 50\% sweep fraction, 715 psia feed and an increased permeate pressure of 250 psia, $\mathrm{CO}_{2}$ recovery and $\mathrm{H}_{2}$ purity are marginally reduced while membrane area is substantially increased. The data in Table 2 is plotted in Figures 1 and 2 below.

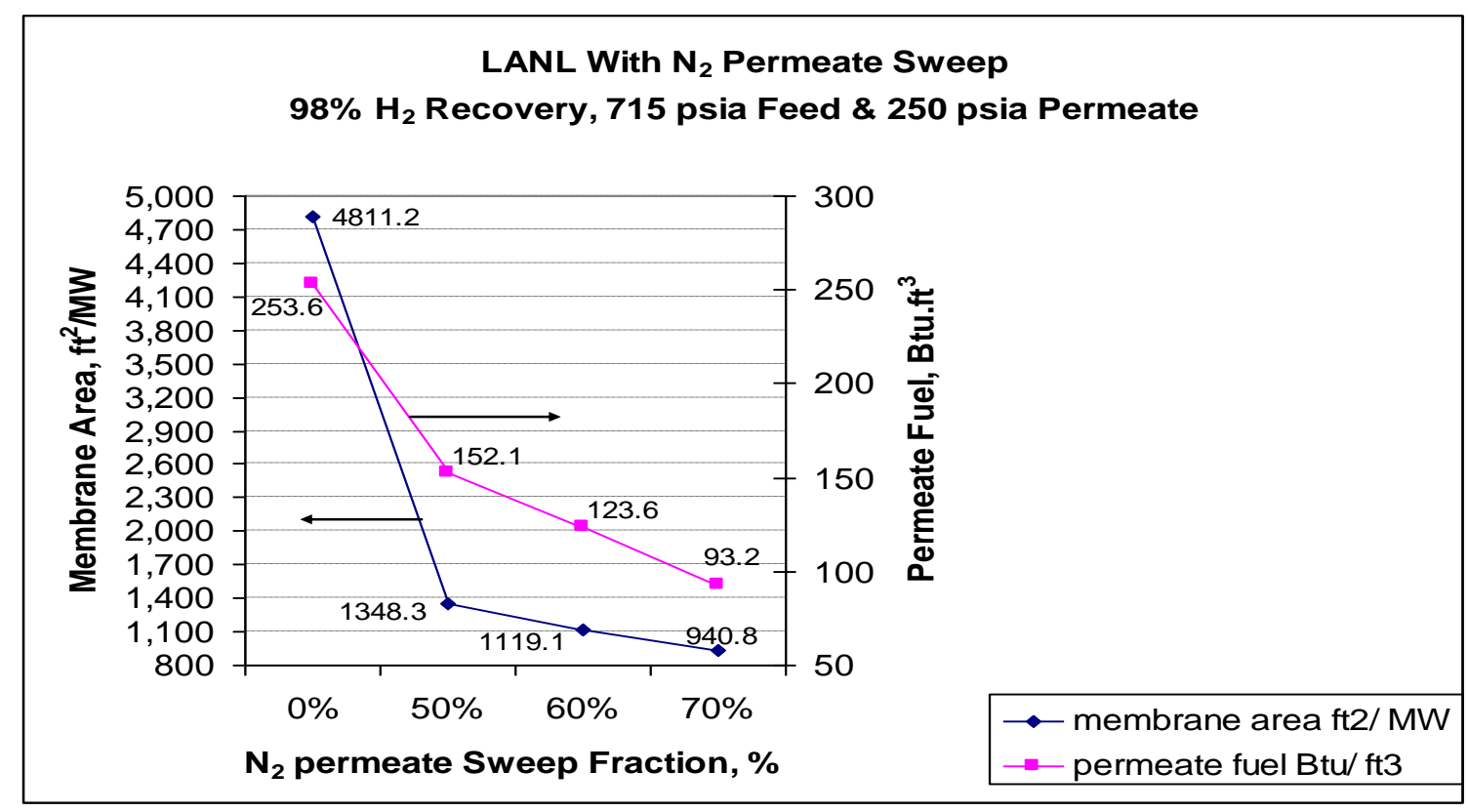

Figure 1 - Membrane Area and Permeate Fuel vs. Sweep Fraction

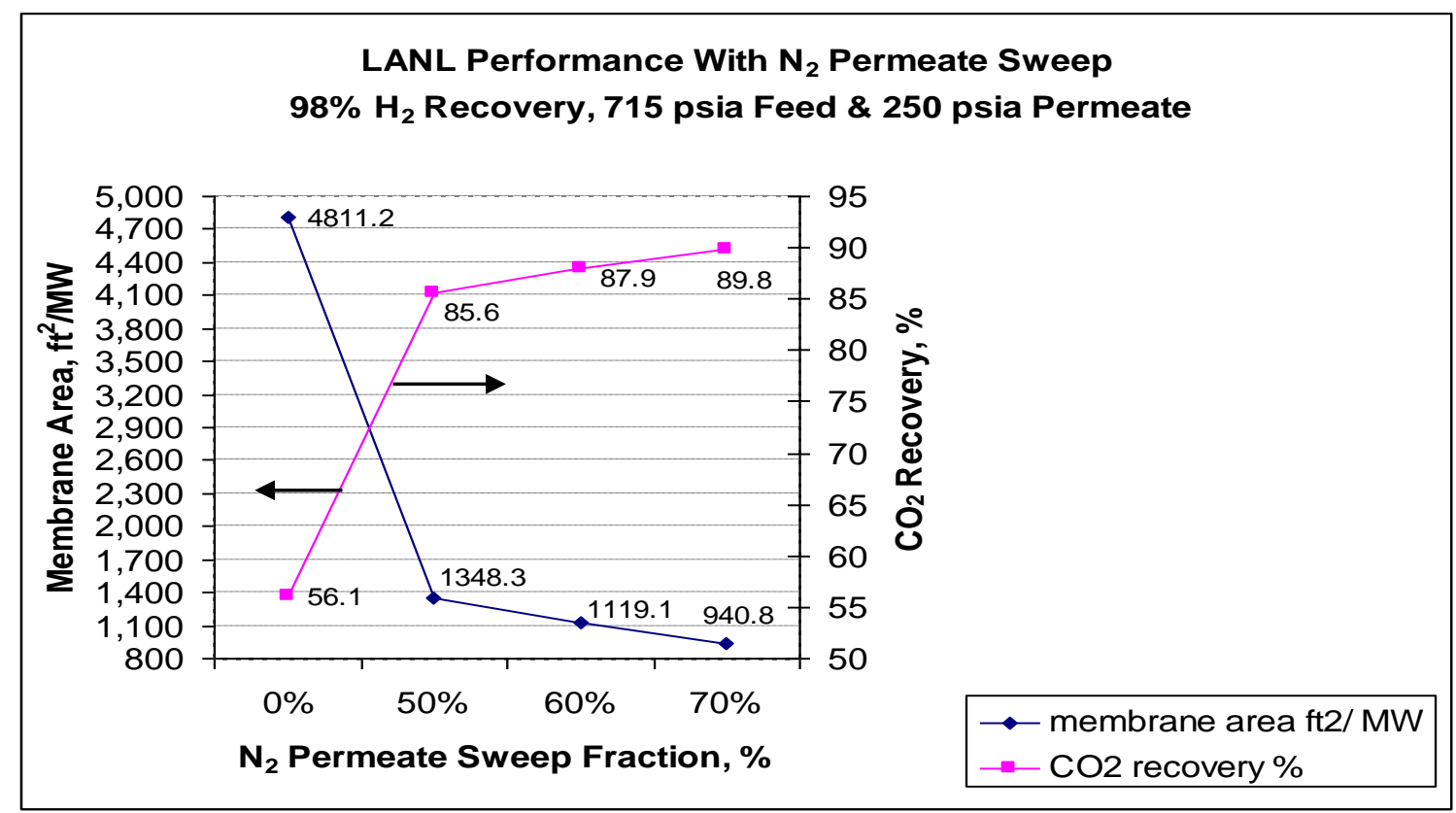

Figure 2 - Membrane Area and $\mathrm{CO}_{2}$ recovery vs. Sweep Fraction 
Also completed were five simulations with feed pressure at 1,015 psia, permeate pressure at 250 psia and nitrogen sweep fractions of $0 \%, 50 \%, 60 \%, 63.5 \%{ }^{2}$ and $70 \%$. Based on information from BP, $63.5 \%$ sweep gas at these pressures gives the desired fuel heating value of $115 \mathrm{Btu} / \mathrm{ft}^{3}$. The results are summarized in Table 3 below.

Table 3 - $\mathrm{N}_{2}$ Permeate Sweep Gas At $98 \% \mathrm{H}_{2}$ Recovery, 1,015 psia Feed

\begin{tabular}{|c|c|c|c|c|c|c|c|}
\hline \multirow{3}{*}{$\begin{array}{c}\text { simulation } \\
\#\end{array}$} & \multirow[b]{2}{*}{ residue } & \multirow[b]{2}{*}{ permeate } & \multicolumn{3}{|c|}{ \& 250 psia Permeate } & \multirow[b]{2}{*}{$\begin{array}{c}\text { membrane } \\
\text { area }\end{array}$} & \multirow[b]{2}{*}{$\begin{array}{l}\text { permeate } \\
\text { fuel }\end{array}$} \\
\hline & & & residue & $\begin{array}{l}\text { sweep } \\
\text { fraction }\end{array}$ & $\begin{array}{l}\text { feed } \\
\text { flux }\end{array}$ & & \\
\hline & $\mathrm{CO}_{2} \mathrm{rec}$. & $\mathrm{H}_{2}$ purity & $\mathrm{CO}_{2}$ purity & $\%$ & $\mathrm{ft}^{3} / \mathrm{ft}^{2}-\mathrm{h}$ & $\mathrm{ft}^{2} / \mathrm{MW}^{*}$ & $\mathrm{Btu} / \mathrm{ft}^{3}$ \\
\hline 6 & $77.6 \%$ & $84.0 \%$ & $86.3 \%$ & $0 \%$ & 21.0 & $1,531.5$ & 288.2 \\
\hline 7 & $88.8 \%$ & $45.3 \%$ & $87.6 \%$ & $50 \%$ & 44.6 & 723.3 & 155.5 \\
\hline 8 & $90.0 \%$ & $36.7 \%$ & $87.7 \%$ & $60 \%$ & 50.0 & 644.8 & 125.7 \\
\hline 9 & $90.4 \%$ & $33.5 \%$ & $87.8 \%$ & $63.5 \%$ & 51.9 & 620.9 & 115.1 \\
\hline 10 & $91.0 \%$ & $27.6 \%$ & $87.9 \%$ & $70 \%$ & 55.5 & 580.6 & 94.7 \\
\hline
\end{tabular}

* One MW at $44 \%$ thermal efficiency equals 32,250 scfh of feed

Comparing the 715 psia feed and 71.5 psia permeate case at $50 \%$ sweep gas fraction, to the increased feed pressure of 1,015 psia with 250 psia permeate pressure, shows a substantially improved performance, converging all operating parameters to within $2-3 \%$, including membrane area. The performance at $63.5 \%$ sweep fraction and $115.1 \mathrm{Btu} / \mathrm{ft} 3$, is even better in all respects, almost equaling the performance at 71.5 psia permeate pressure at 50\% sweep gas fraction and exceeds the NETL specified $\mathrm{CO}_{2}$ capture rate of $90 \%$. The membrane area of $620.9 \mathrm{ft}^{2} / \mathrm{MW}$ is substantially less than the 715 psia feed case and would be about the size of a standard commercial 4 " $\times 5$ ' hollow fiber bundle. The data in Table 3 is plotted in Figures 3 and 4 below.

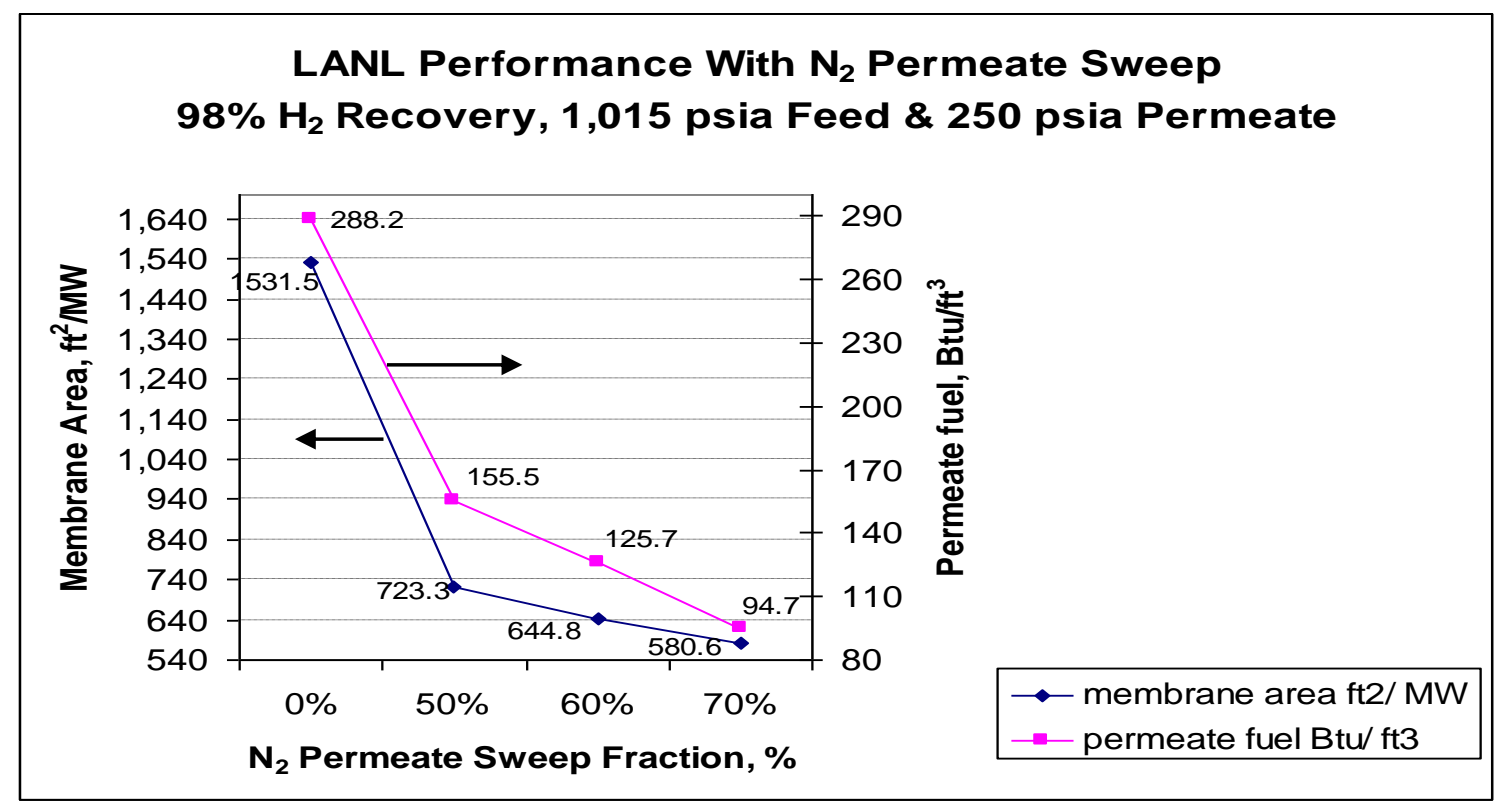

\footnotetext{
${ }^{2}$ Subsequently added
} 
Figure 3 - Membrane Area and Permeate Fuel vs. Sweep Fraction

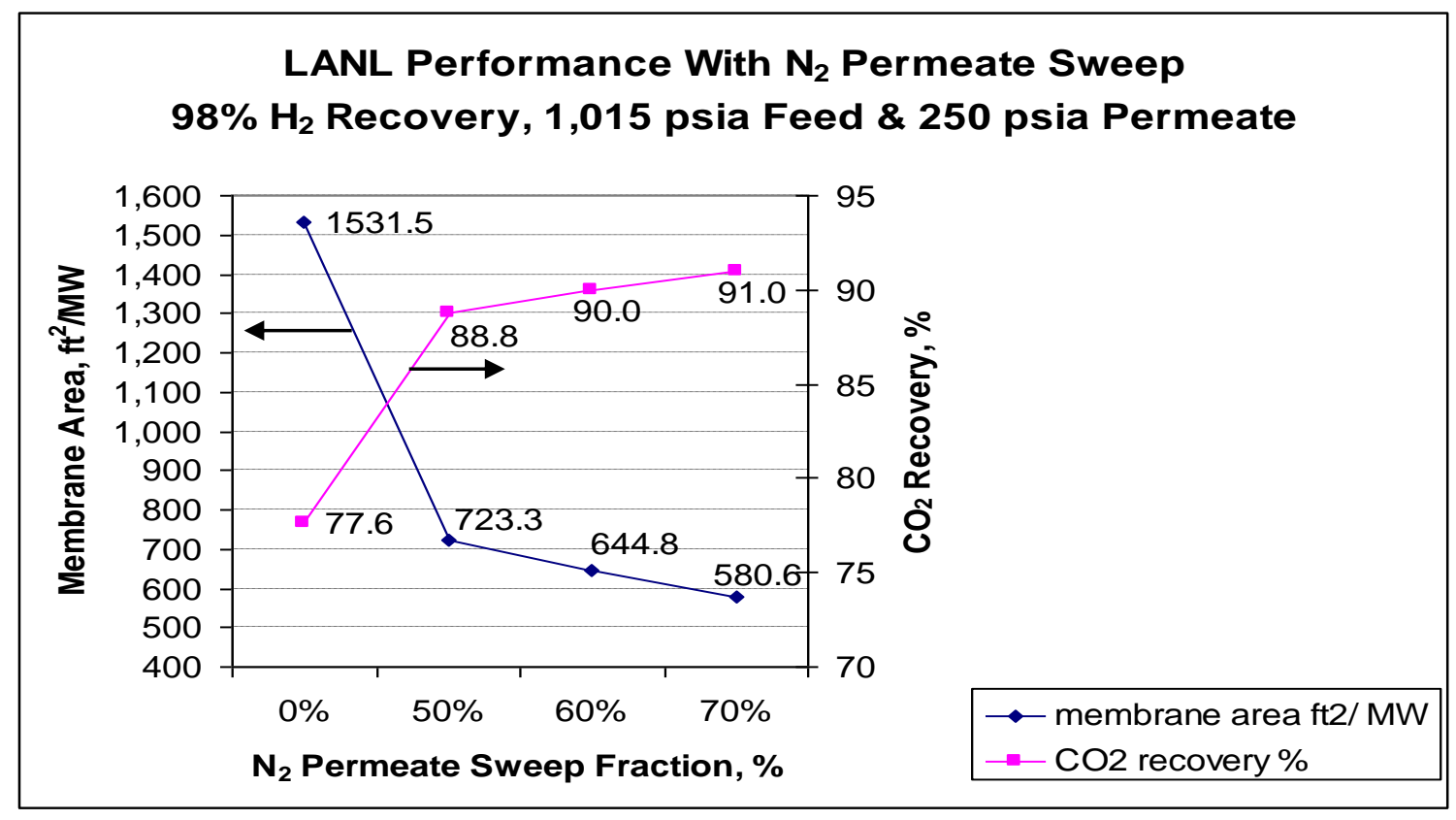

Figure 4 - Membrane Area and $\mathrm{CO}_{2}$ recovery vs. Sweep Fraction 


\section{D-5. PBI MEMBRANE SIMULATION - EFFECT OF MEMBRANE THICKNESS}

LANL provided empirical PBI membrane GPU data and consequently empirical PBI single and mixed gas permeability parameters. Baseline operating performance at LANL test conditions was simulated. Projected goal performance based on a thinner membrane separation layer than the test membrane and higher feed pressure than the test pressure were simulated. The empirical results establish a baseline comparison upon which future goal membrane performance can be judged.

The LANL empirical GPU and permeability data is presented in Table 1 below:

\begin{tabular}{|c|c|c|c|c|c|c|}
\hline \multicolumn{7}{|c|}{ Feed Press. = $260 \mathrm{~cm} \mathrm{Hg}$; Permeate Press. = $76 \mathrm{~cm} \mathrm{Hg}$} \\
\hline & Separation Layer & 0.0012 & $\mathbf{c m}$ & & & \\
\hline & $\begin{array}{c}\text { Single Gas GPU } \\
10^{-6} \mathrm{~cm}^{3} / \mathrm{s} / \mathrm{cm}^{2} / \mathrm{cm} \mathrm{Hg}\end{array}$ & $\mathrm{H}_{2} \alpha$ & Barrer & $\begin{array}{c}\text { Mixed Gas GPU } \\
10^{-6} \mathrm{~cm}^{3} / \mathrm{s} / \mathrm{cm}^{2} / \mathrm{cm} \mathrm{Hg}\end{array}$ & $\mathrm{H}_{2} \alpha$ & Barrer \\
\hline $\mathbf{H}_{2}$ & 5.20 & 1.00 & $6.24 \mathrm{E}-09$ & 7.30 & 1.00 & 8.76E-09 \\
\hline $\mathrm{CO}_{2}$ & 0.12 & 43.33 & $1.44 \mathrm{E}-10$ & 0.17 & 42.94 & 2.04E-10 \\
\hline CO & 0.25 & 20.80 & $3.00 \mathrm{E}-10$ & 0.06 & 121.67 & 7.20E-11 \\
\hline $\mathbf{N}_{2}$ & 0.020 & 260.00 & $2.40 \mathrm{E}-11$ & 0.020 & 365.00 & 2.40E-11 \\
\hline $\mathrm{CH}_{4}$ & 0.010 & 520.00 & $1.20 \mathrm{E}-11$ & 0.030 & 243.33 & $3.60 \mathrm{E}-11$ \\
\hline $\mathrm{H}_{2} \mathrm{~S}$ & 0.004 & 1300.00 & 4.80E-12 & 0.004 & 1825.00 & $4.80 \mathrm{E}-12$ \\
\hline
\end{tabular}

The tested effective membrane separation layer is $0.0012 \mathrm{~cm}$ or $12 \mu \mathrm{m}$. This is a relatively large thickness compared to commercial gas membrane separation layers which are typically about $0.1 \mu \mathrm{m}$. The test feed pressure and trans-membrane pressure (TMP) difference is significantly less than what will be available with an IGCC shift gas. Simulations 1, 2, 3, and 4 are presented in the Appendix and summarized in Table 2 below. Simulations 1 and 2 are based on the LANL empirical permeability data at the test pressure and the test membrane thickness. Simulations 3 and 4 are based on the LANL empirical permeability data at the expected higher shift gas pressure and the test membrane thickness.

Table 2 -Simulations at LANL Test Pressure, IGCC Shift Gas Pressure and $98 \% \mathrm{H}_{\mathbf{2}}$ Recovery

\begin{tabular}{|c|c|c|c|c|c|c|c|c|c|}
\hline $\begin{array}{c}\text { Sim. } \\
\#\end{array}$ & $\begin{array}{c}\text { Data } \\
\text { Source }\end{array}$ & $\begin{array}{c}\text { Feed } \\
P, \mathrm{~cm} \mathrm{Hg}\end{array}$ & $\begin{array}{l}\text { Permeate } \\
\mathrm{P}, \mathrm{cm} \mathrm{Hg}\end{array}$ & $\begin{array}{l}\text { Membrane } \\
\text { Layer, } \mu \mathrm{m}\end{array}$ & $\begin{array}{c}\mathbf{N}_{2} \\
\text { Sweep } \\
\% \\
\end{array}$ & $\begin{array}{c}\text { Permeate } \\
\mathrm{Btu} / \mathrm{Ft}^{3}\end{array}$ & $\begin{array}{c}\mathrm{CO}_{2} \\
\mathrm{Rec} . \\
\%\end{array}$ & $\begin{array}{c}600 \mathrm{MW} \\
\text { Mbr. Area } \\
\mathrm{m}^{2} \\
\end{array}$ & $\begin{array}{c}4 " \times 55^{\prime} \\
\text { elements } \\
\#\end{array}$ \\
\hline 1 & LANL Single Gas & 260 & 76 & 12 & 63.8 & 115.1 & 89.8 & $31,935,278$ & 520,642 \\
\hline 2 & LANL Mixed Gas & 260 & 76 & 12 & 63.9 & 115.0 & 89.8 & $22,738,681$ & 370,709 \\
\hline 3 & LANL Single Gas & 1,015 & 250 & 12 & 64.0 & 115.1 & 90.6 & $1,463,662$ & 23,862 \\
\hline 4 & LANL Mixed Gas & 1,015 & 250 & 12 & 64.1 & 115.0 & 90.5 & $1,042,709$ & 16,999 \\
\hline
\end{tabular}

In simulations 1 and 2, based upon both the test membrane thickness and the test feed pressure, permeation fluxes are extraordinarily low and consequently membrane areas are 
extraordinarily high. It is clear that the test GPUs give an extreme lower performance boundary. The test conditions of $12 \mu \mathrm{m}$ thickness and $260 \mathrm{~cm} \mathrm{Hg}$ feed pressure were not meant to realize acceptable economic performance. Even though Simulations 3 and 4 at the test membrane thickness and the much higher IGCC shift gas operating feed pressure of 1,015 psia reduce membrane area by about $95 \%$ respectively, they are also

unacceptably high. It is noted that marginally higher Mixed Gas test GPU's in each case simulated additional membrane area reductions of about $30 \%$ compared to the single gas data.

The main challenge in designing and fabricating an economic PBI hollow fiber membrane will be the attainment of a substantial reduction in membrane separation layer thickness. Less than $1.0 \mu \mathrm{m}$ separation layer will be necessary if a commercial PBI membrane is to have an acceptable economic membrane area in a $600 \mathrm{MW}$ IGCC power plant. The LANL empirical data has established quite good single and mixed gas PBI permeability and selectivity parameters. The task now is a typical membrane fabrication problem: produce a sufficiently thin, defect free and durable membrane separation layer that enables economic productivity based upon the measured mixed gas permeability and selectivity parameters.

Notwithstanding potential deviations, if any, from the empirical data caused by changes in polymer morphology or an effect on permeability and selectivity in a thinner membrane separation layer operating at higher pressure, it is still helpful to simulate projected membrane area reductions based on LANL empirical permeability data assuming a projected $0.5 \mu \mathrm{m}$ thick separation layer. A $0.5 \mu \mathrm{m}$ thickness is a realistic approach to the commercial gas separation membrane's $0.1 \mu \mathrm{m}$ thickness. Given PBI's high glass transition temperature of $400-450^{\circ} \mathrm{C}$, assuming the same permeability and selectivity performance in a thinner separation layer operating at higher pressure with 5 times the thickness of a commercial membrane is reasonable. Projected GPUs based on the LANL's empirical PBI mixed gas permeability and selectivity data assuming a membrane separation layer thickness of $0.00005 \mathrm{~cm}$ are presented in Table 3 below.

Table 3 - LANL Empirical Data Projected

Separation Layer $0.00005 \quad \mathrm{~cm}$

Single Gas GPU Mixed Gas GPU

\begin{tabular}{ccccccc} 
& $10^{-6} \mathrm{~cm}^{3} / \mathrm{s} / \mathrm{cm}^{2} / \mathrm{cm} \mathrm{Hg}$ & $\mathrm{H}_{2} \alpha$ & Barrer & $10^{-6} \mathrm{~cm}^{3} / \mathrm{s} / \mathrm{cm}^{2} / \mathrm{cm} \mathrm{Hg}$ & $\mathrm{H}_{2} \alpha$ & Barrer \\
\cline { 2 - 7 } $\mathrm{H}_{2}$ & 124.80 & 1.00 & $6.24 \mathrm{E}-09$ & 175.20 & 1.00 & $8.76 \mathrm{E}-09$ \\
$\mathrm{CO}_{2}$ & 2.88 & 43.33 & $1.44 \mathrm{E}-10$ & 4.08 & 42.94 & $2.04 \mathrm{E}-10$ \\
$\mathrm{CO}$ & 6.00 & 20.80 & $3.00 \mathrm{E}-10$ & 1.44 & 121.67 & $7.20 \mathrm{E}-11$ \\
$\mathrm{~N}_{2}$ & 0.48 & 260.00 & $2.40 \mathrm{E}-11$ & 0.48 & 365.00 & $2.40 \mathrm{E}-11$ \\
$\mathrm{CH}_{4}$ & 0.24 & 520.00 & $1.20 \mathrm{E}-11$ & 0.72 & 243.33 & $3.60 \mathrm{E}-11$ \\
$\mathrm{H}_{2} \mathrm{~S}$ & 0.10 & 1300.00 & $4.80 \mathrm{E}-12$ & 0.10 & 1825.00 & $4.80 \mathrm{E}-12$
\end{tabular}


Simulations 5 and 6 based on the LANL empirical single gas and mixed gas permeability data, calculated GPU projections assuming a separation layer of $0.5 \mu \mathrm{m}$ and the expected pressure in an IGCC shift gas are presented in the Appendix and summarized in Table 4 below.

Table 4 - Simulations at LANL Test Data, $0.5 \mu \mathrm{m}$ Separation Layer, IGCC Shift Gas Pressure and $98 \% \mathrm{H}_{2}$ Recovery

\begin{tabular}{|c|c|c|c|c|c|c|c|c|c|}
\hline $\begin{array}{c}\text { Sim. } \\
\#\end{array}$ & $\begin{array}{c}\text { Data } \\
\text { Source }\end{array}$ & $\begin{array}{c}\text { Feed } \\
\mathrm{P}, \mathrm{cm} \mathrm{Hg}\end{array}$ & $\begin{array}{c}\text { Permeate } \\
\mathrm{P}, \mathrm{cm} \mathrm{Hg}\end{array}$ & $\begin{array}{c}\text { Membrane } \\
\text { Layer, } \mu \mathrm{m}\end{array}$ & $\begin{array}{c}\mathrm{N}_{2} \\
\text { Sweep } \\
\%\end{array}$ & $\begin{array}{c}\text { Permeate } \\
{\mathrm{Btu} / \mathrm{Ft}^{3}}^{3}\end{array}$ & $\begin{array}{c}\mathrm{CO}_{2} \\
\text { Rec. } \\
\%\end{array}$ & $\begin{array}{c}600 \mathrm{MW} \\
\text { Mbr. Area } \\
\mathrm{m}^{2}\end{array}$ & $\begin{array}{c}4 " \times 5^{\prime} \\
\text { elements } \\
\#\end{array}$ \\
\hline 5 & LANL Single Gas & 1,015 & 250 & 0.5 & 64.0 & 115.2 & 90.5 & 61,016 & 995 \\
6 & LANL Mixed Gas & 1,015 & 250 & 0.5 & 64.0 & 115.2 & 90.5 & 43,471 & 709 \\
\hline
\end{tabular}

In comparing Tables 2 and 4, the only difference between simulations 4 and 6 is the separation layer thickness: $12 \mu \mathrm{m}$ compared to $0.5 \mu \mathrm{m}$, respectively. Since membrane area and element count vary directly with separation layer thickness $(0.5 / 12=1 / 24)$ the element count in simulation 6 would be expected to be 1/24th of the membrane area and element count in simulation 4 , as it is, i.e., $1 / 24 \times 1,042,709 \approx 43,471$ and $1 / 24 \times 16,999$ $\approx 709$, respectively.

Earlier Pall simulated a PBI membrane performance projection calculating GPUs assuming $0.5 \mu \mathrm{m}$ separation layer thickness and based upon the same LANL permeability data presented in Table 1. The results were given in the "Plot to Enerfex from LANL" which was included in Simulation Memorandum II and is presented again below.

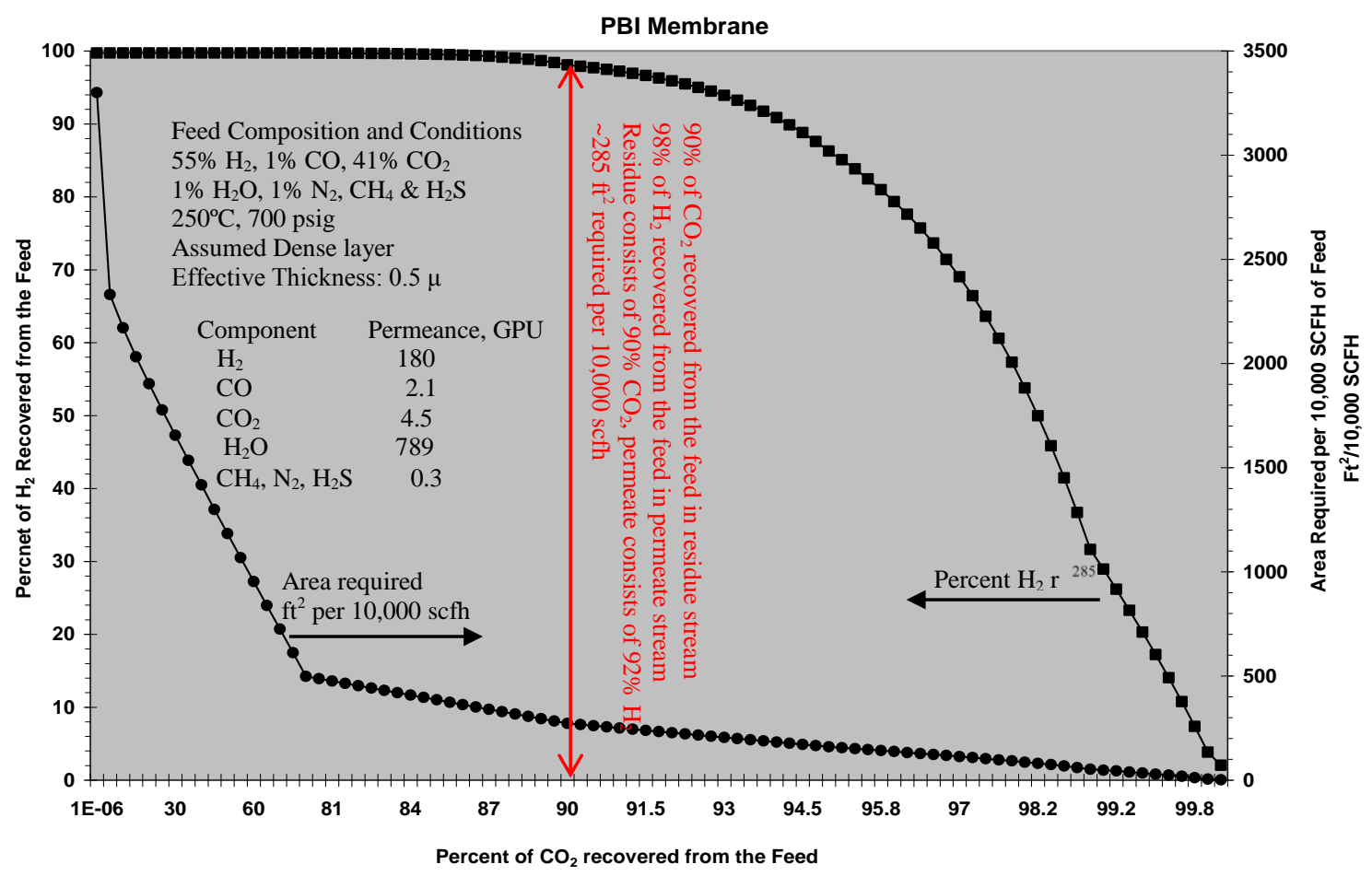

D - 24 
As expected the Pall GPU values are approximately the same as the mixed gas GPU values presented in Table 3 above. Simulation 7, based on the Pall GPU values calculated with a separation layer of $0.5 \mu \mathrm{m}$ and the expected pressure in an IGCC shift gas, is presented in the Appendix and summarized in Table 5 below.

Table 5 - Simulation of Pall GPUs, $0.5 \mu \mathrm{m}$ Separation Layer, IGCC Shift Gas Pressure and $98 \% \mathrm{H}_{2}$ Recovery

\begin{tabular}{|c|c|c|c|c|c|c|c|c|c|}
\hline $\begin{array}{c}\text { Sim. } \\
\#\end{array}$ & $\begin{array}{c}\text { Data } \\
\text { Source }\end{array}$ & $\begin{array}{c}\text { Feed } \\
\mathrm{P}, \mathrm{cm} \mathrm{Hg}\end{array}$ & $\begin{array}{c}\text { Permeate } \\
\mathrm{P}, \mathrm{cm} \mathrm{Hg}\end{array}$ & $\begin{array}{c}\text { Membrane } \\
\text { Layer, } \mu \mathrm{m}\end{array}$ & $\begin{array}{c}\mathrm{N}_{2} \\
\text { Sweep } \\
\%\end{array}$ & $\begin{array}{c}\text { Permeate } \\
\text { Btu/ } / \mathrm{Ft}^{3}\end{array}$ & $\begin{array}{c}\text { CO2 } \\
\text { Rec. } \\
\%\end{array}$ & $\begin{array}{c}600 \mathrm{MW} \\
\text { Mbr. Area } \\
\mathrm{m}^{2}\end{array}$ & $\begin{array}{c}4{ }^{\prime \prime} \times 5^{\prime} \\
\text { elements } \\
\#\end{array}$ \\
\hline 7 & PALL GPU $^{3}$ & 1,015 & 250 & 0.5 & 63.8 & 115.3 & 89.8 & 42,299 & 690 \\
\hline
\end{tabular}

LANL has established baseline single and mixed gas permeability values for the identified shift gas mixture constituents. They have measured GPUs at a $12 \mu \mathrm{m}$ separation layer thickness and 2600 torr feed pressure. Pall and Enerfex have calculated GPUs for a projected $0.5 \mu \mathrm{m}$ separation layer membrane and simulated at IGCC shift gas pressure approximately the same PBI membrane performance, i.e., $235 \mathrm{ft}^{2}$ of membrane area per 10,000 scfh of feed and $242 \mathrm{ft}^{2}$ area of membrane area per 10,000 scfh of feed, respectively, at $98 \% \mathrm{H}_{2}$ recovery and $90 \% \mathrm{CO}_{2}$ recovery. Both results also approximate the order of magnitude performance presented as simulation 9 in Simulation Memorandum IV which was misnamed "Performance".

A $0.5 \mu \mathrm{m}$ separation layer in a membrane having the LANL demonstrated mixed gas permeability is projected to require the equivalent of about $\pm 700,4$ inch diameter by 5 feet long hollow fiber membrane elements for a $600 \mathrm{MW}$ plant. A separator module design could be an arrangement of 9 elements connected on the hollow fiber bore side to common feed and residue headers within a single separator module pressure vessel. The separator module vessel would be sized appropriately to handle the required nitrogen permeate sweep gas volume flow on the shell side of the hollow fiber. Hence a total of \pm 80 separator modules containing 9 elements each might be required for $600 \mathrm{MW}$ plant.

\footnotetext{
${ }^{3}$ Pall GPU calculated based on LANL empirical permeability and assumed $0.5 \mu \mathrm{m}$ thick separation layer.
} 


\section{D-6. EFFECT OF GASIFIER PRESSURE AND CONSEQUENTLY MEMBRANE FEED PRESSURE ON MEMBRANE PERFORMANCE}

The gasifier outlet pressure in Scenario \# 4b of the ASPEN model is given on page 32, Figure 13, of the April to June 2008 Progress Report at about 800 psia. In the same figure, the water Gas Shift Reactor (WGSR) outlet pressure, which provides the membrane feed pressure, is given at about 750 psia. The membrane feed pressure basis in prior memoranda ranged from 715 psia to 1,015 psia. Table 1 below illustrates the performance differences between 750 psia and 1,015 psia feed pressure in prior dry basis feed simulations. As the feed pressure increases, membrane area decreases in approximate proportion and $\mathrm{CO}_{2}$ recovery increases marginally. Reducing feed pressure from 1,015 psia to 750 psia increases membrane area by $63 \%$ and reduces $\mathrm{CO}_{2}$ recovery from $90.5 \%$ to $88.6 \%$.

Table 1 - Membrane Performance Based on LANL Test Data, $0.5 \mu \mathrm{m}$ Separation Layer and $98 \% \mathrm{H}_{2}$ Recovery at 750 psia and 1,015 psia Feed Pressure.

\begin{tabular}{|c|c|c|c|c|c|c|c|}
\hline \multirow{3}{*}{$\begin{array}{l}\text { Feed } \\
\text { P psia }\end{array}$} & \multirow[b]{2}{*}{ Permeate } & \multirow[b]{2}{*}{ Membrane } & \multirow[b]{2}{*}{$\mathrm{N}_{2}$} & \multirow[b]{2}{*}{ Permeate } & \multicolumn{3}{|c|}{$600 \mathrm{MW}$} \\
\hline & & & & & $\begin{array}{l}\mathrm{CO}_{2} \\
\mathrm{Rec} .\end{array}$ & $\begin{array}{l}\text { Mbr. } \\
\text { Area }\end{array}$ & $\begin{array}{c}4 " \times 5 ' \\
\text { elements }\end{array}$ \\
\hline & $\mathrm{P}$, psia & Layer, $\mu \mathrm{m}$ & $\%$ & $\mathrm{Btu} / \mathrm{Ft}^{3}$ & $\%$ & $\mathrm{~m}^{2}$ & \# \\
\hline 01 & 250 & 0.5 & 64.0 & 115.2 & 90.5 & 43,471 & 709 \\
\hline 750 & 250 & 0.5 & 61.5 & 115.5 & 88.6 & 70,906 & 1,156 \\
\hline
\end{tabular}

In NETL's “Cost and Performance Baseline for Fossil Energy Plants: Bituminous Coal and Natural Gas to Electricity Final Report" IGCC case, a GE gasifier at 815 psia is integrated with a GE F class turbine. In an article by Texaco, GE and Praxiar titled "A Less Expensive Route to IGCC Power Generation" several examples of an advanced H system turbine integrated with a GE gasifier operating as high as 1,230 psia are described. Increasing membrane feed pressure would substantially reduce membrane capital cost.

Effect of Methane Percentage in the Shift Gas on Membrane Energy Balance - The heating value in the membrane feed is split between the permeate fuel gas and the raffinate capture gas according to the selectivity of the respective gases over $\mathrm{CO}_{2}$. Methane and carbon monoxide have heating values of $1,012 \mathrm{Btu} / \mathrm{scf}$ and $320 \mathrm{Btu} / \mathrm{scf}$ respectively and each has a negative selectivity over $\mathrm{CO}_{2}$, i.e., $\mathrm{CO}_{2}$ is marginally selective over $\mathrm{CH}_{4}$ and $\mathrm{CO}$. Accordingly both gases have $97.8 \%$ and $95.7 \%$ recovery rates respectively in the raffinate capture gas, substantially higher than the $88.6 \% \mathrm{CO}_{2}$ recovery rate.

Table 2 below presents a material and energy balance for 3\% methane in the feed based on the feed composition provided in the "Plot To Enerfex From LANL". In this case $82.82 \%$ of the feed heating value is recovered in the permeate fuel and $17.18 \%$ is in the raffinate capture gas. Of the $1,173,055 \mathrm{Btu} / \mathrm{hr}$ in the raffinate capture gas $81.7 \%$ is due to methane, $9.9 \%$ to hydrogen and $8.4 \%$ to carbon monoxide. Table 3 shows the MW balance for the $3 \%$ methane case. 
Table 2 - Material and Energy Balance for 3\% Methane in Membrane Feed MIXED GAS DATA AND DRY BASIS FEED FROM "PLOT TO ENERFEX FROM LANL"

\begin{tabular}{|c|c|c|c|c|c|c|c|c|c|}
\hline \multirow[b]{2}{*}{$\mathrm{cm}$} & \multirow[b]{2}{*}{ press. } & \multirow{2}{*}{$\begin{array}{l}750 \\
\mathrm{CO}_{2}\end{array}$} & \multicolumn{2}{|c|}{ FEED PSIA } & \multirow{2}{*}{$\begin{array}{l}250 \\
\mathrm{~N}_{2}\end{array}$} & \multicolumn{2}{|c|}{ PERMEATE PSIA } & \multirow[b]{2}{*}{ Flux STP } & \multirow[b]{2}{*}{$\begin{array}{r}\mathrm{H}_{2} \\
\mathrm{Rec}\end{array}$} \\
\hline & & & $\mathrm{CO}$ & $\mathrm{CH}_{4}$ & & $\mathrm{H}_{2}$ & $\begin{array}{c}\mathrm{N}_{2} \\
\text { sweep }\end{array}$ & & \\
\hline 0.00005 & $\mathrm{~cm} \mathrm{Hg}$ & fract & fract & fract & fract & fract & froct & $\mathrm{cm}^{3} / \mathrm{s}-\mathrm{cm}^{2}$ & fract \\
\hline Feed $=F 1$ & 3878 & 0.4000 & 0.0100 & 0.0300 & 0.0100 & 0.5500 & & 0.2149 & 1.0000 \\
\hline Raffinate $=\mathrm{R} 1$ & 3878 & 0.8555 & 0.0231 & 0.0708 & 0.0238 & 0.0269 & & 0.0890 & 0.0203 \\
\hline Permeate=P1 & 1293 & 0.0299 & 0.0003 & 0.0004 & 0.0001 & 0.3540 & 0.6150 & 0.3271 & 0.9797 \\
\hline
\end{tabular}

\begin{tabular}{|c|c|c|c|c|c|c|c|c|c|c|}
\hline & Btu/cf & $\mathrm{CO}_{2}$ & $\mathrm{CO}$ & $\mathrm{CH}_{4}$ & $\mathrm{~N}_{2}$ & $\mathrm{H}_{2}$ & $\mathrm{~N}_{2}$ sweep & scfh & Btu/hr & $\%$ \\
\hline P1 scfh & 115.21 & 1,467 & 14 & 21 & 5 & 17,379 & 30,194 & $49,095.8$ & $5,656,550$ & $82.82 \%$ \\
\hline R1 scfh & 87.77 & 11,434 & 309 & 946 & 318 & 359 & & $13,365.3$ & $1,173,055$ & $17.18 \%$ \\
\hline F1 scfh & 211.76 & 12,901 & 323 & 968 & 323 & 17,738 & & $32,251.6$ & $6,829,605$ & $100.00 \%$ \\
\hline
\end{tabular}

Table 3 - MW Balance for Membrane Feed Based on "Plot To Enerfex From LANL

\begin{tabular}{lcrrr}
\multicolumn{1}{c}{ MW Balance } & Btu/hr & $\%$ & MW $_{\mathrm{g}}$ & MW $_{\mathbf{e}}$ \\
\hline permeate fuel gas & $5,656,550$ & $82.82 \%$ & $\mathbf{1 . 6 6}$ & $\mathbf{0 . 9 9}$ \\
Raffinate capture gas & $1,173,055$ & $17.18 \%$ & $\mathbf{0 . 3 4}$ & $\mathbf{0 . 2 1}$ \\
Feed F1 & $6,829,605$ & $100.00 \%$ & $\mathbf{2 . 0 0}$ & $\mathbf{1 . 2 0}$
\end{tabular}

Table 4 below presents a material and energy balance at a substantially lower methane feed percentage which, for comparison purposes, is based on a dry basis feed composition of the Scenario \#4b. In this case $95.64 \%$ of the feed heating value is recovered in the permeate fuel and $4.36 \%$ is in the raffinate capture gas. Of the 267,051 $\mathrm{Btu} / \mathrm{hr}$ in the raffinate capture gas $13.1 \%$ is due to methane, $43.8 \%$ to hydrogen and $43.1 \%$ to carbon monoxide. Table 5 shows the MW balance for the low methane percentage case.

Table 4 - Methane Percentage in Feed Based on Dry Basis ASPEN Scenario \#4b MIXED GAS DATA AND DRY BASIS FEED FROM SCENARIO \#4b

\begin{tabular}{|c|c|c|c|c|c|c|c|c|c|}
\hline \multirow[b]{2}{*}{$\begin{array}{r}\mathrm{cm} \\
005\end{array}$} & \multirow[b]{2}{*}{$\begin{array}{l}\text { press. } \\
\mathrm{cm} \mathrm{Hg}\end{array}$} & \multirow{2}{*}{$\begin{array}{l}750 \\
\mathrm{CO}_{2} \\
\text { fract }\end{array}$} & \multicolumn{2}{|c|}{ FEED PSIA } & \multirow{2}{*}{$\begin{array}{l}250 \\
\mathrm{~N}_{2} \\
\text { fract }\end{array}$} & \multicolumn{2}{|c|}{ PERMEATE PSIA } & \multirow[b]{2}{*}{$\begin{array}{l}\text { Flux STP } \\
\mathrm{cm}^{3} / \mathrm{s}-\mathrm{cm}^{2}\end{array}$} & \multirow[b]{2}{*}{$\begin{array}{c}\mathrm{H}_{2} \\
\mathrm{Rec} \\
\text { fract }\end{array}$} \\
\hline & & & $\begin{array}{l}\mathrm{CO} \\
\text { fract }\end{array}$ & $\begin{array}{l}\mathrm{CH}_{4} \\
\text { fract }\end{array}$ & & $\begin{array}{c}\mathrm{H}_{2} \\
\text { fract }\end{array}$ & $\begin{array}{r}\mathrm{N} \\
\text { swe }\end{array}$ & & \\
\hline eed $=F 1$ & 3878 & 0.4012 & 0.0117 & 0.0011 & 0.0137 & 0.572 & & 0.2204 & 1.0000 \\
\hline Raffinate=R1 & 3878 & 0.9066 & 0.0286 & 0.0027 & 0.0345 & 0.0287 & & 0.0863 & 0.0196 \\
\hline ermeate=P1 & 1293 & 0.0293 & 0.0003 & 0.0000 & 0.0001 & 0.3553 & 0.6150 & 0.3481 & 0.9804 \\
\hline
\end{tabular}

\begin{tabular}{|c|c|c|c|c|c|c|c|c|c|c|}
\hline & Btu/cf & $\mathrm{CO}_{2}$ & $\mathrm{CO}$ & $\mathrm{CH}_{4}$ & $\mathrm{~N}_{2}$ & $\mathrm{H}_{2}$ & $\mathrm{~N}_{2}$ sweep & scfh & Btu/hr & $\%$ \\
\hline P1 scfh & 115.23 & 1,487 & 16 & 1 & 7 & 18,042 & 31,230 & $50,780.6$ & $5,851,496$ & $95.64 \%$ \\
\hline R1 scfh & 21.21 & 11,414 & 360 & 35 & 434 & 361 & & $12,590.1$ & 267,051 & $4.36 \%$ \\
\hline F1 scfh & 190.28 & 12,901 & 376 & 35 & 441 & 18,402 & & $32,155.1$ & $6,118,547$ & $100.00 \%$ \\
\hline
\end{tabular}

Table 5 - MW Balance for Feed Based on Dry Basis ASPEN Scenario \# 4b

\begin{tabular}{lcrrr}
\multicolumn{1}{c}{ MW Balance } & Btu/cf & \multicolumn{1}{c}{$\%$} & MW $_{\mathbf{g}}$ & $\mathbf{M W}_{\mathbf{e}}$ \\
permeate fuel gas & 115.23 & $95.64 \%$ & $\mathbf{1 . 7 1}$ & $\mathbf{1 . 0 3}$ \\
Raffinate capture gas & 21.21 & $4.36 \%$ & $\mathbf{0 . 0 8}$ & $\mathbf{0 . 0 5}$ \\
Feed F1 & 190.28 & $100.00 \%$ & $\mathbf{1 . 7 9}$ & $\mathbf{1 . 0 8}$
\end{tabular}

D - 27 
A content $3 \%$ methane in the membrane feed gas resulting in a high recovery rate of methane in the raffinate capture gas lowers net energy recovery in the permeate fuel gas. Lowering the level of methane in the feed gas to about a $0.1 \%$, as in Scenario \#4b, increases energy recovery in the permeate fuel gas by about $18.5 \%$. The methane content in Scenario \#4b appears to be more representative of what would be expected from a GE gasifier.

Effect of Water and Hydrogen Sulfide on Membrane Performance - Tables 6 and 7 below present a one MW simulation mass and energy balance based on the Scenario \# 4b feed composition, which includes $\mathrm{H}_{2} \mathrm{~S}$ and $\mathrm{H}_{2} \mathrm{O} . \mathrm{H}_{2} \mathrm{~S}$ permeability is taken from the LANL mixed gas data presented in Memorandum V. The permeability $\mathrm{H}_{2} \mathrm{O}$ is considered to be higher than $\mathrm{H}_{2}$ based on the relative $\mathrm{H}_{2} \mathrm{O}$ and $\mathrm{H}_{2}$ permeability in found in polyimide and is assumed to be $10 \%$ more than the LANL $\mathrm{H}_{2}$ mixed gas permeability presented in Memorandum V. The presence of water in the permeate lowers the permeate $\mathrm{N}_{2}$ sweep fraction to $41 \%$ needed to yield the $115 \mathrm{Btu}$./cf fuel heating value design basis. This is opportune since it has been determined that the nitrogen sweep available is limited to the ASU which is sized to provide a required amount of $\mathrm{O}_{2}$ to the gasifier and Claus units. The energy balance in Table 7 again is typical of the lower $\mathrm{CH}_{4}$ feed percentage.

\section{Table 6 - Methane Percentage in Feed Based on ASPEN Scenario \#4b MIXED GAS DATA AND FEED FROM SCENARIO \#4b \\ 750 FEED PSIA}

\begin{tabular}{|c|c|c|c|c|c|c|c|c|c|c|c|}
\hline \multicolumn{12}{|l|}{ PBI } \\
\hline $\mathrm{cm}$ & press. & $\mathrm{CO}_{2}$ & $\mathrm{CO}$ & $\mathrm{CH}_{4}$ & $\mathrm{~N}_{2}$ & $\mathrm{H}_{2}$ & $\mathrm{H}_{2} \mathrm{~S}$ & $\mathrm{H}_{2} \mathrm{O}$ & $\mathrm{N}_{2}$ & Flux STP & H2 Rec \\
\hline 0.00005 & $\mathrm{~cm} \mathrm{Hg}$ & fract & fract & fract & fract & fract & fract & fract & fract & $\mathrm{cm}^{3} / \mathrm{s}-\mathrm{cm}^{2}$ & fract \\
\hline Feed $=F 1$ & 3,878 & 0.3054 & 0.0089 & 0.0008 & 0.0104 & 0.4355 & 0.0047 & 0.2343 & & 0.1817 & 1.0000 \\
\hline Raffinate $=\mathrm{R} 1$ & 3,878 & 0.8805 & 0.0288 & 0.0027 & 0.0351 & 0.0295 & 0.0162 & 0.0073 & & 0.0526 & 0.0196 \\
\hline \multirow[t]{2}{*}{ Permeate $=P 1$} & 1293 & 0.0419 & 0.0005 & 0.0000 & 0.0002 & 0.3549 & 0.0000 & 0.1930 & 0.4100 & 0.2185 & 0.9804 \\
\hline & Btu/cf & $\mathrm{CO}_{2}$ & $\mathrm{CO}$ & $\mathrm{CH}_{4}$ & $\mathrm{~N}_{2}$ & $\mathrm{H}_{2}$ & $\mathrm{H}_{2} \mathrm{~S}$ & $\mathrm{H}_{2} \mathrm{O}$ & $\mathrm{N}_{2}$ & & $\mathrm{H}_{2}$ rec. \\
\hline P1 scfh & 115.17 & 2,130 & 24 & 1 & 10 & 18,035 & 0.4226 & 9,808 & 20,83 & $50,814.8$ & $98.0 \%$ \\
\hline R1 scfh & 21.45 & 10,770 & 352 & 33 & 429 & 360 & 198 & 89 & & $12,231.3$ & $\mathrm{CO}_{2}$ rec. \\
\hline F1 scfh & 144.76 & 12,900 & 376 & 34 & 439 & 18,395 & 199 & 9,897 & & $42,239.7$ & $83.5 \%$ \\
\hline
\end{tabular}

Table 7 - Energy Balance for Feed Based on ASPEN Scenario \# 4b

\begin{tabular}{lccrrrr}
\multicolumn{1}{c}{ MW Balance } & Btu/cf & scfh & \multicolumn{1}{c}{ Btu/hr } & \multicolumn{1}{c}{$\%$} & $\mathbf{M W}_{\mathbf{g}}$ & $\mathbf{M W}_{\mathbf{e}}$ \\
permeate fuel & 115.17 & $50,814.8$ & $\mathbf{5 , 8 5 2 , 2 5 0}$ & $\mathbf{9 5 . 7 1 \%}$ & $\mathbf{1 . 7 2}$ & $\mathbf{1 . 0 3}$ \\
Raffinate gas capture & 21.45 & $12,231.3$ & $\mathbf{2 6 2 , 3 5 0}$ & $\mathbf{4 . 2 9 \%}$ & $\mathbf{0 . 0 8}$ & $\mathbf{0 . 0 5}$ \\
Feed F1 & 144.76 & $42,239.7$ & $\mathbf{6 , 1 1 4 , 6 0 0}$ & $\mathbf{1 0 0 . 0 0 \%}$ & $\mathbf{1 . 7 9}$ & $\mathbf{1 . 0 8}$
\end{tabular}


Effect of Higher Feed pressure with Scenario \#4b Feed Composition - Table 8 below shows that increasing feed pressure from 750 psia to 1,015 psia substantially reduces membrane area and marginally increases $\mathrm{CO}_{2}$ recovery. However, at both feed pressures the membrane area is larger than earlier dry basis simulations at the same feed pressure shown in Table 1 above. The reason for this is the lower $\mathrm{CO}_{2}$ feed concentration in the Scenario \#4b feed and the consequently higher enrichment ratio to the $\mathrm{CO}_{2}$ concentration in the rafinate. The $\mathrm{CO}_{2}$ enrichment ratio in the dry basis case is about 2/3 that of the ratio in the Scenario \#4b case. Membrane area generally varies directly with enrichment ratio. In addition with the Scenario \#4b feed, the membrane is now also a $\mathrm{H}_{2} \mathrm{O} / \mathrm{CO}_{2}$ membrane recovering $99 \%$ of the feed $\mathrm{H}_{2} \mathrm{O}$ at a mass flow equal to half the mass flow of the $\mathrm{H}_{2}$.

Table 8 - Membrane Performance Based Scenario \#4b, $0.5 \mu \mathrm{m}$ Separation Layer and 98\% $\mathrm{H}_{2}$ Recovery at 750 psia and 1,015 psia Feed Pressure.

\begin{tabular}{|c|c|c|c|c|c|c|c|}
\hline $\begin{array}{l}\text { Feed } \\
\text { P. psia }\end{array}$ & $\begin{array}{l}\text { Permeate } \\
\text { P. psia }\end{array}$ & $\begin{array}{l}\text { Membrane } \\
\text { Layer, } \mu \mathrm{m}\end{array}$ & $\begin{array}{c}\mathrm{N}_{2} \text { Sweep } \\
\%\end{array}$ & $\begin{array}{l}\text { Permeate } \\
{\mathrm{Btu} / \mathrm{Ft}^{3}}^{3}\end{array}$ & $\begin{array}{c}\mathrm{CO}_{2} \mathrm{Rec} . \\
\%\end{array}$ & $\begin{array}{c}600 \mathrm{MW} \\
\text { Mbr. Area } \\
\mathrm{m}^{2}\end{array}$ & $\begin{array}{c}4 " \times 5 \text { ' elements } \\
\#\end{array}$ \\
\hline 1,015 & 250 & 0.5 & 41.5 & 115.42 & 86.8 & 64,120 & 1,045 \\
\hline 750 & 250 & 0.5 & 41.0 & 115.17 & 83.5 & 109,760 & 1,789 \\
\hline
\end{tabular}




\section{D-7. MEMBRANE UNIT SIZE REDUCTION WITH AN PBI HOLLOW FIBER MEMBRANE VS. A PALL PBI COATED S/S TUBE}

The initial PBI membrane tested was a $12 \mu$ thick dense PBI separation layer coated on a Pall Corporation sintered S/S 0.25 inch diameter tube. Normalized permeability values in Barrer units were calculated from the empirical Pall Tube membrane data and then used to simulate projected performance of an asymmetric hollow fiber PBI membrane having a $0.5 \mu$ thick dense PBI separation layer. An asymmetric PBI hollow fiber is made totally from PBI polymer and comprises a micro-porous supporting hollow fiber having a thin dense separating layer formed in situ on either the inside bore or the outside shell of the porous hollow fiber wall. A typical hollow fiber membrane will have an outside diameter of $500 \mu$, a dense separating layer thickness of $0.1 \mu$ to $0.5 \mu$ and a supporting microporous substrate wall thickness of about $100 \mu$. Sample PBI hollow fibers produced have these same dimensions. Compared to the Pall Tube support system, the asymmetric hollow fiber configuration can achieve a substantially thinner $0.1 \mu$ to $0.5 \mu$ separation layer and a much higher area per volume. The area and volume reductions possible with a hollow fiber membrane recommend it as the membrane design of choice. A size comparison of a hollow fiber and a tubular design is presented in Table 1 below. In both cases $\mathrm{CO}_{2}$ capture is $90 \%$ with a feed temperature of $250^{\circ} \mathrm{C}$, a feed pressure of 750 psia and a permeate pressure of 250 psia.

Table 1 - Pall Tube vs. a Hollow Fiber

Basis: Membrane area and volume per $600 \mathrm{MW}$ power plant

$\begin{array}{ccc} & 0.25 " \text { O.D. } 12 \mu \text { layer s/s tube } & 500 \mu \text { O.D. } 0.5 \mu \text { layer Hollow Fiber } \\ \text { Membrane Area, } \mathrm{m}^{2} & 1,759,317 & 73,232 \\ \text { Membrane Volume, } \mathrm{m}^{3} & 1,675,750 & 5,492 \\ \text { Membrane Bundle Volume, } \mathrm{m}^{3 *} & 2,234,333 & 7,323\end{array}$

* $75 \%$ membrane volumetric packing density

For the same size $\mathrm{CO} 2$ capture plant, the Pall tube design requires 24 times more membrane area and 305 times more membrane volume. Note the substantially better area to volume ratio with a hollow fiber.

Increase $\mathrm{H}_{2}$ and $\mathrm{CO}_{2}$ Recovery with Higher $\mathrm{H}_{2}$ Selectivity by Lowering Membrane Feed Temperature -LANL PBI $\mathrm{H}_{2} / \mathrm{CO}_{2}$ selectivity and. $\mathrm{H}_{2}$ permeability at $400^{\circ} \mathrm{C}$ and $250^{\circ} \mathrm{C}$ shows that selectivity increases and permeability decreases as the feed temperature is lowered. All membrane simulations so far have been based on the $250^{\circ} \mathrm{C}$ data. In an effort to simulate increased $\mathrm{H}_{2}$ and $\mathrm{CO}_{2}$ recovery with higher selectivity, the data in Figure 1 was extrapolated to $215^{\circ} \mathrm{C}$ and $170^{\circ} \mathrm{C}$ to estimate the selectivity and permeability values shown in Table 2 below.

Table 2 - LANL PBI data extrapolated to $170^{\circ} \mathrm{C}$ and $215^{\circ} \mathrm{C}$

\begin{tabular}{ccccc} 
Feed $\mathrm{H}_{2} \mathrm{O} \%$ & Sat. $\mathrm{H}_{2} \mathrm{O}, \%$ & $\mathrm{~T},{ }^{\circ} \mathrm{C}$ & $\alpha_{\mathrm{H} 2 / \mathrm{CO} 2}$ & $\mathrm{H}_{2}$ perm., Barrer \\
\hline 23 & 75 & 250 & 43 & 88 \\
23 & 41 & $215^{\star}$ & 60 & 50 \\
16 & 16 & $170^{*}$ & 90 & 20 \\
*Extrapolated & & & &
\end{tabular}

$$
\text { D - } 30
$$


The estimated selectivity and permeability values extrapolated in the plot in Figure 1 were simulated to yield $98 \% \mathrm{H}_{2}$ recovery in all cases at 250 psia and 450 psia permeate pressure. For comparison the $250^{\circ} \mathrm{C}$ selectivity and permeability data was also simulated to yield $98 \% \mathrm{H}_{2}$ recovery. The results are summarized in Table 3 below.

\begin{tabular}{|c|c|c|c|c|c|}
\hline $\begin{array}{c}\text { Feed Temp., } \\
{ }^{\circ} \mathrm{C}\end{array}$ & $\begin{array}{c}\text { Permeate, } \\
\text { psia }\end{array}$ & $\begin{array}{c}\mathrm{H}_{2} / \mathrm{CO}_{2} \\
\text { selectivity }\end{array}$ & $\begin{array}{l}\mathrm{CO}_{2} \\
\text { recovery }\end{array}$ & $\mathrm{CO}_{2}$ purity & membrane, $\mathrm{m}^{2}$ \\
\hline 250 & 250 & 43 & $83.8 \%$ & $88.1 \%$ & 107,446 \\
\hline 250 & 450 & 43 & $63.0 \%$ & $84.4 \%$ & 271,904 \\
\hline $215^{\star}$ & 250 & 60 & $88.0 \%$ & $88.5 \%$ & 193,091 \\
\hline $170^{*}$ & 250 & 90 & $91.8 \%$ & $89.1 \%$ & 478,543 \\
\hline $215^{\star}$ & 450 & 60 & $68.5 \%$ & $85.5 \%$ & 555,138 \\
\hline $170^{*}$ & 450 & 90 & $72.0 \%$ & $86.5 \%$ & $1,785,293$ \\
\hline
\end{tabular}

* Extrapolated data

The best performance was at $170^{\circ} \mathrm{C}$ and 250 psia permeate pressure where $\mathrm{CO}_{2}$ recovery exceeded the NETL goal of $90 \%$ while recovering $98 \%$ of the $\mathrm{H}_{2}$. The extrapolated values are preliminary and should be considered only as a fair accuracy of how selectivity would increase as feed temperature is decreased. The PBI hollow fiber will have to be tested at lower temperatures to measure the exact increase in selectivity.

Two Simulations were done to illustrate reduced membrane area using the extrapolated permeability and selectivity at $170^{\circ} \mathrm{C}, 250$ psia permeate pressure and a membrane separation layer thickness of $0.1 \mu$. Set parameters were $98 \% \mathrm{H}_{2}$ recovery in one simulation and $90 \% \mathrm{CO}_{2}$ in the other. The results are presented in Table 4 below.

Table 4 - $0.1 \mu$ Hollow Fiber Membrane performance at $98 \% \mathrm{H}_{2}$ and $90 \% \mathrm{CO}_{2}$ Recovery at $170^{\circ} \mathrm{C}$ and 250 psia Permeate Pressure with $42 \% \mathrm{~N}_{2}$ Permeate Sweep

\begin{tabular}{cccccc}
$\mathrm{H}_{2} / \mathrm{CO}_{2}$ selectivity & $\mathrm{H}_{2}$ recovery & $\mathrm{H}_{2}$ purity & $\mathrm{CO}_{2}$ recovery & $\mathrm{CO}_{2}$ purity & membrane, $\mathrm{m}^{2}$ \\
\hline 90 & $98.0 \%$ & $47.8 \%$ & $91.8 \%$ & $89.0 \%$ & 95,340 \\
90 & $100.0 \%$ & $41.0 \%$ & $90.4 \%$ & $92.4 \%$ & 110,040
\end{tabular}

The standard separation layer in commercial hollow fiber glassy polymer membranes is $0.1 \mu$ and therefore an assumption of achieving a $0.1 \mu$ in a PBI hollow fiber membrane is an acceptable technical challenge. 


\section{D-8. SPECIFIC MEMBRANE AREA OF A SEVEN-LUMEN HOLLOW FIBER MEMBRANE (HFM) COMPARED WITH A SINGLE-LUMEN HFM}

A single-lumen shell side separation layer HFM will provide substantially greater specific membrane area $\left(\mathrm{m}^{2} / \mathrm{m}^{3}\right)$ than a multiple-lumen shell side or lumen side separation layer HFM.

SRI's preliminary evaluation of a seven-lumen HFM sample provided by White Fox has been reported. The average cross sectional dimensions of the sample are shown in a pictorial representation of a one meter unit length HFM in Figure 1.

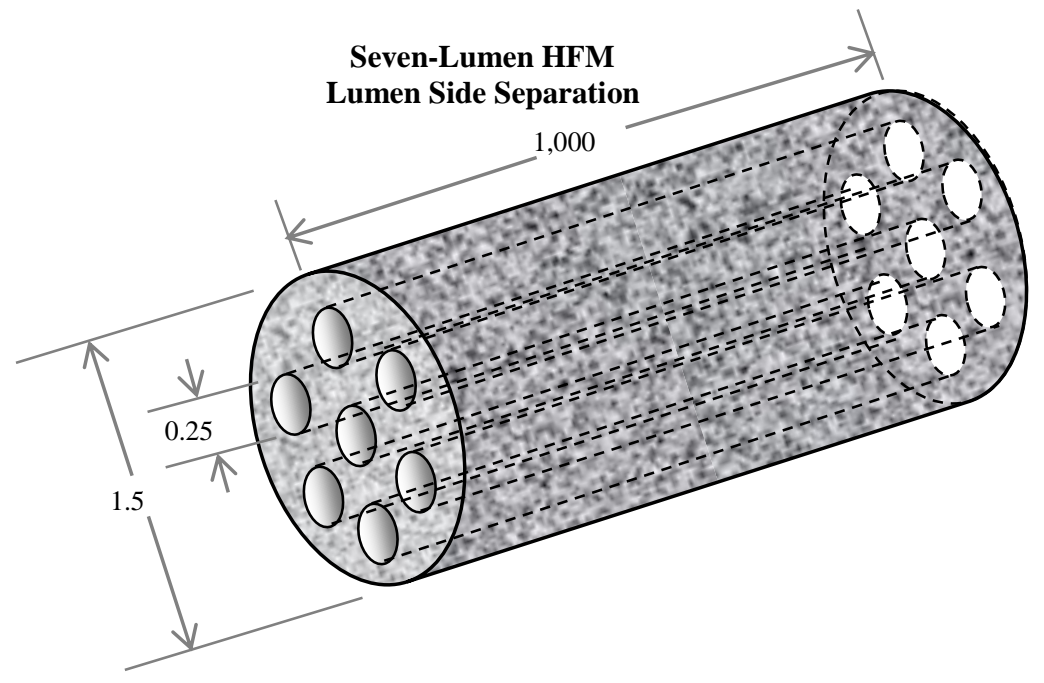

Figure 1 - A one meter long unit seven-lumen lumen side separation layer HFM, having the average cross sectional dimensions of the White Fox sample WF-MB-102208.

Assuming a thin dense defect free separation layer is on the inside surface of each lumen, then the specific separation layer area $\mathrm{m}^{2} / \mathrm{m}^{3}$ is:

$1.0 \mathrm{~m} \times 7 \times \pi \times 0.25 \mathrm{~mm} / 1,000 \mathrm{~mm} / \mathrm{m}=5,495 \times 10^{-6} \mathrm{~m}^{2}$ of separation layer area, divided by $1.0 \mathrm{~m} \times \pi \times(1.5 \mathrm{~mm} / 2 / 1000 \mathrm{~mm} / \mathrm{m})^{2}=1.766 \times 10^{-6} \mathrm{~m}^{3}$ of $\mathrm{HFM}$ volume $=$ $3,111 \mathrm{~m}^{2} / \mathrm{m}^{3}$.

If instead, it the separation layer is on the shell side of the seven-lumen HFM and each lumen's inside surface is porous, then the specific separation layer area in $\mathrm{m}^{2} / \mathrm{m}^{3}$ is:

$1.0 \mathrm{~m} \times \pi \times 1.5 \mathrm{~mm} / 1,000 \mathrm{~mm} / \mathrm{m}=4,710 \times 10^{-6} \mathrm{~m}^{2}$ of membrane area, divided by $1.0 \mathrm{~m} \times \pi \times(1.5 \mathrm{~mm} / 2 / 1000 \mathrm{~mm} / \mathrm{m})^{2}=1.766 \times 10^{-6} \mathrm{~m}^{3}$ of HFM volume $=2,667 \mathrm{~m}^{2} / \mathrm{m}^{3}$.

Therefore, a seven-lumen HFM having separation layers on the inside of each lumen has $17 \%$ more specific separation layer area than a similar diameter HFM having a separation layer on the outside of the HFM. 
A one meter unit length single-lumen lumen side separation layer HFM having the same lumen diameter as the seven-lumen HFM and a wall thickness of $0.075 \mathrm{~mm}$ equal to half the average distance between lumens in the seven-lumen HFM is shown in Figure 2.

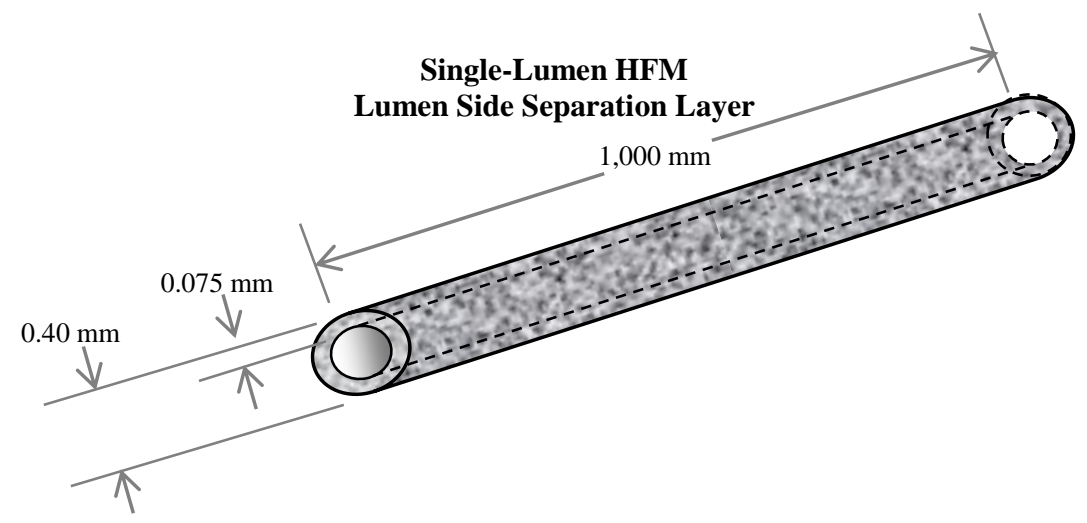

Figure 2 - A one meter long unit single-lumen lumen side separation layer HFM, having the same average lumen diameter as the White Fox sample, WF-MB-102208.

If a separation layer is on the lumen side of the single-lumen HFM, then the total separation layer area for seven single-lumen HFMs would be the same as the sevenlumen HFM or $5,495 \times 10^{-6} \mathrm{~m}^{2}$. The volume of seven single-lumen HFMs in Figure 2 is: $7 \times 1.0 \mathrm{~m} \times \pi \times(0.4 \mathrm{~mm} / 2 / 1000 \mathrm{~mm} / \mathrm{m})^{2}=0.8792 \times 10^{-6} \mathrm{~m}^{3}$ of HFM volume, and the specific membrane area for seven single-lumen HFM is $6,250 \mathrm{~m}^{2} / \mathrm{m}^{3}$.

Seven single-lumen HFMs having a separation layer on the lumen side, a $0.075 \mathrm{~mm}$ wall thickness and a $0.25 \mathrm{~mm}$ lumen diameter, has about double the specific membrane area of the seven-lumen HFM.

A one meter unit length single-lumen lumen side separation layer HFM having the same lumen diameter as the seven-lumen HFM, and a wall thickness of $0.15 \mathrm{~mm}$ equal to the average distance between lumens in the seven-lumen HFM, is shown in Figure 3.

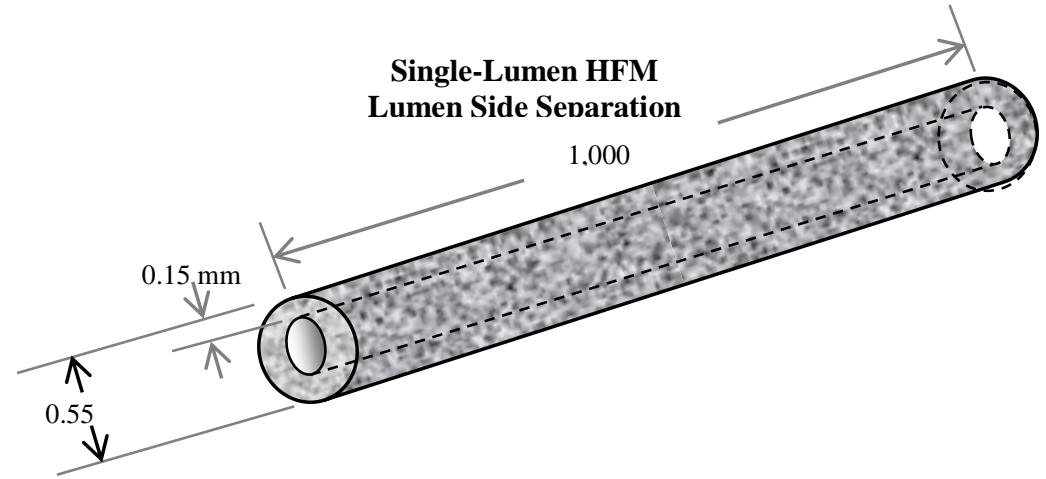

Figure 3 - A one meter long unit single-lumen lumen side HFM, having the same average lumen diameter as the White Fox sample WF-MB-102208. 
For the $0.15 \mathrm{~mm}$ wall thickness in Figure 3, the total volume of seven single-lumen HFMs is $7 \times 1.0 \mathrm{~m} \times \pi \times(0.55 \mathrm{~mm} / 2 / 1000 \mathrm{~mm} / \mathrm{m})^{2}=1.662 \times 10^{-6} \mathrm{~m}^{3}$, and the specific membrane area for seven single-lumen HFMs is $3,306 \mathrm{~m}^{2} / \mathrm{m}^{3}$ or about the same specific membrane area as the seven-lumen HFM.

SEM pictures of the White Fox seven-lumen HFM, and a single-lumen polysulfone and a single-lumen polyimide HFM, shown in Figures 4 and 5 respectively, have wall thicknesses that vary from a minimum of about $0.040 \mathrm{~mm}$ to a maximum of about 0.100 $\mathrm{mm}$.

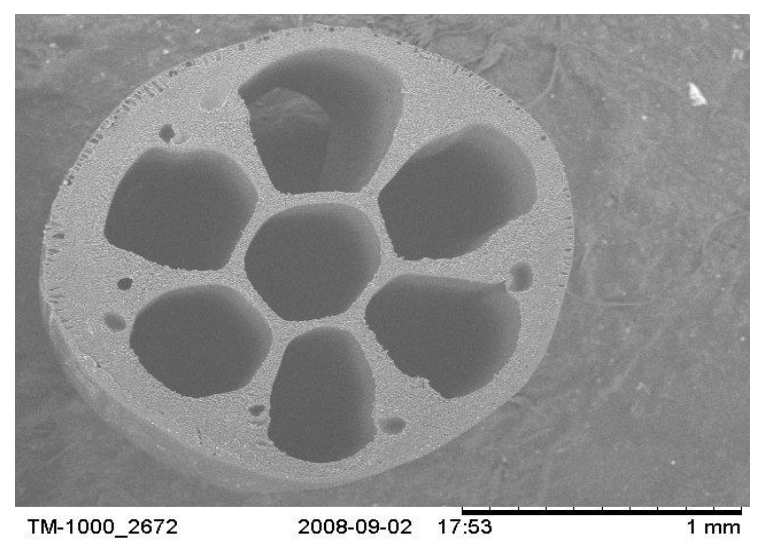

Figure - 4 White Fox seven-lumen HFM

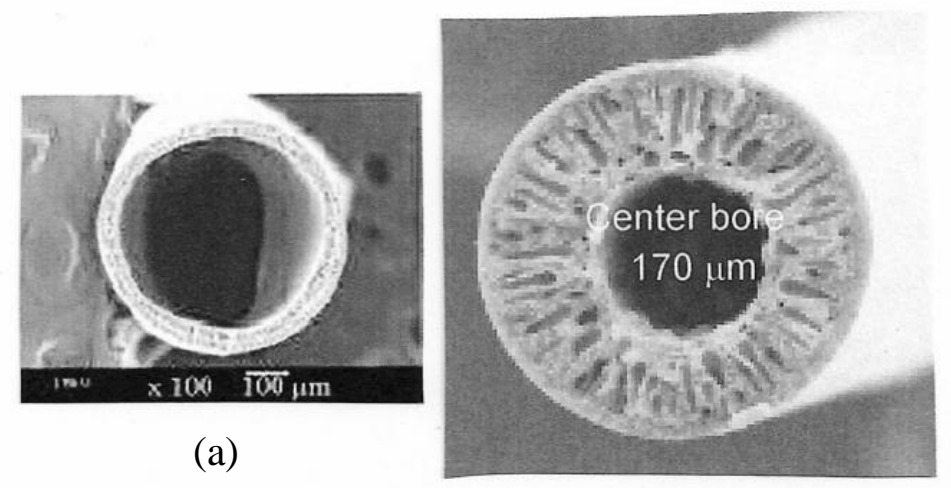

(b)

Figure - 5 (a) Asymmetric polysulfone single-lumen HFM; (b) Composite single-lumen HFM polyimide separation layer on porous polysulfone. 
Specific Membrane Area of a Seven-Lumen Lumen Side Separation Layer HFM Compared with a Single-Lumen Shell Side Separation Layer HFM - A one meter unit length single-lumen shell side separation layer HFM, having the same lumen diameter as the seven-lumen HFM, and a wall thickness of $0.075 \mathrm{~mm}$, equal to half the average distance between lumens in the seven-lumen HFM, is shown in Figure 6.

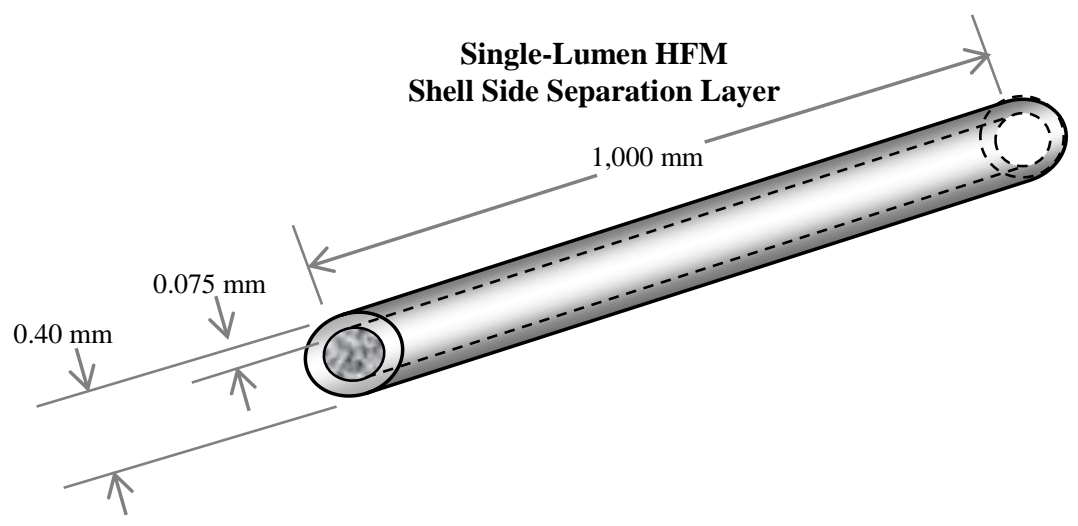

Figure 6 - A one meter long unit single-lumen shell side separation layer HFM, having the same lumen diameter as the White Fox sample WF-MB-102208.

Since the separation layer is situated on the shell side of the single-lumen HFM, the specific separation layer area in $\mathrm{m}^{2} / \mathrm{m}^{3}$ is:

$1.0 \mathrm{~m} \times \pi \times 0.40 \mathrm{~mm} / 1,000 \mathrm{~mm} / \mathrm{m}=1,256 \times 10^{-6} \mathrm{~m}^{2}$ of membrane area, divided by $1.0 \mathrm{~m} \times \pi \times(0.40 \mathrm{~mm} / 2 / 1000 \mathrm{~mm} / \mathrm{m})^{2}=0.1256 \times 10^{-6} \mathrm{~m}^{3}$ of HFM volume $=10,000$ $\mathrm{m}^{2} / \mathrm{m}^{3}$, which is $321 \%$ greater than the seven-lumen side HFM.

A one meter unit length single-lumen shell side separation layer HFM, having the same lumen diameter as the seven-lumen HFM, and a wall thickness of $0.15 \mathrm{~mm}$ equal to the average distance between lumens in the seven-lumen HFM, is shown in Figure 7.

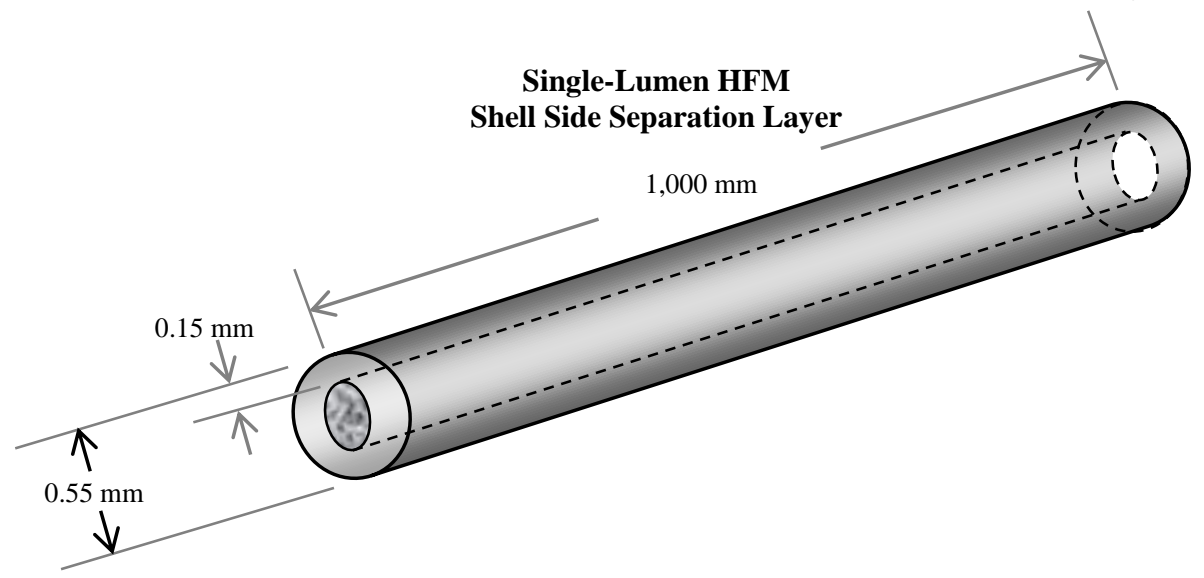

Figure 7 - A one meter long unit single-lumen shell side separation layer HFM, having the same lumen diameter as the White Fox sample WF-MB-102208. 
Since the separation layer is situated on the shell side of the single-lumen HFM, the specific separation layer area in $\mathrm{m}^{2} / \mathrm{m}^{3}$ is:

$1.0 \mathrm{~m} \times \pi \times 0.55 \mathrm{~mm} / 1,000 \mathrm{~mm} / \mathrm{m}=1,727 \times 10^{-6} \mathrm{~m}^{2}$ of membrane area, divided by $1.0 \mathrm{~m} \times \pi \times(0.55 \mathrm{~mm} / 2 / 1000 \mathrm{~mm} / \mathrm{m})^{2}=0.2375 \times 10^{-6} \mathrm{~m}^{3}$ of HFM volume $=7,723$ $\mathrm{m}^{2} / \mathrm{m}^{3}$, which is $234 \%$ greater than the seven-lumen side HFM.

A summary of relative specific membrane areas for seven and single-lumen HFMs discussed above is given in Table 1 .

Table 1 - Summary of Relative Separation Layer Specific Membrane Area, $\mathrm{m}^{2} / \mathrm{m}^{3}$

\begin{tabular}{|c|c|c|c|c|c|c|}
\hline & Separation layer & HFM dia. & Wall thickness & Lumen dia. & $\frac{\text { Sp. Mbr. Area, }}{\mathrm{m}^{2} / \mathrm{m}^{3}}$ & Sp. Mbr. area \\
\hline Seven lumen HFM & shell side & $1.50 \mathrm{~mm}$ & $0.150 \mathrm{~mm}$ & $0.250 \mathrm{~mm}$ & 2,667 & 1.00 \\
\hline Seven lumen HFM & lumen side & $1.50 \mathrm{~mm}$ & $0.150 \mathrm{~mm}$ & $0.250 \mathrm{~mm}$ & 3,111 & 1.17 \\
\hline Single lumen HFM & lumen side & $0.55 \mathrm{~mm}$ & $0.150 \mathrm{~mm}$ & $0.250 \mathrm{~mm}$ & 3,306 & 1.24 \\
\hline Single lumen HFM & lumen side & $0.40 \mathrm{~mm}$ & $0.075 \mathrm{~mm}$ & $0.250 \mathrm{~mm}$ & 6,250 & 2.34 \\
\hline Single lumen HFM & shell side & $0.55 \mathrm{~mm}$ & $0.150 \mathrm{~mm}$ & $0.250 \mathrm{~mm}$ & 7,273 & 2.73 \\
\hline Single lumen HFM & shell side & $0.40 \mathrm{~mm}$ & $0.075 \mathrm{~mm}$ & $0.250 \mathrm{~mm}$ & 10,000 & 3.75 \\
\hline
\end{tabular}

Depending on wall thickness, a single-lumen HFM with a $0.25 \mathrm{~mm}$ lumen diameter, having a lumen side or shell side separation layer, will have greater than two or three times the membrane area per unit HFM volume, respectively, compared to a seven-lumen HFM with either a lumen side or shell side separation layer.

Commercial gas separating HFMs are typically a single-lumen HFM having a shell side separation layer. An example of a commercial module containing a 4" $\times 5$ ' fiber bundle or HFM element, a $0.600 \mathrm{~mm}$ O.D. HFM and a separation layer area of $61.3 \mathrm{~m}^{2}$, has a specific membrane area of $6,667 \mathrm{~m}^{2} / \mathrm{m}^{3}$. An HFM packing density of $65 \%$ gives an effective specific HFM element area of $4,333 \mathrm{~m}^{2} / \mathrm{m}^{3}$. 


\title{
D-9. A SIMULATED IGCC/PBI HOLLOW FIBER MEMBRANE (HFM) PROCESS MASS BALANCE
}

\begin{abstract}
A Simulated IGCC/PBI Hollow Fiber Membrane (HFM) Process Mass Balance Shows That A Lumen-side Feed Will be Needed to Minimize Pressure Drops In Both The Feed Side And The Permeate Side Of A Membrane Separation Layer (MSL) - Table 1 below is the simulated membrane process mass balance for a $1.0 \mathrm{MW}$ IGCC / $\mathrm{PBI} \mathrm{CO} 2$ capture plant.
\end{abstract}

Table 1 - 1.0 MW PBI membrane process mass balance

\begin{tabular}{|c|c|c|c|c|c|c|c|c|c|c|c|}
\hline & Btu/scf & $\mathrm{CO}_{2}$ & $\mathrm{CO}$ & $\mathrm{CH}_{4}$ & $\mathrm{~N}_{2}$ & $\mathbf{H}_{2}$ & $\mathrm{H}_{2} \mathrm{~S}$ & $\mathrm{H}_{2} \mathrm{O}$ & $\mathbf{N}_{2}$ & Total & $\begin{array}{c}\text { Fraction } \\
\text { of Feed }\end{array}$ \\
\hline Permeate, scfh & 137 & 1,295 & 30 & 1 & 6 & 17,766 & 0 & 5,203 & 17,815 & 42,116 & $111.9 \%$ \\
\hline Retentate, scfh & 26 & 11,605 & 762 & 27 & 461 & 243 & 204 & 24 & & 13,326 & $35.4 \%$ \\
\hline Feed, scfh & 162 & 12,900 & 792 & 28 & 467 & 18,009 & 204 & 5,227 & & 37,627 & $100.0 \%$ \\
\hline
\end{tabular}

The volumetric feed rate decreases by permeation through the MSL to become a retentate volumetric flow of $13,326 \mathrm{scfh}$, which is $35.4 \%$ of the incoming feed. The combined permeate and sweep gas volumetric flow rate is $42,116 \mathrm{scfh}$ or $111.9 \%$ of the incoming feed. Of the feed flow, $64.6 \%$ or 24,301 scfh permeates through the MSL, where it is mixed and diluted with $17,815 \mathrm{scfh}$ of $\mathrm{N}_{2}$ sweep gas on the permeate side of the MSL.

Optimization of an IGCC/PBI membrane process, in addition to minimizing total membrane area and maximizing specific membrane area, also must minimize feed to retentate pressure drop to maintain the highest possible captured $\mathrm{CO}_{2}$ pressure, and permeate pressure drop, to maintain a specified gas turbine fuel pressure of 290 psia. Process optimization in this case requires a lumen-side feed and a shell-side permeate to minimize pressure drops by taking advantage of the decreased retentate flow and to accommodate the high permeate flow.

For lumen-side feed in a seven lumen HFM in Figure 1 below, the sweep gas effect is reduced because the permeate side of the MSL is imbedded within the porous substrate which blocks the $\mathrm{N}_{2}$ sweep from effectively mixing on the permeate side of the MSL. 


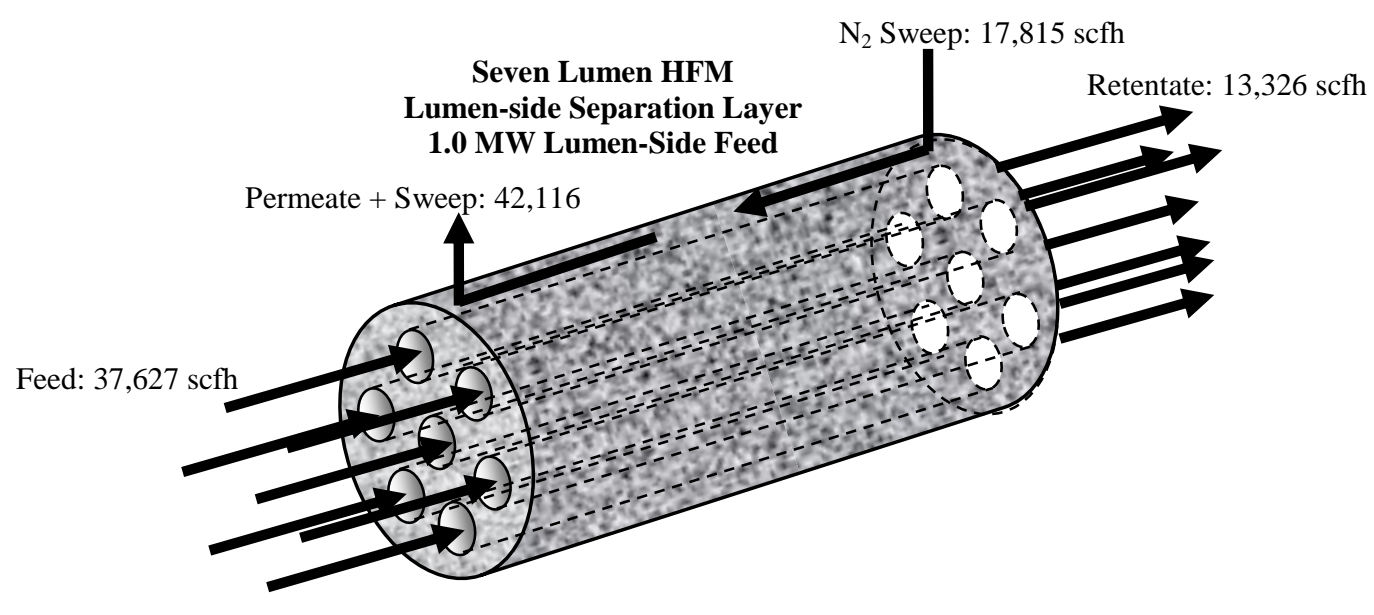

Figure 1 - Seven Lumen Lumen-side Separation layer

For lumen-side feed in a seven lumen HFM in Figure 2 below, the MSL is on the shellside which allows $\mathrm{N}_{2}$ sweep gas to directly sweep the permeate side of the MSL unimpeded by a porous substrate. However, the lumen surface area is not close to the feed side of the MSL, which lowers $\mathrm{H}_{2}$ partial pressure difference and $\mathrm{H}_{2}$ permeation driving force at the MSL.

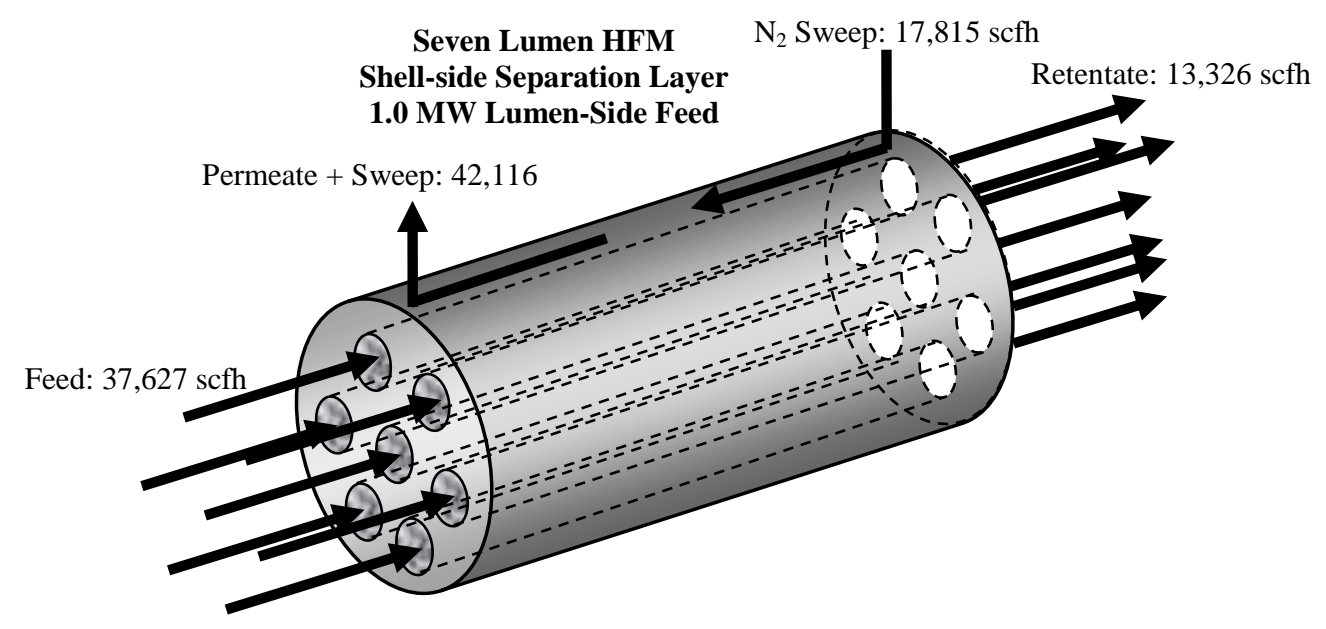

Figure 2 - Seven Lumen Shell-side Separation layer

The lumen-side feed single lumen HFM with a shell-side MSL, as shown in Figure 3 below, in addition to having much greater specific membrane area than a seven lumen HFM (see PBI Simulation Memorandum VIII), provides for a direct $\mathrm{N}_{2}$ sweep gas on the permeate side of the MSL. Also, all of the lumen surface area is close to the MSL, maximizing $\mathrm{H}_{2}$ partial pressure difference and $\mathrm{H}_{2}$ permeation driving force. 


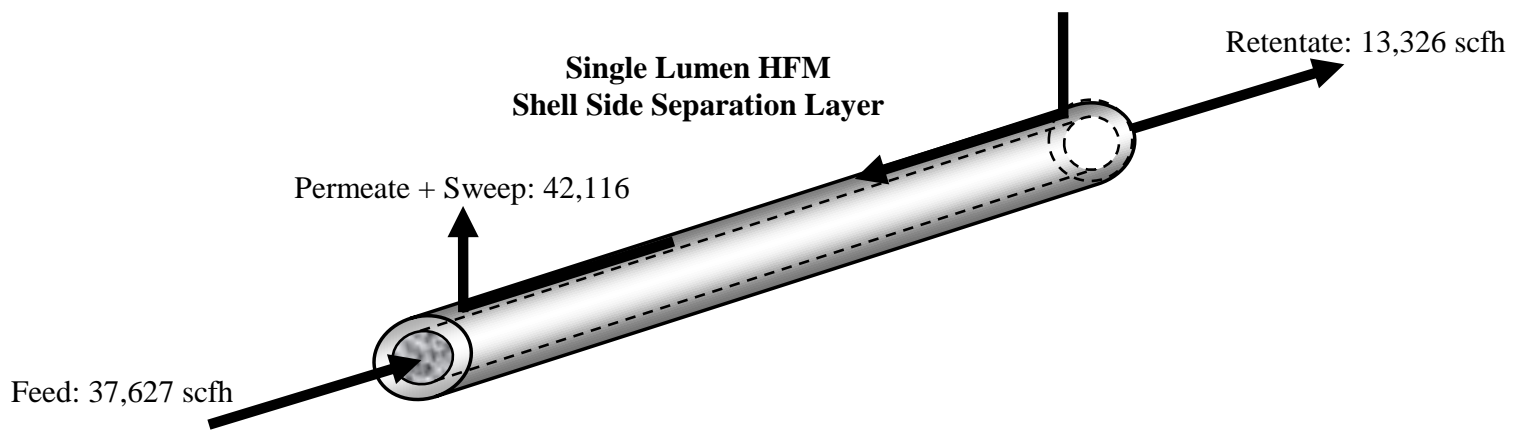

Figure 3 - Single Lumen Shell-side Separation layer

The high permeate volume flow in the IGCC / PBI case requires a shell-side permeate to minimize pressure drop to maintain a specified gas turbine fuel pressure of $290 \mathrm{psia}$. The large decrease in feed to retentate volume flow enables a minimum lumen-side feed to retentate pressure drop to maintain a higher captured $\mathrm{CO}_{2}$ pressure.

\section{Fabricating a Single Lumen Lumen-side Feed HFM with a trans-membrane} pressure Difference of 490 psi - Prism Membranes recently provided a comment on the possibility of a single lumen HFM having a lumen-side feed pressure of $777 \mathrm{psia}$, a permeate side pressure of 290 psia. They believe "it is certainly possible to operate with a 490 psia differential between the lumen-side and shell-side" if a HFM design considers PBI material strength, final OD and ID dimensions, and "the way the fiber is spun to generate wall structure (strength)".

\section{Benefits of a single lumen lumen-side feed and shell-side separation layer compared to Multi-lumen HFM -}

1. Lower pressure drop with lumen-side feed and shell-side permeate

2. Up to $10,000 \mathrm{~m}^{2} / \mathrm{m}^{3}$ specific membrane area.

3. Lower substrate pressure drop with the lumen closer to the MSL.

4. Greater sweep gas effect.

5. Commercial membrane design standard.

Table 2 below shows an element area comparison between a seven lumen HFM and a single lumen HFM for a 4" $\times 5$ ' HFM element per. Since both HFM assume a shell-side MSL, permeate pressure drop would be low and $\mathrm{N}_{2}$ sweep gas effect would be good. The MSL areas / 4" $\times 5$ ' for each HFM are in the same ratio as the ratio of their respective specific membrane areas given in Table 1 above.

Table 2 - HFM performance and MSL area per element comparison

\begin{tabular}{|c|c|c|c|}
\hline & MSL & HFM O.D. & $\begin{array}{c}\text { MSL area } / 4 " \times 5^{\prime} \text { * } \\
\mathrm{m}^{2}\end{array}$ \\
\hline ven lumen HFM & shell side & $1.50 \mathrm{~mm}$ & 21.4 \\
\hline ingle lumen HFM & shell side & $0.55 \mathrm{~mm}$ & 58.4 \\
\hline
\end{tabular}

D - 39 
* $65 \%$ HFM packing efficiency / 4"×5' element

Conclusions from Memoranda VIII and IX:

1. The single lumen HFM provides substantially higher specific membrane area necessary for gas separation.

2. The single lumen HFM provides lower substrate pressure drop where lumen-side flow is needed to lower permeate and sweep gas flow pressure drop. 


\section{D-10. SELECTIVE RUBBERY MEMBRANE TO SEPARATE $\mathrm{H}_{2} \mathrm{~S}$ FROM THE PBI $\mathrm{CO}_{2}$ RETENTATE}

Poly (ether urethane) designated as PU3, a rubbery material, was suggested as a $\mathrm{H}_{2} \mathrm{~S}$ selective membrane to remove $\mathrm{H}_{2} \mathrm{~S}$ from the $\mathrm{CO}_{2}$ retentate stream from a PBI membrane $\mathrm{CO}_{2}$ capture process. Among rubbery membranes, PU3 has a relatively high $\mathrm{H}_{2} \mathrm{~S} / \mathrm{CO}_{2}$ selectivity compared to a common rubbery membrane material such as polymethyldisiloxane (PDMS), and could be high enough to be useful in effectively separating $\mathrm{H}_{2} \mathrm{~S}$ from $\mathrm{CO}_{2}$. Rubbery membranes in general are selective for more condensable gases such as $\mathrm{H}_{2} \mathrm{~S}\left(-60.7^{\circ} \mathrm{C}\right.$ normal b. p.) compared to $\mathrm{CO}_{2}$ (-78.3 normal sublimation point). PBI, a glassy membrane, on the other hand has the reverse selectivity, being more selective by size difference for $\mathrm{CO}_{2}$ (3.30 ̊ kinetic diameter) compared to $\mathrm{H}_{2} \mathrm{~S}$ (3.52 $\AA$ kinetic diameter). Permeability and selectivity of PU3, PDMS and PBI are given in Table 1.

Table 1 - Permeability and selectivity of polyetherurethane (PU3) and polymethydisiloxane (PMDS)

\begin{tabular}{|c|c|c|c|c|c|c|c|}
\hline$\underline{\text { Polymer }}$ & Gas Composition (mol\%) & Perm & ability, & $\times 10^{-10}$ & & Selectivity & \\
\hline & $\left(\mathrm{CH}_{4} / \mathrm{CO}_{2} / \mathrm{H}_{2} \mathrm{~S}\right)$ & $\mathrm{CH}_{4}$ & $\mathrm{CO}_{2}$ & $\mathrm{H}_{2} \mathrm{~S}$ & $\mathrm{H}_{2} \mathrm{~S} / \mathrm{CH}_{4}$ & $\mathrm{H}_{2} \mathrm{~S} / \mathrm{CO}_{2}$ & $\mathrm{CO}_{2} / \mathrm{H}_{2} \mathrm{~S}$ \\
\hline $\mathrm{PU3}^{*}$ & $(70.8 / 27.9 / 1.3)$ & 4.7 & 58.8 & 271 & 57.7 & 4.6 & 0.22 \\
\hline PMDS & Single Gas Data & 800 & 2700 & 8400 & 10.5 & 3.1 & 0.32 \\
\hline PBI & $(1 / 41 / 1)$ & 0.360 & 2.040 & 0.048 & 0.133 & 0.024 & 42.5 \\
\hline
\end{tabular}

The reference paper cited in Table 1 proposed a PU3 membrane to separate $\mathrm{H}_{2} \mathrm{~S}$ from $\mathrm{CH}_{4}$ because of its relatively high selectivity of 57.7, and to be used in two step series combination with a glassy membrane like cellulose acetate, which is typically used to separate $\mathrm{CO}_{2}$ from $\mathrm{CH}_{4}$ having a relatively high $\mathrm{CO}_{2} / \mathrm{H}_{2} \mathrm{~S}$ selectivity of 22.1 . Although PU3 $\mathrm{H}_{2} \mathrm{~S} / \mathrm{CO}_{2}$ selectivity at 4.6 is $48 \%$ higher than PDMS, it is still low compared to a PBI selectivity of 42.5 for $\mathrm{CO}_{2}$ over $\mathrm{H}_{2} \mathrm{~S}$.

Two simulations were done for membrane processes separating $\mathrm{H}_{2} \mathrm{~S}$ from $\mathrm{CO}_{2}$ using as single PU3 membrane process and a two step PBI / PU3 membrane process. The logical location for a PU3 membrane, which must operate at a relatively low temperature compared to the PBI membrane separating $\mathrm{CO}_{2}$ and $\mathrm{H}_{2}$, would be before $\mathrm{CO}_{2}$ sequestration compression, where the gas stream has been cooled to about $100^{\circ} \mathrm{F}$. The first step PBI membrane would still operate with hot gas feed.

Simulation results of the single step PU3 membrane process and the two step PBI/PU3 membrane process, both having $99 \% \mathrm{H}_{2} \mathrm{~S}$ recovery, is graphically illustrated in Figure 1. 
$\mathrm{CO}_{2} \%$ Recovery At $99 \% \mathrm{H}_{2} \mathrm{~S}$ Recovery As A Function Of Permeate Pressure

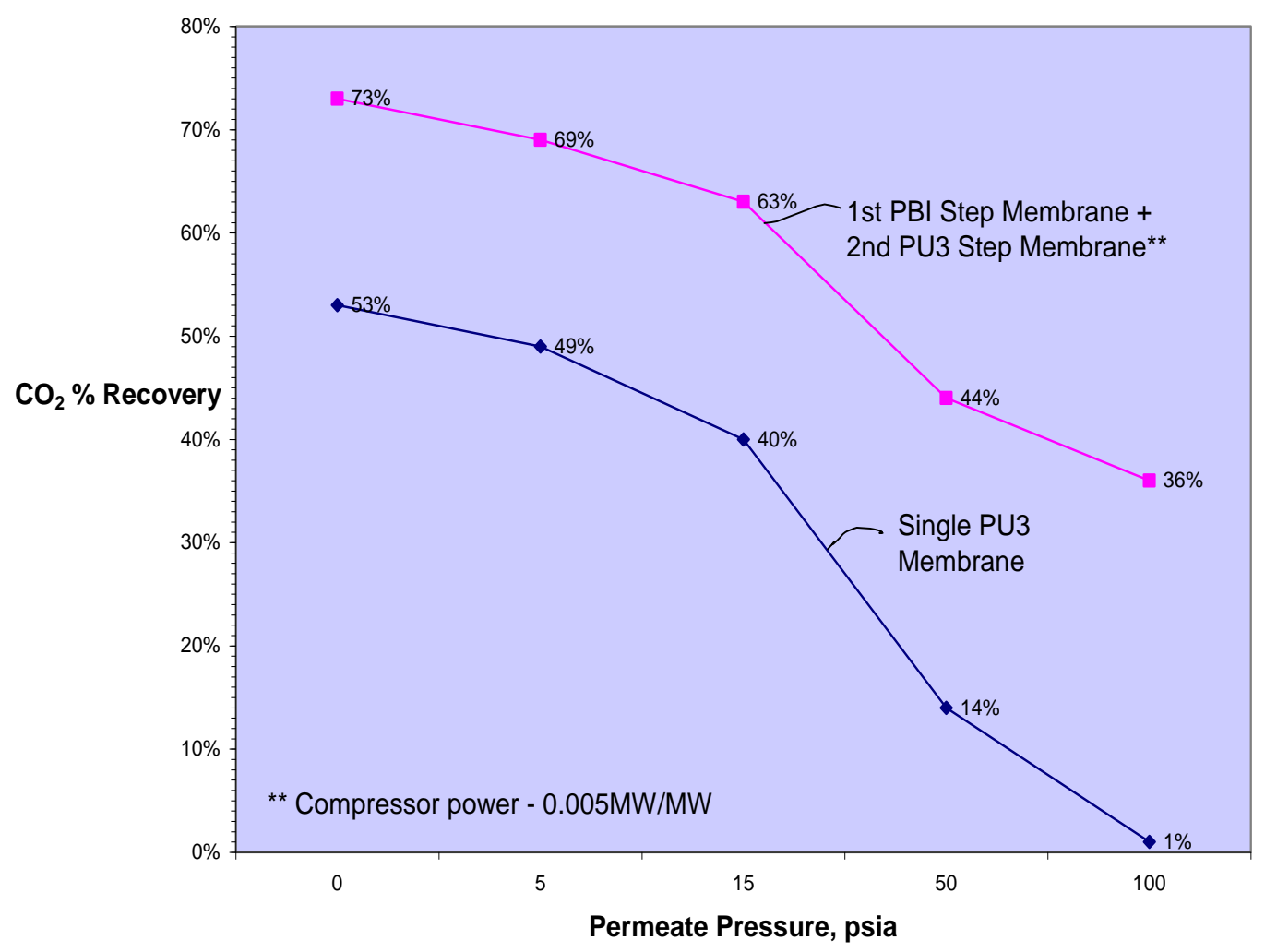

Figure $1-\mathrm{CO}_{2}$ recovery at different permeate pressures when $\mathrm{H}_{2} \mathrm{~S}$ recovery is $99 \%$

The results in Figure 1 show that a PU3 $\mathrm{H}_{2} \mathrm{~S} / \mathrm{CO}_{2}$ selectivity of 4.6 , in either a single PU3 membrane process, or a two step PU3/PBI membrane process, is not high enough to achieve $99 \% \mathrm{H}_{2} \mathrm{~S}$ removal and still provide even near $90 \% \mathrm{CO}_{2}$ capture. In an extreme case of zero PU3 membrane permeate pressure, the highest $\mathrm{CO}_{2}$ capture is only $73 \%$ in the PBI/PU3 two step membrane process.

Simulations were done to determine $\mathrm{H}_{2} \mathrm{~S}$ recovery when $\mathrm{CO}_{2}$ recovery is $90 \%$. Results of a two step PBI /PU3 membrane processes with $90 \% \mathrm{CO}_{2}$ recovery are graphically illustrated in Figure 2. Simulations of a single PU3 membrane could not reach $90 \% \mathrm{CO}_{2}$ capture with any $\mathrm{H}_{2} \mathrm{~S}$ recovery, and furthermore, $\mathrm{CO}_{2}$ capture rates of any significance had only low of $\mathrm{H}_{2} \mathrm{~S}$ recovery. 
$\mathrm{H}_{2} \mathrm{~S} \%$ Recovery At $90 \% \mathrm{CO}_{2}$ Recovery As A Function Of Permeate Pressure

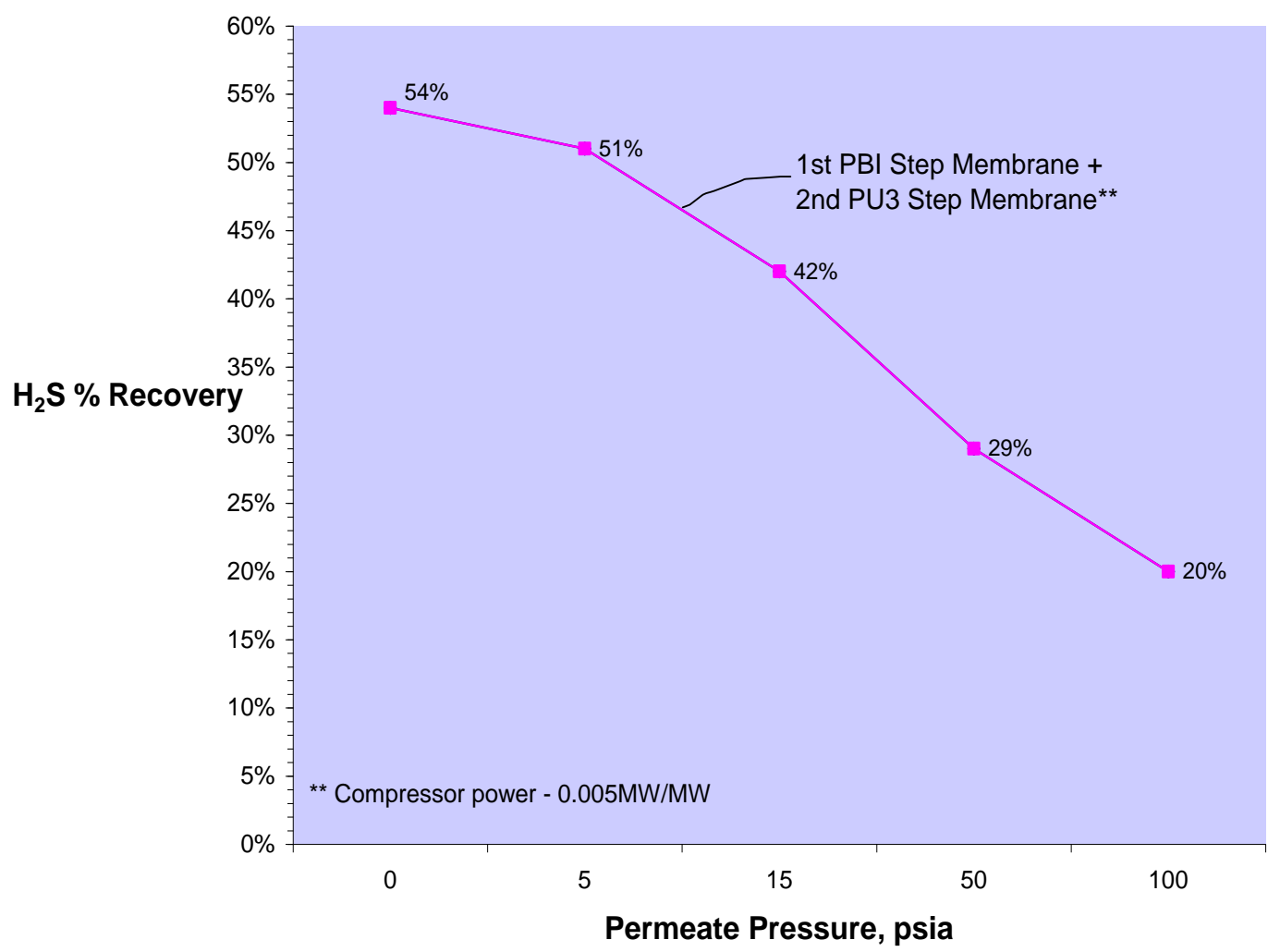

Figure $2-\mathrm{H}_{2} \mathrm{~S}$ recovery at different permeate pressures when $\mathrm{CO}_{2}$ recovery is $90 \%$

The results in Figure 2 shows that a PU3 $\mathrm{H}_{2} \mathrm{~S} / \mathrm{CO}_{2}$ selectivity of 4.6, in a two step membrane process with a PBI membrane as the first step, is not high enough to achieve $99 \% \mathrm{H}_{2} \mathrm{~S}$ removal when $\mathrm{CO}_{2}$ recovery is $90 \%$. In an extreme case of zero PU3 membrane permeate pressure in the second PU3 step of a two step process, the highest achievable $\mathrm{H}_{2} \mathrm{~S}$ recovery is $54 \%$. 


\section{D-11. PRELIMINARY DESIGN CONSIDERATIONS FOR A TEST SKID PBI MEMBRANE MODULE-}

The test skid module will have a membrane fiber element similar in size to a commercial Air Products PA3010 Prism membrane separator module which was previously discussed and reported on. The PA3010 module has about $70 \mathrm{ft}^{2}$ of effective membrane area contained in a nominal 3 inch diameter by a 1 foot long fiber element containing hollow fibers of about $575 \mu \mathrm{m}$ O.D. with about $63 \%$ fiber packing density. The PBI test module with the same nominal element dimensions and fiber packing density will have hollow

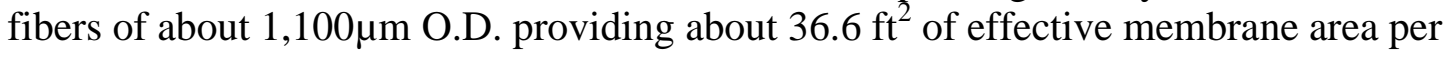
test module. The larger PBI fiber O.D. is necessary to maintain a lumen side pressure drops of $\leq 15$ psi. Two PBI test modules will be fabricated and placed in parallel in the test skid giving about $73.2 \mathrm{ft}^{2}$ total effective membrane area. The test PBI hollow fiber specifications are given in Table 1 .

\begin{tabular}{|c|c|}
\hline Table $\mathbf{- 1}$ & PBI Test Module: $3^{\prime \prime} \times 1$ ' Element \\
\hline Fiber O.D/I.D. & $1100 \mu \mathrm{m} / 750 \mu \mathrm{m}$ \\
\hline Lumen side/shell side vol. ratio & 0.79 \\
\hline Element volume, $\mathrm{m}^{3}$ & 0.00148 \\
\hline Fiber volume, $\mathrm{m}^{3}$ & 0.00094 \\
\hline Fiber packing & $63.0 \%$ \\
\hline Total fiber length per element, $\mathrm{m}$ & 985 \\
\hline Number of fibers per element & 3,232 \\
\hline Module membrane area, $\mathrm{m}^{2}$ & 3.4 \\
\hline Module membrane area, $\mathrm{ft}^{2}$ & 36.6 \\
\hline Specific membrane area, $\mathrm{m}^{2} / \mathrm{m}^{3}$ & $2,292^{*}$ \\
\hline
\end{tabular}

* Based on a shell side MSL. In the case of a Lumen side MSL, module membrane area $=24.9 \mathrm{ft}^{2}$ with a specific membrane area $=1,562 \mathrm{~m}^{2} / \mathrm{m}^{3}$

The PBI test module performance is based on two design cases:

1. A conservative case using $250^{\circ} \mathrm{C}$ performance data, and

2. An aggressive case using $170^{\circ} \mathrm{C}$ performance data.

The conservative case provides a good $\mathrm{H}_{2}$ GPU and $\mathrm{H}_{2} / \mathrm{CO}_{2}$ selectivity. The aggressive case provides a lower $\mathrm{H}_{2}$ GPU and a higher $\mathrm{H}_{2} / \mathrm{CO}_{2}$ selectivity.

The membrane design criteria for each design case are:

1. $36.6 \mathrm{ft}^{2}$ of membrane area per module

2. $125 \mathrm{Btu} / \mathrm{scf} \mathrm{LHV}$ in the permeate fuel

3. $1.0 \mu \mathrm{m}$ thickness membrane separation layer MSL

4. $90 \% \mathrm{CO}_{2}$ capture rate 
Criteria 2 and 4 are set by NETL. Criterion 3 is chosen as a reasonably best case for a first generation White Fox hollow fiber membrane. However it is possible that the first generation White Fox hollow fiber MSL may be $2 \mu \mathrm{m}-3 \mu \mathrm{m}$ thick.

The design cases determine:

1. $\mathrm{H}_{2} \mathrm{GPU}$

2. $\mathrm{H}_{2} / \mathrm{CO}_{2}$ selectivity

The design criteria determine:

1. $\mathrm{H}_{2}$ recovery

2. Power separation efficiency

3. Parasitic compression power*

4. Permeate $\mathrm{kWe} / \mathrm{ft}^{2}$ or membrane power density

5. Permeate $\mathrm{kWe}$

* Includes retentate compression to 1,000 psia

A summary of the simulation results for the two design cases are presented in Table 2.

\begin{tabular}{|c|c|c|}
\hline & Conservative $250^{\circ} \mathrm{C}$ case & Aggressive $170^{\circ} \mathrm{C}$ case \\
\hline $\mathrm{H}_{2} \mathrm{GPU}^{*}$ & 87.6 & 20.0 \\
\hline $\mathrm{H}_{2} / \mathrm{CO}_{2}$ selectivity* & 42.90 & 90.00 \\
\hline $\mathrm{H}_{2}$ recovery & $82.0 \%$ & $96.6 \%$ \\
\hline Power separation efficiency & $79.4 \%$ & $93.8 \%$ \\
\hline Parasitic compression power & $6.0 \%$ & $7.0 \%$ \\
\hline Power density, $\mathrm{kWe} / \mathrm{ft}^{2}$ & 0.236 & 0.039 \\
\hline Permeate KWe & 17.25 & 2.88 \\
\hline
\end{tabular}

*Values are determined by the respective design case temperatures

With the given design criteria, only the aggressive case has sufficient selectivity to achieve $96.6 \% \mathrm{H}_{2}$ recovery and $90 \% \mathrm{CO}_{2}$ capture. However, as expected due to the inverse relationship between selectivity and permeability and GPU, higher selectivity also comes with substantially lower productivity as shown by lower membrane power density and permeate $\mathrm{kWe}$. Reducing the MSL to $0.165 \mu \mathrm{m}$ in a later generation hollow fiber, a thickness typical of today's commercial gas separation membranes, would raise productivity of the aggressive case to that of the conservative case.

\section{PBI Test Module Optimization and Later PBI Membrane Optimization -}

In PBI Simulation Memorandum XIII a conservative design case and an aggressive design case were presented based on $1.0 \mu \mathrm{m}$ MSL (membrane separation layer), $125 \mathrm{Btu} / \mathrm{scf} \mathrm{LHV}$ permeate and $90 \% \mathrm{CO}_{2}$ capture and a design modification of each case. The two cases and their two modifications presented in Figures 1, 2, 3 and 4 in

$$
\mathrm{D}-45
$$


the Memorandum, are summarized in Figure $-2 \mathrm{a}$ below. Figure -1 achieves a power density of $0.236 \mathrm{kWe} / \mathrm{ft}^{2}$ and $90 \% \mathrm{CO}_{2}$ capture but has $82.0 \% \mathrm{H}_{2}$ recovery due to insufficient $\mathrm{H}_{2} / \mathrm{CO}_{2}$ selectivity. Figure -3 achieves a $\mathrm{H}_{2}$ recovery of $96.6 \%$ and $90 \% \mathrm{CO}_{2}$ capture but has a lower power density of $0.039 \mathrm{kWe} / \mathrm{ft}^{2}$ due to low $\mathrm{H}_{2}$ GPU.

Figure -2 modifies Figure - 1 by lowering $\mathrm{CO}_{2}$ capture to $75.3 \%$ in order to raise $\mathrm{H}_{2}$ recovery to $96.6 \%$, although also lowering power density by about a $45 \%$, from 0.236 $\mathrm{kWe} / \mathrm{ft}^{2}$ to $0.130 \mathrm{kWe} / \mathrm{ft}^{2}$, and lowering permeate LHV by $5 \%$, from $125 \mathrm{Btu} / \mathrm{scf}$ to 118.7 Btu/scf. Figure -4 modifies Figure -3 by reducing the MSL from $1.0 \mu \mathrm{m}$ to $0.165 \mu \mathrm{m}$ to increase $\mathrm{H}_{2}$ GPU from 20 to 121.2 which raises power density from $0.039 \mathrm{kWe} / \mathrm{ft}^{2}$ to $0.238 \mathrm{kWe} / \mathrm{ft}^{2}$.

Based on achieved MSL thicknesses in sample fibers to date, it appears a best case scenario for a test module in the next twelve months is to be optimized with an MSL of $1.0 \mu \mathrm{m}$ or somewhat thicker. Accordingly it will be necessary to operate the test module at the conservative $250^{\circ} \mathrm{C}$ design case to maintain sufficiently high $\mathrm{H}_{2}$ GPU and a reasonably high membrane power density of $0.130 \mathrm{kWe} / \mathrm{ft}^{2}$. The relatively thick $1.0 \mu \mathrm{m}$ MSL should also prevent defects that will likely be present from penetrating the MSL with consequent selectivity loss. However because of insufficient selectivity at $250^{\circ} \mathrm{C}$, $\mathrm{CO}_{2}$ capture will be reduced from $90 \%$ to $75.3 \%$ to increase $\mathrm{H}_{2}$ recovery from $82.0 \%$ to

\begin{tabular}{|c|c|c|c|c|}
\hline Table - 2a & Test Module & $\begin{array}{l}\text { Optimized } \\
\text { Test Module }\end{array}$ & Test Module & $\begin{array}{c}\text { Later } \\
\text { Optimization }\end{array}$ \\
\hline & $\begin{array}{c}\text { Figure - } \mathbf{1} \\
\text { Conservative } 250^{\circ} \mathrm{C} \text { case } \\
\end{array}$ & $\begin{array}{c}\text { Figure - } \mathbf{2} \\
\text { Conservative } 250^{\circ} \mathrm{C} \text { case } \\
\end{array}$ & $\begin{array}{c}\text { Figure }-\mathbf{3} \\
\text { Aggressive } 170^{\circ} \mathrm{C} \text { case }\end{array}$ & $\begin{array}{c}\text { Figure }-\mathbf{4} \\
\text { Aggressive } 170^{\circ} \mathrm{C} \text { case } \\
\end{array}$ \\
\hline MSL & $1.0 \mu \mathrm{m}$ & $1.0 \mu \mathrm{m}$ & $1.0 \mu \mathrm{m} \gg>>>>>>$ & $\gg \gg>>>0.165 \mu \mathrm{m}$ \\
\hline $\mathrm{H}_{2} \mathrm{GPU}$ & 87.6 & 87.6 & $20.0>>>>>>>>$ & >>>>>>121.2 \\
\hline $\mathrm{H}_{2} / \mathrm{CO}_{2}$ selectivity & 42.9 & 42.9 & 90.0 & 90.0 \\
\hline CO2 capture & $90.0 \%$ > >>>>> & >>>>>>>75.3\% & $90.0 \%$ & $90.0 \%$ \\
\hline $\mathrm{H}_{2}$ recovery & $82.0 \%>>>>>>>$ & $>>>>>>96.6 \%$ & $96.6 \%$ & $96.6 \%$ \\
\hline Power separation efficiency & $79.4 \% \gg \gg>>>>>$ & >>>>>>>93.7\% & $93.8 \%$ & $93.8 \%$ \\
\hline Parasitic compr. power & $6.0 \%$ & $6.0 \%$ & $7.0 \%$ & $7.0 \%$ \\
\hline Permeate LHV, Btu/scf & $125.0 \gg>>>>>>>$ & >>>>>>>118.7 & 125.0 & 125.0 \\
\hline Power density, $\mathrm{kWe} / \mathrm{ft}^{2}$ & $0.236>>>>>>>>$ & $\gg>>>>>0.130$ & $0.039>>>>>>>$ & $>>>>>0.238$ \\
\hline
\end{tabular}

96.6\%. The later optimization fiber in Figure -4 , with a thinner and a defect free MSL, which is more characteristic of state of the art gas separation membranes, will enable $90 \% \mathrm{CO}_{2}$ capture, $96.6 \% \mathrm{H}_{2}$ recovery and a $0.238 \mathrm{kWe} / \mathrm{ft}^{2}$ membrane power density.

\section{Membrane Module Fabrication from ANSI Pipe and Flanges -}

Commercial membrane module housings used in high pressure $\mathrm{CO}_{2}$ removal service are typically fabricated from high pressure and temperature rated pipes and flanges per ANSI standards. An example of a Cynara commercial membrane module is shown in Figures 1 below. 


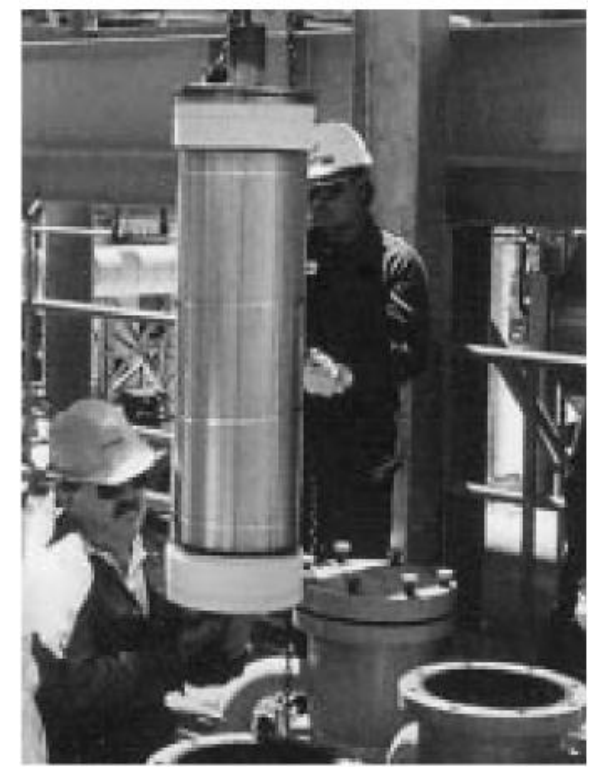

Figure - 1 Commercial $\mathrm{CO}_{2}$ removal element, pipe and flange housing assembly.

Figure -2 below is a schematic of a PBI pipe and flange module separating $\mathrm{CO}_{2}$ and $\mathrm{H}_{2}$ from shift gas feed.

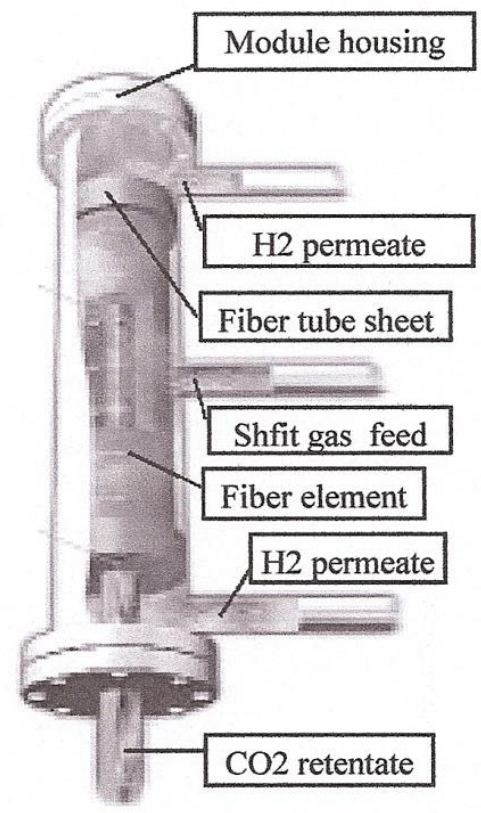

Figure - 2 PBI membrane module.

Standard ANSI class pipes and flanges are available from $1 / 2$ inch pipe size up to 24 inch pipe size. The mechanical design of the proposed 3.5 inch O. D. test module presented in PBI Simulation Memorandum XIII is based on standard ANSI pipe and flanges and will therefore be readily scaleable to a larger module diameter. Furthermore, experience has demonstrated that membrane performance in a small test module closely predicts performance in larger modules under similar operating conditions. 
The specified ANSI B36.19 s/s schedule 40 pipe for the module housing is service rated to $1,196 \mathrm{psig}$ at $500^{\circ} \mathrm{F}\left(260^{\circ} \mathrm{C}\right)$ and $1,084 \mathrm{psig}$ at $700^{\circ} \mathrm{F}\left(371^{\circ} \mathrm{C}\right)$. The specified ANSI

$\mathrm{B} 16.5600 \mathrm{lb}$ class s/s schedule 40 pipe size flange is service rated to $1,200 \mathrm{psig}$ at $500^{\circ} \mathrm{F}$ $\left(260^{\circ} \mathrm{C}\right)$ and $1,065 \mathrm{psig}$ at $700^{\circ} \mathrm{F}\left(371^{\circ} \mathrm{C}\right)$. 


\section{D-12. PBI TEST MODULE AND SKID SPECIFICATIONS}

Test Module Membrane Specifications - A proposed test module operating specification was presented in Simulation Memorandum XIII, Addendum 1, Table 2a, under Test Module Figure -3 , the aggressive $170^{\circ} \mathrm{C}$ case, and presented here again in Table 1 below. The table also illustrates the affects of a thinner membrane separation layer (MSL) in the Figure -3 case such as a proportional increase in $\mathrm{H}_{2} \mathrm{GPU}$ and membrane area power density.

\begin{tabular}{|c|c|c|c|}
\hline Table - 1 & Test Module & Test Module & Test Module \\
\hline & $\begin{array}{c}\text { Figure }-\mathbf{3} \\
\text { Aggressive } 170^{\circ} \mathrm{C} \text { case } \\
\end{array}$ & $\begin{array}{c}\text { Figure }-3^{\prime} \\
\text { Aggressive } 170^{\circ} \mathrm{C} \text { case }\end{array}$ & $\begin{array}{c}\text { Figure }-\mathbf{3}^{\prime \prime} \\
\text { Aggressive } 170^{\circ} \mathrm{C} \text { case }\end{array}$ \\
\hline MSL & $1.0 \mu \mathrm{m} \gg>>>>>>$ & $\gg \gg>>>0.5 \mu \mathrm{m}$ & $\gg \gg>>>0.165 \mu \mathrm{m}$ \\
\hline $\mathrm{H}_{2} \mathrm{GPU}$ & $20.0>>>>>>>>>$ & $\gg>>>>40.0$ & $>>>>>121.2$ \\
\hline $\mathrm{H}_{2} / \mathrm{CO}_{2}$ selectivity & 90.0 & 90.0 & 90.0 \\
\hline $\mathrm{CO} 2$ capture & $90.0 \%$ & $90.0 \%$ & $90.0 \%$ \\
\hline $\mathrm{H}_{2}$ recovery $(\mathrm{LHV})$ & $96.6 \%$ & $96.6 \%$ & $96.6 \%$ \\
\hline Power separation efficiency & $93.8 \%$ & $93.8 \%$ & $93.8 \%$ \\
\hline Parasitic compressor power & $7.0 \%$ & $7.0 \%$ & $7.0 \%$ \\
\hline Permeate LHV, Btu/scf & 125.0 & 125.0 & 125.0 \\
\hline Power density, $\mathrm{kWe} / \mathrm{ft}^{2}$ & 0.039 > >>>>> & >>>>>0.078 & $\gg>>>>0.238$ \\
\hline
\end{tabular}

Membrane Element Specifications - The PBI test module is based on a nominal 3 inch diameter by 1 foot long membrane element having hollow fibers of about 1,100 $\mu \mathrm{m}$ O.D. with a $63 \%$ fiber packing density yielding $36.6 \mathrm{ft}^{2}$ of effective shell side membrane area. Two PBI test separator modules will be fabricated housing two membrane elements and placed in parallel in the test skid providing $73.2 \mathrm{ft}^{2}$ of total effective membrane area. The membrane element specifications based on a shell side MSL are presented in Table 2 below.

\begin{tabular}{|c|c|}
\hline Table $\mathbf{- 2}$ & Test Module: 3" $\times 1$ ' Element $^{\prime}$ \\
\hline Fiber O.D/I.D. & $1100 \mu \mathrm{m} / 750 \mu \mathrm{m}$ \\
\hline Lumen side/shell side vol. ratio & 0.79 \\
\hline Element volume, $\mathrm{m}^{3}$ & 0.00148 \\
\hline Fiber volume, $\mathrm{m}^{3}$ & 0.00094 \\
\hline Fiber packing & $63.0 \%$ \\
\hline Total fiber length per element, $\mathrm{m}$ & 985 \\
\hline Number of fibers per element & 3,232 \\
\hline Module membrane area, $\mathrm{m}^{2}$ & 3.4 \\
\hline Module membrane area, $\mathrm{ft}^{2}$ & 36.6 \\
\hline Specific membrane area, $\mathrm{m}^{2} / \mathrm{m}^{3}$ & 2,292 \\
\hline
\end{tabular}


Mechanical Specifications - The test module housing hardware mechanicals are shown in Figure 1 below.

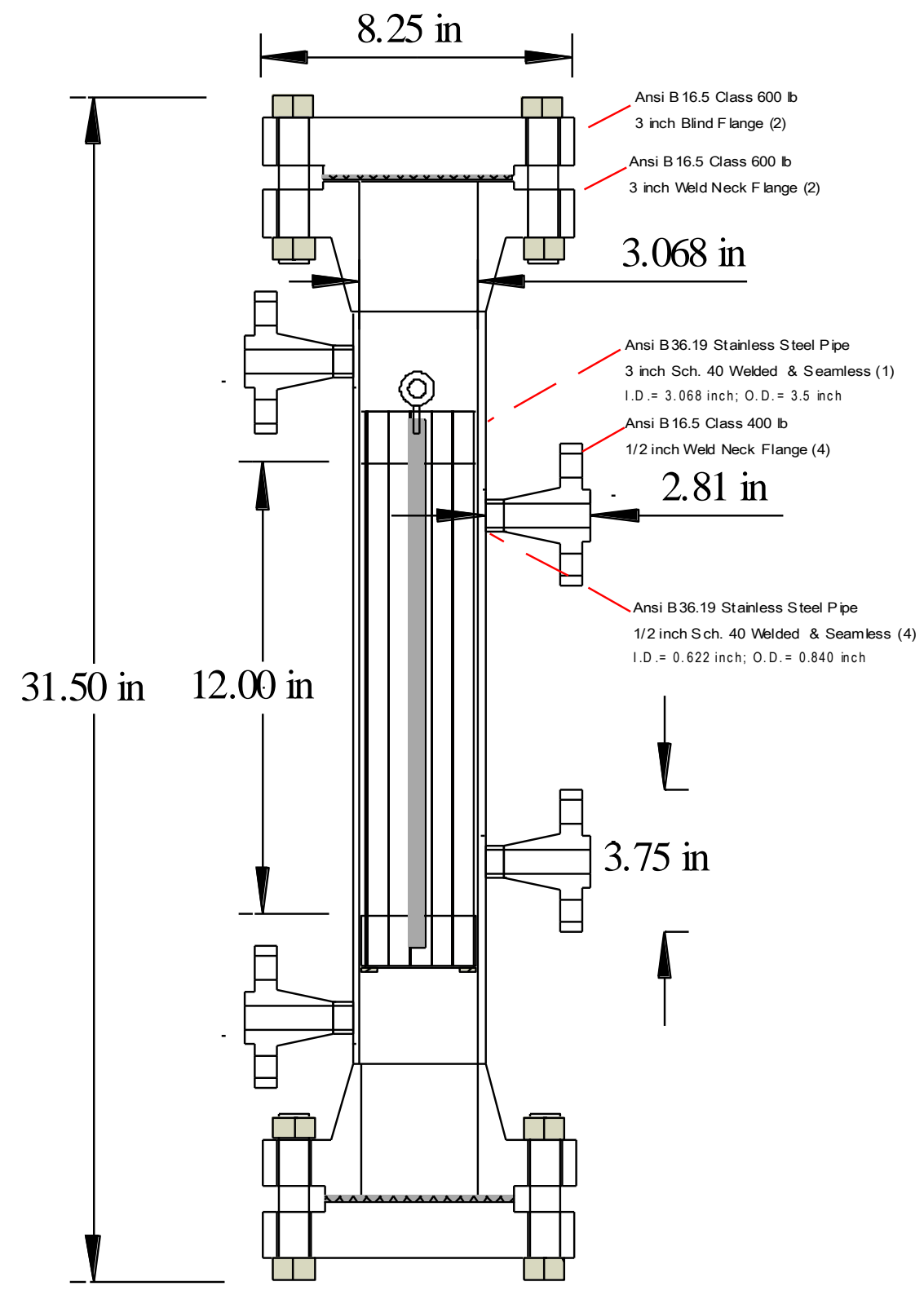

Figure -1 PBI test module mechanicals.

The test module will be fabricated from ANSI stainless steel pipe and flanges with all welded construction. All materials of construction will meet the specified test site pressure and temperature process conditions. All accessible high temperature surfaces will be adequately insulated and otherwise shielded to maintain personnel safety and to maintain the optimum membrane operating temperatures. 
Test Skid Process Flow Diagram (PFD) - A test skid process flow diagram is presented in Figure 2 below. The mass and energy balance in the drawing table is based on the Figure $-3,1.0 \mu \mathrm{m}$ case given in Table 1 having a membrane element specified in Table 2. The stream compositions, $\mathrm{CO}_{2}$ retentate capture rate, $\mathrm{H}_{2}$ permeate recovery and mass and energy flows are controlled by control valves RTCV in retentate stream 2 CO2CAP and control valve PMCV in stream 4 permeate H2FL.

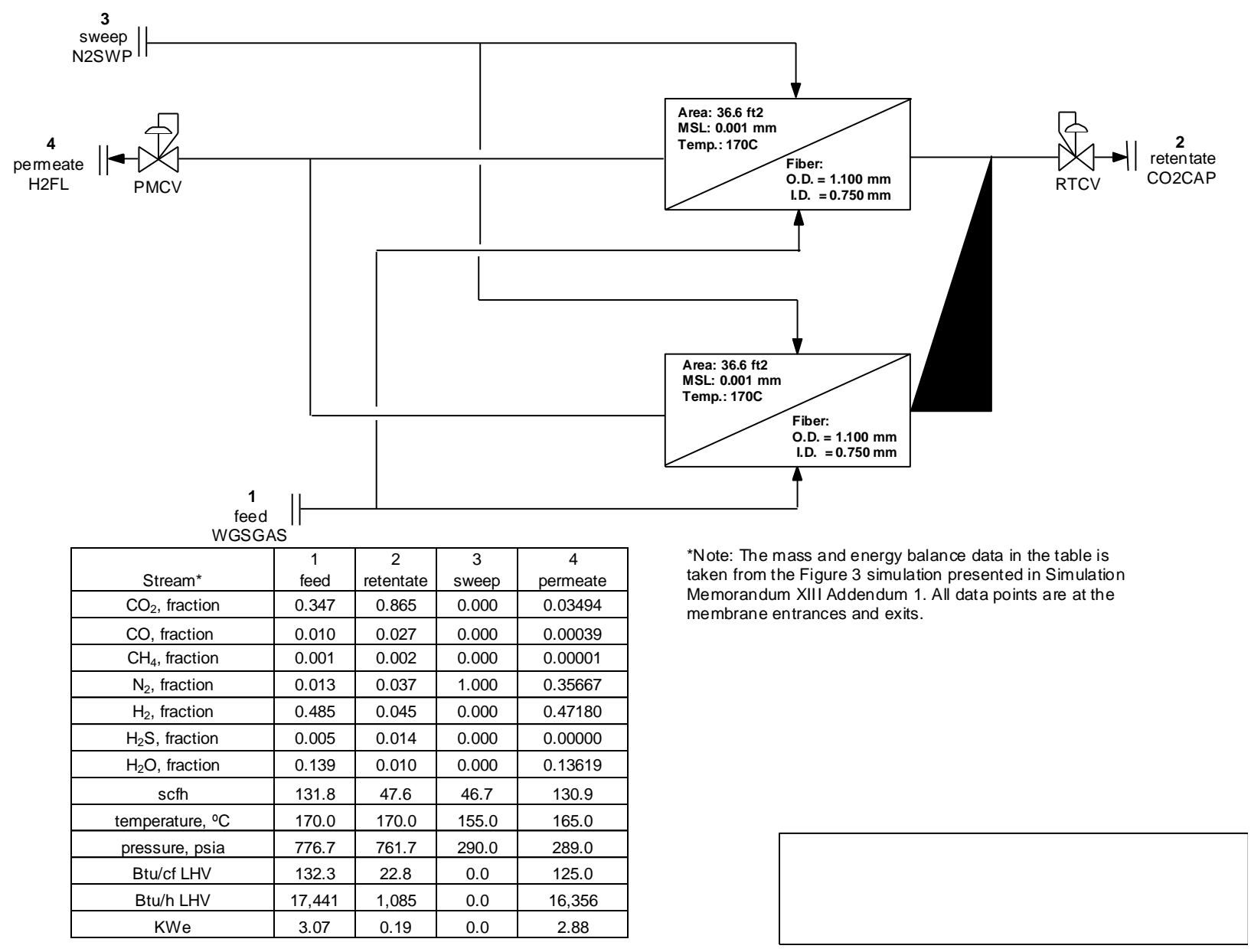

Figure 2 - Test skid process flow diagram

Test Skid Process and Instrument Diagram (PID) - The test skid PID is presented in Figure 3. The PID shows two test modules fitted in parallel with manually operated 
isolation valves, remotely operated butter-fly quick shutdown valves, blow down pressure relief valve PR1/2BF, mass turbine flow meters, sample ports, and pressure and temperature indicators.

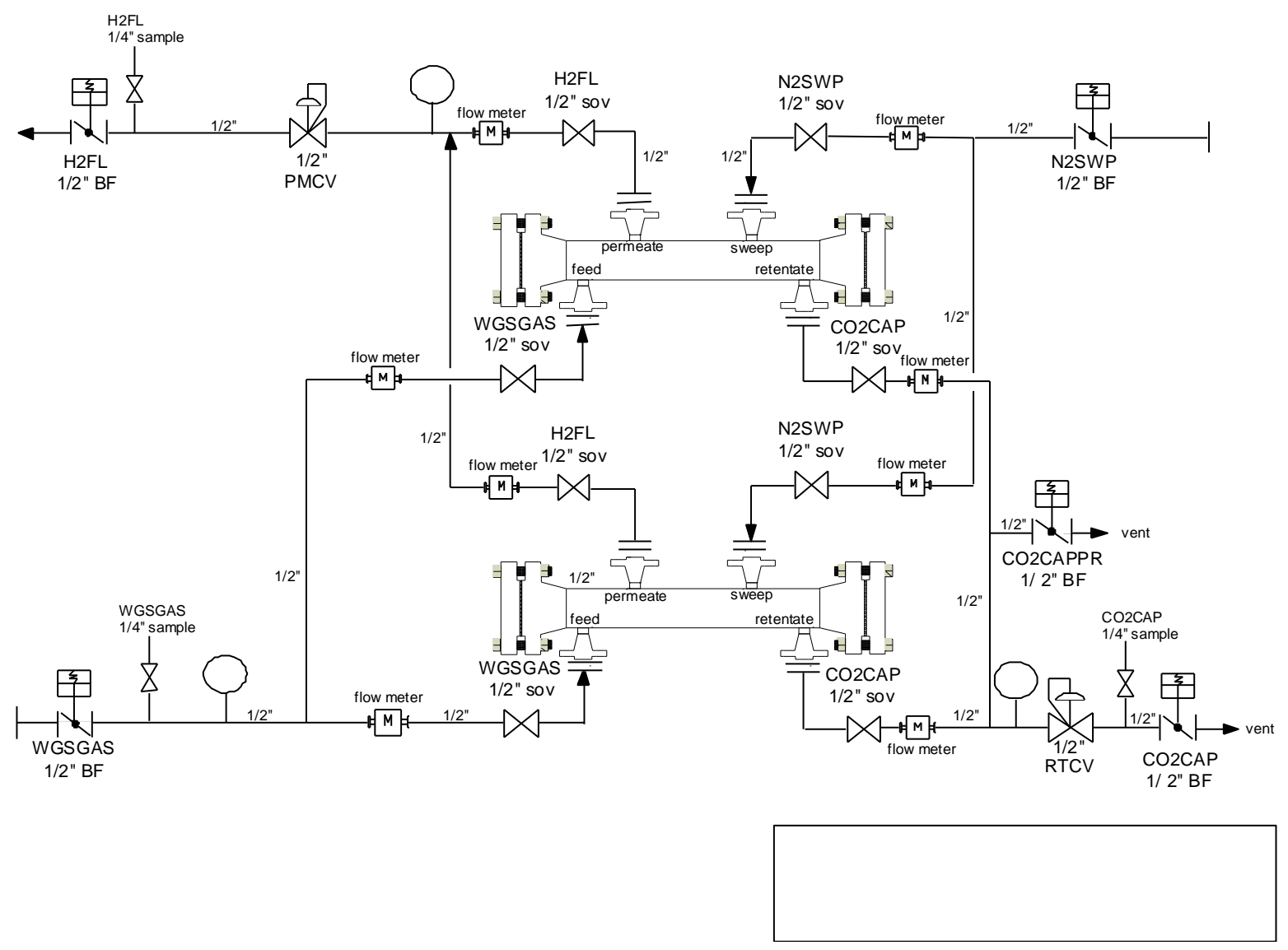

Figure 3 - Test Skid PID diagram

\section{PBI Test Skid start-up and shut-down Protocols -}

1. Start-up

a. Open membrane shut-off vales (sov) (8):

i. WGSGAS $1 / 2 "$ sov (2)

ii. CO2CAP $1 / 2$ " sov (2)

iii. H2FL $1 / 2$ " sov (2)

iv. N2SWP $1 / 2$ " sov (2)

b. Open membrane butterfly valves:

i. WGSGAS $1 / 2 "$ BF (1)

ii. CO2CAP $1 / 2 "$ BF (1)

iii. H2FL $1 / 2$ " BF (1)

iv. N2SWP $1 / 2$ " BF (1)

c. Set permeate pressure control valve PMCV $1 / 2$ " to establish $274.3 \mathrm{psig}$ (289.0 psia) in H2FL permeate stream. Set retentate pressure control valve RTCV 1/2" to establish 747.0 psig (761.7 psia) in CO2CAP retentate stream. 
d. Record pressures, temperatures and flows:

i. Feed - WGSGAS P/T and turbine meter M indicators

ii. Retentate $-\mathrm{CO} 2 \mathrm{CAP} \mathrm{P} / \mathrm{T}$ and turbine meter $\mathrm{M}$ indicators

iii. Permeate $-\mathrm{H} 2 \mathrm{FL} \mathrm{P} / \mathrm{T}$ and turbine meter $\mathrm{M}$ indicators

iv. Sweep - N2SWP P/T and turbine meter M indicators

e. Take gas samples at WGSGAS 1/4", CO2CAP 1/4" and H2FL 1/4"

2. Scheduled shut-down

a. Close butterfly valves WGSGAS $1 / 2$ " BF, H2FL 1/2" BF and CO2CAP $1 / 2$ " $\mathrm{BF}$ and open blow down relief valve CO2CAP PR $1 / 2$ " BF

b. After a predetermined number of minutes purging the membrane close butterfly valve N2SWP $1 / 2$ " BF

c. Close blow down relief valve CO2CAP PR $1 / 2$ " BF when all P indicators reach $0.0 \mathrm{psig}$

d. Close all membrane isolation valves (SOV) (8)

3. Emergency shut-down:

a. Closes membrane butterfly valves:

i. WGSGAS $1 / 2 " \mathrm{BF}$

ii. $\mathrm{H} 2 \mathrm{FL} \frac{1}{2}$ ” $\mathrm{BF}$

iii. CO2CAP $1 / 2$ " BF

iv. N2SWP $1 / 2$ " BF

4. Post operation membrane purge confirmation:

a. Open relief blow down CO2CAP PR $1 / 2$ " BF and then open N2SWP $1 / 2$ " $\mathrm{BF}$ for a predetermined number of minutes

b. Close N2SWP $1 / 2 " B F$

c. Close relief blow down CO2CAP PR $1 / 2$ " BF when pressure indicators are $0.0 \mathrm{psig}$

\section{Preliminary Test Module Skid Elevations and Plan Drawings -}




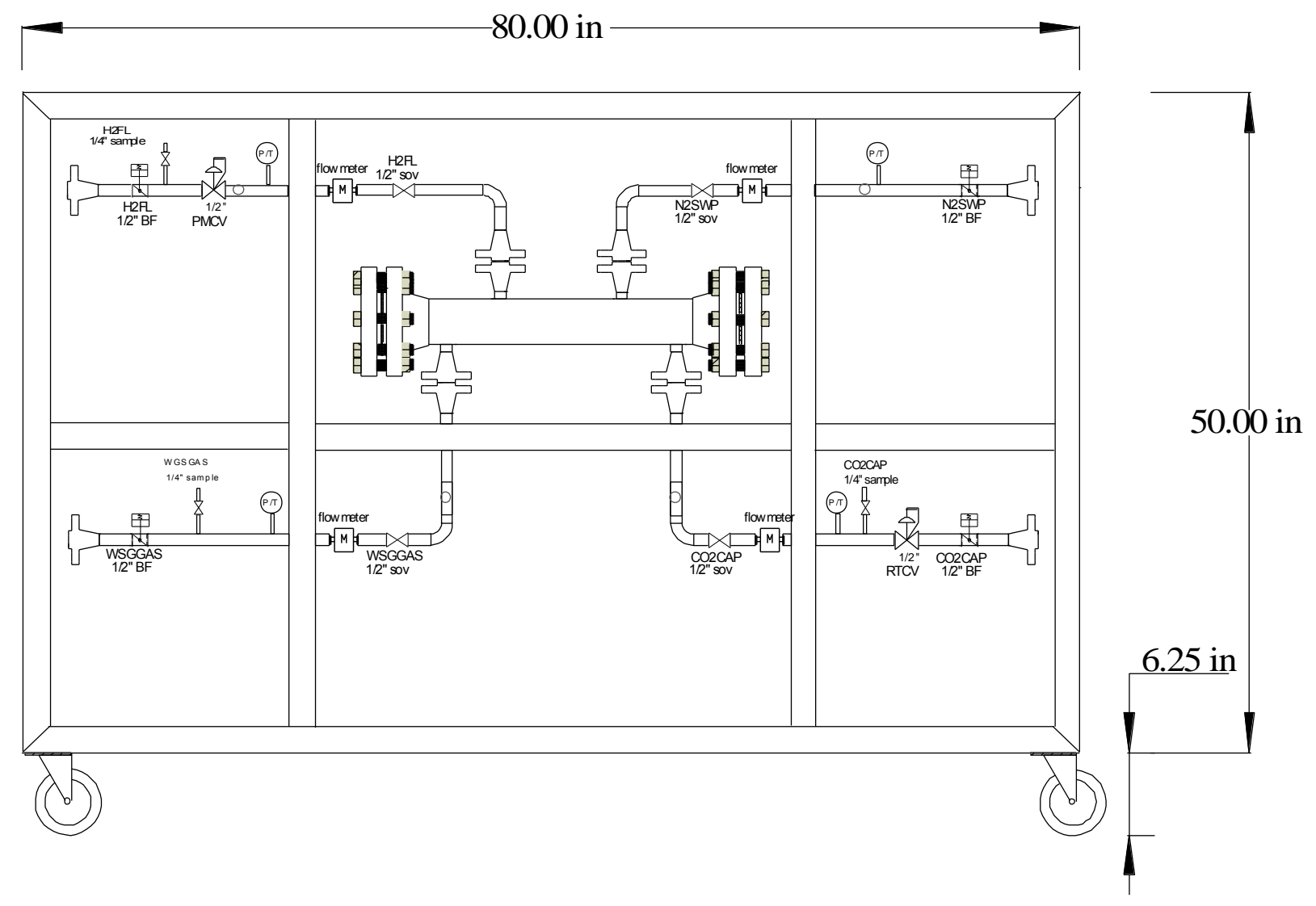

Figure 4 - Front elevation view

D - 54 

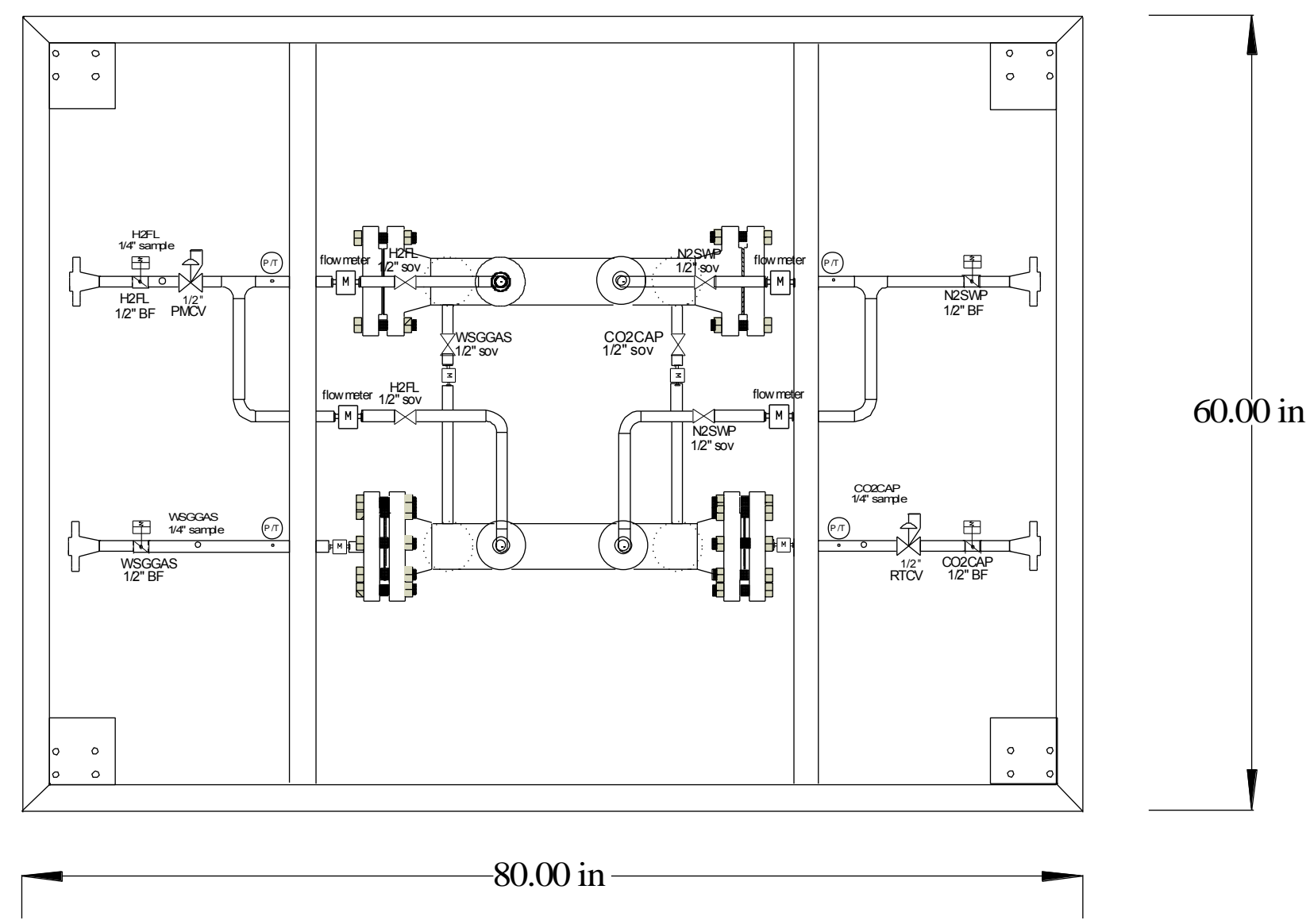

Figure 5 - Top plan view 


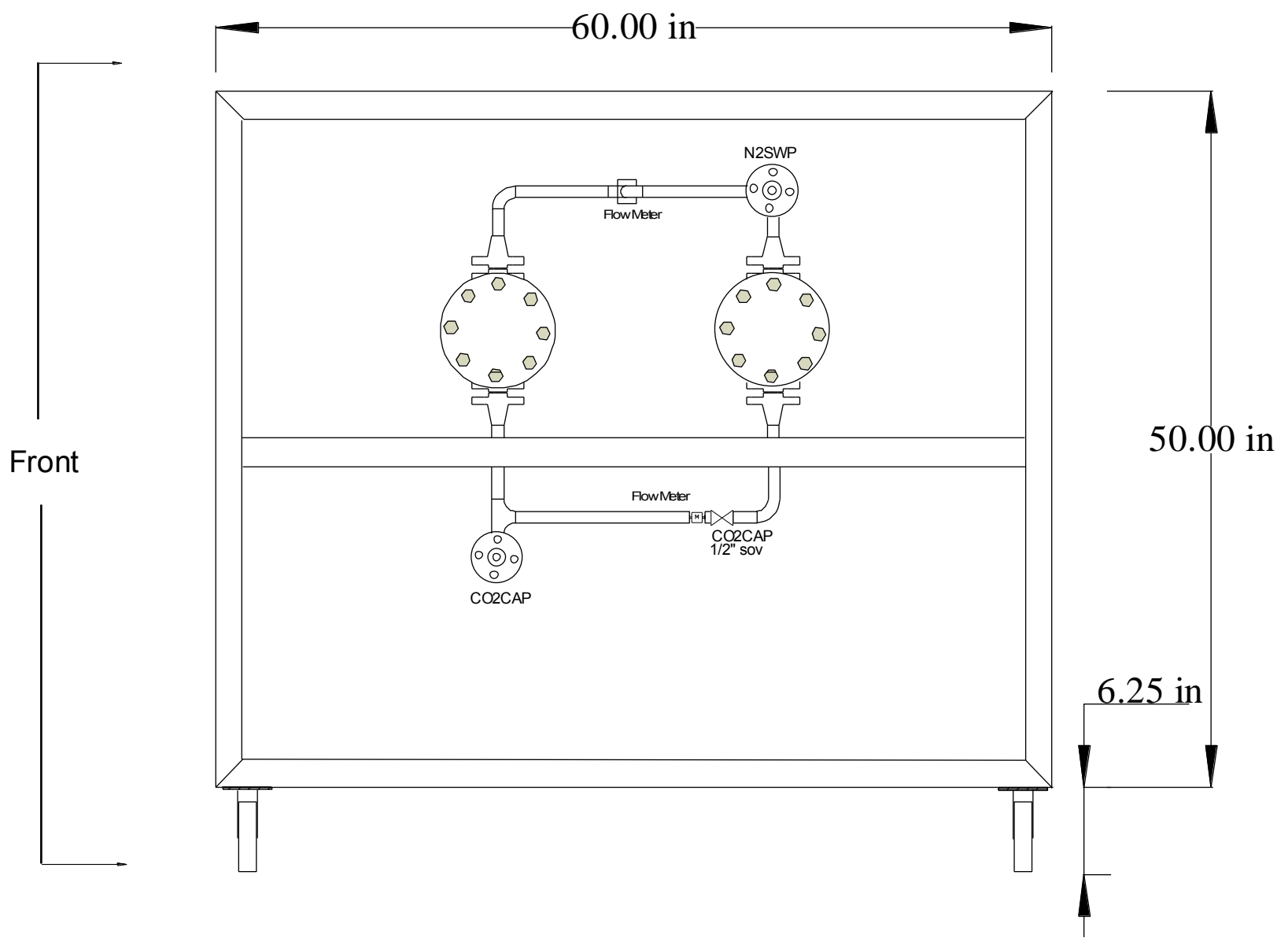

Figure 6 - Right side elevation view

D - 56 


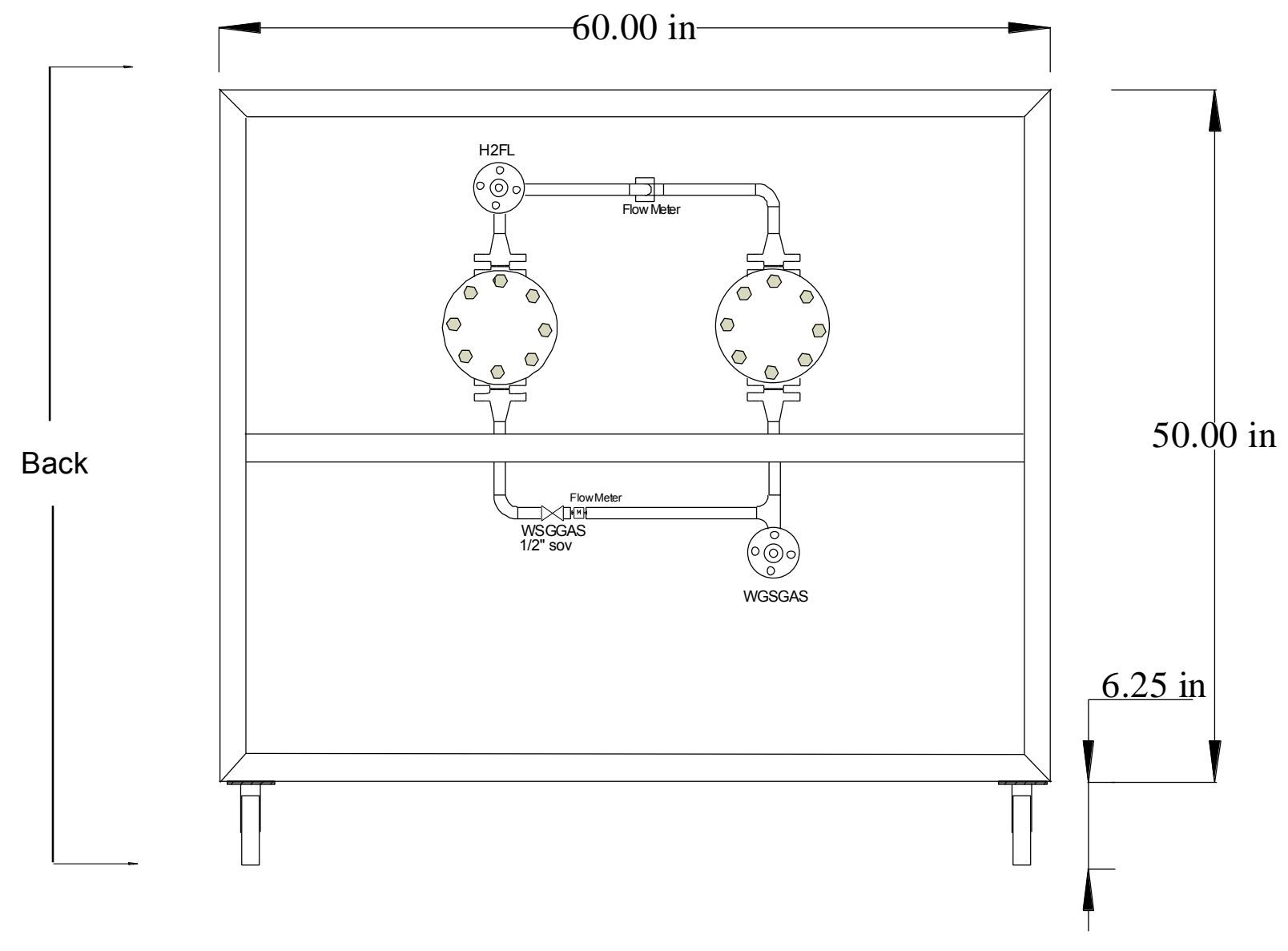

Figure 7 - Left side elevation view

Figures 4, 5, 6 and 7 show preliminary layout drawings of the two test modules and associated valves, piping and fittings set in an existing Enerfex pilot skid frame having the overall given dimensions. A separate control panel, not shown, will have switches to operate the butter-fly valves, labeled gauges or a display screen for all pressure and temperature indicators and turbine meters readings and sample tubes connected to all sample ports. Not shown is insulation and shielding of all hot surfaces to prevent personnel injuries and to maintain the proper membrane operating temperature.

\section{Effect on Test Module Performance by Changing Hollow Fiber Dimensions- A} change in dimensions in the hollow fiber O.D. and I.D. will affect the test module performance in some respects and not in others. If a $600 \mu \mathrm{m}$ O.D. by a $400 \mu \mathrm{m}$ I.D. fiber is packaged in the test module as described above for the 1100 O.D. fiber, i.e., having a nominal 3 inch diameter by 1 foot long membrane element with $63 \%$ fiber packing density, then the shell side membrane area is $67 \mathrm{ft}^{2}$ and $134 \mathrm{ft}^{2}$ for two modules in parallel in the test skid. The membrane element specifications for such a fiber based on a shell side MSL are presented in Table 3 below. 


\begin{tabular}{|c|c|}
\hline Table - 3 & Test Module: $3 "$ " × 1' Element \\
\hline Fiber O.D/I.D. & $600 \mu \mathrm{m} / 400 \mu \mathrm{m}$ \\
\hline Lumen side/shell side vol. ratio & 0.79 \\
\hline Element volume, $\mathrm{m}^{3}$ & 0.00148 \\
\hline Fiber volume, $\mathrm{m}^{3}$ & 0.00094 \\
\hline Fiber packing & $63.0 \%$ \\
\hline Total fiber length per element, $\mathrm{m}$ & 3,308 \\
\hline Number of fibers per element & 10,854 \\
\hline Module membrane area, $\mathrm{m}^{2}$ & 6.2 \\
\hline Module membrane area, $\mathrm{ft}^{2}$ & 67 \\
\hline Specific membrane area, $\mathrm{m}^{2} / \mathrm{m}^{3}$ & 4,200 \\
\hline
\end{tabular}

The $600 \mu \mathrm{m}$ O.D. fiber with the same percent packing density occupies the same fiber volume as the $1100 \mu \mathrm{m}$ O.D, fiber. However the smaller O.D. fiber yields about 11 times the number of fibers and about 1.8 times more membrane surface area and specific membrane area. Assuming the same viscous free flow through the porous support layer and the same membrane separation layer thickness, $\mathrm{H}_{2}$ GPU and membrane power density $\left(\mathrm{kWe} / \mathrm{ft}^{2)}\right.$ would be the same for both fibers. Commercial Separator modules using the smaller O.D. fiber would need $45 \%$ fewer separator units per MW. 


\section{D-13. SINGLE STAGE OPTIMIZATION FOR LOWER $\mathrm{H}_{2} / \mathrm{CO}_{2}$ SELECTIVITY}

$\mathrm{H}_{2}$ Recovery Optimization with Lower Permeability and Higher Selectivity at $\mathbf{1 7 0}^{\circ} \mathrm{C}$ - Previous PBI Simulation Memoranda have shown that with design parameters of 778.7

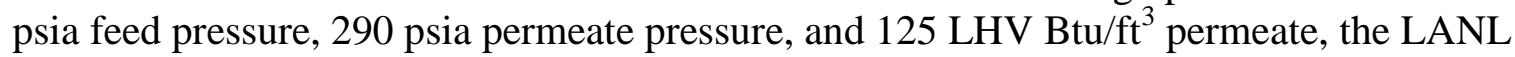
measured $\mathrm{H}_{2} / \mathrm{CO}_{2}$ selectivity of 42.9 at $250^{\circ} \mathrm{C}$ could not achieve both the $96+\% \mathrm{H}_{2}$ recovery and $90 \% \mathrm{CO}_{2}$ capture targets. See PBI Simulation Memoranda VI and VII. The LANL $\mathrm{H}_{2} / \mathrm{CO}_{2}$ mixed gas selectivity data was presented in PBI Simulation Memorandum $\mathrm{V}$. With the given design parameters higher $\mathrm{H}_{2} / \mathrm{CO}_{2}$ selectivity is required to achieve the performance targets.

Therefore to achieve both $\mathrm{H}_{2}$ recovery and $\mathrm{CO}_{2}$ capture targets an aggressive case was proposed based on an extrapolation of membrane performance to $170^{\circ} \mathrm{C}$ from two LANL permeability and selectivity data points at $250^{\circ} \mathrm{C}$ and $400^{\circ} \mathrm{C}$, thereby decreasing $\mathrm{H}_{2}$ permeability from $87.6 \mathrm{Barrer}$ at $250^{\circ} \mathrm{C}$ to $20 \mathrm{Barrer}$ at $170^{\circ} \mathrm{C}$ with a consequent increase in $\mathrm{H}_{2} / \mathrm{CO}_{2}$ selectivity from 42.9 to 90.0 . See PBI Simulation Memorandum VII.

Table 1 compares two PBI single stage membrane performance cases: one at $250^{\circ} \mathrm{C}$ and a $\mathrm{H}_{2} / \mathrm{CO}_{2}$ selectivity of 42.9 and the other, the so called aggressive case, extrapolated to $170^{\circ} \mathrm{C}$ and a $\mathrm{H}_{2} / \mathrm{CO}_{2}$ selectivity of 90.0 .

Table 1 - Single stage higher selectivity and lower permeability performance for $778.7 \mathrm{psia}$ feed pressure, $90 \% \mathrm{CO}_{2}$ capture, and $125 \mathrm{LHV} \mathrm{Btu/cf}$ permeate

\begin{tabular}{|c|c|c|c|c|c|c|c|c|c|c|c|c|}
\hline Case & $\begin{array}{l}\text { perm. } \\
\text { psia }\end{array}$ & $\begin{array}{l}\text { retent. } \\
\text { psia }\end{array}$ & temp. & $\mathrm{l} / \mathrm{\textrm {CO } _ { 2 }}$ & $\begin{array}{l}\text { MSL } \\
\mu \mathrm{m}\end{array}$ & $\begin{array}{c}\text { Sweep gas } \\
\text { compression } \\
\text { MW/MWe }\end{array}$ & $\begin{array}{l}\text { Net } \\
\text { MWe }\end{array}$ & $\begin{array}{c}\text { Net } \\
\mathrm{kWe} / \mathrm{ft}^{2}\end{array}$ & $\begin{array}{c}\text { MBR. } \\
\mathrm{m}^{2} / \mathrm{MWe}\end{array}$ & $\begin{array}{l}\text { acfh/ } \\
\text { element }\end{array}$ & $\begin{array}{l}\mathrm{H}_{2} \\
\text { rec. }\end{array}$ & $\begin{array}{l}\mathrm{H}_{2} \\
\text { GPU }\end{array}$ \\
\hline 1 & 290 & 761.7 & $250^{\circ} \mathrm{C}$ & 2.9 & 1.334 & 0283 & 0.863 & 0.207 & 437 & 281 & $85.8 \%$ & 65.7 \\
\hline 2 & 290 & 761.7 & $170 C^{-}$ & 90.0 & 0.165 & 0.0288 & 0.971 & 0.231 & 402 & 279 & $96.6 \%$ & 12 \\
\hline
\end{tabular}

In Case 1 the lower selectivity of 42.9 at $250^{\circ} \mathrm{C}$ only achieves $85.8 \% \mathrm{H}_{2}$ recovery with a feed pressure of $778.7 \mathrm{psia}$, a permeate pressure of $290 \mathrm{psia}$, a $90 \% \mathrm{CO} 2$ capture rate and a permeate LHV of $125 \mathrm{Btu} / \mathrm{cf}$. In Case 2, the aggressive case, the $\mathrm{H}_{2}$ recovery is substantially higher at $96.6 \%$.

Due to mechanical volume constraints in the module housing and membrane fiber element design, the maximum actual volumetric feed flow is limited to about \pm 280 acfh per element. In order not to exceed the actual volumetric feed flow limit, membrane thickness changes inversely with $\mathrm{H}_{2}$ GPU. The higher the $\mathrm{H}_{2}$ GPU the lower the membrane thickness that is needed to maximize the module unit's feed flow to the limiting feed flow. In all cases in Table 1 and Table 2 the average of membrane energy 
density in $\mathrm{kWe} / \mathrm{ft}^{2}$ and of specific membrane area in $\mathrm{m}^{2} / \mathrm{MWe}$ vary within a narrow range of $\pm 10.6 \%$ and $\pm 8.7 \%$ respectively.

$\mathrm{H}_{2}$ Recovery Optimization with higher permeability and Lower Selectivity at $250^{\circ} \mathrm{C}$ - A way to optimize higher $\mathrm{H}_{2}$ recovery and $\mathrm{CO}_{2}$ capture in single stage membrane is to lower permeate back pressure. In Case 3 in Table 2, with a selectivity of 42.9, permeate pressure is reduced from 290 psia to 135 psia which increases $\mathrm{H}_{2}$ recovery from $85.8 \%$ to $96.1 \%$ while maintaining $90 \% \mathrm{CO}_{2}$ capture. Although power is needed to compress the permeate to 290 psia, net MWe in Case 3 increases to 0.911 compared to 0.863 in Case 1 . The 0.911 net MWe in Case 3 is $93.2 \%$ of the 0.977 net MWe achieved in the aggressive Case 2 at $170^{\circ} \mathrm{C}$ in Table 1 . In Case 4 Table 2, lowering the permeate pressure further to 70 psia increases $\mathrm{H}_{2}$ recovery to $99.5 \%$ although with a greater reduction in net MWe to 0.876 when the permeate is recompressed from 70 psia to 290 psia. If an energy conversion means having $60 \%$ efficiency equivalent to a combined cycle efficiency was available and able to utilize 70 psia permeate, thus obviating the need to compress the permeate from 70 psia to 290 psia, then the net MWe would be 1.028 not 0.876 .

Table 2 - Single stage lower permeate pressure for 778.7 psia feed pressure, $90 \%$ $\mathrm{CO}_{2}$ capture, and $125 \mathrm{LHV}$ Btu/cf permeate

\begin{tabular}{|c|c|c|c|c|c|c|c|c|c|c|c|c|}
\hline Case & $\begin{array}{r}\text { perm. } \\
\text { psia }\end{array}$ & $\begin{array}{c}\text { retent. } \\
\text { psia }\end{array}$ & temp. & $\mathrm{\alpha H}_{2} / \mathrm{CO}_{2}$ & $\begin{array}{r}\text { MSL } \\
\mu \mathrm{m} \\
\end{array}$ & $\begin{array}{c}\text { permeate } \\
+ \\
\text { swp. } \\
\text { compr. } \\
\text { MW/MWe } \\
\end{array}$ & $\begin{array}{l}\text { Net } \\
\text { MWe }\end{array}$ & $\begin{array}{c}\text { Net } \\
\mathrm{kWe} / \mathrm{ft}^{2}\end{array}$ & $\begin{array}{c}\text { MBR. } \\
\mathrm{m}^{2} / \mathrm{MWe}\end{array}$ & $\begin{array}{l}\text { acfh/ } \\
\text { element }\end{array}$ & $\begin{array}{l}\mathrm{H}_{2} \\
\text { rec. }\end{array}$ & $\begin{array}{c}\mathrm{H}_{2} \\
\mathrm{GPU} \\
\end{array}$ \\
\hline 3 & 135 & 761.7 & $250^{\circ} \mathrm{C}$ & 42.9 & 1.519 & 0.0902 & 0.911 & 0.218 & 392 & 280 & $96.1 \%$ & 57.7 \\
\hline 4 & 70 & 761.7 & $250^{\circ} \mathrm{C}$ & 42.9 & 1.595 & 0.1736 & 0.876 & 0.211 & 376 & 282 & $99.5 \%$ & 54.9 \\
\hline 5 & 135 & 761.7 & $250^{\circ} \mathrm{C}$ & 25.0 & 2.305 & 0.0850 & 0.804 & 0.191 & 448 & 279 & $84.4 \%$ & 38.0 \\
\hline 6 & 70 & 761.7 & $250^{\circ} \mathrm{C}$ & 25.0 & 2.402 & 0.1619 & 0.784 & 0.187 & 428 & 279 & $88.2 \%$ & 36.5 \\
\hline
\end{tabular}

In cases 5 and 6 a $\mathrm{H}_{2} / \mathrm{CO}_{2}$ selectivity of 25.0 at the reduced permeate pressures yields unacceptably low net $\mathrm{MWe}$ and $\mathrm{H}_{2}$ recovery.

Case 3 Table 2 appears to be the optimum Case with a $\mathrm{H}_{2} / \mathrm{CO}_{2}$ selectivity of 42.7 and a permeate pressure of 135 to yield $96.1 \% \mathrm{H}_{2}$ recovery and a net MWe of 0.911 which $93.2 \%$ of the aggressive case's net MWe. Lowering the permeate pressure further as in case 4 Table 2 to 70 psia increases $\mathrm{H}_{2}$ recovery $99.5 \%$ however due the higher permeate compression ratio of 290/70, net MWe is reduced to 0.876 . The membrane power density in Cases 3 and 4 is $0.218 \mathrm{kWe} / \mathrm{ft}^{2}$ and $0.211 \mathrm{kWe} / \mathrm{ft}^{2}$ respectively, which is $94.4 \%$ and $91.3 \%$ of the aggressive case membrane power density respectively. 
Mechanical design constraints in the module and membrane element, which limit the maximum actual volumetric flow, requires a relatively thicker dense layer of $1.5 \mu \mathrm{m}$ in Case 3 which is about ten times that of the aggressive case. Having a thicker composite dense layer should be a significant enabling factor in eliminating the micro-hole defects which have been the main challenge in perfecting performance of hollow fiber PBI membranes samples produced to date.

\section{Optimum Case 3 Performance Relative to SRI Test Results of Produced Hollow}

Fiber WFX-45 - In Figure 1 it appears that the data point for the optimum Case 3

simulation result presented in Table 2 with a selectivity of 42.9 and a $\mathrm{H}_{2}$ GPU of 57.7 is proximate to the higher test data point for WFX-45. A future produced hollow fiber having about a $1.5 \mu \mathrm{m}$ dense layer thickness and somewhat higher selectivity than WFX45 would match the performance of the optimum Case 3 simulation.

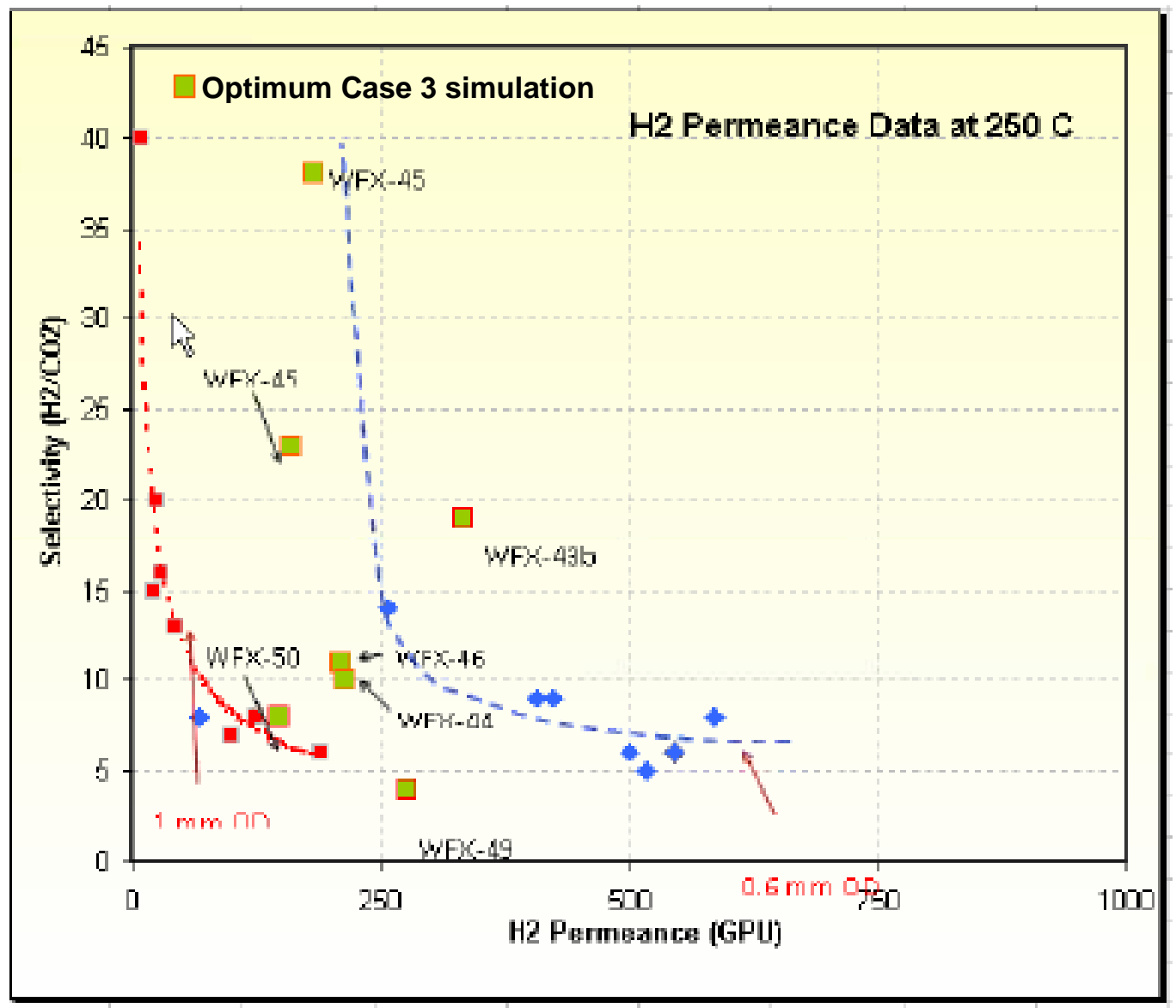

Figure-1 SRI White Fox hollow fiber test results 


\section{There are Two Common Types of 2-Stage Configuration -}

1. A series configuration where the first stage retentate is fed to the second stage and the second stage permeate is compressed and recycled to the first stage feed, and,

2. A cascade configuration where the first stage permeate is compressed and fed to the second stage and the second stage retentate is recycled to the first stage feed.

Figure 1 shows a flow diagram of each configuration.

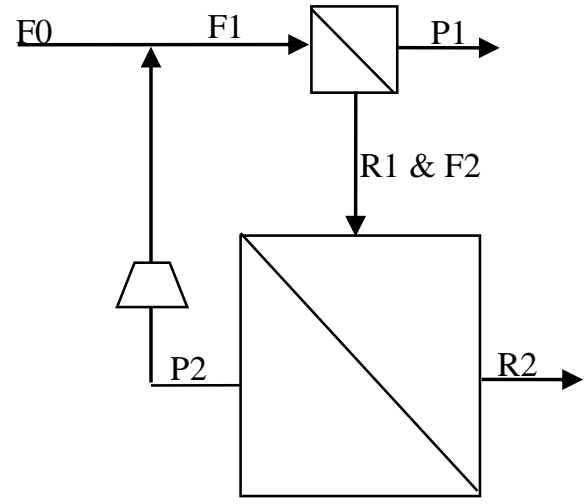

Series Configuration

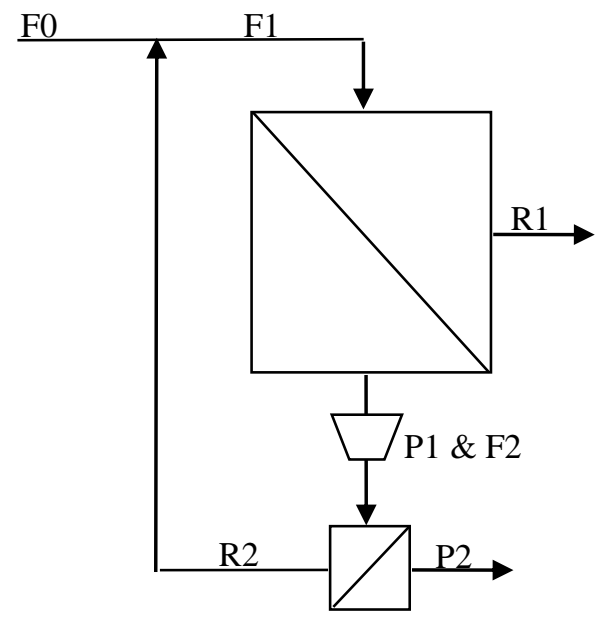

Cascade Configuration

Figure 1 - Typical 2-stage configurations.

In general the first stage of the series configuration and the second stage of the cascade configuration are usually the smaller membrane area stage. In these stages, at typical industrial operating temperature and pressure such as $\mathrm{CO}_{2}$ removal from natural gas for example, the more permeable component, usually the more condensable solubility limited gas like $\mathrm{CO}_{2}$, has higher mixed gas selectivity over a less condensable diffusivity limited gas like $\mathrm{CH}_{4}$. This mixed gas effect is caused by operating the smaller stage at low recovery of the higher permeability gas on the permeate side of the membrane and as a consequence having higher partial pressure of the more permeable gas in the feed to retentate side of the membrane. The higher partial pressure on the feed side of the membrane causes the fractional free volume in the membrane material, through which all the gas molecules must permeate, to become saturated with dissolved more permeable gas molecules, thus lowering the mixed gas permeability of the diffusivity limited gas like $\mathrm{CH}_{4}$ by impeding its transport through the fractional free volume. Under these operating conditions the recovery of the diffusivity limited gas in the second stage recycle, $\mathrm{P} 2$ in the series configuration and $\mathrm{R} 2$ in cascade configuration, ranges from $33 \%$ to $37 \%$ and $96 \%$ to $99 \%$ respectively. The purity of the more permeable gas in permeate $\mathrm{P} 1$ of the series configuration and permeate $\mathrm{P} 2$ of the cascade configuration is Typically 
$93 \%$ to $96 \%$ and recovery $81 \%$ to $95 \%$ depending on the feed concentration of the more permeable gas in F0.

In general the second stage of the series configuration and the first stage of the cascade configuration have the larger membrane area. In these stages the recovery of the more permeable gas in the permeate is higher. The consequent lower partial pressure of the more permeable gas on the feed to retentate side of the membrane results in a lower mixed gas selectivity of the more permeable gas over the less permeable gas because the permeation of the less permeable diffusivity limited gas is not impeded by a partial pressure driven abundance of the more condensable molecules dissolved in the membrane fractional free volume. Under these operating conditions the purity and recovery of the less permeable diffusivity limited gas in the retentate R2 of the series configuration and retentate R1 of the cascade configuration can be up to $98 \%$ and $97 \%$ to $99 \%$ respectively.

2-Stage PBI Membrane Series Configuration - As a general rule the series configuration is used when the concentration of the more permeable gas in feed F0 is $40 \%$ or higher and the cascade configuration when the concentration of the more permeable component is less than $40 \%$. Since the PBI membrane feed F0 contains about $49 \% \mathrm{H}_{2}, 35 \% \mathrm{CO}_{2}, 14 \% \mathrm{H}_{2} \mathrm{O}$ and a combined $2 \%$ of $\mathrm{N}_{2}, \mathrm{CO}, \mathrm{H}_{2} \mathrm{~S}$ and $\mathrm{CH}_{4}$ and the concentration of $\mathrm{H}_{2}$, the next most permeable gas after $\mathrm{H}_{2} \mathrm{O}$, is greater than $40 \%$, a series configuration is a logical choice. At $250^{\circ} \mathrm{C}$, the $\mathrm{PBI}$ membrane operating temperature is substantially higher than the dew point of the most condensable gases in the feed F0 and therefore there is no expectation of selectivity differences between the stages due to solubility induced mixed gas effects. For simplification an initial 2-stage simulation of a four component feed $\mathrm{F} 0$ containing $50 \% \mathrm{H}_{2}, 35 \% \mathrm{CO}_{2}, 14 \% \mathrm{H}_{2} \mathrm{O}$ and $1 \%$ of $\mathrm{N}_{2}$ is assumed. Initially, a mixed gas $\mathrm{H}_{2} / \mathrm{CO}_{2}$ selectivity of 42.9 is assumed in both stages.

However, a difference in stage selectivity can also exist due to differences in membrane morphology such that the fractional free in one membrane is reduced or increased compared to the other, thus increasing or decreasing the stage selectivity respectively. Accordingly a 2-stage system with selectivity of 42.9 and 25.0 is also simulated. The smaller fractional free volume membrane stage would have higher selectivity for smaller gas molecules.

A series configuration simulation result, where both stages have a $\mathrm{H}_{2} / \mathrm{CO}_{2}$ selectivity of 42.9, is shown in Appendix 1 - "Series Configuration 42.9/42.9". As can be seen in the summary in Table 1 below, the performance of the 2-stage series configuration has virtually the same result as the 1-stage Case 3 presented in Memorandum XV Part 1. However an unrealistically high second stage feed flow rate of 1,587 acfh/element is necessary, consequently requiring an unrealistically low recycle flow to stage feed ratio of $3.33 \%$. The first stage $\mathrm{CO}_{2}$ retentate recovery is $90.3 \%$ making the need for a second the need for a second stage unnecessary. Compared to 1-stage Case 3, the two stage configuration has a diminished $\mathrm{H}_{2}$ recovery of $95.4 \% \%$. 
Table 1 - 1-stage Case 3 and 2-stage series 429./42.9 at lower permeate pressure with 778.7 psia feed pressure, $90 \% \mathrm{CO}_{2}$ capture, and $125 \mathrm{LHV} \mathrm{Btu/cf} \mathrm{permeate}$

\begin{tabular}{|c|c|c|c|c|c|c|c|c|c|c|c|c|}
\hline & $\begin{array}{c}\text { perm. } \\
\text { psia }\end{array}$ & $\begin{array}{c}\text { retent. } \\
\text { psia }\end{array}$ & temp. & $\mathrm{aH}_{2} / \mathrm{CO}_{2}$ & $\begin{array}{c}\mathrm{MSL} \\
\mu \mathrm{m}\end{array}$ & $\begin{array}{c}\text { permeate }+ \\
\text { swp. compr. } \\
\mathrm{MW} / \mathrm{MWe}\end{array}$ & $\begin{array}{c}\mathrm{Net} \\
\mathrm{MWe}\end{array}$ & $\begin{array}{c}\mathrm{Net} \\
\mathrm{kWe} / \mathrm{ft}^{2}\end{array}$ & $\begin{array}{c}\mathrm{MBR} . \\
\mathrm{m}^{2} / \mathrm{MWe}\end{array}$ & $\begin{array}{c}\text { acfh/ } \\
\text { element }\end{array}$ & $\begin{array}{c}\mathrm{H}_{2} \\
\text { rec. }\end{array}$ & $\begin{array}{c}\mathrm{H}_{2} \\
\mathrm{GPU}\end{array}$ \\
\hline $\begin{array}{c}\text { 1-stage } \\
\text { Case 3 }\end{array}$ & 135 & 761.7 & $250^{\circ} \mathrm{C}$ & 42.9 & 1.519 & 0.0901 & 0.911 & 0.218 & 392 & 280 & $96.1 \%$ & 57.7 \\
\hline $\begin{array}{c}\text { 2-stage } \\
\text { series }\end{array}$ & 135 & 746.7 & $250^{\circ} \mathrm{C}$ & $42.9 / 42.9$ & 1.519 & 0.0903 & 0.921 & 0.213 & 400 & $293 / 1587$ & $95.4 \%$ & 57.7 \\
\hline
\end{tabular}

A series configuration simulation having a first stage $\mathrm{H}_{2} / \mathrm{CO}_{2}$ selectivity of 42.9 and a second stage $\mathrm{H}_{2} / \mathrm{CO}_{2}$ selectivity of 25.0 is shown in Appendix 1 - "Series Configuration 42.9/25.0". The results summarized in Table 2 shows the second stage has substantially poorer performance that the 1-stage Case 3. Though the acfh/element feed flow rate is acceptable in each stage, compared to 1-stage Case 3 the membrane power density per unit area is about $43.6 \%$ lower and the membrane area per MWe is about $76.5 \%$ higher. The first stage $\mathrm{CO}_{2}$ recovery in the retentate at $90.3 \%$ makes the need for a second stage unnecessary. $\mathrm{H}_{2}$ recovery of $92.2 \%$ with a $\mathrm{CO}_{2}$ capture of $90 \%$ is less than the $95.4 \% \mathrm{H}_{2}$ recovery in the 2-stage with the same selectivity in each stage and worse compared to the $96.1 \% \mathrm{H}_{2}$ recovery in 1 - stage Case 3 .

Table 2 - 1-stage Case 3 and 2-stage series 42.9/25.0 at lower permeate pressure with 778.7 psia feed pressure, $90 \% \mathrm{CO}_{2}$ capture, and $125 \mathrm{LHV} \mathrm{Btu} / \mathrm{cf}$ permeate

\begin{tabular}{|c|c|c|c|c|c|c|c|c|c|c|c|c|}
\hline & $\begin{array}{c}\text { perm. } \\
\text { psia }\end{array}$ & $\begin{array}{c}\text { retent. } \\
\text { psia }\end{array}$ & temp. & $\mathrm{aH}_{2} / \mathrm{CO}_{2}$ & $\begin{array}{c}\mathrm{MSL} \\
\mu \mathrm{m}\end{array}$ & $\begin{array}{c}\text { permeate }+ \\
\text { swp. compr. } \\
\mathrm{MW} / \mathrm{MWe}\end{array}$ & $\begin{array}{c}\mathrm{Net} \\
\mathrm{MWe}\end{array}$ & $\begin{array}{c}\mathrm{Net} \\
\mathrm{kWe} / \mathrm{ft}^{2}\end{array}$ & $\begin{array}{c}\mathrm{MBR} . \\
\mathrm{m}^{2} / \mathrm{MWe}\end{array}$ & $\begin{array}{c}\text { acth/ } \\
\text { element }\end{array}$ & $\begin{array}{c}\mathrm{H}_{2} \\
\text { rec. }\end{array}$ & $\begin{array}{c}\mathrm{H}_{2} \\
\mathrm{GPU}\end{array}$ \\
\hline $\begin{array}{c}\text { 1-stage } \\
\text { Case 3 }\end{array}$ & 135 & 761.7 & $250^{\circ} \mathrm{C}$ & 42.9 & 1.519 & 0.0943 & 0.911 & 0.218 & 392 & 280 & $96.1 \%$ & 57.7 \\
\hline $\begin{array}{c}\text { 2-stage } \\
\text { series }\end{array}$ & 135 & 746.7 & $250^{\circ} \mathrm{C}$ & $42.9 / 25.0$ & 1.519 & 0.0903 & 0.889 & 0.123 & 692 & $339 / 196$ & $92.2 \%$ & 57.7 \\
\hline
\end{tabular}

A 1-stage Case 3a and 2-stage series configuration simulation results wherein all stages are assumed to have a $\mathrm{H}_{2} / \mathrm{CO}_{2}$ selectivity of 25.0 is presented in Appendix 1 -"1-Stage Configuration 25.0" and "Series Configuration 25.0/25.0". It can be seen in the results summarized in Table 3 below that the performance of the 1-stage Case $3 \mathrm{a}$ with a selectivity of 25.0 does not perform nearly as well as the 1-stage case 3 with a selectivity of 42.9. Critical parameters such as $\mathrm{H}_{2}$ recovery and therefore feed gas energy recovery are substantially below our performance targets. The 2 -stage series configuration 25.0 once again, as in the in previous higher selectivity 1-stage and series configuration comparison cases, has virtually the same performance as the 1-stage Case 3a. As in the previous series configuration 42.9/42.9 case an unachievable second stage feed flow rate of 1,541 acfh/element and a consequently unrealistically low recycle flow to feed stage ratio of $3.75 \%$ is required. The first stage $\mathrm{CO}_{2}$ retentate recovery is $90.3 \%$ making the need for a second the need for a second stage unnecessary. Compared to 1-stage Case 3a, the two stage configuration 25.0 performs like the 1-stage 3 a process but with diminished $\mathrm{H}_{2}$ recovery of $83.9 \%$ compared to $84.9 \%$ 
Table 3 - 1-stage Case 3a and 2-stage series 25.0/25.0 at lower permeate pressure with 778.7 psia feed pressure, $90 \% \mathrm{CO}_{2}$ capture, and $125 \mathrm{LHV} \mathrm{Btu/cf}$ permeate

\begin{tabular}{|c|c|c|c|c|c|c|c|c|c|c|c|c|}
\hline & $\begin{array}{c}\text { perm. } \\
\text { psia }\end{array}$ & $\begin{array}{c}\text { retent. } \\
\text { psia }\end{array}$ & temp. & $\mathrm{aH}_{2} / \mathrm{CO}_{2}$ & $\begin{array}{c}\mathrm{MSL} \\
\mu \mathrm{m}\end{array}$ & $\begin{array}{c}\text { permeate }+ \\
\text { swp. compr. } \\
\mathrm{MW} / \mathrm{MWe}\end{array}$ & $\begin{array}{c}\mathrm{Net} \\
\mathrm{MWe}\end{array}$ & $\begin{array}{c}\mathrm{Net} \\
\mathrm{kWe} / \mathrm{ft}^{2}\end{array}$ & $\begin{array}{c}\mathrm{MBR} . \\
\mathrm{m}^{2} / \mathrm{MWe}\end{array}$ & $\begin{array}{c}\text { acfh/ } \\
\text { element }\end{array}$ & $\begin{array}{c}\mathrm{H}_{2} \\
\text { rec. }\end{array}$ & $\begin{array}{c}\mathrm{H}_{2} \\
\mathrm{GPU}\end{array}$ \\
\hline $\begin{array}{c}\text { 1-stage } \\
\text { Case 3 }\end{array}$ & 135 & 761.7 & $250^{\circ} \mathrm{C}$ & 42.9 & 1.519 & 0.0902 & 0.911 & 0.218 & 392 & 280 & $96.1 \%$ & 57.7 \\
\hline $\begin{array}{l}\text { 1-stage } \\
\text { Case 3a }\end{array}$ & 135 & 761.7 & $250^{\circ} \mathrm{C}$ & 25.0 & 1.519 & 0.0911 & 0.753 & 0.285 & 299 & 412 & $84.9 \%$ & 57.7 \\
\hline $\begin{array}{c}\text { 2-stage } \\
\text { series }\end{array}$ & 135 & 746.7 & $250^{\circ} \mathrm{C}$ & $25.0 / 25.0$ & 1.519 & 0.0900 & 0.809 & 0.274 & 321 & $440 / 1541$ & $83.9 \%$ & 57.7 \\
\hline
\end{tabular}

Conclusions - In all industrial cases, a 2-stage system of either configuration will give higher recovery and purity in both the retentate and permeate output compared to a 1stage system. In a typical industrial 2-stage application one stage has increased mixed gas selectivity and lower permeate recovery and the other decreased mixed gas selectivity and higher permeate recovery. In the present $\mathrm{PBI}$ case the high $\mathrm{H}_{2} / \mathrm{CO}_{2}$ selectivity and the $\mathrm{H}_{2}$ concentration of 42.9 and $49 \%$ respectively, enables a 1-stage membrane to get high purity and recovery in both permeate and the retentate without the need to go to a 2stage system.

Because of the high $\mathrm{H}_{2} \mathrm{~F} 0$ feed concentration a 2-stage configuration with a lower selectivity in the second series stage does not improve performance. The feed gas mixture in this case has a high enough $\mathrm{H}_{2}$ partial pressure and selectivity to yield desired performance in 1-stage by simply lowering the permeate pressure from 290 psia to 135 psia. Specific Recompression power is about the same in the 1-stage with reduced permeate pressure and 2-stage case.

\section{The Optimized Single Stage Case 3 Simulated Performance Converging With an Expected WFX-45 Fiber Performance with a Thicker Dense Layer} Optimized Single Case 3 Performance and WFX-45 Test Data -The plot in Figure 1 above shows the optimized single stage Case 3 simulated performance, which is close to the best predicted performances of the so called Aggressive Case previously reported, converging to the SRI test results for White Fox fiber WFX-45 . Case 3 recovers $96.1 \%$ of the feed $\mathrm{H}_{2}$ and captures $90 \%$ of the feed $\mathrm{CO}_{2}$ while achieving $93.2 \%$ of the energy recovery, $94.4 \%$ of the membrane area power density and $99.5 \%$ of the $\mathrm{H}_{2}$ recovery of the Aggressive Case which was based on extrapolated LANL temperature data at $170^{\circ} \mathrm{C}$. See Table 1 below comparing the Single stage Case 3 and Aggressive Case simulation results. 


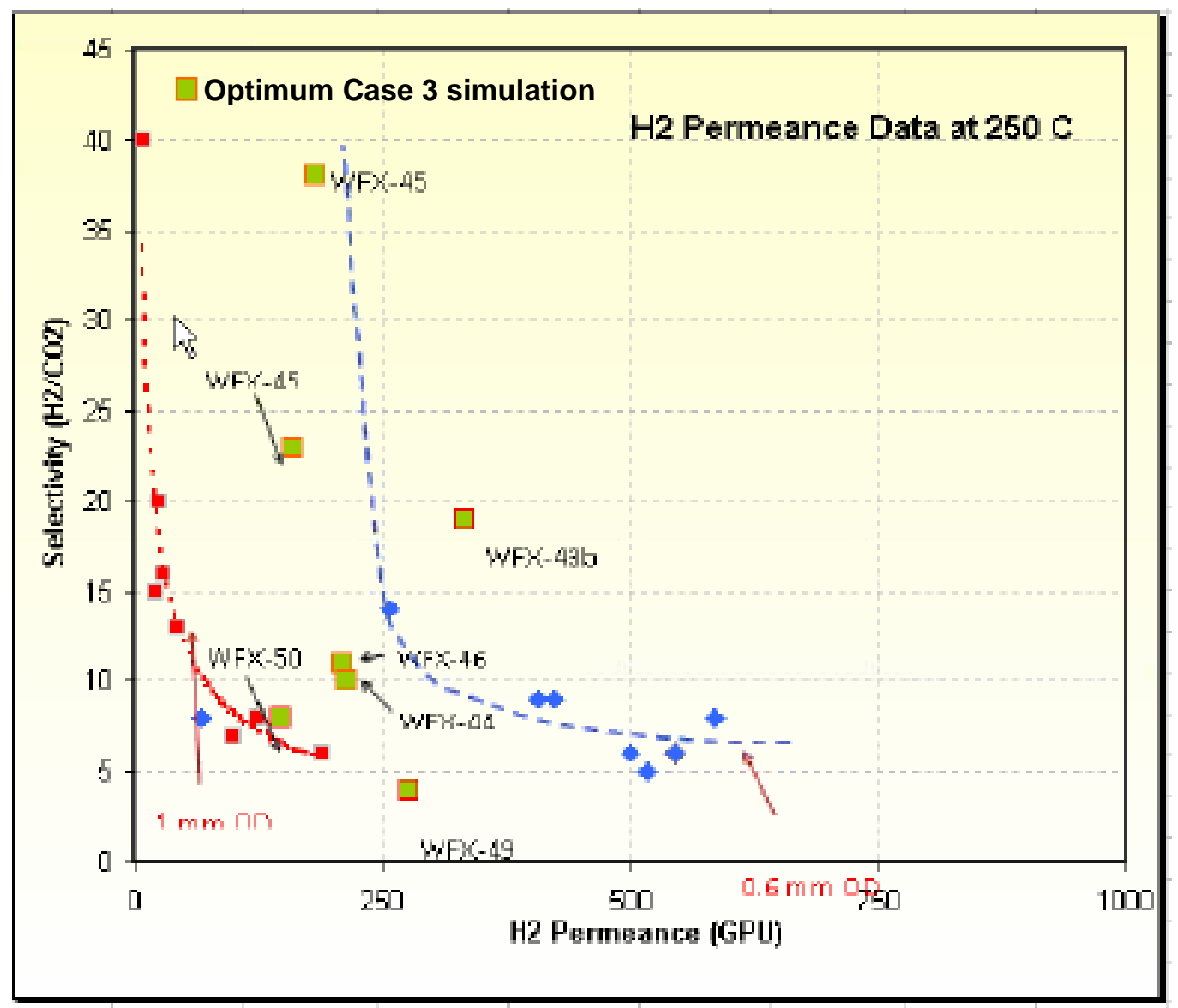

Figure-1 SRI test results for WFX-45 presented in the March 24, 2010 Webex meeting with the Optimum Case 3 simulation result inserted.

The significance of the Case 3 simulation is it achieves this performance based on un-extrapolated data at $250^{\circ} \mathrm{C}$ by reducing permeate pressure from 290 psia to 135 psia causing a modest compression power demand of $0.083 \mathrm{MW}$ per MW produced. Furthermore it has a dense layer thickness of $1.5 \mu \mathrm{m}, \mathrm{a} \mathrm{H}_{2}$ GPU of 57.5 and $\mathrm{H}_{2} / \mathrm{CO}_{2}$ selectivity of 42.9. This selectivity is close to the test selectivity of 38 measured for the short term WFX-45 data point which had a higher $\mathrm{H}_{2}$ GPU of 183 due to WFX-45's substantially thinner dense layer of about $0.05 \mu \mathrm{m}$ estimated from an SRI SEM of the fiber. After a period of exposure to $250^{\circ} \mathrm{C}$ the selectivity was reduced to 23 and the $\mathrm{H}_{2}$ GPU to 160 .

The WFX-45 fiber dense layer thickness is $1 / 30^{\text {th }}$ of the Case 3 simulated membrane dense layer thickness. A substantially thicker dense layer as in the simulated Case 3 may be a factor for maintaining initial selectivity or minimizing initial selectivity reduction during long term exposure to high temperature and pressure conditions. 
Table 1 - Case 3 single stage lower permeate pressure and the aggressive case for 778.7 psia feed pressure, $90 \% \mathrm{CO}_{2}$ capture, and $125 \mathrm{LHV}$ Btu/cf permeate

\begin{tabular}{|c|c|c|c|c|c|c|c|c|c|c|c|c|}
\hline & perm. & retent. & & & & $\begin{array}{c}\text { permeate } \\
+ \\
\text { swp. } \\
\text { compr. }\end{array}$ & $\mathrm{Net}$ & $\mathrm{Net}$ & $\mathrm{MBR}$. & acfh/ & $\mathrm{H}_{2}$ & $\mathrm{H}_{2}$ \\
Case & psia & psia & temp. & $\mathrm{aH}_{2} / \mathrm{CO}_{2}$ & $\mu \mathrm{m}$ & $\mathrm{MW} / \mathrm{MW}$ & $\mathrm{MWe}$ & $\mathrm{kWe} / \mathrm{ft}^{2}$ & $\mathrm{~m}^{2} / \mathrm{MWe}$ & element & rec. & $\mathrm{GPU}$ \\
\hline 3 & 135 & 761.7 & $250^{\circ} \mathrm{C}$ & 42.9 & 1.519 & 0.0830 & 0.911 & 0.218 & 392 & 280 & $96.1 \%$ & 57.7 \\
Aggressive & 290 & 761.7 & $170 \mathrm{C}=$ & 90.0 & 0.165 & 0.0288 & 0.971 & 0.231 & 402 & 279 & $96.6 \%$ & 121.2 \\
\hline
\end{tabular}

Conclusion - The optimized Single Stage Case 3 simulation predicts a respectable PBI test module performance could result with a White Fox WFX-45 fiber having a thicker dense layer. Applying a thicker dense layer of $\sim 1.5 \mu \mathrm{m}$ in the manufacture of the fiber could be more easily realized than $\sim 0.1 \mu \mathrm{m}$. Furthermore, a substantially thicker dense layer should eliminate micro-hole defects common in the $\sim 0.1 \mu \mathrm{m}$ thin dense layer fibers produced and tested to date, and may offer stable long term selectivity and robustness under expected high temperature and pressure conditions. 


\section{D-14. FIBER LENGTH AS A FUNCTION OF $\mathrm{H}_{2}$ GPU}

Two simulations sets were done at different $\mathrm{H}_{2}$ GPU's to show the variation in fiber length and number of test modules as a function of $\mathrm{H}_{2}$ GPU. Both sets assumed a 50 $\mathrm{kW}_{\text {th }}$ feed rate having $3.7 \% \mathrm{H}_{2} \mathrm{O}$ content, a fiber dimension of $600 \mu \mathrm{m}$ O.D. $\times 400$ with shell side dense layer (MSL). The number of required test modules is based on a 1" $\times 1$ ' test module element having $367 \mathrm{~m}$ of fiber and a $63 \%$ fiber packing density.

The first simulation set has the following membrane performance:

- $\mathrm{H}_{2} / \mathrm{CO}_{2}$ selectivity $=42.9$

- Permeate pressure $=135$ psia

- $\mathrm{H}_{2}$ recovery $=98.3 \%$

The first simulation set results are presented in Table 1 below.

Table 1

\begin{tabular}{|c|c|c|c|c|}
\hline $\mathrm{MSL}, \mu \mathrm{m}$ & H2 GPU & Fiber length, $\mathrm{m}$ & No. of $1 " \times 1 "$ modules & feed factor* \\
\hline 0.50 & 175 & 1,730 & 4.7 & 4.2 \\
\hline 0.75 & 117 & 2,600 & 7.1 & 2.8 \\
\hline 1.00 & 88 & 3,450 & 9.4 & 2.1 \\
\hline 1.50 & 58 & 5,250 & 14.3 & 1.4 \\
\hline 2.00 & 44 & 6,930 & 18.9 & 1.1 \\
\hline
\end{tabular}

As expected both the fiber length and the number of test modules decreases as the $\mathrm{H}_{2}$ GPU increases. In theory then the lowest fiber length and lowest number of modules is only limited by the minimum practical MSL thickness. However there is another limitation of maximum practical feed flow rate on the feed side of the membrane. A module's mechanical design determines the maximum feed flow it is capable of processing. Based on a known maximum feed flow rate of a known commercial membrane module, it appears that the practical $\mathrm{H}_{2}$ GPU upper limit may be about 88 assuming the membrane performance parameters listed above. This gives a minimum fiber length range between 3,450 and 5,250 $\mathrm{m}$ and a minimum number of test modules ranging between 9.4 and 14.3.

The second simulation set has the following membrane performance:

- $\mathrm{H}_{2} / \mathrm{CO}_{2}$ selectivity $=28.6$

- Permeate pressure $=15$ psia

- $\mathrm{H}_{2}$ recovery $=95.7 \%$

The second simulation set is meant to show the effect of a lower $\mathrm{H}_{2} / \mathrm{CO}_{2}$ but at the same $\mathrm{H}_{2}$ GPU as the first simulation set. To maintain a $\mathrm{H}_{2}$ recovery of about $96.0 \%$ it is necessary to reduce the permeate pressure to $15 \mathrm{psia}$. The upside of the lower permeate pressure is a substantially lower fiber length and a lower number of test modules for any given $\mathrm{H}_{2}$ GPU. The downside is a substantial increase in permeate compression power to achieve the specified combustion turbine fuel injection pressure. 
The results of the second simulation set are presented in Table 2 below.

Table 2

\begin{tabular}{|c|c|c|c|c|}
\hline $\mathrm{MSL}, \mu \mathrm{m}$ & $\underline{\mathrm{H} 2 \mathrm{GPU}}$ & Fiber length, $\mathrm{m}$ & No. of $1 " \times 1 "$ modules & feed factor ${ }^{*}$ \\
\hline 0.50 & 175 & 1,175 & 3.2 & 6.2 \\
\hline 0.75 & 117 & 1,765 & 4.8 & 4.1 \\
\hline 1.00 & 88 & 2,360 & 6.4 & 3.1 \\
\hline 1.50 & 58 & 3,530 & 9.6 & 2.1 \\
\hline 2.00 & 44 & 4,690 & 12.8 & 1.6 \\
\hline
\end{tabular}

In the second simulation set it appears that the practical module feed flow rate limits the $\mathrm{H}_{2}$ GPU upper limit to about 58. This gives a minimum fiber length range between 3,530 and 4,690 $\mathrm{m}$ and a minimum number of test modules ranging between 9.6 and 12.3. 


\section{D-15. ELEMENT AND PERFORMANCE SPECIFICATIONS CHANGING THE SIZE PBI TEST MODULE}

Simulation Memorandum XIV presented a proposed nominal 3" diameter $\times 1$ ' long test element as optimum for a test PBI membrane module. The 3 " $\times 1$ foot module fiber element Specifications are presented in Table 1 below.

\begin{tabular}{|c|c|}
\hline \multicolumn{2}{|l|}{$\begin{array}{l}\text { Table }-\mathbf{1} \\
3 " \times 1 \text { 'Test Module Fiber Element }\end{array}$} \\
\hline Fiber O.D/I.D. & $1100 \mu \mathrm{m} / 750 \mu \mathrm{m}$ \\
\hline Lumen side/shell side vol. ratio & 0.79 \\
\hline Element volume, $\mathrm{m}^{3}$ & 0.00148 \\
\hline Fiber volume, $\mathrm{m}^{3}$ & 0.00094 \\
\hline Fiber packing & $63.0 \%$ \\
\hline Total fiber length per element, $\mathrm{m}$ & 985 \\
\hline Number of fibers per element & 3,232 \\
\hline Module membrane area, $\mathrm{m}^{2}$ & 3.4 \\
\hline Module membrane area, $\mathrm{ft}^{2}$ & 36.6 \\
\hline Specific membrane area, $\mathrm{m}^{2} / \mathrm{m}^{3}$ & 2,292 \\
\hline
\end{tabular}

After discussions among the project team with respect to some of the engineering challenges of building a PBI multi-fiber test module, particularly with respect to an effective fiber potting and element seal, i.e., sealing the feed to retentate side of the membrane from the permeate side of the membrane, at the high temperature and pressure conditions of operation, it was decided that a functional 1" diameter $\times 1$ ' long a PBI test module would be easier to fabricate within the project schedule. The 1" $\times 1$ ' element specifications are presented in Table 2 below.

\begin{tabular}{|c|c|}
\hline $\begin{array}{l}\text { Table } \mathbf{- 2} \\
1 " \times 1 \text { 'Test Module fiber Element }\end{array}$ & \\
\hline Fiber O.D/I.D. & $600 \mu \mathrm{m} / 400 \mu \mathrm{m}$ \\
\hline Lumen side/shell side vol. ratio & 0.76 \\
\hline Element volume, $\mathrm{m}^{3}$ & 0.00016 \\
\hline Fiber volume, $\mathrm{m}^{3}$ & 0.00010 \\
\hline Fiber packing & $63.0 \%$ \\
\hline Total fiber length per element, $\mathrm{m}$ & 367 \\
\hline Number of fibers per element & 1,205 \\
\hline Module membrane area, $\mathrm{m}^{2}$ & 0.69 \\
\hline Module membrane area, $\mathrm{ft}^{2}$ & 7.4 \\
\hline Specific membrane area, $\mathrm{m}^{2} / \mathrm{m}^{3}$ & 4,200 \\
\hline
\end{tabular}


Significantly the $1 " \times 1$ ' test element provides 1.8 times more specific membrane area, i.e., $\mathrm{m}^{2}$ of membrane area per $\mathrm{m}^{3}$ of element volume, with only $37.4 \%$ of the number of fibers of the $3 " \times 1$ ' test module and essentially no change in the lumen side to shell side volume ratio.

Comparing Earlier and Current Test Module Performance Specifications - The 3" x 1 ' test element performance was based on extrapolated permeability and selectivity of the Aggressive Case at $170^{\circ} \mathrm{C}$, a $1.0 \mu \mathrm{m}$ thick membrane separation layer (MSL) and a permeate back pressure of 290 psia. The $1 " \times 1$ ' test module performance is based on measured permeability and selectivity at $250^{\circ} \mathrm{C}$, a $1.5 \mu \mathrm{m}$ thick MSL and a permeate back pressure of 135 psia. A performance comparison of the two test elements is presented in Table 3 below.

\begin{tabular}{|l|c|c|}
\hline \multicolumn{3}{|l|}{ Table - 3 } \\
Test module comparative performance at $125 \mathrm{Btu} / \mathrm{scf}$ LHV permeate \& $90 \% \mathrm{CO}_{2}$ capture \\
\hline Test element & $1^{\prime \prime} \times 1^{\prime}$ & $3{ }^{\prime} \times 1$ \\
\hline Operating temperature, ${ }^{\prime} \mathrm{C}$ & 250 & 170 \\
\hline $\mathrm{H}_{2} \mathrm{GPU}, \mathrm{cm}^{3} / \mathrm{cm}^{2} / \mathrm{sec} /{\mathrm{cm} \mathrm{Hg} \times 10^{-6}}^{-6}$ & 57.7 & 20.0 \\
\hline $\mathrm{H}_{2} / \mathrm{CO}_{2}$ selectivity & 42.90 & 90.00 \\
\hline $\mathrm{H}_{2}$ recovery & $96.1 \%$ & $96.6 \%$ \\
\hline Power separation efficiency & $93.3 \%$ & $93.8 \%$ \\
\hline Membrane separation layer, $\mu \mathrm{m}$ & 1.5 & 1.0 \\
\hline Permeate operating pressure, $\mathrm{psia}$ & 135 & 290 \\
\hline Parasitic compression power & $7.2 \%$ & $2.8 \%$ \\
\hline Net MWe/MWe & 0.928 & 0.972 \\
\hline Net Area power density, $\mathrm{kWe} / \mathrm{ft}^{2}$ & 0.220 & 0.039 \\
\hline $\mathrm{m}^{2} /$ net MWe & 422 & 2,433 \\
\hline Net permeate KWe / element & 1.63 & 1.40 \\
\hline $\mathrm{m}^{3} /$ net MWe & 0.10 & 1.06 \\
\hline
\end{tabular}

The current $1 " \times 1$ ' test element configuration operating at the Case 3 simulated performance given in Simulation Memorandum XV - Part 1 Addendum 1, Table 2, at a permeate pressure of 135 psia and a temperature of $250^{\circ} \mathrm{C}$, shows substantially better performance than the earlier 3" $\times 1$ ' test element configuration operating at the Figure -3 simulated performance given in Simulation Memorandum XIV, Table 1, at a permeate pressure of $290 \mathrm{psia}$ and a temperature of $170^{\circ} \mathrm{C}$. Lowering the permeate pressure and raising the membrane operating temperature enables $96.1 \% \mathrm{H}_{2}$ recovery approaching the $96.6 \% \mathrm{H}_{2}$ recovery of the Aggressive Case at $170^{\circ} \mathrm{C}$.

As a result of the higher GPU at $250^{\circ} \mathrm{C}$ and the higher trans-membrane pressure drop with 135 psia permeate back pressure, membrane power density in the current element is 5.6 times higher enabling an $82.7 \%$ reduction in $\mathrm{m}^{2} /$ net MWe. Net MWe/MWe is $95.5 \%$ of the Aggressive Case. Significantly this performance will be achieved with an MSL of 1.5 $\mu \mathrm{m}$ which will provide a more robust and durable membrane compared to typical gas 
separation membrane MSLs of about $0.1 \mu \mathrm{m}$ thickness which operate at much lower temperatures of $38^{\circ} \mathrm{C}$ to $60^{\circ} \mathrm{C}$.

Reducing the fiber dimensions from $1100 \mu \mathrm{m}$ O.D. by $750 \mu \mathrm{m}$ I.D. to $600 \mu \mathrm{m}$ O.D. by $400 \mu \mathrm{m}$ I.D. increases the specific membrane area 1.8 times which gives a $90.5 \%$ reduction in $\mathrm{m}^{3} /$ net $\mathrm{MWe}$. 


\section{D-16. PBI ASYMMETRIC MEMBRANE PERFORMANCE}

Till now all engineering membrane performance simulations and designs have used empirical performance data provided by LANL. See PBI Simulation Memorandum V. LANL single gas data for $\mathrm{H}_{2}$ and $\mathrm{CO}_{2}$ from testing using a $12 \mu \mathrm{m}$ dense PBI layer coated onto a 0.5 inch O.D. Pall Accusep ${ }^{\mathrm{TM}} \mathrm{s} / \mathrm{s}$ porous tube are presented in Table 1 below.

Table 1 - LANL Empirical Data

Feed Press. = $260 \mathrm{~cm} \mathrm{Hg}$; Permeate Press. $=76 \mathrm{~cm} \mathrm{Hg}$; Temp. $=250^{\circ} \mathrm{C}$; Pall Accusep ${ }^{\mathrm{TM}}$ tube $=0.5$ in. O.D.

Shell Side Dense Separation Layer $=0.0012 \mathrm{~cm}$

Single Gas GPU

$10^{-6} \mathrm{~cm}^{3} / \mathrm{s} / \mathrm{cm}^{2} / \mathrm{cm} \mathrm{Hg}$

Single Gas Barrer

\begin{tabular}{cccc} 
& $10^{-6} \mathrm{~cm}^{3} / \mathrm{s} / \mathrm{cm}^{2} / \mathrm{cm} \mathrm{Hg}$ & $\mathrm{H}_{2} \alpha$ & $10^{-10} \mathrm{~cm}^{3} \times \mathrm{cm}^{2} / \mathrm{cm}^{2} / \mathrm{cm} \mathrm{Hg}^{\mathrm{H}_{2}}$ \\
\cline { 2 - 4 } $\mathrm{CO}_{2}$ & 5.20 & 1.00 & 62.4 \\
& 0.12 & 43.33 & 1.44
\end{tabular}

SRI's PBI asymmetric hollow fiber $24 \mathrm{~b}-4$ which was tested at $250^{\circ} \mathrm{C}$ had a measured $\mathrm{H}_{2}$ GPU of about 115 and a $\mathrm{H}_{2} / \mathrm{CO}_{2}$ selectivity of about 43 . The average effective dense separation layer thickness observed by SEM is estimated to be about $0.5 \mu \mathrm{m}$ after heat treatment. As of this date the performance has been sustained at test conditions for 500 hours. The SRI test data is presented in Table 2 below.

Table 2 - SRI Empirical Data for Fiber 24b-4

Feed Press. = $260 \mathrm{~cm} \mathrm{Hg}$; Permeate Press. = $76 \mathrm{~cm} \mathrm{Hg}$; Temp. = 250C; Asymmetric Hollow Fiber = 0.6 mm 0.D.

\begin{tabular}{|c|c|c|c|}
\hline & $\begin{array}{c}\text { Shell Side Dense Separation Layer = } \\
\text { Single Gas GPU } \\
10^{-6} \mathrm{~cm}^{3} / \mathrm{s} / \mathrm{cm}^{2} / \mathrm{cm} \mathrm{Hg}\end{array}$ & $\begin{array}{r}0.00005 \mathrm{~cm} \\
\mathrm{H}_{2} \alpha \\
\end{array}$ & $\begin{array}{c}\text { Single Gas Barrer } \\
10^{-10} \mathrm{~cm}^{3} \times \mathrm{cm} / \mathrm{s} / \mathrm{cm}^{2} / \mathrm{cm} \mathrm{Hg}\end{array}$ \\
\hline $\mathbf{H}_{2}$ & 115 & 1.00 & 57.5 \\
\hline $\mathrm{CO}_{2}$ & 2.67 & 43 & 1.38 \\
\hline
\end{tabular}

Significantly and what was hoped for was that intrinsic PBI permeation properties in Barrer at the same test conditions would be about the same for both a PBI hollow fiber membrane and the LANL Accusep ${ }^{\mathrm{TM}}$ tube membrane. In other words, the best case outcome was to confirm the same intrinsic permeation properties in a thin PBI dense layer hollow fiber as achieved in a much thicker PBI dense layer on a 0.5 in diameter O.D. porous steel tube. SRI has achieved this with single gases and it is expected that similar results will follow for mixed gas feeds. 


\section{D-17. COMPARISON OF HOLLOW-FIBER AND SPIRAL-WOUND FLAT SHEET MEMBRANE PERFORMACE}

The MTR Proteous pre-combustion membrane was presented to NETL on November 13, 2009 in a presentation titled "Novel Polymer Membrane Process For Pre-Combustion $\mathrm{CO}_{2}$ Capture From Coal-Fired Syngas." Permeance and selectivity data for the MTR Proteous membrane is presented in slide 15 of the MTR presentation in Figure 1. From Appendix I it can be seen that the Proteous membrane at about $200^{\circ} \mathrm{C}$ has a $\mathrm{H}_{2}$ permeance of about $240 \mathrm{GPU}$ and $\mathrm{H}_{2} / \mathrm{CO}_{2}$ selectivity of about 15 .

SRI has developed an asymmetric hollow fiber PBI pre-combustion $\mathrm{CO}_{2}$ capture membrane made from polybenzimidazole (PBI). Permanence and selectivity data for the SRI PBI membrane for fiber $24 b-4$ is presented in Figure 2. From Figure 2, it can be seen that the PBI membrane at about $200^{\circ} \mathrm{C}$ has a $\mathrm{H}_{2}$ permeance of about $175 \mathrm{GPU}$ and $\mathrm{H}_{2} / \mathrm{CO}_{2}$ selectivity of about 43 .

Single stage membrane performance using the given permeance and selectivity data was simulated for $90 \% \mathrm{CO}_{2}$ capture for both membranes. The feed and permeate pressure used was that given in the MTR presentation Slide 16 shown in Appendix III. Membrane thickness was set at $0.50 \mu \mathrm{m}$. A $\mathrm{N}_{2}$ permeate sweep equal to $48 \%$ of the total permeate flow was assumed. Feed composition was set at a typical shifted coal-fired syngas: $\mathrm{H}_{2}=$ $54.2 \%, \mathrm{CO}_{2}=38.8 \%, \mathrm{H}_{2} \mathrm{O}=3.7 \%, \mathrm{~N}_{2}=1.5 \%, \mathrm{CO}=1.1 \%, \mathrm{H}_{2} \mathrm{~S}=0.6 \%$ and $\mathrm{CH}_{4}=0.1 \%$. The comparative performance results are presented in Table 1 below.

Table 1 -Single Stage Performance Comparison of an MTR Proteous membrane and an SRI PBI membrane

\begin{tabular}{|c|c|c|}
\hline Membrane & $\mathrm{H}_{2}$ recovery, $\%$ & kWth recovery, $\%$ \\
\hline MTR Proteous & $68.7 \%$ & $66.7 \%$ \\
\hline SRI PBI & $98.3 \%$ & $95.5 \%$ \\
\hline
\end{tabular}

The SRI PBI membrane recovers $43 \%$ more feed $\mathrm{H}_{2}$ and correspondingly $43 \%$ more thermal energy from the feed than the MTR Proteous membrane. The SRI PBI membrane achieves its goals of $98.3 \% \mathrm{H}_{2}$ recovery and $90 \% \mathrm{CO}_{2}$ capture without requiring multiple stages, multiple recycle streams, and multiple rotating machinery with substantial parasitic power.

In order for the MTR Proteous Membrane to achieve $98.7 \% \mathrm{H}_{2}$ recovery and $90.4 \% \mathrm{CO}_{2}$ capture, as calculated from the data in Slide 16 of the MTR presentation, a process including four membrane stages, three recycle streams, and two compressors and a refrigeration plant, together drawing $7 \%$ of a power plant's power, is required.(Figure 3 ).

The SRI PBI single stage membrane process enables substantially better performance because it meets $\mathrm{H}_{2}$ recovery and $\mathrm{CO}_{2}$ capture goals without the power draining machinery necessary for the multiple membrane stages and distillation column as in the MTR membrane process. 


\section{Mixed-Gas Performance of}

MTR Proteus Membrane
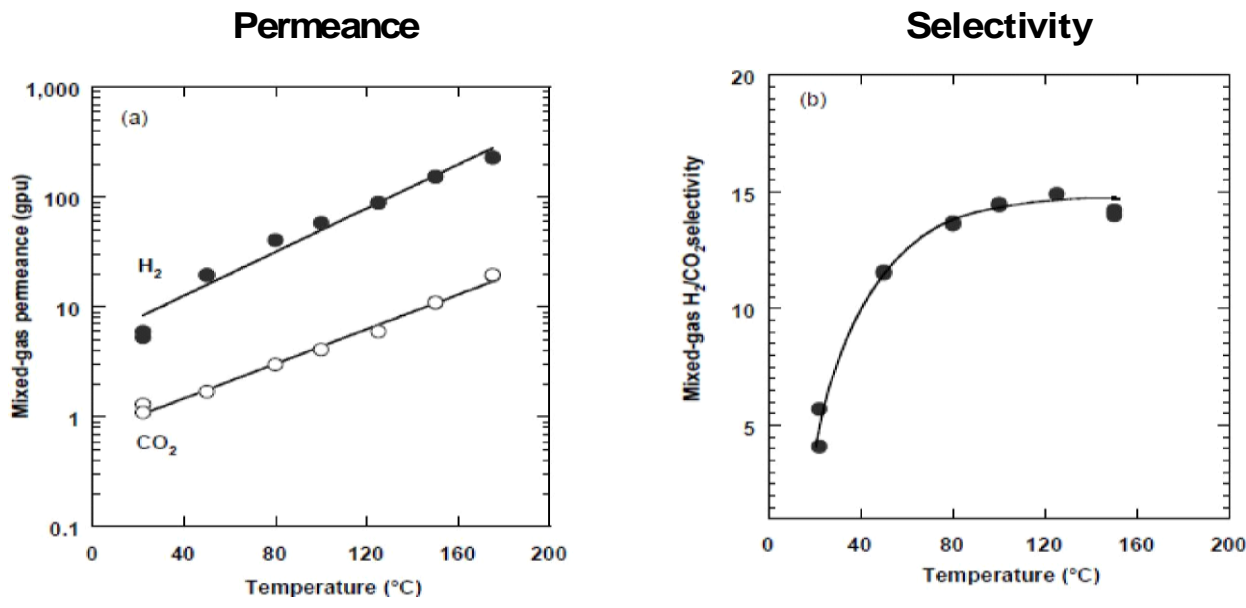

$\mathrm{H}_{2} / \mathrm{CO}_{2}$ selectivity increases with increasing temperature presumably because $\mathrm{CO}_{2}$ selectivity decreases rapidly at elevated temperature.

15

Figure 1. MTR membrane data.

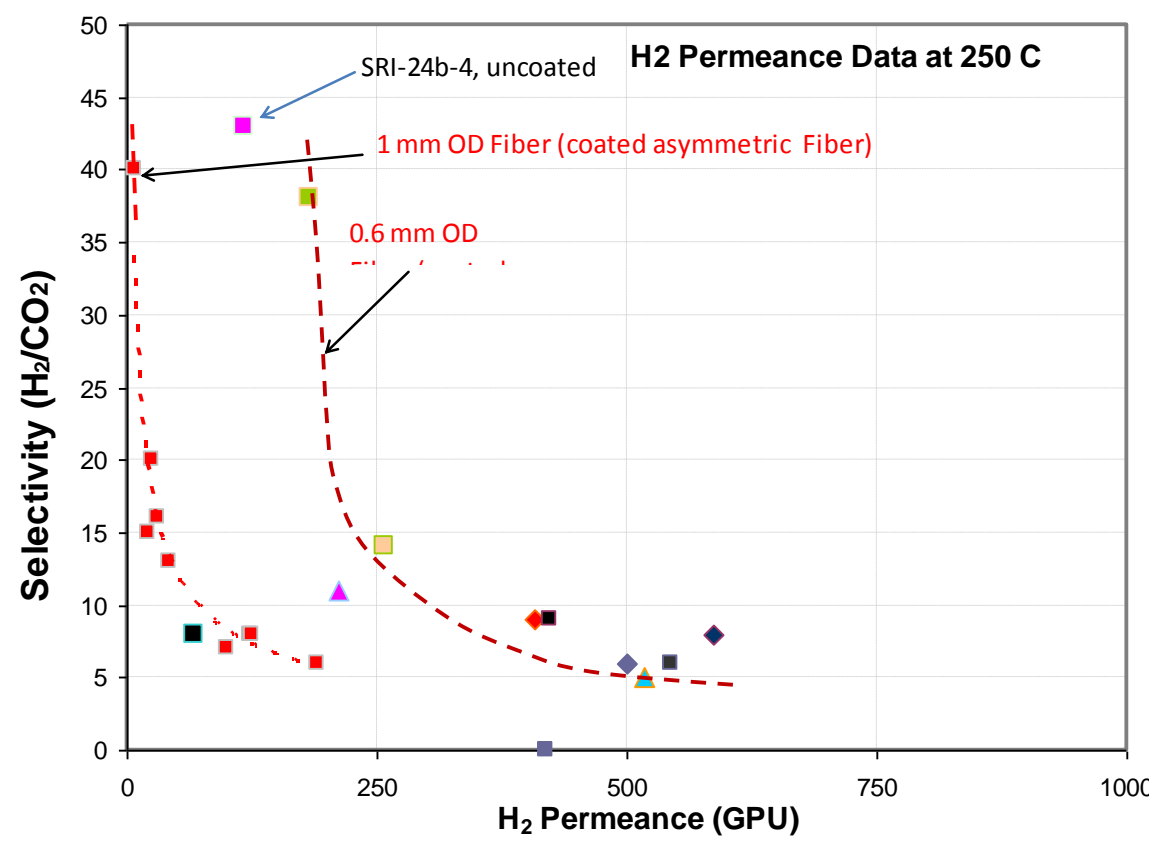

Figure 2. SRI data with asymmetric PBI hollow fiber 


\section{A POSSIBLE MEMBRANE PROCESS DESIGN}

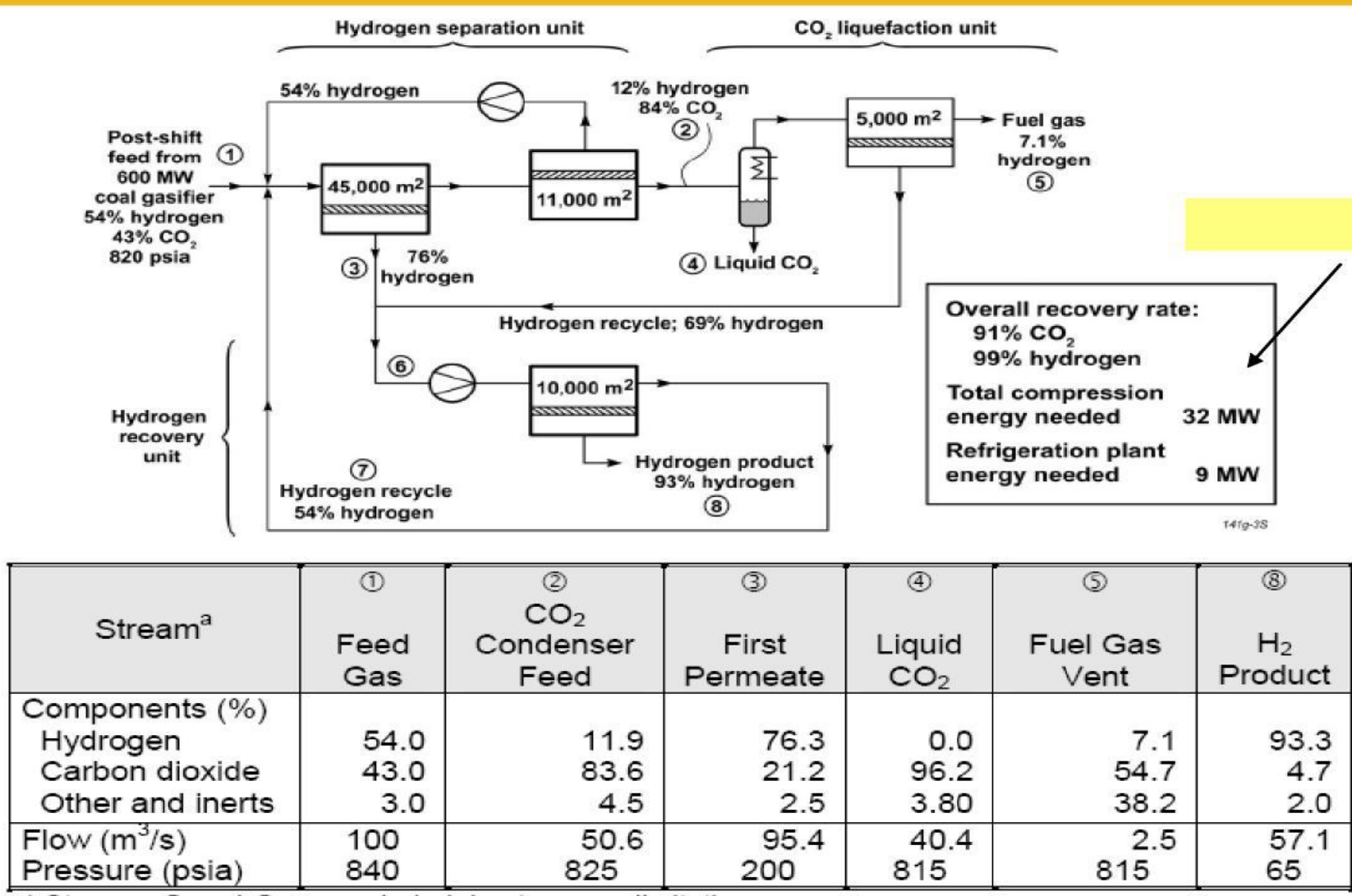

Figure 3. MTR process flow sheet 